\title{
THE IMAGINABLE CITY
}

Large-scale design in New Plymouth's Central Area can coordinate Visual Perceptions to evoke recognition in the Human Imagination; and thereby help to form the city's Identity.
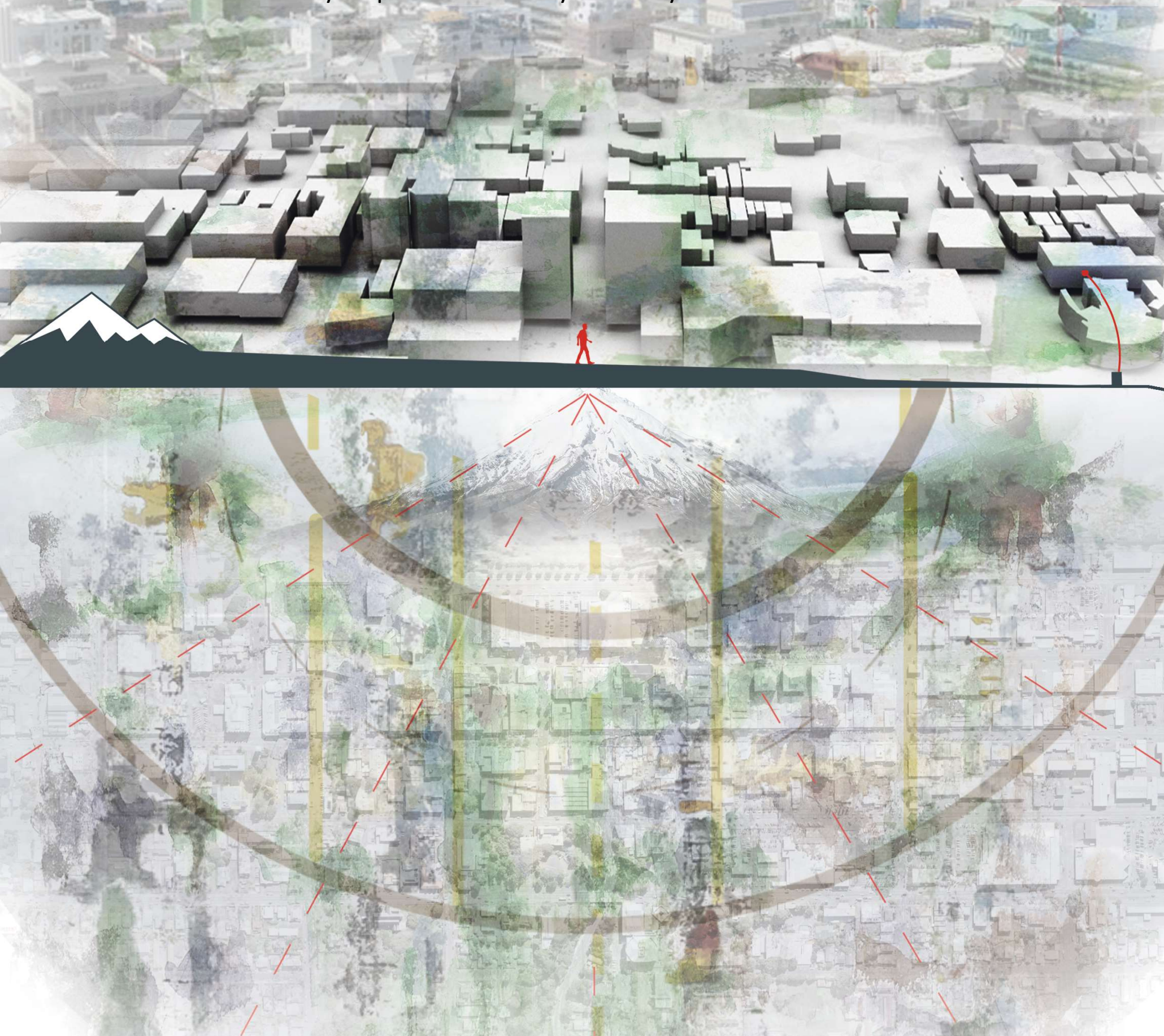
The Imaginable City

Large-scale design in New Plymouth's Central Area can coordinate Visual Perceptions to evoke recognition in the Human Imagination; and thereby help to form the city's Identity. By Yunyun Tian

A 120-point thesis submitted to the Victoria University of Wellington in partial fulfilment of the requirements for the degree of Master of Landscape Architecture

\section{Victoria University of Wellington \\ School of Architecture}




\section{THE IMAGINABLE CITY}

Large-scale design in New Plymouth's Central Area can coordinate Visual Perceptions to evoke recognition in the Human Imagination; and thereby help to form the city's Identity.
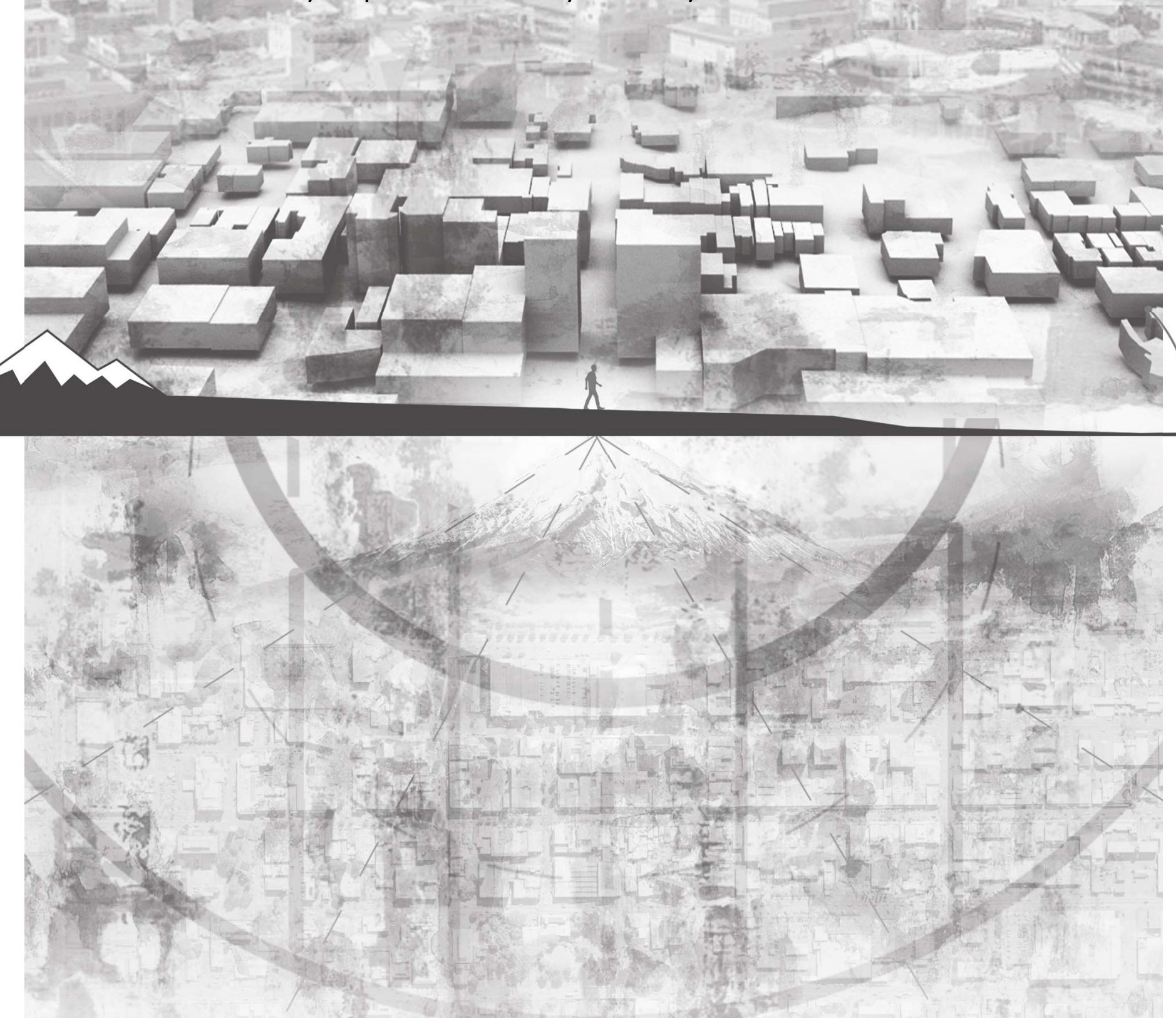


\section{ACKNOWLEDGEMENTS}

Completing a thesis is not easy, it would not been possible without the contribution, guidance, and assistance of various individuals who participated in this journey.

First of all, I would like to offer my sincerest thanks to my supervisor, Warwick McLeod, for taking me under your supervision, sharing the knowledge, and offering countless support and guidance. I would not be able to progress this far without your assistant.

To my friends, thank you for always being by my side to cheer me up throughout this challenging year.

To my landscape colleges, thank you for sharing the passion and stress throughout this long journey, it has been a pleasure to study alongside you for the past five years.

Finally, to my family, thank you for your unconditional love and support, always backing me up and encourage me to achieve a greater accomplishment.

Again, thank you to everyone for your time and care during the completion of this thesis. 


\section{ABSTRACT}

The latter half of the 20th century saw rapid urban development, implemented to meet rapid growth and changing infrastructural needs. Cities around the world became designed homogeneously. In the early decades of the 21st century, the re-inhabitation of the post-industrial city has brought opportunities to bring new ideas to this homogeneity; yet templates and formulas still seem to gain ground: cities are losing their identity, as well as their imaginability. Within this problematic context, New Plymouth Central Area is a representative urban space. New Plymouth District Council has proposed a banally universal design framework, that promises only to continue burying the unique identity of its urban space, rather than liberating it to the imagination. The contemporary discipline still tends to design directly for universal human needs; an approach that ends up suggesting a city's identity to its citizens, rather than empowering citizens to imagine, and then create, that identity.

This design-led research proposes that landscape design and urban planning can recover the identity of New Plymouth Central Area by enhancing its legibility and imaginability. It explores techniques for coordinating mental recognition with visual perceptions, to evoke human imagination of a large-scale urban landscape. It argues that imaginable space can be achieved by creating a mentally identifiable system, with urban patterns, for human physical experimentation and mental recognition to navigate; through agency of this urban system to allow those same dynamics to permeate the history and cultural value of the site; to strengthen the citizen's recognition of self-identity, which always relates to, and measures itself by, identity of the land.

The outcomes of this research are: an abstract design method that communicates the mental recognition of landscape and its relation to the designed environment; and a physical design solution, testing the abstract method, for a legible and imaginable New Plymouth City. 


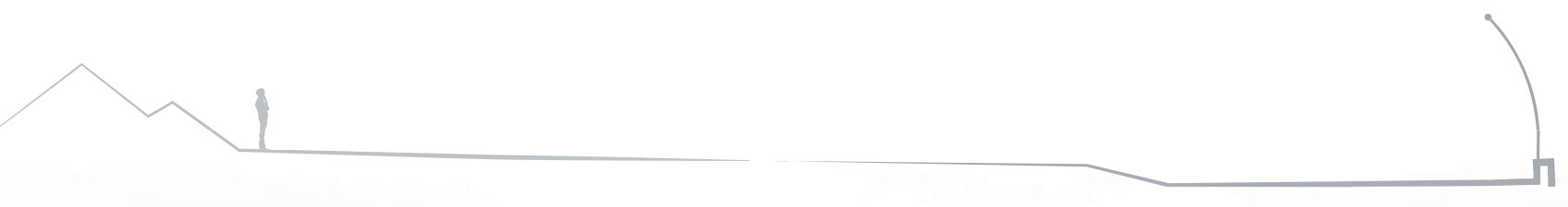

\section{CONTENT}

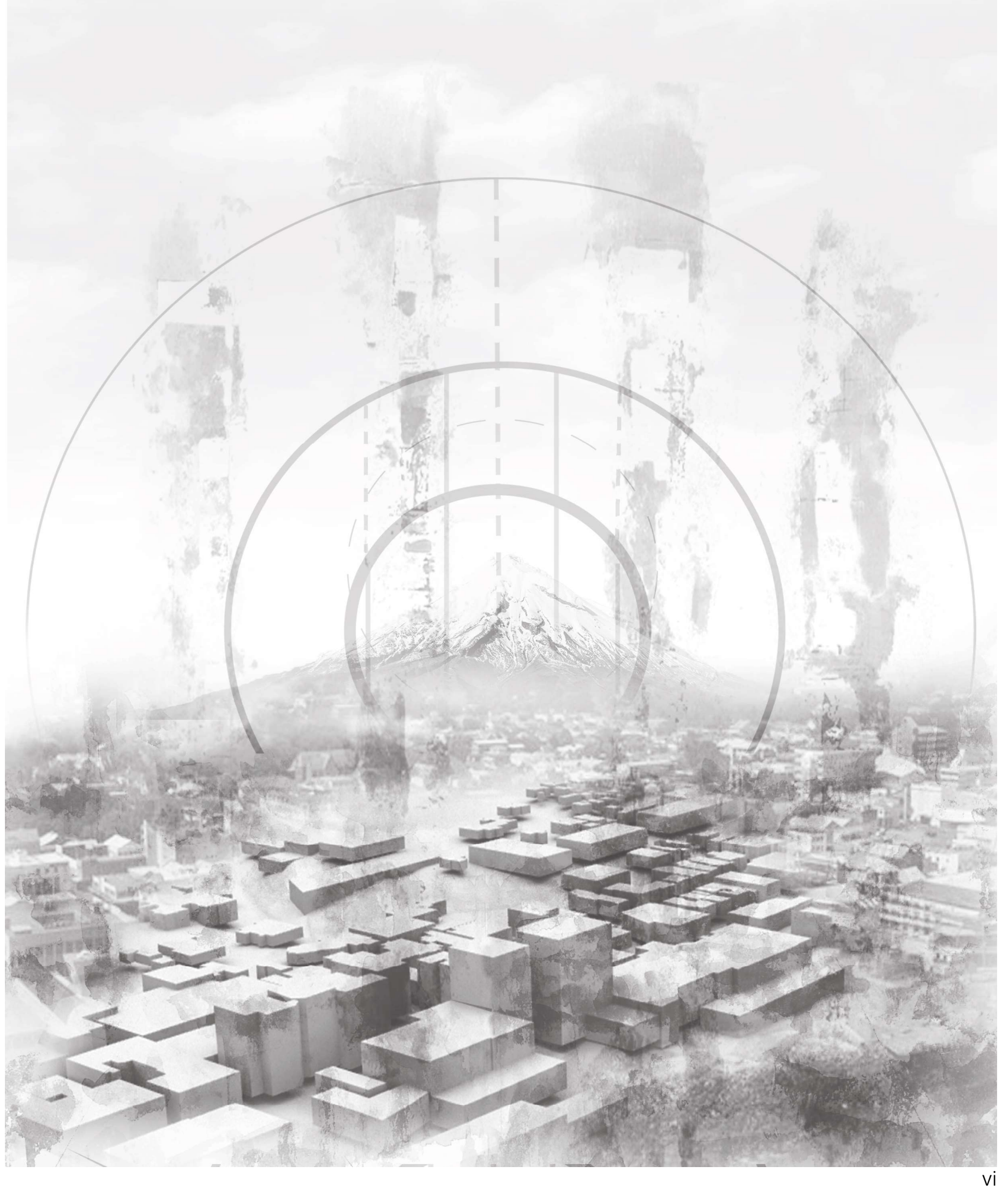


01. Introduction

1.1 Introduction

Prefacace

Discipline Context

Site In Irodroduction 04

NPDC'S Design framewowork 05

Problem Statement

Research Scope 08

1.2 Precedent Theory

1.3 Research Frame 11 .

Research Que

Research__Aim and_Objiectives

Methódology

Thesis Struncture

2.1 Context Study

2.2 Site Description

Site History 19.

Site Assets 21.

Inforormation Analys 25 .

2.3 Site Pattern 27

2.4 Problem Identification and Reflection 33 
3.1 Literature Reviews

Mental Image

Landscape_Memories

Unbban Order and Patterns

Viśual Land_

3.2 Precedent Reviews and Case Studies

Hatatshepsut Temple_Axis__L Luxor

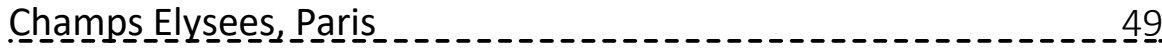

Journey from Wellington Harbour to Civic Square _ _ _ _ _ 53

Journey from Wellington Botanic Garden to Wellington Harbour 57.

Pukeahu Memorial Park, Wellington

Cuba Streets, Wellington

\section{Site Analysis}

4.1 Define Research Method

4.2 Mental Image Analysis

H_uman Scale Analysis 83

Street Scale Analysis 103

Context Scale Analysis 117

4.3 Site Research Summery 123 
5.2 Master-plan

5.3 Master-plan Finalization

6.1 Maori War Memorial 183

6.2 World War I Memorial

6.3 Huatoki Plaza

6.4 Huatoki Stream Reforestation 205

07. Conclusion

7.1 Reflection

7.2 Limitations 


\section{1}

INTRODUCTION

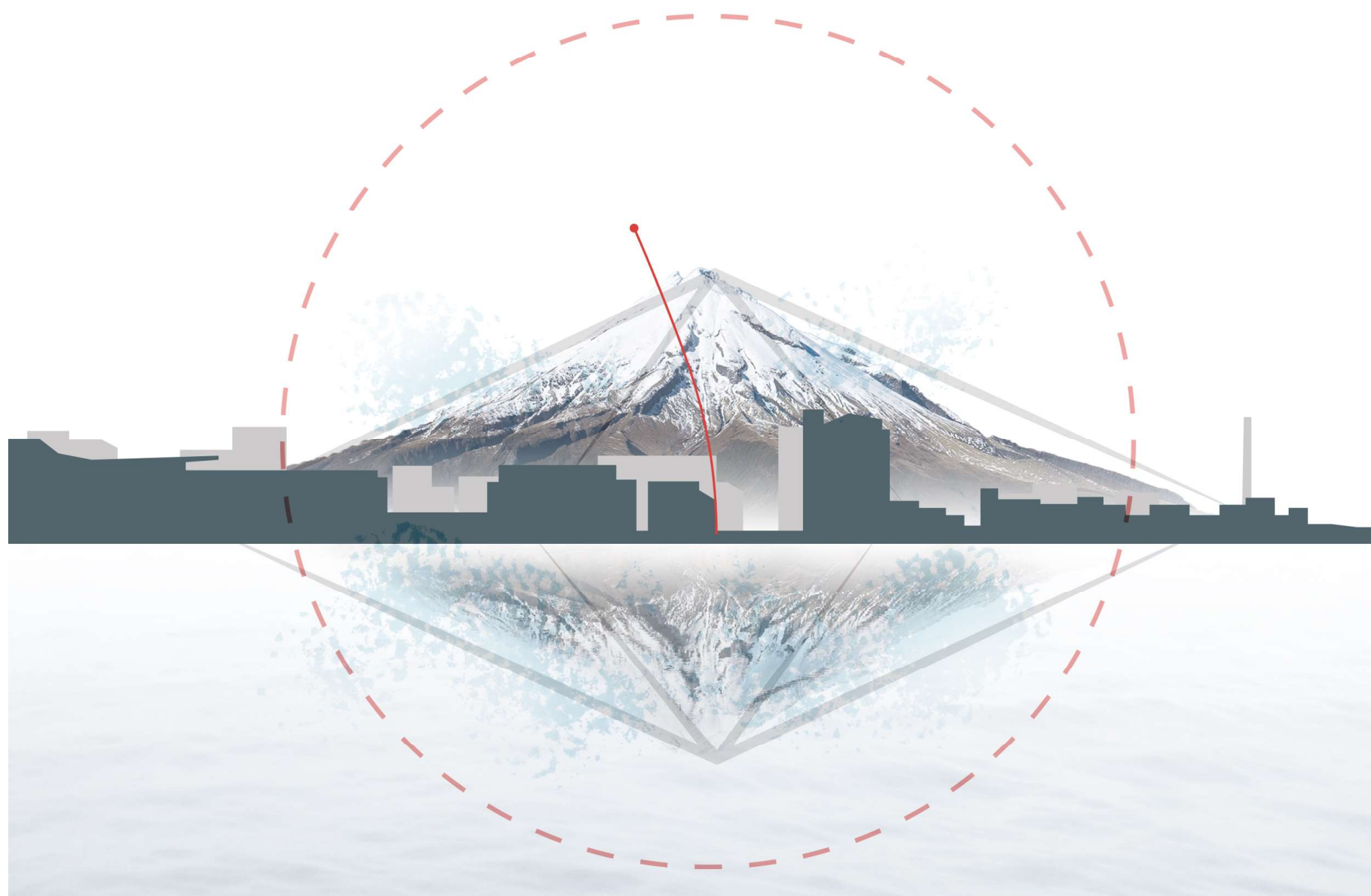




\section{PREFACE}

My motivation for this research comes from a recognition of how culture and landscape influence each other in different ways. I was born in southern China, where I lived for 13 years before immigrating to New Zealand. I spent four years in New Plymouth for high school, then moved to Wellington for university studies. This dramatic change in living environment caught my interest in environment-recognition; and started me thinking about how landscape is designed against different cultural backgrounds; how the occupants' culture is reflected in the land; how the identity of land-scape orientates the occupants' recognition; how it frames or prompts their experience in, or as I prefer to call it, their experimentation with, place.

Landscape identity - defined as place identity, placeness, character of a place, image of a place, meaning of a place - is, in the contemporary built environment, the fundamental factor in landscape architecture. But placeness, character, image, and meaning are not attributes of landscape: they are attributed to landscape, by people. They are, together, the everyday story narrated by and for citizens. Together they are the story by which the individual understands the city's identity. Even if our activity be quite small and intimate in scale, we often connect our physical experience with the landscape, and then transform this experience into something meaningful in our mind. Therefore, the mental landscape, the landscape of the imagination, is always at work in strengthening a historical and cultural understanding of a place.

Just as any conversation cannot get to agreed insights without there being two equal parties to question and answer, refine and define, the design of the urban form has an equal role in creating the image of the city, imagining its identity. Throughout their history, human beings are constantly involved in a changing landscape identity; always seeking to improve their living environment, consciously and unconsciously making its 'identity' more and more authentic to their lived experience. This is the process that triggers a citizen's sense of belonging with the city. Humans read the urban form's identity through mental and physical experimentation; the urban form responds with change and re-imaging.

Imagination can be easily achieved in a small-scale landscape. But to read the identity of a large-scale landscape, such as a city, requires a highly legible system, to be achieved through the landscape's design. A legible, pedestrian-friendly city should constantly create and re-create a sense of belonging to the city; by mapping the image in a citizen's imagination. 


\section{DISCIPLINE CONTEXT}

The imagination of a city develops hand-in-hand with the reality of a city; what it has been made, by the course of its history. New Plymouth is a typical New Zealand small coastal city: it is there because of the needs of coastal- and rail-freight transportation in the late 19th century. That century's grid template formed its first urban structure; thereafter it was taken up in the same waves of urban theory that changed all cities worldwide.

Cars became popularized in the mid-20th century, to transport the baby boomer generation. Rapid urban development was necessary in order to house this growing population. Enormous urban renewal plans were developed, with the destruction of old city centres and working-class neighbourhoods to allow a caroriented development and the homogenization of cities (Van der Werf, et.al, 2016) Jane Jacobs stood against this development; she addressed the importance of human experience within landscape, instead of privileging urban function (1961). Kevin Lynch introduced "landscape legibility" to urban assessment (1960).

In the late 20th century, many abandoned industrial and logistical areas were left over for landscape development. Many urban landscape projects all over the world have taken this opportunity to recover landscape identity and design toward a legible cityscape (Waldheim, 2016).

Major cities in New Zealand, such as Auckland and Wellington, have developed legible landscape features among waterfronts and other pedestrian-dominated spaces. However, in secondary urban areas in New Zealand, such as New Plymouth, the industrial system still functions. These secondary urban cities bear rich historical and culture value; but most of its features are buried under their industrialised urban development.

Secondary cities of New Zealand deserve an urban design refreshment, above and beyond the existing homogenized urban system; given the design opportunities in their rich historical and cultural backgrounds. These cities require a more legible design; one which reflects a city's cultural and historical identity. Pedestrian power should take over the freight-dominated urban system. Encouraging slow pedestrian movement will trigger a new consciousness, a mental imagination, of landscape. 


\title{
SITE INTRODUCTION
}

\author{
New Plymouth
}

New Plymouth is selected as the site for this design-led research.

New Plymouth is classified as a large urban city, secondary to other major urban cities, with a population of 57,600 in 2018 (NZ Government, 2018). New Plymouth is located on the west coast of the North Island. It is the only NZ classified urban area within Taranaki Region. New Plymouth city's current identity is known for the vision of Mt Taranaki, the Coastal Walkway, the Wind Wand, and Len Lye Centre.

The central area of New Plymouth is the business, retail and commercial centre to the entire Taranaki region. Most people come to the central area for shopping, eating, visiting, meeting, and entertainment.

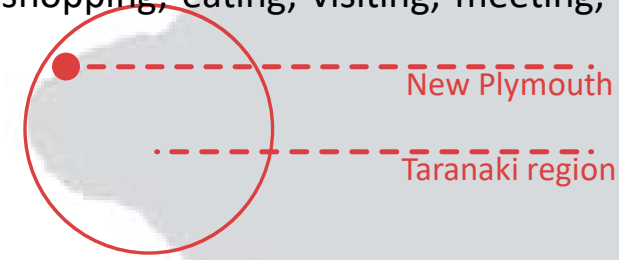

New Plymouth bears a significant Maori historical and cultural value. There are more than 30 iwis identified in the New Plymouth District. Iwi of Puke Ariki, Te Kawau, Waimanu, Puke Rangi, and Mawhera were settled alongside Huatoki Stream (NPDC, 2013). They used Huatoki Stream as a food source at least until the earliest colonial settlement in the early nineteenth century (NPDC, 2012). Part of Huatoki Stream was then buried under concrete.

Residents of New Plymouth district are proud of their living environment, and the history it bears within. While New Plymouth's population is continuously increasing, it is aging - the population over 45 is expected to increase from $38 \%$ to $46 \%$ in the next 15 years (NPDC, 2010). A pedestrian-friendly and age-friendly urban system could cooperate with this trend, to provide a higher-quality living style and legible urban landscape. 


\section{NEW PLYMOUTH DISTRICT COUNCIL CENTRAL AREA DESIGN GOALS}

In December 2011, the New Plymouth District Council passed a resolution to become a signatory to the Urban Design Protocol. The Urban Design Protocol was developed in 2005 to assist development to consider best practice design in the urban environment. It was based on the need for guidance regarding urban environment management and was the result of collaboration between the Ministry for the Environment, a range of local government representatives and industry experts (NPDC, 2013).

Council held a survey in 2012, asking citizens their thoughts on the central area, which received almost 200 responses (NPDC, 2012). The image below shows the key-words of people's opinions, provide by NPDC's Document.

What is the Central Area known for?

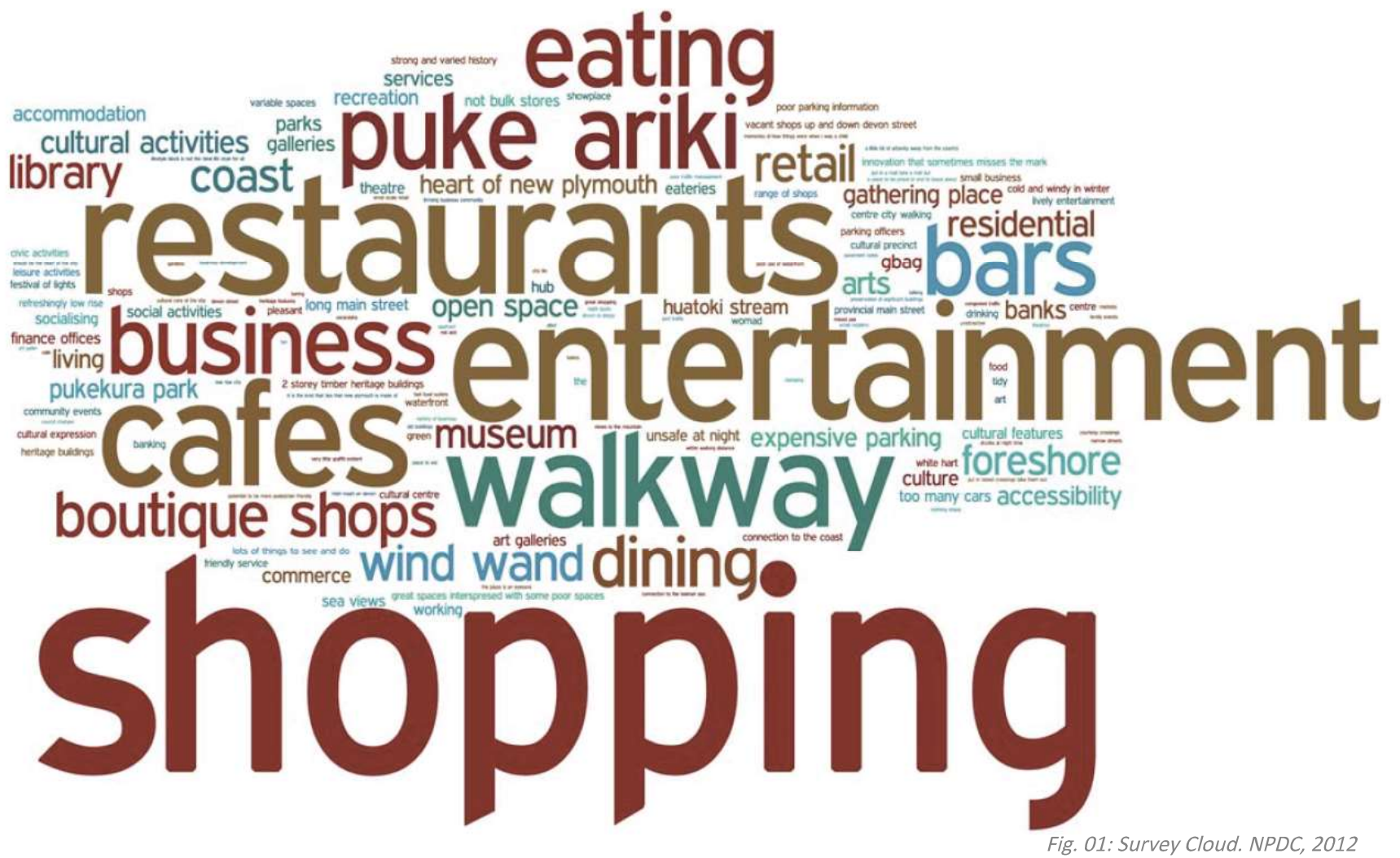




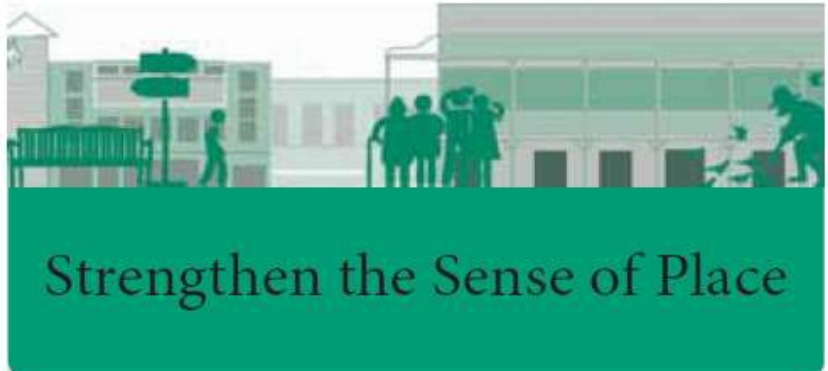

- Green Coastal Centre-

- New Plymouth will promote healthy and sustainable living and business in the Central Area through best practice management of the natural environment and a good quality public space network.

\section{- Good Urban Manners-}

- Ensuring new development in the Central Area is well designed and contributes positively to the amenity, sense of place and streetscape of the surrounding area.

- Human scaled built environment.

\section{- Respect for the past}

- Identification and support for precincts and character areas

Fig. 02: Strengthen the Sense of Place. NPDC, 2012

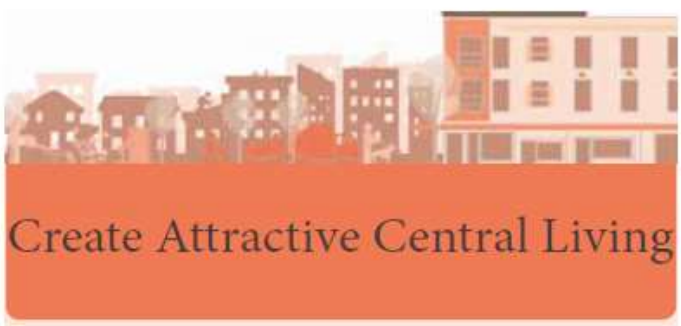

- People friendly spaces and good accessibility to nearby public places e.g. the Coastal Walkway, Pukekura Park.

- Promote a wide range of housing choices

- Investigate barriers to good quality medium density housing in the Central Area and develop appropriate incentives.

Fig. 03: Create Attractive Living. NPDC, 2012

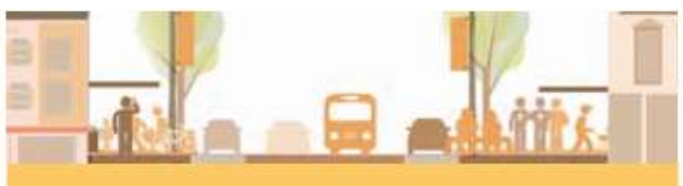

Allow Freedom of Movement

- Pedestrian Precinct- Balance between users; human pace and increased pedestrian permeability.

- Public Transport- Letting people know; traffic information and education.

- Streetscape Plan-Safe movement and an efficient network.

Fig. 04: Freedom of Movement. NPDC, 2012

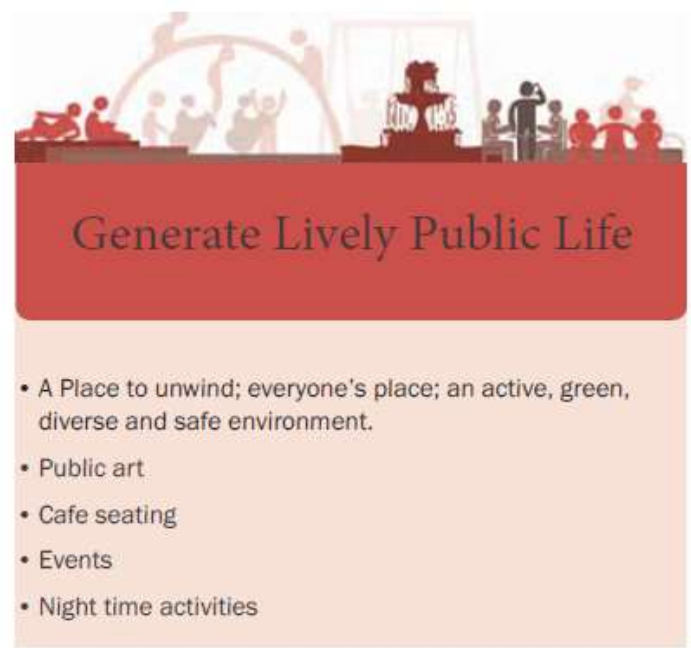

Fig. 06: Generate Lively Public Life. NPDC, 2012 


\section{PROBLEM STATEMENT}

A city is a construction in space on a vast scale, it is a temporal art to be perceived in long spans of time on different occasions and from different people (Lynch, 1960). Every citizen has had long associations with the city; their image of the city is soaked in memories and meaning. Humans' imagination of their landscape reflects on their self-identity, evoking a sense of belonging with their living environment. The problem that arises for the discipline is that cities around the world are designed homogeneously; they are losing their identity as well as their imaginability. Contemporary landscape architecture tends to focus on small-scale design without thinking about the systematic identity of the large-scale context. The city is losing its legibility as a whole and becoming uninteresting to move within and experiment within - people mostly just stay in their cars. It is the role of landscape architects to recover the legibility and imaginability of cities.

Under this problematic context, New Plymouth Central Area is a representative urban space. New Plymouth District Council has proposed urban planning strategies, as listed in the previous section. These strategies seem general and banal, and may only continue to bury the unique identity of New Plymouth, by proposing to replace the particular with the universal. Contemporary urban planners are likely to make the same decision as New Plymouth District Council, creating design decisions based on universal human needs, but ignoring the uniqueness of different design contexts. It is necessary to explore a distinctive design system to enhance the identity of New Plymouth. 


\section{RESEARCH SCOPE}

This design-led research investigation proposes a design-led response to the Problem Statement by recover the identity of New Plymouth's central area through designing a legible and imaginable city scape. The primary scope of research integrated into two approaches: understand the mental image of landscape, provide an imaginable landscape design solution.

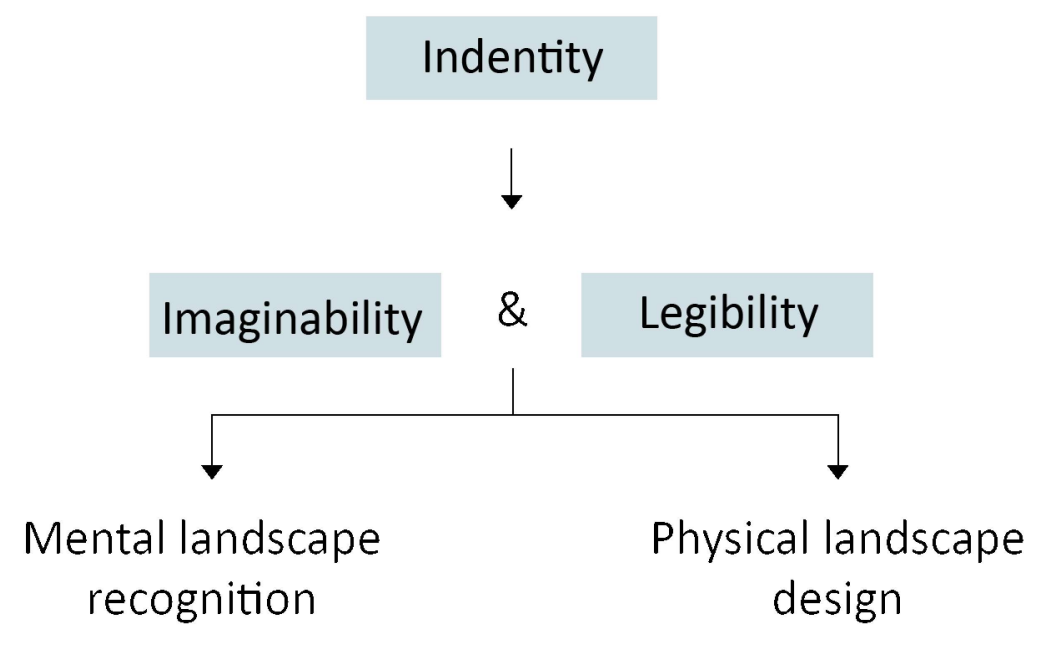

Fig. 1.07: Research Scope Diagram 


\section{2 \\ PRECEDENT THEORY}

"Imagination is needed to observe large scale perspective, while the large
landscape must have influences of the masterly compositions."
- André Le Nôtre (as cited in Steenbergen \& Reh, 1996)

Kevin lynch introduced the concept of "landscape legibility" in 1960. A city should not identify as a thing itself. He suggested a legible city would concentrate especially on one visual quality: the apparent clarity of cityscape, which can be recognized and be organized into a coherent pattern (Lynch, 1960). Urban elements are interrelated to each other. Interrelationships of subjects are perceived by the inhabitants, who develop an image in their minds.

Lynch believed a legible cityscape possesses a high degree of imageability. He drew out the importance of visual preservation of satisfaction through experimenting with the city. He posits this mental image is correlated to the observers' well-being, and their relationship with the environment. Lynch identified five physical elements - edge, path, district, node, and landmark - that would evoke mental imaginations (Lynch, 1960). His theory pointed a direction to further landscape cognition studies.

Critics of Lynch's theory argue that a city's mental image is a much more complicated subject. People would have different perceptions of space based on theirgender, age, familiarity with thearea, religion, etc. Anne Stenros suggested that, in the perception of space, the human body operates at three levels that appear simultaneously: the perception level, of physical reality; the memory level, or images filtered through our personal history; and the abstract level, which on a general level organizes and directs perception, memory and action in the environment (Stenros, 1993).

Simon Schama suggested memories connect personal history to the land; they trigger mental recognition. Landscape is culture before it is nature. Our imagination projects onto natural elements, which become the identity known to the human (1995). Christian an Norberg-Schulz, who introduced genius loci, has argued that the task for the landscape architect is to visualize the spirit of space and create meaningful design (1979).

To perceive the identity of a city requires both a conscious experience and an active mind. Visual attractiveness will stimulate recognition and memories. Of the senses of the human body, Vision is the most dominant. Humans first visualize, then symbolize landscape to understand it, and then create space (Norberg-Schulz, 1979). The visual sense adjudges spaciousness and its related indicators, such as degree of openness, building density, and the nature of spatial boundaries: the essential elements in landscape perception and preference. (Nijhuis, et al., 2011). 
However, visual landscape design is most often related to small-scale landscape identity. On a large scale, urban order and patterns create balance between the individual and society; they link the small-scale landscape identity to the larger context; they provide a medium in which everything can grow and unfold organically (Hilberseimer, 1949). Urban order and density is a complex but substantial issue, with many connections with the value of a settlement. Lynch used the concept "grain" to represent urban texture (1981). Understanding the density, grain, and access system - the city's internal order - are the principal features by which we may judge its performance.

This research will discover and improve New Plymouth's existing identity by creating and re-creating a mental image in citizens' minds. It will investigate an abstract method to represent the cognitive perception of the city's identity. It will examine New Plymouth's urban order, and reinforce this pattern into a more recognizable design strategy. It will emphasise historical and cultural value. It will design a visually orientated pedestrian-friendly city. 


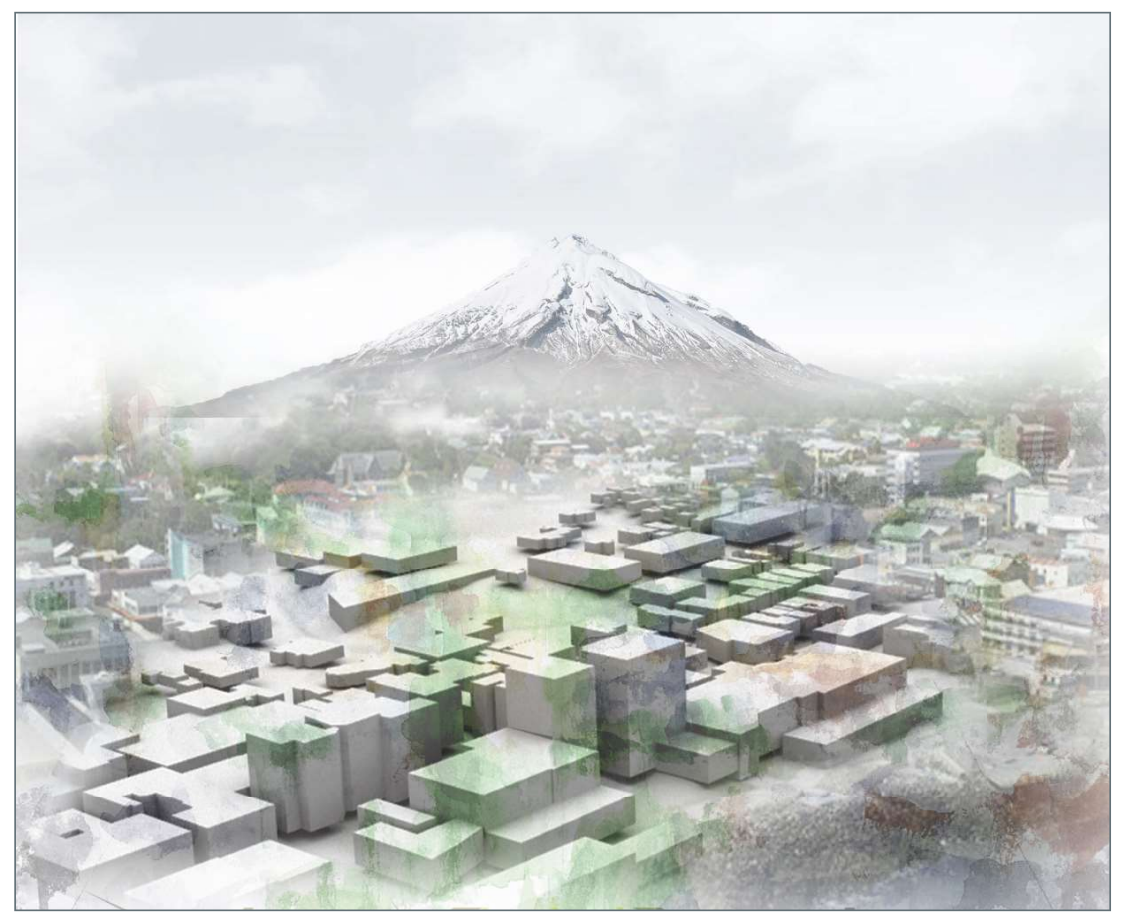

\section{RESEARCH QUESTION}

How to Transform Visual Perceived Landscape Interventions in a small scale to Mental Recognized Landscape Context, in order to achieve a legible urban design? 


\section{RESEARCH AIM AND OBJECTIVES}

The primary aim of this research is to incorporate an abstract design method to develop a physical design solution that will reorientate people's mental image of New Plymouth's Central Area through visually directed movement.

Five objectives for achieving the design aim are:

1. Analyse the site; reveal the history and cultural assets within New Plymouth central area; understand the identity of New Plymouth

2. Examine the existing patterns of New Plymouth city; understand the urban order behind these patterns; develop new urban orders to re-orientate occupation.

3. Investigate a method to transform the abstract mental landscape image onto paper; test this method through New Plymouth site studies.

4. Study human visual behaviour through movement; apply a mental-image representation method; explore opportunities to achieve visually orientated large-scale landscape imagination.

5. Employ and test these previous four objectives the design process. 


\section{METHODOLOGY}

This design-led research process will be in three main stages: theoretical research; analytical studies; and design testing (Diagram to the right). These three stages revise and review each other, to achieve the research goal: the orientated mental image of a city.

This research's main challenge is to understand the abstract concept of mental image: and to integrate this abstraction into a physical design. It will investigate methods to represent the abstracted image on paper, by introducing the intuitional painting technique from the discipline of fine art. This method will be applied and tested through the entire research process.

This research will go through five key stages,

1. Understand New Plymouth's existing condition: study the site and examine citizens' awareness of historically valuable places in New Plymouth; research through GIS mapping; study the existing urban pattern through plans and sections; frequent site-visits to examine the large-scale pattern with walked experience. (Objective.1.2)

2. Review literature and precedent, selected based on site problems; reinforce the research topic and investigate an approach to mental image and landscape design. (Objective.3)

3. Experience the site as a pedestrian and a driver; study the visual experience by moving through the site at different speeds and in different transportation. (Objecve.4, test objective.2.3)

4. Explore design opportunities at a context scale; start a design framework and develop it into a master plan (Objective.5, test objective.3.4)

5. Develop human-scale design which informs the framework; design-development and reflection. (Objective.5) 


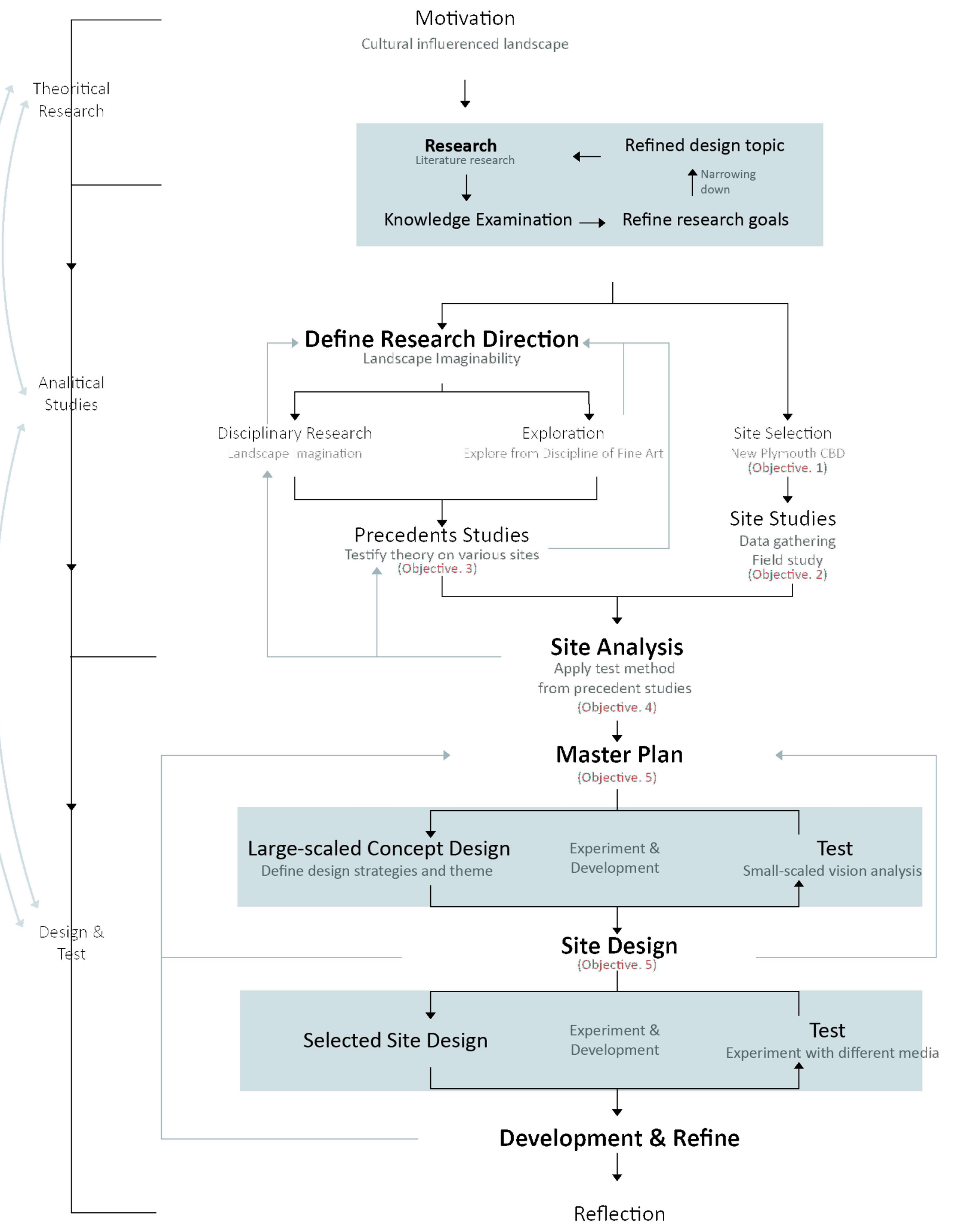

Research Process

Reviews

Fig. 1.08: Methodology Diagram 
Identity

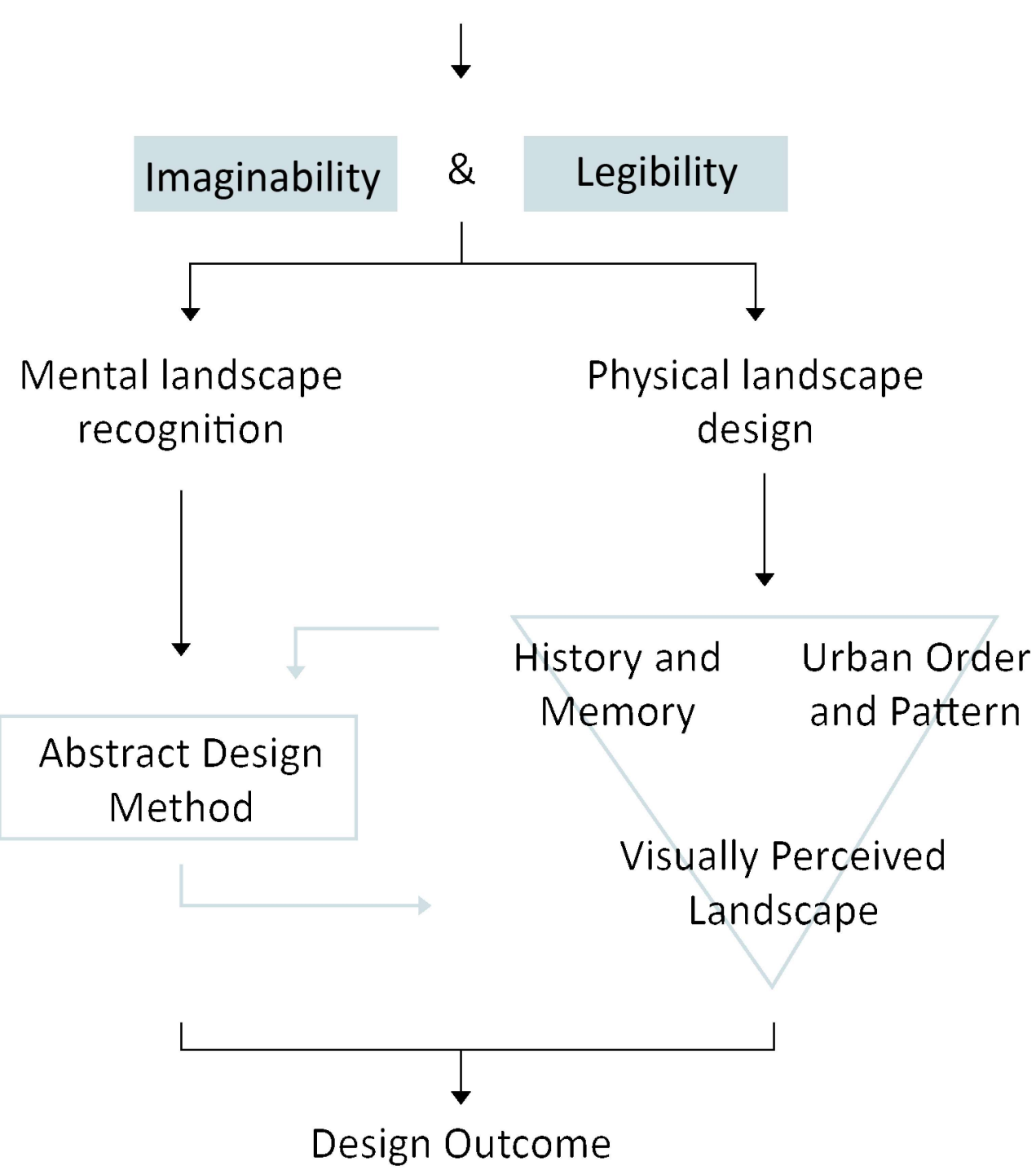




\section{THESIS STRUCTURE}

\section{Chapter 1.}

Introduction

Chapter 2 (Stage1, Objective1.2). Site Description

Introducing the research site, New Plymouth.

A description of the site conditions and assets in relation to its historical and cultural value.

Chapter 3 (Stage2, Objective2.3.4.5).

Theory

Exploring the research topic; Reviewing principal theorists in relation to the design aim and objectives; reviewing theories of historic landscape design, landscape metrics, and visual landscape assessment.

Searching precedents around the world that relate to the research goal. Reviewing their design techniques alongside research objectives.

\section{Chapter 4 (Stage3, Objective.4)} Site Analysis

Studies based on human scale, street scale and context scale. Testing the urban pattern through human-scale analysis. Understanding how a largescaled pattern affects human experience. Examining the visual quality of the site through movement. Revising previous research, creating the city's mental mapping.
Chapter 5 (Stage4, Objective2.5) Master-plan

Reviewing previous chapters, summarizing the site challenge and related design solutions. Re-orienting the site system in context scale, to cooperate with its historical value. Adjusting the urban orders and patterns to achieve a better mental image of the city.

Testing the framework through humanscaled visual analysis. Examining the consistency of visually-directed movement through the city. Iterating the master-plan and selecting critical sites for smaller-scaled design.

Chapter 6 (Stage5, Objective5) Site Design

Site concept design and design development, allowing small landscape interventions to inform the larger context. Redirecting view shfts towards designated historical features. Keeping a similar design-style through each selected site to achieve consistency and legibility.

\section{Chapter 7}

Conclusion

Concluding and reflecting on the research solution; stating the constraints and limitations; discussing other potential applications of the findings 


\section{2}

\section{SITE DESCRIPTION}

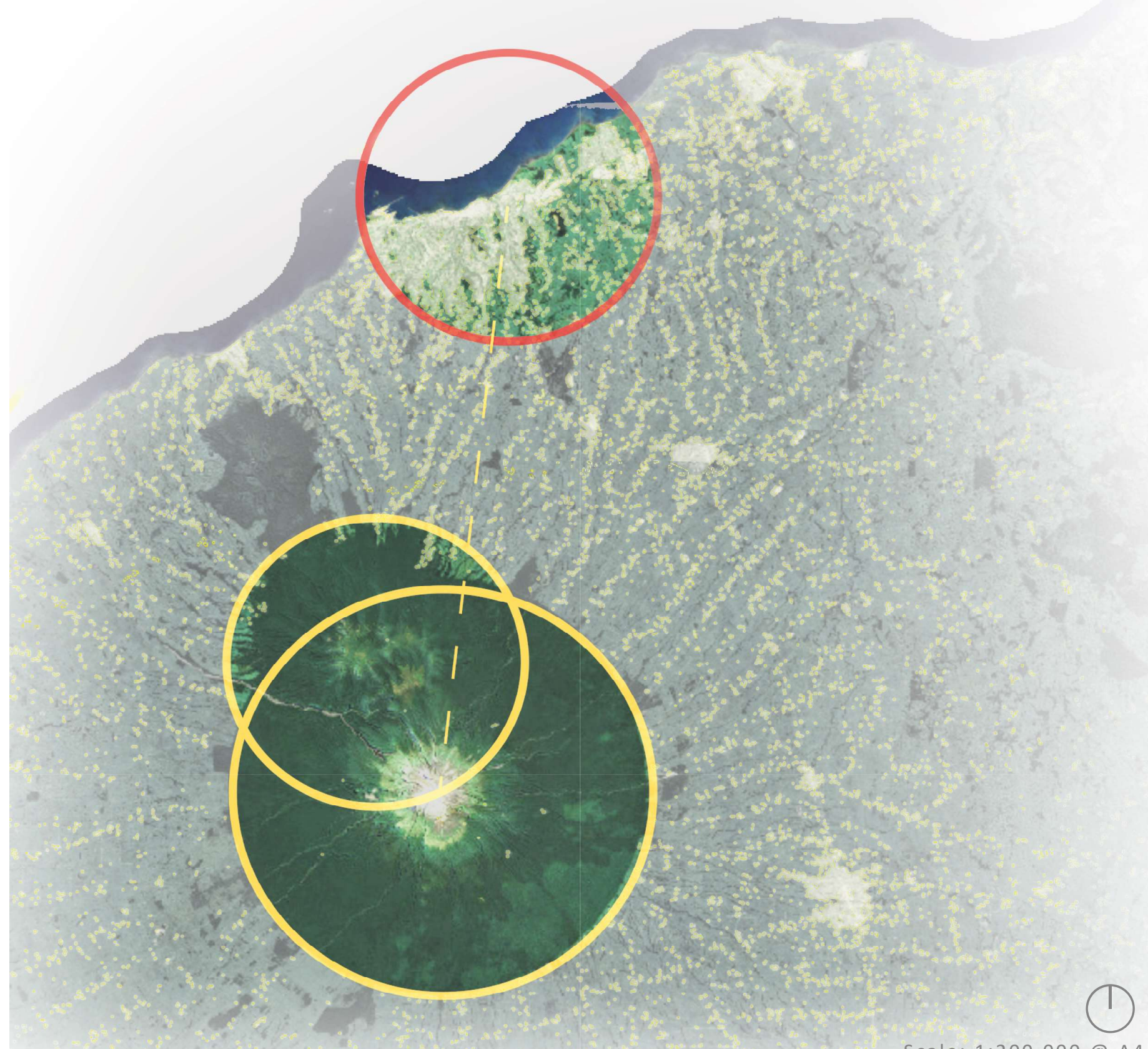




\section{CONTEXT INTRODUCTION}

Taranaki is a region in the west of New Zealand's North Island. It is named after its main geographical feature, the stratovolcano of Mount Taranaki, the second highest mountain in the North Island. New Plymouth is the major city of Taranaki region, located at the northern shoreline of the region.

The map below shows the New Plymouth district settlement. The commercial and business zone is located by the northern coastal line; the industrial area is located to the west of the commercial and business centre. The residential areas still lie outside the commercial and industrial areas, because it was developed along Garden City lines. Residential zones kept separate, the commercial area is relatively flat, formed on a grid, while the residential areas followed the pattern of the topographic landforms. Suburbs spread from the main roads, then fade into dairy-farmland.

The defined research site is the commercial centre of New Plymouth (Central Area). which is the business, retail and commercial centre to the entire Taranaki region. The current commercial/central area was developed before the residential area, so bears rich historical value; but it also displays the problematic issues shared among towns of 19th-century landscape design. The site is determined by an era of functionalism. The urban area is orientated towards the port, and freight to and from it. However, when the port reduced in size and the railway shifted, the left -over space was converted to provide for the economic needs of the town.

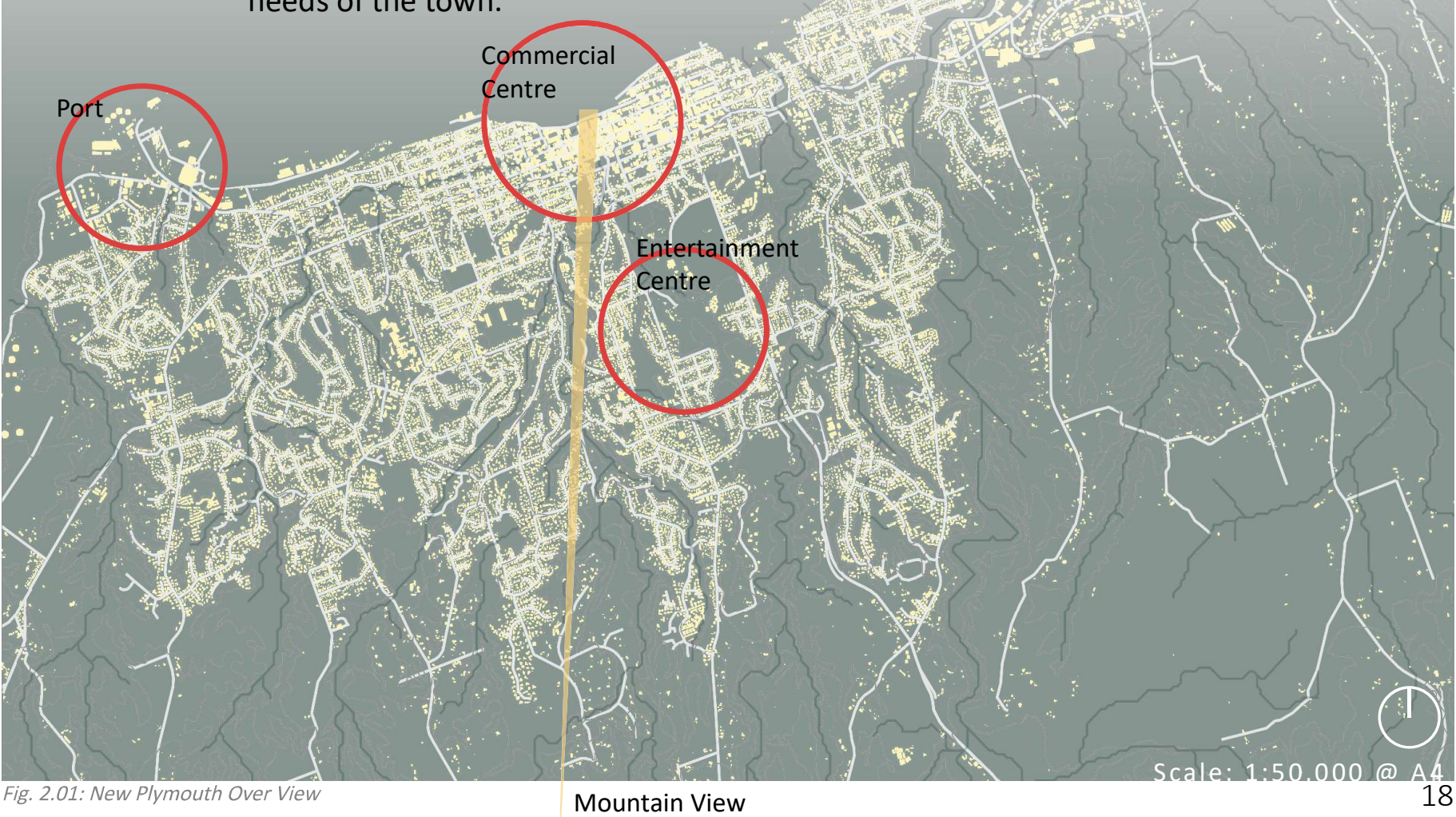




\section{DEVELOPMENT HISTORY}

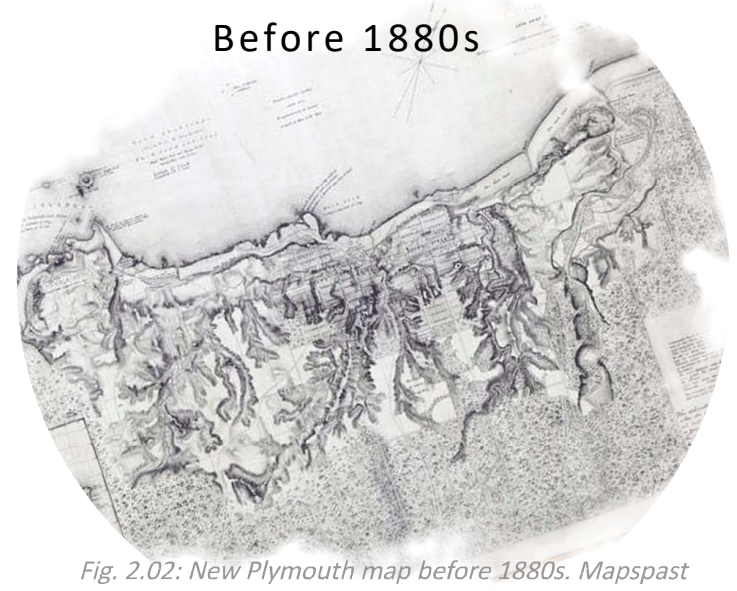

$1930 s$

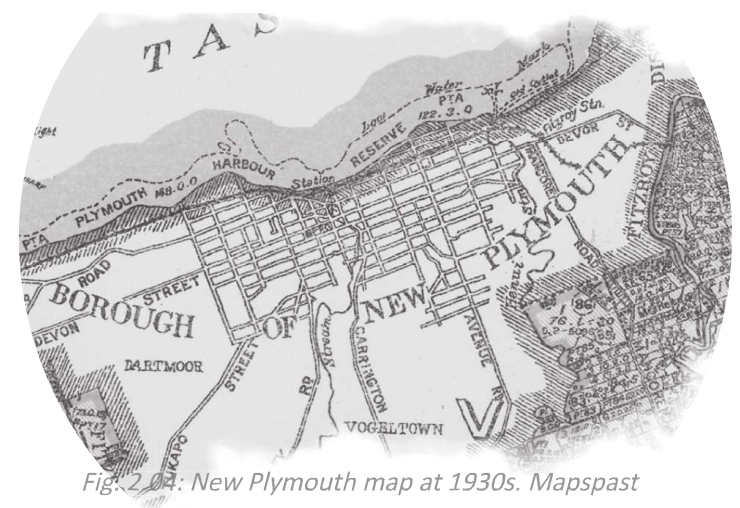

\section{$1980 s$}

Centre City Shopping Development

Richmond Centre

Development

New Plymouth District

Council formed

7 Day shopping

\section{$1990 s$}

The Warehouse and Public Car Park development on Devon Street

Decommissioning the Pedestrian Mall and the consequent Devon Street upgrade

New Plymouth District Plan development
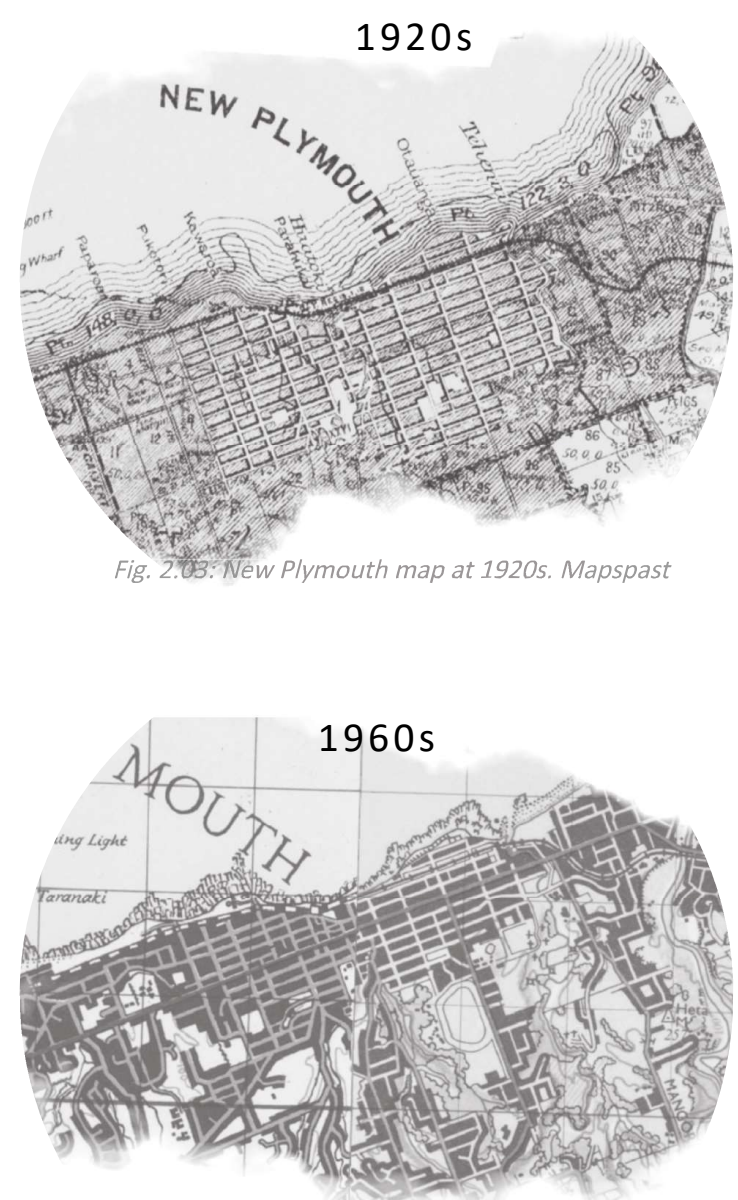

Fig. 2.05: New Plymouth map at 1960s. Mapspast
$2000 s$

Installation of CCTV cameras

Puke Ariki Building and Landing

Wind wand installed

Coastal walkway construction begins

Central Bus Station

Huatoki Plaza

\section{$2010 s$}

Let's Go intiatives-cycle parksBrougham Street Upgrade

Earthquake Prone Building upgrades or demolitions

Len Lye Centre

Police Station

redevelopment

Redevelopment of the

YMCA site 

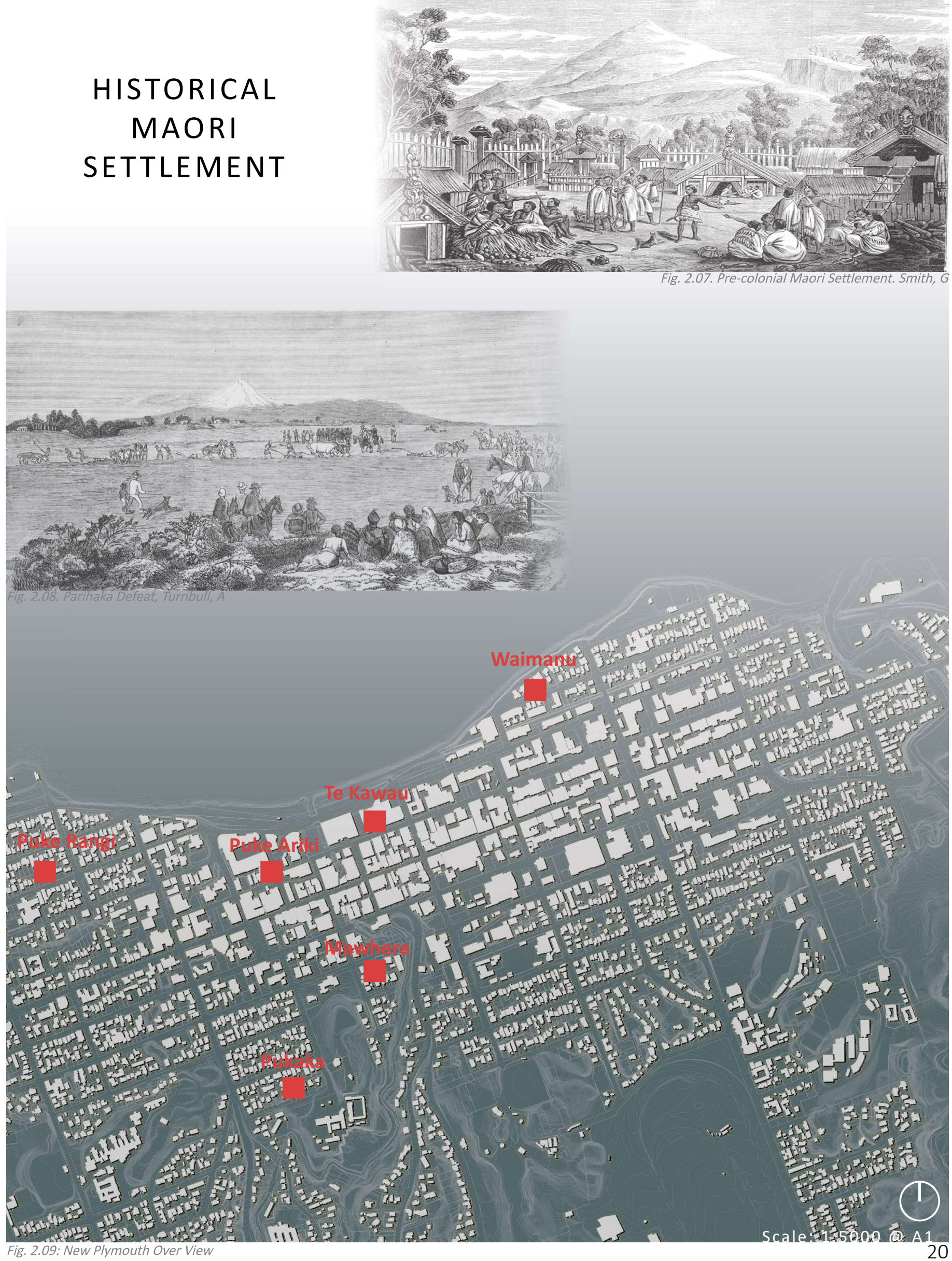


\section{NATURE ASSETS}

The Central Area is a highly modified built environment, with almost no previous land cover retained, a high proportion of impervious surfaces, and many changes to the original landform. Most green spaces are well designed, with the notable exception of the walkway of Huatoka Stream.
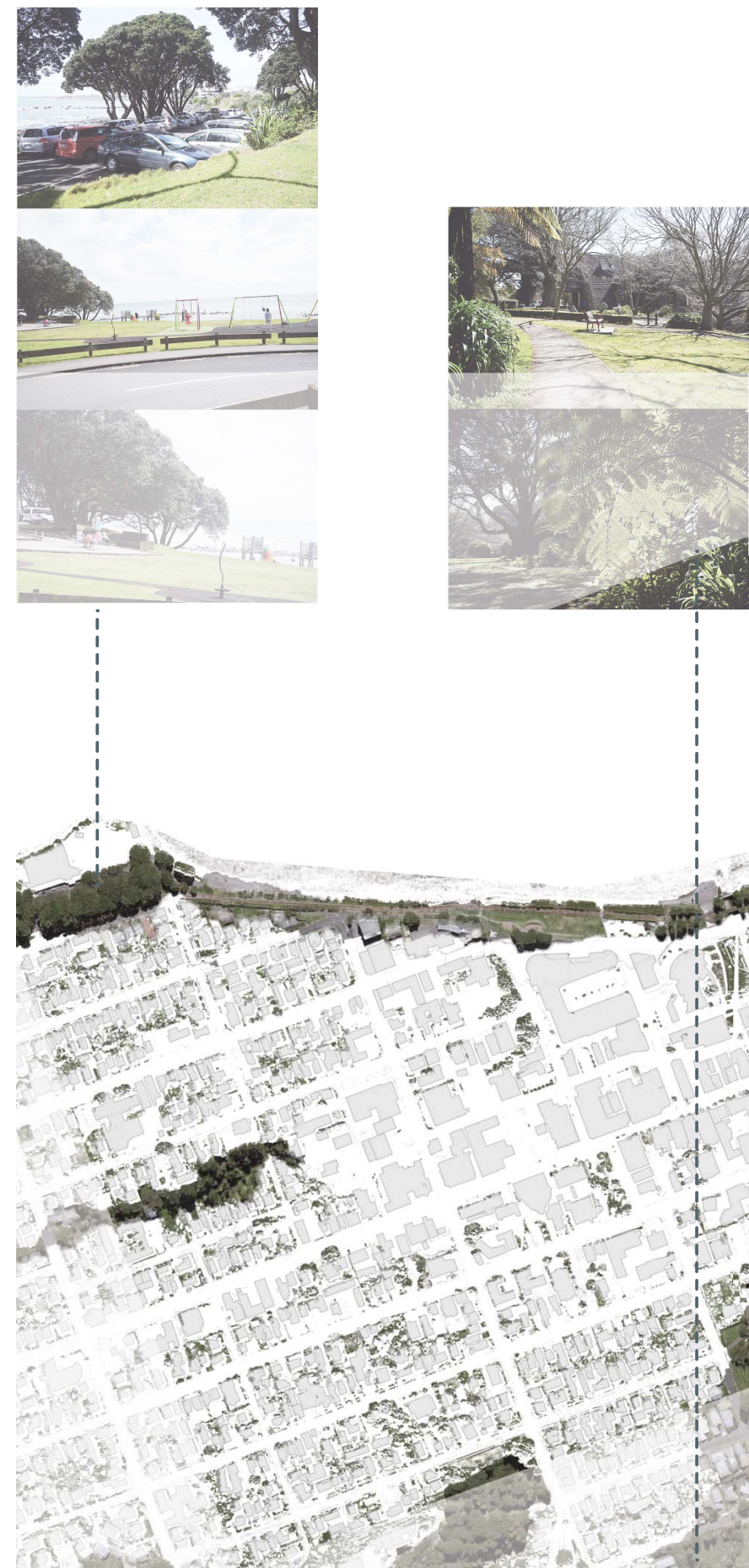

Huatoki Stream Walkway
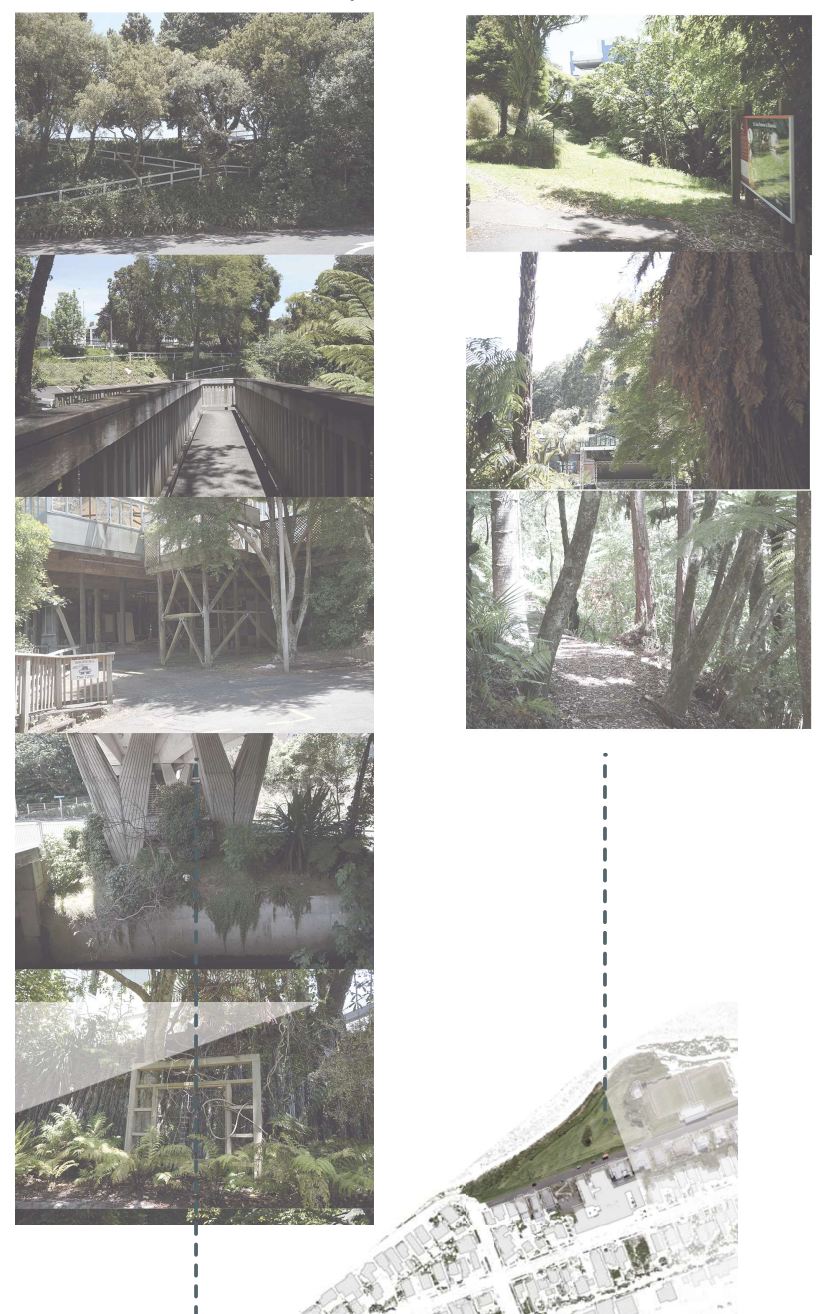

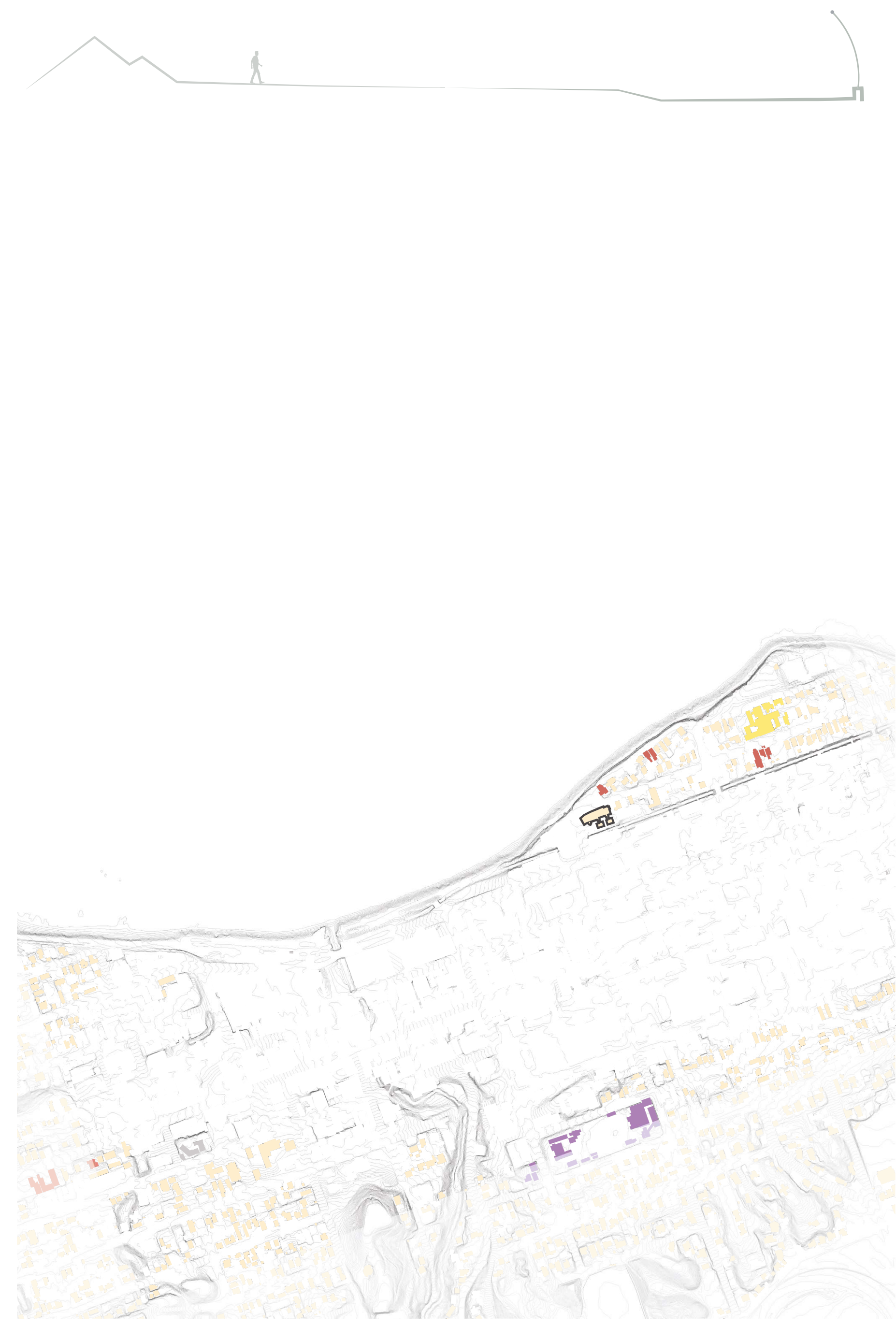


\section{FACADE}

Active Façades are rarely established in the Central Area. Devon Street, the town centre, is the only activated street. Active façades are facing backward to green spaces. The activity zone is separated by open space and the coastal walkway.

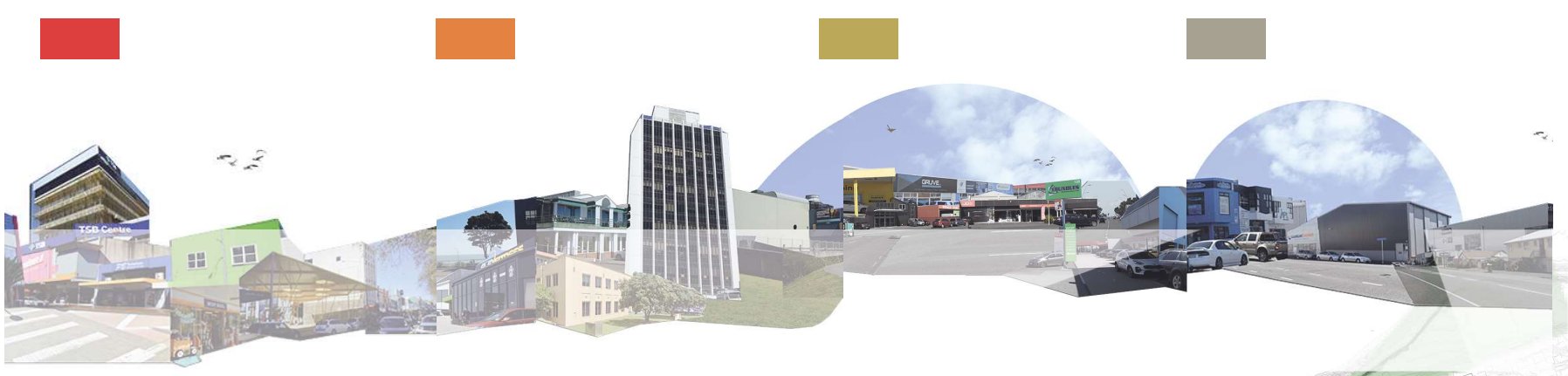



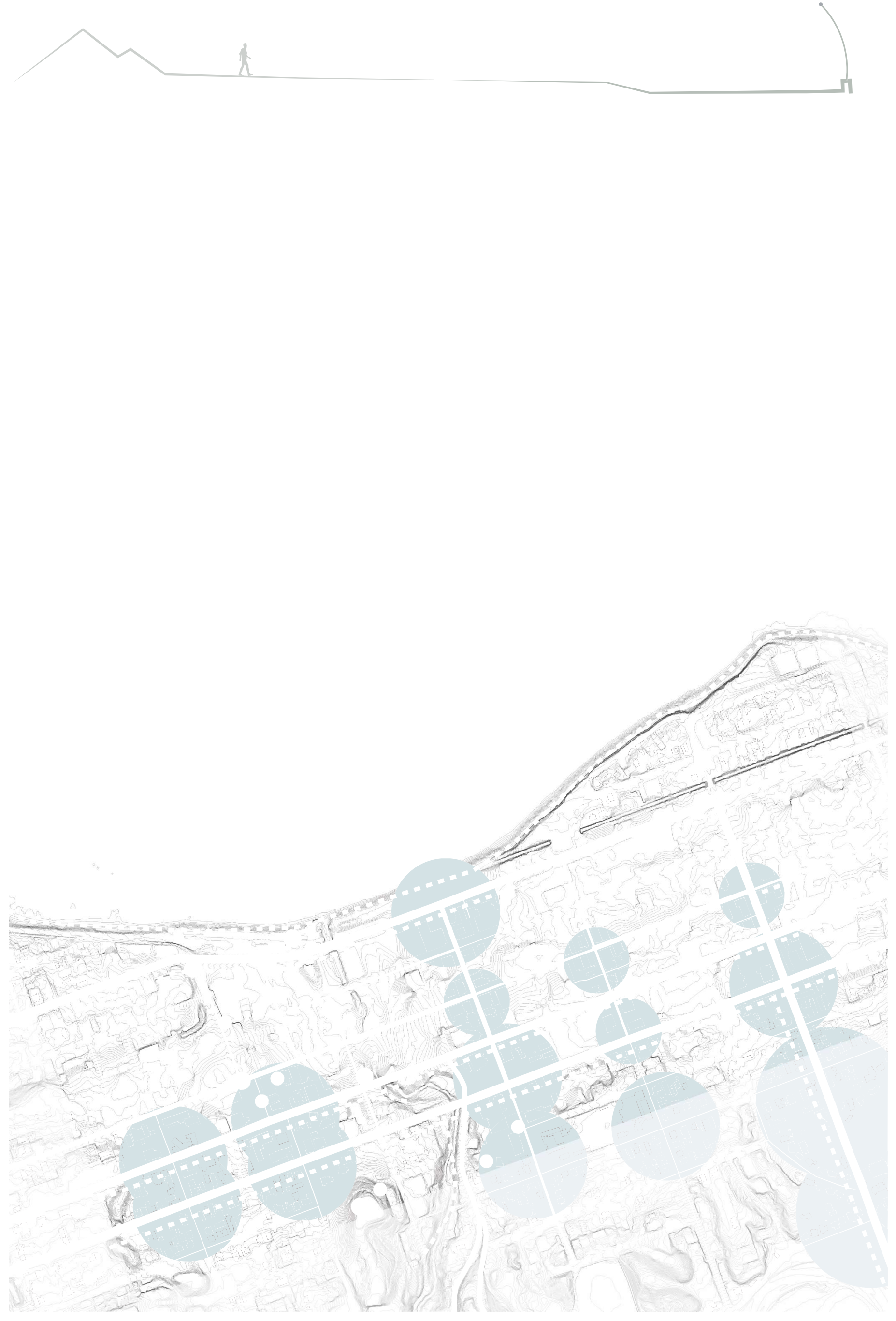


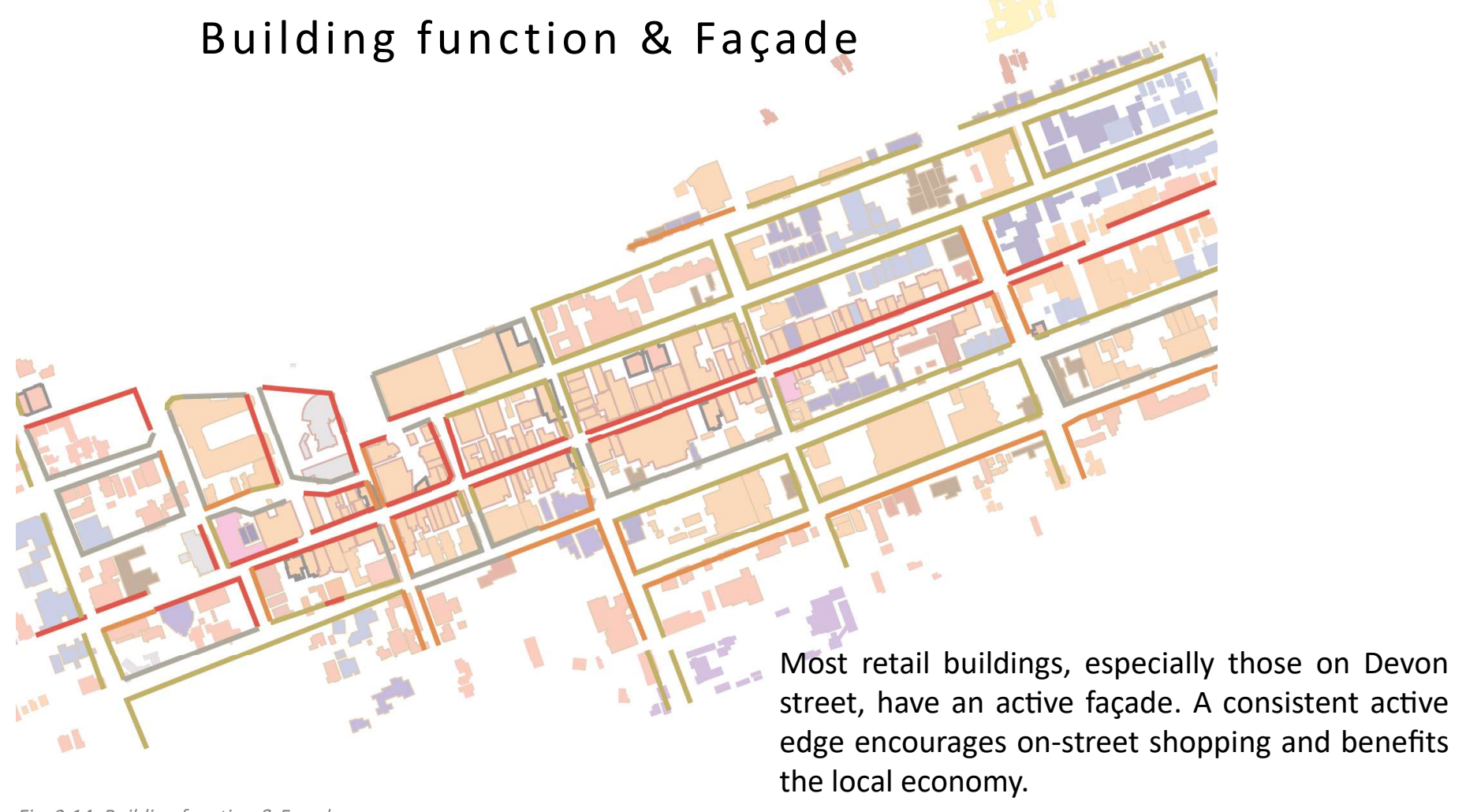

Fig. 2.14: Building function \& Façade

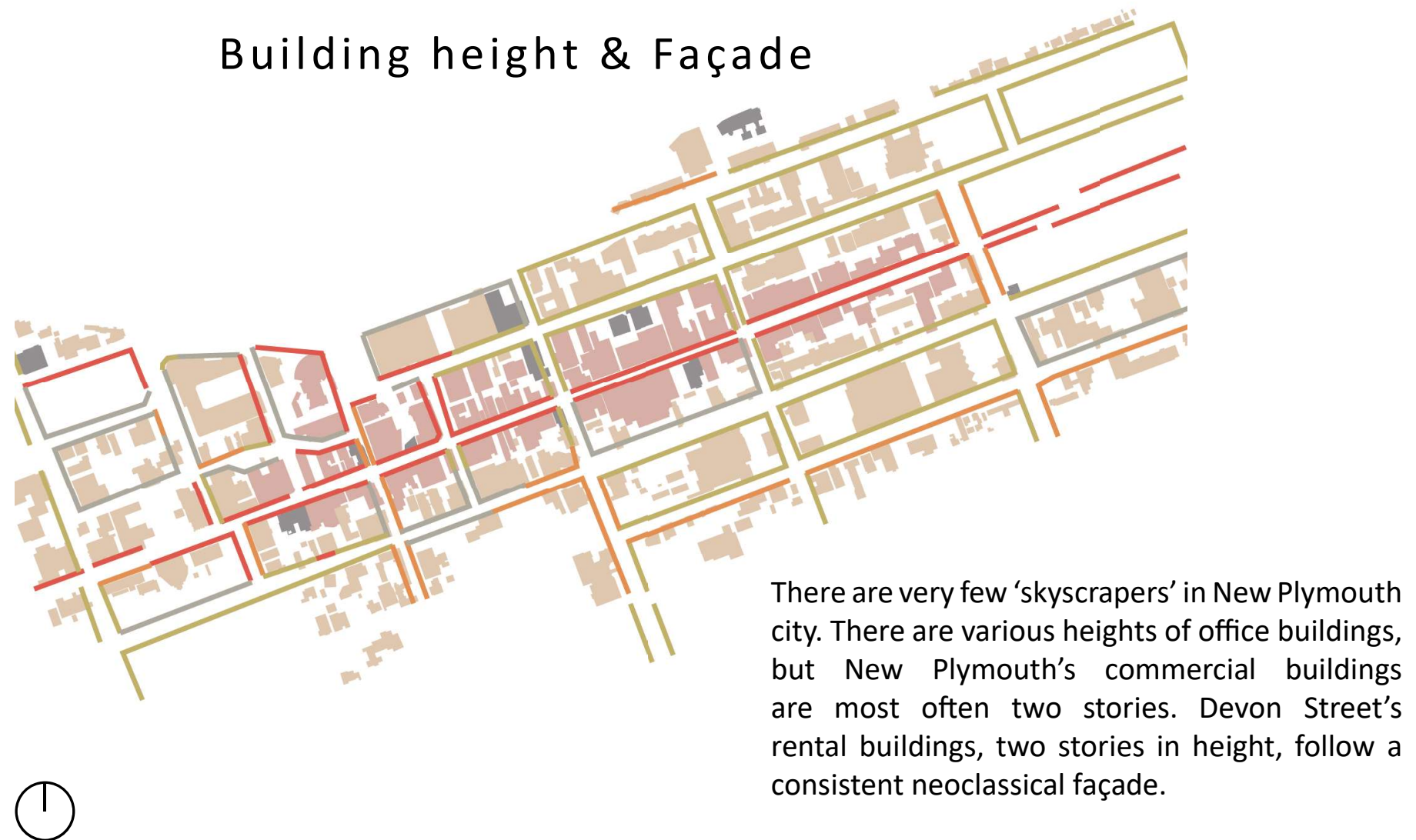


2.2 Site Description

\section{Building function \& Traffic Intensity}
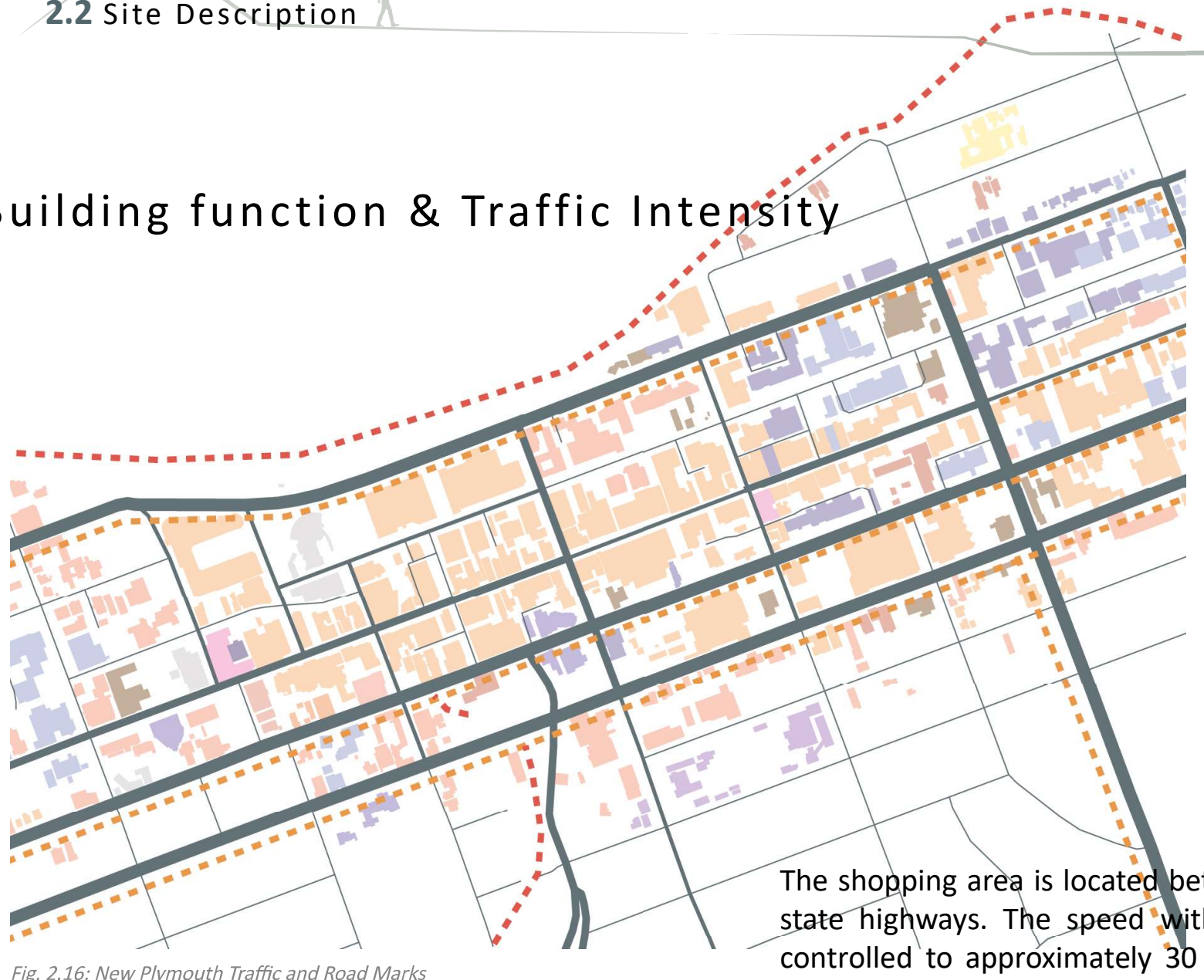

Fig. 2.16: New Plymouth Traffic and Road Marks

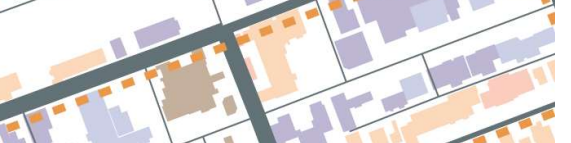

The shopping area is located between two busy state highways. The speed within this area is controlled to approximately $30 \mathrm{~km} / \mathrm{h}$ in Devon Street, to support on-going pedestrian-friendly street design.

\section{Green space \& Traffic Intensity}

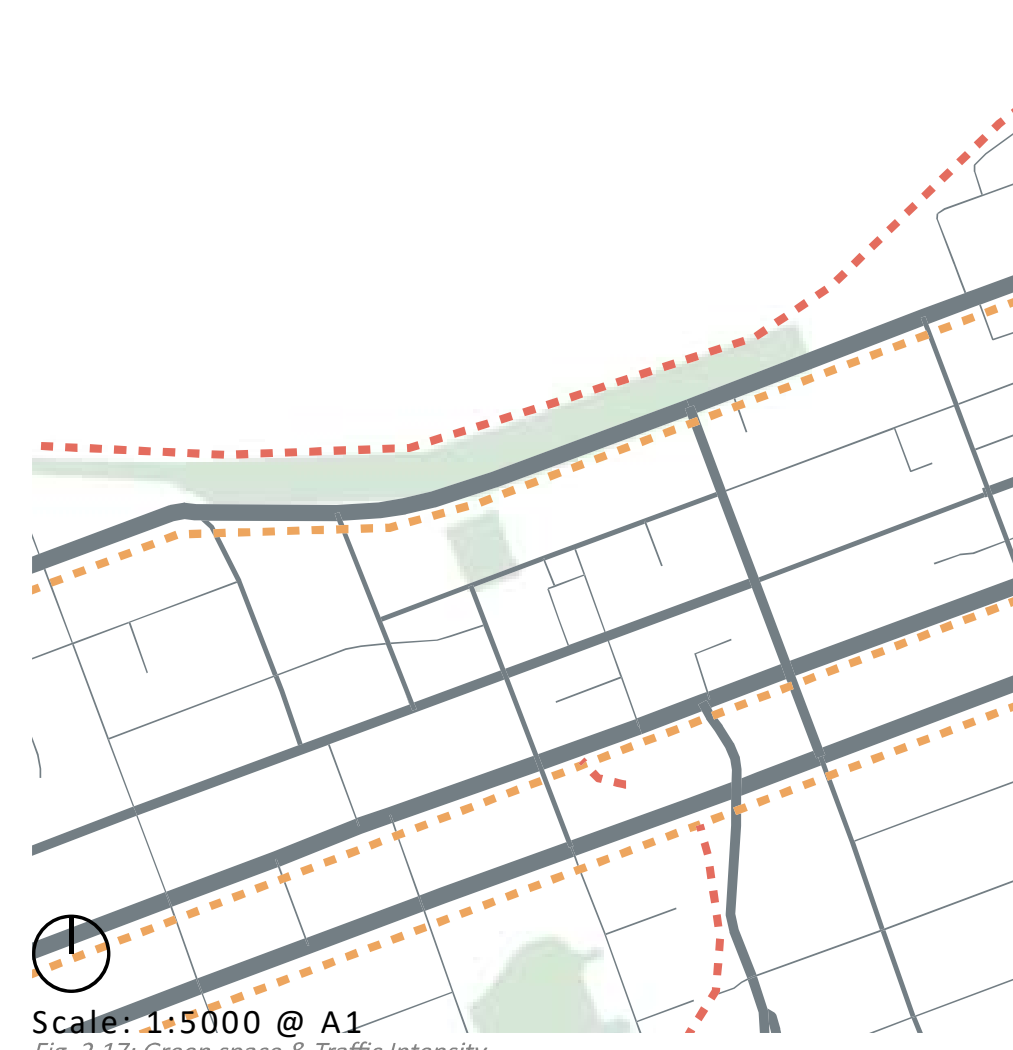


2.3 Site Pattern

\section{SITE PATTERN}

Site pattern trace the past developments, telling the historical stories of New Plymouth.

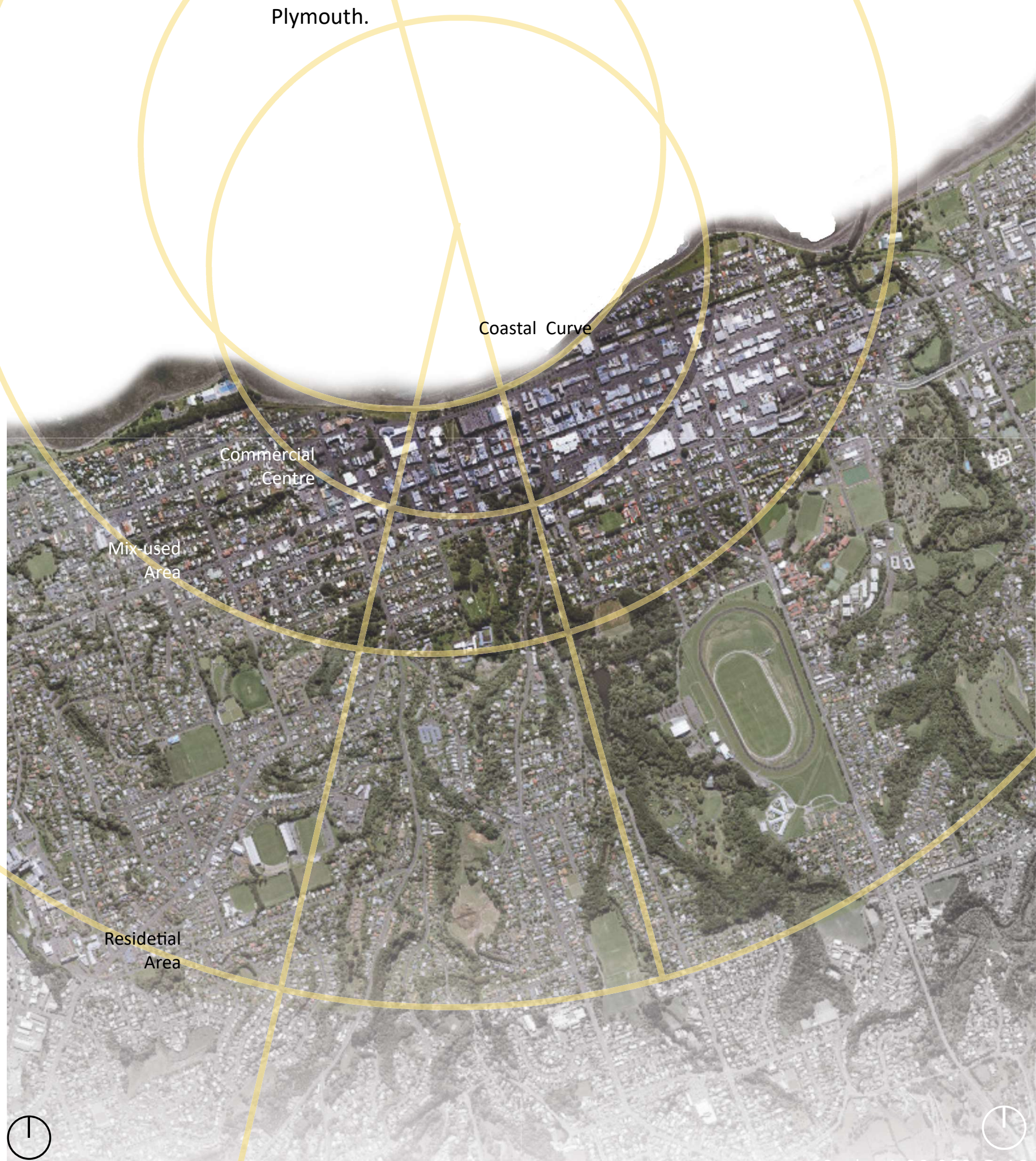

Scale:1:5000@A1 


\section{TOPOGRAPHICAL PATTERN}

New Plymouth Central Area has been historically reshaped to be relatively flat and formed on a grid. The southern area of New Plymouth is higher, hilly, and its streets wrap around this hilly topography more organically. As this map suggests, a distinct semi-circular line appears between the natural topography and the sudden change to flat land where it meets the city centre area. 


\section{BUILDING}

\section{PATTERN}

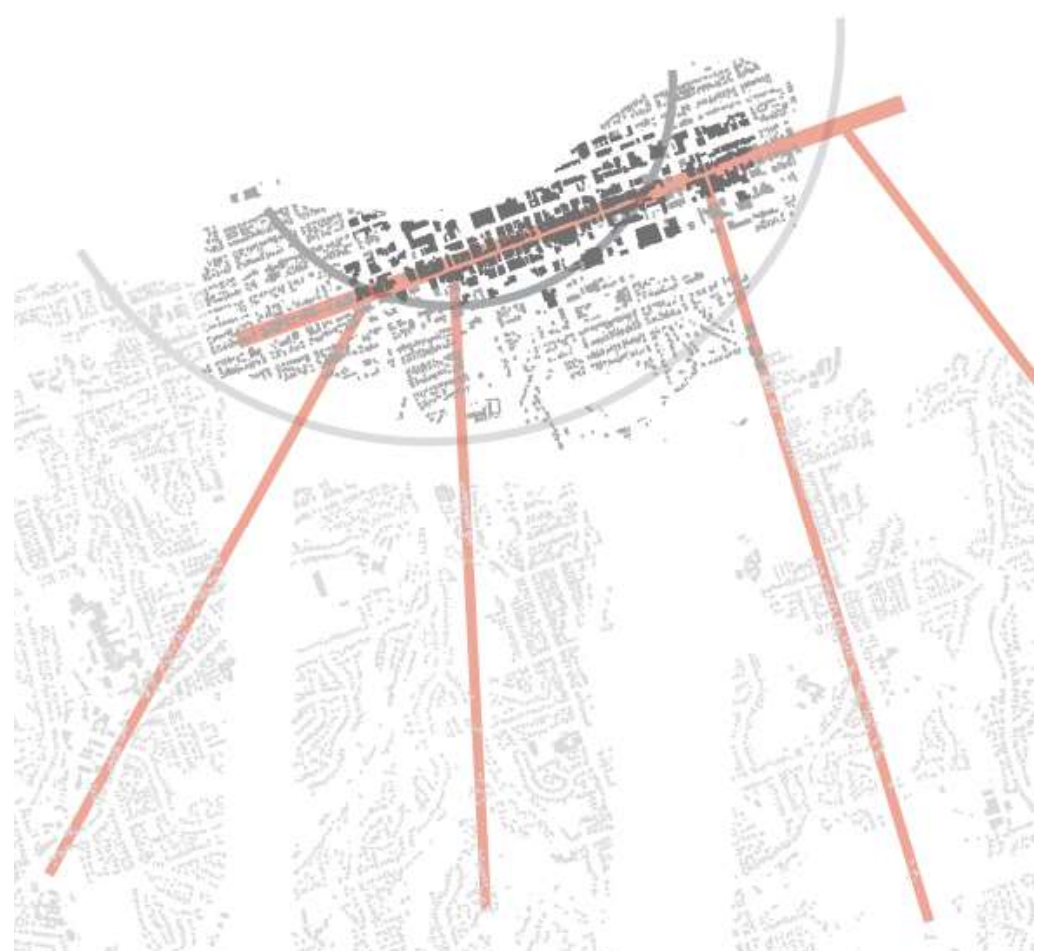

These maps represent the gentle transition of building sizes from the city centre to the residential area. Commercial and office buildings with large-footprint and high-rise blocks are located within the first circle. Buildings of a smaller size dominate the second ring. Outside the second ring, buildings are mostly residential. These follow the contours of the landform, rather than the grid. This planning can be traced back to the central area's functionalist development, being reserved as a "garden-city style" residential area. 


\section{STREET \\ PATTERN}

New Plymouth's central area streets are of typical late 19th century design. Areas were planned with a similar street width, on a uniform grid pattern. The meandering streets of the residential areas beyond the city provide a more vibrant pedestrian experience. 


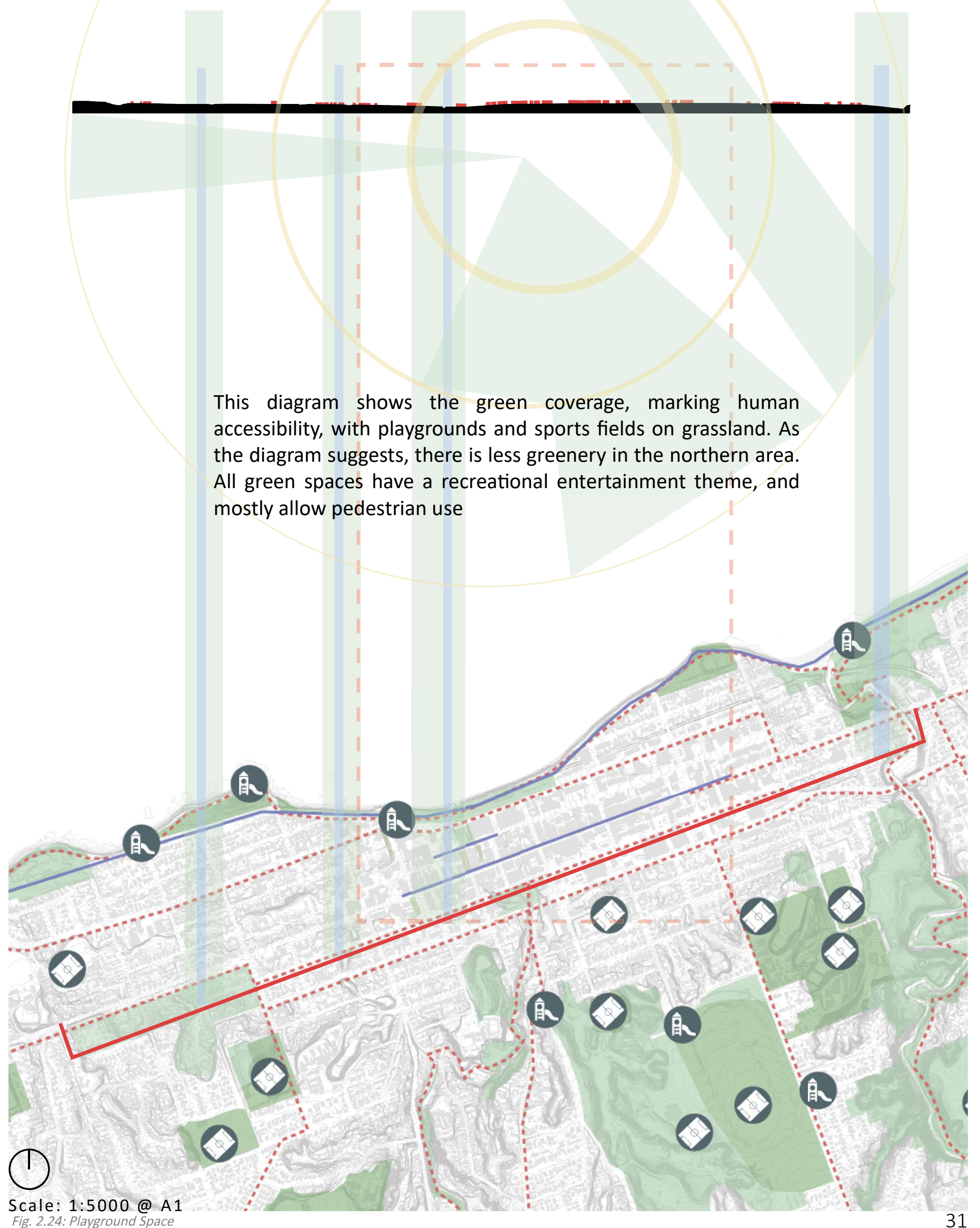




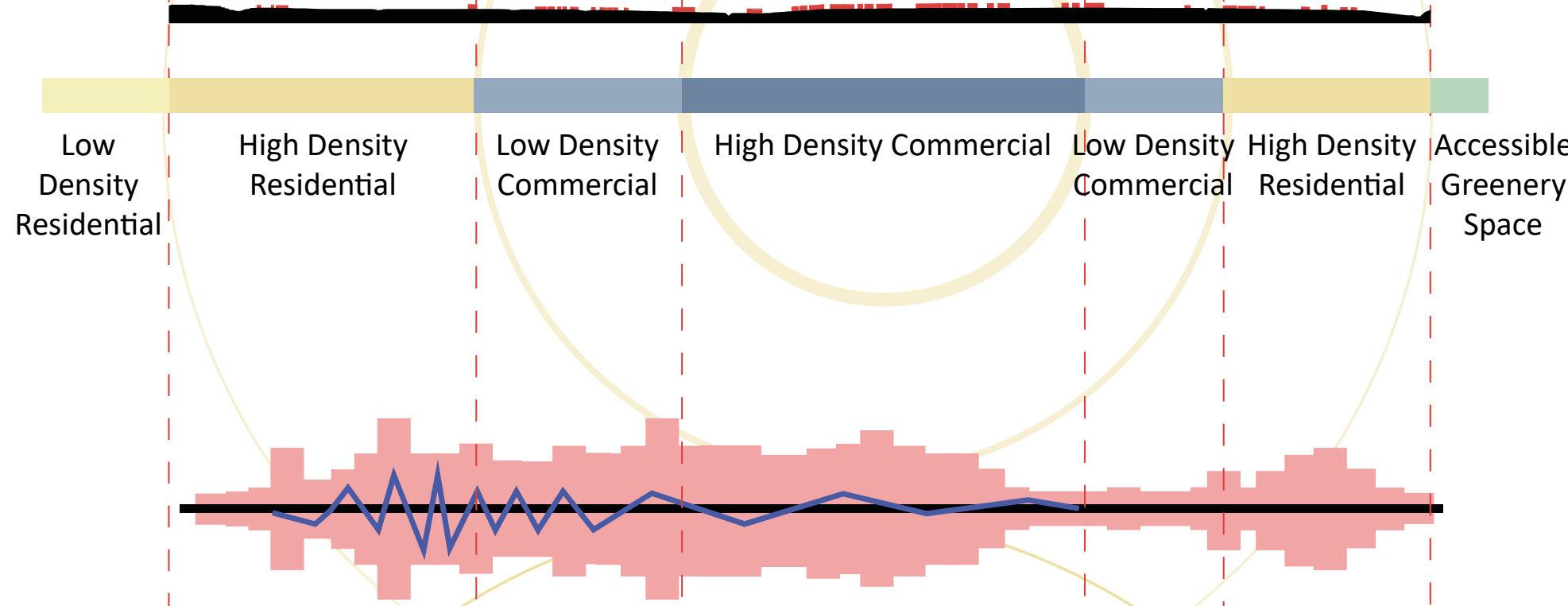

These diagrams suggest culturally/historically significant intervention-intensity across the district. The western part speaks a more intense story than the eastern part

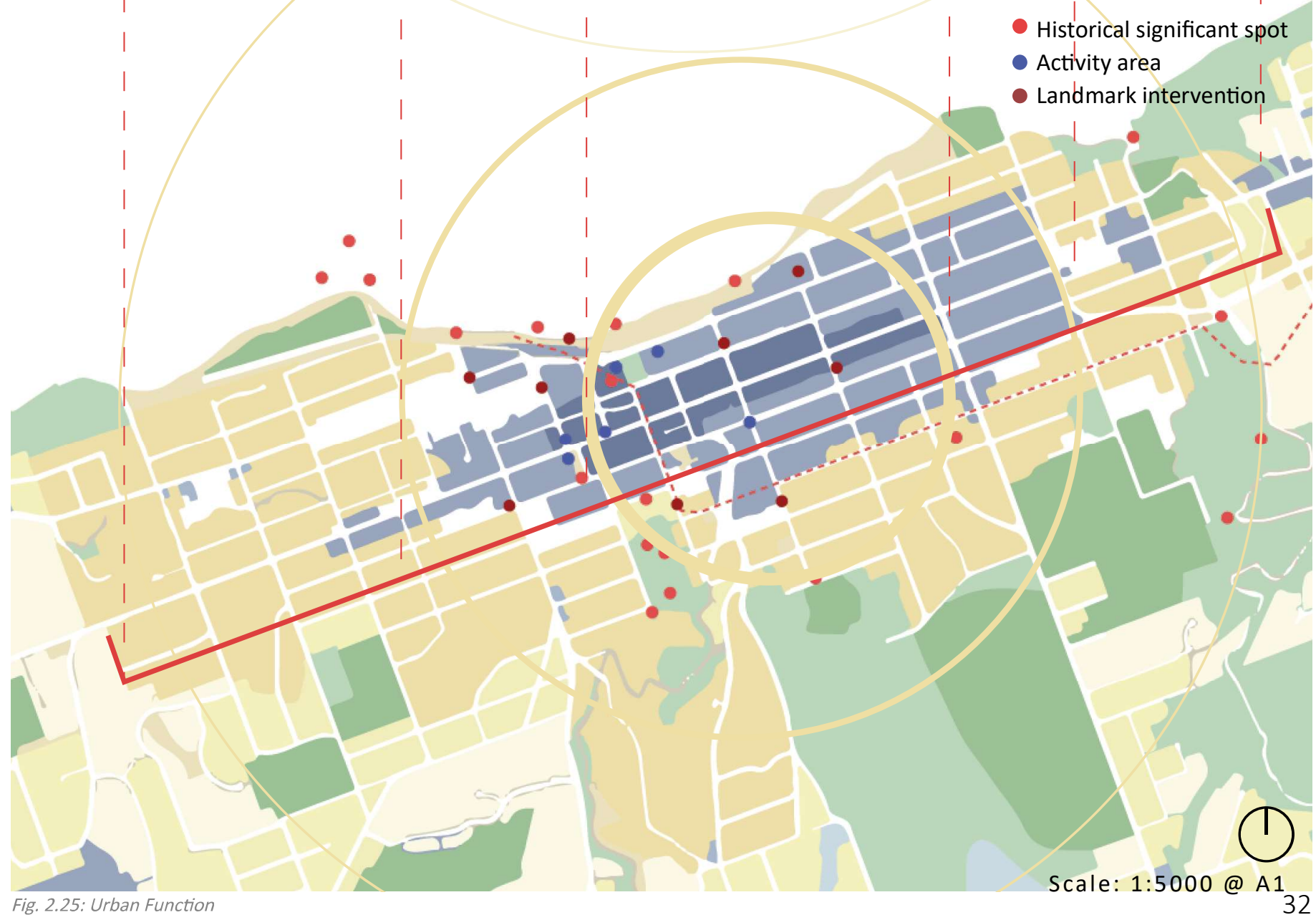




\section{PROBLEM IDENTIFICATION}

This chapter introduced the site history, describes the site condition, and explores the issues that cause New Plymouth Central Area to be an illegible space. After the industrialized development, New Plymouth and its central area were developed into a homogenized land to fit freight-orientated functional needs. Green spaces were removed, pedestrian rights were giving away to traffic. Lack of public-activity space and active building facade has taken away the vibrancy of pedestrian life in the central area. Heavy traffic dominates the coastal edge; industrial warehouses and high-rise buildings face backward to the coast and block the ocean view.

Despite New Plymouth's Central Area being deficient as a living environment, it still has value, which has already been transformed into individual memory. This chapter investigates the hidden logic behind New Plymouth's urban planning and finds a pattern that tells a story of the city's historical development. 


\section{REFLECTION}

Through several maps, in plan on various scales, this chapter introduced New Plymouth's current condition. New Plymouth's central area represents a historical form. The current cityscape speaks a historical language, that of functionalis urban design. This language will need to be respected because it is part of the image already formed in citizens' minds.

However, the plan view has its limitations; it does not show the ground experience. Images presented through plans are uncoloured, and illegible to an ordinary observer.

Sections and perspectives communicate the ground experience, but they are limited to the relatively small-scale. It is necessary to investigate a method to represent the entire city's image and employ it towards further site studies. 


\section{3}

\section{Theory}

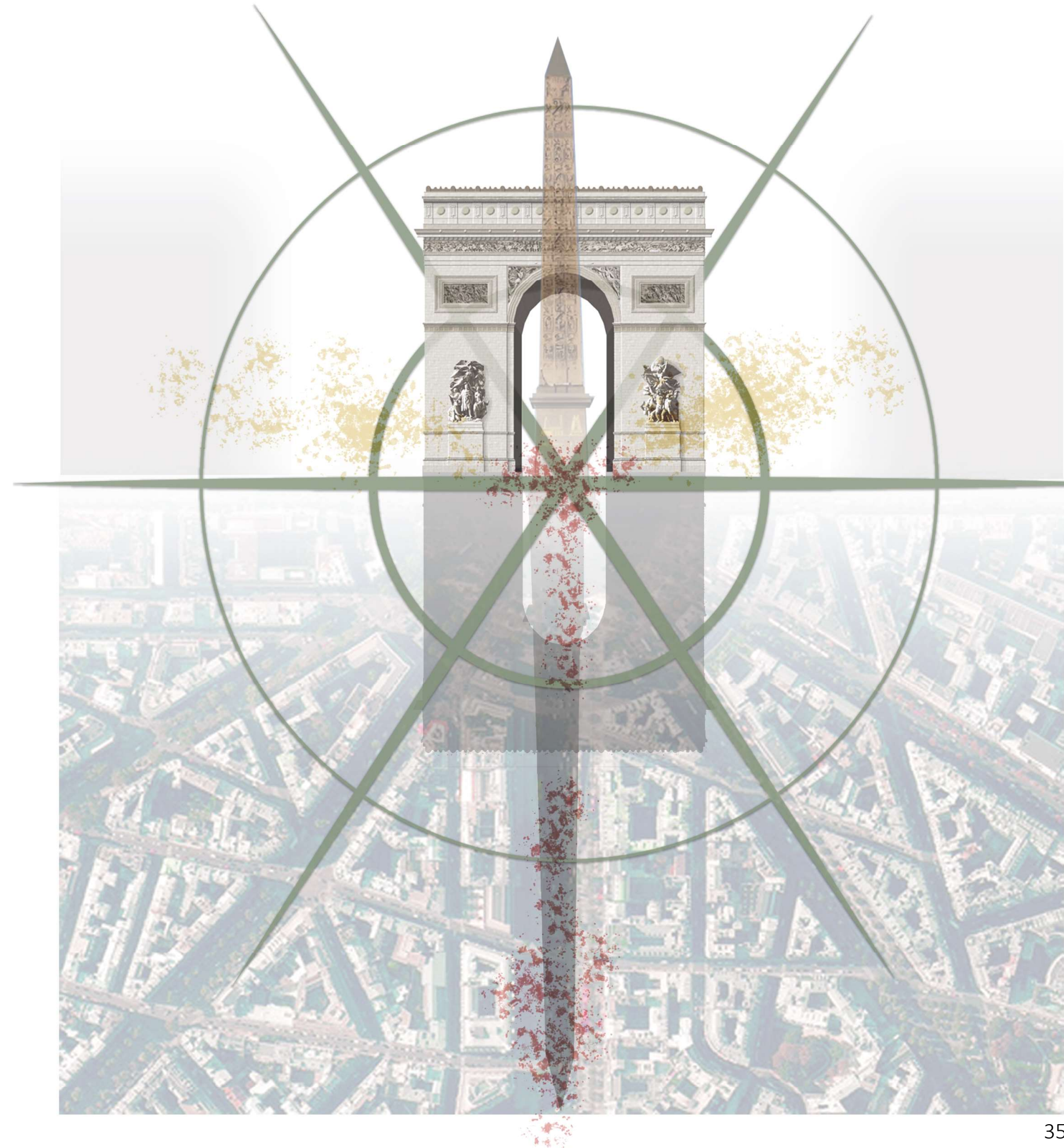




\section{LITERATURE REVIEW INTRODUCTION}

This chapter reviews theorists, precedents, and case studies, in relation to the research question: How to Transform VisuallyPerceived Landscape Interventions in small scale to a MentallyRecognized Landscape Context, in order to achieve a legible urban design?

The literature review will be divided into four sections: each reflects one of the research objectives:

1. Objective.3: : to investigate a method to transform the abstract mental landscape image onto paper; and test this method through New Plymouth site studies.

The first section will explore techniques from the discipline of fine art, especially impressionist artworks, to investigate an intuitional painting and presentation method; and understand what a mental image of landscape could look like to the eye of an artist.

2. Objective.1: to analyse the site, reveal the history and cultural assets within New Plymouth's central area; to understand the historical identity of New Plymouth.

The second section investigates how historical memory can transform and enrich the mental image, and strengthen the sense of belonging through experimenting in the landscape.

3. Objective.2: to examine existing patterns of New Plymouth city; to understand the planning strategies behind these patterns, and develop new urban orders to re-orientate occupation.

The third section investigates the power of urban orders and patterns, and how pattern can trigger mental recognition of landscape, and influence decision-making within the city.

4.

Objective.4: : to study human visual behaviour in movement;

by applying mental image representation method, and exploring opportunities to achieve a visually-orientated, large-scale landscape imagination.

The fourth section studies humans' unconscious visual behaviours through movement. 


\section{Mental Image}

\section{- Intuitional Landscape Understanding from the Discipline of Fine Art.}

Principal Artists:

Claude Monet, Camille Pissarro, Vincent Van Gogh

It is essential to look more deeply at the question, what does the mental image look like? Kevin Lynch had his concept, and drew it as a set of maps, derived from verbal interviews. He defined an approach, and took a small sample, only looking for those five elements (paths, edges, nodes, districts, landmarks) defined by his theory. People always have some vivid image in their minds, but if they can only describe their imagination verbally, that presents a landscape designer with problems of translation into, and out of, form and space. To find more methods, to address that problem, requires casting the net wider to draw in other means of showing the image. One of these methods is Painting.

Artists, especially impressionists, found their way to represent their imagination by drawing this image on the canvas. Impressionist artists explored new painting styles to express their passion for what they see within the world. Claude Monet spent his lifetime observing water, investigating the wave, and the light's reflection from the water (Fig.14). Camille Pissarro was interested in urban streets and farmland (Fig.15). Their painting technique applied heavy layers of paints, re-tracing his imagination of the world through vibrant colours and layers of strokes. Their painting no longer addresses the texture of objects themselves but a personal expression of the image in their mind.

The impressionist artworks were appreciated by the following generations and gradually developed into post-impressionism. Post-impressionists inherited their painting techniques, to express their emotions along with the presence of mental images. Vincent Van Gogh, whom Camille Pissarro influenced, was known as the father of Expressionism. His painting technique strongly reflects his emotions (Fig.16). Viewers can experience his mental progression, through his lifetime, through his painting. In his artwork, objects are endowed with an identity. They become not only an object itself but a presentation of Van Gogh's mental recognition of time and space.
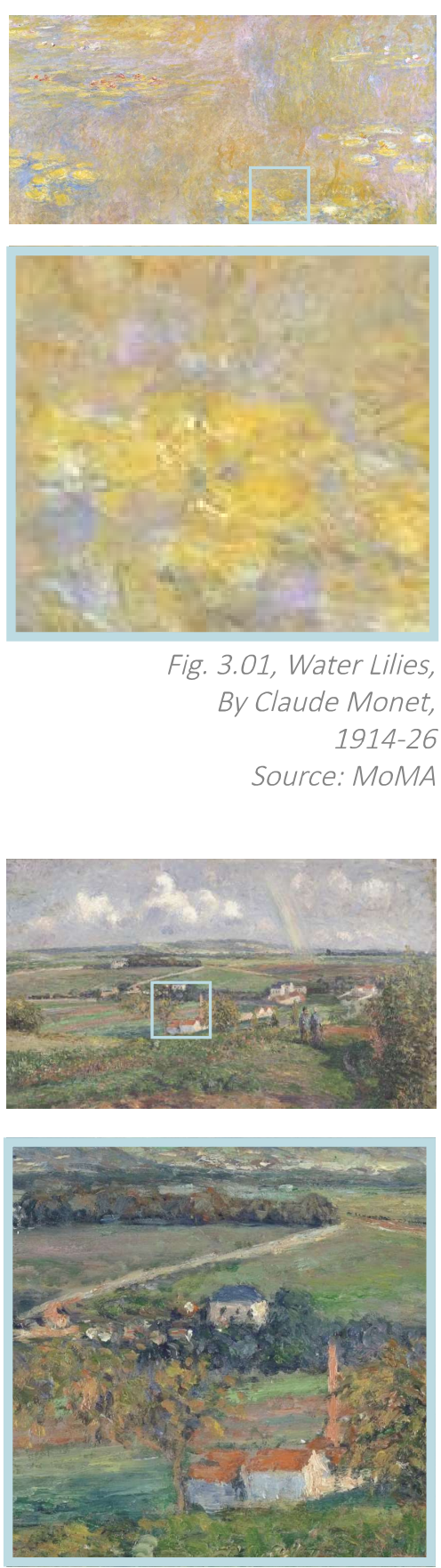

Fig. 3.02, Rainbow at Pontoise By Camille Pissarro, 1877 Source: Dailyartmagazine 
Unlike the classical artist who paints every stroke precisely, Impressionists relied on their intuitional recognition. Monet, Pissarro, and Van Gogh each actively observed the world, processing the landscape's visual image through their mind, searching for the world's essence by painting their mental image on the canvas. An intuitional method of landscape representation would demonstrate an unconscious recognition of the place. Landscape can be observed as a mass of colours and strokes rather than a combination of objects. This thesis will explore the site without paying too much attention to the literal landscape objects but looking at them as a group of visually perceived organisms; try to find a way to look at site from an artist's perspective; study and develop the essential identity of the site.

To look at the landscape from an artists' perspective requires one to actively perceive the visually observed image through the mind. The landscape architects' role is to trigger this active experiencing/ experimenting mode by designing a legible space and stimulating mental recognition of landscape and memories.
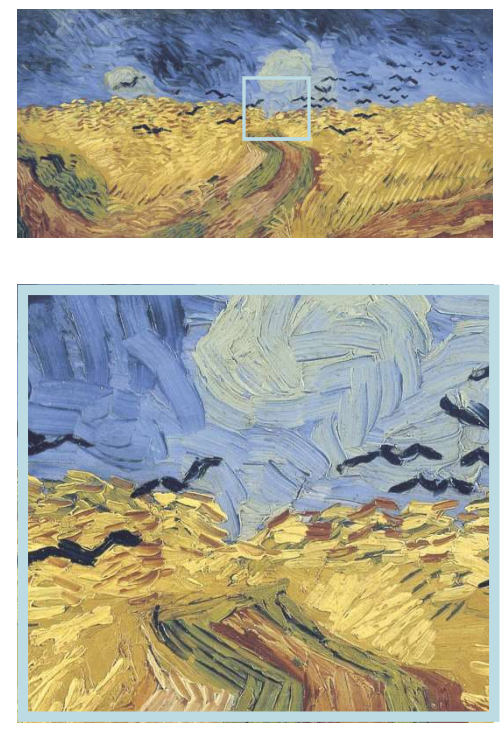

Fig.3.03, Wheatfield with Crows By Vincent Van Gogh, 1890 Source: VanGoghMuseum 


\title{
Landscape Memories
}

\author{
- History and Culture Trigger Landscape Recognition \\ Principal Theorists: \\ W. J. T. Mitchell, Simon Schama, Christian Norberg-Schulz, \\ Panita Karamanea
}
"It is better to paint from memory, for thus your work will be your own." - Paul Gauguin (Gauguin, 1936, pg.27)

Memories associated with the landscape are an essential tool to create social identities (Mitchell, 1994). A mental image of landscape, painted from memories, evokes a sense of belonging in individuals.

Simon Schama in Landscape and Memory says, "Before it can ever be a repose for the senses, landscape is the work of the mind (1995, pg.6-7). "Landscape and memory are concepts that are strongly interwoven in the identity of a place and its inhabitants. Schama suggested, "landscapes are culture before they are nature (1995, pg.61)." He argued that human-constructed imagination projected onto nature subjects, such as wood, water, and rock, establishes a myth/vision on the ground. The landscape is more than a place; it reflects people and their socially constructed ideas of place, the sense of place. Schama focuses on landscape memories that express ideas and carry meanings. He suggested, the memory of landscape can be a method to stimulate sensory by activating latent characteristic that connects and refers to the past.

Culture influences our recognition of the landscape; our ancestors have given place power and meaning, which carries through the generations. Today, our generation listens to historical narratives, and we are influenced by the spirit of landscape and its meaning. Norberg-Schulz argues landscape architectural design is meant to visualize the spirit of space or "genius loci", and the task for landscape architects is to create meaningful places (NorbergSchulz, 1976). He suggests that human settlement and landscape have a figure-ground relationship: both parties consist of landscape identity. Norberg-Schulz believes that humans understand space by visualization and symbolization. A successful design landscape should help trigger memories and recognize identity. 
When discussing genius loci, landscape architect Simon Bell suggested it is the quality that makes one location or landscape different from others. Placeness is essential to us and our life because our sense of identity may be bound up with a particular place, and we may refer to ourselves by reference to particular places (Bell, 1993).

Panita Karamane suggested landscape identity has two aspects: one has to do with the physical features of a site that give it a unique spatial character, and the other refers to the relationship of human-being to a specific landscape and what it means to them (Karamane, 2015).

To design towards landscape's identity requires a clear recognition of the memories borne within: these are always associated with its history and culture. Memories of a city derive from the historical usage of space and social-cultural events. This research focuses on historical and cultural recognition of landscape rather than defining the program of spaces. Therefore, this research seeks to embrace the form of the city's history and memories through design, to trigger active consideration when experiencing the designed space. 


\title{
Urban Orders and Pattern
}

\author{
- Urban Order is the Foundation of a Legible City \\ Principal Theorists: \\ Ludwig Hilberseimer, Kevin Lynch
}

"Reason is the first principle of all human work... City planning is, in essence, a work of order."

- Mies van der Rohe (1944, as cited in Hilberseimer, 1944)

Urban order and pattern was a frequently discussed subject in the architecture and landscape architecture disciplines of the midtwentieth century.

Ludwig Hilberseimer believed that only a "structural change," a complete erasure and restructuring of traditional urban form, would bring about this necessary order. He applied this principal theory in his commission of a plan of urban "renewal" of Detroit city (Fig. 17-18). His plan fundamentally reconceived the urban pattern portion of the Motor City and provided a new urban diagram (Waldheim, 2016). Hilberseimer introduced a reasonably functional urban planning theory, but his practical approach now seems radical. Complete erasure of old urban from is unachievable in the contemporary build environment, and undesirable; in hindsight the application of his theory, experienced as the 'urban renewal' of the 1960 s and ' $70 \mathrm{~s}$, is considered to have been made at great cost.

In his book The New Regional Pattern, Hilberseimer discussed how patterns are organized around the distribution of transportation and communication networks, across an essentially horizontal field of landscape. He was committed to a sense of order, as an organic relation of equal and unequal parts, each in their own relation to the whole (Hilberseimer, 1944). He argued the abstraction of the grid was informed by the natural environment: topography, hydrology, vegetation, wind patterns, and the like (1949).

Kevin Lynch argued the cities of the day were deficient as a living environment. They had suffered from uncontrolled development, rapid growth, and changing infrastructural needs. He suggested the pattern and order of urban forms had a critical affect on rising urban development. He discussed how massive force could be harnessed for reshaping the metropolis, but that power applied for re-planning the metropolis should be carefully chosen, based

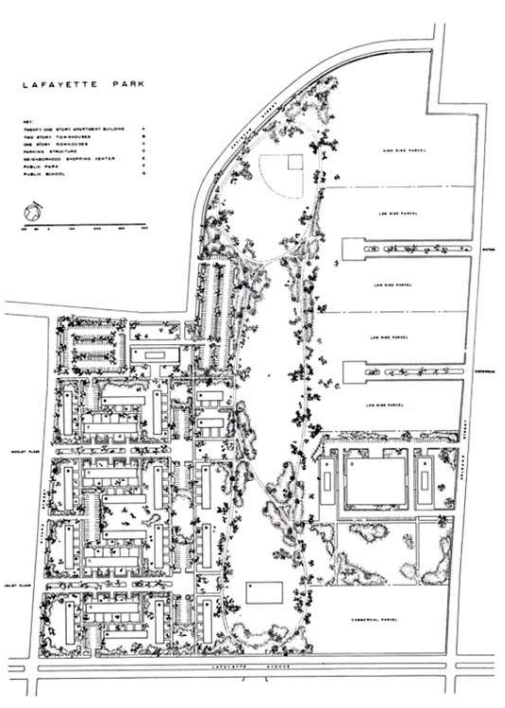

Fig. 3.04

site plan of planning module with

town houses and

courtyard houses,

Hilberseimer, L \&

Mies van der Rohe, L.

Lafayette Park, Detroit,

1956.

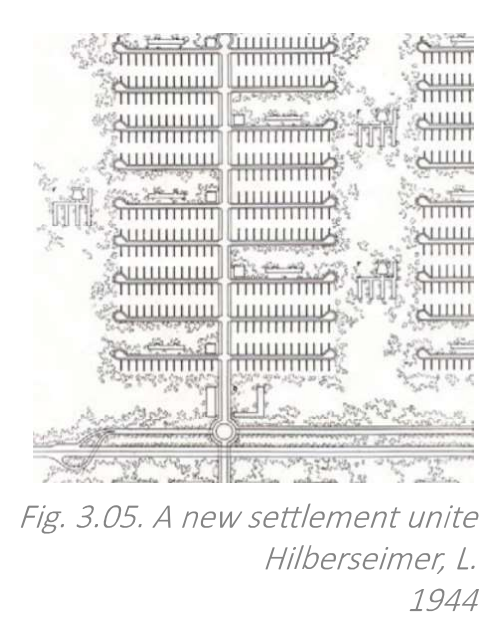
on its objectives and alternatives. 


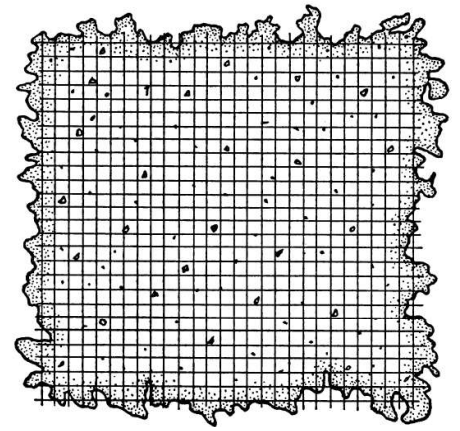

Fig. 3.06. The Disperesed Sheet, Lynch, K

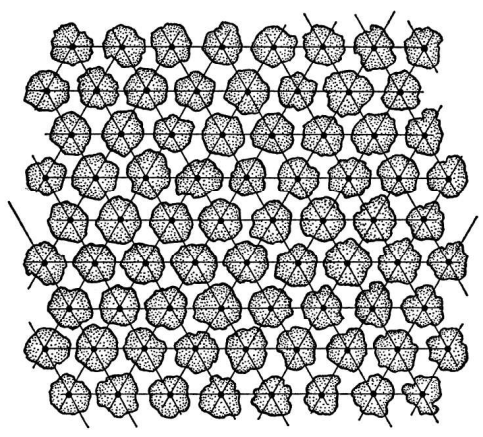

Fig. 3.07, The Galaxy, Lynch, K
Lynch also offered five patterns that can best represent the potential of urban life (Fig. 19-23). He clarifi ed that these patterns would be a set of actions based on urban growth, rather than a static pattern. He suggested a five-step application method for applying patterns to urban development with rules and regulations: controlling urban agglomeration; channelling transportation; defining hierarchical activity space; linking open space under a designated system; accommodating a wide variety of activities.

Lynch's theory offers a practical approach to a pattern-orientated urban-order system; it offers a template for reading, and possibly for designing, a city's legibility. However, his theory is still debatable, not just on its feasibility and cost, but its efficacy. His theory was associated with some urban renewal projects of the 1960s and '70s which in hindsight were not successful. Metropolitan life is a very individualized subject; and cannot really be represented completely or adequately by the five patterns he offered. The application of his method would need to be tested under different citys' different circumstances: and making his theory into a set of policies would still result in large areas of uncertainty and debate.

Hilberseimer explained the importance of formal urban order, and Lynch suggested this order can be achieved through the metropolitan pattern. However, their studies are based on a the mid-to-late 20th century built environment, which is different from our condition in the 21st-century. The practical solutions they gave for landscape architects are out of date. Urban order and pattern directs perception in a general way, recognizing and classifying space on an abstract level. There is a need to fi nd a new method to bring patterns into the city in order to achieve a largescale mental image.

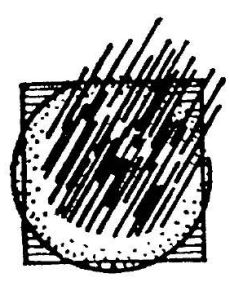

Fig. 3.08, The Core, Lynch, K

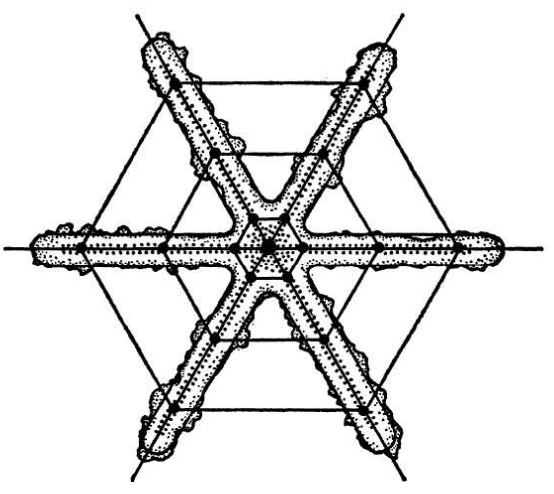

Fig. 3.09, The Star, Lynch, K

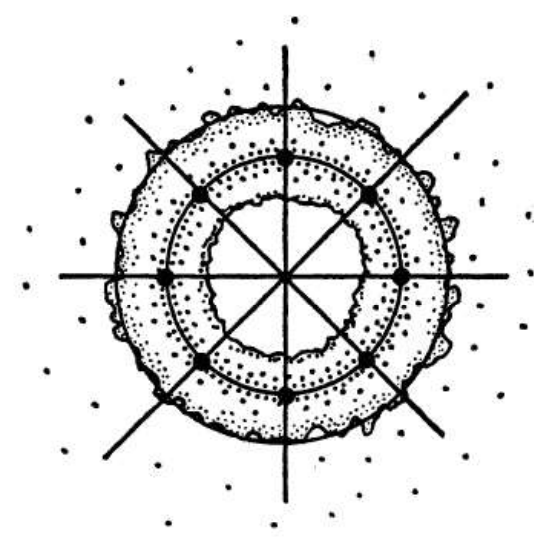

Fig. 3.10, The Ring, Lynch, $K$ 


\title{
Visual Landscape Assessment
}

\author{
- Visual behaviour and Perception of Landscape \\ Principal Theorists: \\ Clemens Steenbergen, Wouter Reh, Simon Bell, Steffen Nijhuis
}

Theorist Christian Norberg-Schulz believed that human-made places are related to nature in three evolutionary ways: the human being visualizes and collects an understanding of nature; the human symbolizes this understanding; and the human uses this understanding to create space (1980). This section will study the first of these: visual perception of landscap,e and how the visual image can relate to the meaning of landscape.

The sense received by our brain is referenced to association and expectations already in the mind (Bell, 1996). We use senses to analyze our surroundings, and of these senses, vision stands out. Vision provides the most information, and it is the sense in which we "image" (Bell, 1999).

Steenbergen and Reh (1996) discuss the relationship between viewpoint, perspective, and horizon in European gardens (Fig.24). They examine the employment of mathematically designed geometric perspective in creating the visual perspectives in those gardens' landscape architecture. They argue that in the observation of the spatial attributes of a geometric plan, the proportions of that geometry presuppose and affirm a subjective point of view. This is important, because in that subjectivity, geometry observed through perspective view must then be able to prompt, and mingle with, other subjective mental processes such as memory and identity.

Perspetive discoveries are closely related to the discovery of the horizon. However, when the human body moves across the landscape, the horizon is continuously shifting. Frankl (1968) argues that visible form derives from the journey of perceiving, which is a sequential unfolding of information as our body moves

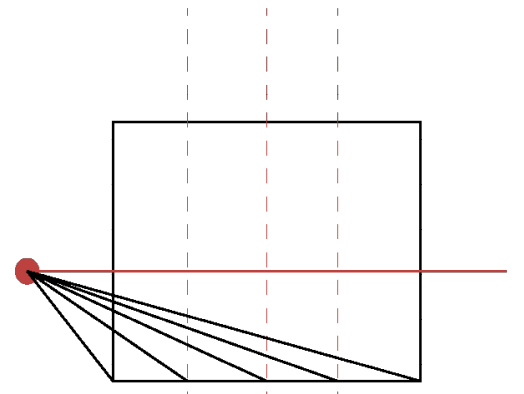
through space.
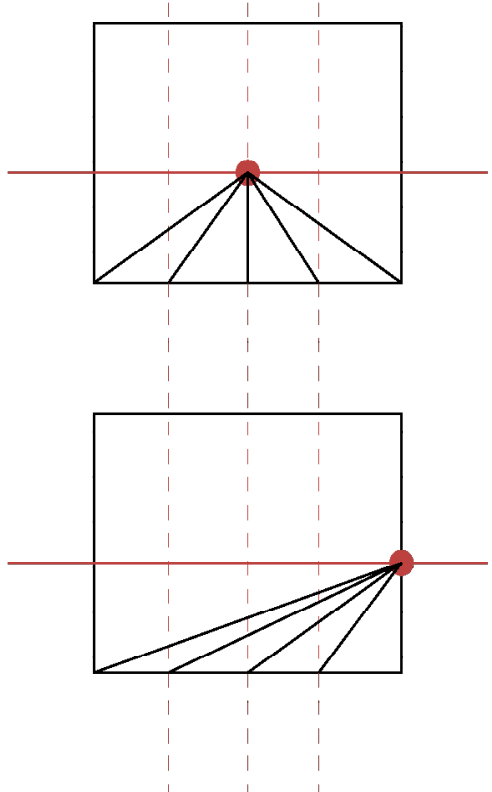

Fig. 3.11. Perspective construction in which optical foreshortening is determined by the lines of vision intersecting with the vertical picture plan. Steenbergen, C\& Reh, W. 1996 


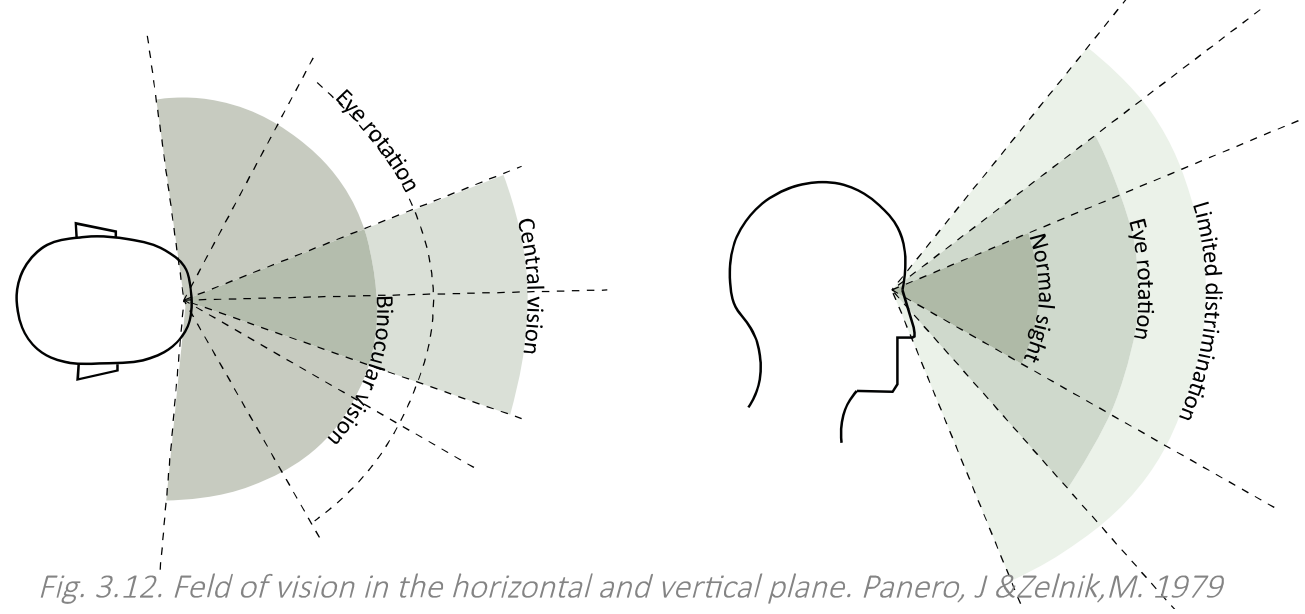

Dimitris Pikionis suggests that humans and landscape are a single entity, as the relationship between humans and landscape is created from walking and experiencing/experimenting (1989). The perceptual space operated by the human's eyes either moves perpendicular to, or is horizontally related to, topographical changes. Depth of vision shifts through the length of visible space. These characteristics are of great importance to landscape design, as they can be applied to achieve a certain spatial quality and establish space relationships.

We experience and experiment with landscape by movement; we interpret every single image through a landscape-journey. Visible forms of landscape can be claimed as a construction of time and space (Hoogstad, 1990). Movement itself results in different visual images. Three movement-modes are summarized by Hoeven and Nijhuis (2011): stationary, slow-motion, and fast motion. Speed of movement determines visual angle and the focus towards the landscape. The shape of movement, such as procession, stroll, or ramble, also affects visual perception.

Understanding human visual performance is critical to landscape design,; but despite that, humans' unconscious movement will sometimes cause different outcomes than the design anticipates or intends. A visual landscape is not only an aesthetic thing, but it also equates with ownership and control of one's movement (O'Malley et al., 2010). Carefully planned landscape gets closer to the expected outcome, by directing movement with well-arranged spatial dimensions and layout, to establish visual form. 
3.2 Precedent Reviews and Case Studies

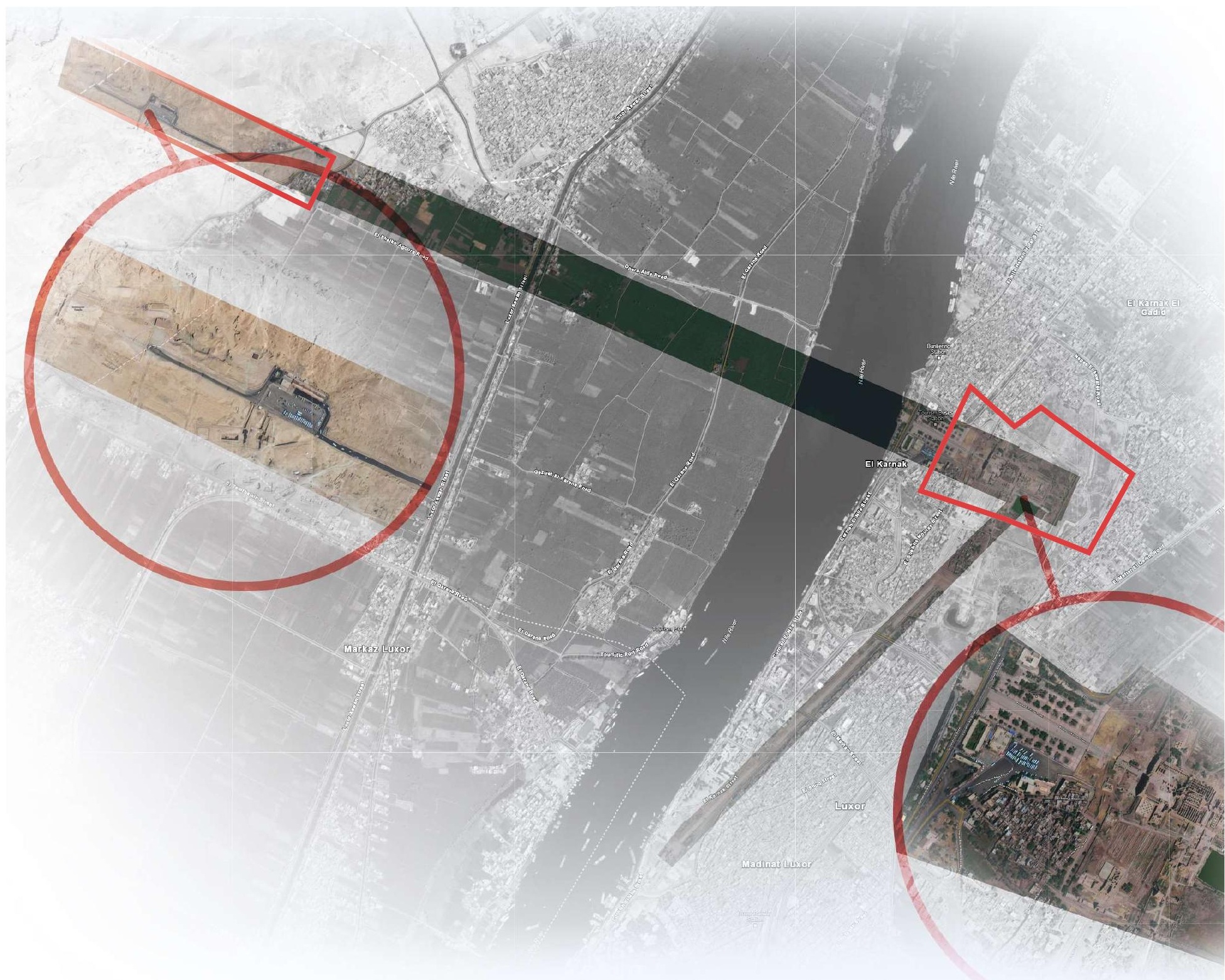

Scale: 1:10000@A1

Fig. 3.13 Hatshepsut Temple Axis to Karnark Temple 


\section{Hatshepsut Temple Axis to Karnark Temple}

Form and Material recall landscape memories

\section{Form and History}

Many of the earthworks and stone monuments from the Neolithic period are placed on axes of alignment with the summer or winter solstices. The site of Karnak Temple, a large ancient Egyptian temple complex located on the Nile River's east bank in Luxor, was probably one, because in the Middle Kingdom and New Kingdoms an alignment is maintained, through the developing temple complex's main axis, with the point on the horizon where the sun rises at the winter solstice. Karnak Temple complex was developed by the immediate predecessors and successors of Hatshepsut, the queen of Egypt 1507-1458 BC; and the most dramatic contribution to this axis took place during her reign, with the extension of the axis across the river Nile to her mortuary te mple on the west bank. The central axis of Hatshepsut Mortuary Temple points directly down the axis of Karnak temple, so that the first beam of light of sunrise on the winter solstice strikes her mortuary shrine, along an avenue piercing Karnak Temple, from the east horizon. Traditionally, the west bank was the location of necropolises in Ancient Egypt - the pyramids were constructed on the west bank of Memphis (current-day Cairo). Hatshepsut's mortuary temple is in that tradition: it sits in the side of a pyramid-shaped hill, the opposite side of which is the Valley of the Kings, Kuxor's traditional burial site for its royalty.

Therefore this axis joins a point in the east which yearly represents yearly renewal, with a place in the west which regularly receives the dead: a cycle of death and rebirth is formed and enacted, each year with the solstice, and at every royal funeral. 


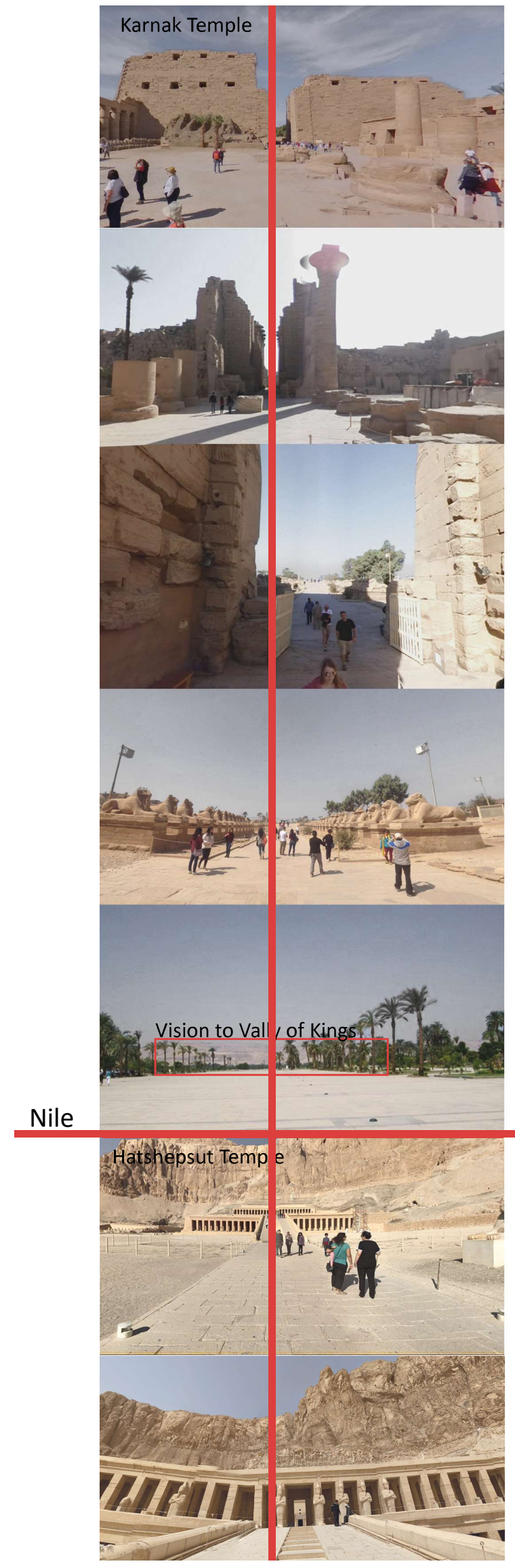

Axes of alignment fom Luxor Temple to Hatshepsut Temple
Symmetrical sculpture strengthen the axes of alignment.

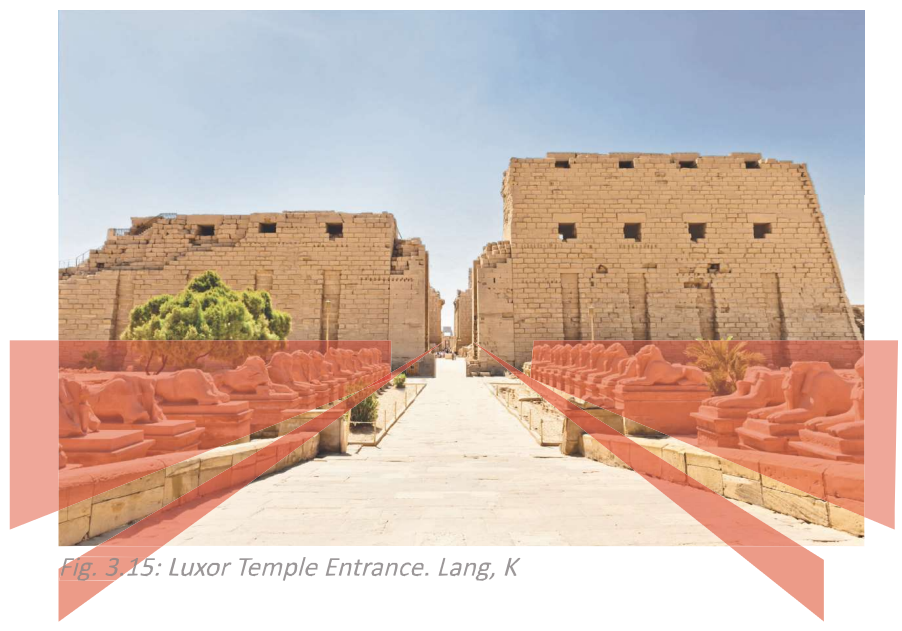

Hatshepsut Temple's form reflecting to the mountain in the background.

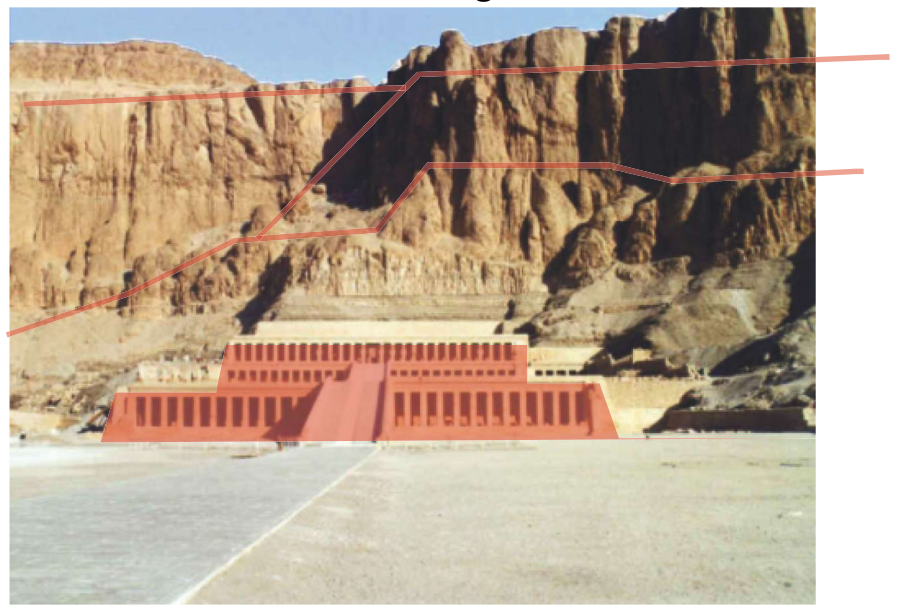

Fig.3.16: Hatshepsut Temple. Cohen, B

Winter solstice strikes on Hatshepsut Temple

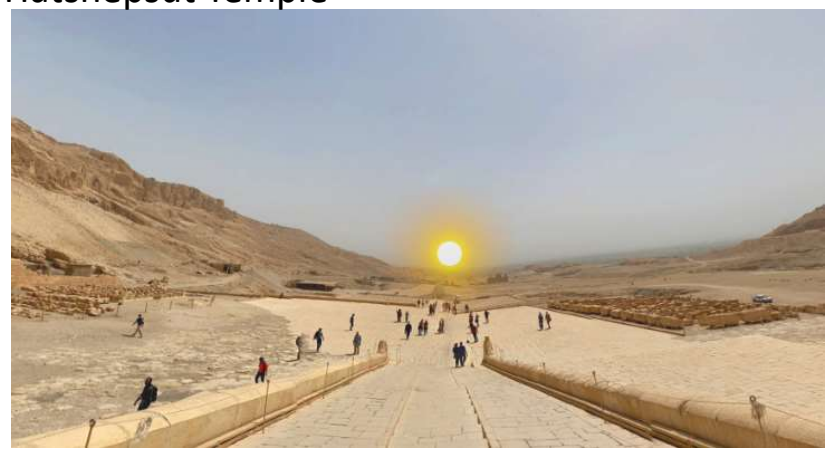

Fig.3.17: Winter Solstice on Hatshepsut Temple. Google 


\section{Material}

This east-west axis crosses the north-south axis of the Nile, which likewise enacts a cycle of renewal with its annual flood and replenishing of the flood-plain. That axis is in turn copied by the Avenue of Sphinxes, which connects Karnak temple with Luxor Temple, the palace of Egypt's sovereign, to its south. The limestone from which these temples are made was quarried from the hill in which the sovereigns are buried in the Valley of the Kings, almost literally telling the cycle of death and rebirth in solid and void. This double-axis determined Luxor's legibility. Rituals of commemoration and observance, as well as every day's commerce on the streets and the river, would have reinforced the image of this city in people's minds as something continuous in time, understanding a place within larger cycles of history, birth, death, and rebirth.

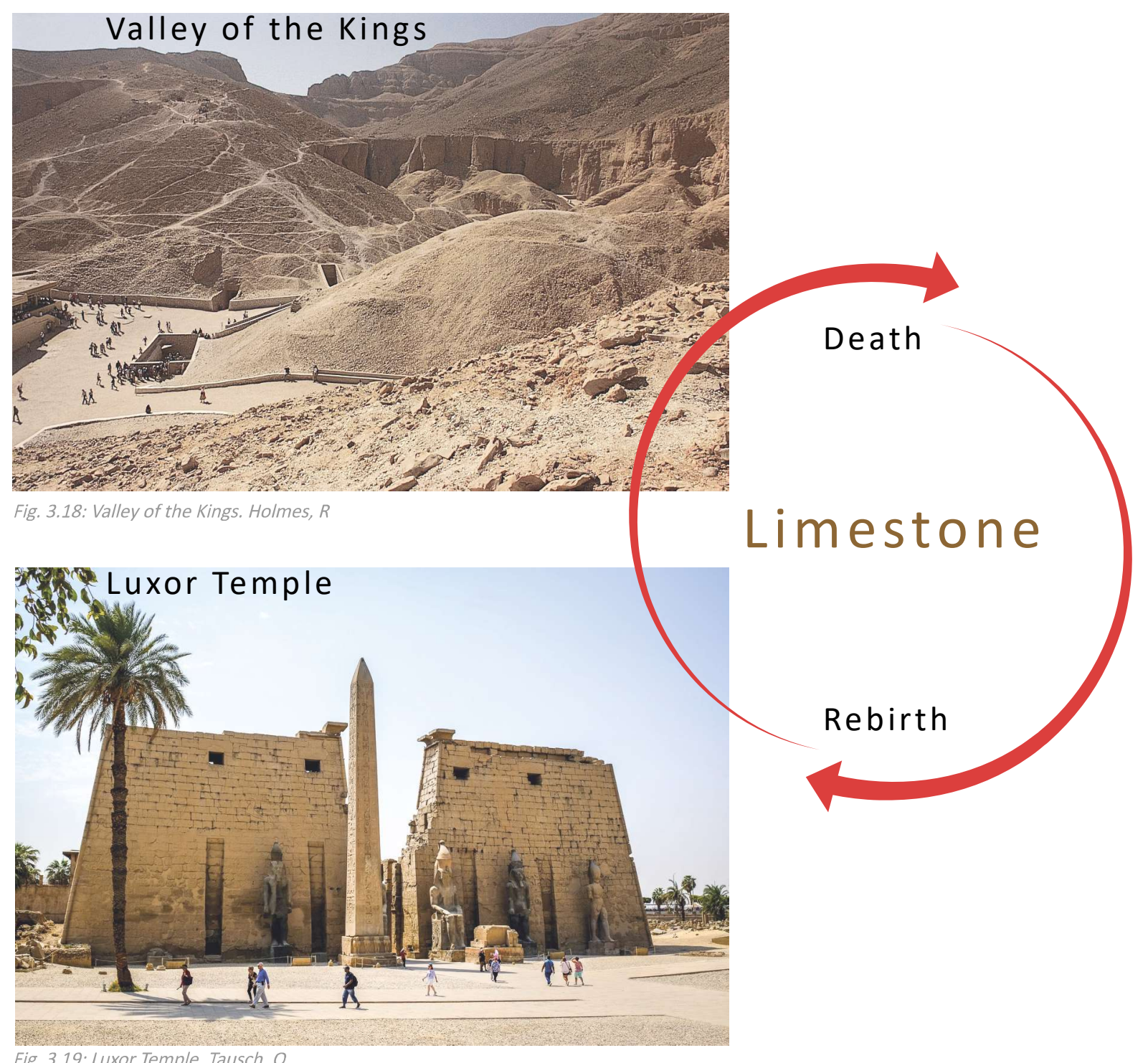


Precedent Reviews and Case Studies

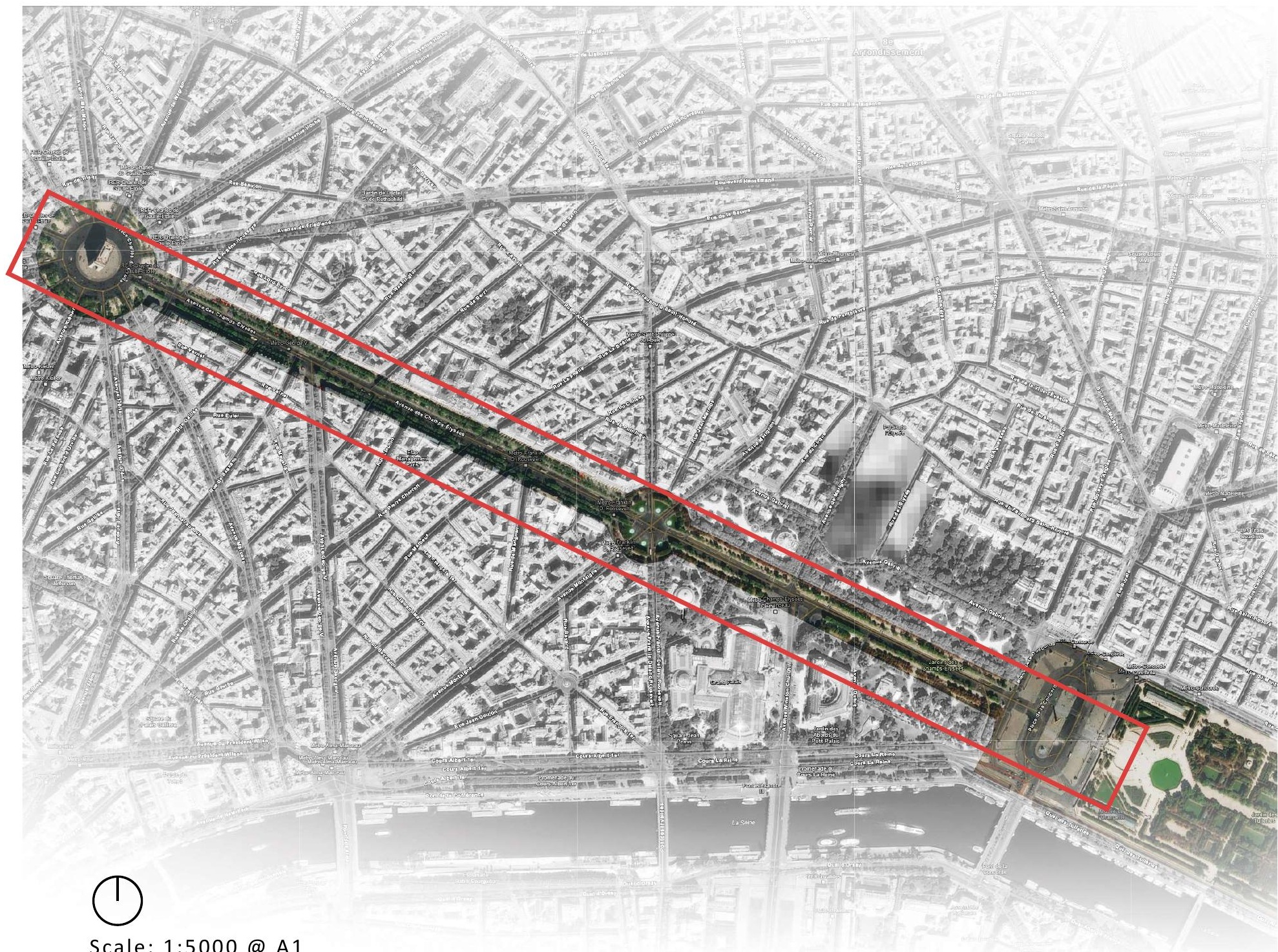

Fig. 3.20: Champs-Élysées 


\section{Champs-Élysées, Paris}

Functions and event recall landscape memories

\section{History}

The Champs-Élysées axis is one of the most iconic in the world. For centuries it has been a natural road to Paris' westward defenses: its direction determined by the crown of a hill at the west end, and, at the east end, a bend in the river Seine of 6 degrees from its upriver course parallel to the axis of the Louvre Palace.This bend and new axis was formalised with design in the 17th century by André Le Nôtre, into the axial avenue and Tuileries gardens extending from the Louvre Palace. The west end's hill-crest was capped by the Arc de Triomphe in 1835, which soon after became a natural main pivot-point in Haussman's redesign of Paris; the Luxor Obelisk was placed on the axis in the nineteenth century; and at the end of the twentieth century I M Pei's Louvre Pyramid and Spreckleman's hypercube-formed Grand Arch de la Defense each contributed to further refining and extending this axis. So Parisians receive a subconscious lesson in the history of their city, and its relationship to wider history, as they walk the Champs Elysees.

\section{Street life}

The Champs-Élysées is one of the most iconic luxury residential and shopping streets in the world. Distinct monuments can be seen from a far distance at both ends of the street, as a constant reminder of its history. Extra-wide sidewalks allow spaces for café and retail shops. Many cafés and restaurants provide outdoor seating. Street planting enhances the street's image and provide colorful banners and tree shadows to achieve a comfortable pedestrian environment. A tourist's image along a luxurious street recalls the highly formal atmosphere of the context of Paris. These make for opportunities for pedestrians to stop at Champs-Élysées and think about the city that they live in. 
Functions and event recall historical memories

The Champs-Élysées is one of the most iconic luxury residential and shopping streets in the world. Distinct monuments can be seen from a far distance at both ends of the street, as a constant reminder of its history. Extra-wide sidewalks allow spaces for café and retail shops. Many cafés and restaurants provide outdoor seating. Street planting enhances the street's image and provide colorful banners and tree shadows to achieve a comfortable pedestrian environment. A tourist's image, walking this luxurious street, recalls the highly geometric, radial design of the larger context of Paris. These make for opportunities for pedestrians to stop at Champs-Élysées and think about the city that they live in.
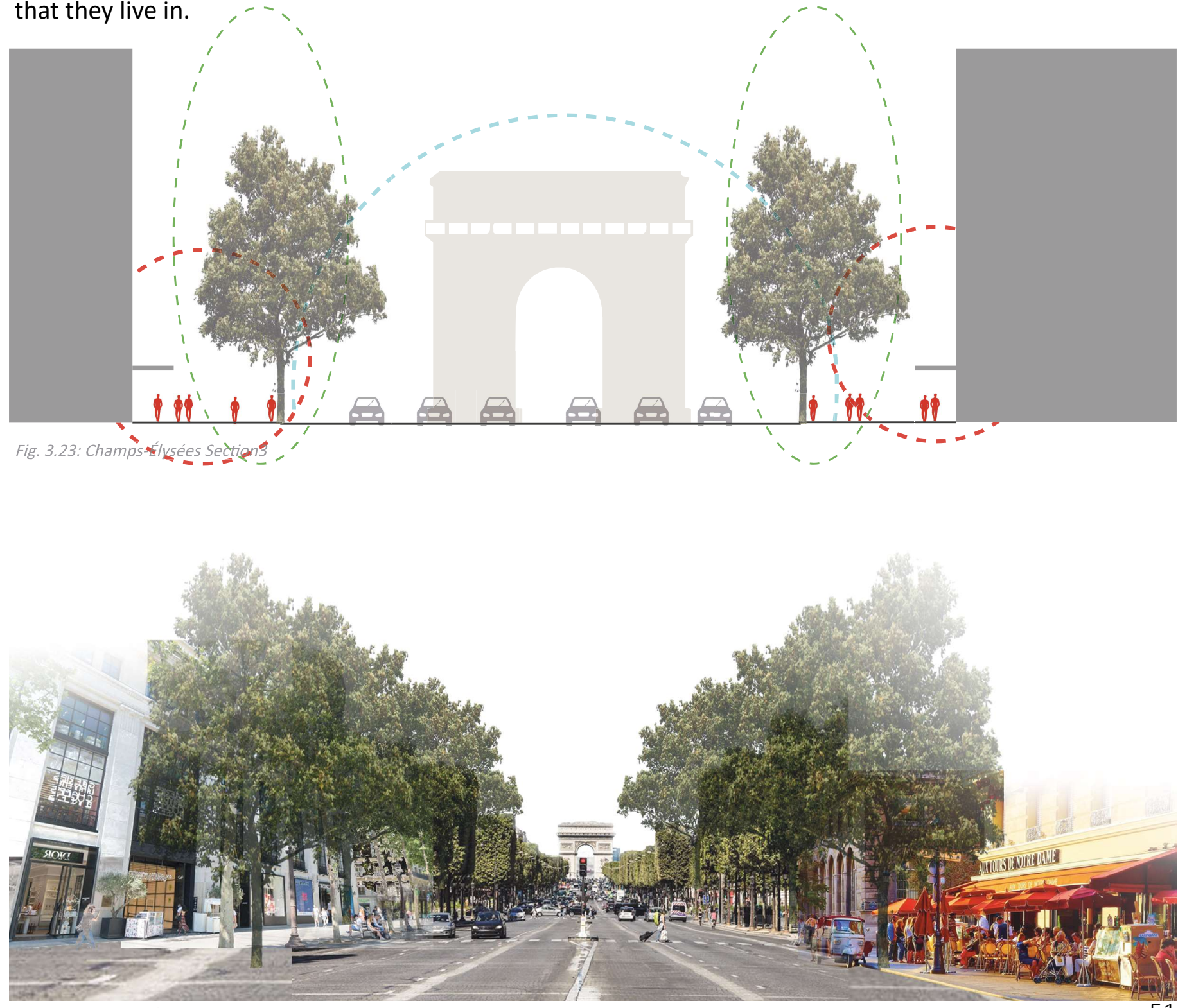
3.2 Precedent Reviews and Case Studies

Champs-Élysées and the Urban Pattern of Paris

The urban order of Paris city performs in a star shape, with the Arc de Triomphe being the centre of the star. People will understand the arrangement of Paris city when standing at the Arc de Triomphe roundabout and looking towards the main streets around it; with the ChampsÉlysées being one of the most significant streets out of the eight. At this point, the planning logic of Paris and its history starts to unfold in the viewer's mind; therefore, a mental image of Paris begins to show itself, every iconic structure joins together as the image of Paris.

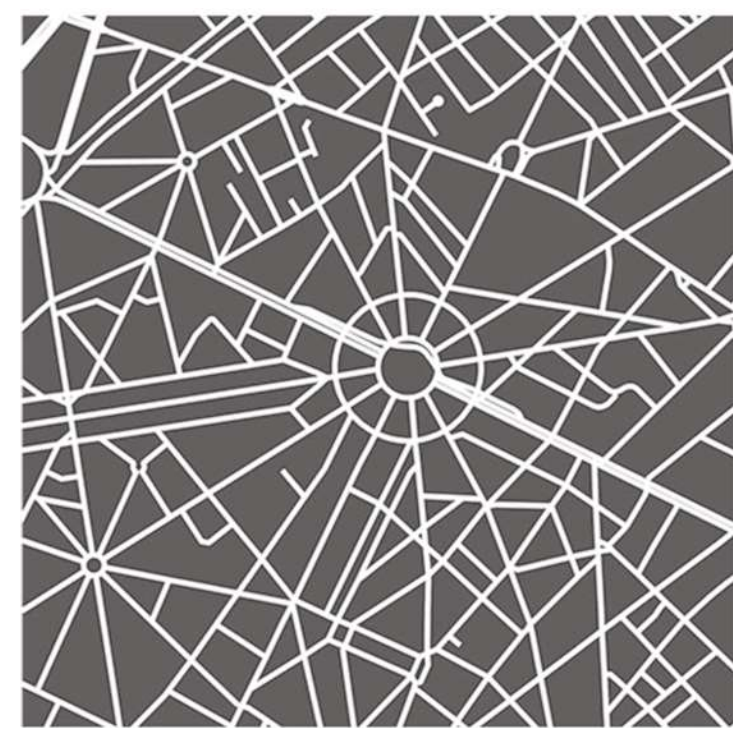

Fig. 3.25: Paris Urban Pattern. Beoing, G

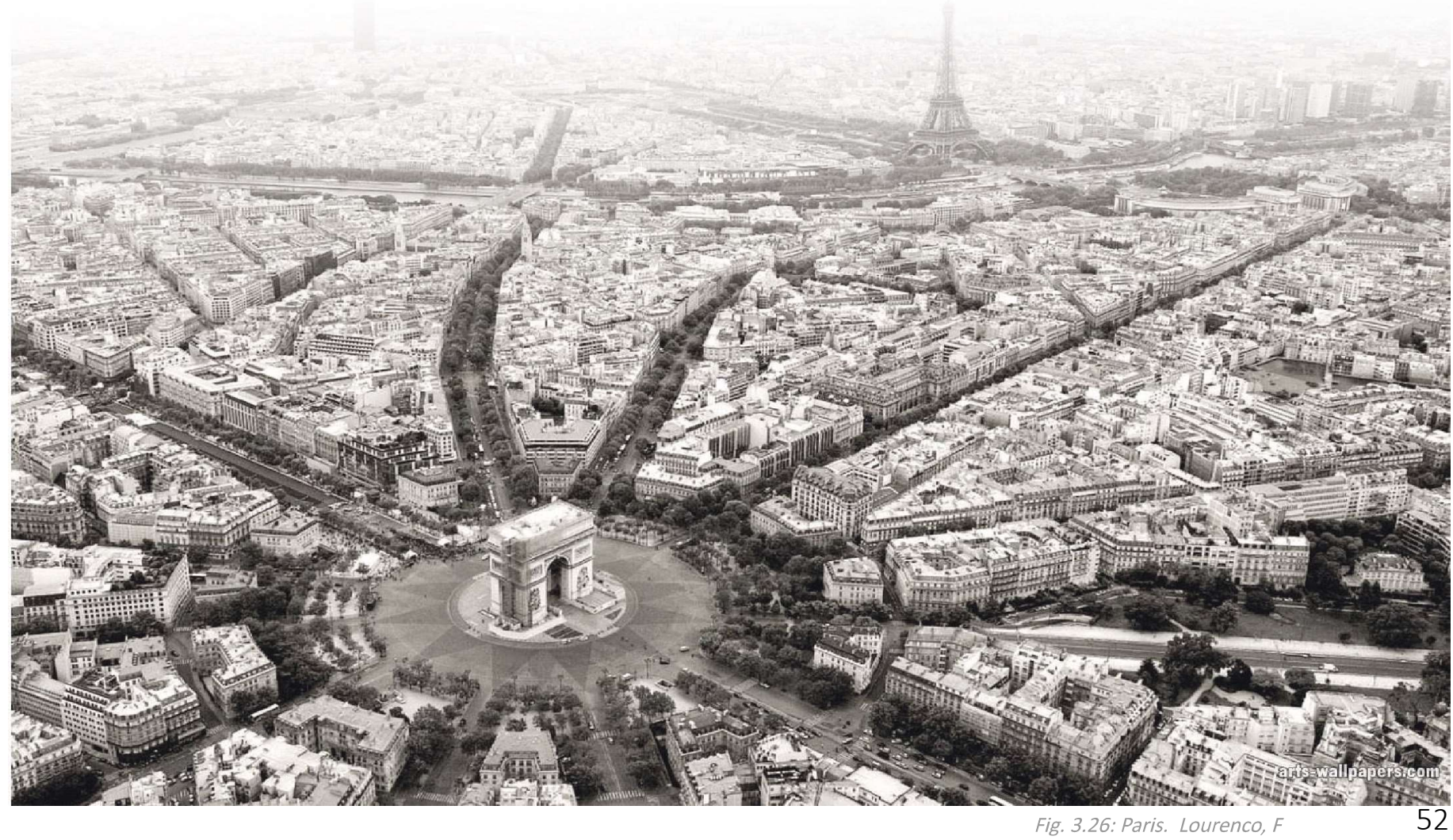


3.2 Precedent Reviews and Case Studies

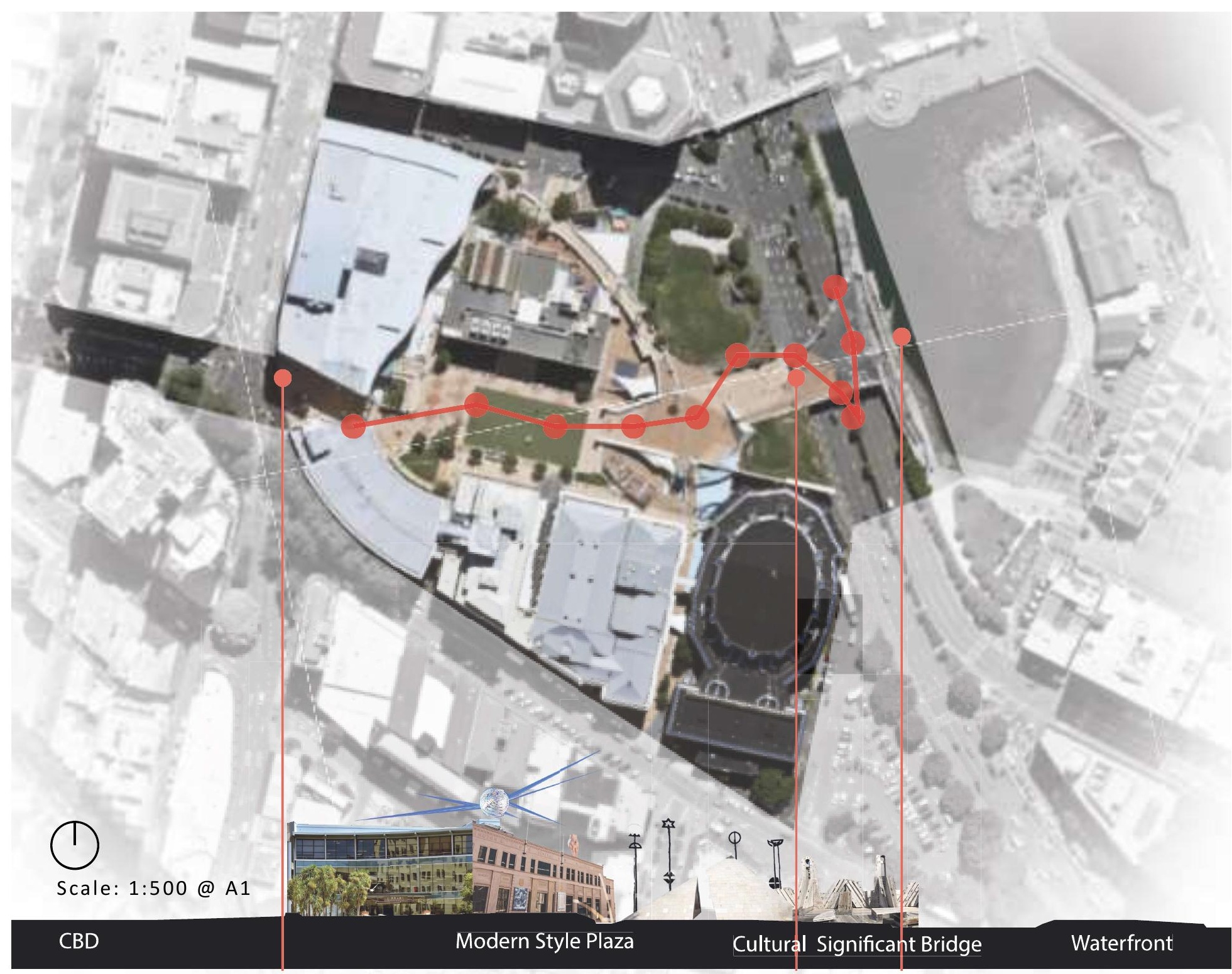

Fig. 3.27: Wellington Harbour - City to Sea Bridge - Civic Square 


\section{Wellington Harbour - City to Sea Bridge - Civic Square}

Historical landscape studies

Landscape design and sculptures evoke historical related context recognition

Te Ngākau Civic Square is a public square in central Wellington. The square is surrounded by council buildings, each with a distinctive architectural style narrating Wellington's urban history: Wellington Town Hall is a late Victorian/ Edwardian building in the neo-classical style; it is flanked on the east side by one of Wellington's first post-modern buildings, the Michael Fowler Centre; and on the west side Wellington Council offices, in plain, mid-century style; the City Gallery on the north side of the square is Deco. At the west end of the square is the Central Library, which is a post-modern building, shaped as an arcing wave. When this most recent building was built, the area on its east side and between the City Gallery and the Town Hall was enclosed, to create a pedestian-only civic square; and an attempt was made to reconfigure this space - formerly an axial street parallel with the facades of the other buildings - so that its rectilinear lines would be softened and might respond more to the arcing facade of the new library building. As a result the image presented to the user is a kind of compromise between two matrices, the rectilinear and the arcing organic.
These two matrices sit on top of eachother uncomfortably, and make for many more awkward, or compromised, designdecisions at smaller scales. Over the decades, each effort to create an identity for this blue-chip site has been heavyhanded; as a result the compromises are clumsy, the image is confused and confusing. For all that, the square is used for public events and is a popular place for office workers to eat their lunch on warm summer days.

This study took a journey from Wellington Harbour waterfront, over the City to Sea Bridge, to the Civic Square. The journey is of specal historical and cultural signifi cance, because this is the hinge-point where, in pre-settlement times, the deepwater meetng the bluffs widened and flattened to become a bay at the bottom of Te Aro plain; so a place where one could imagine the first Polynesian landings in the area. This axis represents Wellington's centre, around which Wellington's contemporary form and activity hinges. These interconnected sites have received a lot of landscape design aimed at improving the legibility of Wellington City's identity. 
The first part of the journey, from the harbour to the City to Sea Bridge, bears significant Maori history, indicated in sculpture and in formal landscape design. These encourage memory sharing and social communication between different points of recognition of this space.
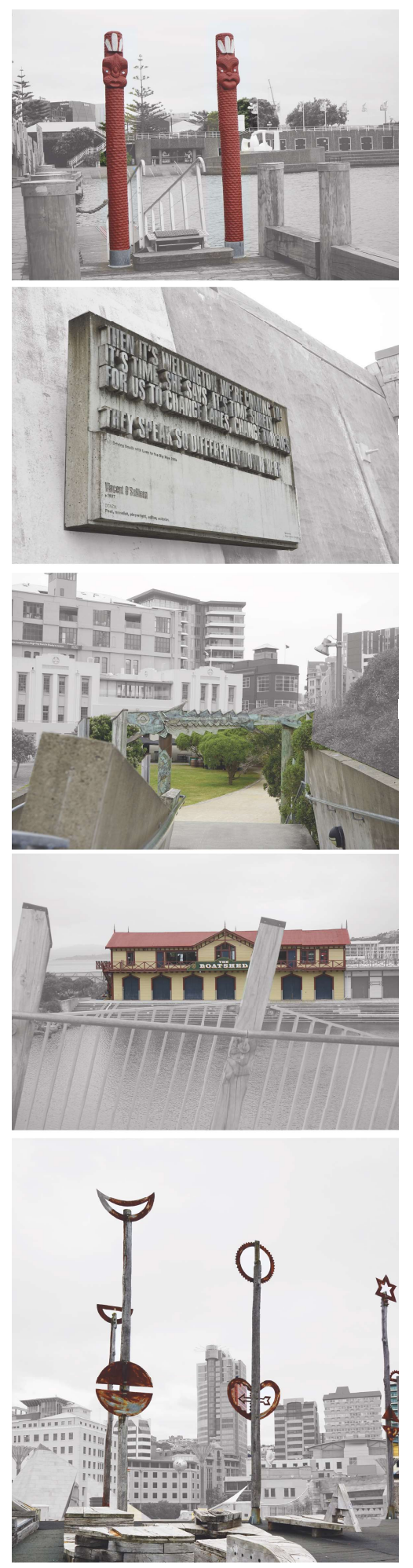

Cultural or historical significant intervention Background image in contrast with landscape interventions

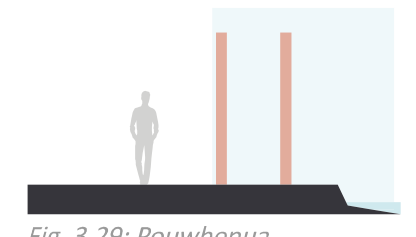

Fig. 3.29: Pouwhenua
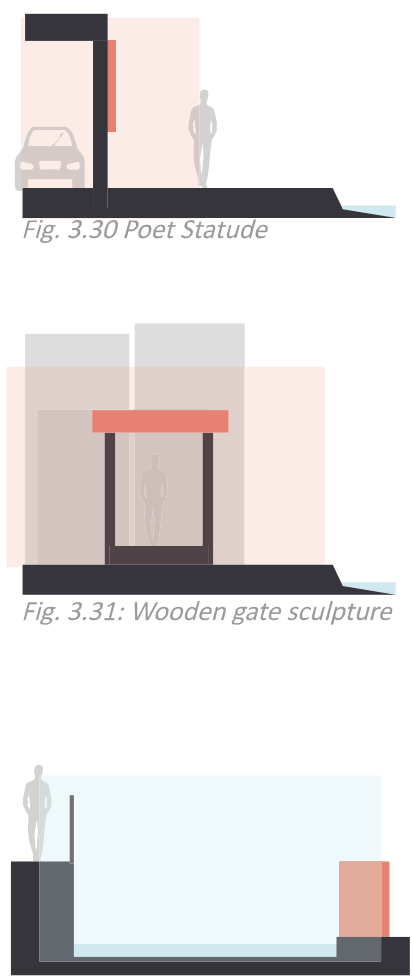

Fig. 3.32: Heritage building across harbour

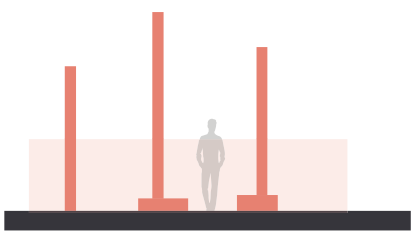

Fig. 3.33: Native Timber Sculpture 
3.2 Precedent Reviews and Case Studies

Approaching Civic Square from the bridge presents a different historical value: the modern plaza and twentieth-century colonial architecture. The topographical arrangement allows the pedestrian views from progressively higher points, seeing the Wellington commercial centre's skyscrapers as this plaza's background. This journey's historical value enriches the physical experience/experiment, allowing it to become one of the most legible routes from the waterfront to the heart of Wellington City.
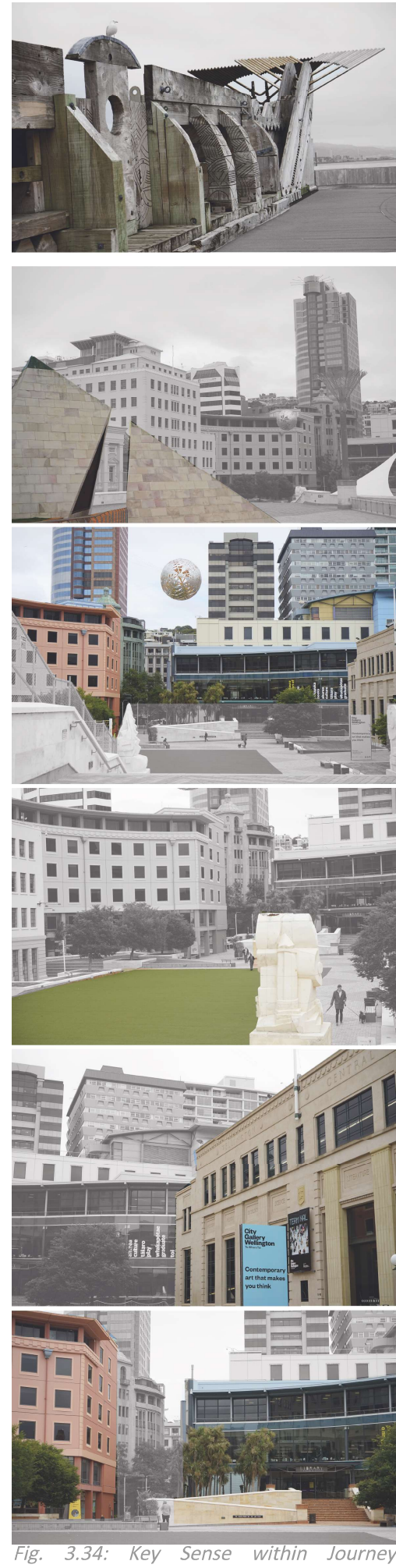

Wellington Harbour to Civic Square 2

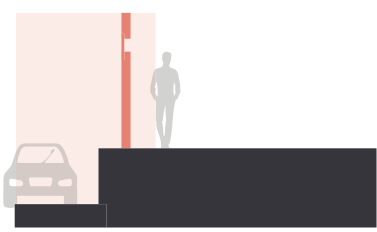

Fig. 3.35: Bridge Side Facade

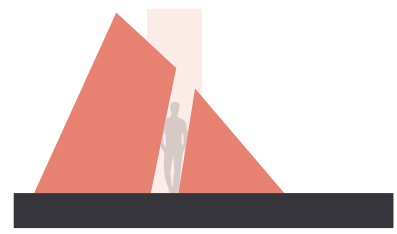

Fig. 3.36 The Mountain

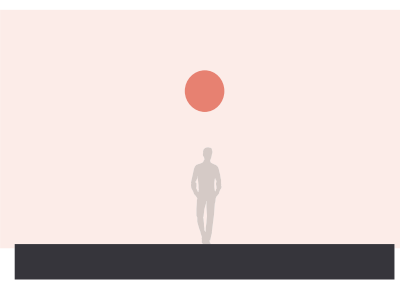

Fig. 3.37: Silver Fern

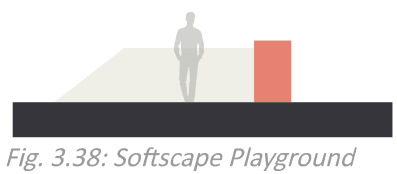

Fig. 3.38: Softscape Playground
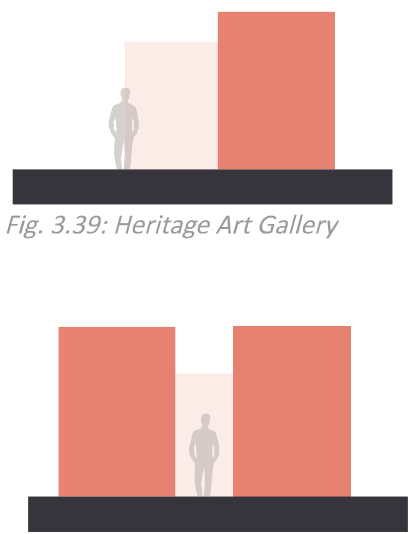

Fig. 3.40: Narrow Path Between Heritage Buildings 
3.2 Precedent Reviews and Case Studies

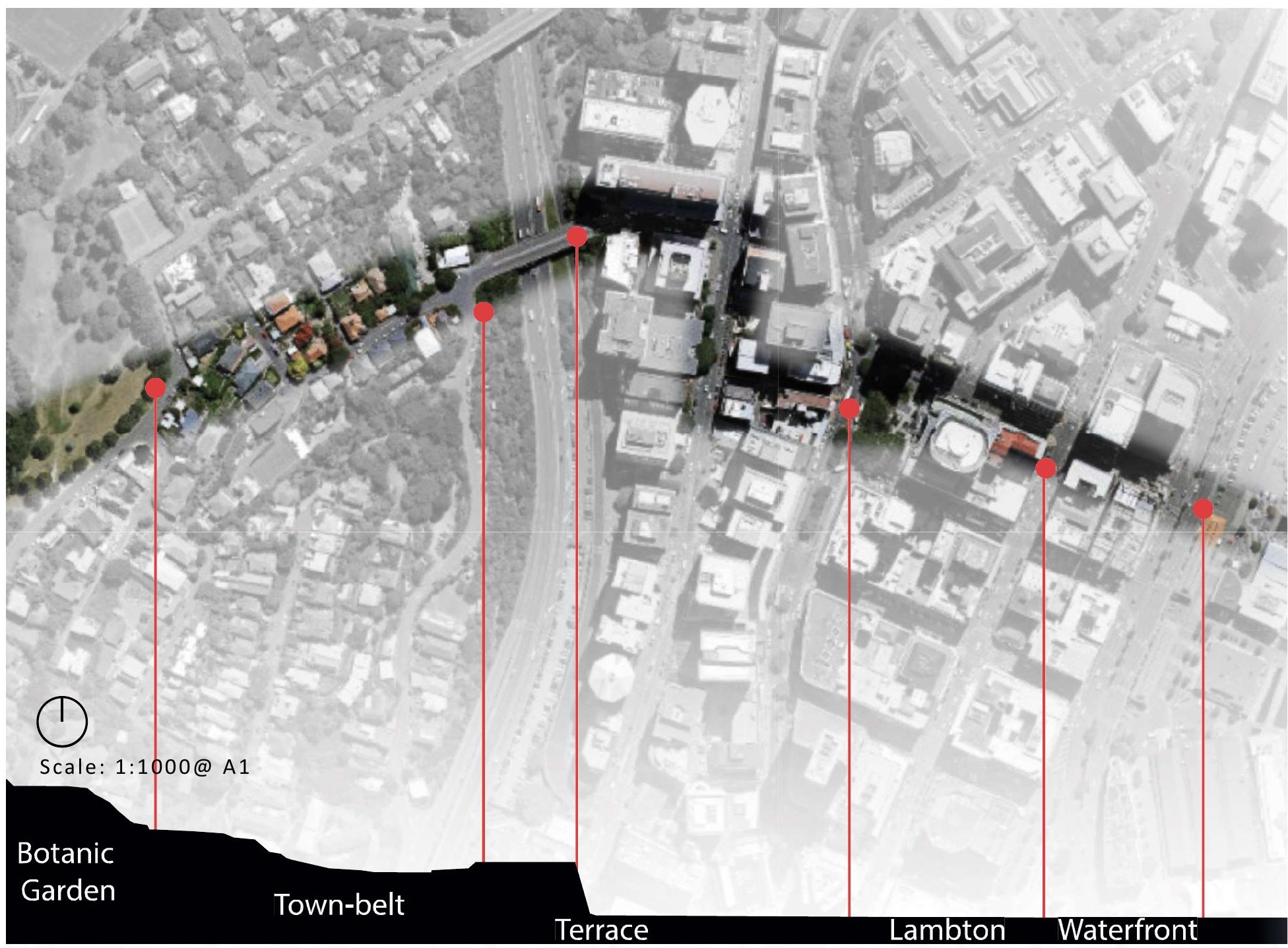

Fig. 3.41: Botanic Garden - The Terrace - Woodward Street - Midland Park-Wellington Harbour 
Botanic Garden - The Terrace - Woodward Street - Midland Park- Wellington Harbour

Personal memory and context-recognition studies through a journey

Wellington's central area was either reclaimed land, or built on relatively flat land, between two hilly sites to its east and west. This unique location has successfully become one of Wellington city's most recognizable identities, along with its windy weather. This study aims to discover Wellington's legibility on a context-scale, by experiencing/ experimenting a journey from hilly to flat land. It explores what it is to shift between atmospheres, urban forms and building types; and investigates the potential of a walking journey to trigger the mental imagination of the identity of Wellington.
This journey starts from Wellington's botanic garden, where the atmosphere is one of enclosure, by the vegetation and hilly topography. The walk goes downhill through a residential town belt, where vegetation fades away and small architectural structures stand out from the scene. Approaching The Terrance over the motorway, the city's business and commercial skyscrapers are laid out before the eyes. Entering Lambton Quay, through a brick-paved pedestrian-only walkway, our walk flattens out (this was the original waterline, from now on it is reclaimed land). The walk crosses Midland Park, seeing the ocean view ahead. Our journey ends up at Wellington's waterfront, where one escapes again the noises of a busy city. This complexity of a variety of environmental conditions allows different types of spaces to interact in the mind; achieving metal recognition of a large-scale image. 
Through mobile experimenting, our mind tends to capture minor details less than when we stand still and observe. Our mental perception of space will be a blurred image; represented in simplified colour blocks.

As the environmental condition changes through this journey, the sense of placeness also shifts, from a vegetation-covered town belt to a hard-surfaced urban environment. This journey takes in the hilly quality of Wellington, to experience enhanced topographical recognition, and to get a comparison with how urban form, arranged functionally, composes movement, visual information, memory, and image.

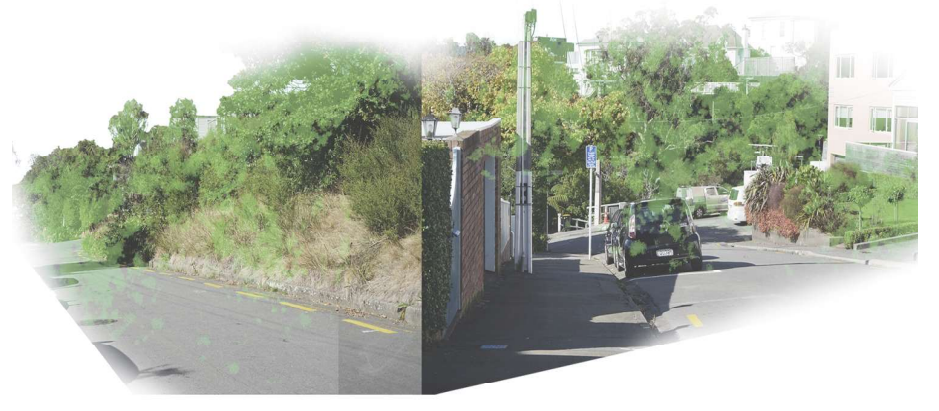

Fig. 3.42: Photo Montage 1 - Town Belt

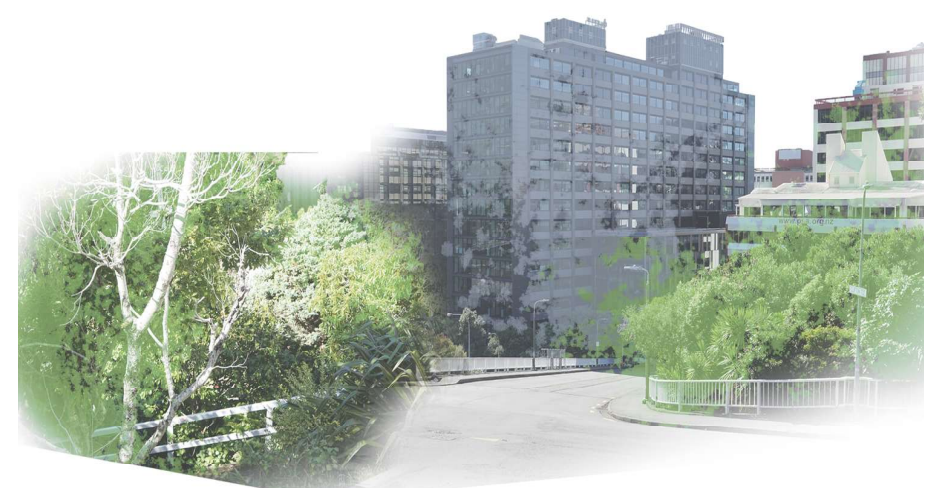

Fig. 3.43: Photo Montage 2 - Transition to skyscraper

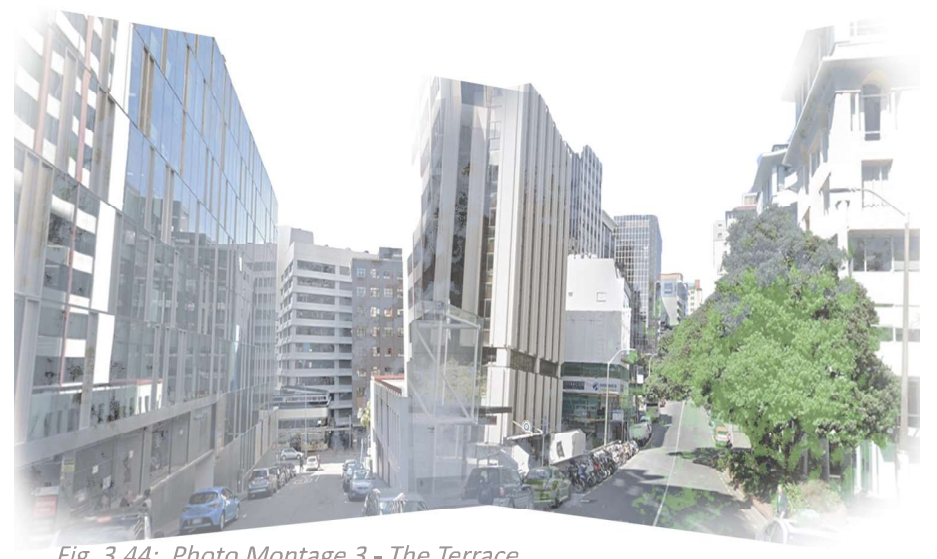

Primary attraction

Background image

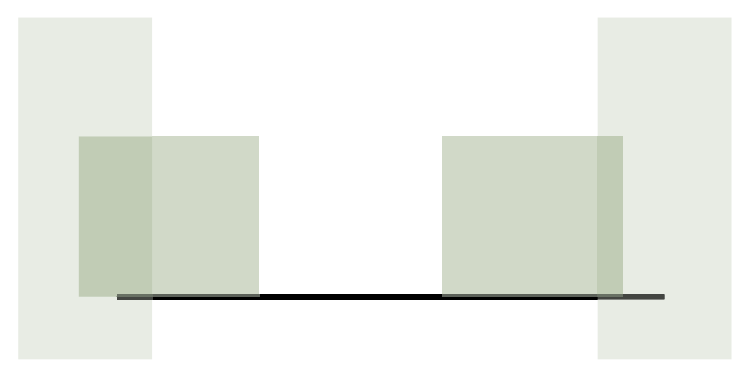

Fig. 3.45: Mind Captured Image 1 - Town Belt

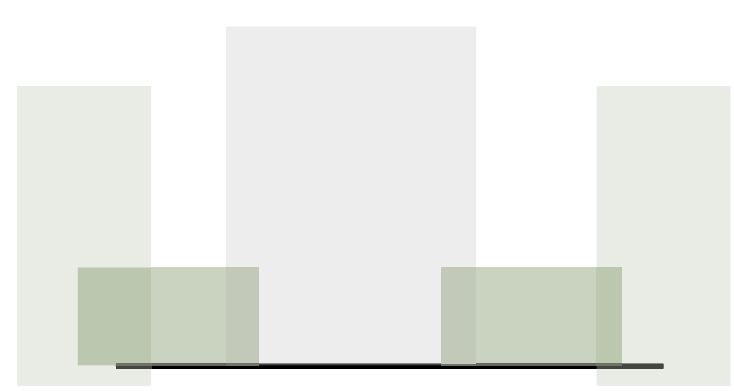

Fig. 3.46: Mind Captured Image 2 - Transition to skyscraper

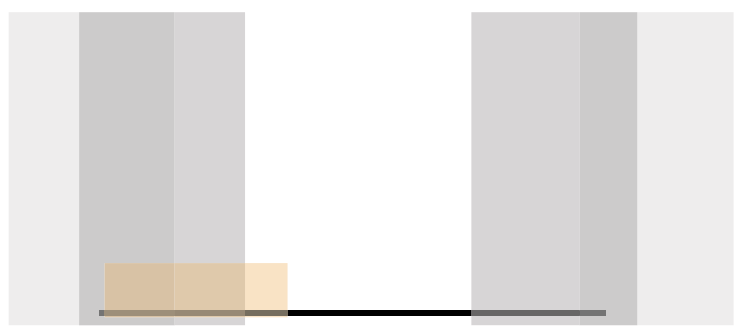




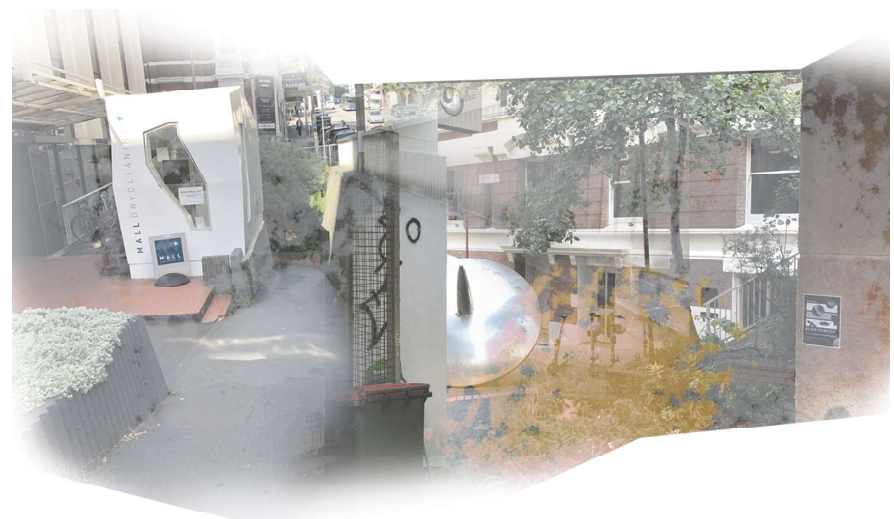

Fig. 3.42: Photo Montage 4 - Pedestrian Entry to Lambton Quay

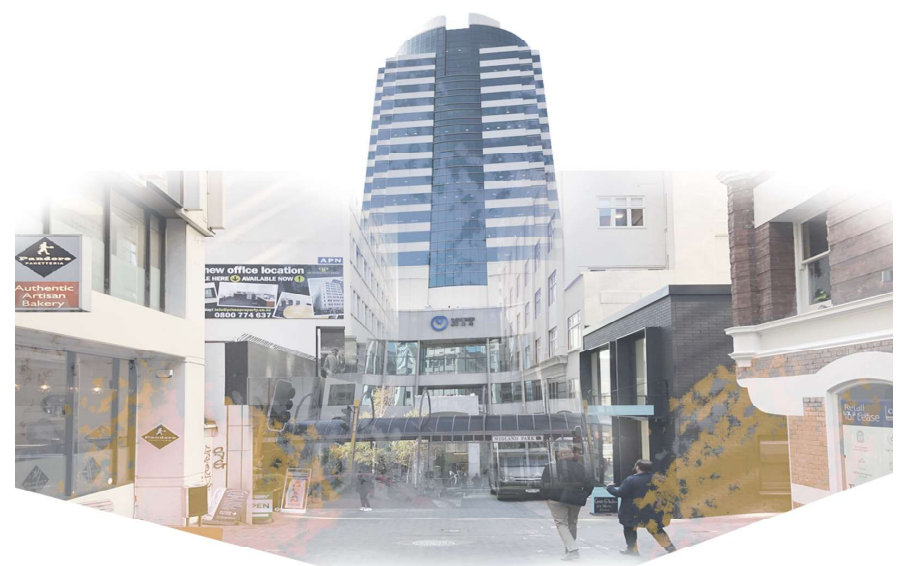

Fig. 3.42: Photo Montage 5- Vision Towards Lambton Quay

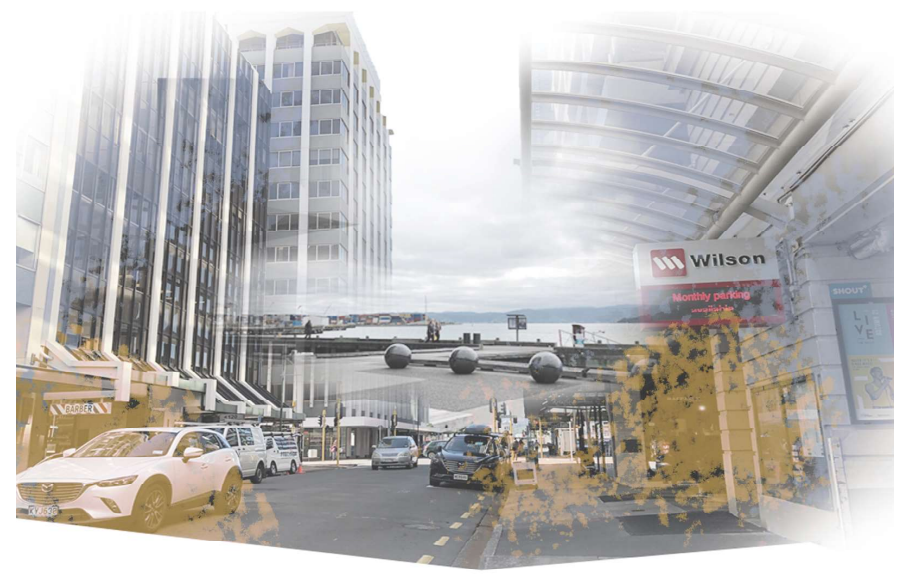

Fig. 3.43: Photo Montage 6 - Waring Taylor St

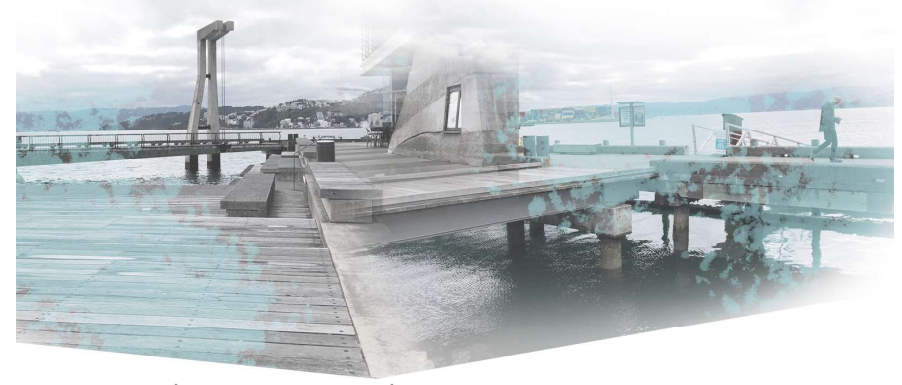

Fig. 3.44: Photo Montage 7 - The Water Front

\section{Built form}

Active shop front

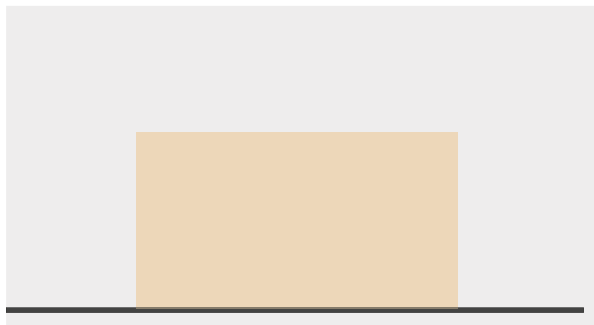

Fig. 3.42: Mind Captured Image 4 - Pedestrian Entry to Lambton Quay

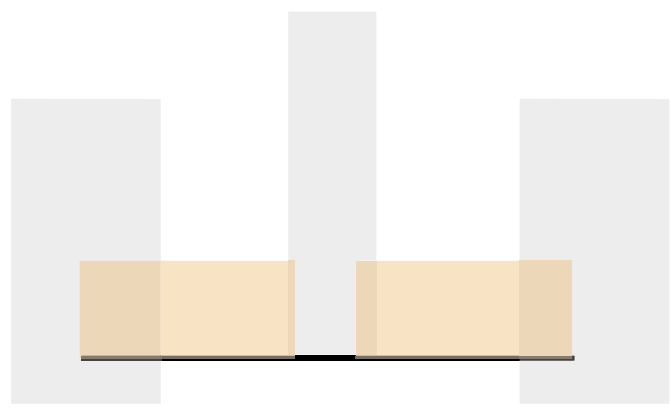

Fig. 3.42: Mind Captured Image 5 - Vision Towards Lambton Quay

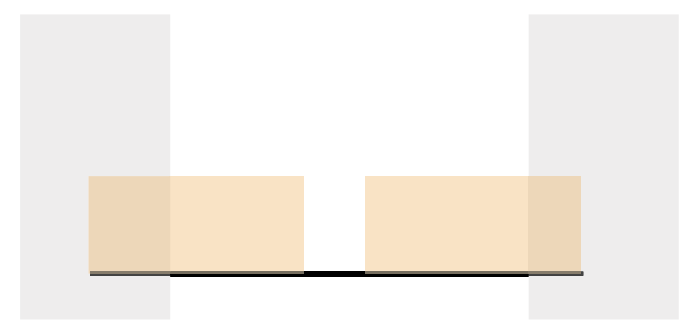

Fig. 3.43: Mind Captured Image 6-Waring Taylor St

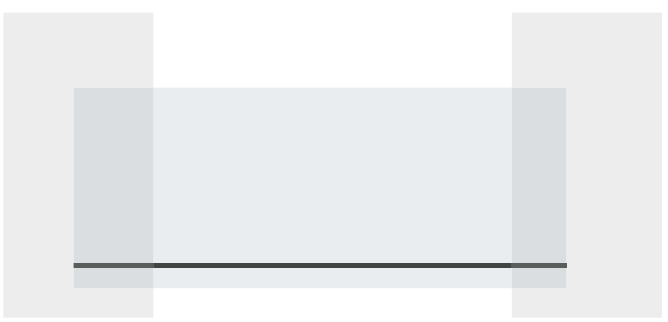


3.2 Precedent Reviews and Case Studies

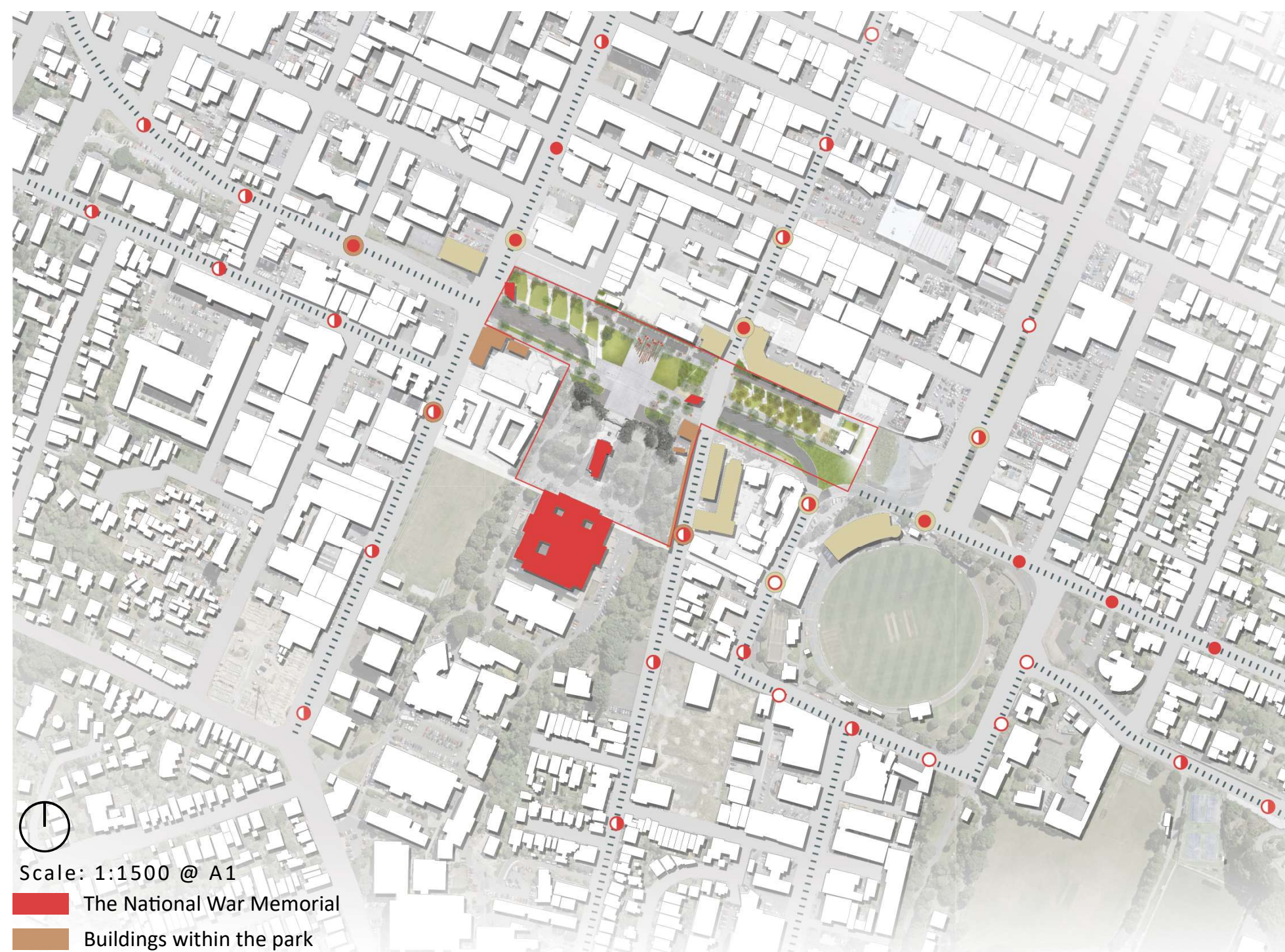

Buildings closely related to the park

Visibility to the monument 


\title{
Pukeahu Memorial Park, Wellington
}

\author{
Visual landscape studies \\ External intervention effect visual deign
}

\begin{abstract}
When the National War Memorial was built in 1932, its tall carillon tower made it highly visible from most areas of the capital. In 2015, Pukeahu Memorial Park was constructed to uniy the National Memorial precinct.
\end{abstract}

Today Pukeahu Memorial Park is used for signifi cant remembrance events. It is also becoming a popular place for leisure activities, such as skateboarding. It attracts pedestrians from Mt Cook and Te Aro districts. Most people walking to work will walk through this park, and some decide to stay; and this park has become part of everyday life for Wellington's citizens.
This case study aims to understand how Pukeahu Memorial Park, especially the National War Memorial monument, becomes part of the image for the surrounding streets. And how the park integrates into a memorable image for residents around this area.

This study examines the theory that "the human has a moving relationship to the landscape"; approaching Pukeahu Memorial Park from different directions, seeking to understand the connection between observers' visual relationship with the Memorial Park simultaneous with their physical relationship to the street they're walking. 


\section{Tory Street}

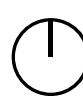

Walking up Tory street from the lower north end, on a moderate gradient up to the south, the National War Memorial monument shows up halfway along the journey. The distinctive monument immediately attracts attention, dragging one's view towards it. The street's layout contributes to the monument's visual interest; consistently, unattractive concrete building façades push one's eyes to search for something new. The image of Pukeahu Memorial Park then immediately becomes the target.
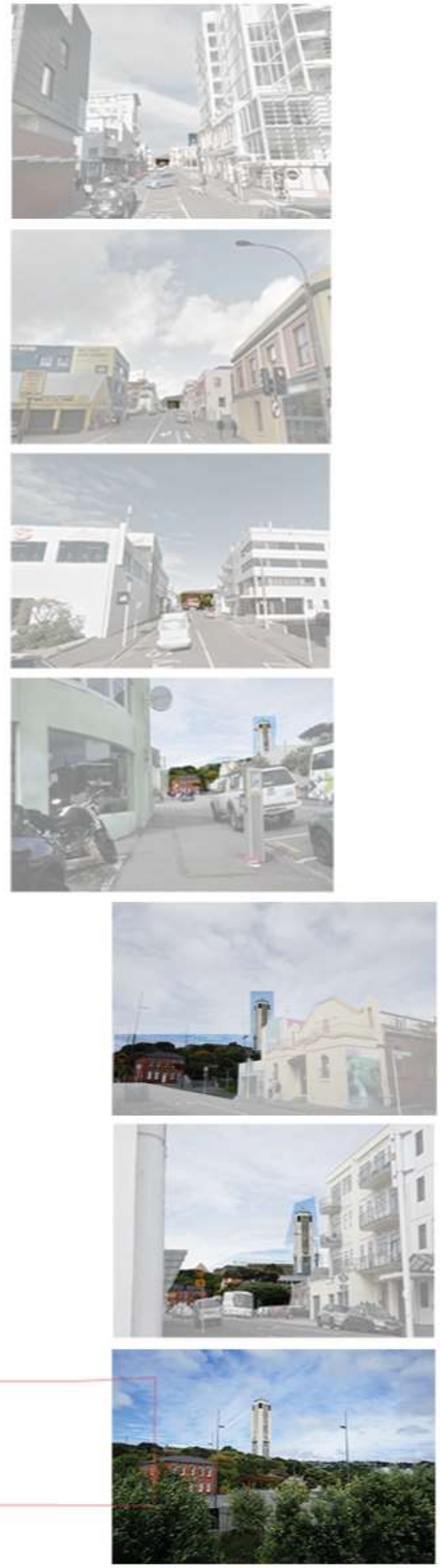

Fig. 3.46: Key Sense from Tory St walking towards Pukeahu Memorial Park 

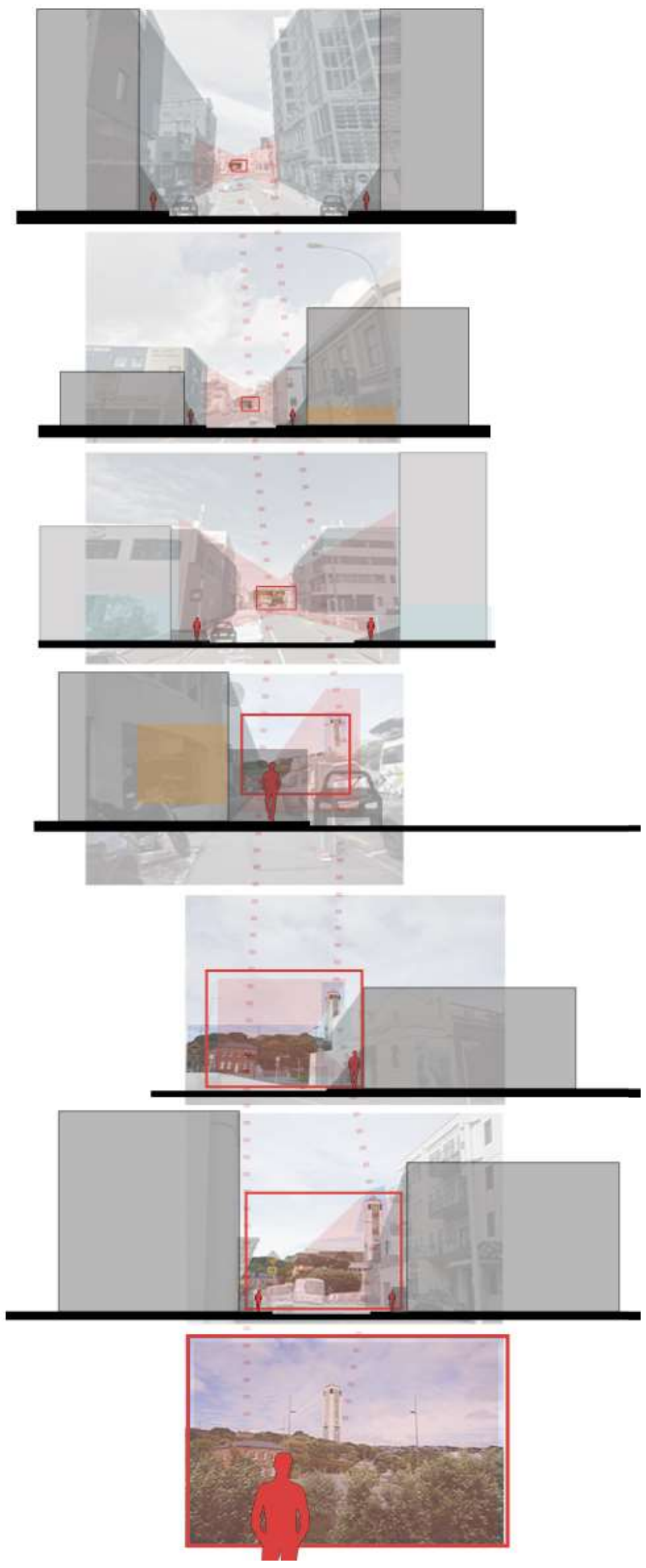

Fig. 3.47: Mind Captured Image from Tory St walking towards Pukeahu Memorial Park

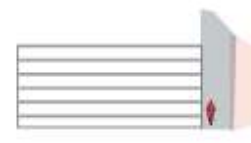

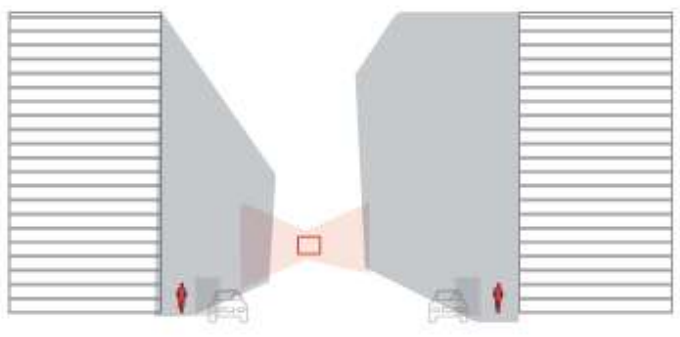
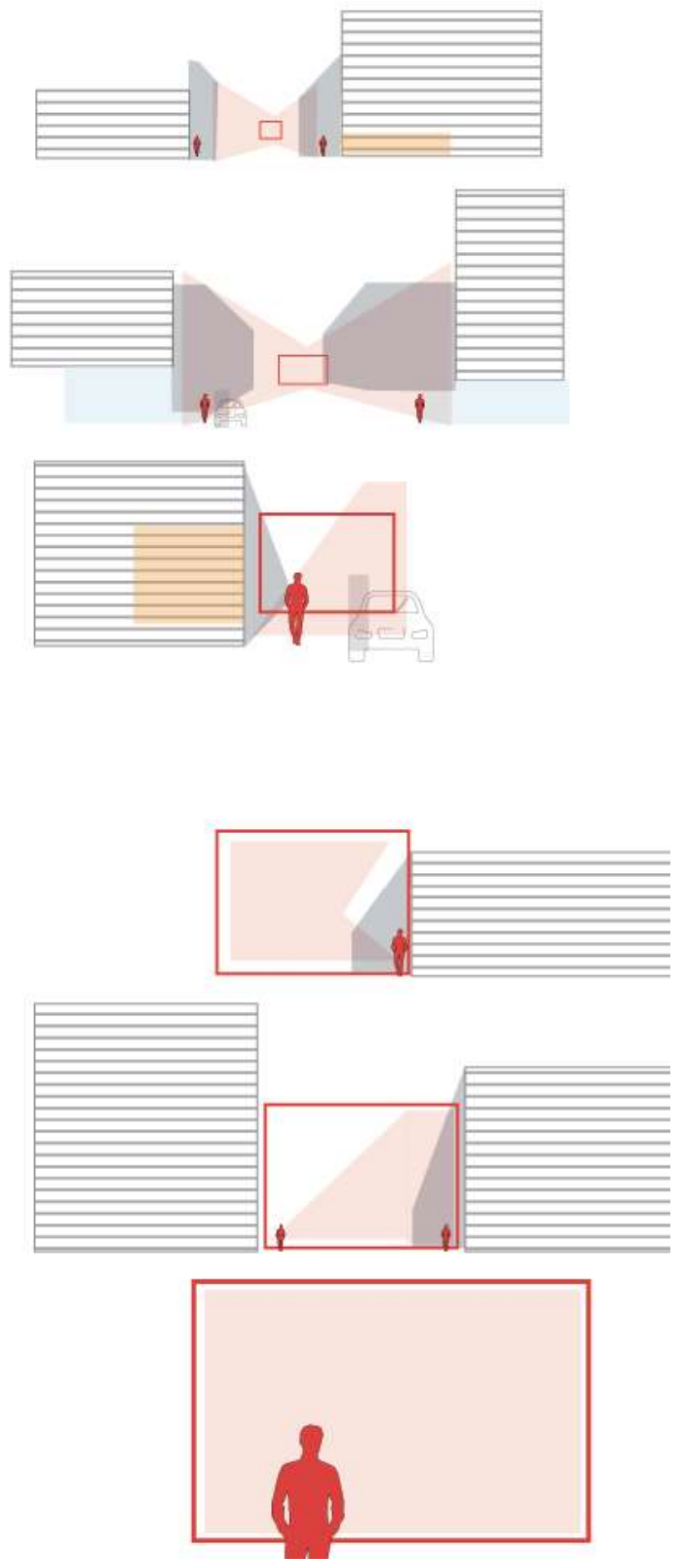


\section{Ellice Street}

Approaching Pukeahu Memorial Park from the top of Ellice Street is a steep journey down, with the eyes shifting viewing-angle the whole time. First the eyes catch the monument, then notice the fast-moving traffic along the State Highway. The building façades seem less attractive, so the eyes look beyond them, unless confronted by a few wild tree branches.
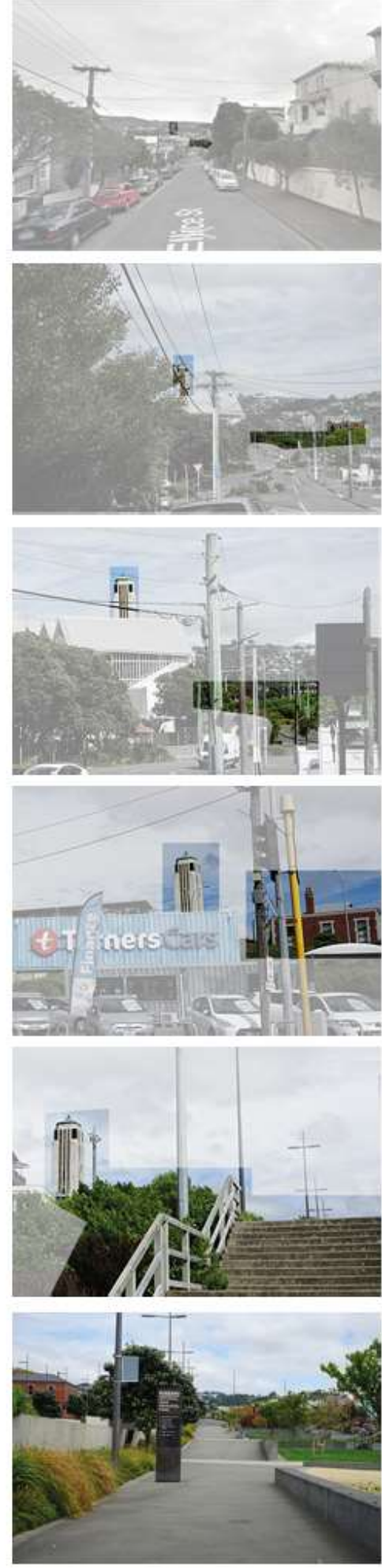
3.2 Precedent Reviews and Case Studies
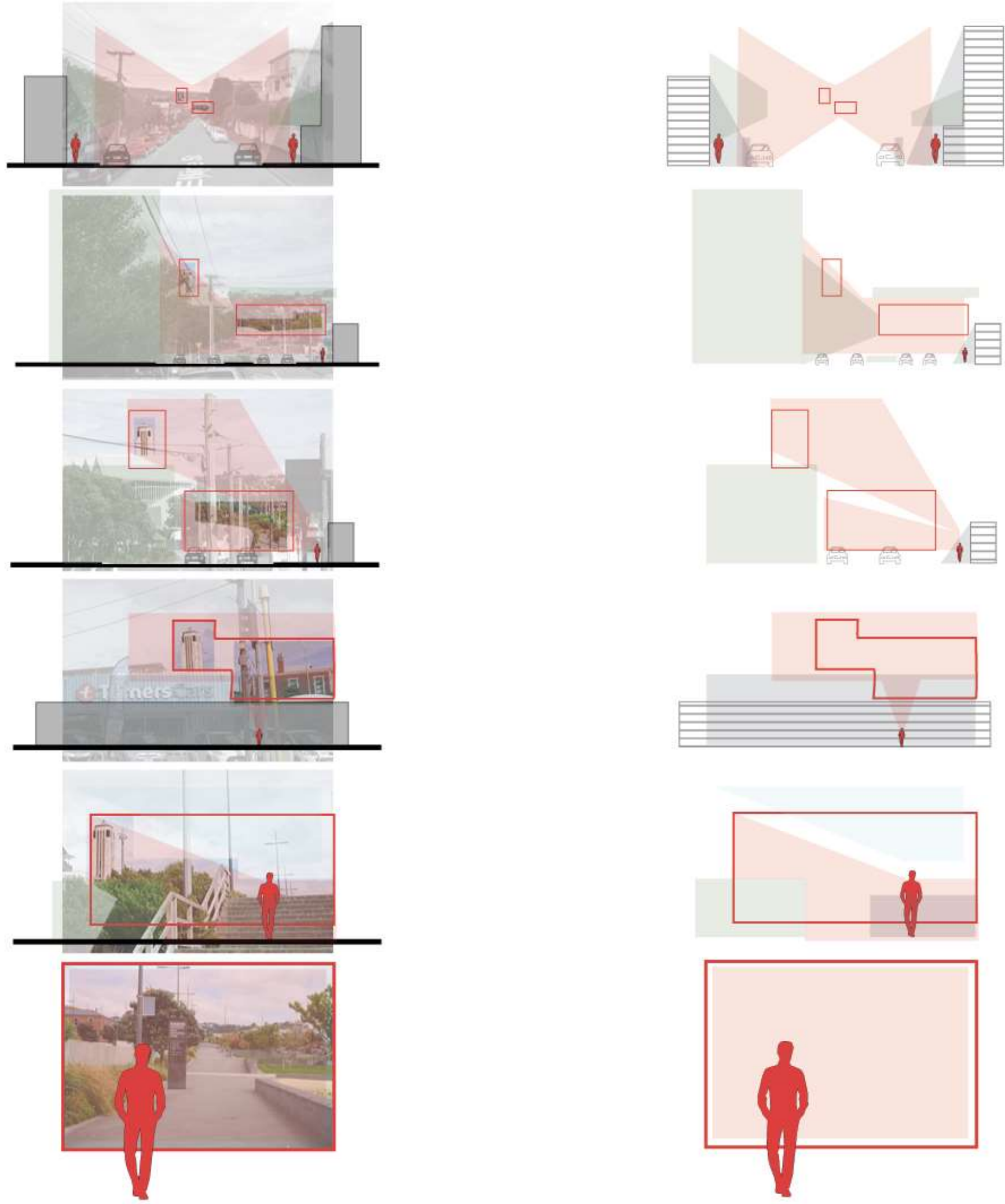


\section{NZ State Highway 1}

The National War Memorial monument is the first thing a driver sees, coming out of the Mt Victoria tunnel, and this is when drivers realize they are arriving into the city centre. It is a relatively curvy journey along the State Highway, and its visual relationship to Pukeahu Memorial Park is weaker than the other two streets'. There are parts of the journey where trees completely hide the monument, the eyes have to search for it. When space opens up, the monument shows up suddenly, which gives the viewer a strong sense of the place.
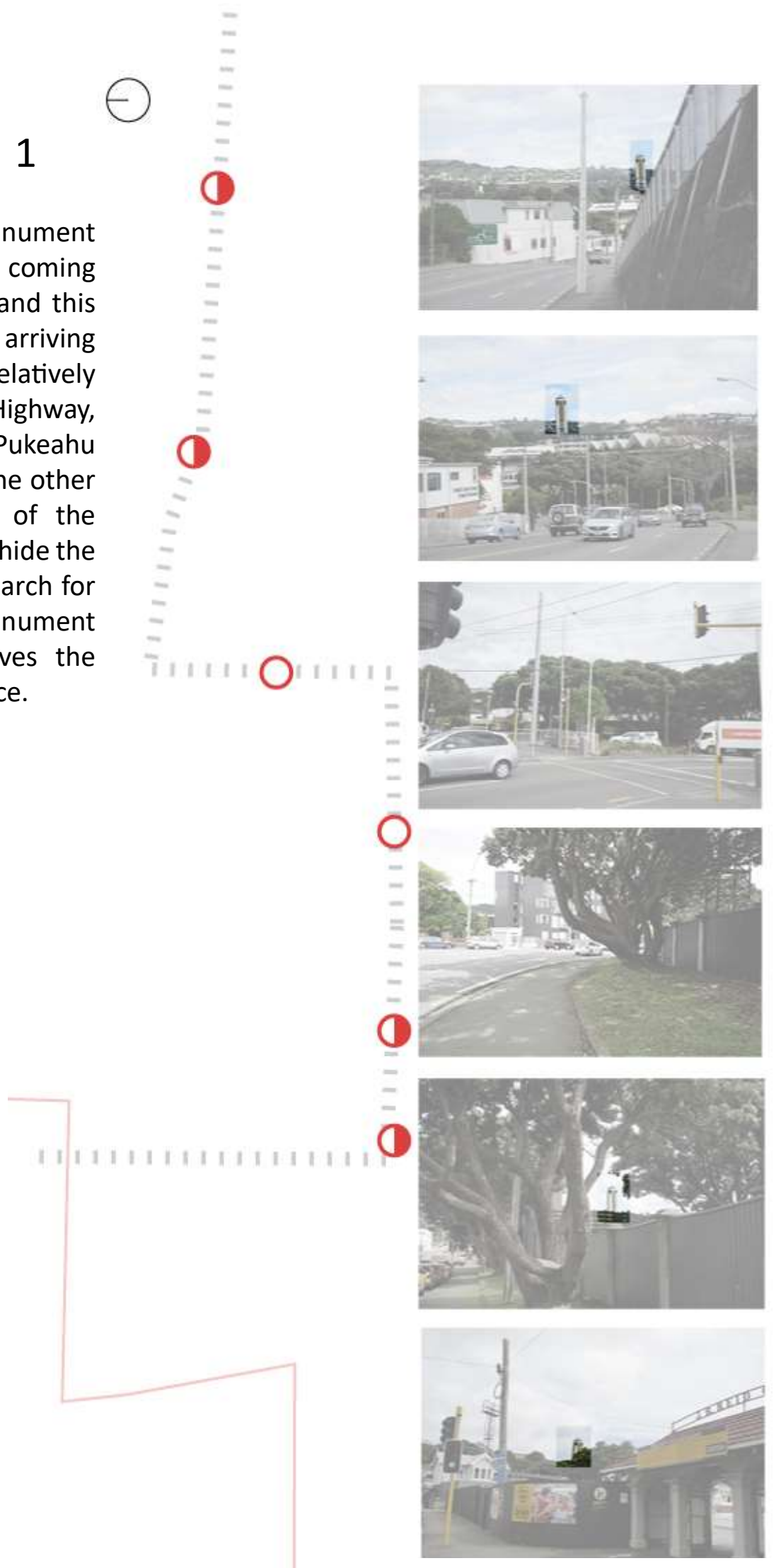

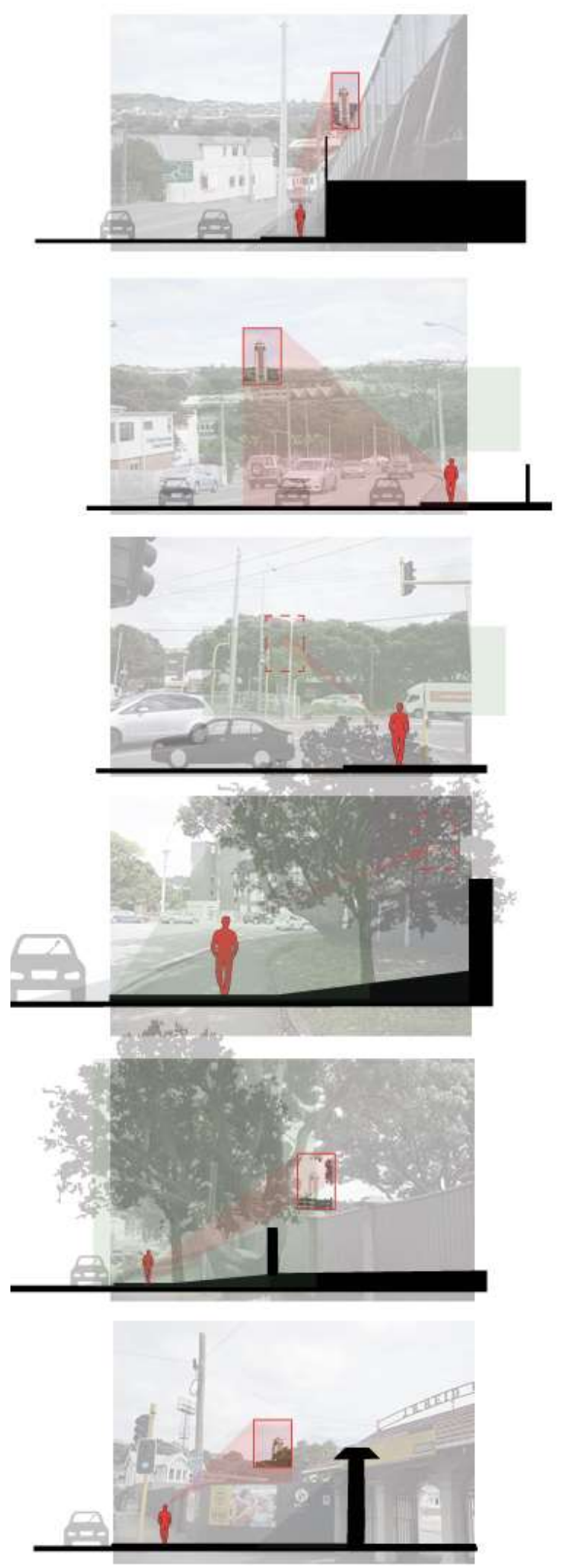
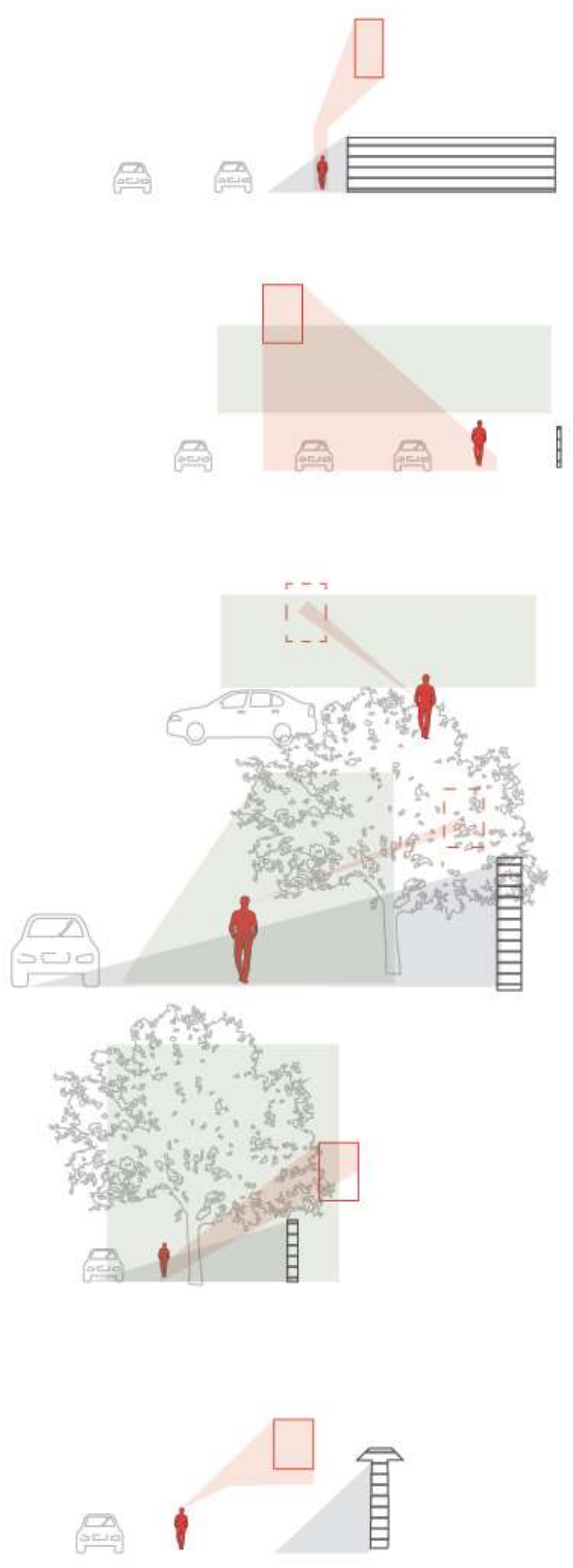
3.2 Precedent Reviews and Case Studies

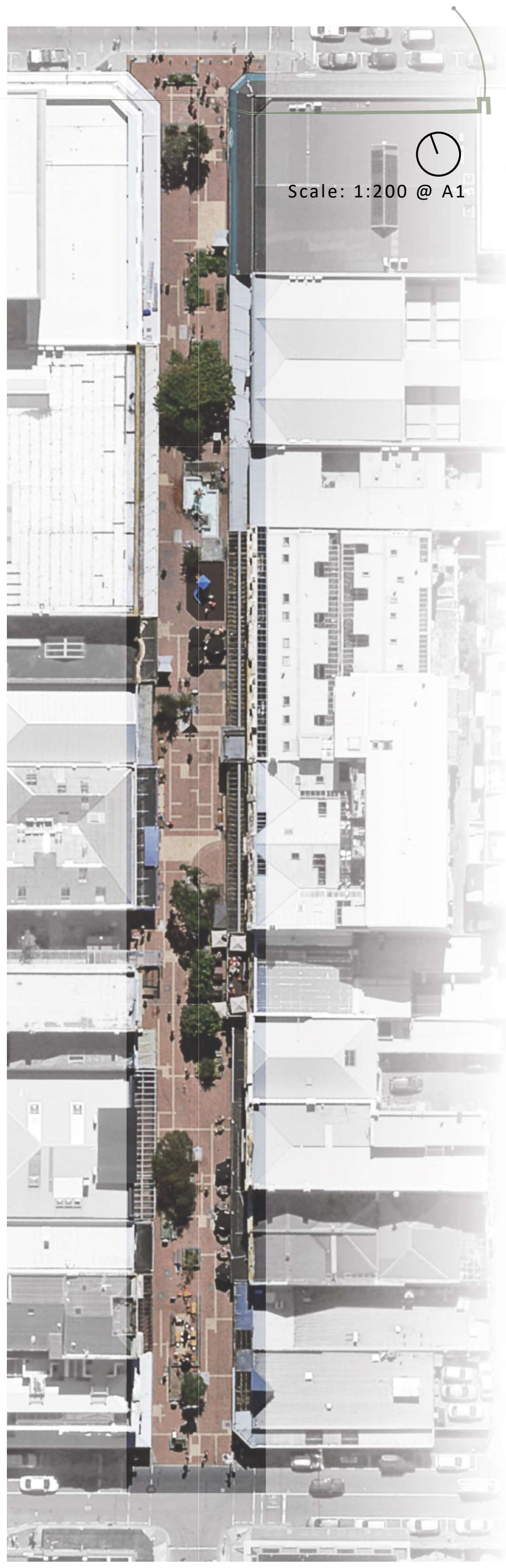




\title{
Cuba Street, Wellington
}

\author{
Visual landscape studies \\ Internal intervention effects visual design
}

Cuba Street is one of the most prominent streets in Wellington city. It is a pedestrian-only street made up of cafes, venues, shops, restaurants, and bars. Despite the introduction of retroactive earthquake regulations, the Neo-Baroque and Art Deco style of the street's facade has largely been preserved, rewarding the eye's movement. A number of street interventions, such as the bucket fountain, have been made in the center of Cuba Street. They've become iconic to the street, and direct pedestrian movement.

This case study looks at internal street interventions: how they affect movement and direct a different view across the street. The study particularly notes street sculpture, planting blocks, outdoor seating, venues, and ground patterns; looking at how vision relates to them, and their territorial affect. 
3.2 Precedent Reviews and Case Studies

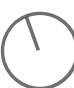

Scale:1:200@A1

Intense planting block and sitting area

Centre of Cuba Street

Bucket fountain and playground

nd pattern and venue A street performance and event place

Outdoor dinning area

Semi-private sitting area Without defined function
Ground pattern

Planting blocks \& sitting areas

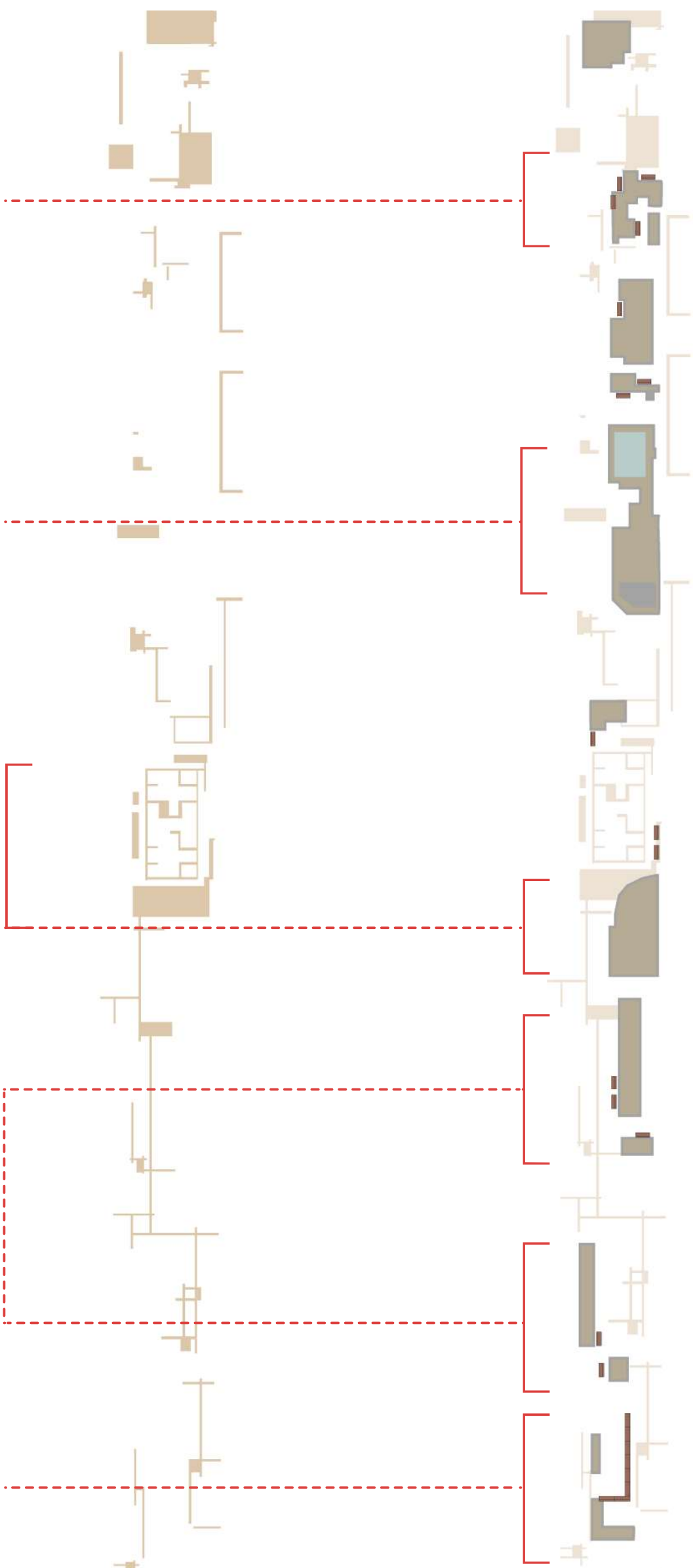


3.2 Precedent Reviews and Case Studies

Interventions vs retail shops

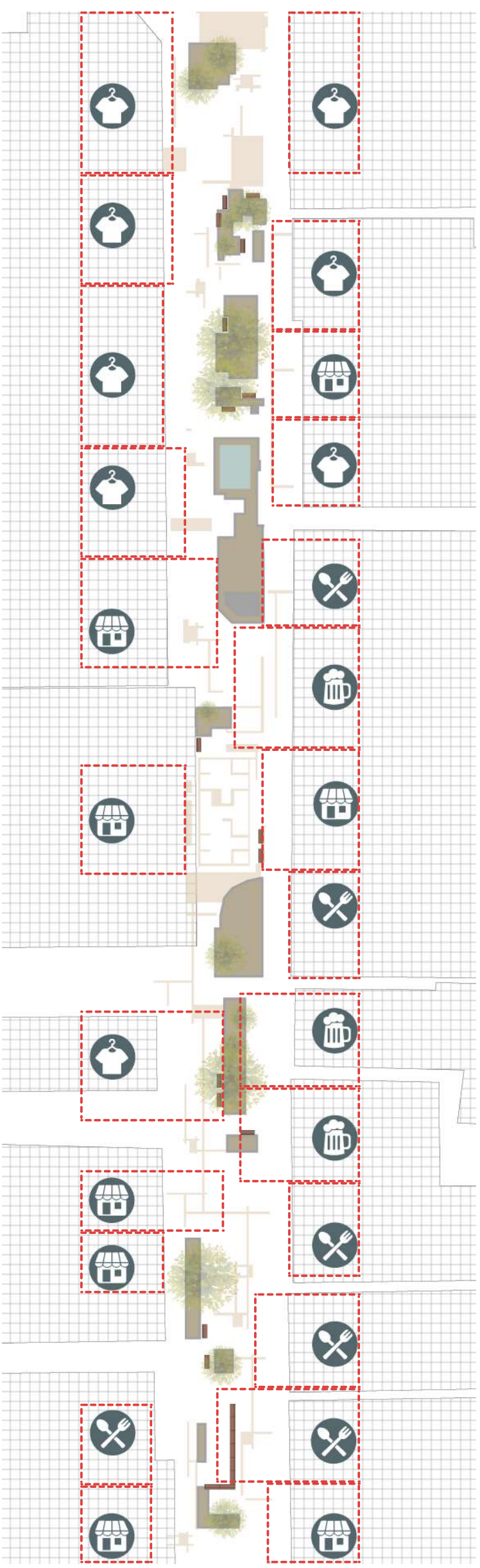

Interventions vs view shafts

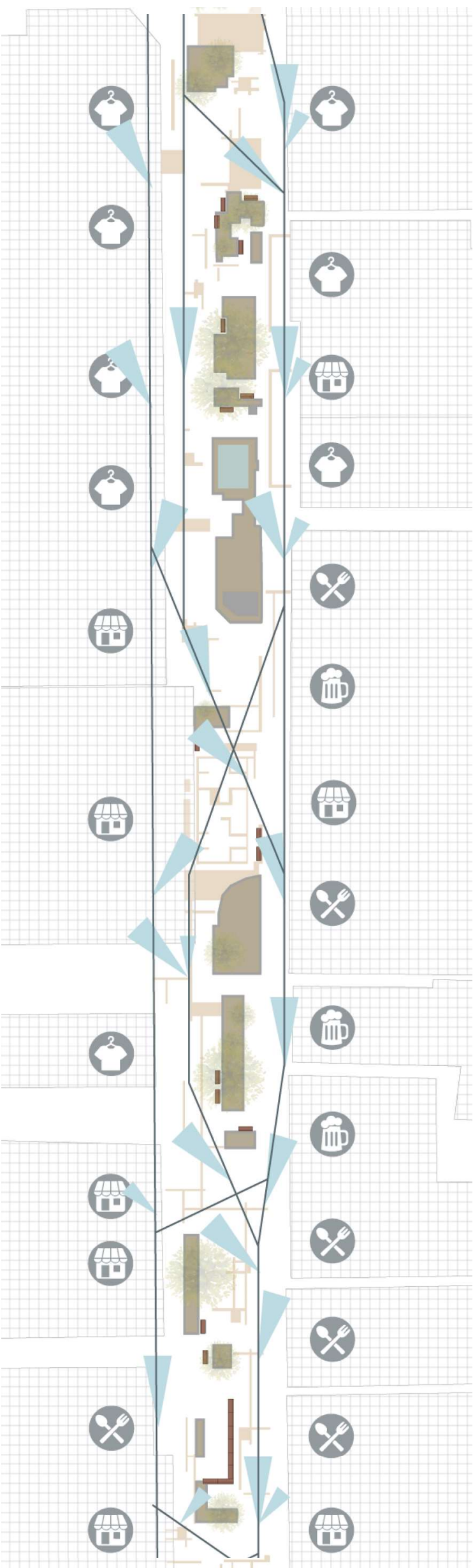



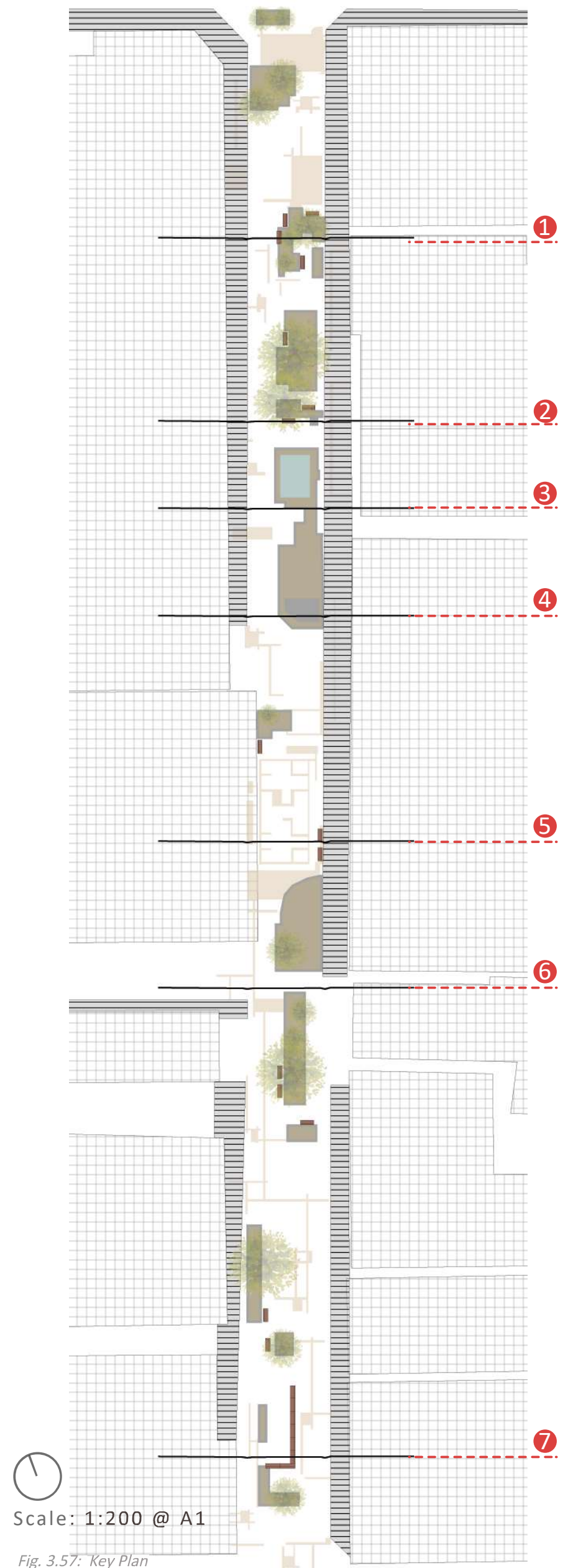

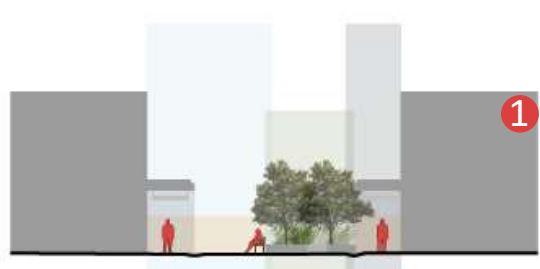

Fig. 3.58: Section 1
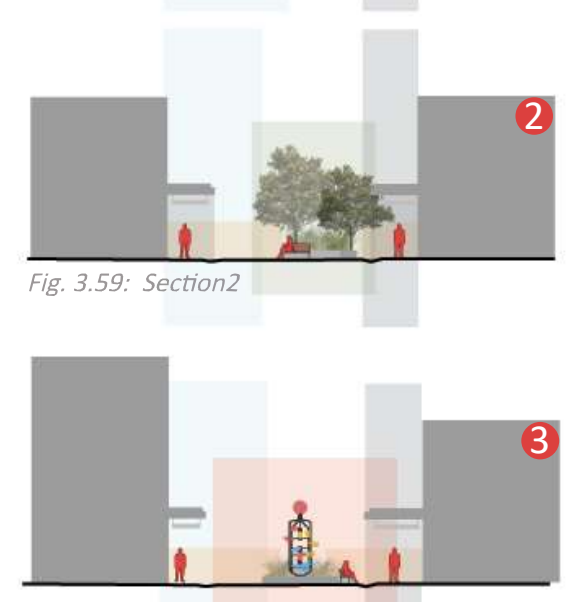

Fig. 3.60: Section3
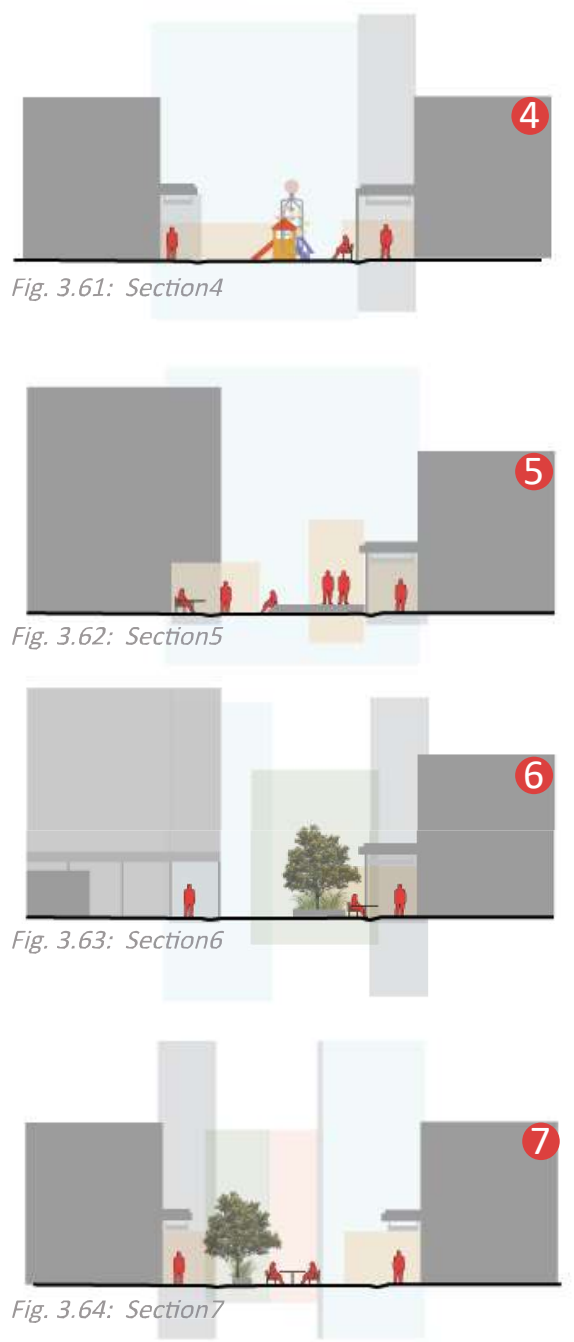

Section Scale: 1:200@A1 
(1)

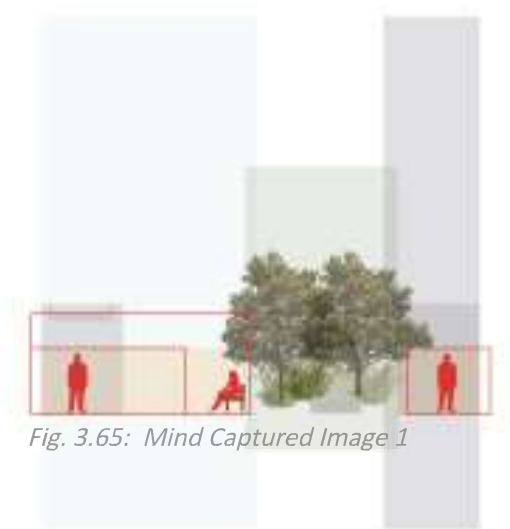

2

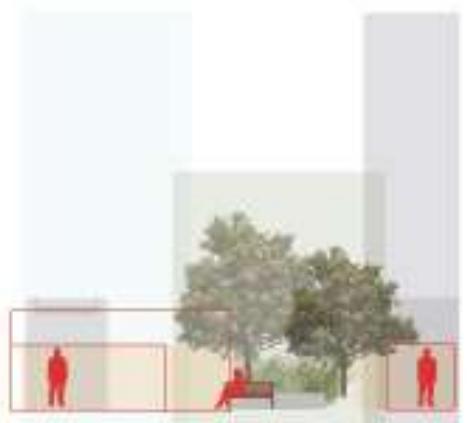

Fig. 3.66: Mind Captured Image 2

3

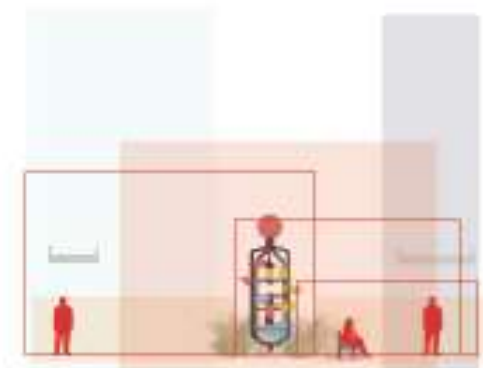

Fig. 3.67: Mind Captured Image 3

4

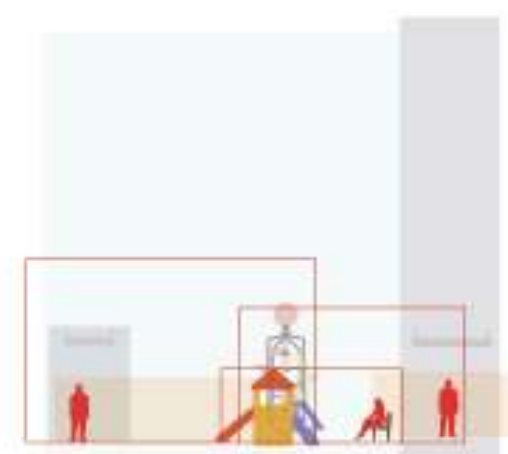

Fig. 3.68: Mind Captured Image 4
5

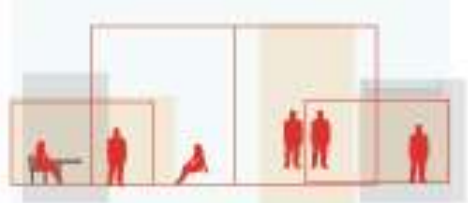

Fig. 3.69 Mind Captured Image 5

6

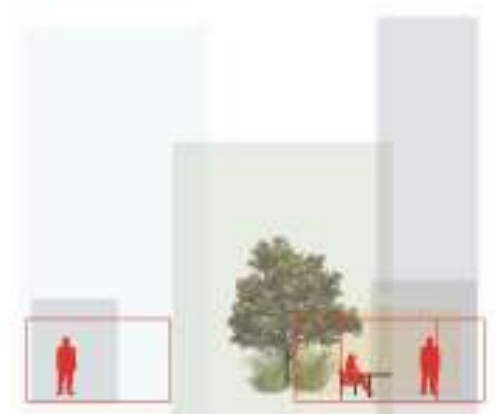

Fig. 3.70: Mind Captured Image 6

(7)

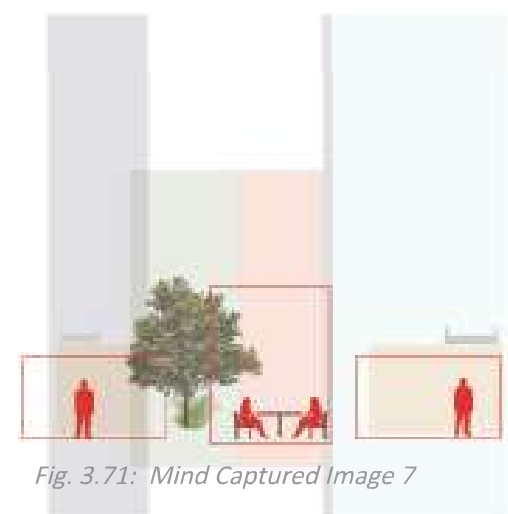

Street furniture plays the role of framing one's vision; and they affect movement. A person's eyes will target an area, from a further distance, which has a different quality to the space they are currently standing in. Sometimes the eyes attach to something special, such as sculptures. Then a person's movement will tend to follow that vision, out of curiosity.

Street interventions also enrich the street's image, by providing a more complex walking environment; forcing observers to think about their movement, which will then form a concrete memory. 


\section{CONCLUSION}

This chapter investigated one's recognition of the landscape, and methods of representing this personal recognition. It explained that an artists' perception of objects reflects the world, space and time. For instance, Monet painted the reflection of light, sky, and water-lily, rather than painting the texture of water. Impressionist painting inspires a way to look at the landscape, and this method will be employed and developed in the next chapter.

The study also reviewed the importance of historical memory on the land, understanding that memory is one of the most effective linkages that connect individuals to the landscape. Examining this idea through two historically significant precedents, the ChampsÉlysées and Hatshepsut Temple Axis, discovered their methods of connecting the contemporary use of landscape to the image that it used to be. When people think about Paris and Luxor, they will think about Champs-Élysées and Hatshepsut Temple Axis as part of their character because they are representative of the city's history and culture.

The Champs-Élysées and Hatshepsut Temple Axes both have strong visual legibility. When understanding landscape on a largescale, vision plays the most important role, because it can reach the farthest distance. This study also reviewed techniques of visual design conventionally utilised in landscape architecture, and examined two case studies in detail, to understand how human visual perception operates mobile, in time. 


\section{FURTHER RESEARCH}

Further research will employ the knowledge and techniques tested in this chapter to: investigate those historical and cultural assets on the site, which represent a regional and district context; examine the site's visual image and physical experience; and study how together they transform into a large scale image, and what this image looks like. 


\section{SITE ANALYSIS}




\section{CHAPTER INTRODUCTION}

The second chapter introduced the site, with plan drawings and photographs, and described the logic behind the New Plymouth Central Area's urban planning. The third chapter established that humans have a moving relationship to the landscape and build their images at human scale. This chapter will look at the site from the human scale, and attempt to understand humans' visual and physical relationships to the site, through a grounded experiment. Several journeys will be undertaken, to analyse this moving relationship, in New Plymouth's central area. According to those precedent and case studies in the previous chapter, instantaneous visual images become a moving image; the mind will unconsciously record the movement, to form an imagination of this journey.

This chapter aims to understand the legibility of New Plymouth central area, by analyzing the mental image, through minor-scale to context-scale.

This chapter will include:

- Investigation of an abstract method to represent the mental image of space and test it through a process of site analysis.

- Analysis of the site from human scale, looking at the ground assemblage in relation to the human body.

- Representation of a range of photomontages of a journey, and abstracting them into an easy-to-read diagram of human perception.

- Searching of the latent historical characteristics within the central area.

- Finding design opportunities 


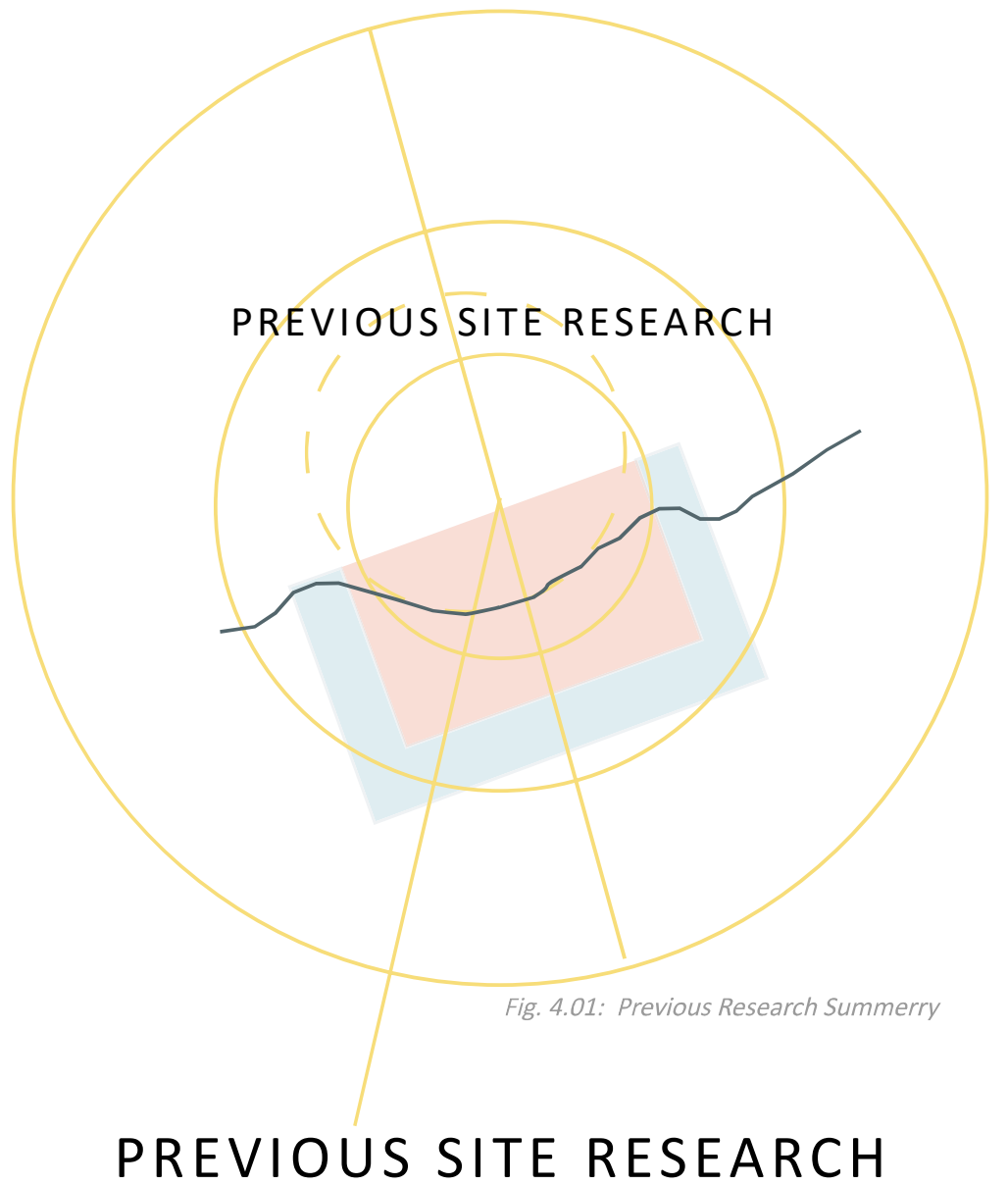

Previous studies investigated the pattern of New Plymouth's urban settlement, and the reason behind this planning. New Plymouth was planned as a garden city. The centralized commercial and industrial areas are located in the early-developed space. The residential areas were developed later, and consequently surround the central area. Residential buildings are rarely found in the central area.

New Plymouth's landform identifies the boundary of urban development. The residential areas follow the natural topography of the land. The central area is comparatively flat or flattened, paved with concrete, and its spaces are functionalist. The street layout of New Plymouth's central area still serves a function of car-dominance. Except for Devon Street, which is effectively the town centre, in most streets the pedestrian experience is relatively dull. Lack of vegetation, a massive number of carparks and industrial sheds, and non-active building façades, keep the city from being a legible city. 
The central area of New Plymouth functions around four major east-west streets, as identified below. Further studies will analyze the perception of these east-west moving experiences, and explore research techniques.

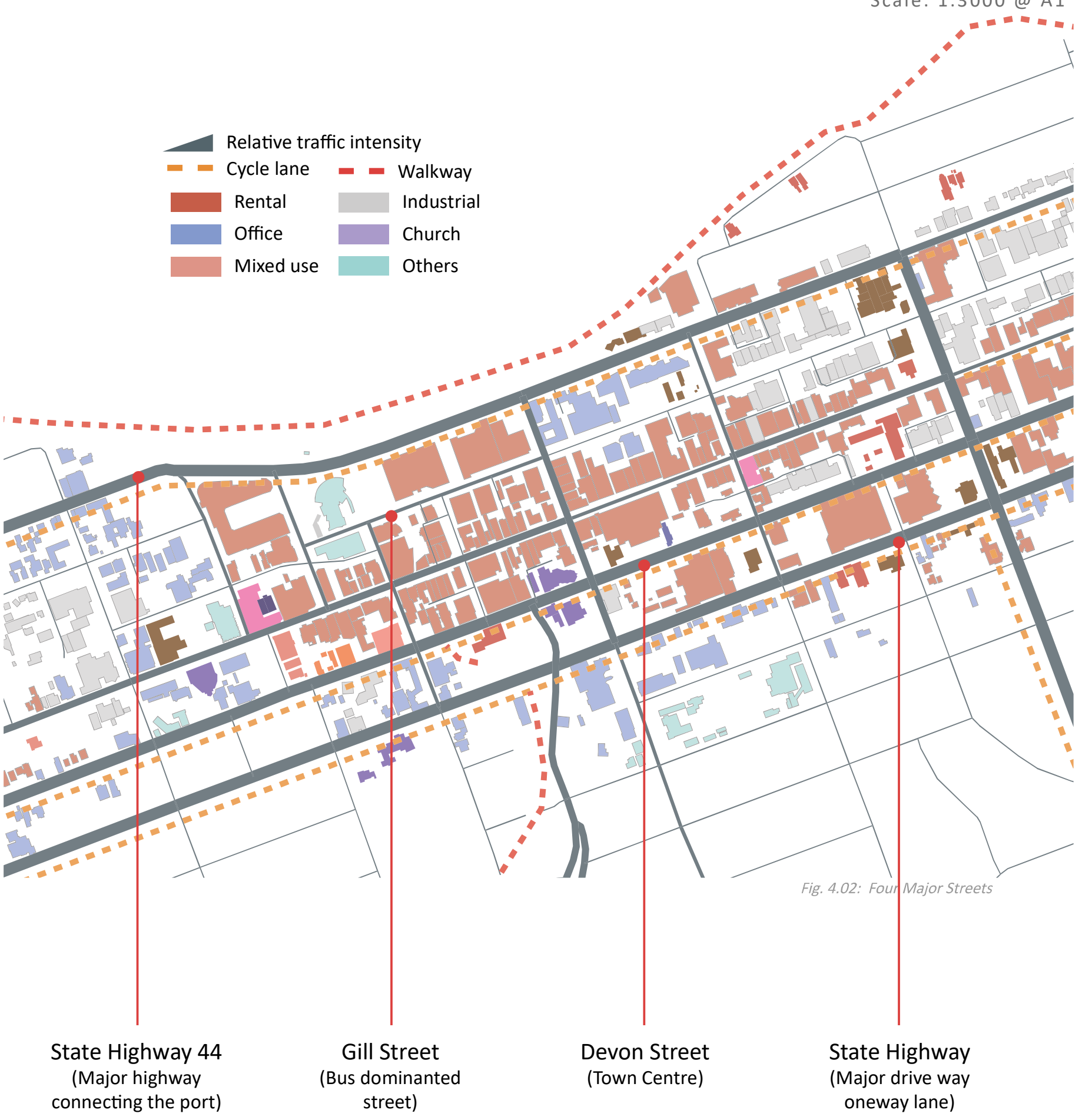



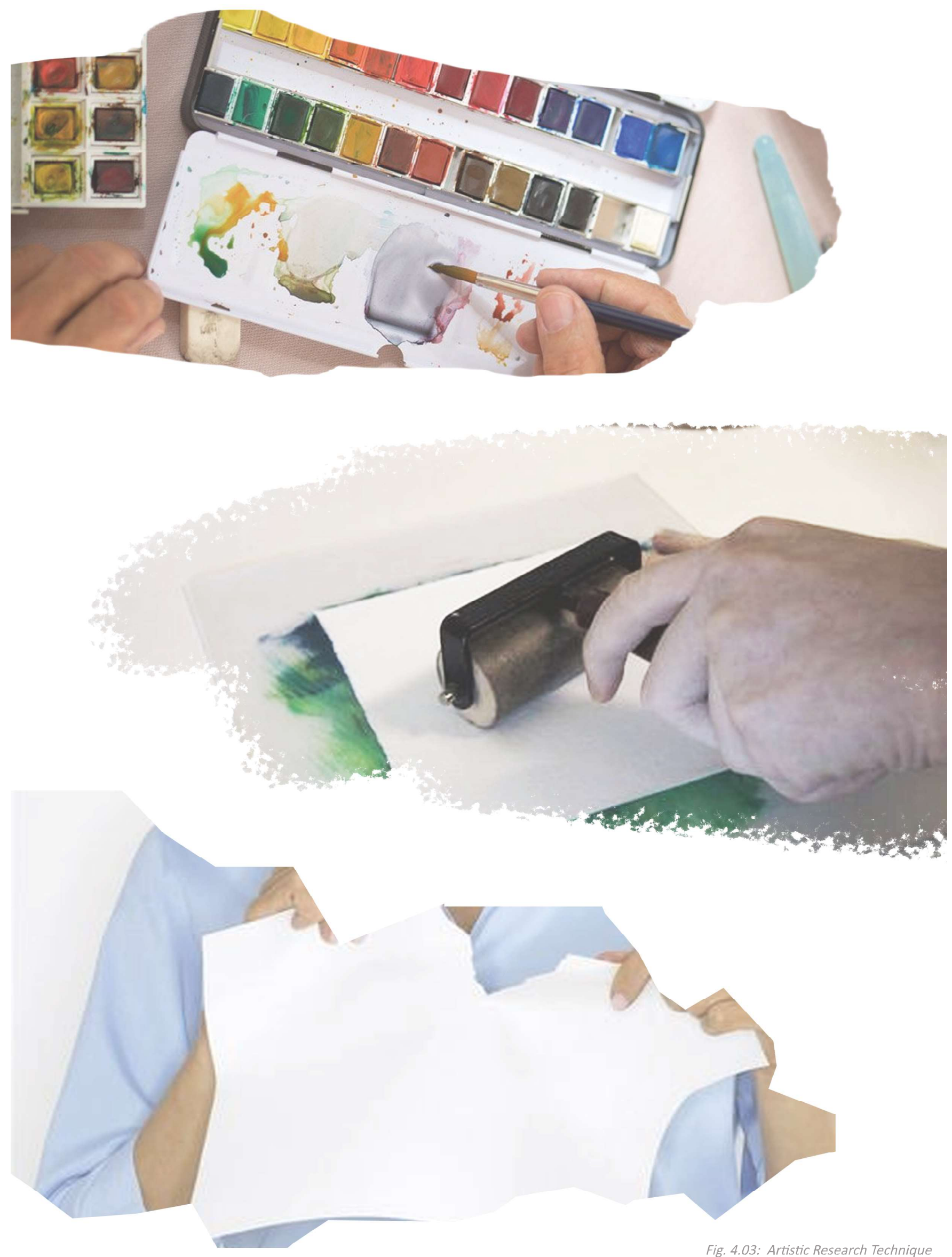


\section{RESEARCH TOOLS}

The previous chapter introduced the impressionist painters' perception of the world. They see objects as reflected colours, and they reinterpret the object with brushstrokes. The world, in an artists' mind, is a collection of colours.

This method is applicable in large-scale landscape image representation. The visual image from a particular space can be abstracted into a collection of colours. Painting techniques, such as strokes and colour layouts, express emotions within space and time. When small bits of colour join together, that will create an image of a large-scale context, just like a pointillist's painting of the Impressionist movement.

This chapter will employ painting and crafting techniques in site-analysis; that procedure requires a degree of intuitional interpretation and expression. Monotype-printing, watercolour, and paper crafting are selected in relation to their different degrees of intuitional input, and in relation to degrees of familiarity and certainty gained through experiencing and experimenting with the site. It will explore methods of representing mental recognition of the site and look for inspiration for design opportunities. 


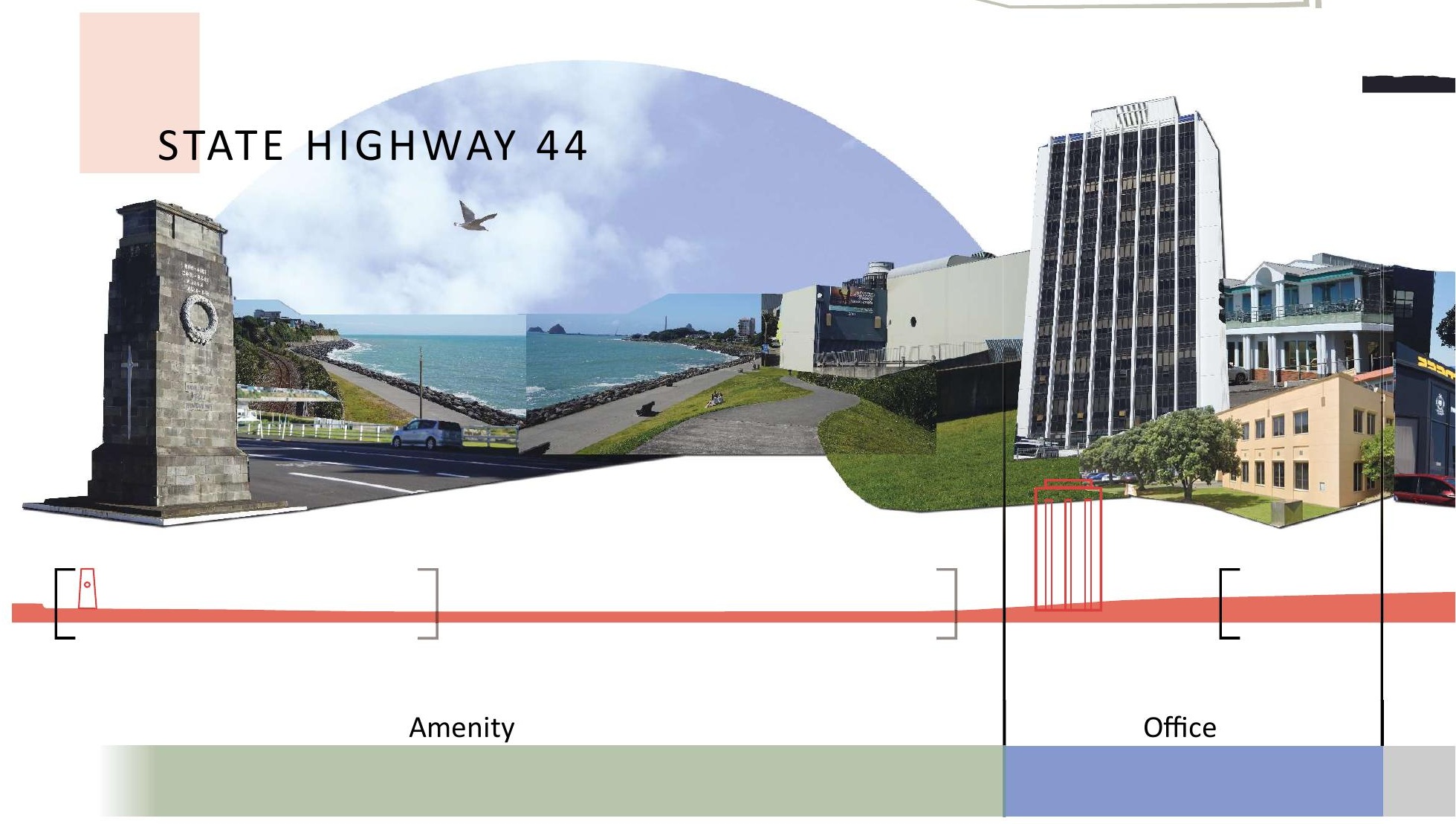

[View from east to west

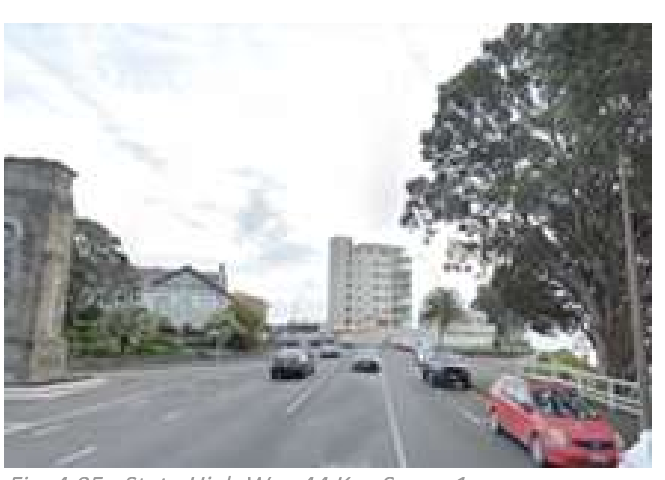

Fig. 4.05: State High Way 44 Key Sense 1

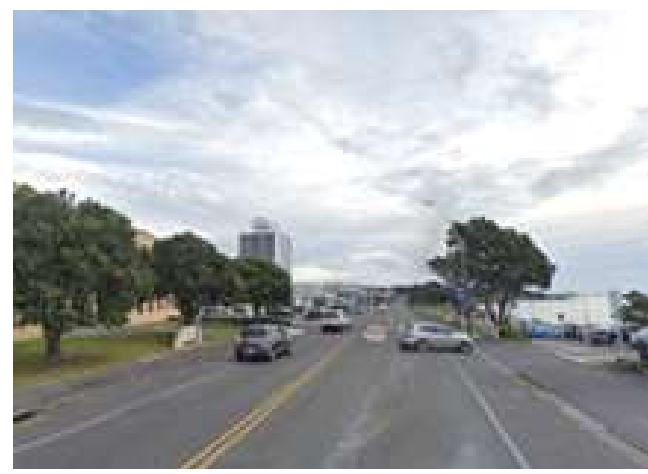

Fig. 4.07: State High Way 44 Key Sense 2

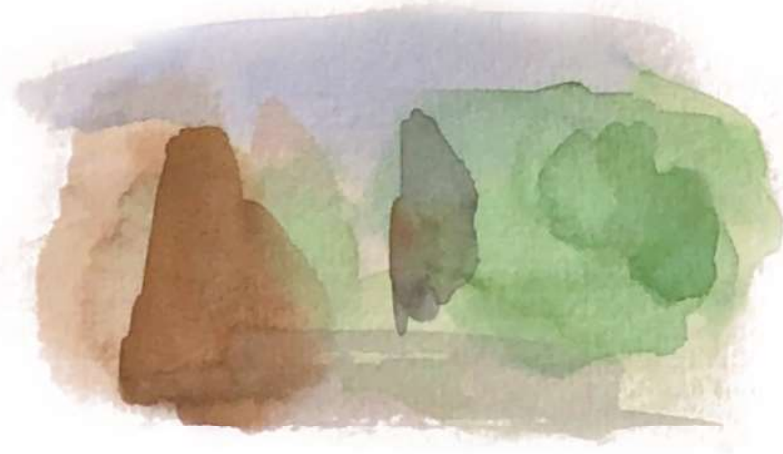

Fig. 4.06: Mind Captured Image State High Way 44 Key Sense 1

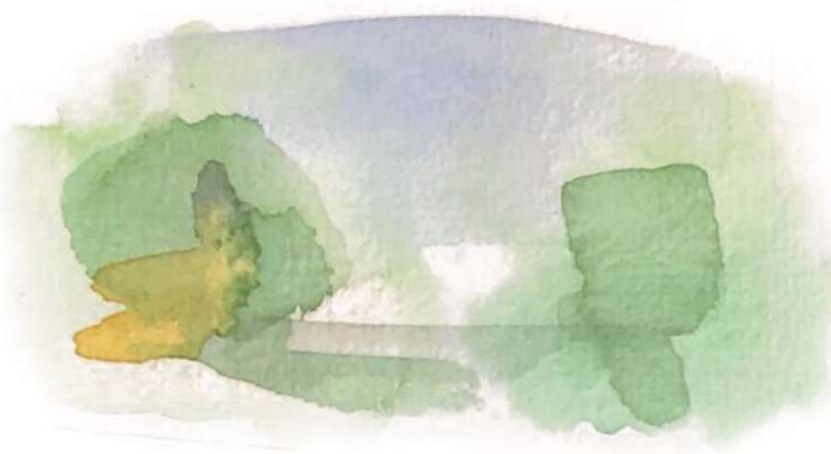

Fig. 4.08: Mind Captured Image State High Way 44 Key Sense 2 


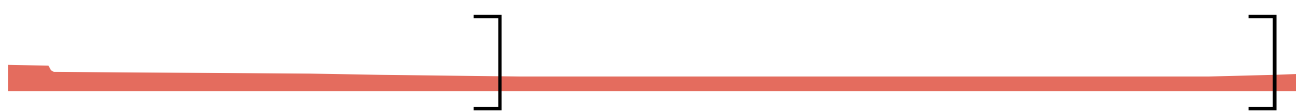

View from west to east

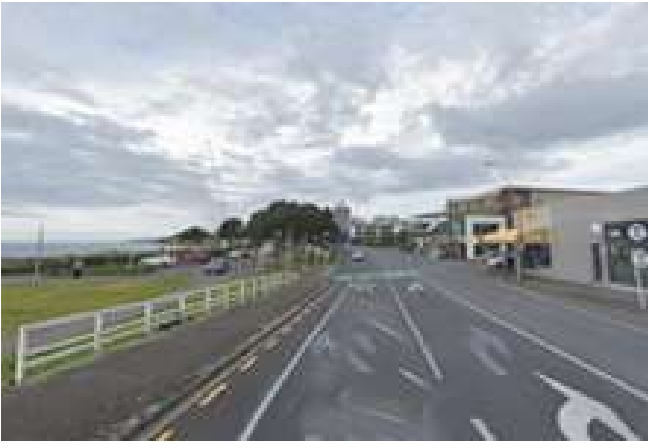

Fig. 4.13: State High Way 44 Key Sense 5

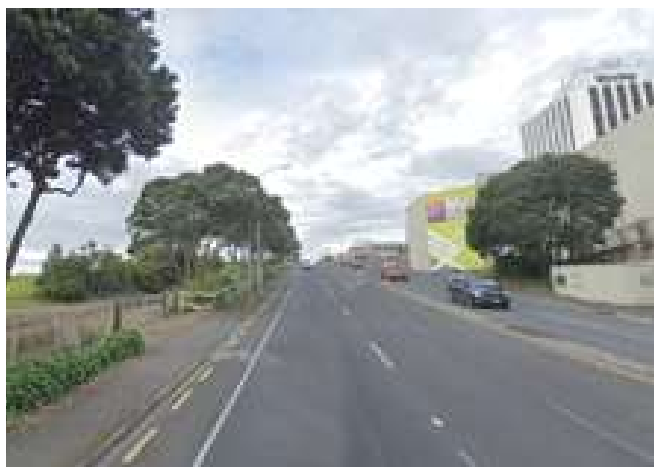

Fig. 4.15: State High Way 44 Key Sense 6

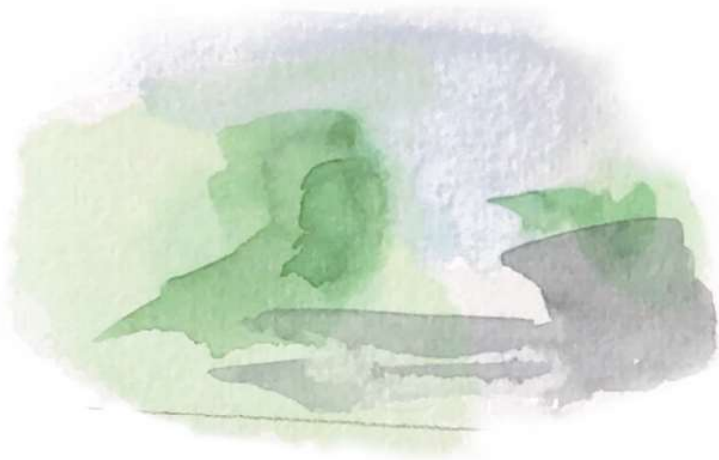

Fig. 4.14: Mind Captured Image State High Way 44 Key Sense 5

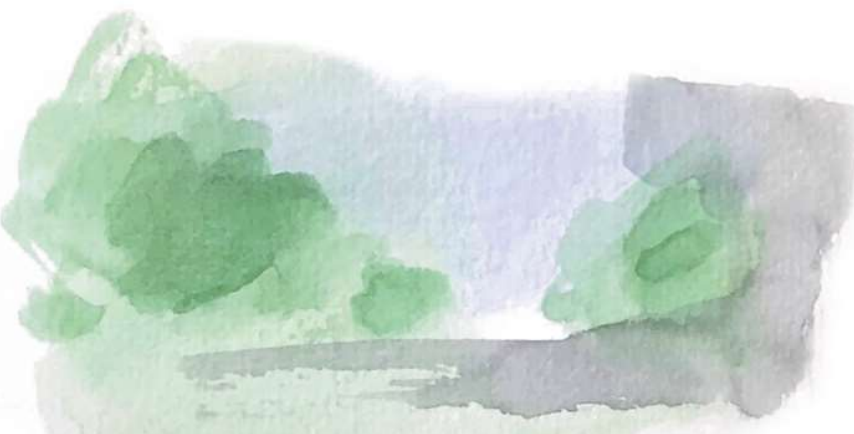

Fig. 4.16: Mind Captured Image State High Way 44 Key Sense 6

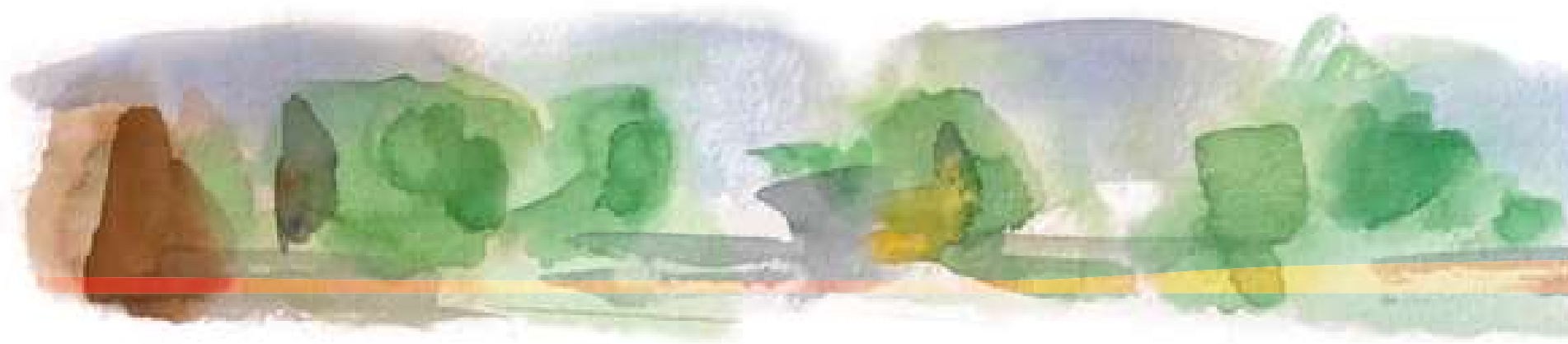



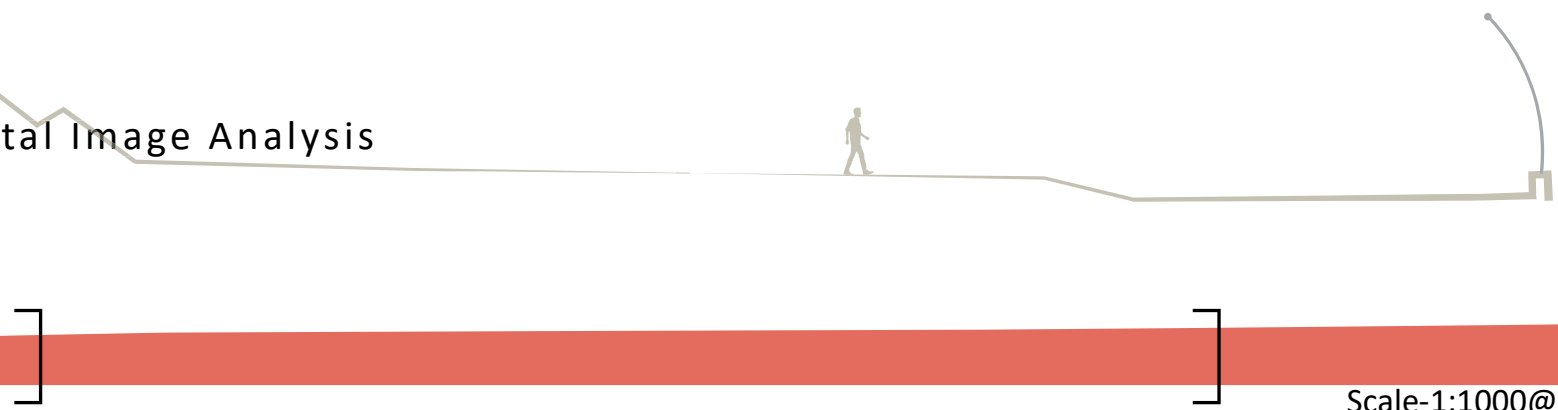

Scale-1:1000@A1

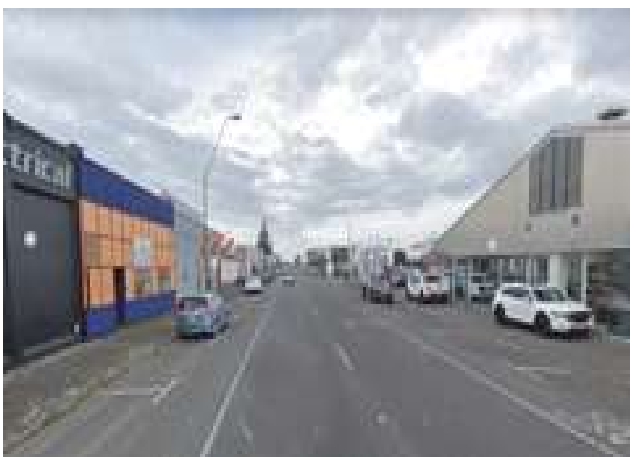

Fig. 4.17: State High Way 44 Key Sense 7

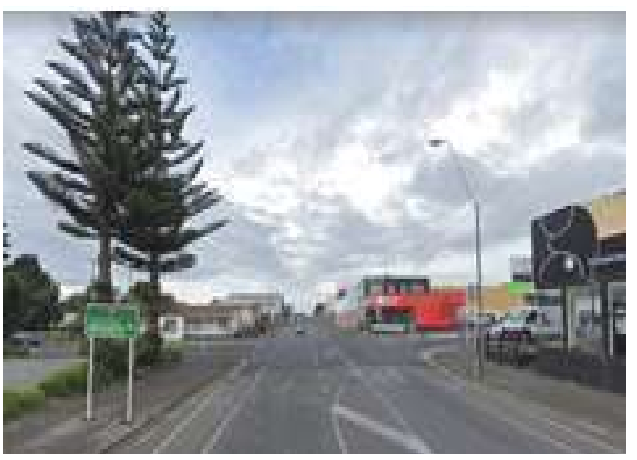

Fig. 4.19: State High Way 44 Key Sense 8

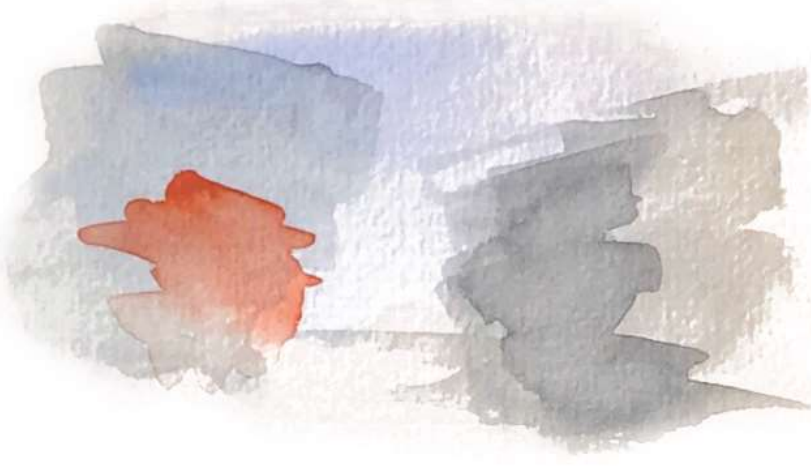

Fig. 4.18: Mind Captured Image State High Way 44 Key Sense 7

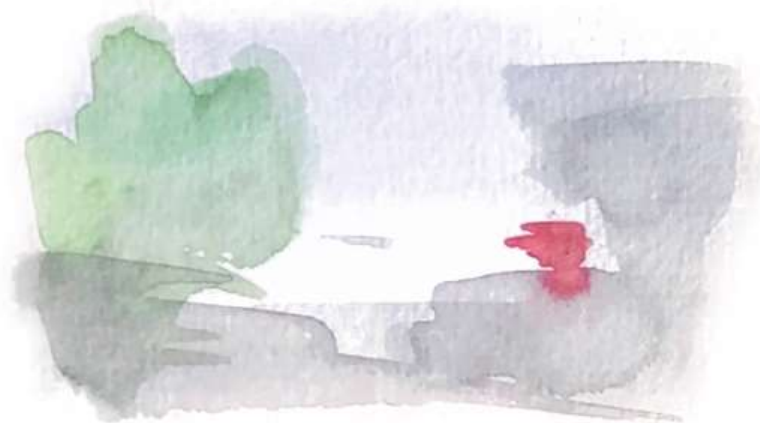

Fig. 4.20: Mind Captured Image State High Way 44 Key Sense 8

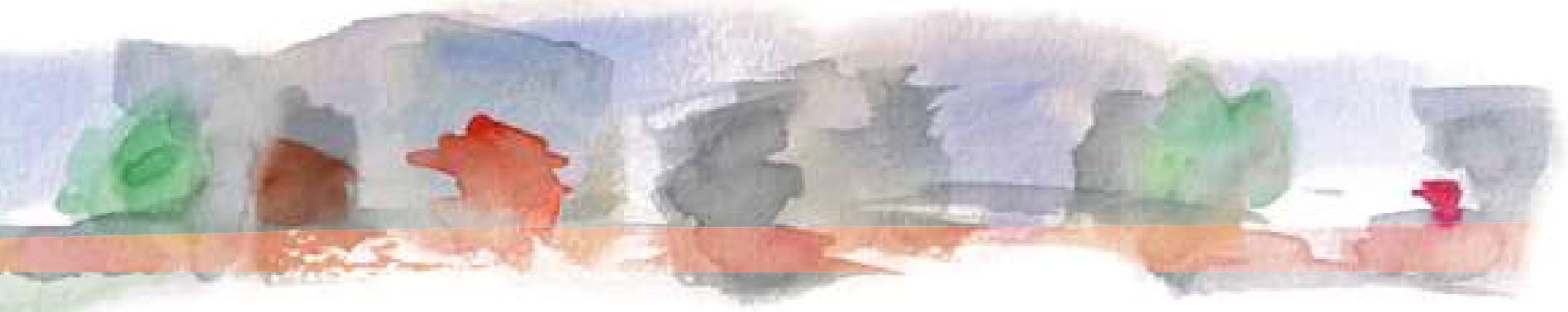

Fig. 4.21: Mind Captured Sectional Image State High Way 44 


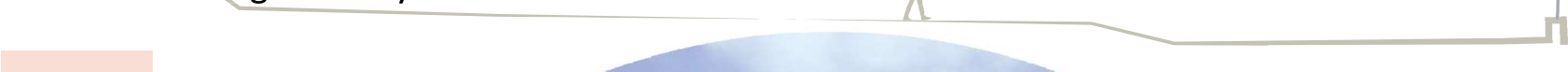

\section{GILL STREET}

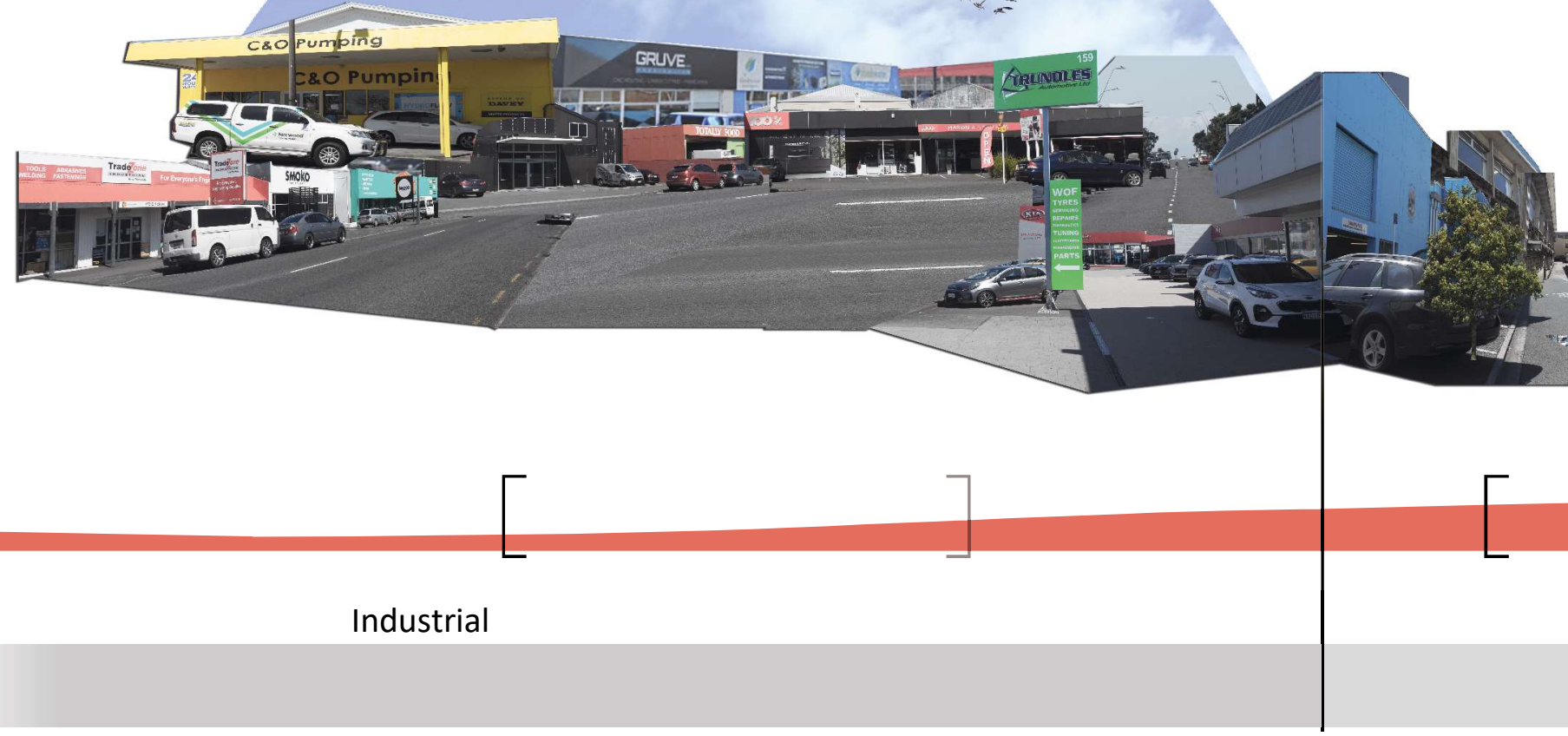

[View from east to west

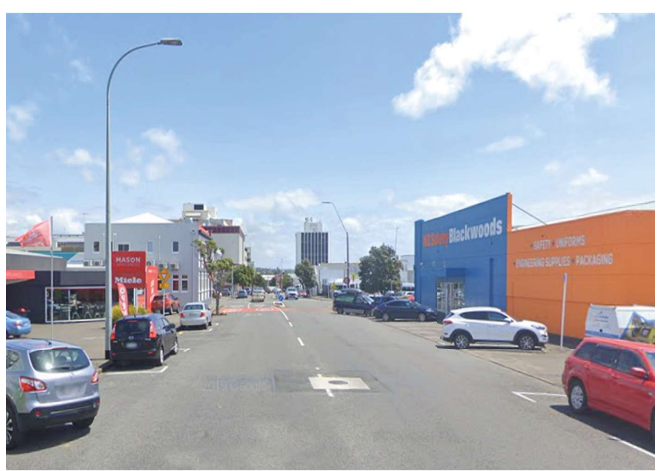

Fig. 4.23: Gill Street Key Sense 1

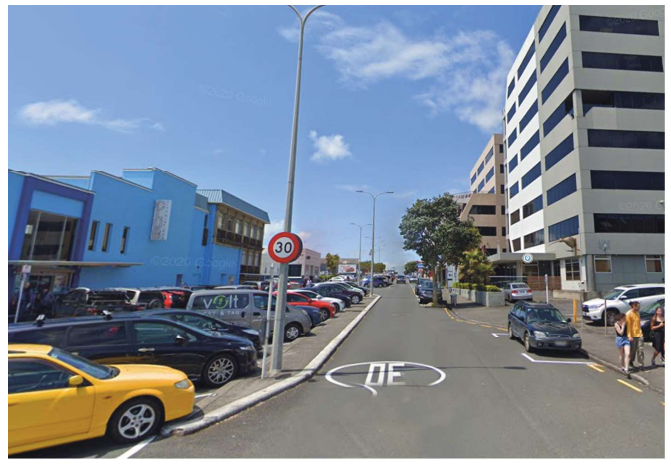

Fig. 4.25: Gill Street Key Sense 2

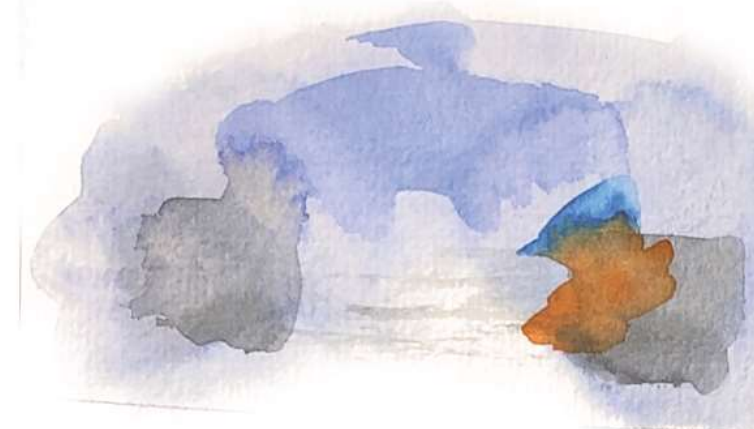

Fig. 4.24: Mind Captured Image Gill Street Key Sense 1

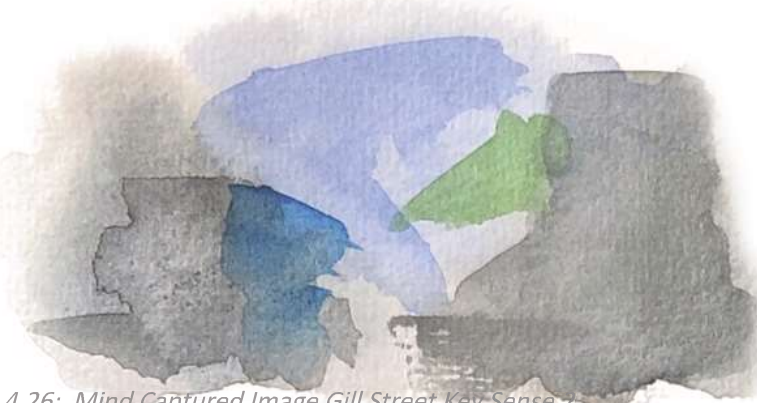


] ]

View from west to east

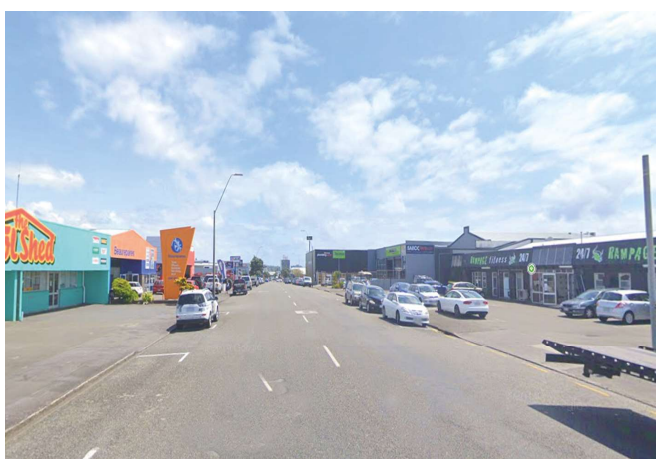

Fig. 4.31: Gill Street Key Sense 5

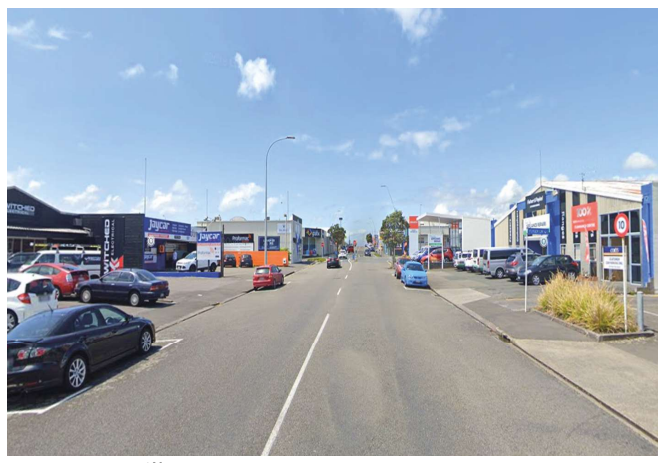

Fig. 4.33: Gill Street Key Sense 6

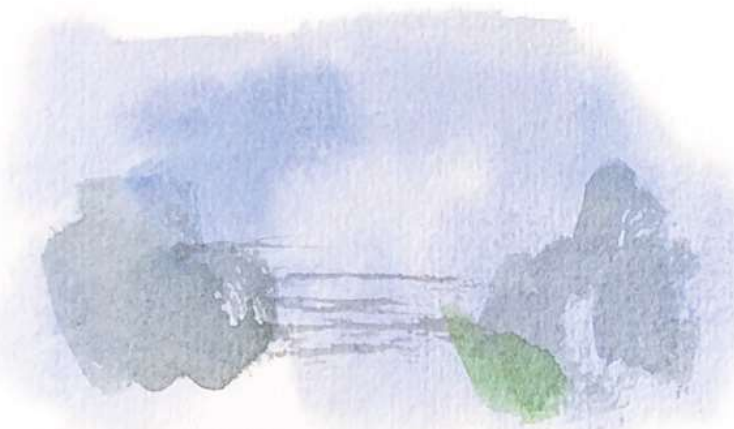

Fig. 4.32: Mind Captured Image Gill Street Key Sense 5

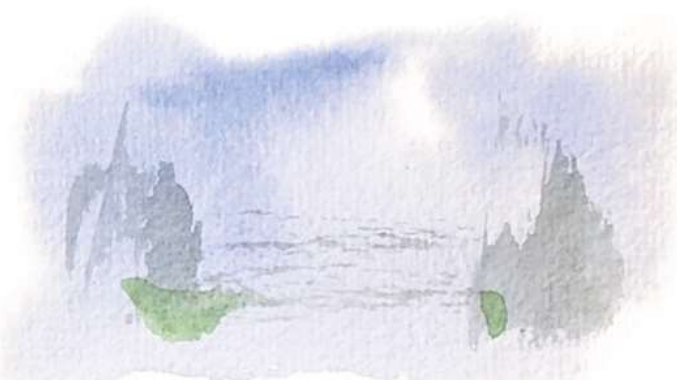

Fig. 4.34: Mind Captured Image Gill Street Key Sense 6

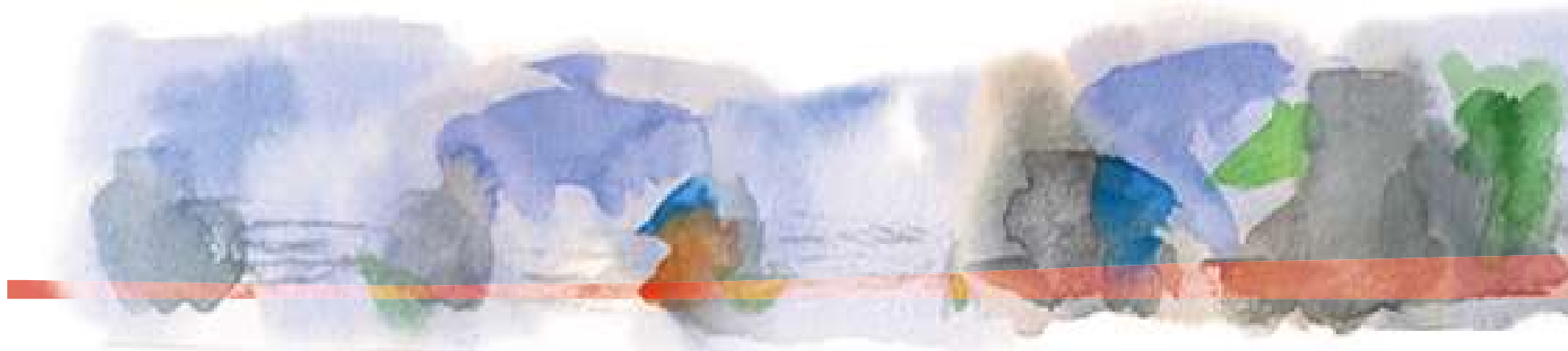




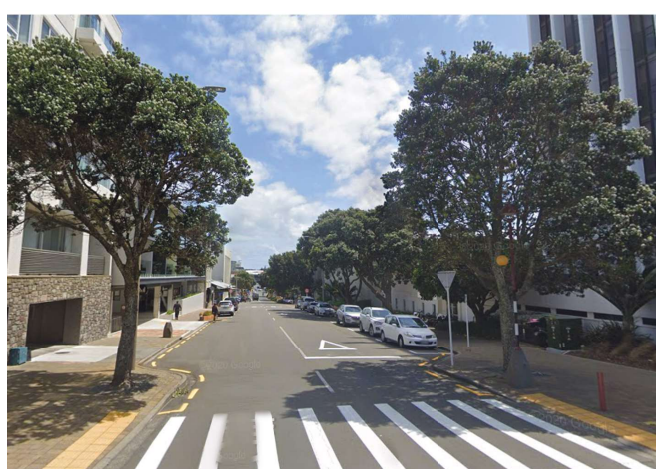

Fig. 4.35: Gill Street Key Sense 7

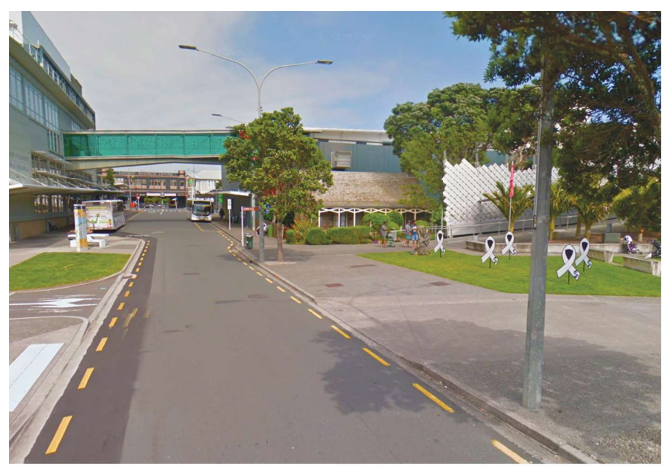

Fig. 4.37: Gill Street Key Sense 8

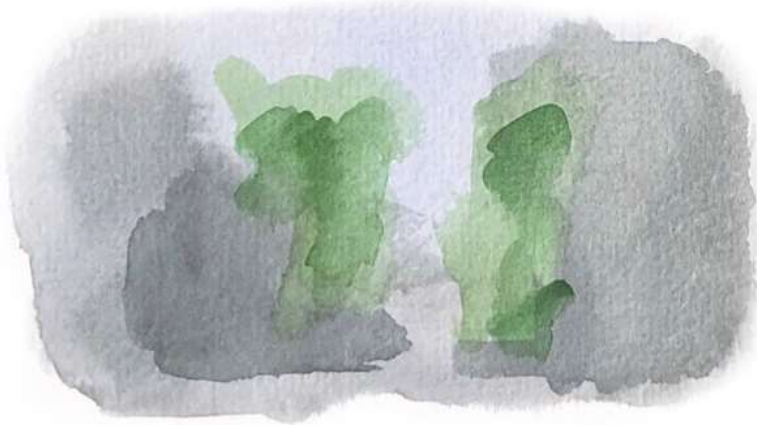

Fig. 4.36: Mind Captured Image Gill Street Key Sense 7

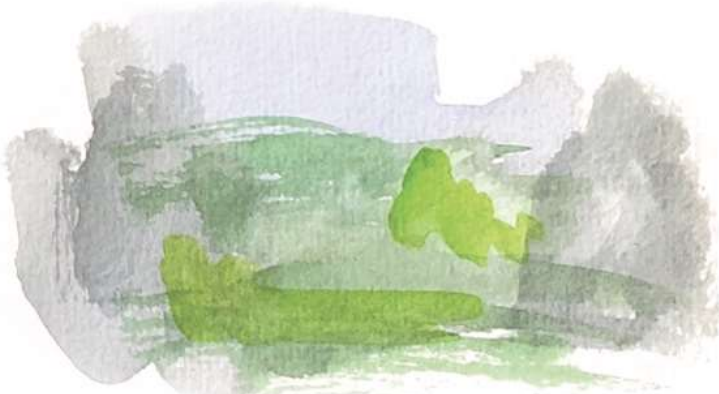

Fig. 4.38: Mind Captured Image Gill Street Key Sense 8

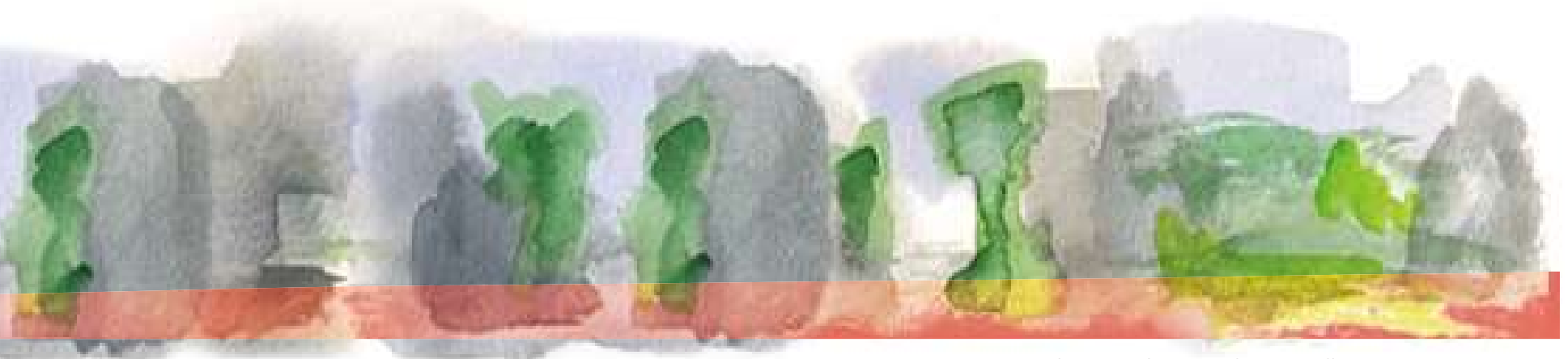

Fig. 4.39: Mind Captured Sectional Image Gill Street 

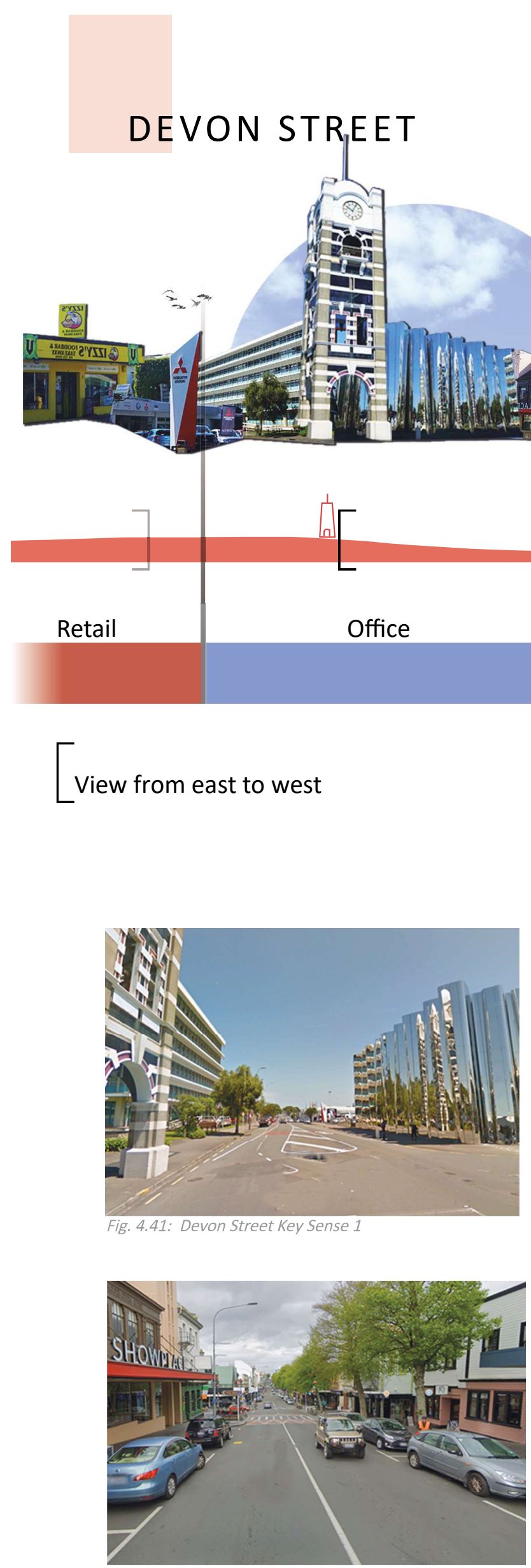

Fig. 4.43: Devon Street Key Sense 2

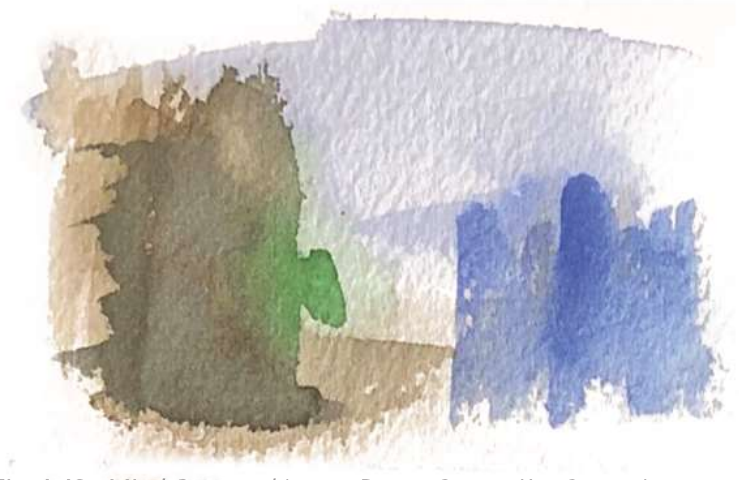

Fig. 4.42: Mind Captured Image Devon Street Key Sense 1

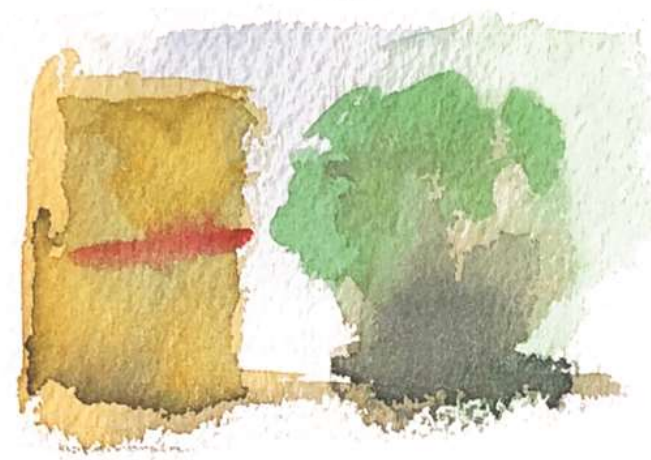

Fig. 4.44: Mind Captured Image Devon Street Key Sense 2 

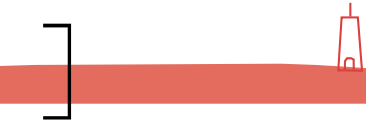

View from west to east

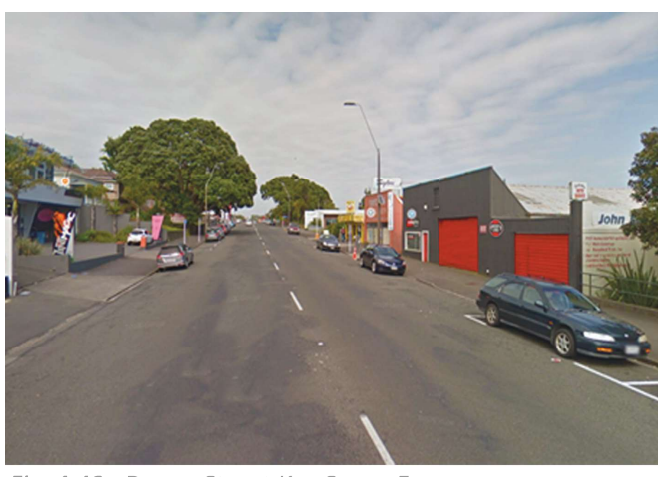

Fig. 4.49: Devon Street Key Sense 5

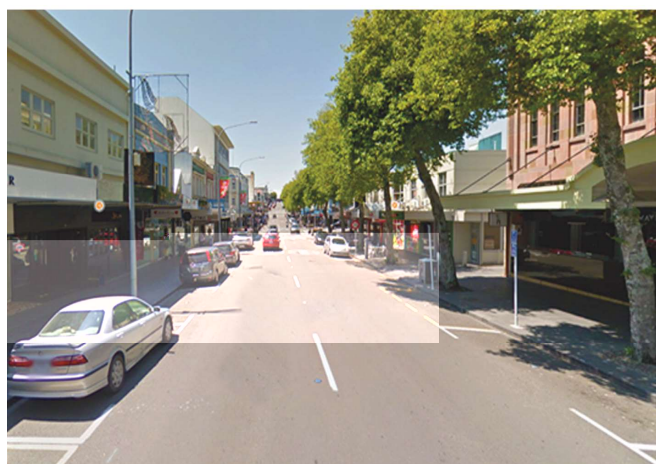

Fig. 4.51: Devon Street Key Sense 6

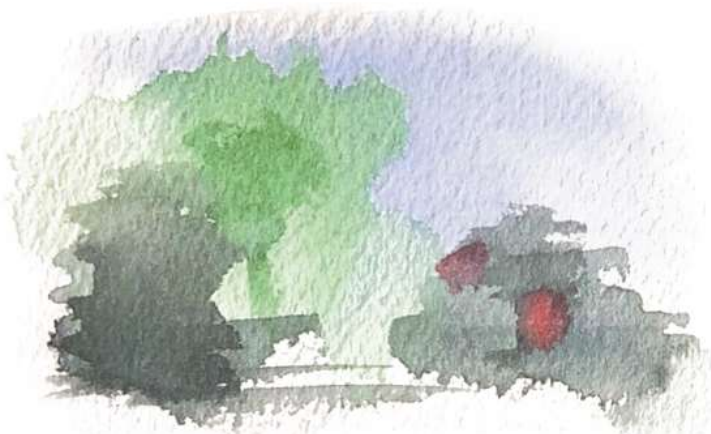

Fig. 4.50: Mind Captured Image Devon Street Key Sense 5

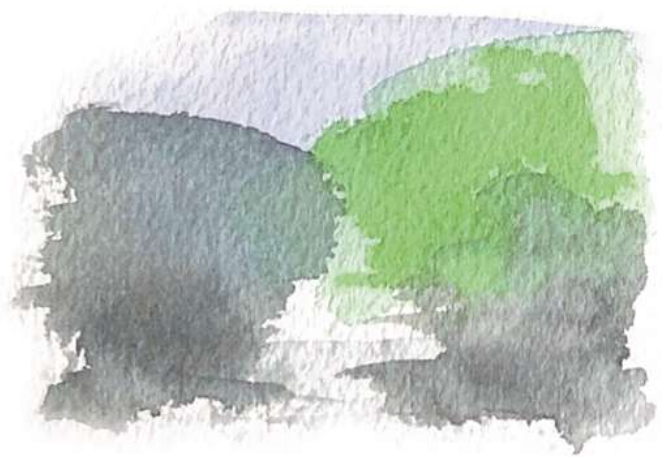

Fig. 4.52: Mind Captured Image Devon Street Key Sense 6

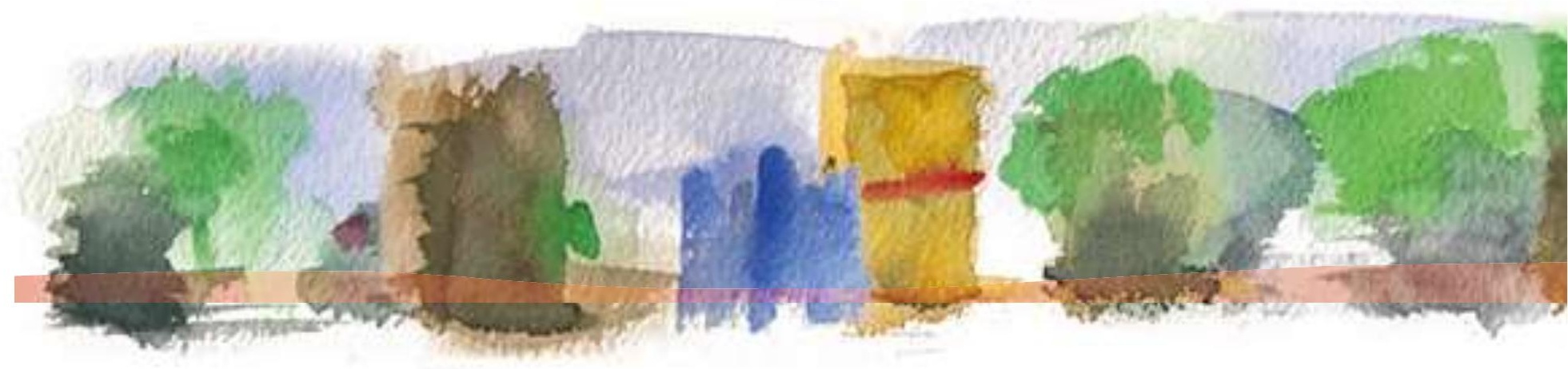



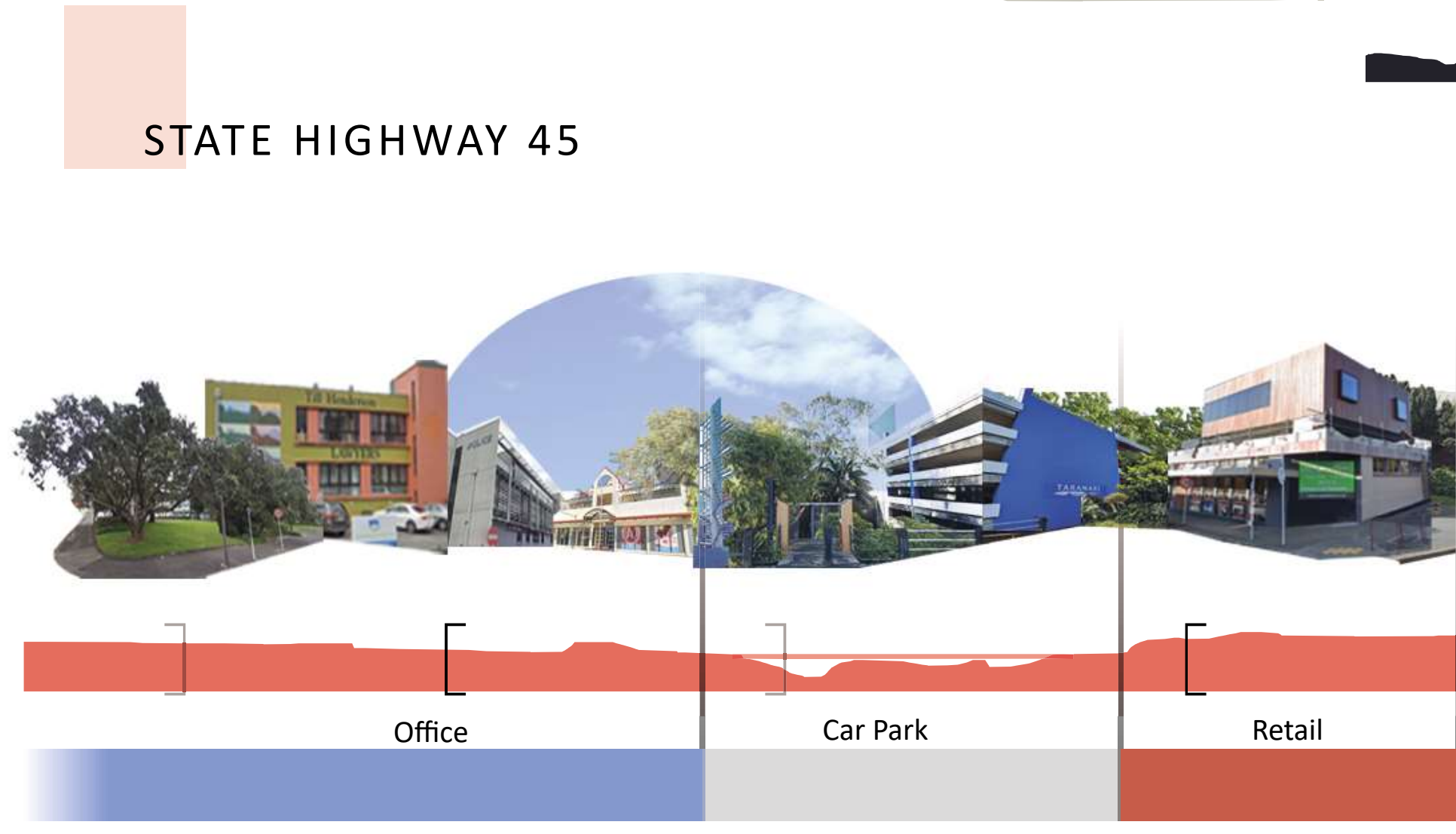

View from east to west
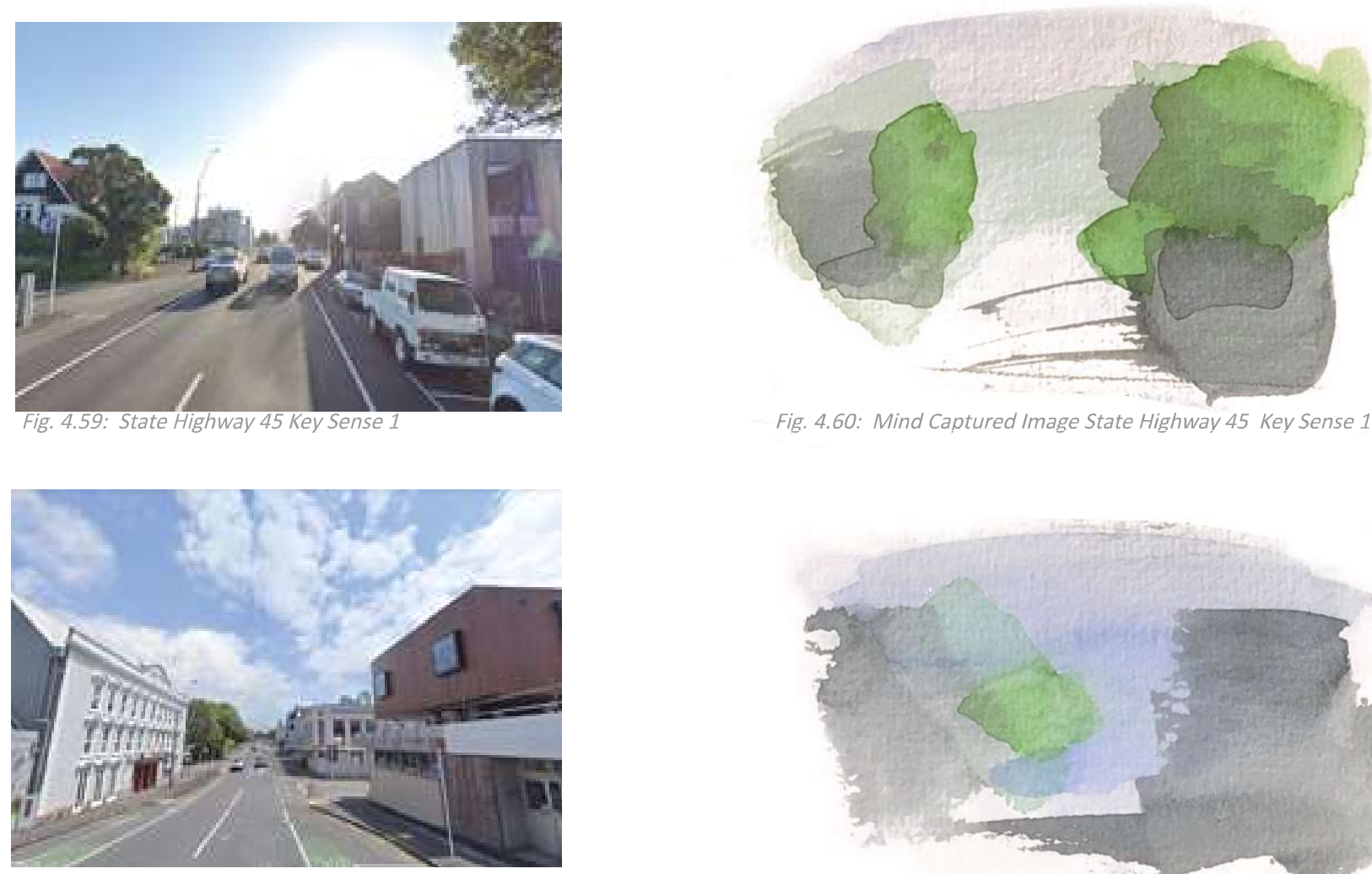

Fig. 4.60: Mind Captured Image State Highway 45 Key Sense 1

Fig. 4.61: State Highway 45 Key Sense 2

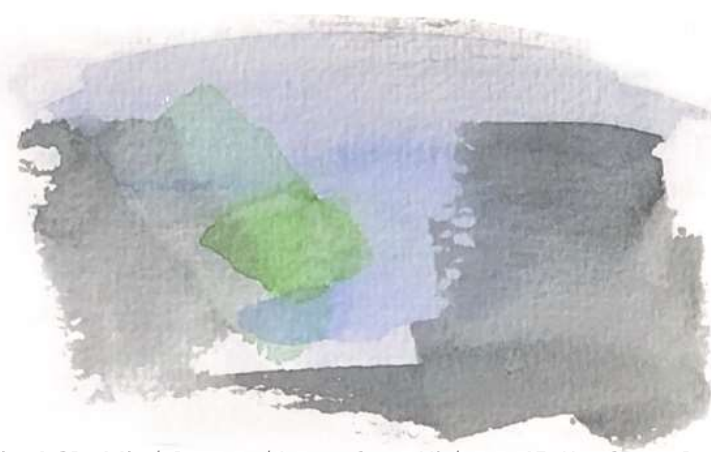

Fig. 4.62: Mind Captured Image State Highway 45 Key Sense 2 


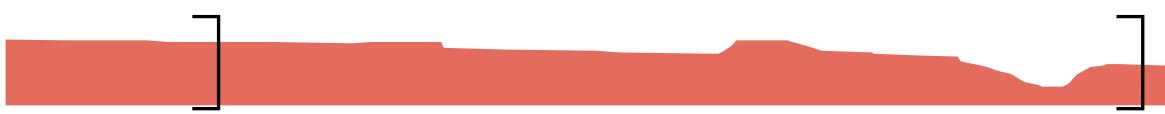

View from west to east

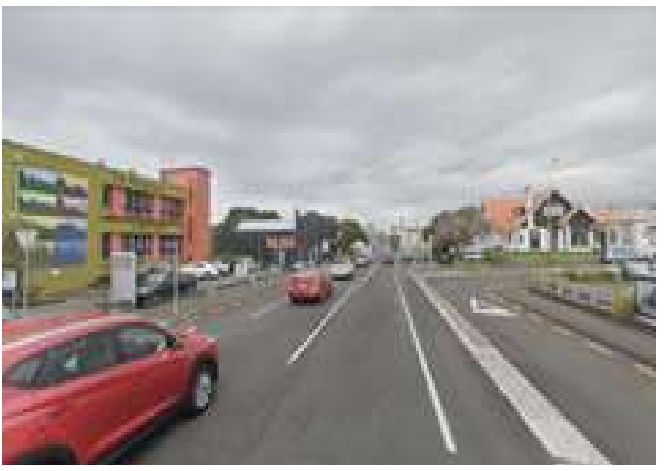

Fig, 4.67: State Highway 45 Key Sense 5

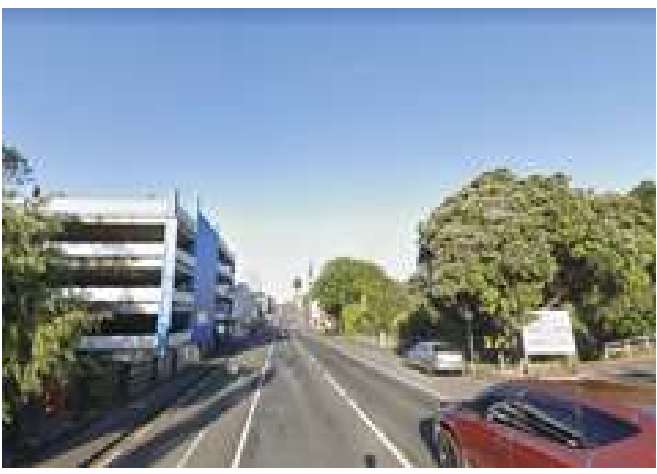

Fig. 4.69: State Highway 45 Key Sense 6

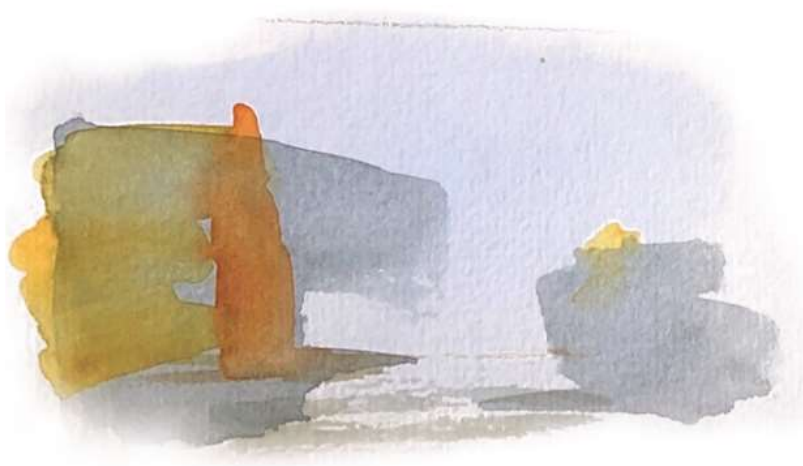

Fig. 4.68: Mind Captured Image State Highway 45 Key Sense 5

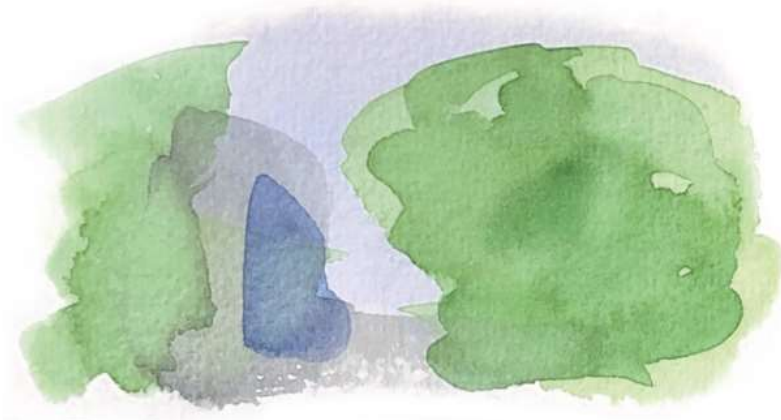

Fig. 4.70: Mind Captured Image State Highway 45 Key Sense 6

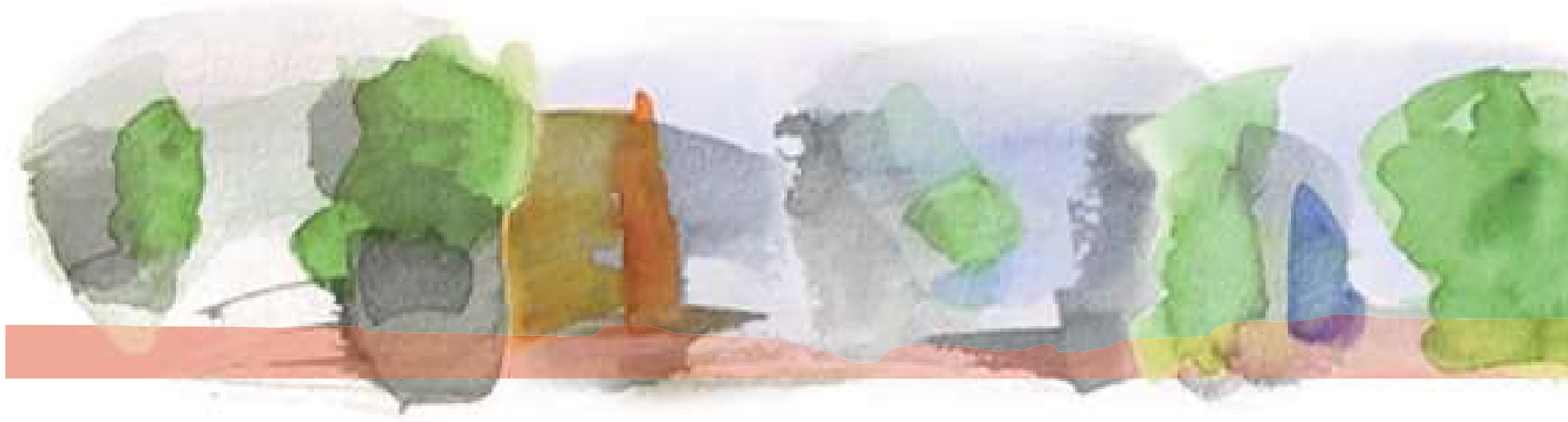




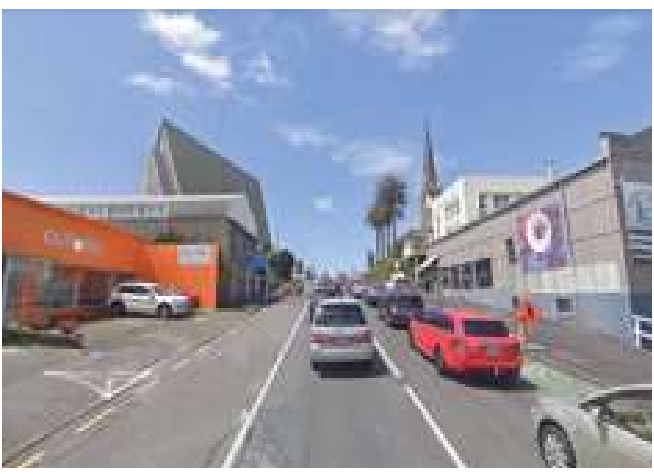

Fig. 4.71: State Highway 45 Key Sense 7

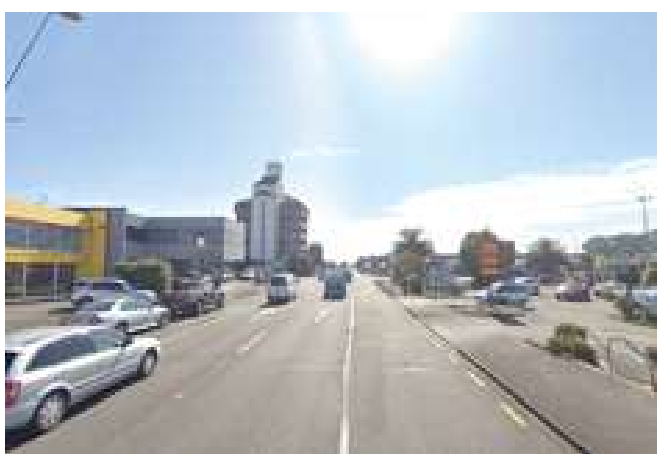

Fig. 4.73: State Highway 45 Key Sense 8

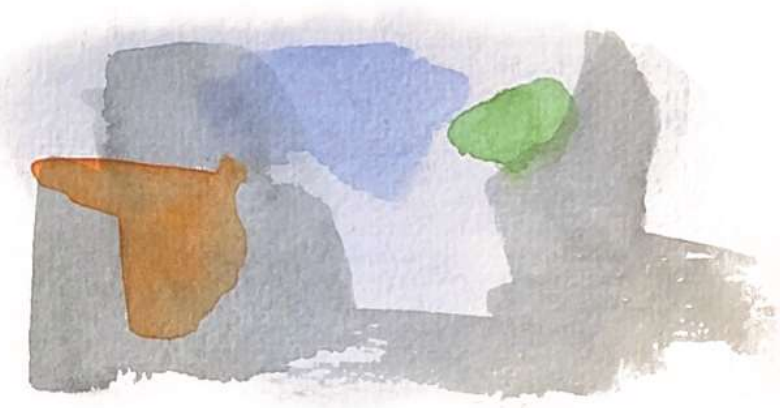

Fig. 4.72: Mind Captured Image State Highway 45 Key Sense 7

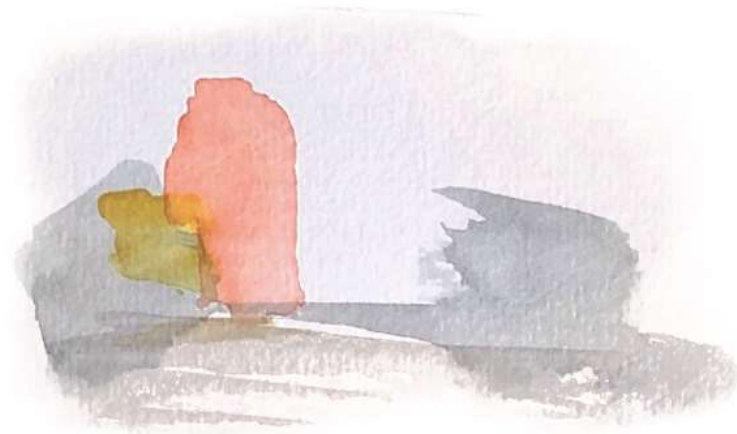

Fig. 4.74: Mind Captured Image State Highway 45 Key Sense 8
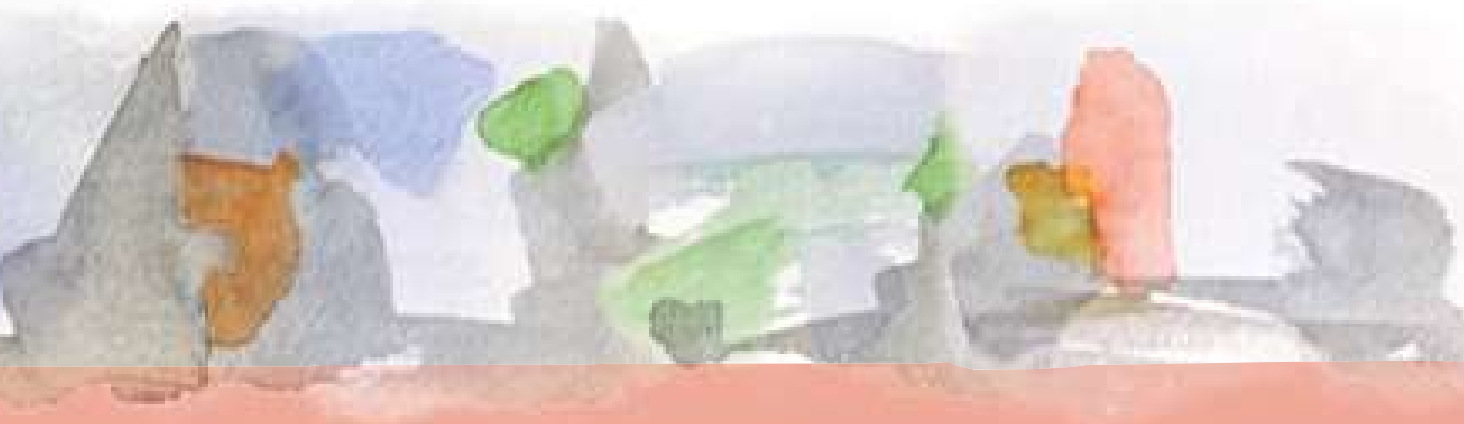

Fig. 4.75: Mind Captured Sectional Image State Highway 45 
A mental image of streets can be represented by multiplying perspective images as shown in watercolour. In most street images, grey, the colour of concrete and building blocks, is the most dominant colour.

Green, the colour of vegetation, bounces between blocks of grey; they tend to be hidden away unless people consciously look for street vegetation.

Blue, the colour of sky and openness, tends to appear consistently throughout a long distance view, but fades away, while the grey takes over.

Other colours come from building façades, features and monuments, which are rarely found in New Plymouth.

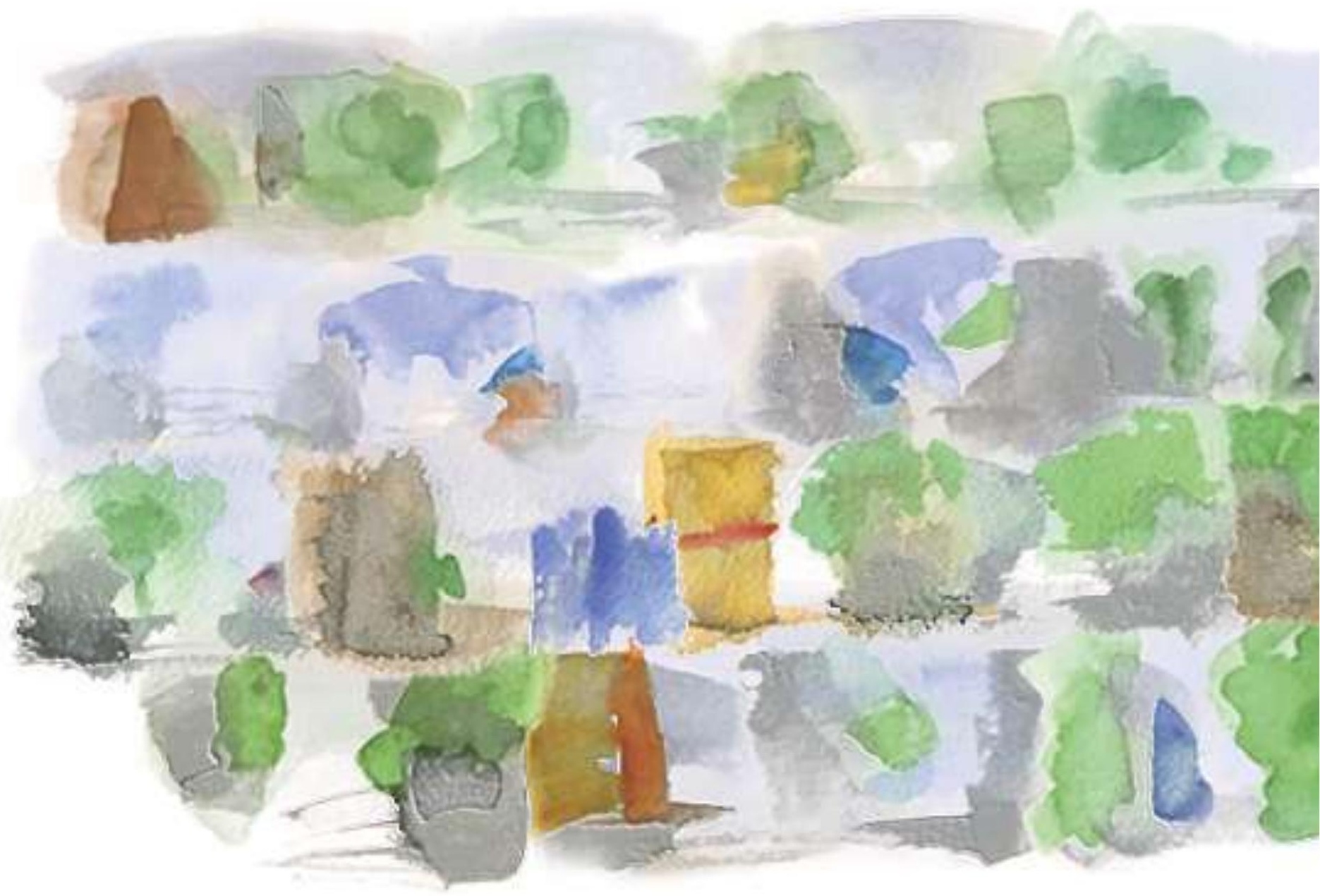


An image of New Plymouth's central area can be roughly summarized by combining the images of four significant streets into the image shown below.

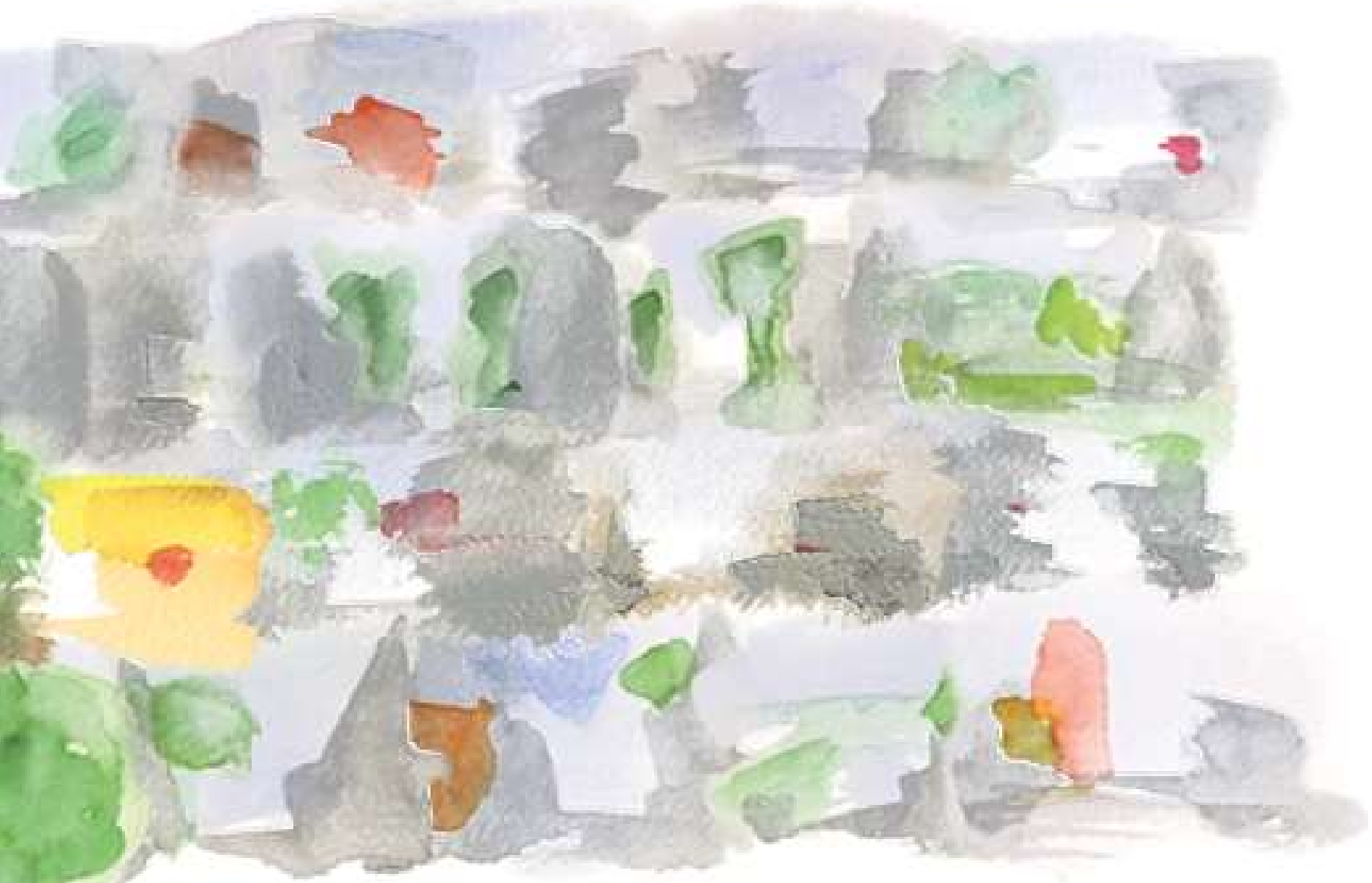

Fig. 4.76: Combined Mind Captured Image 
When the grey colour is erased out of the previous image, those colours that remain are relatively mentally attractive, and trigger mental recognition of space. Moreover, these coloured areas are most likely to be handled by landscape architects.

As the image shows, these colours are out of order, and it is difficult to find relationships between any pieces of them.

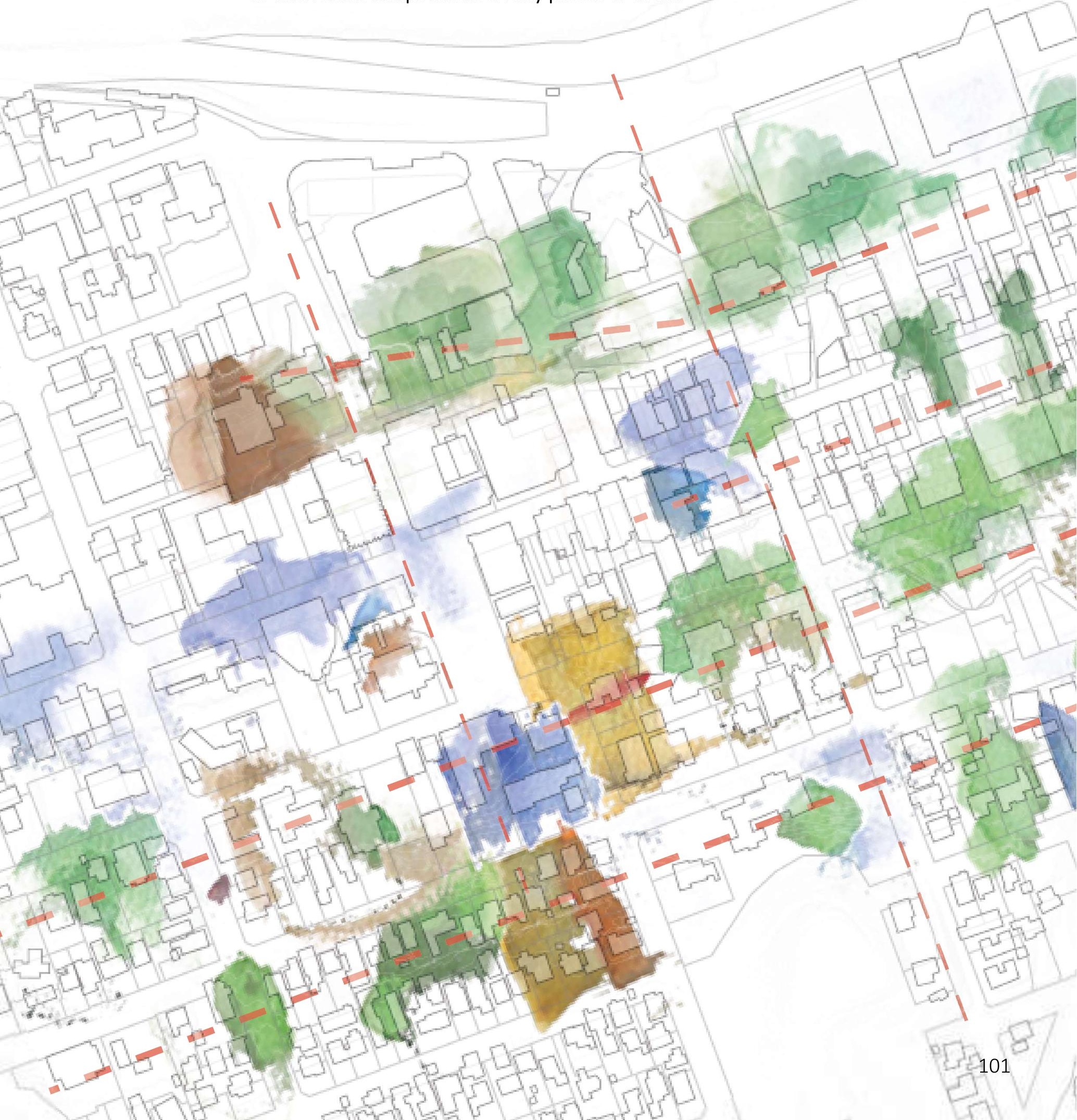




\subsection{Mental Image Analysis}

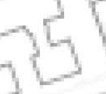




\section{North-South Streets}

Having been tested on a limited area, with the previous experimentations on the east-west streets with watercolour, this method has emerged successfully as a means of site representation and analysis.

The following section tests the mental image of the north-south streets. It is less likely that people would recognize the quality of these streets; however, each of them has unique spatial values. Most importantly, these north-south streets connect the residential area (higher ground) of New Plymouth to the waterfront, with rectilinear avenues. Users of these streets would be able to see the ocean from a further distance. This visually significant moment strongly represents the identity of New Plymouth; triggering spatial recognition.

The following section will employ the monotype printing method, which affords more control of shape and texture, to represent quality of space. Based on the study of method testing from the previous section, the following section will analyse each street as a whole-journey experiment, rather than pulling information from selected sections and perspectives. 


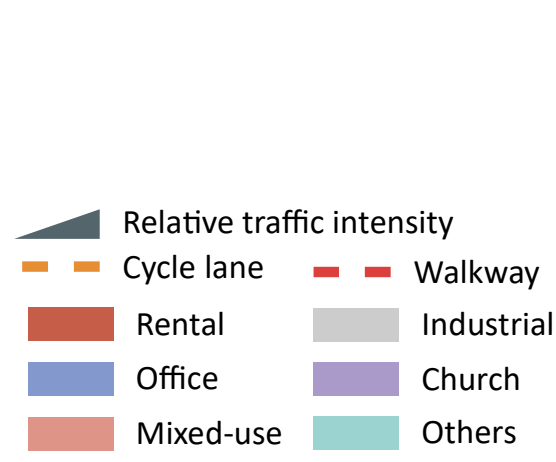

Scale: 1:3000@A1

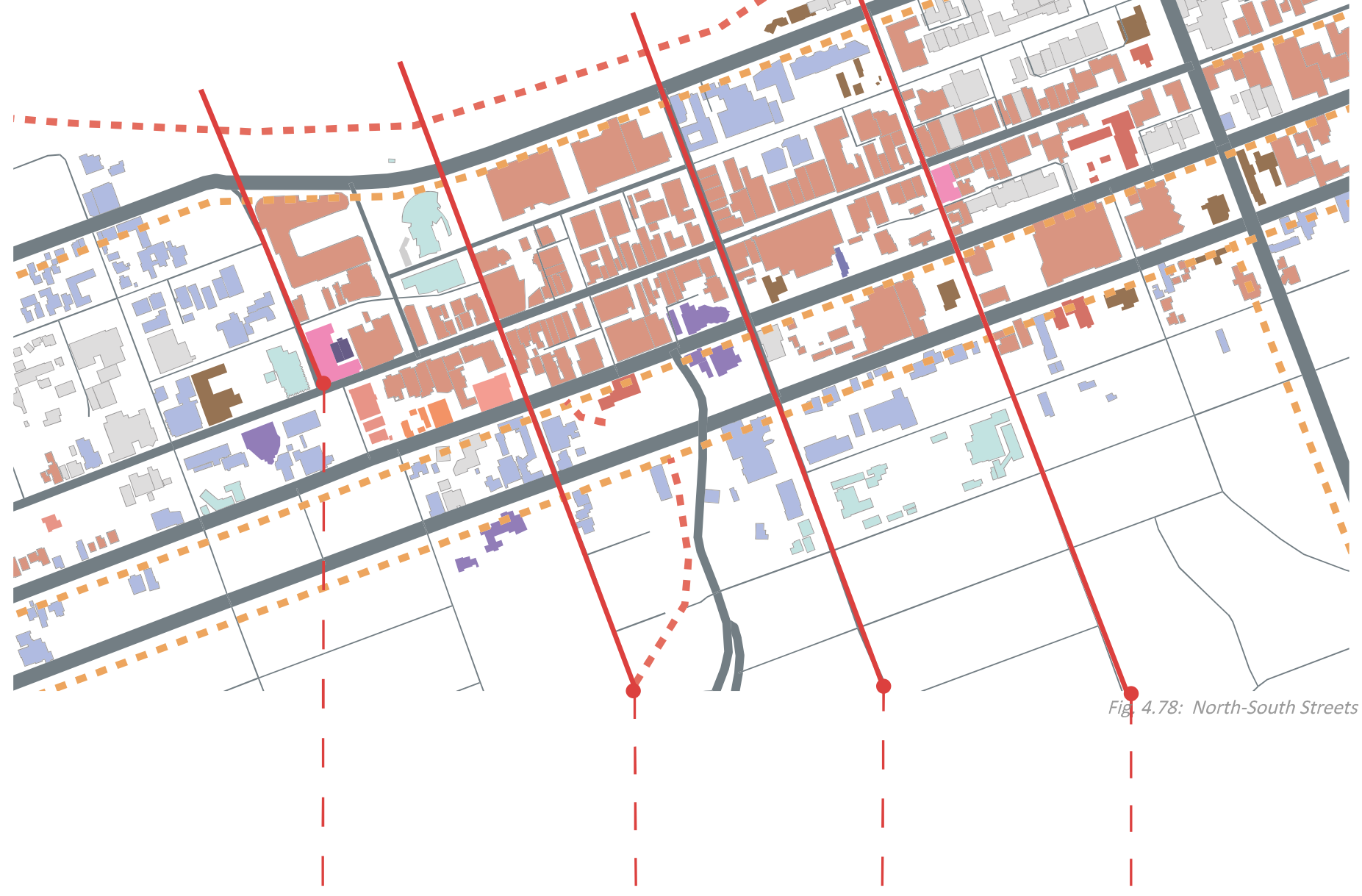




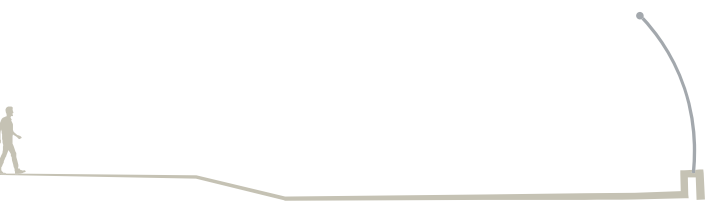

\section{Queen Street}
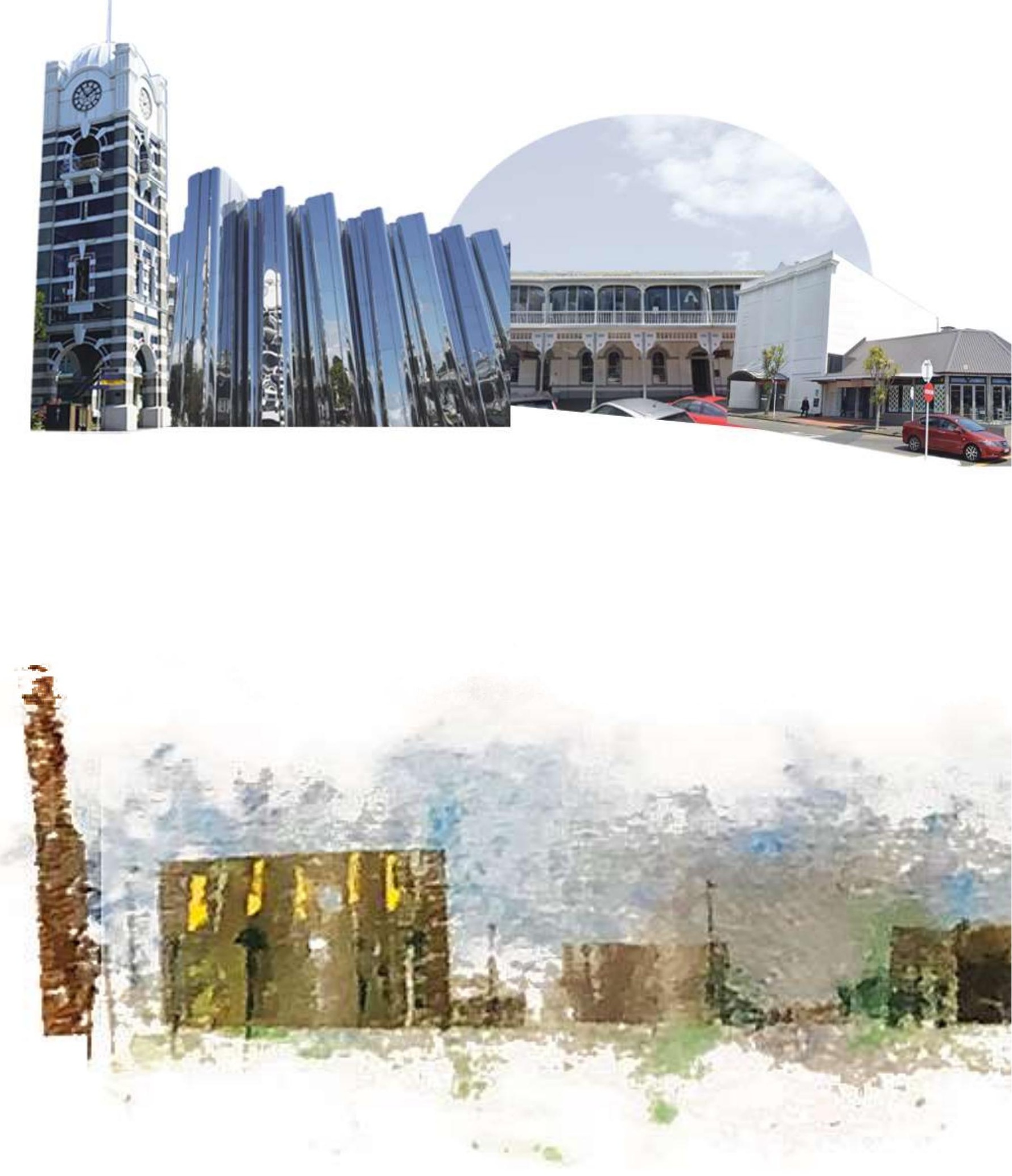

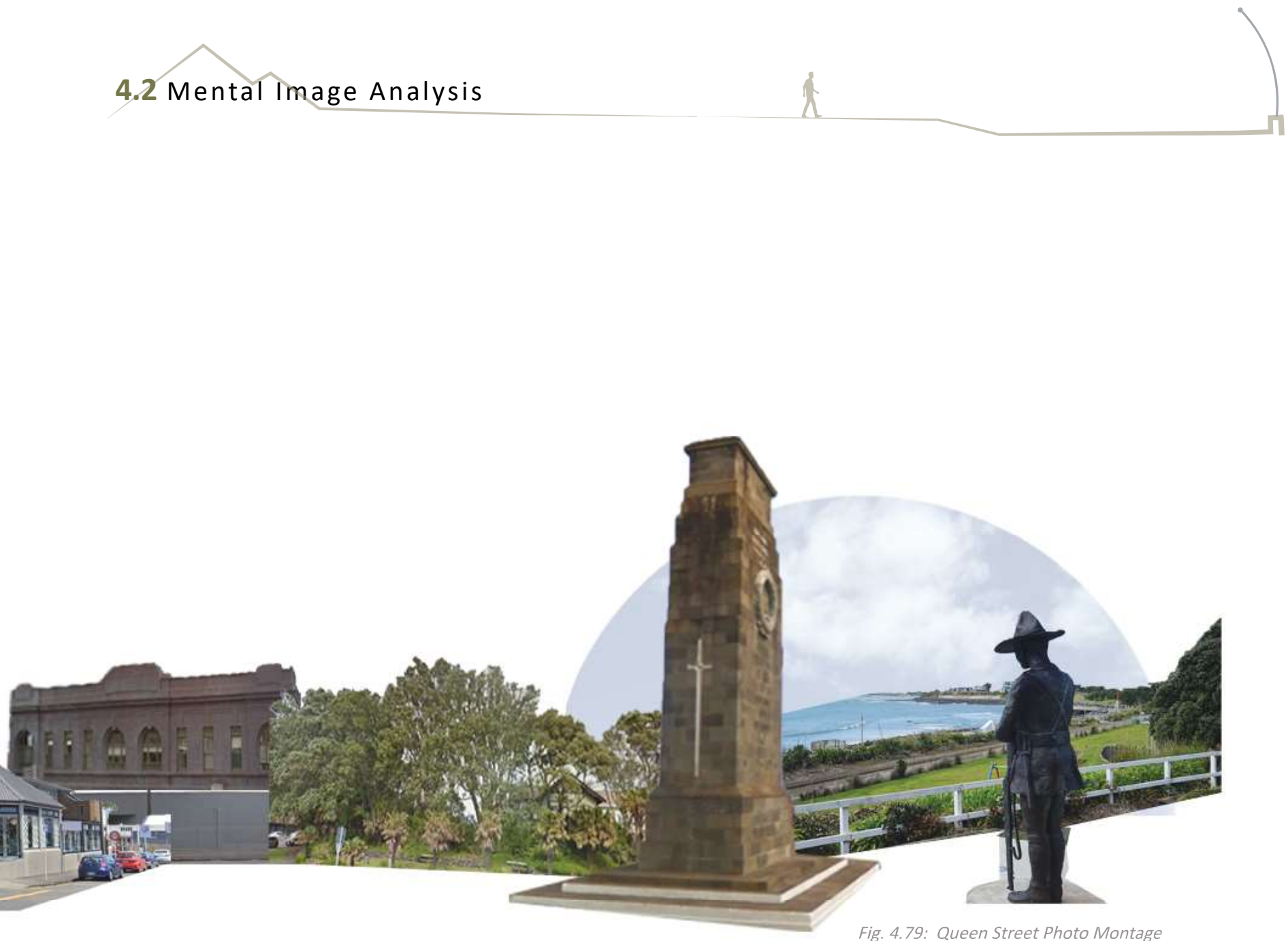

Fig. 4.79: Queen Street Photo Montage

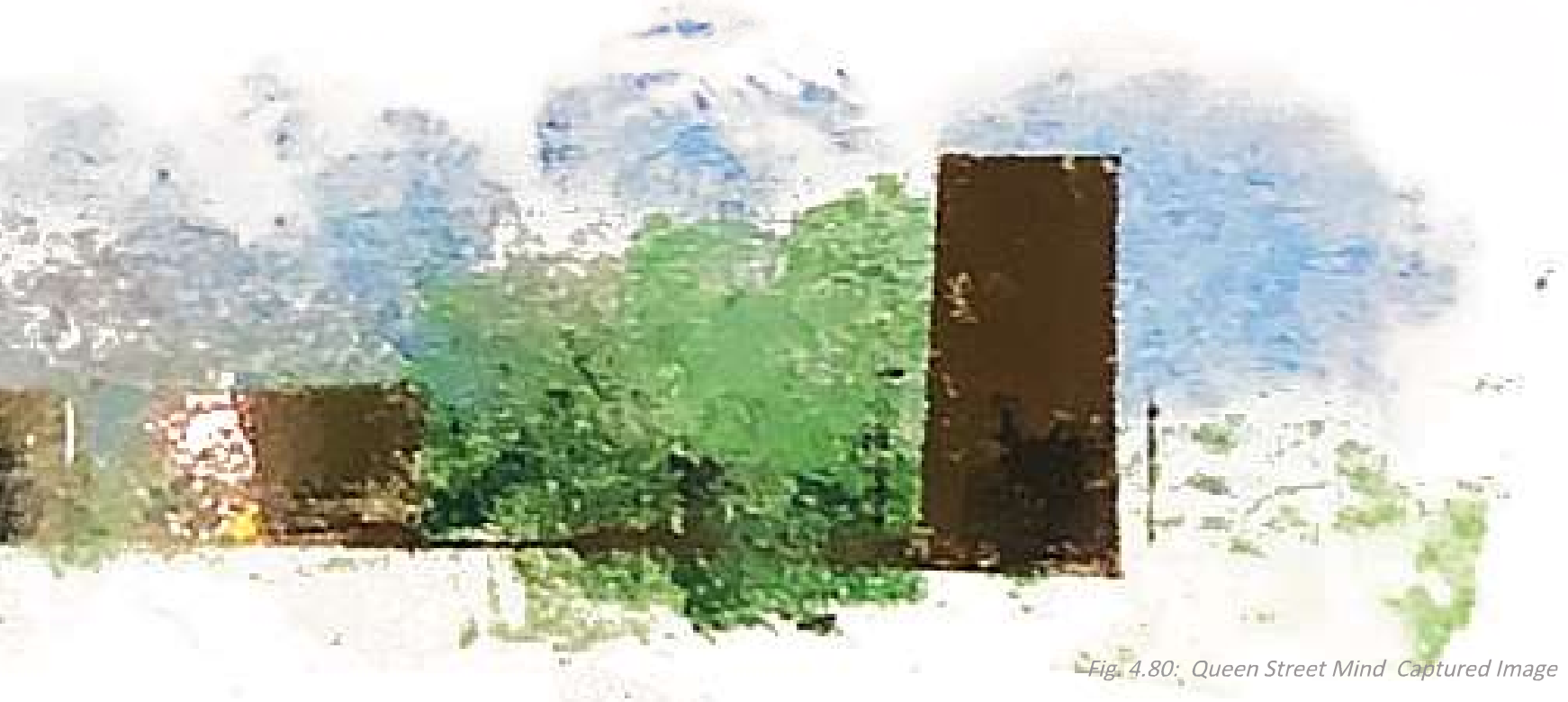



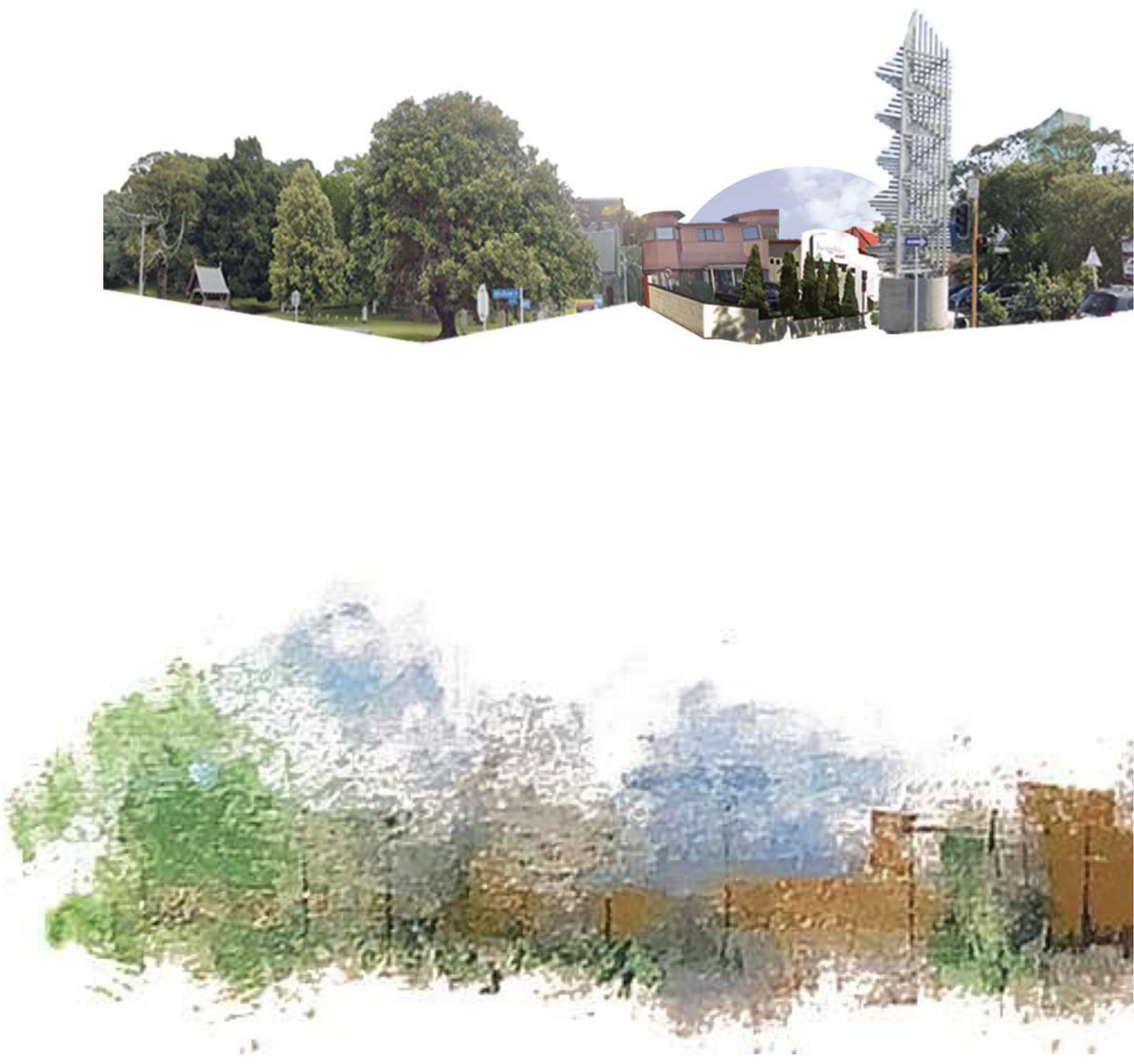


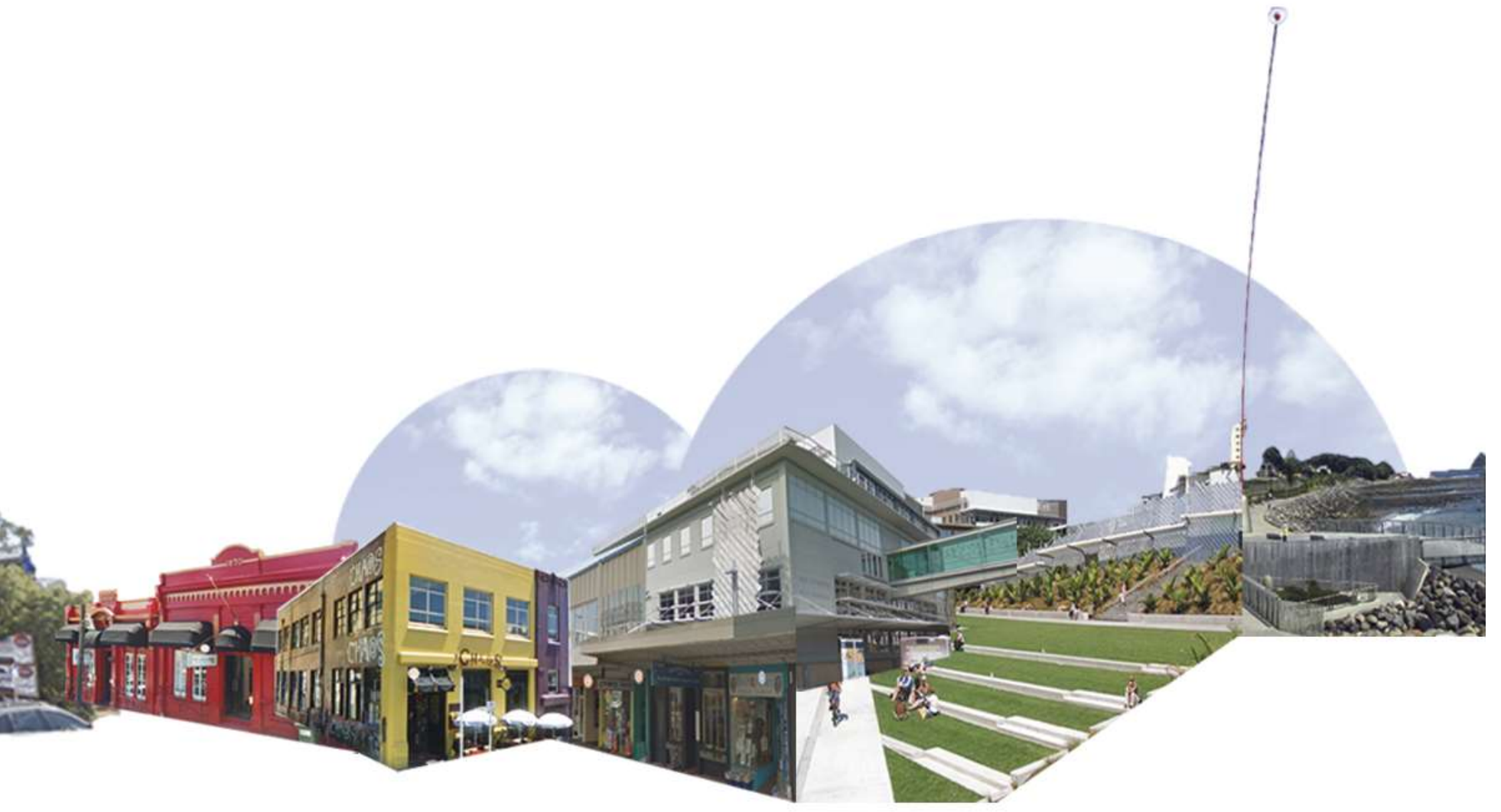

Fig. 4.81: Brougham Street Photo Montage
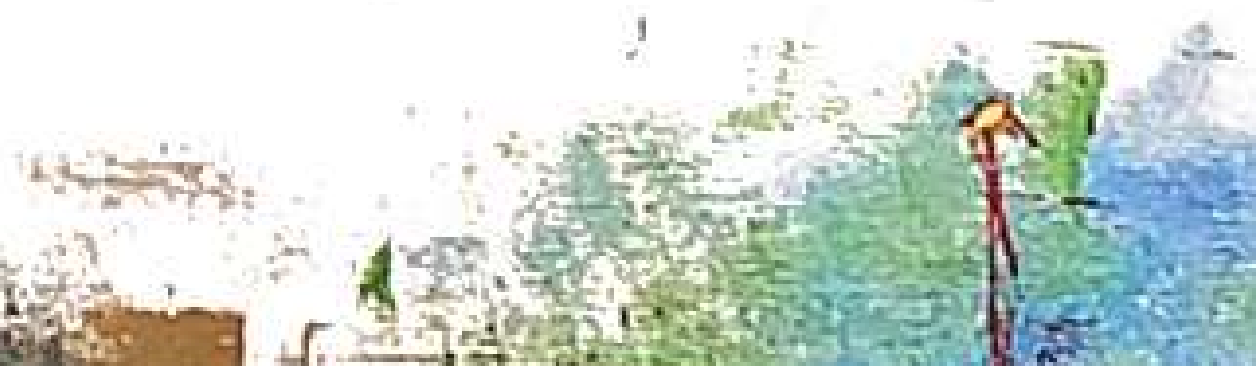

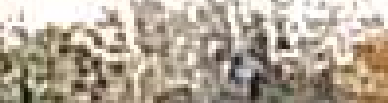

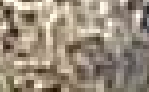

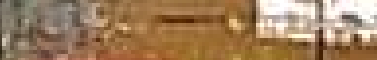

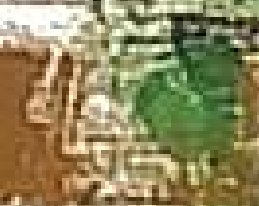

N

nycis

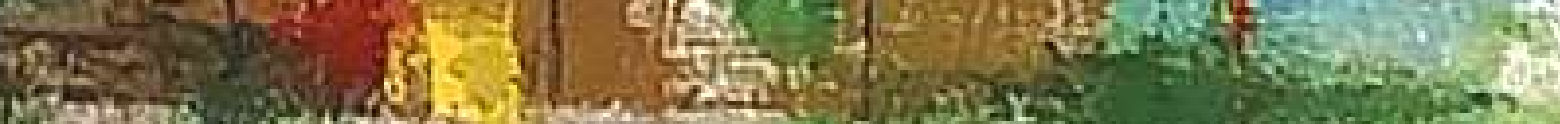

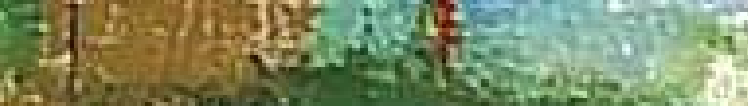

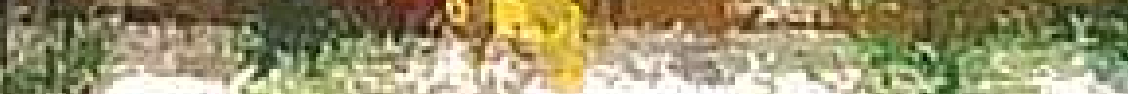
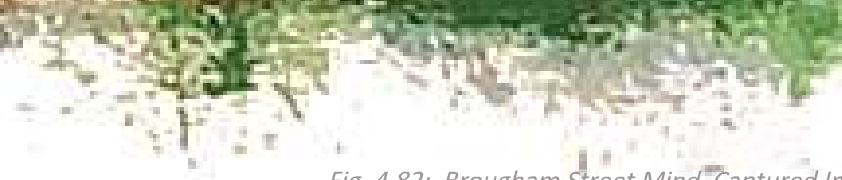

Fig. 4.82: Brougham Street Mind"Captured Image 


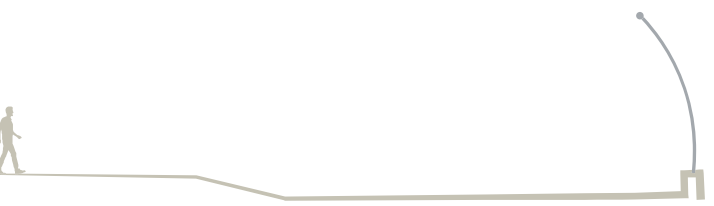

\section{Liardet Street}
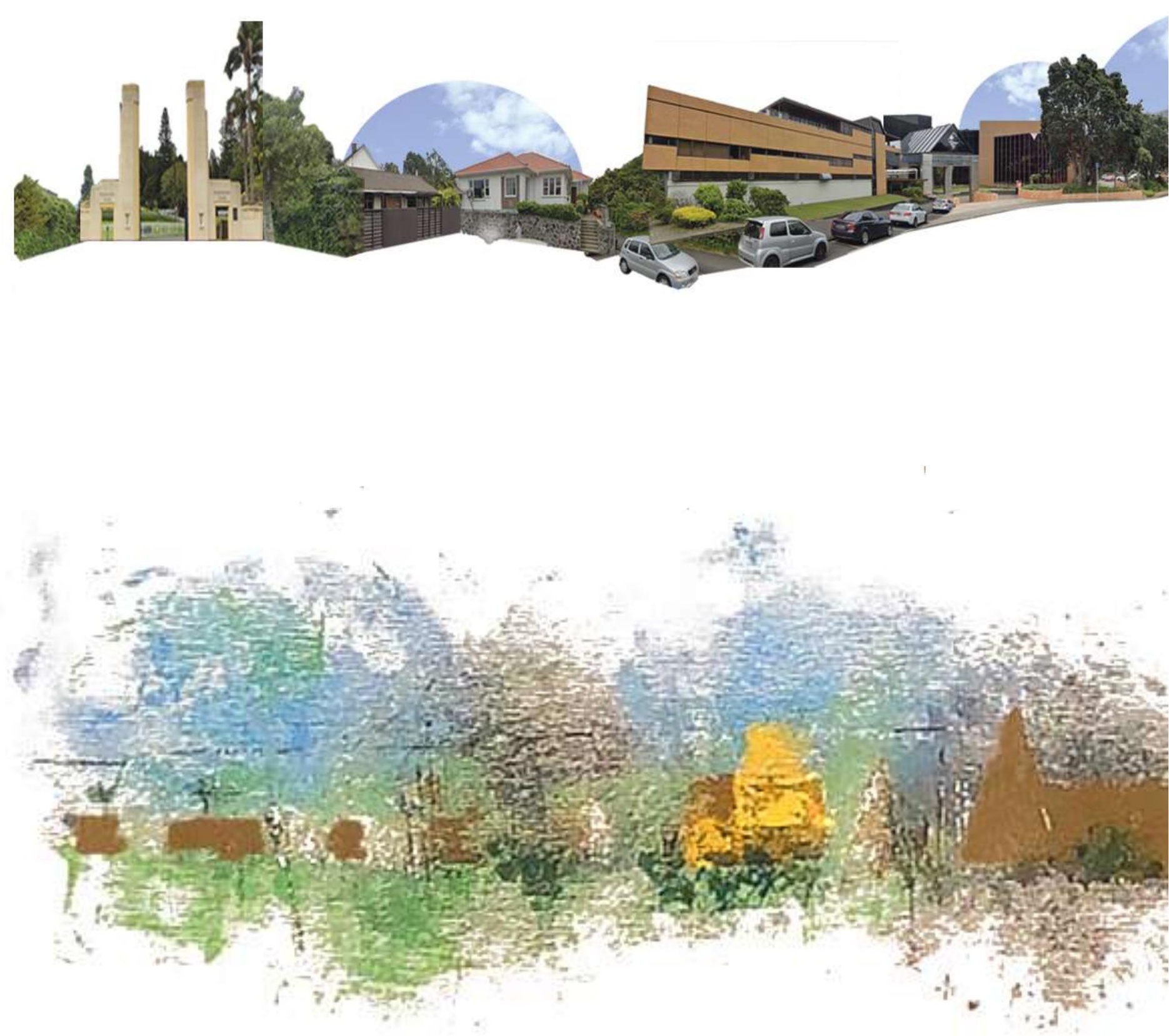


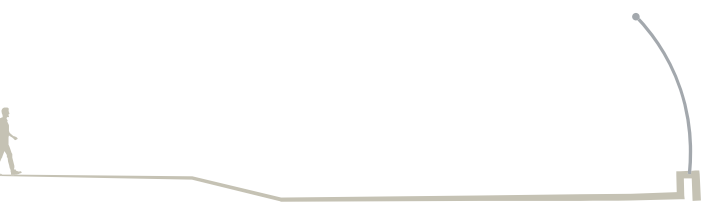

\section{Govert Street}
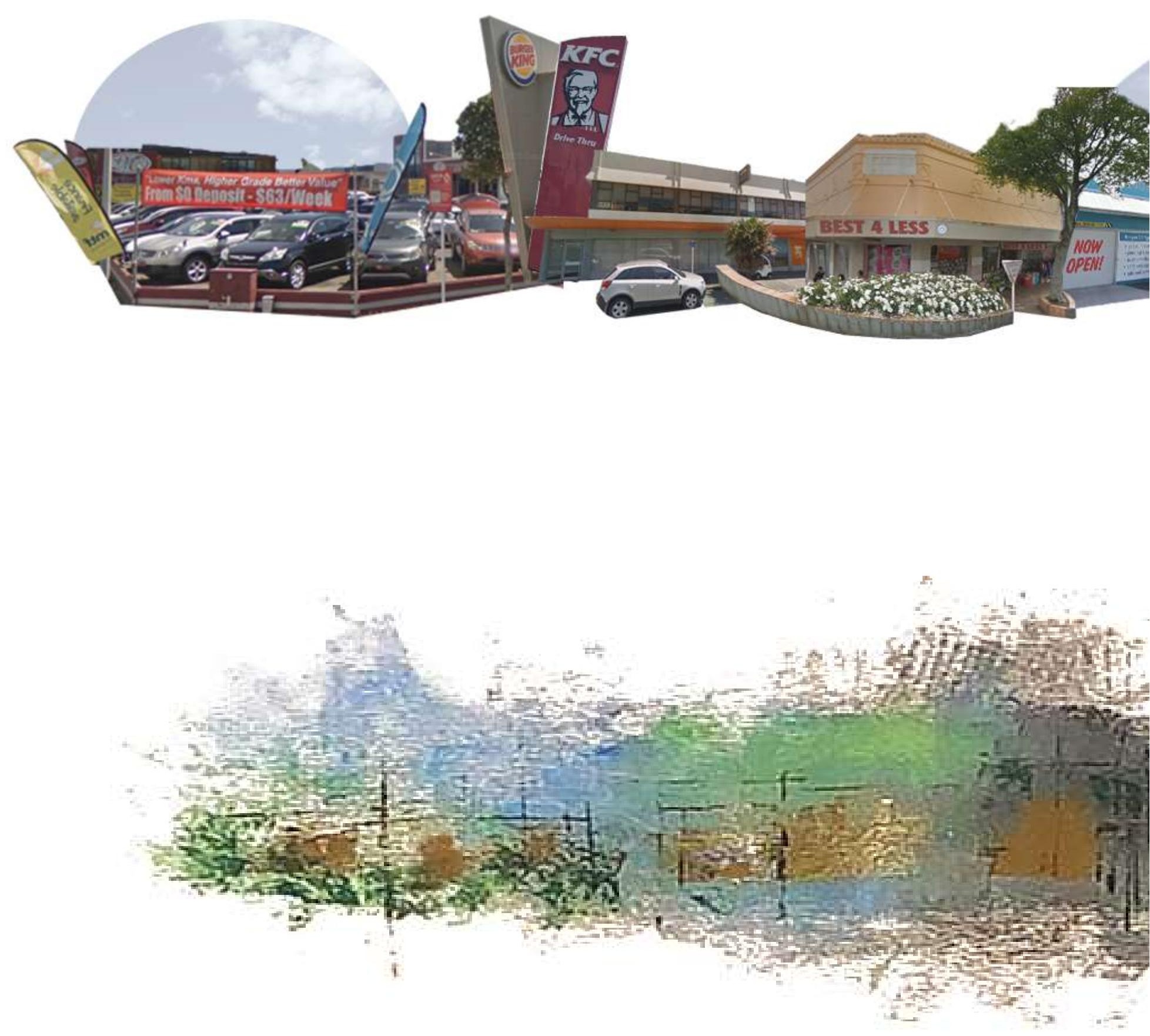


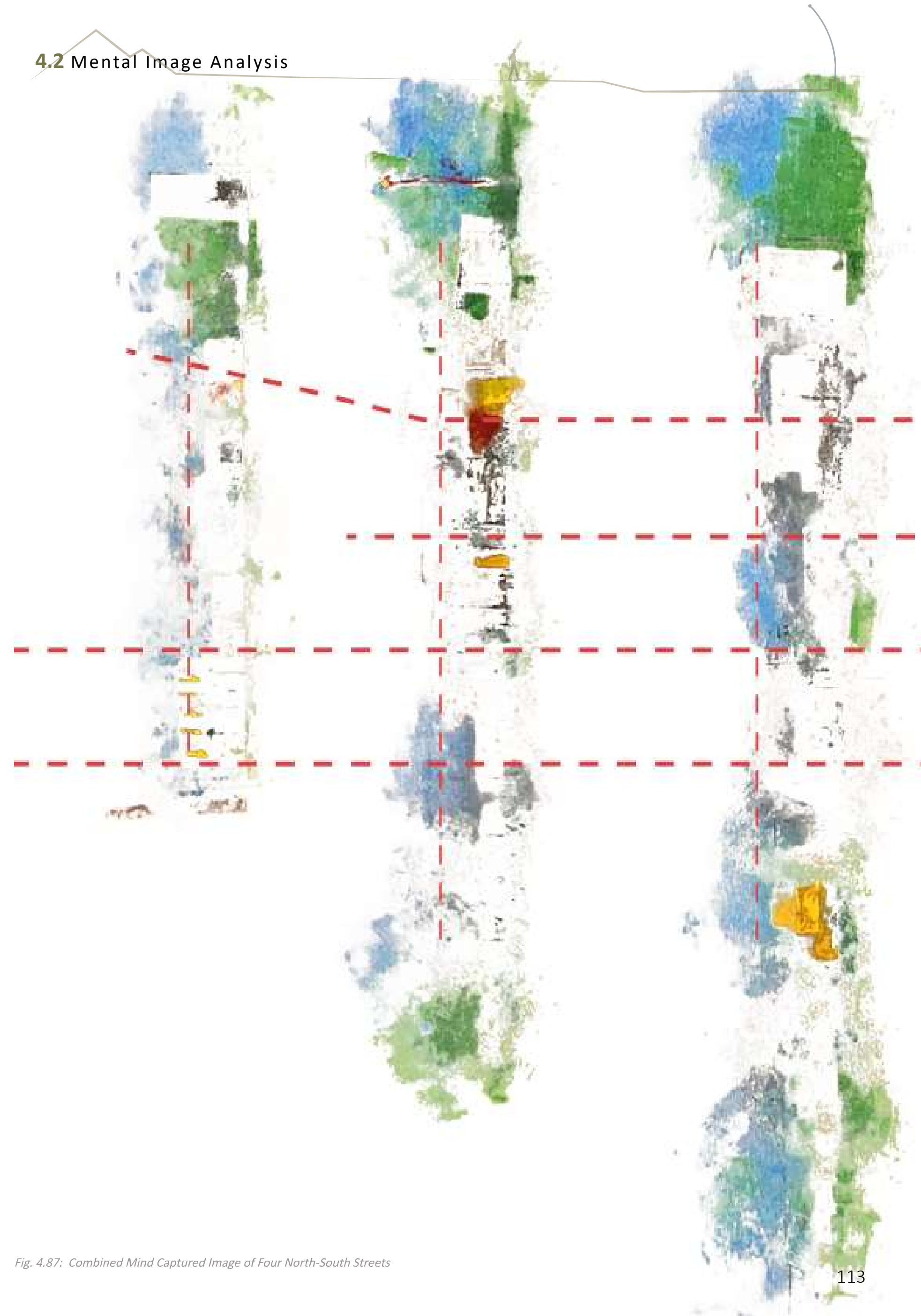




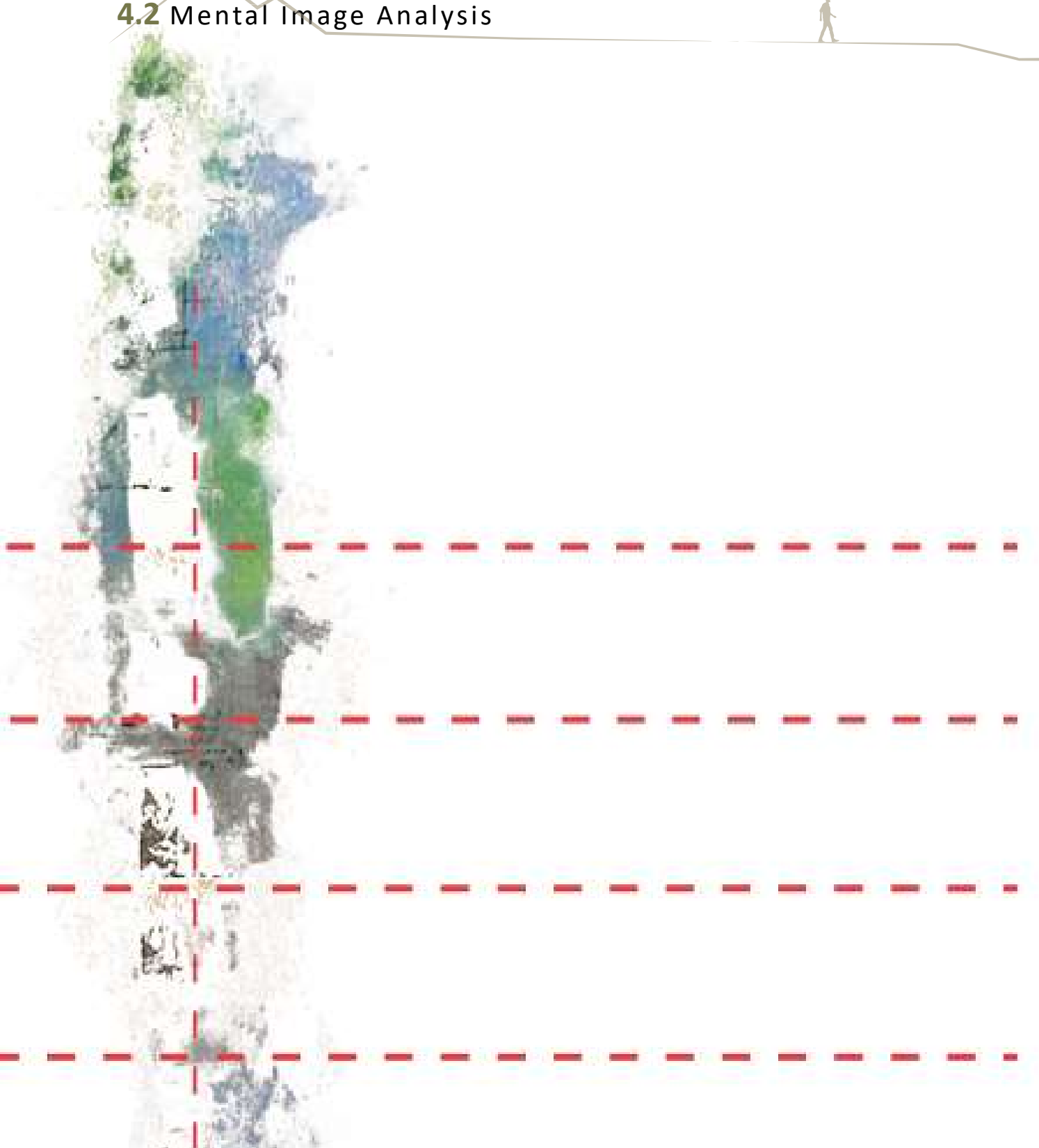

2.
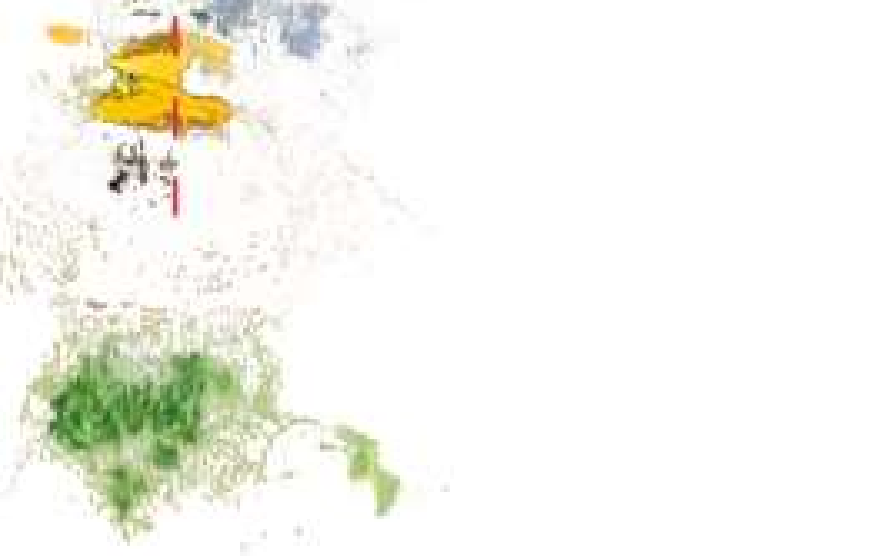

Brown blocks show the figure-ground relationship as a section in previous pages. This image removes the brown building blocks, and focuses the landscape factors. Vast fields of green and blue colours appear at the northern end of the streets, indicating the coastal walkway of New Plymouth. Other than that, the rest of the streets seem similar to each other. These north-south streets are relatively lacking in identity, compared to the east-west streets. Users tend to understand them as a connection between the east-west streets rather than having their own legibility. 
The iterated New Plymouth city centre's mental image map is shown below by combining previous sections' results. Colour still seems to be fractured, which means when people think about the city, they can only remember those coloured pieces.

A few spots have a complex of colours (in the red circles), which are the existing activity centre. However, these spaces' power is easily distracted by other popped-up colours around them, which indicates the sense of placeness are easily faded away once people left the colour complex.

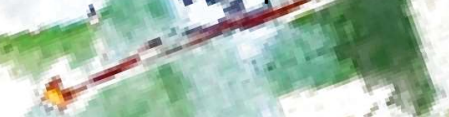

Lack of consistency between colours shown in this map could mislead the user's understanding of the city's arrangement and impact their decision-making through the city.

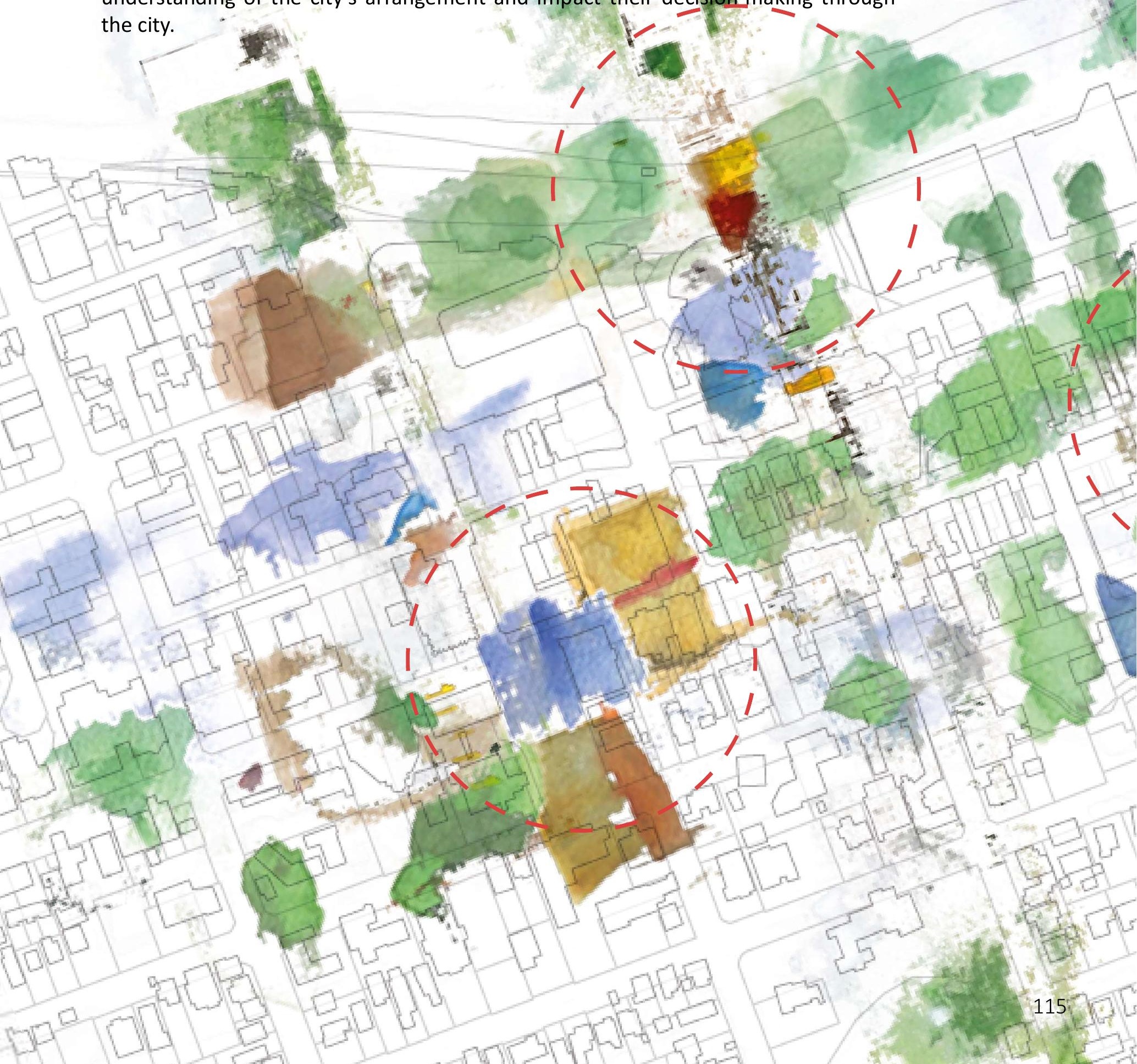


A third study looks at the image of the large-scale city, using a paper-crafting method.

Building on the degree of certainty that developed from the previous studies, this paper-crafted model selects only relevant colour pieces from the site; investigating the texture and layering of papers, testing different peeling techniques to represent the quality of the large-scale site.

This model was built from pieces of small paper, looking at each piece of land and pulling out the most representative colour, and investigating the interactions between colours. This study re-exams the site at small scale; re-investigating the relationship and interaction between places and their impact on the mental image of the whole city.

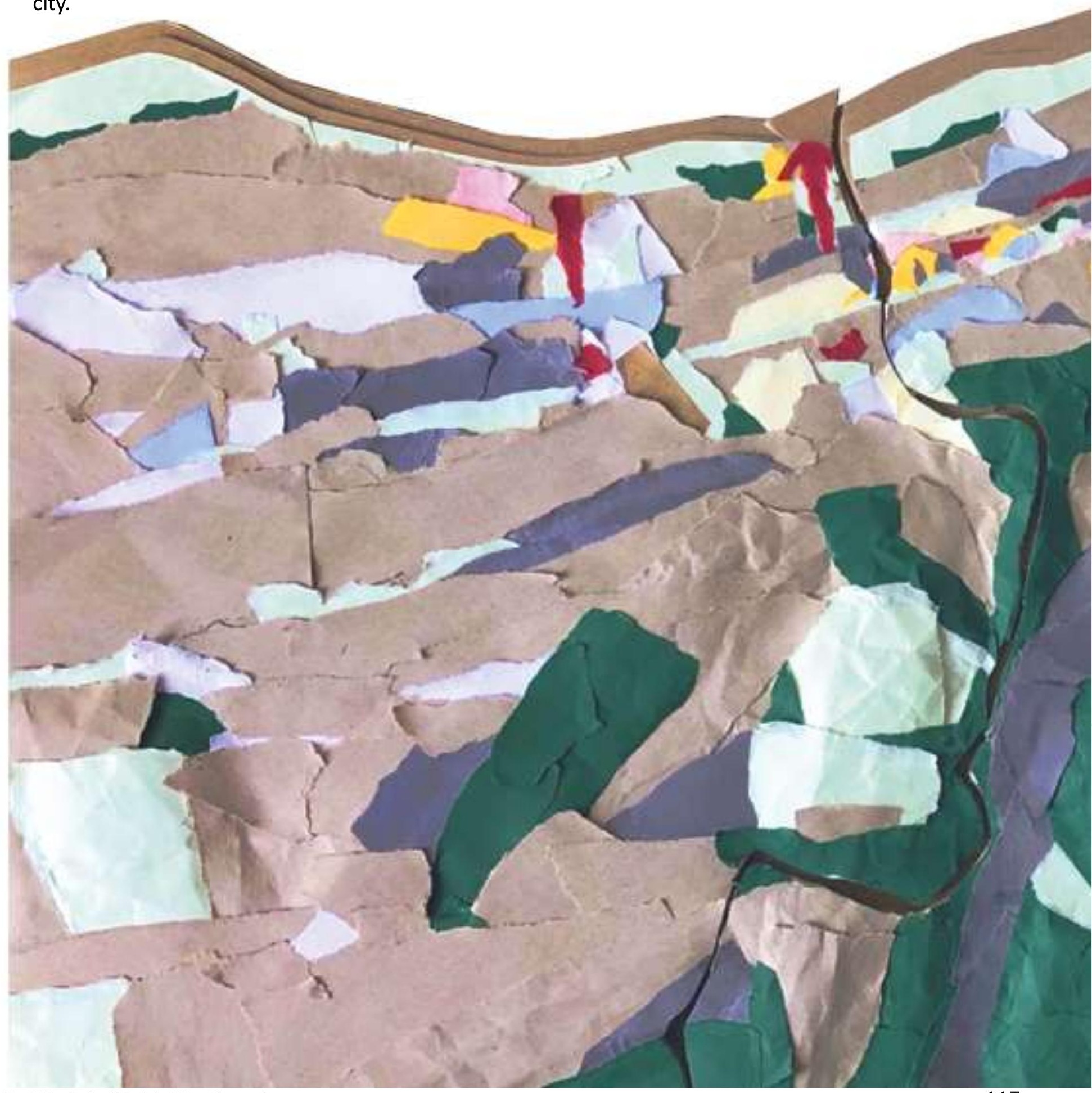




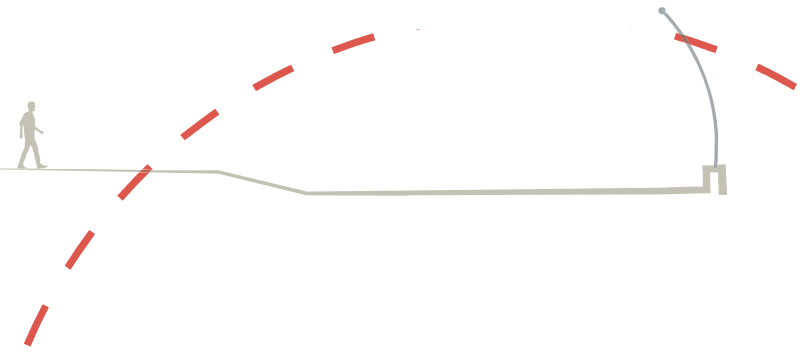

The most conspicuous area in this model is the east-welst line (marked in doted red line), due to its complexity of colours. Vast green fields at the southern half of the image seem to push towards the centre and join the green coastal line.

|

Small-scale excitement (such as a piece of red colour paper) could become the city's highlight. The power of a landmark structure has influence extending a far distance, and influences the quality of surrounding areas.

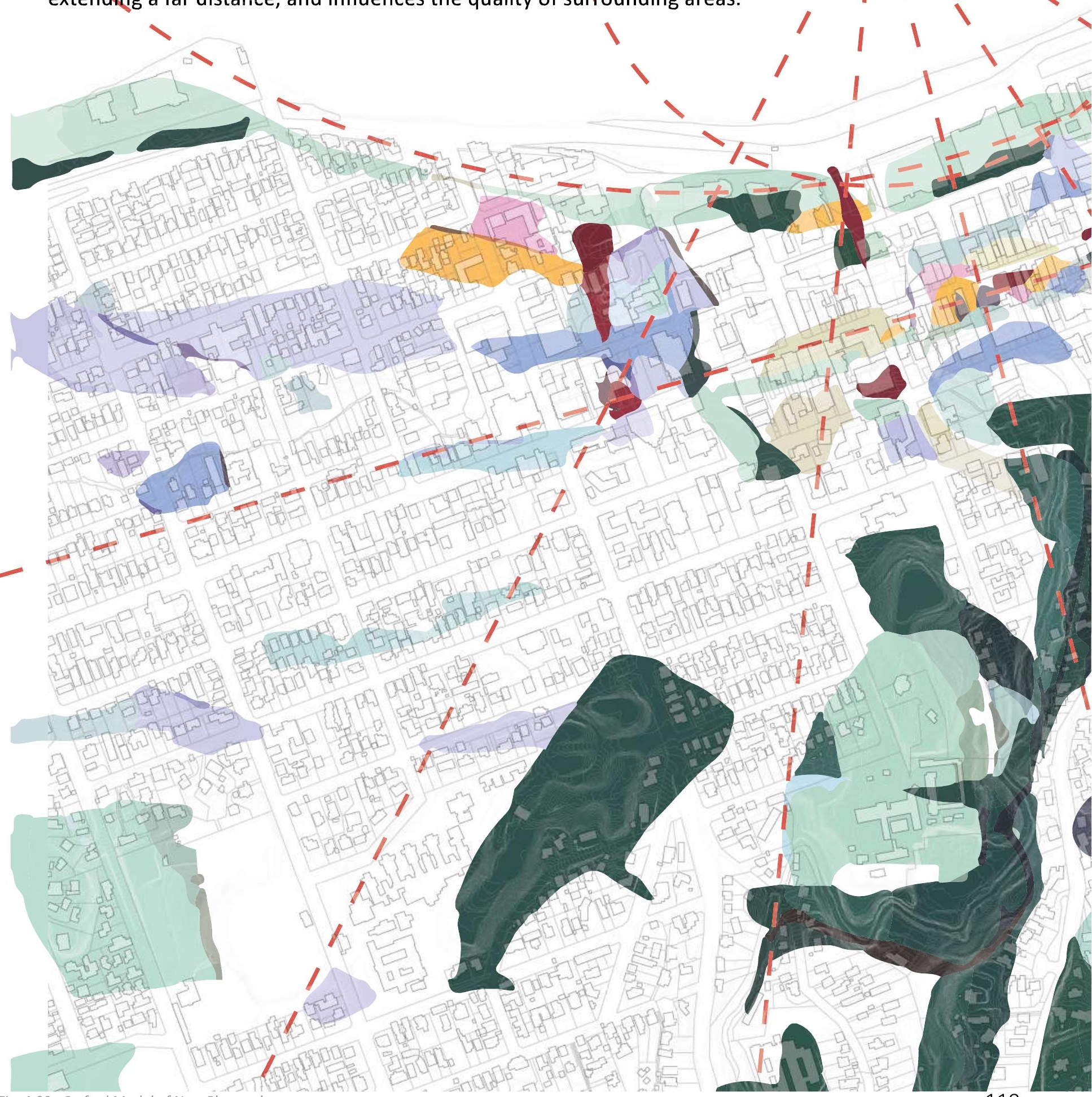




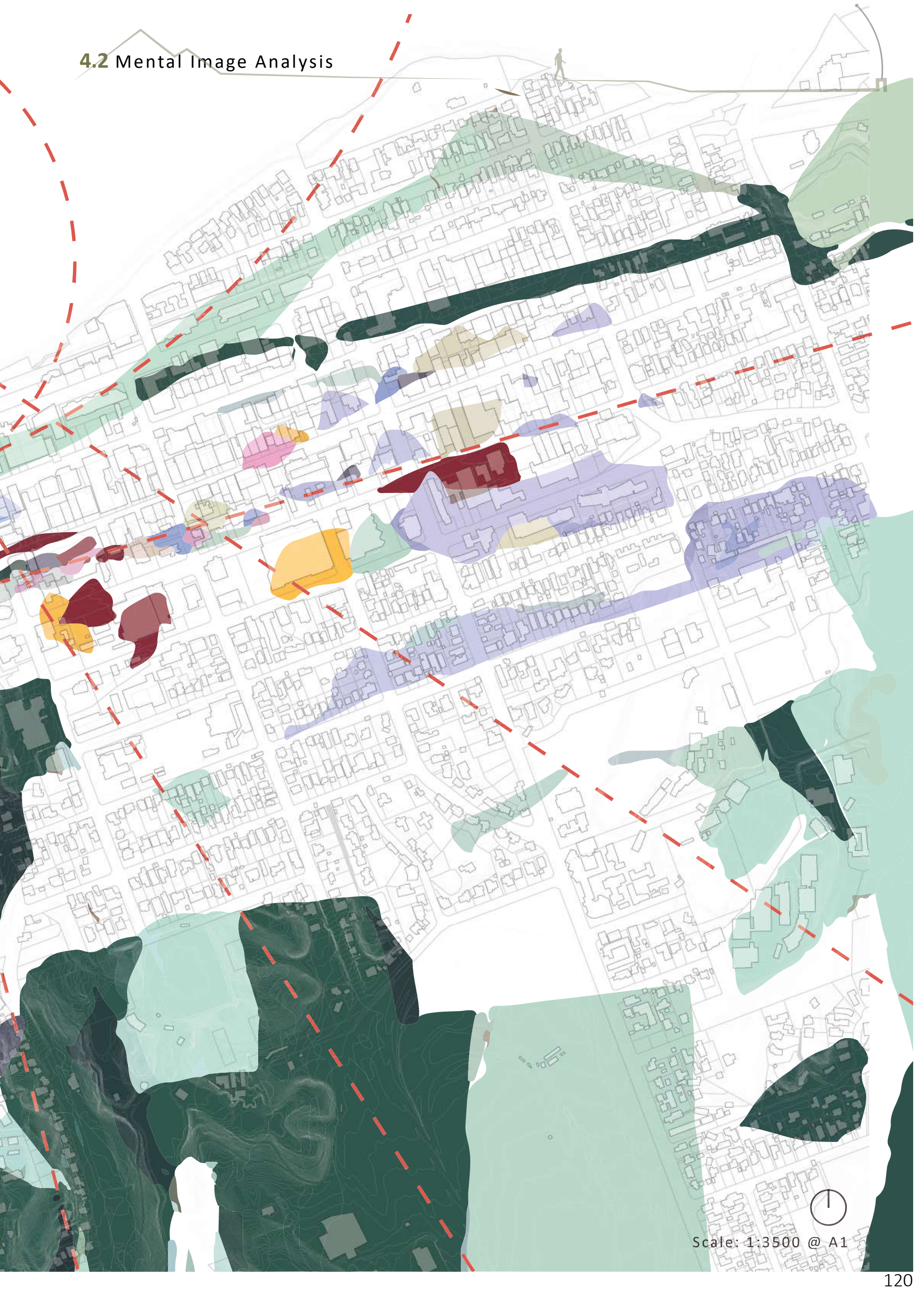




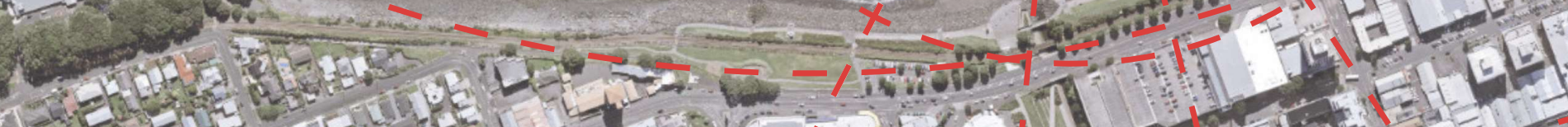

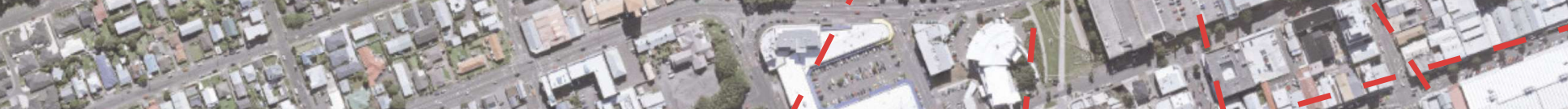

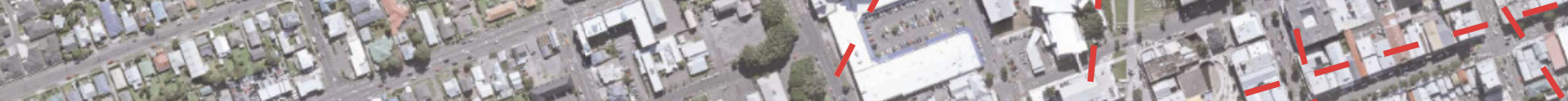

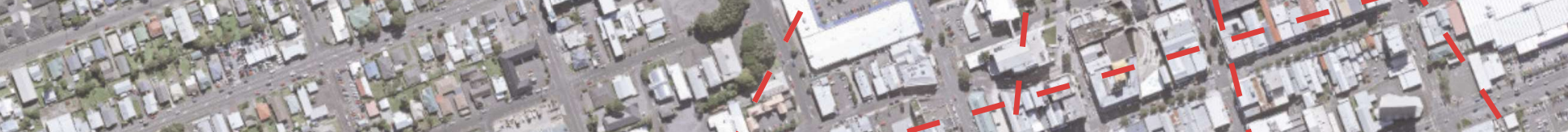

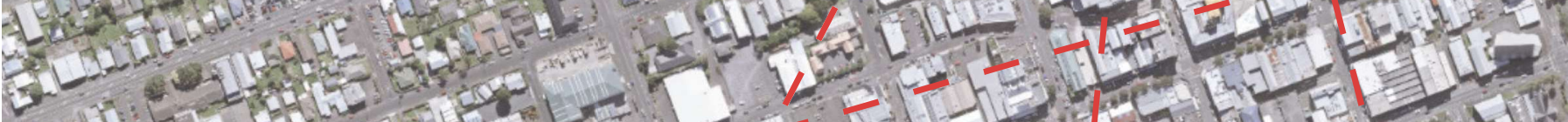

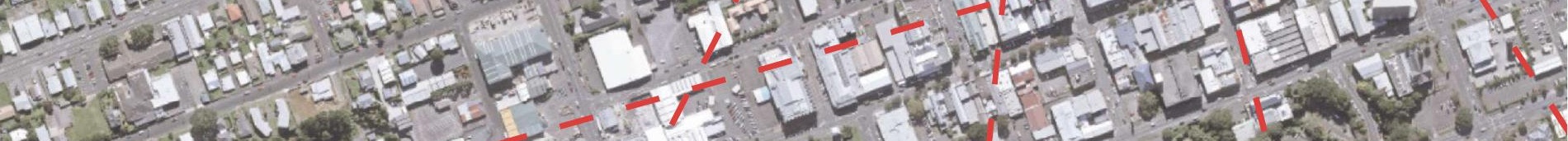

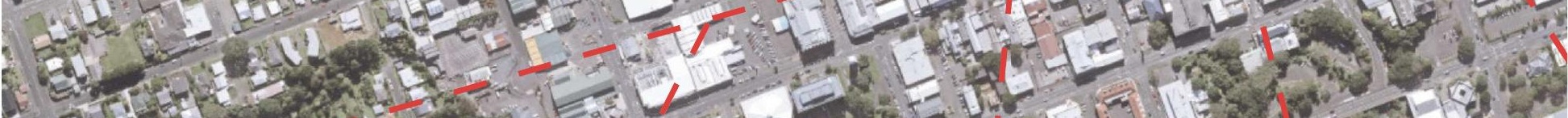

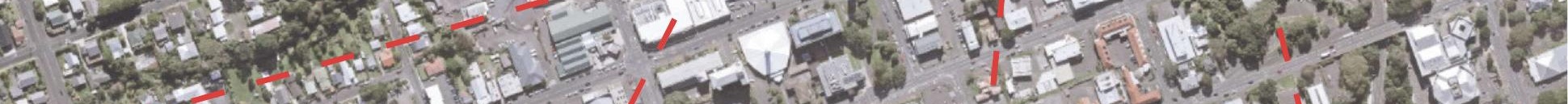

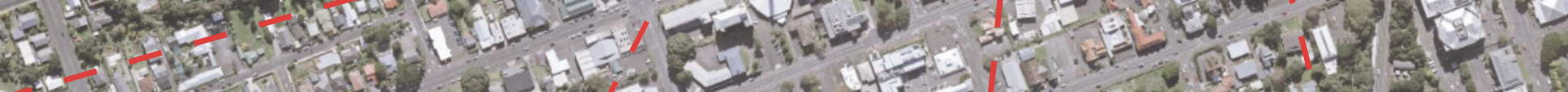

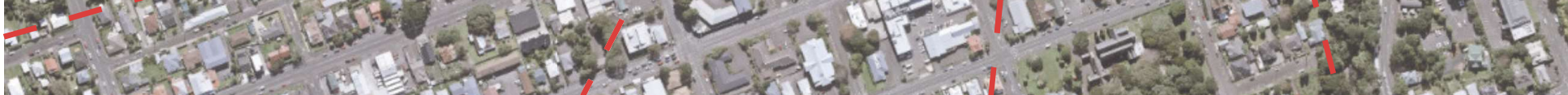
175.5.

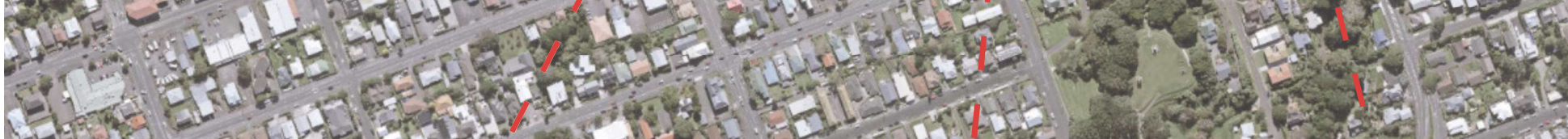

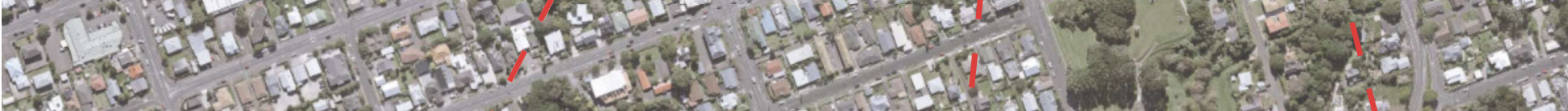

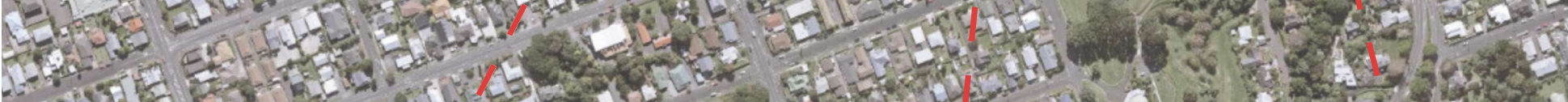

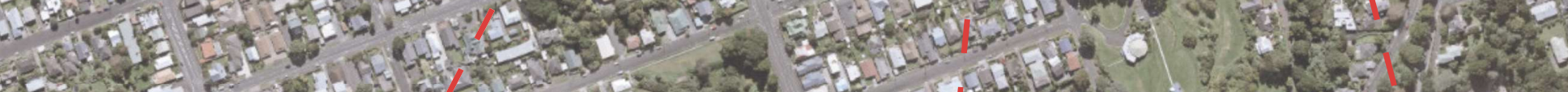

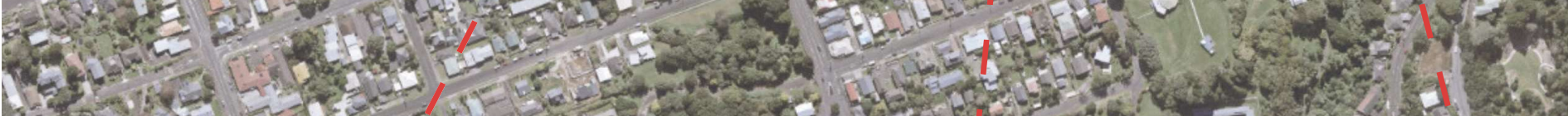
Wh2

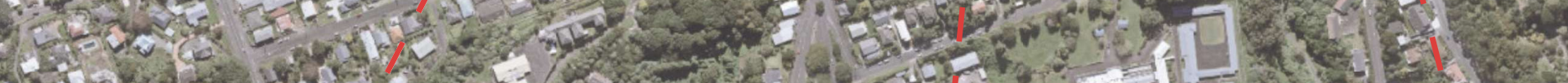

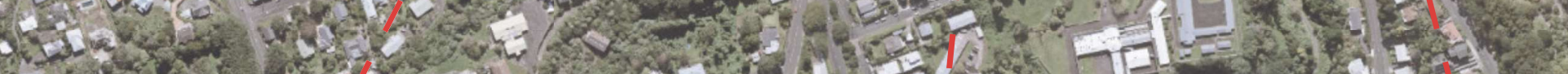

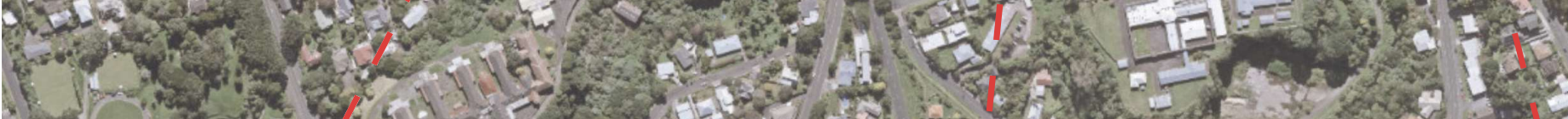

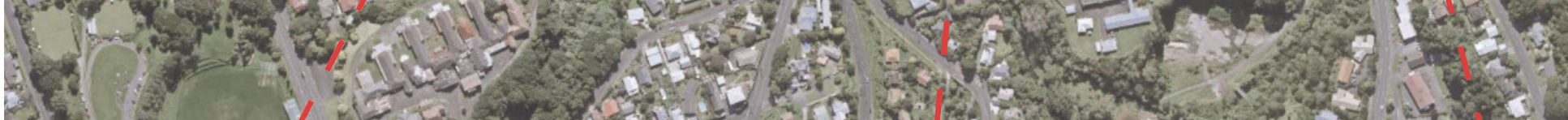

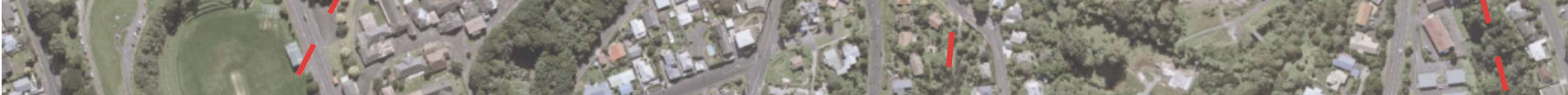

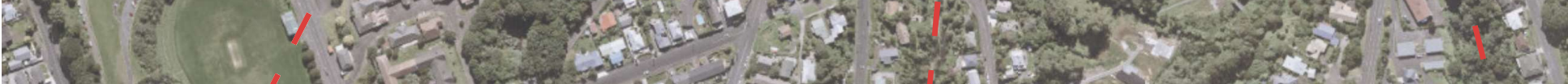

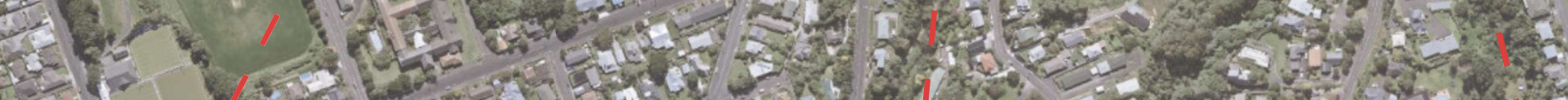

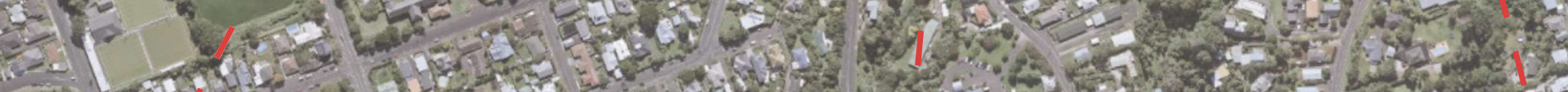

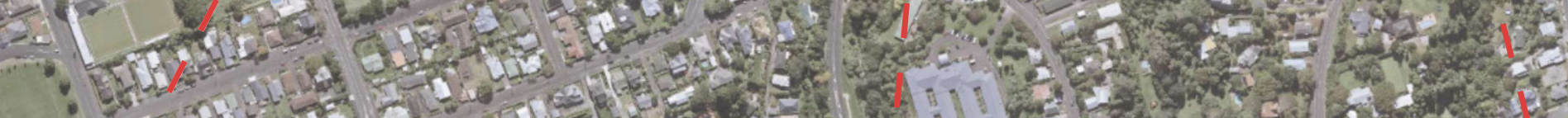
- Lof

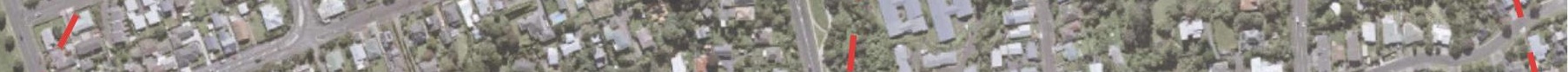

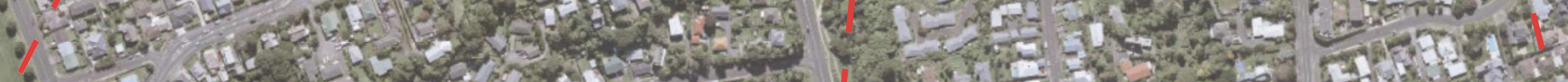


$1.5=$

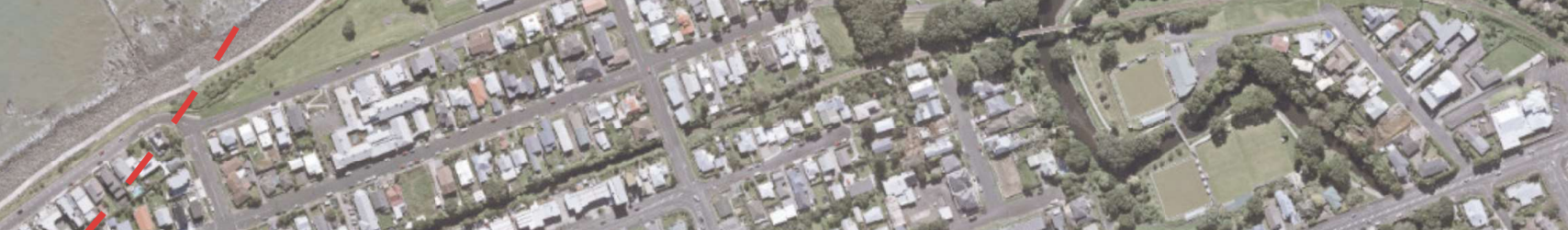

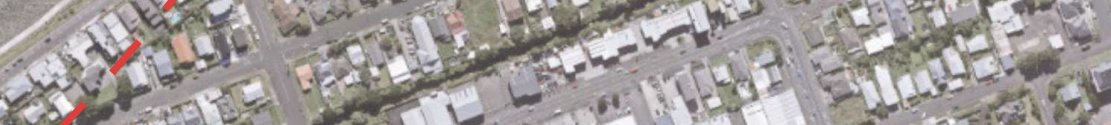

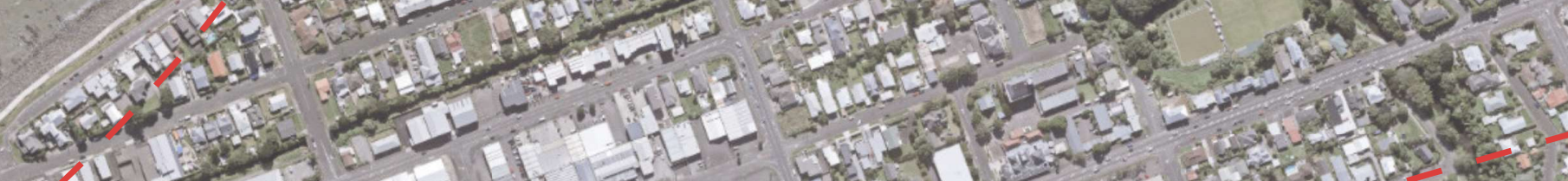

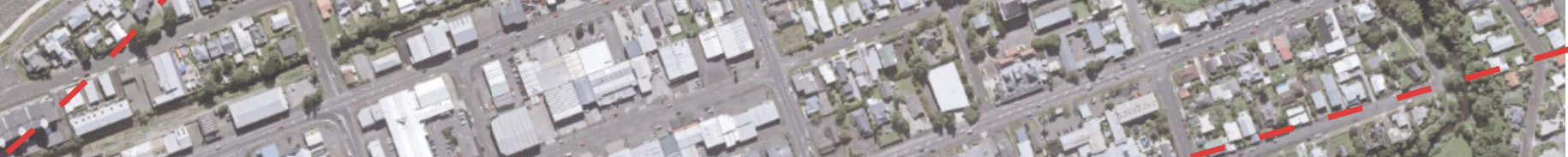

(5), T.5. (5.

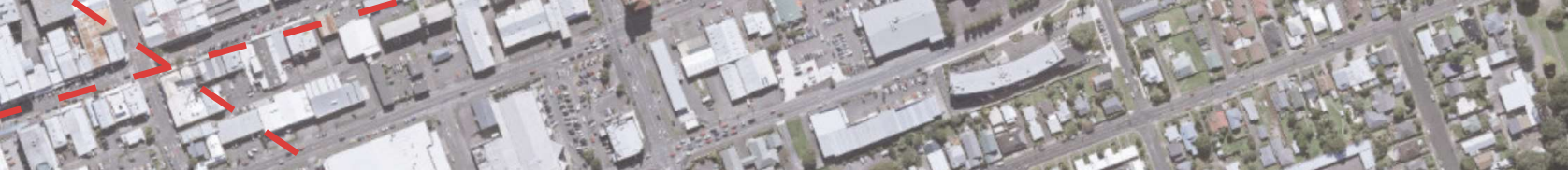

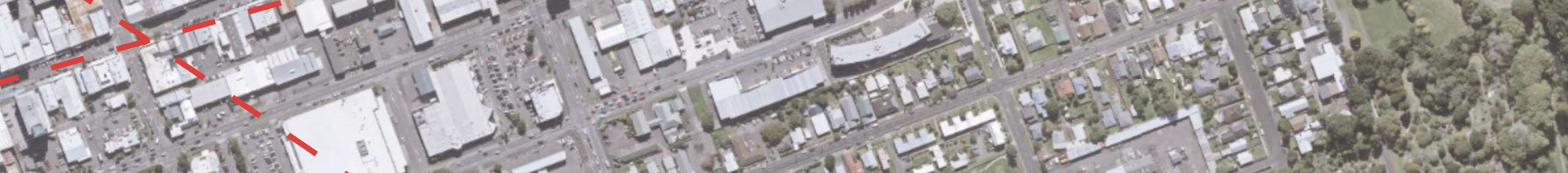
at -1 a

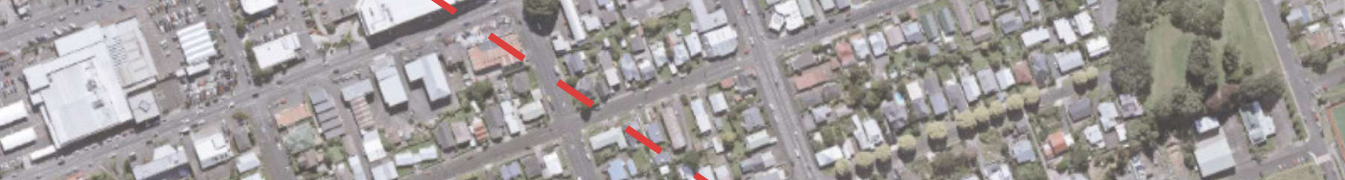

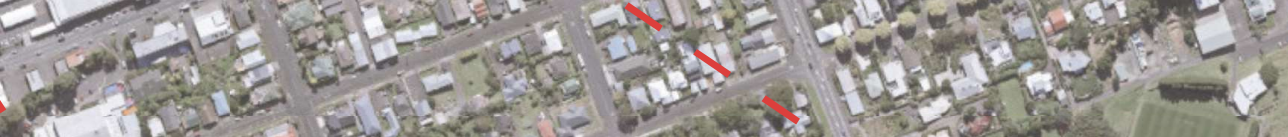
H.

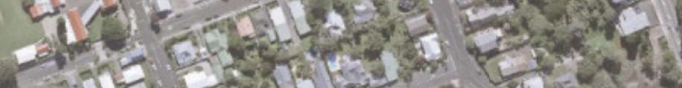

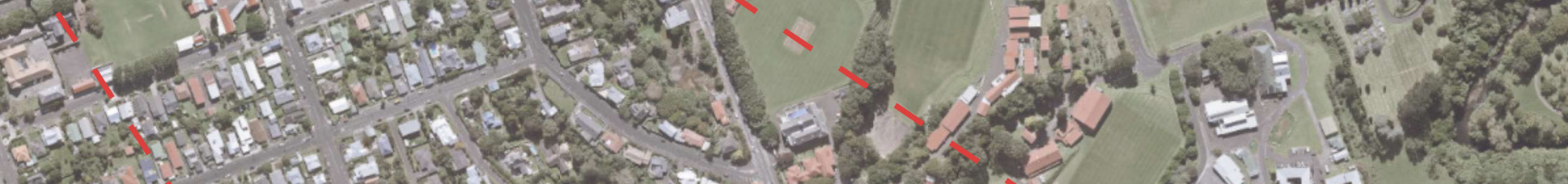

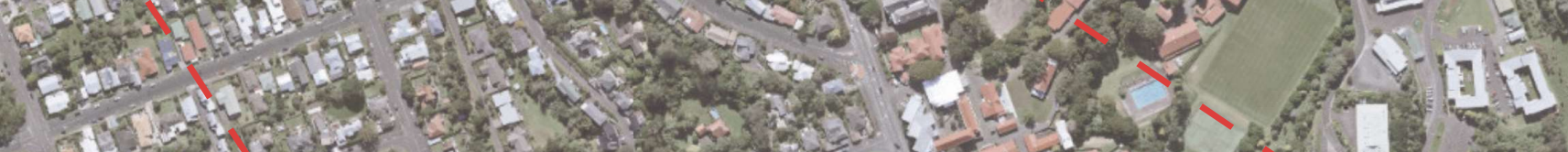

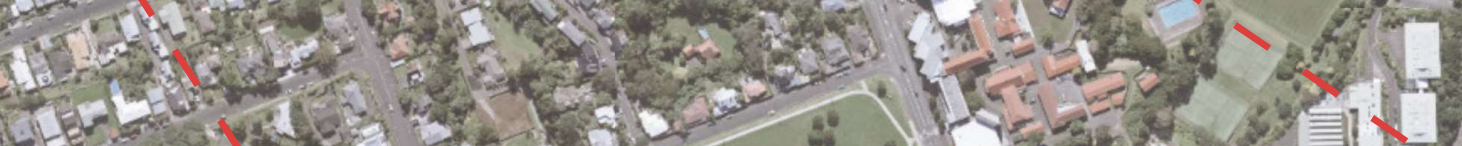
a.1.1. tersion:

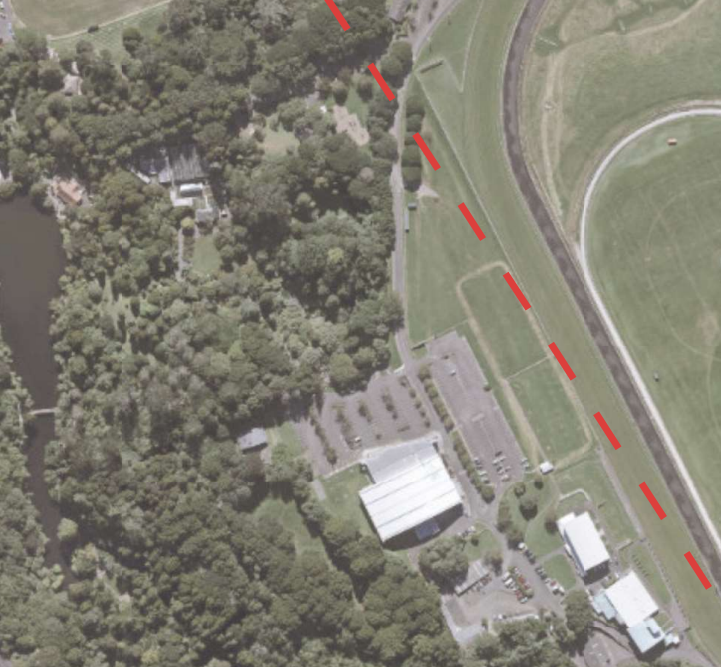

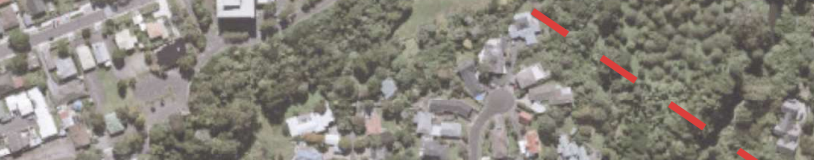

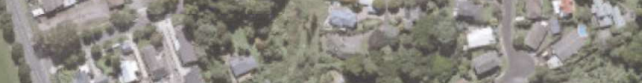

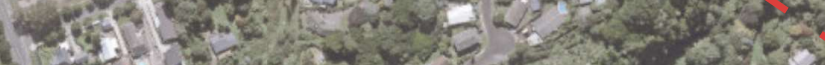

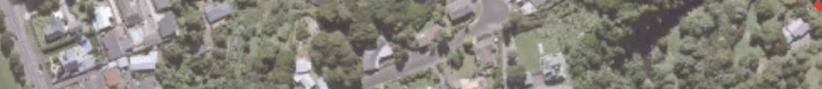

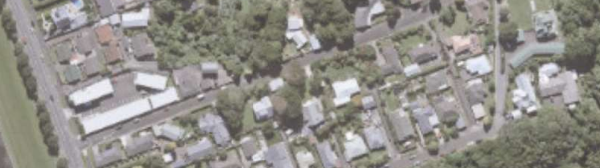
Ler 2

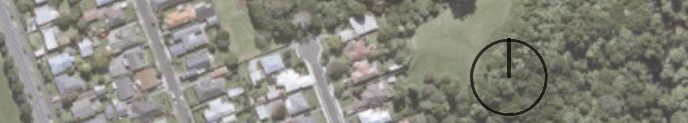
Su sing 


\section{CHAPTER CONCLUSION}

Three methods are tested in this chapter, through different scales , with various degrees of control on the material. This study allows for an abstract understanding of the site, by transforming the site to a set of colours; the coloured map is then reviewed as a painting, to understand how the composition of the large-scale site becomes an image reflected on people's minds.

The outcome of this chapter suggests that the activated area of New Plymouth is limited to its central town streets. Areas of activity are disconnected and separated; which explains why people of New Plymouth spent most of their outdoor time in their cars. Industrial services and warehouses are distributed without any order; they require a vast space and intensive transportation, which retards pedestrian movement and blocks off areas of activity one from one another. The southern green belt is disconnected from the concrete-paved urban fabric; the result of heavy-handed industrialization in the second half of the 20th century.

Materials-wise, watercolours, on a very watery base, are harder to handle; they tend to follow the fluidity of the water and leave marks on the paper naturally as it drys; but the light and transparent colours blend, and create a richer compositional image. Monotype printing produces the ideal outcome, both in the level of control of shape and in texture; however, monotype prints require a long time to dry. The paper crafting model requires less intuitional input, but the result seems to be literal, looking similar to an aerial photo. 


\section{SITE RESEARCH SUMMERY}

Revisiting studies from the previous chapters shows a sharp disconnect between the physical urban planning (as addressed in chapter2) of the large-scale city and its mental image (discussed in this chapter). Ordinary people experience and experiment with the city through human-scale movement. However, in New Plymouth, recognition small-scale at this small-scale does not cohere with the large-scale planning system. When people think about the city, their imagination is jumping between those iconic areas rather than thinking about the city as a complete image.

Despite the mental image of New Plymouth being fragmented, people could still rely on the site's history and their personal experience on the land to search for a sense of belonging. But, as identified in the previous chapter, most historical sites, including Huatoki Stream, are buried under the concrete pavement. The existing New Plymouth planning system unconsciously permeates into the citizen's daily lifestyle, becoming the only version of history present, to trigger any sense of belonging or personal mental recognition of space.

Further studies would add another layer of imageability, based on the existing layer, shifting the city's mental image towards a more organized urban system, bringing out the site's historical value. 


\section{5}

\section{MASTER PLAN}

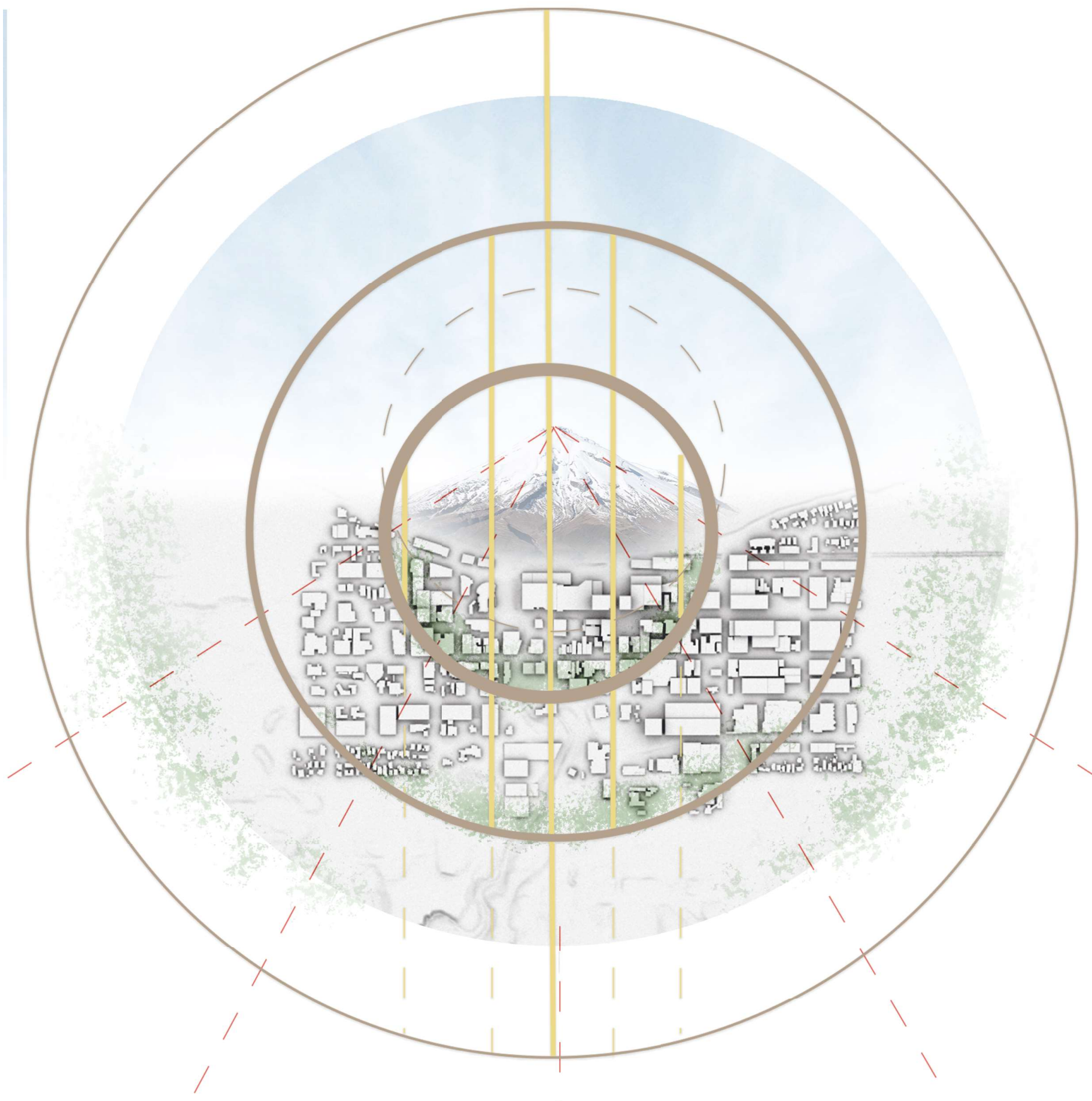




\section{Urban pattern}

A few spots have a complex of colours (in the red circles), which mean they are the existing activitycentres. However, these spaces' power is easily distracted by other popped-up colours around them, which indicates a sense of placeness easily fades away, once people have left the colour complex
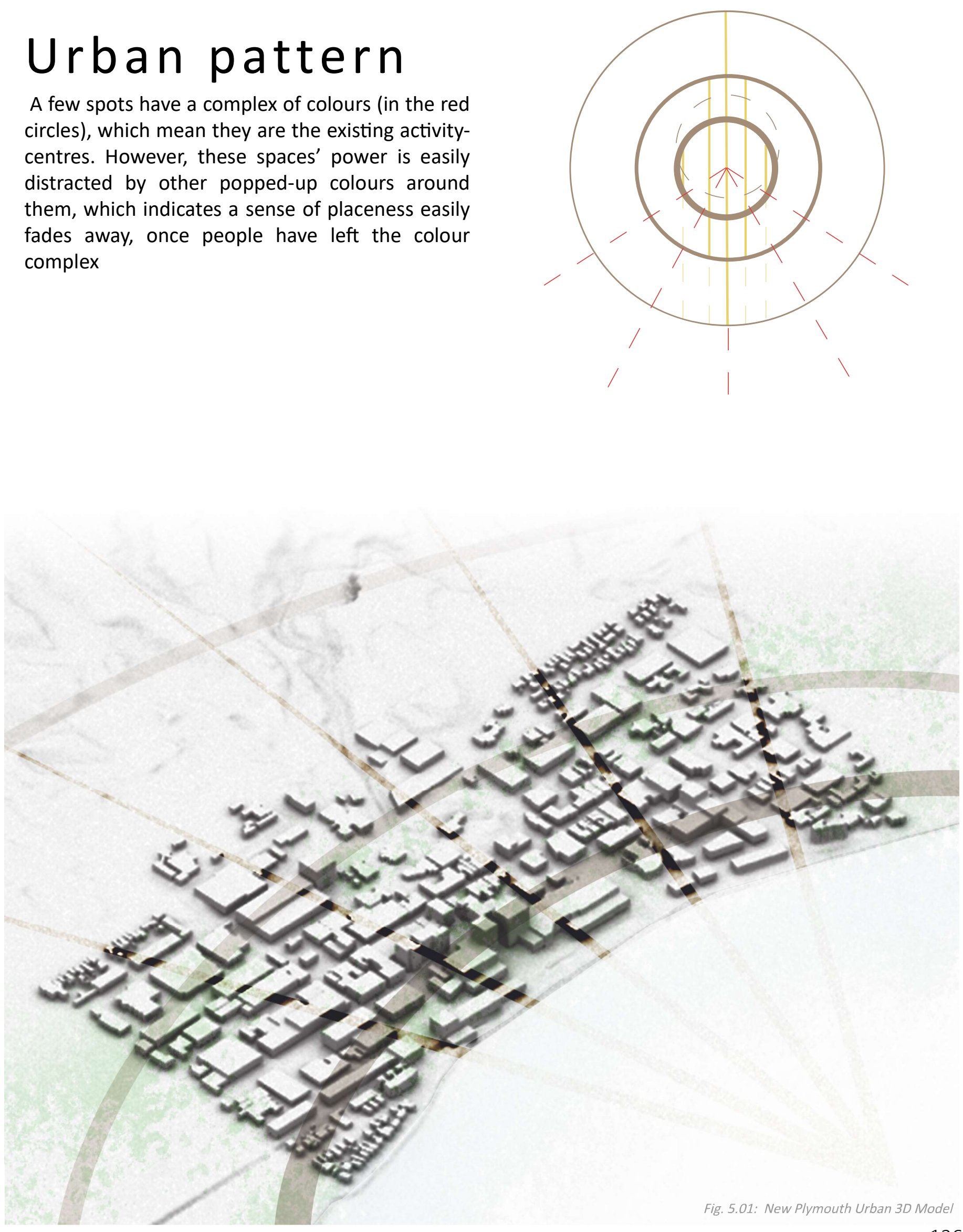


\section{PRIMARY PATTERN}

Previous studies investigated the urban patterns behind urban construction's logic and discovered a blurred pattern that people mentally received by experimenting with the urban area. This chapter would re-enforce the city's historical pattern and design a master plan to engage citizens' mental recognition.

Circle patterns are employed as the basic pattern behind planning. The circle shape is symbolic of Taranaki region because the region's coastline is in a semicircle shape and the outline of $\mathrm{Mt}$ Taranaki Reserve is in a perfect circle. Besides, the circle shape was identified from previous site analytical studies.

However, the circular shape would expect to be a mentally understood image rather than a literal circular pathway cutting through the existing urban fabric. The goal is to merge the circular pattern into the existing grid pattern. Allow local citizen to physically discover the hidden circular pattern behind the urban system.

The proposed master plan also re-evaluates NPDC's design goals and selects their proposal into consideration. (Refer to chapter 1):

- Respect the past, identification and support for precincts and character areas.

- Investigate barriers to good quality medium density housing in the Central Area and develop appropriate incentives.

- Balance between users; human pace and increased pedestrian permeability.

- Public investment used as leverage for private investment.

- A Place to unwind; everyone's place; an active, green, diverse and safe environment. (NPDC, 2013) 


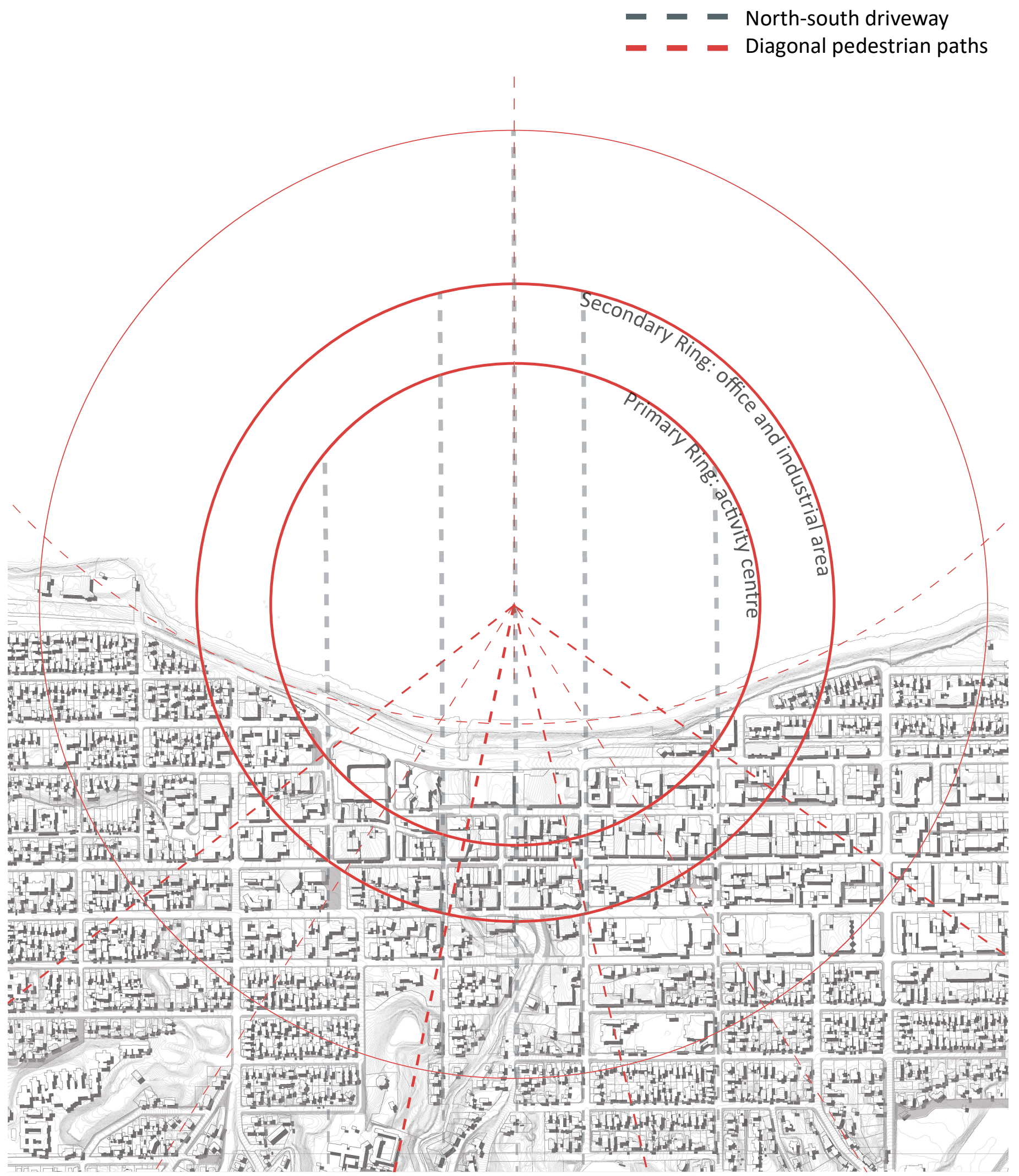


Green corridors are proposed, to direct pedestrians to access the waterfront. The design will increase the coverage of greenery on the eastern side of the city.

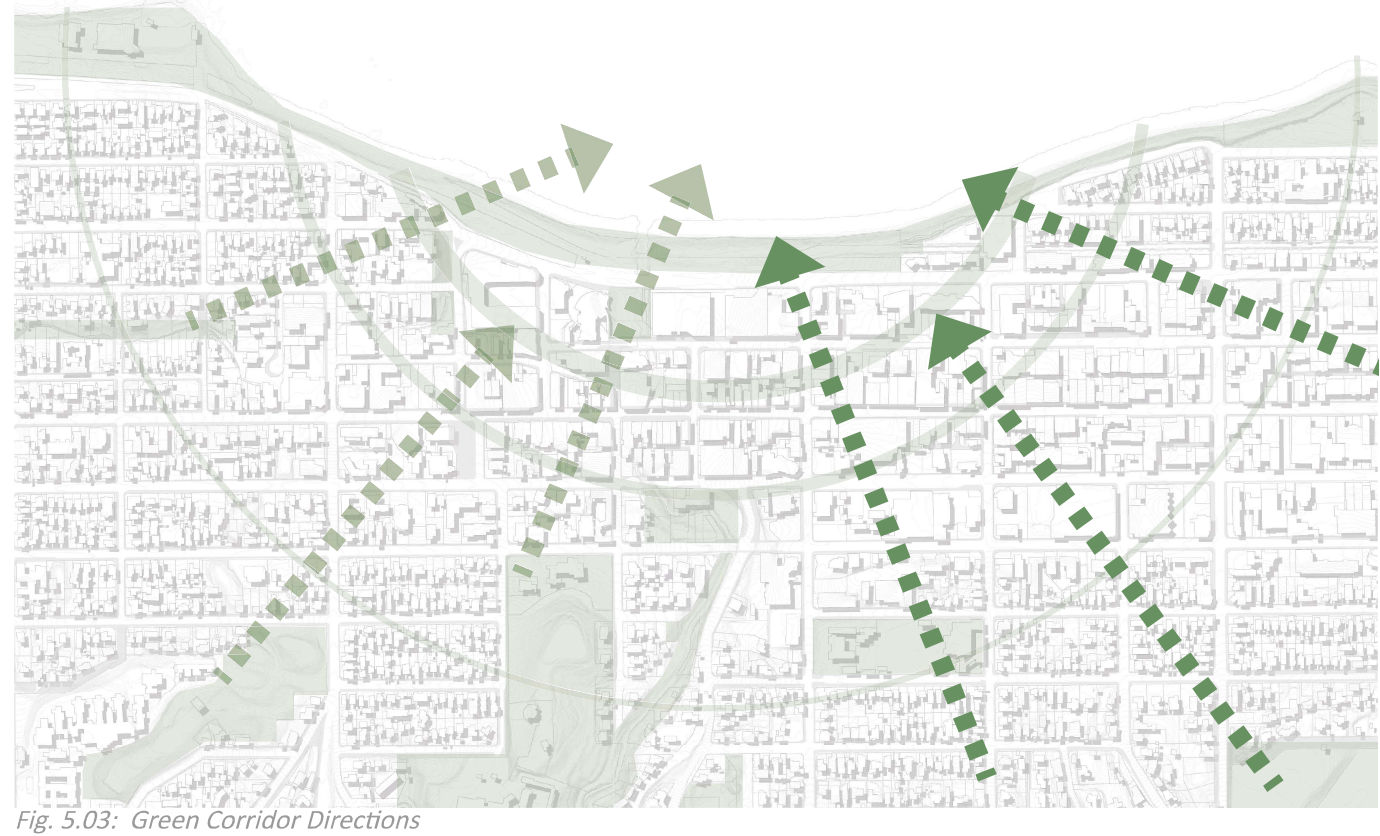

The design daylights Huatoki Stream, one of New Plymouth's historical assets, building a connection from the town's green belt to the waterfront.

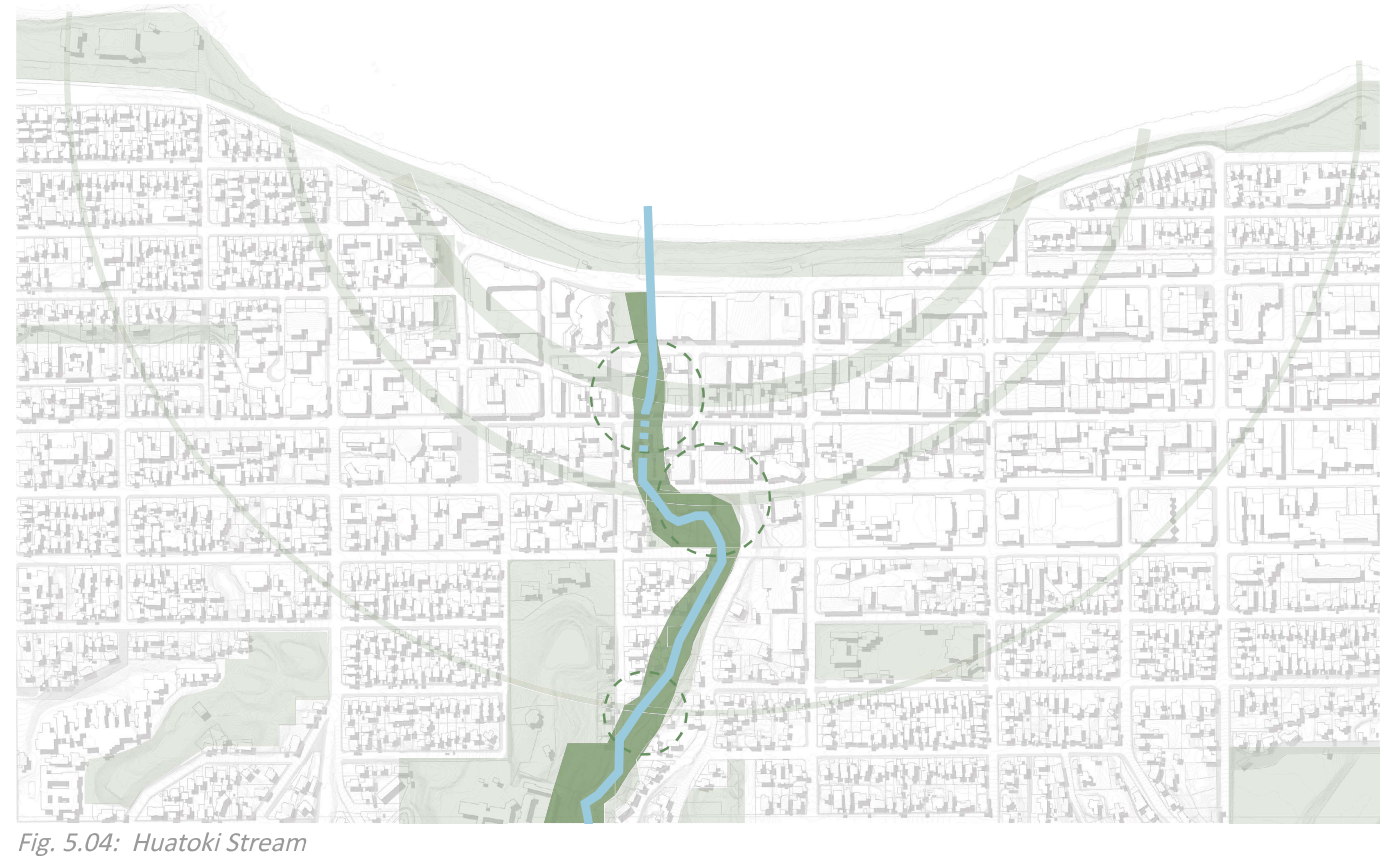


5.2 Master-plan

The urban open space arrangement follows the concentric circular pattern.

- - Paths allow pedestrians to explore the way diagonally towards the waterfront.

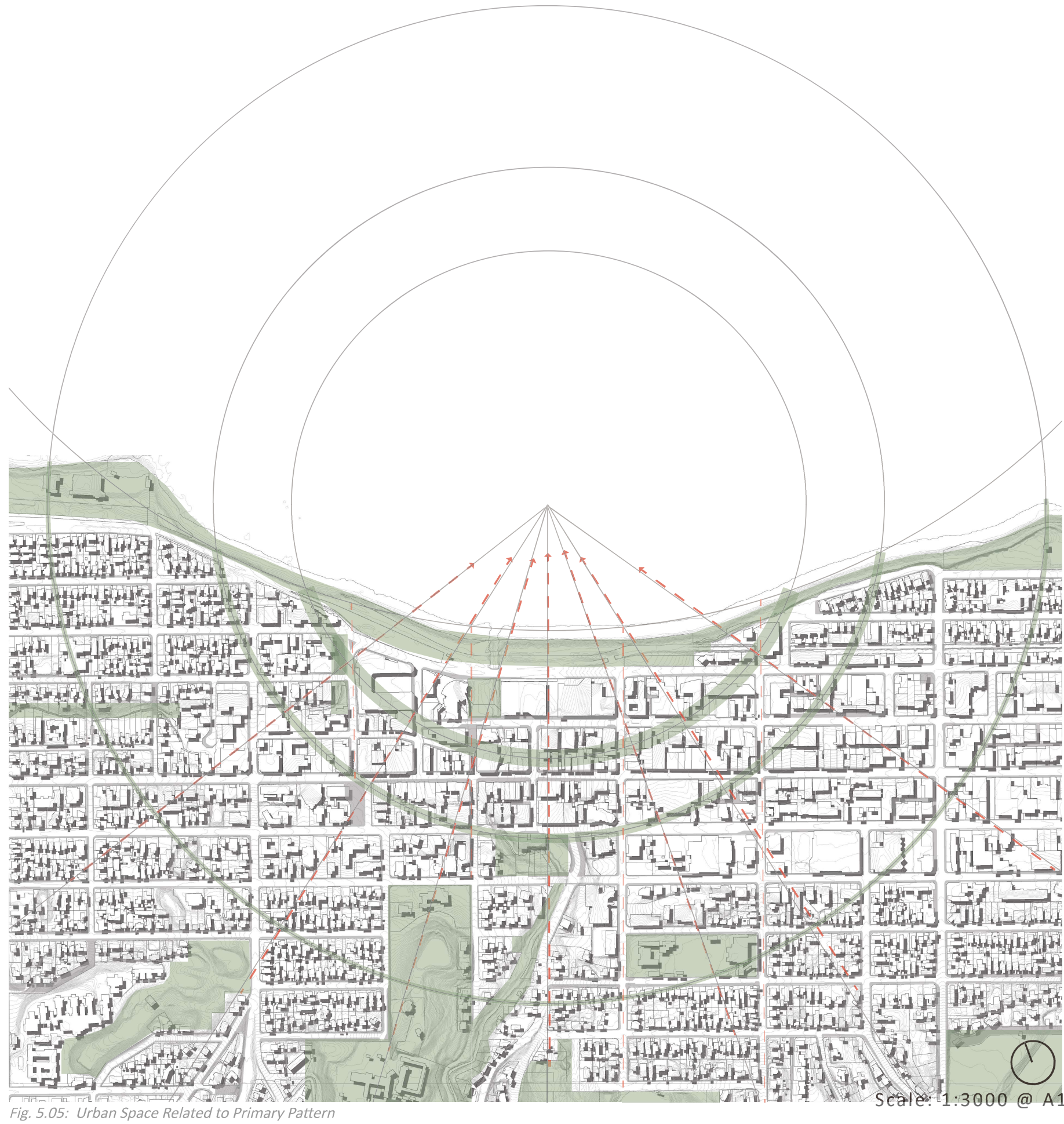


As the plan shows, green space is proposed along the pattern of concentric circles. Designated green corridors between buildings lead pedestrians towards the waterfront, diagonally (in red lines). The circle pattern is suggested subtly, coming to the surface in the green space only as an arcing pedestrian pathway. People have to search for the complete pattern; this discovery action will lead them to the waterfront. Key sites are marked in red points, explained in the next two pages.
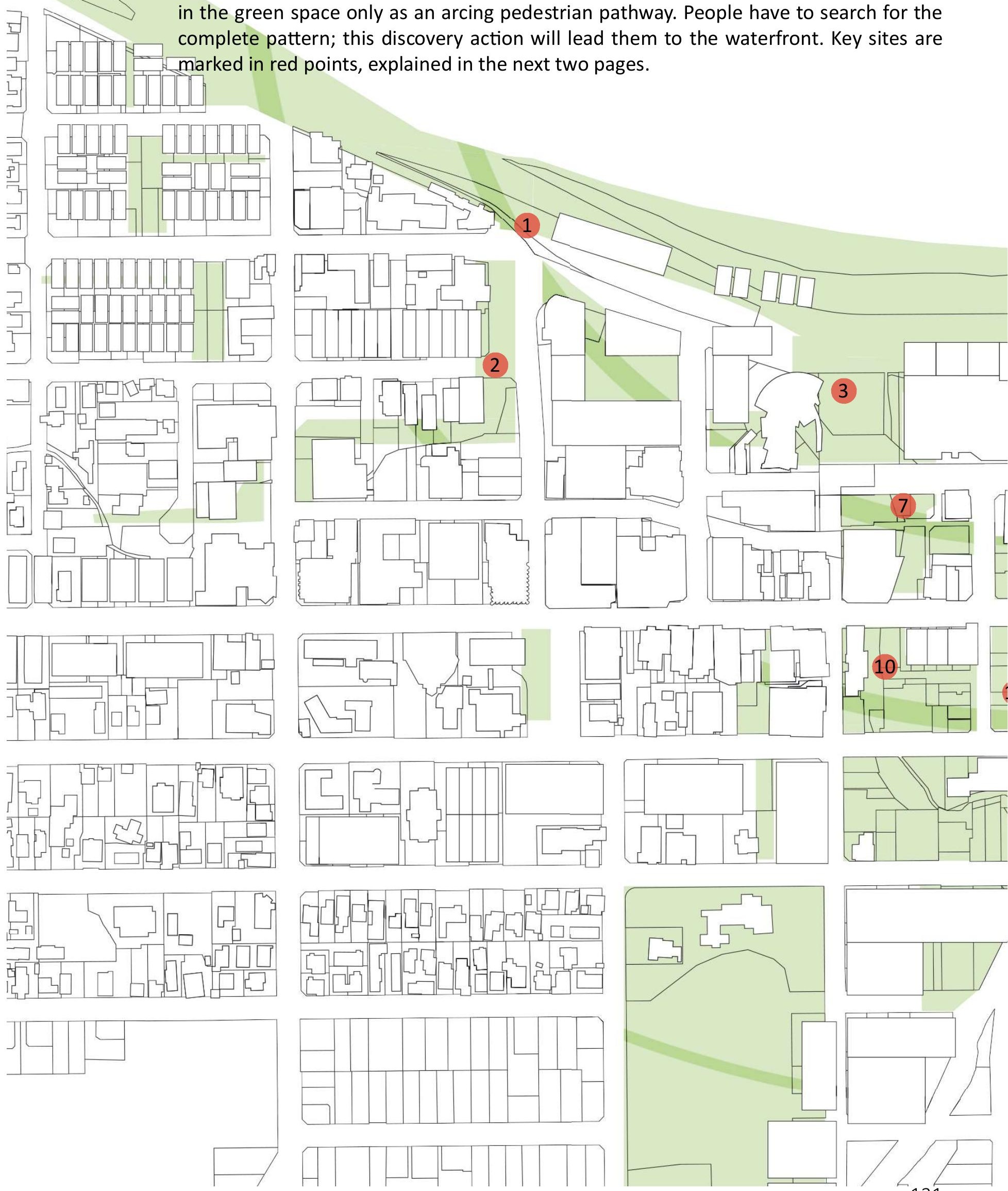

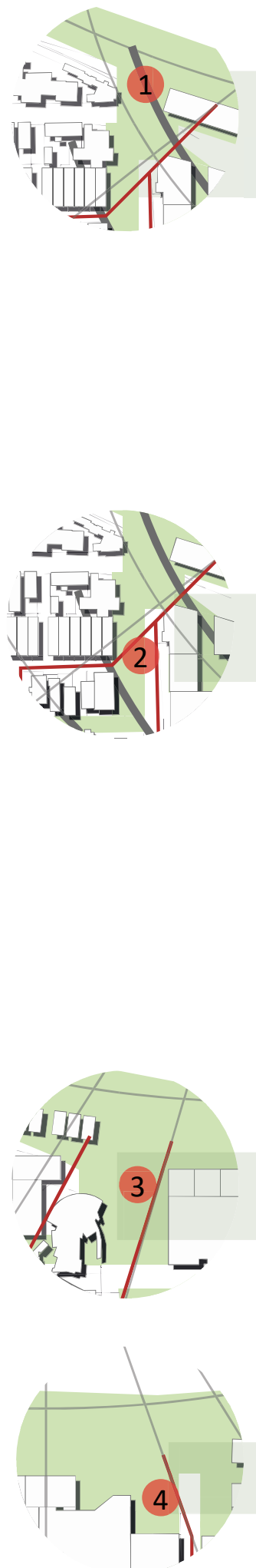

The design proposes a re-alignment of the Cenotaph, and development of this site into a more complete World War I memorial, highlightng the diagonal axis towards the centre of the circle. Detailed design is shown in the next chapter.

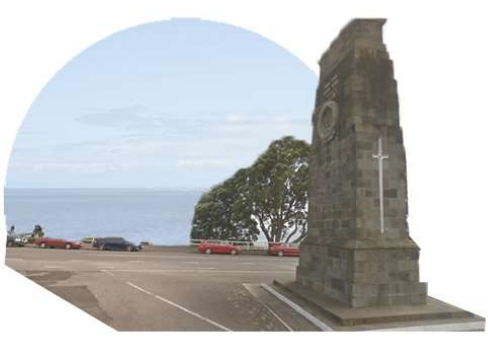

Fig. 5.08: Existing Site 1

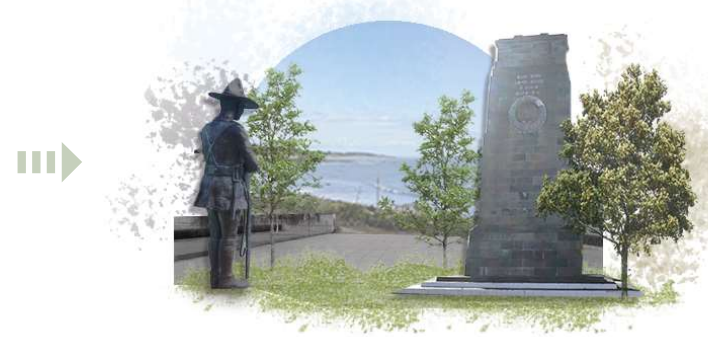

Fig. 5.09: Designed Site 1

The existing planting is cleared, daylighting the hidden stream as a residential garden.

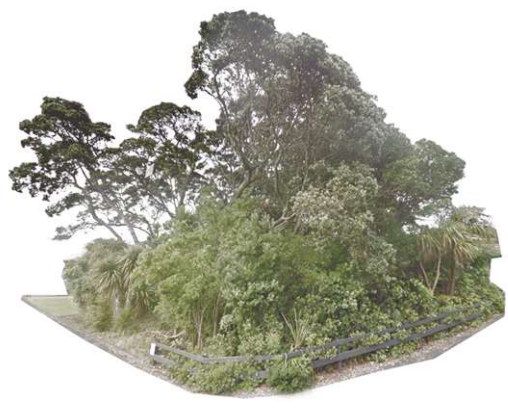

Fig. 5.10: Existing Site 2

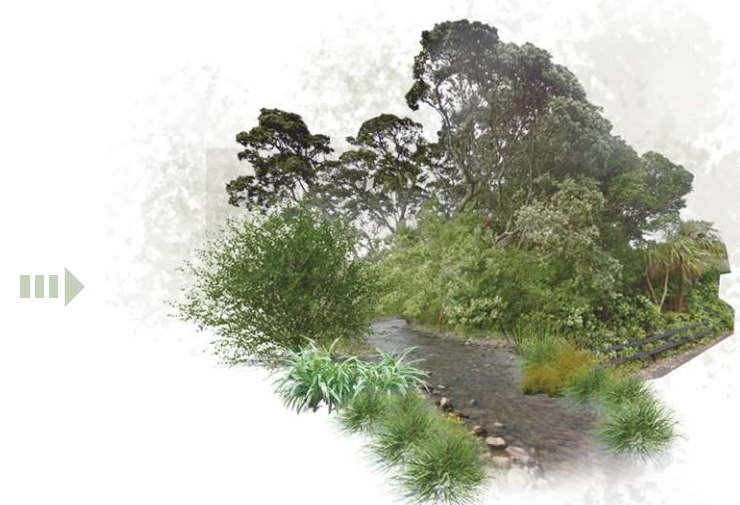

Fig. 5.11: Designed Site 2

The existing Pukeariki landing is kept, using the pattern within this park for later design.

The existing car park becomes a park, contrasting symmetrically with Pukeariki landing.

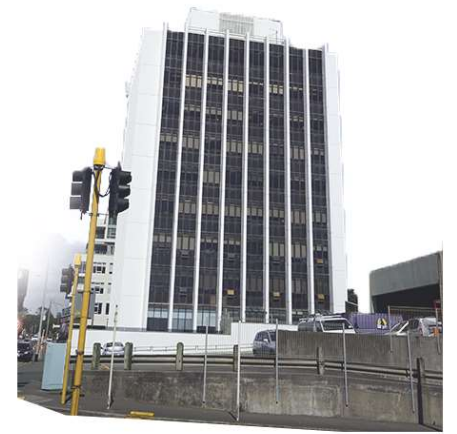

Fig. 5.12: Existing Site 4
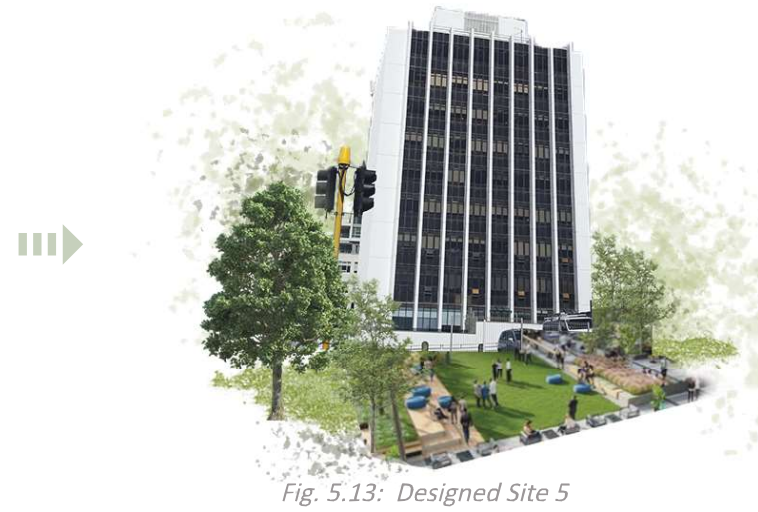
5.2 Master-plan

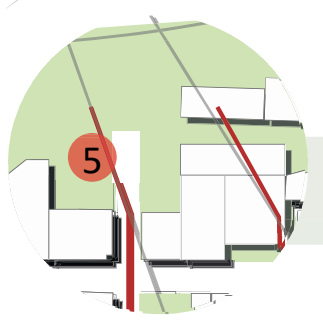

Opposite 4 Liardet St, Remove Existing building, connection to the vegetated waterfront.
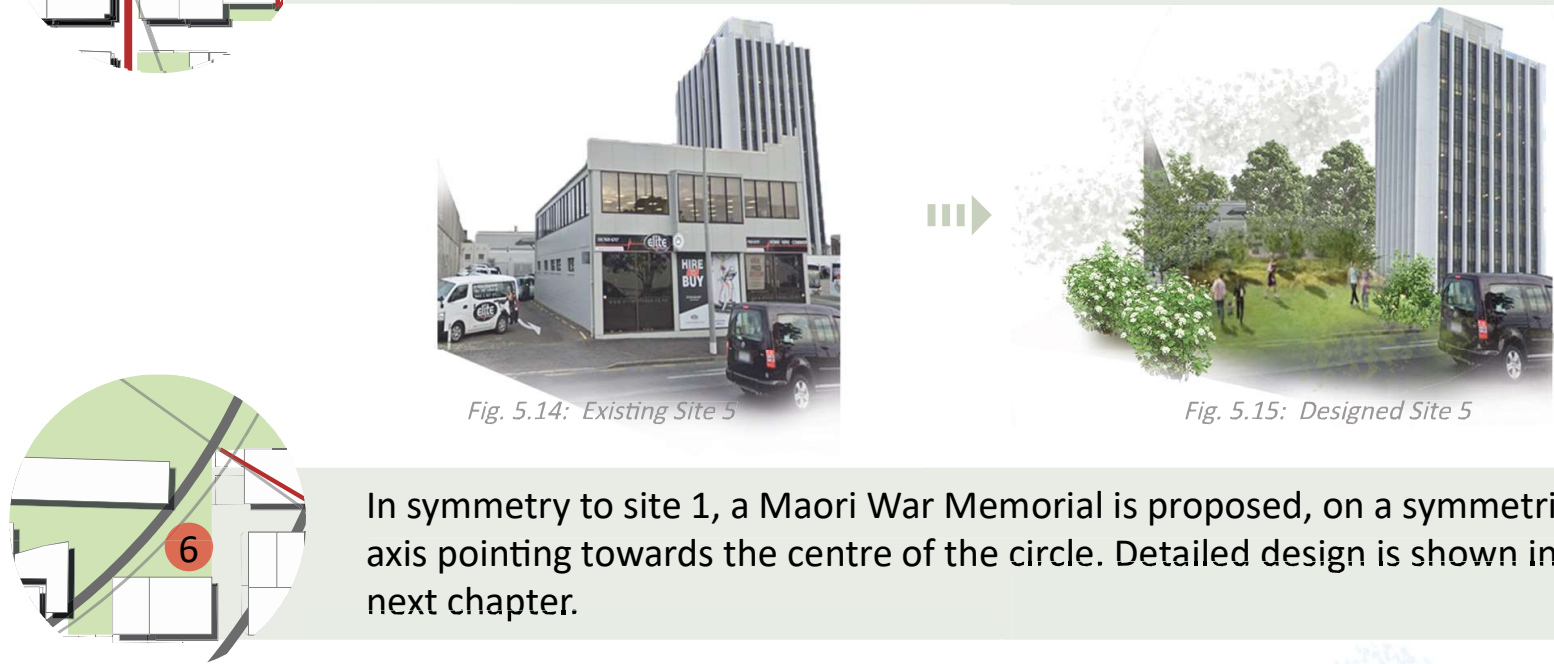

In symmetry to site 1, a Maori War Memorial is proposed, on a symmetric axis pointing towards the centre of the circle. Detailed design is shown in the next chapter.

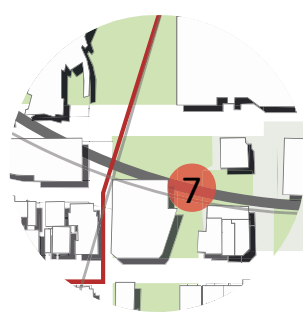

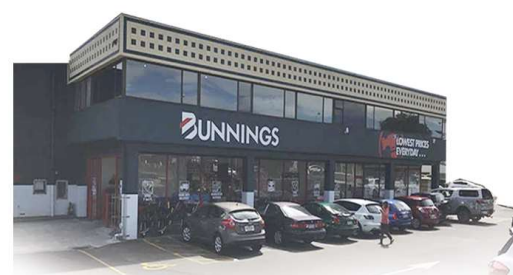

Fig. 5.16: Existing Site 6

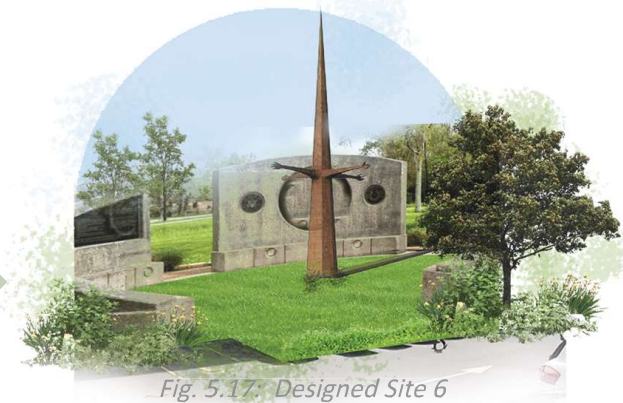

Fig. 5.17: Designed Site 6

Huatoki Plaza is redesigned, to create a more vibrant and vegetated public space. Detailed design is shown in the next chapter.

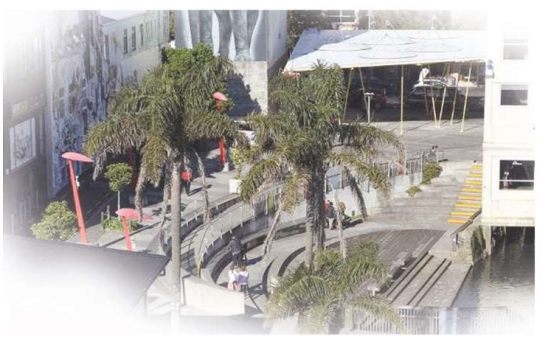

Fig. 5.18: Existing Site 7

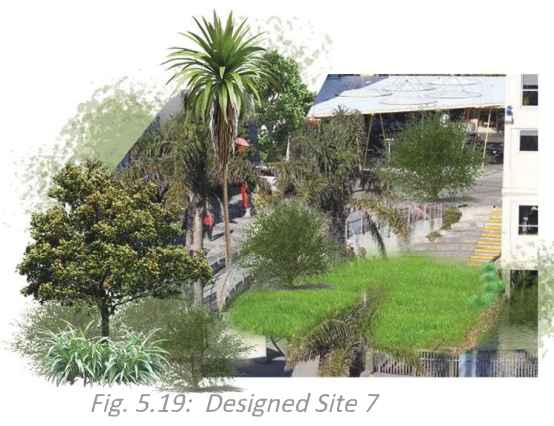

Symmetrically opposite the Huatoki Plaza, the Farmers Market is shifted to this site from Huatoki Plaza, and an activated shopping frontage is introduced.

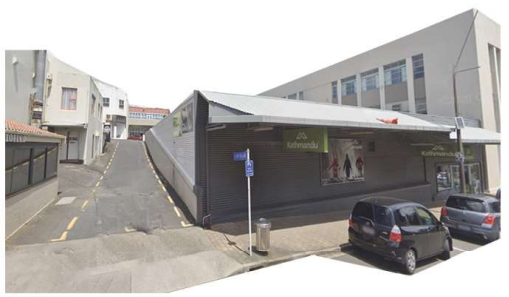

Fig. 5.19: Existing Site 8
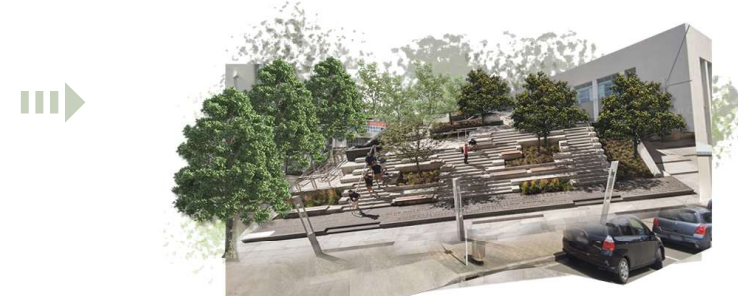

Fig. 5.20: Designed Site 8 


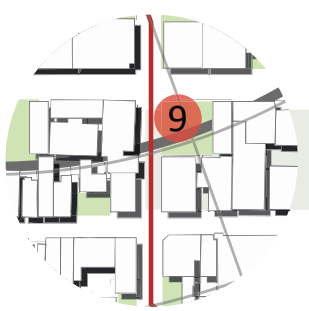

A residential green yard follows the circular walkway.

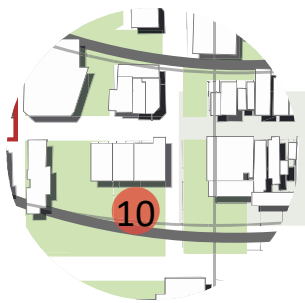

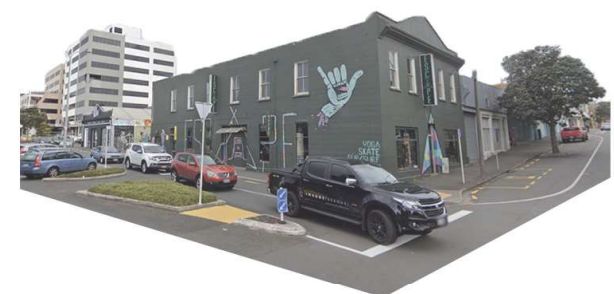

Fig. 5.21: Existing Site 9

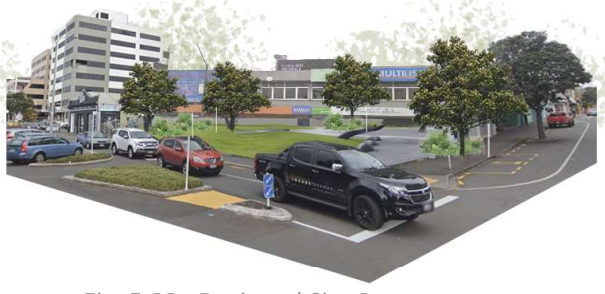

Fig. 5.22: Designed Site 9

The existing housing is cleared, allowing this space for reforestation, to enhance Huatoki stream's biodiversity. Detailed design is shown in the next chapter.

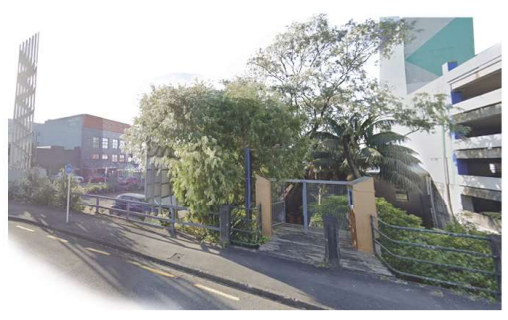

Fig. 5.23: Existing Site 10

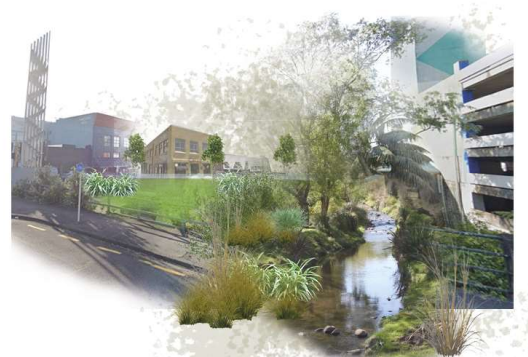

Fig. 5.24: Designed Site 10

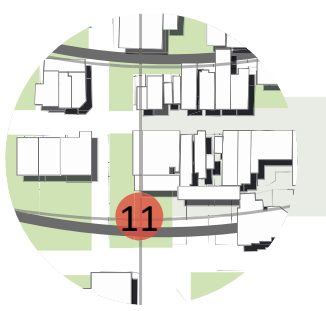

Vegetated public space is picked up and extended from site 10, drawing out the 2nd concentric circle.

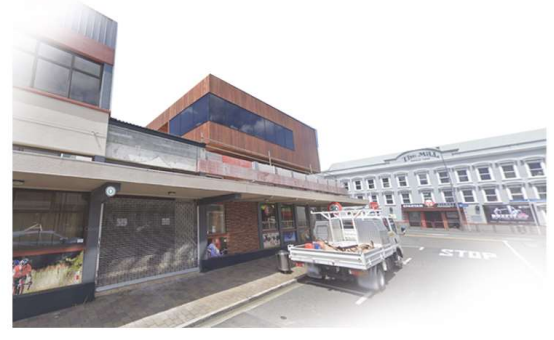

Fig. 5.25: Existing Site 11
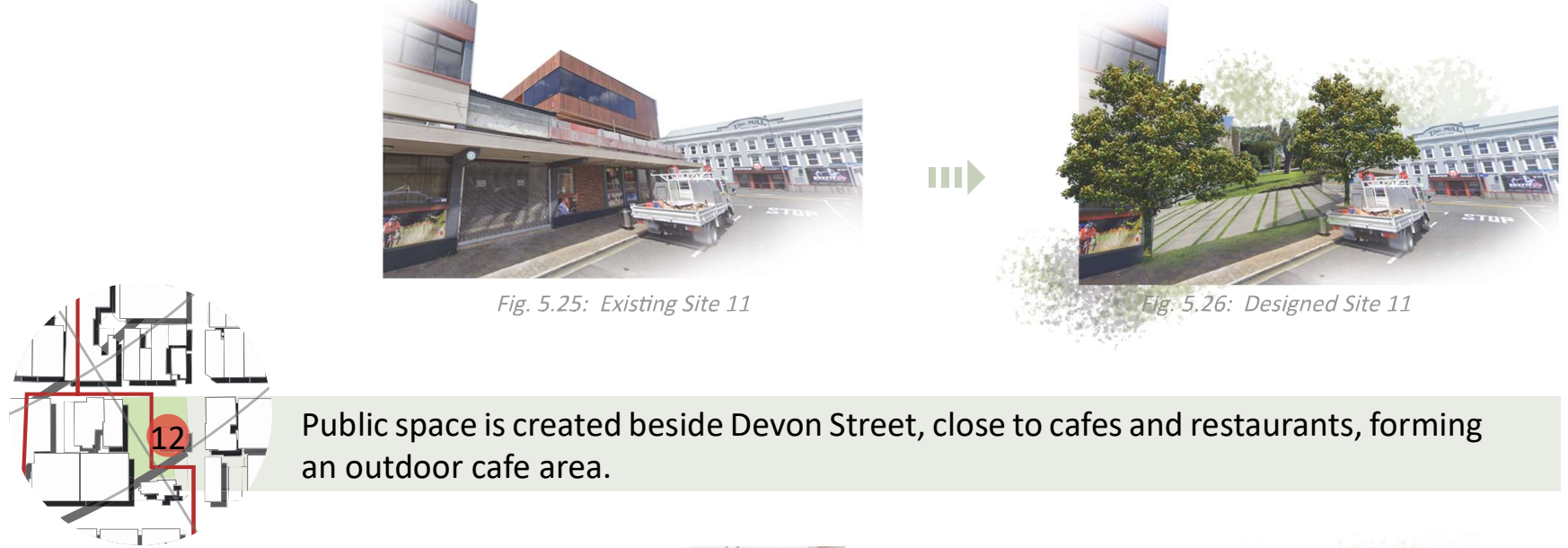

Public space is created beside Devon Street, close to cafes and restaurants, forming an outdoor cafe area.

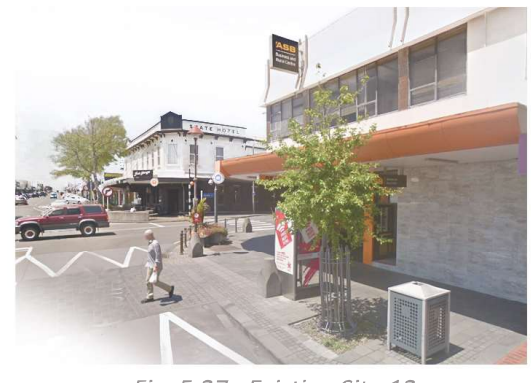

Fig. 5.27: Existing Site 12
III)

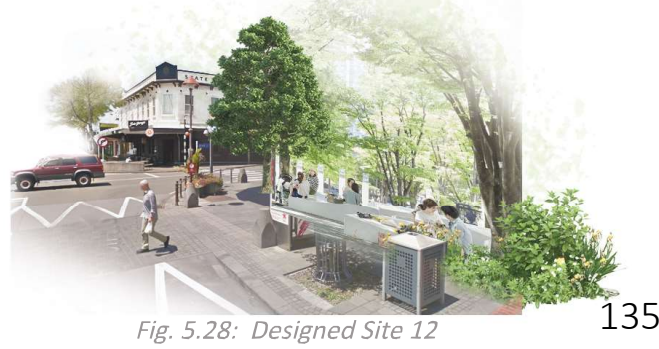




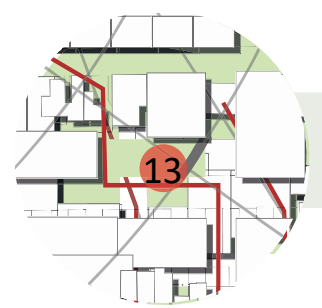

A residential green yard is created, following the concentric circular pattern. A narrow walkway is provided, which leads to the waterfront.

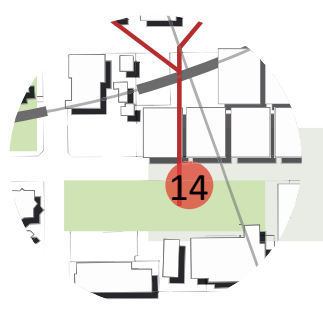

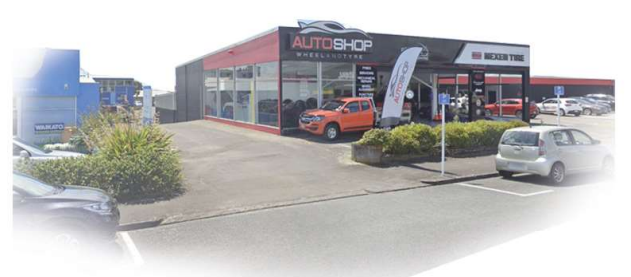

Fig. 5.29: Existing Site 13

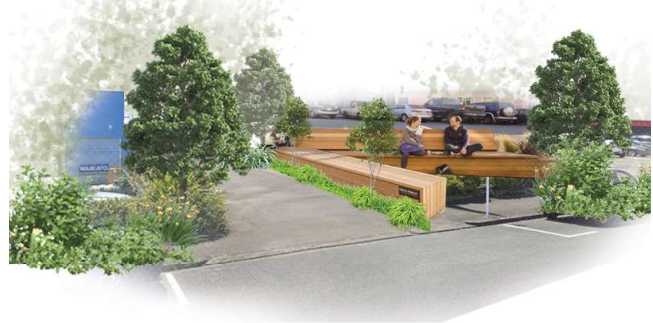

Fig. 5.30: Designed Site 13

The hidden stream is daylighted, creased a pleasant street edge. Water are expected to be shallow, with vegetation covers around it.
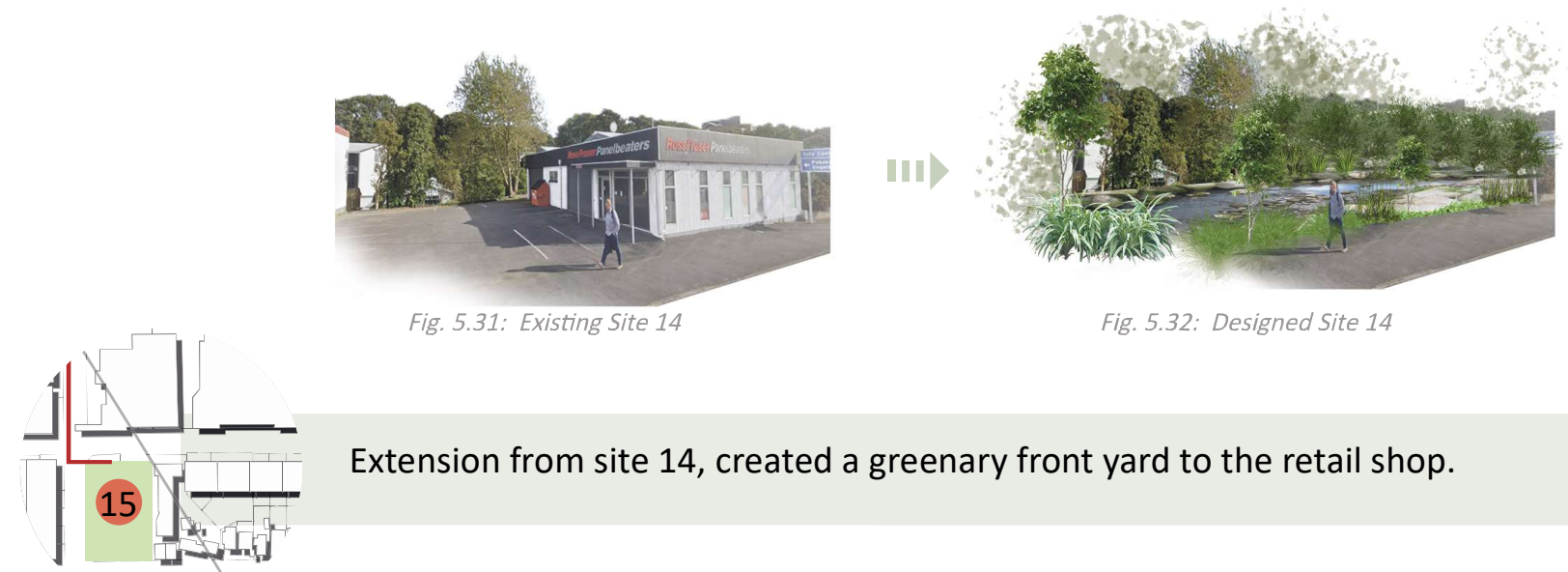

Fig. 5.32: Designed Site 14

Extension from site 14, created a greenary front yard to the retail shop.

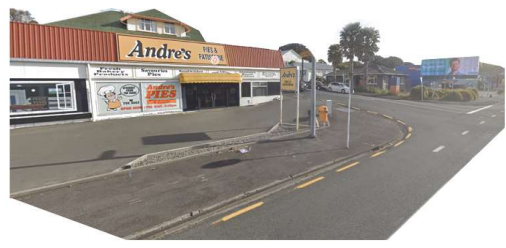

Fig. 5.33: Existing Site 15

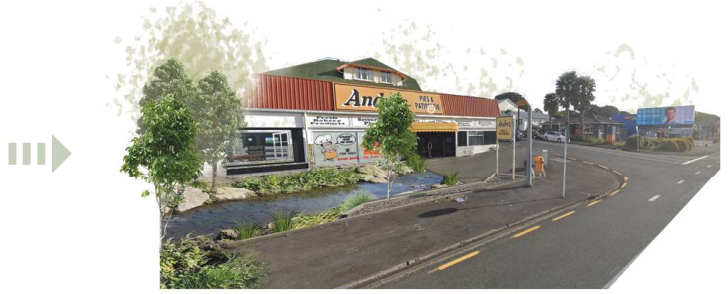

Fig. 5.34: Designed Site 15 
The function and distribution of buildings are reorientated to the concentric circle pattern, to ensure an active city life within the centrat circle.

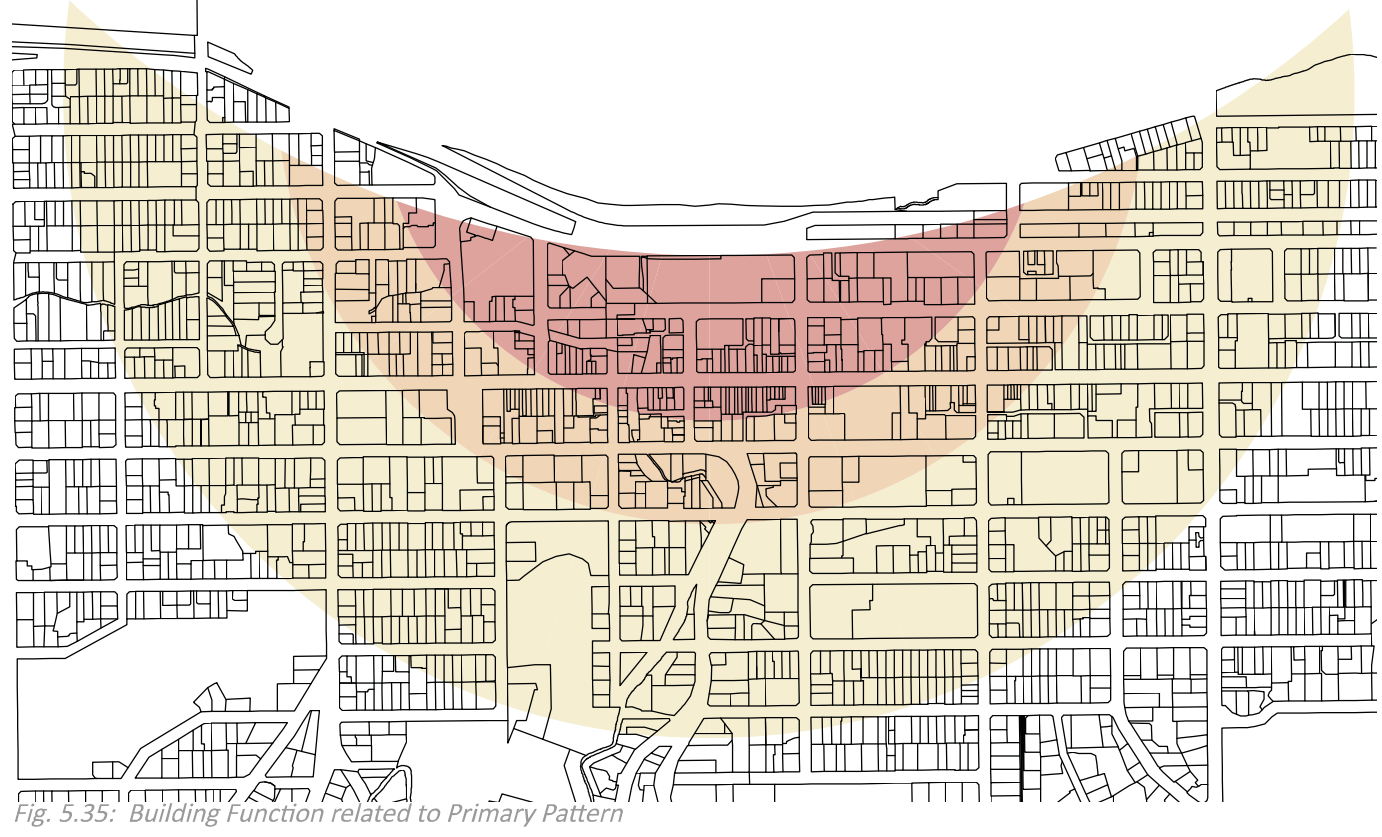

Intense active frontage within the central circle

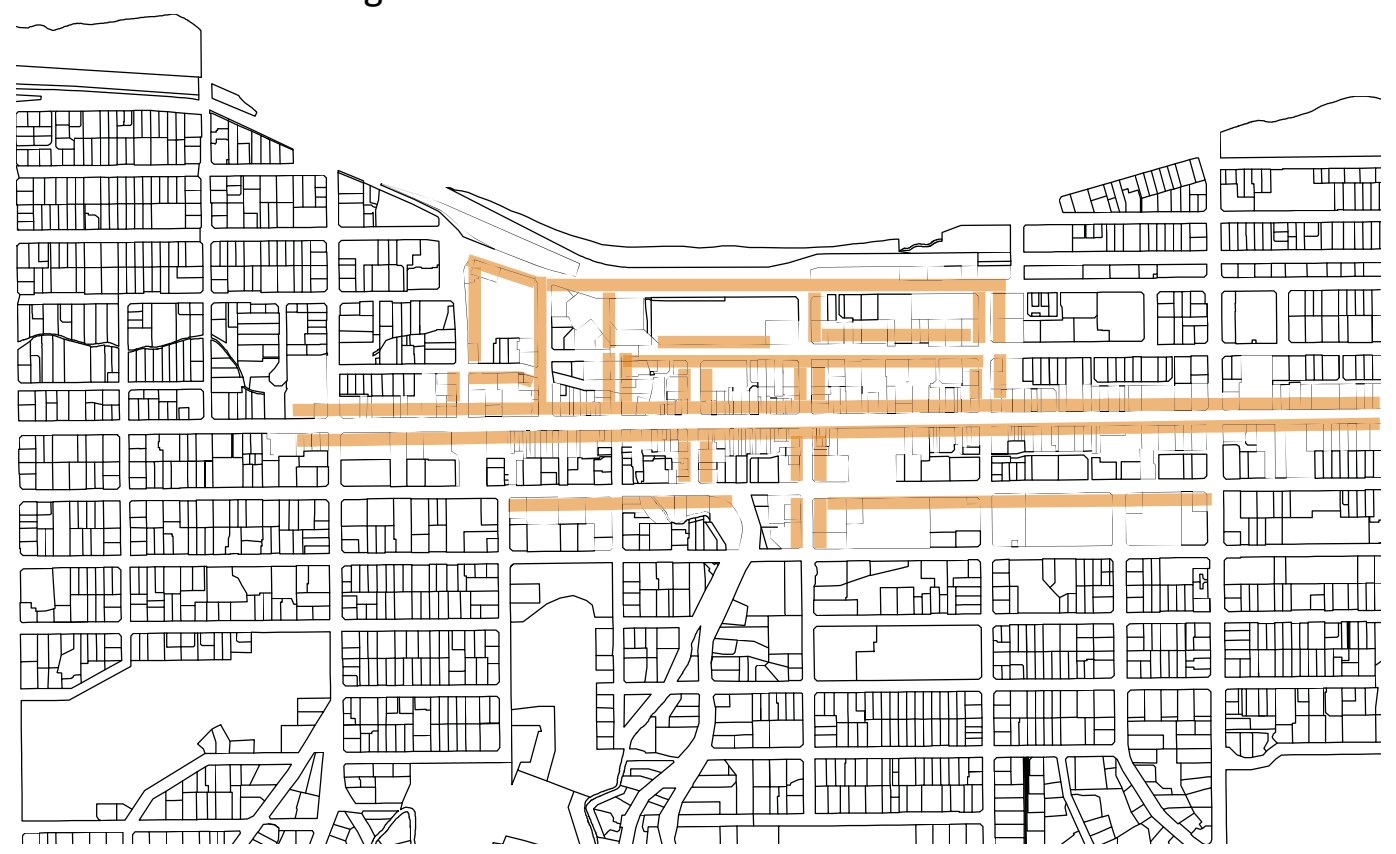

Fig. 5.36: Proposing Intensive Open Shop Front 


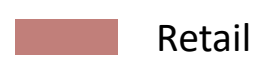

Mixed-use, residential/retail
Office

Industrial
Age-friendly accommodation

Residential

Greenery

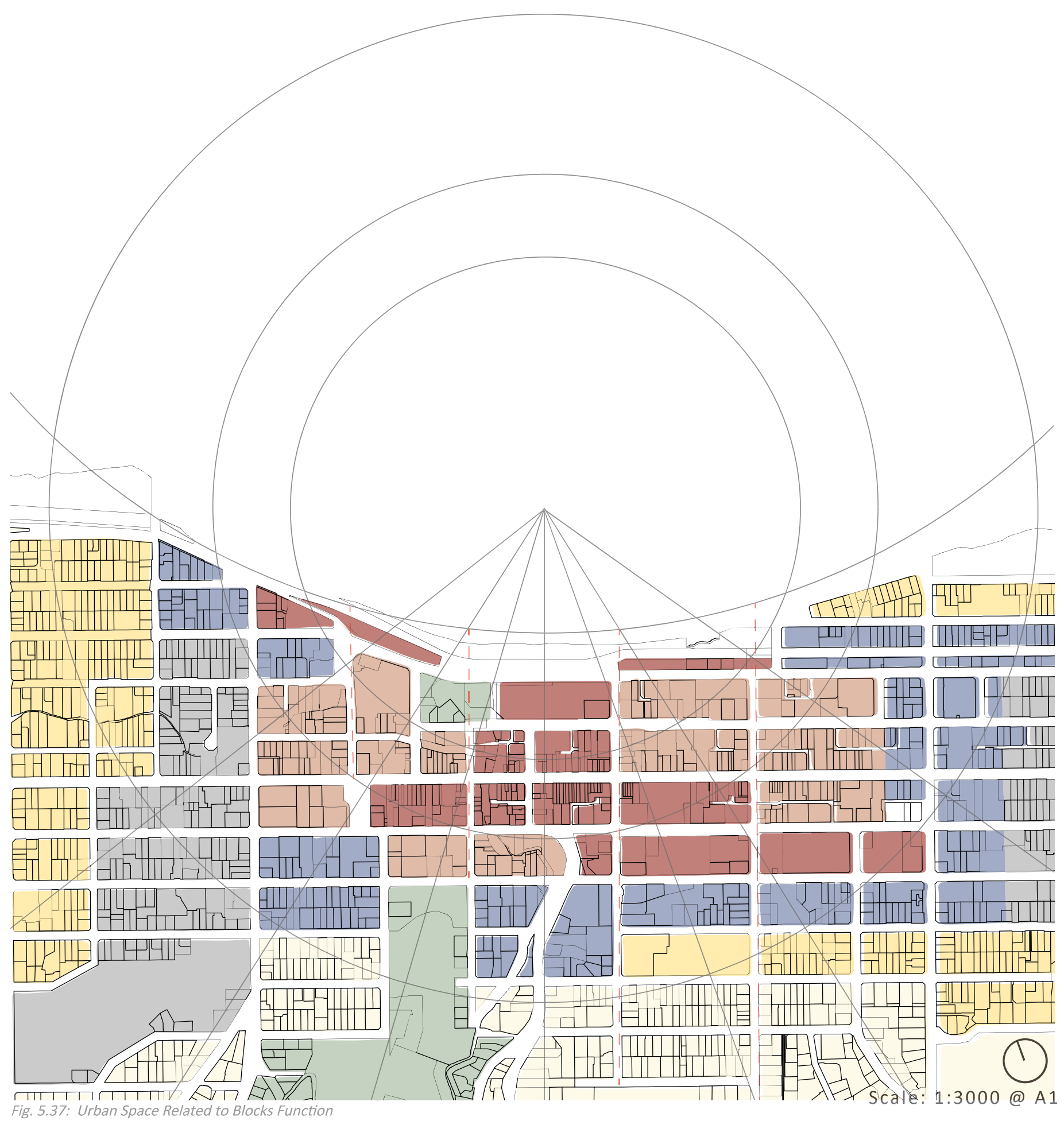



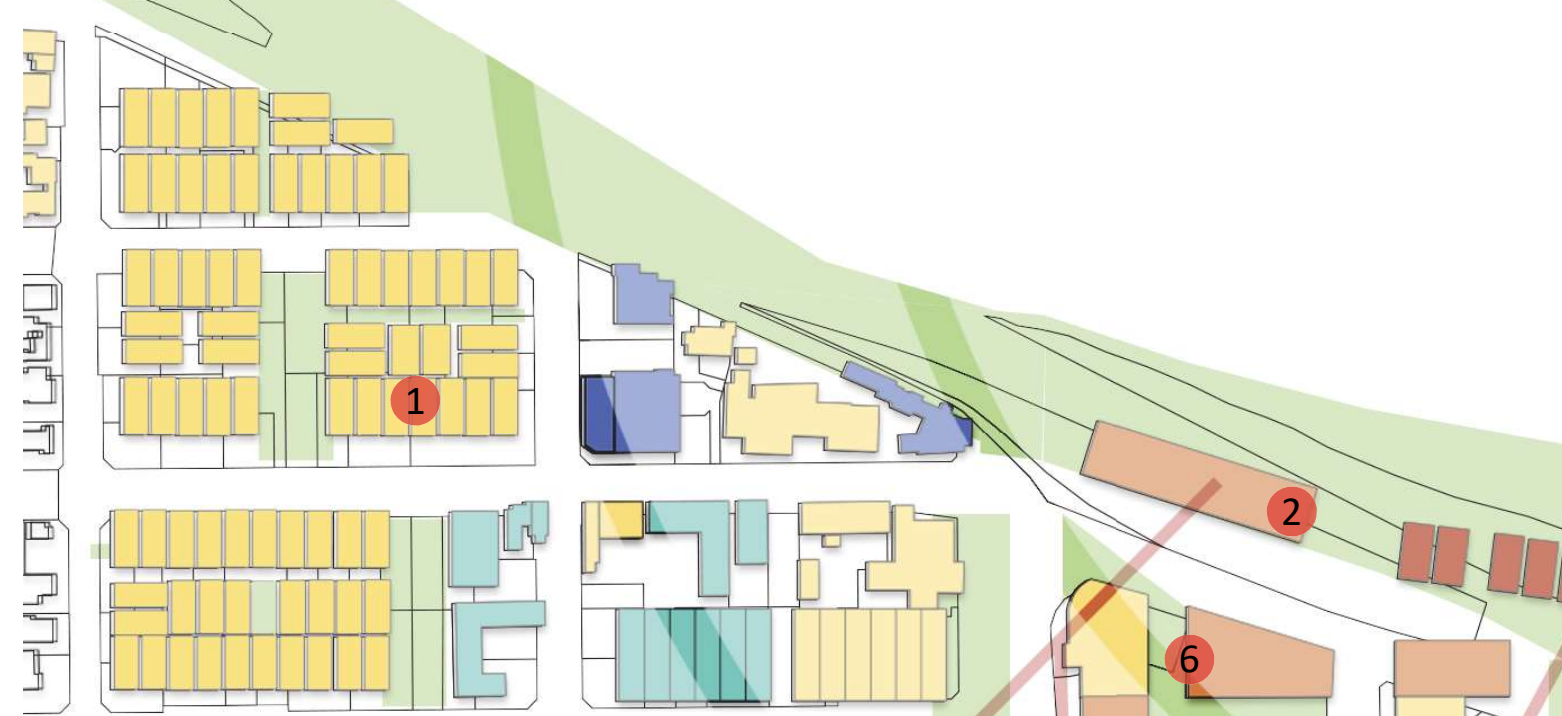

$\Rightarrow$ gitgare
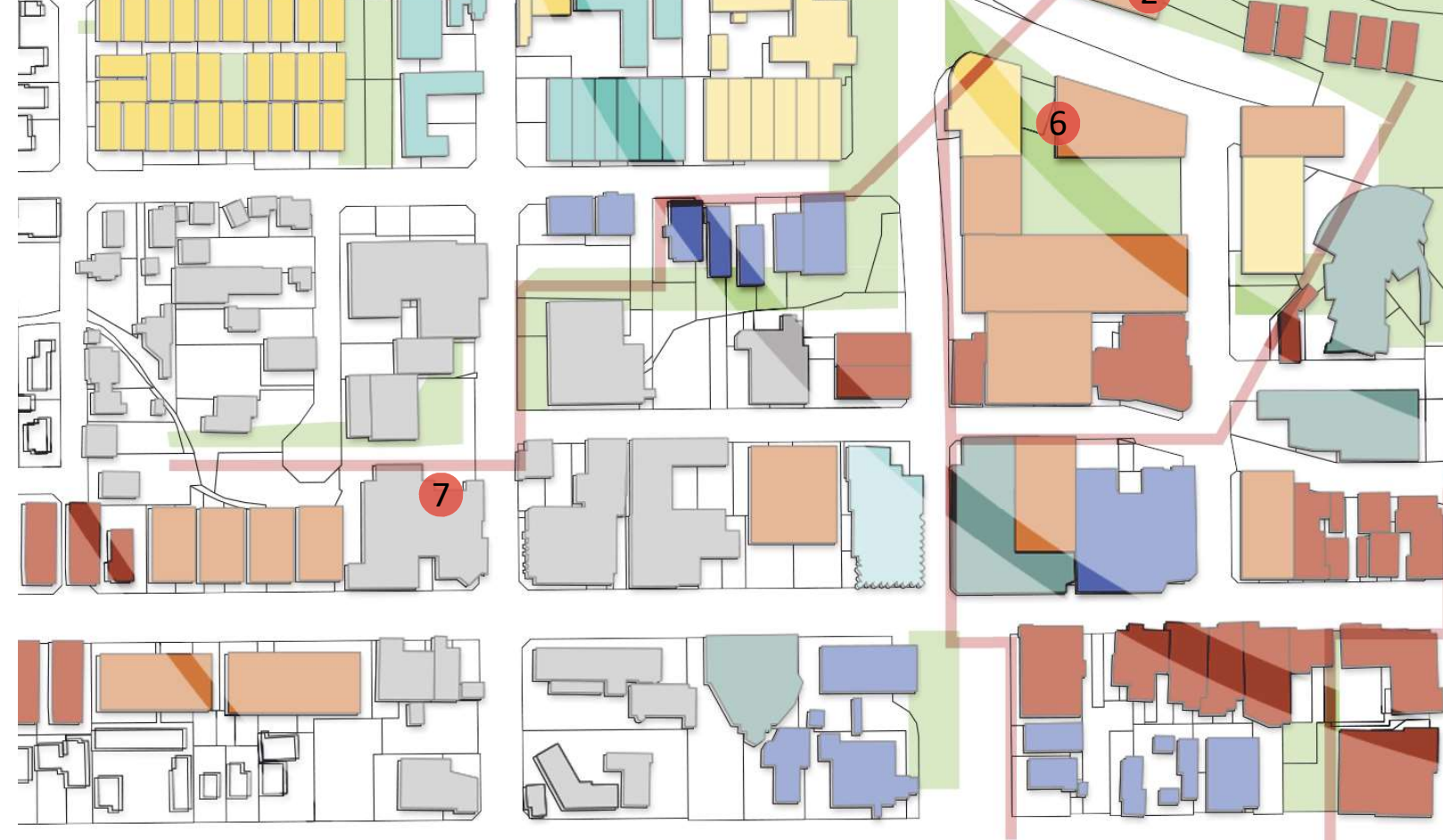
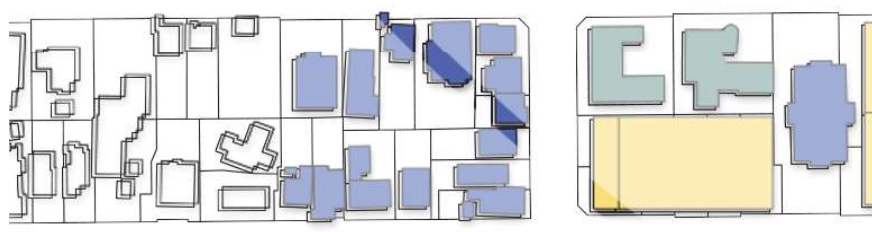

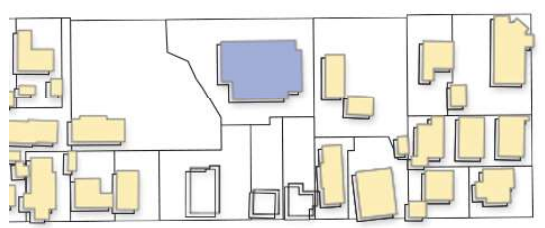

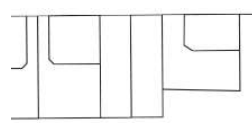

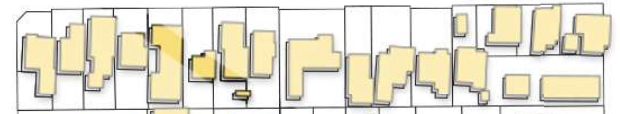

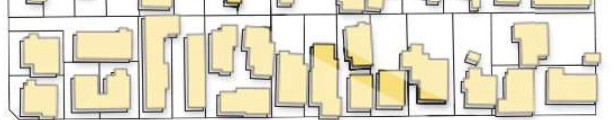
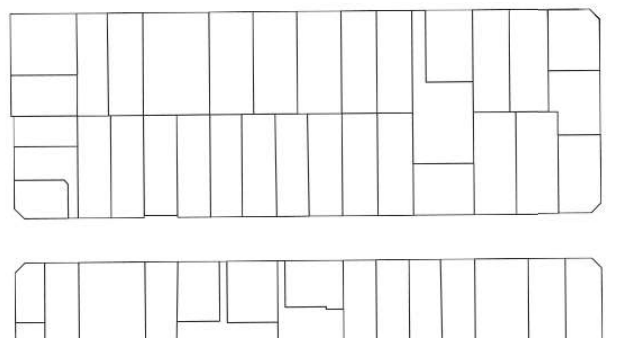
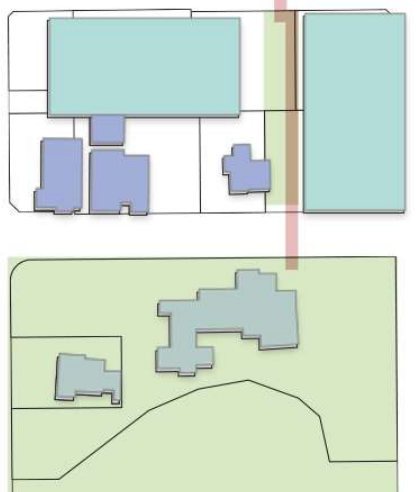

15
3
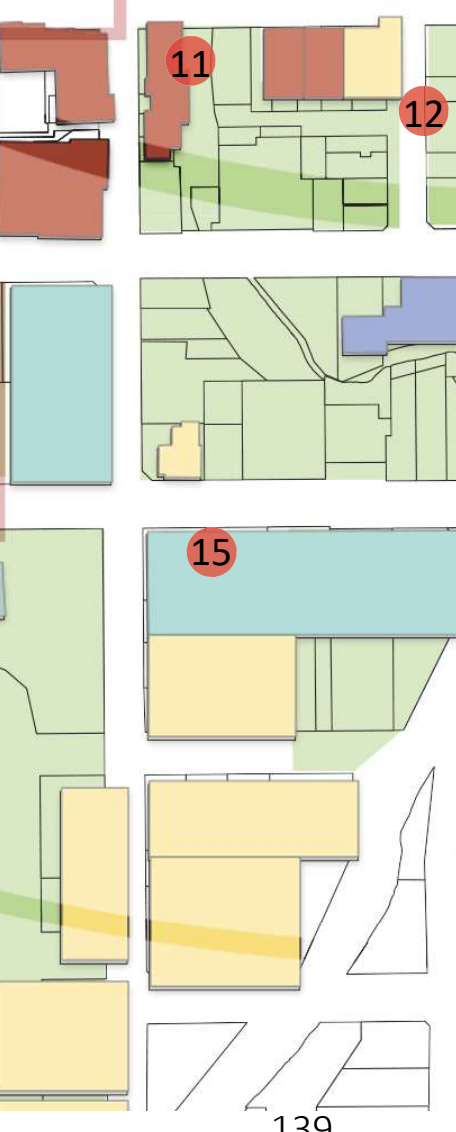


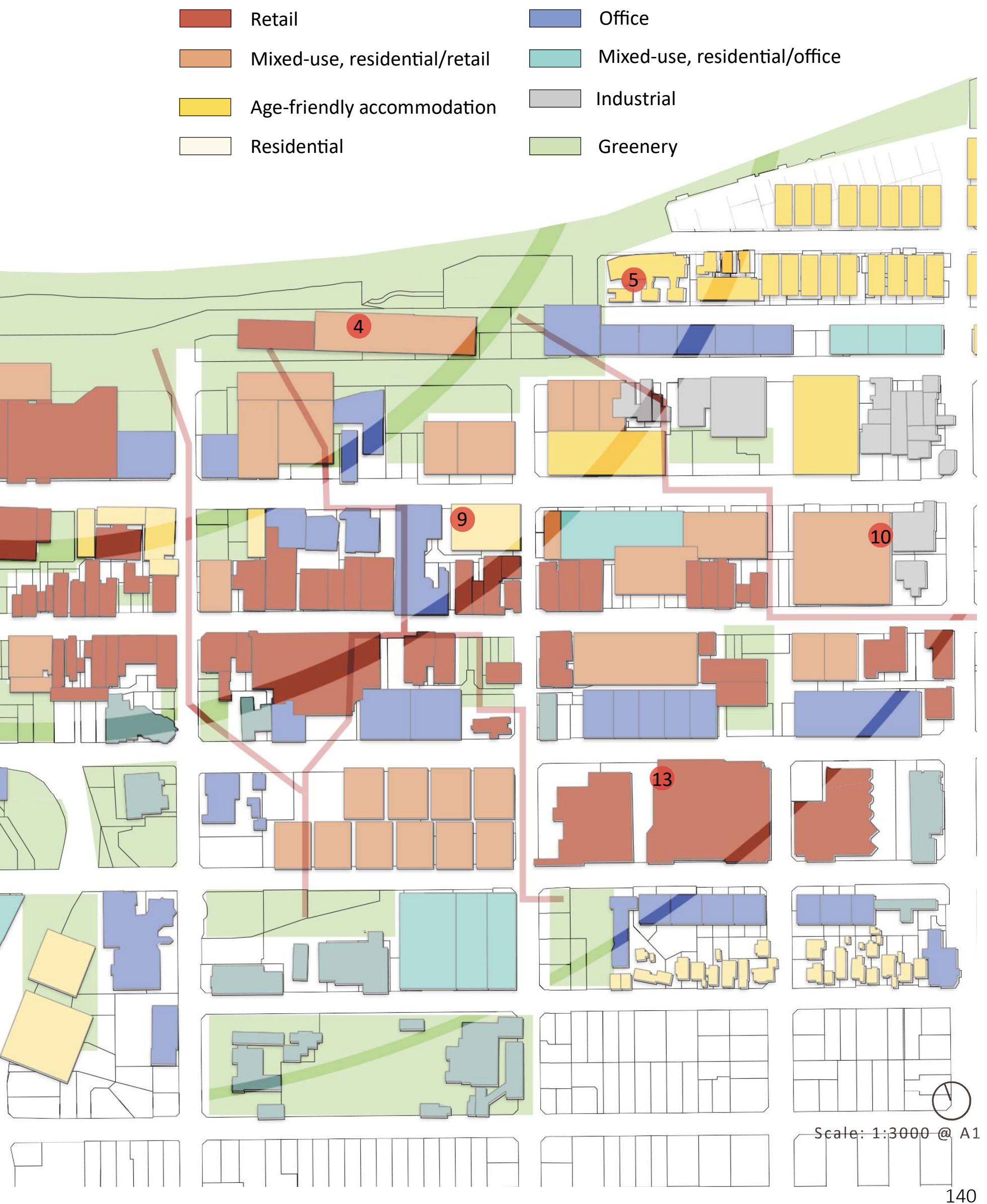




\section{Retail}

Mix-used, residential/retail

Age-friendly accommodation

Residential
Office

Mix-used, residential/office

Industrial

Greenery

An age-friendly housing development will offer accommodation for New Plymouth's elderly close to the city centre.

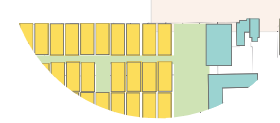

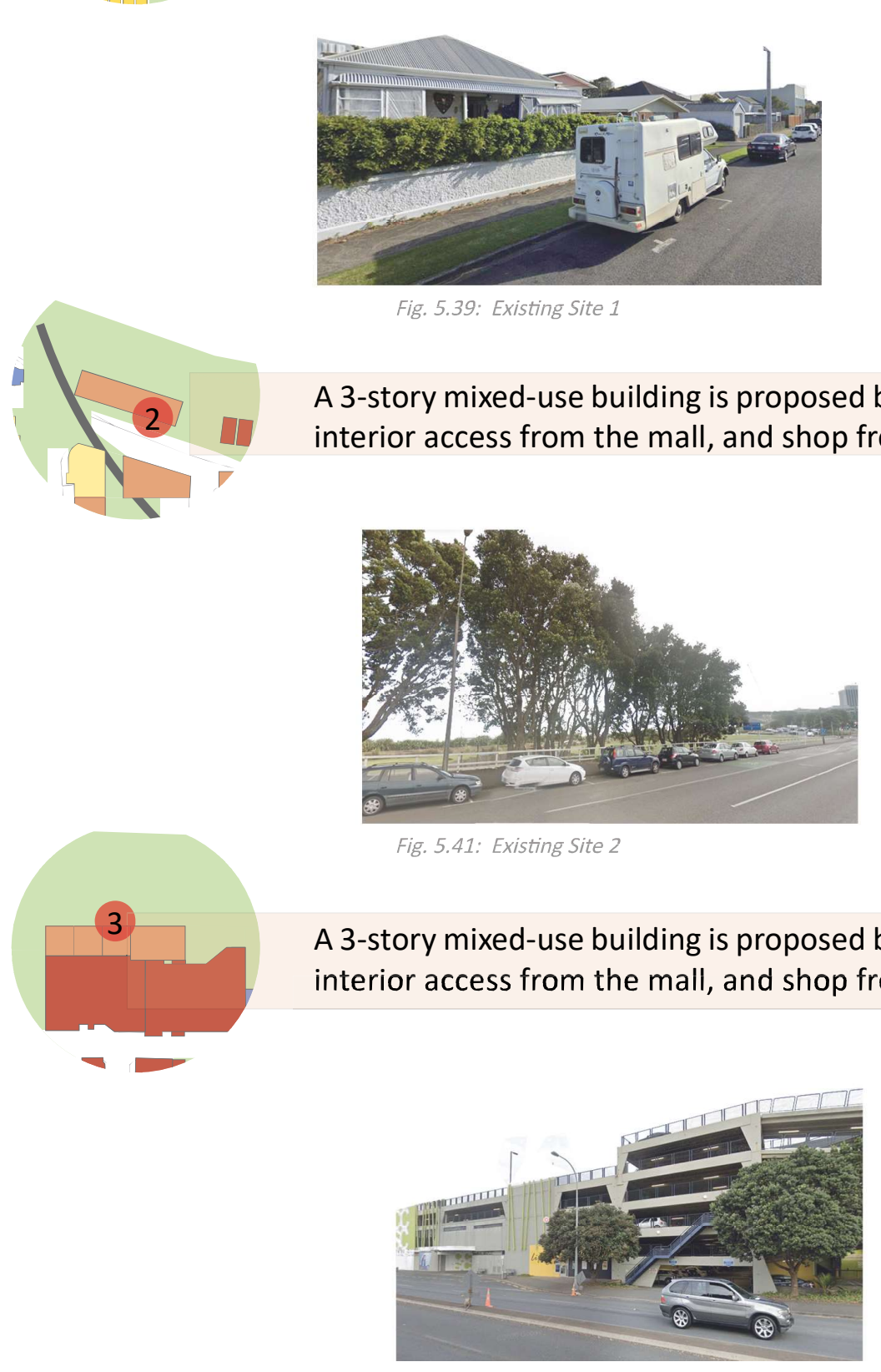

Fig. 5.41: Existing Site 2
Fig. 5.43: Existing Site 3

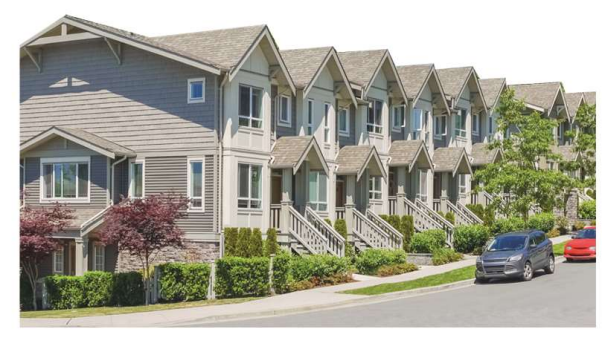

Fig. 5.40: Designed Site 1

A 3-story mixed-use building is proposed behind the central shopping mall, with interior access from the mall, and shop frontage facing the waterfront.

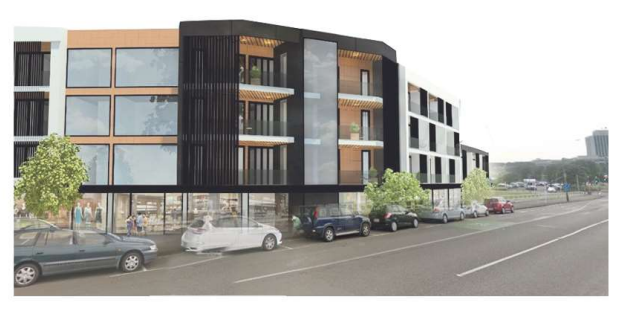

Fig. 5.42: Designed Site 2

A 3-story mixed-use building is proposed behind the central shopping mall, with interior access from the mall, and shop frontage facing the waterfront.

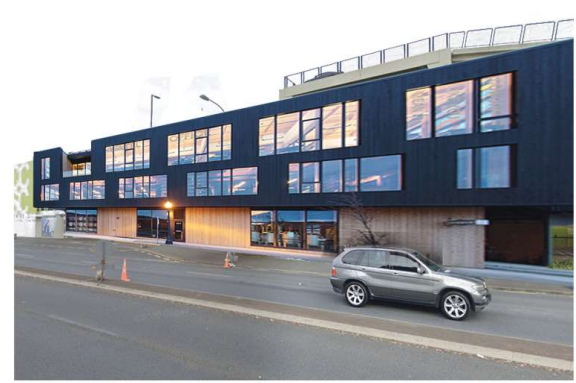

Fig. 5.44: Designed Site 3 


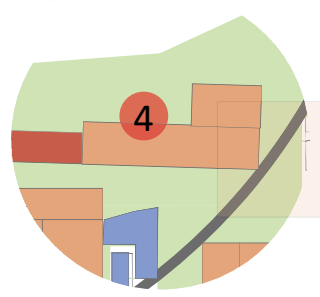

A 3-story mixed-use building is proposed along the coastal road, symmetrically oppose site 2 .

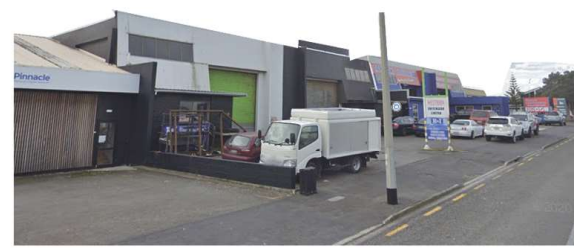

Fig. 5.45: Existing Site 4

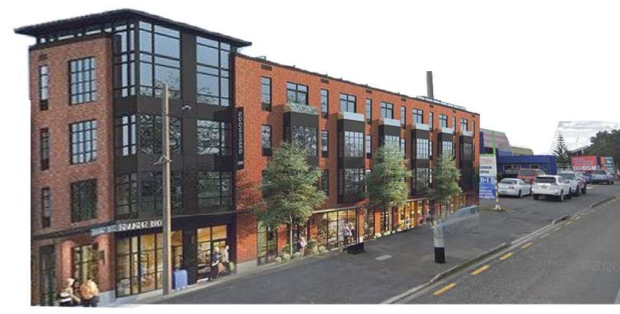

Fig. 5.46: Designed Site 4

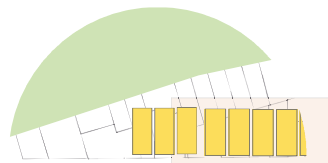

$7 \square[5$
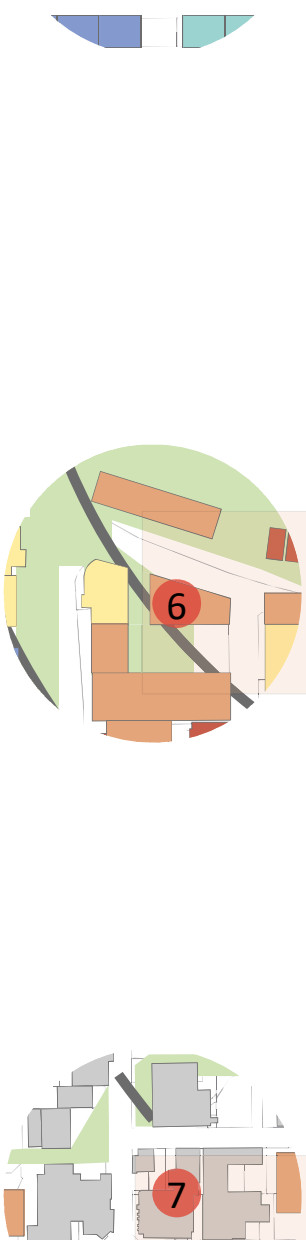

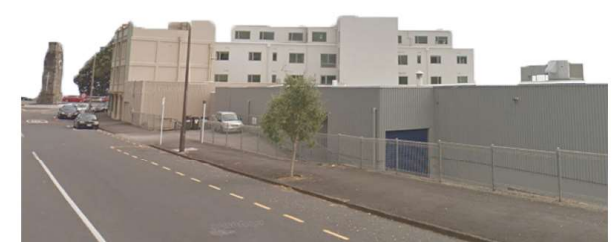

Fig. 5.49: Existing Site 6

An age friendly housing development will offer accommodation for New Plymouth's elderly close to the city centre, symmetrically opposite site 1.

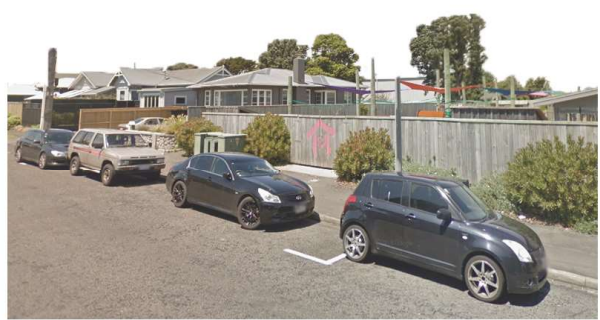

Fig. 5.47: Existing Site 5

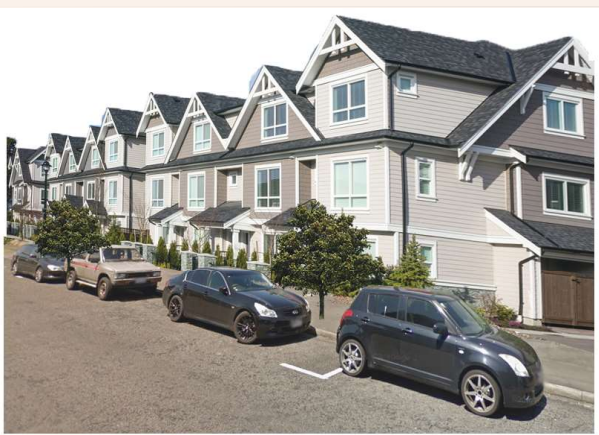

Fig. 5.48: Designed Site 5

A mixed-use building development is proposed, re-purposing the site by demolishing the existing shopping blocks, and re-installing them below residential apartments.

The industrial area is extended, to follow the new traffic-intensive road.

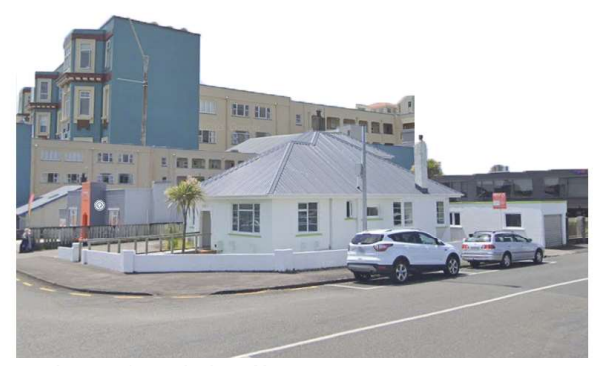

Fig. 5.51: Existing Site 7

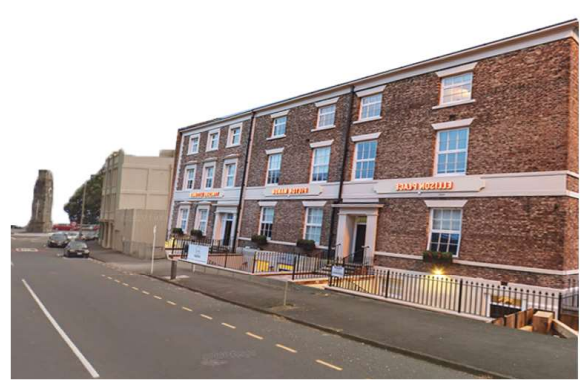

Fig. 5.50: Designed Site 6

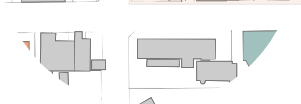




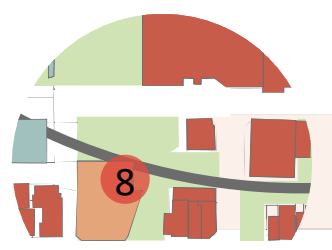

The design proposes activate frontage buildings to co-ordinate with the new Huatoki Plaza, achieving a new living centre of New Plymouth.

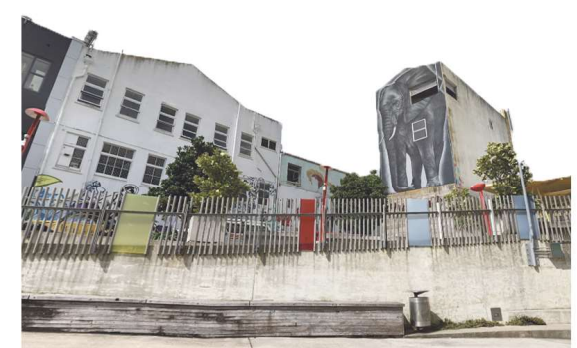

Fig. 5.53: Existing Site 8

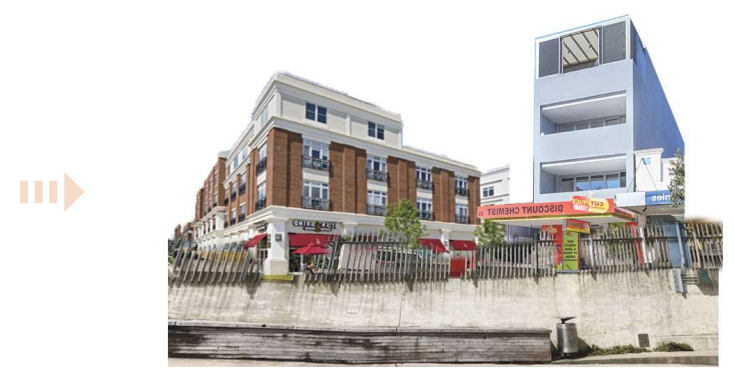

Fig. 5.54: Designed Site 8

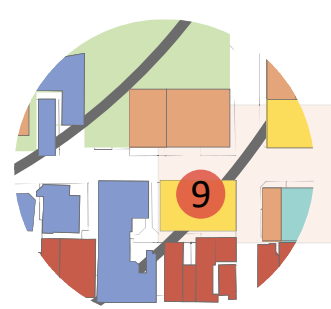

The design proposes a residential building around this area, by removing the industrial building. Since the highway is shifted, there's no benefit for an industrial building here.

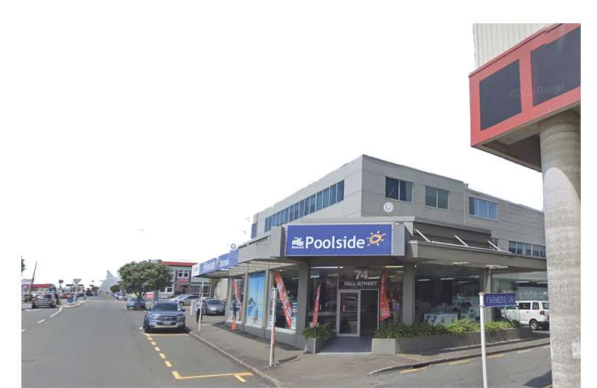

Fig. 5.55: Existing Site 9

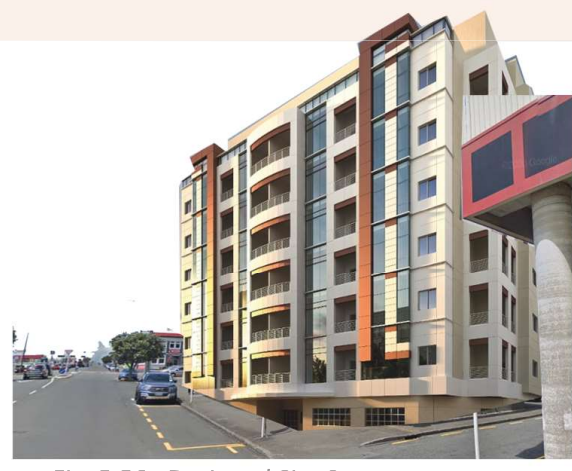

Fig. 5.56: Designed Site 9

The design relocated industrial garage building along the traffic intended roads, shifts the existing office building to southern central area.

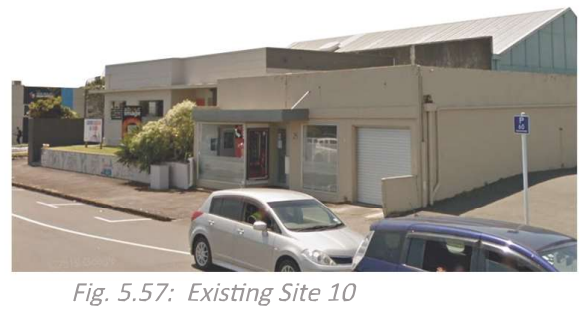

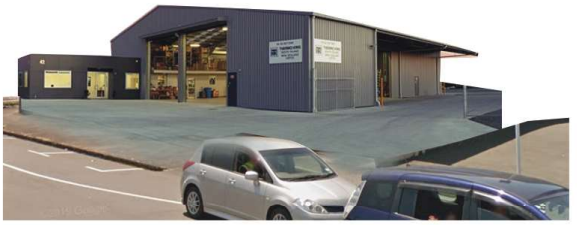

Fig. 5.58: Designed Site 10

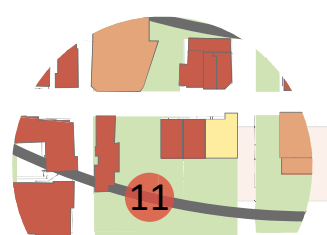

Non-heritage buildings are removed to daylight Huatoki stream.

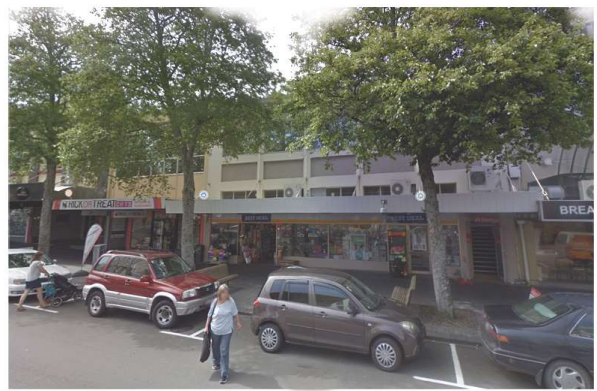

Fig. 5.59: Existing Site 11

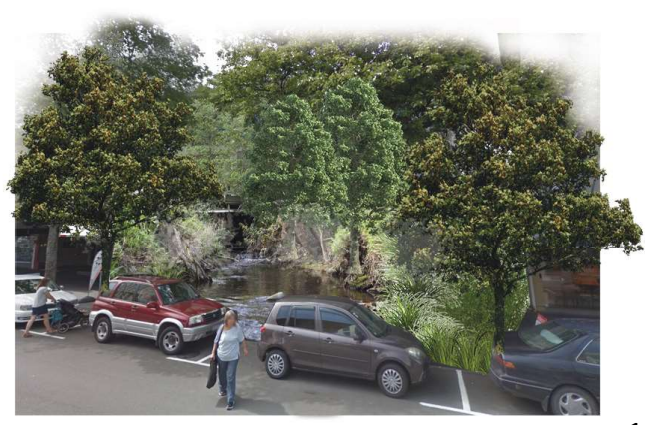

Fig. 5.60: Designed Site 11 
$-$
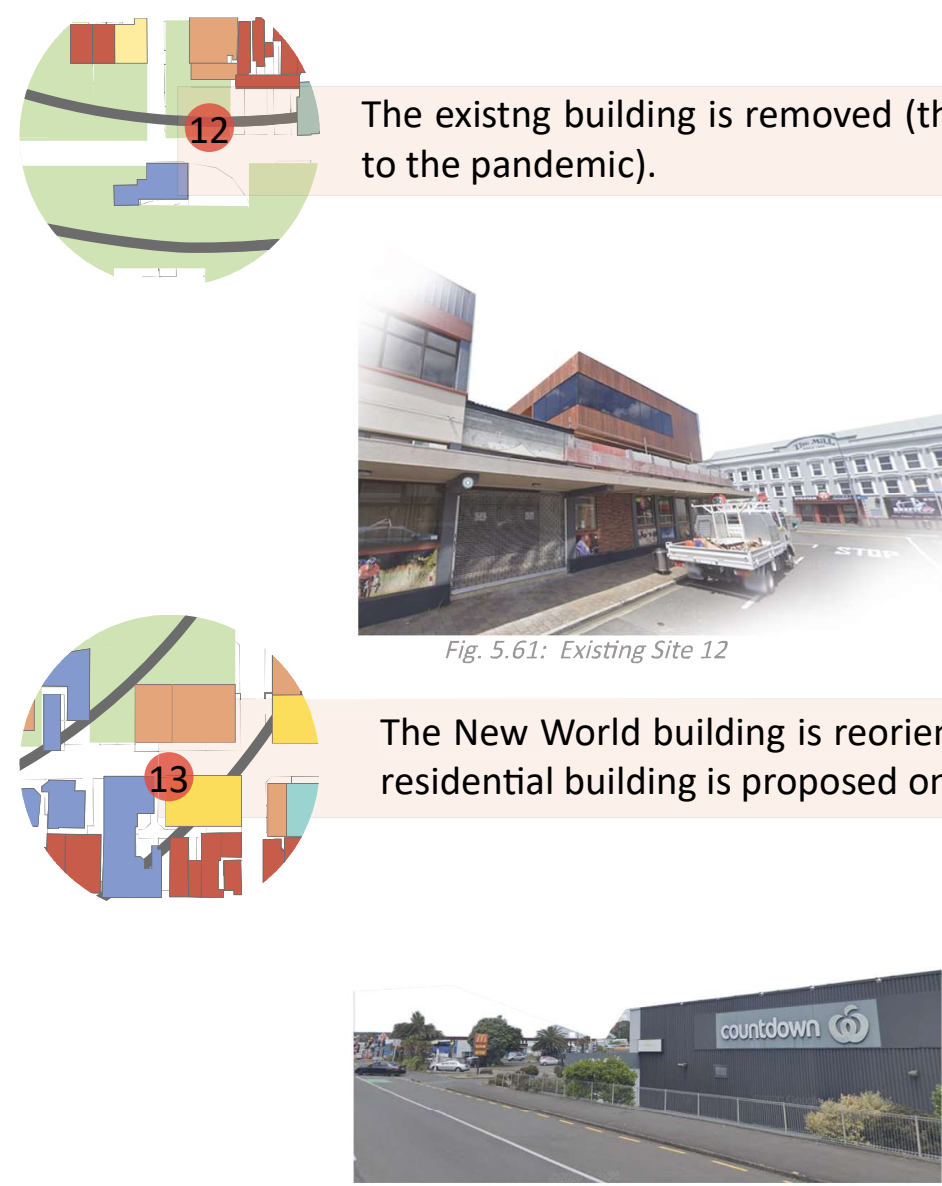

Fig. 5.63: Existing Site 13 to the pandemic).
The existng building is removed (the business in his building is closing down due
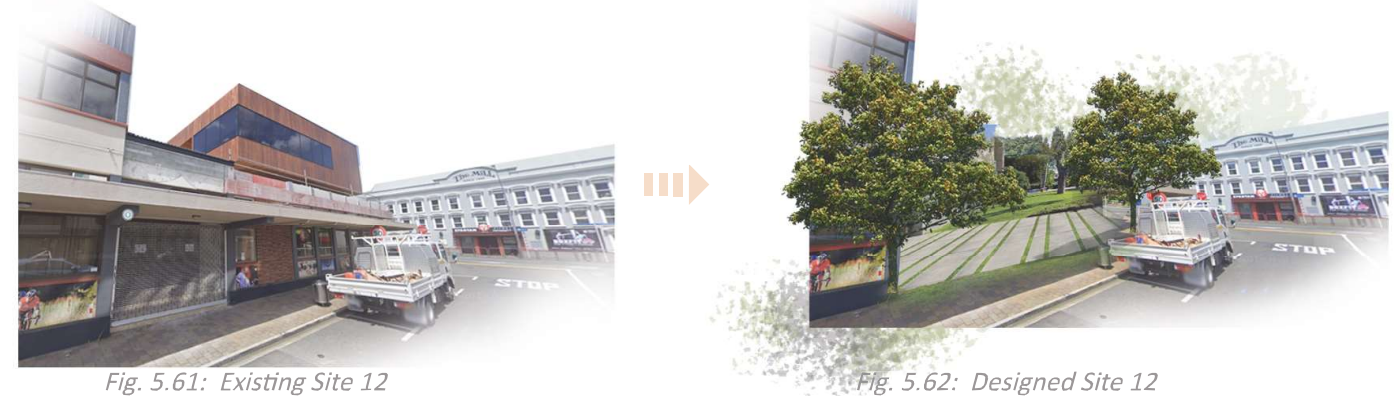

The New World building is reoriented, to join the block with Coundown. A residential building is proposed on the existing New World space.

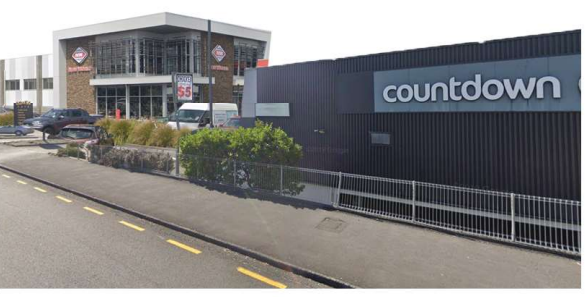

Fig. 5.64: Designed Site 13

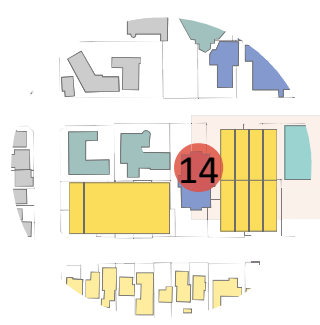

A multi-floor office building is proposed, to accommodate more businesses at the southern Central Area.
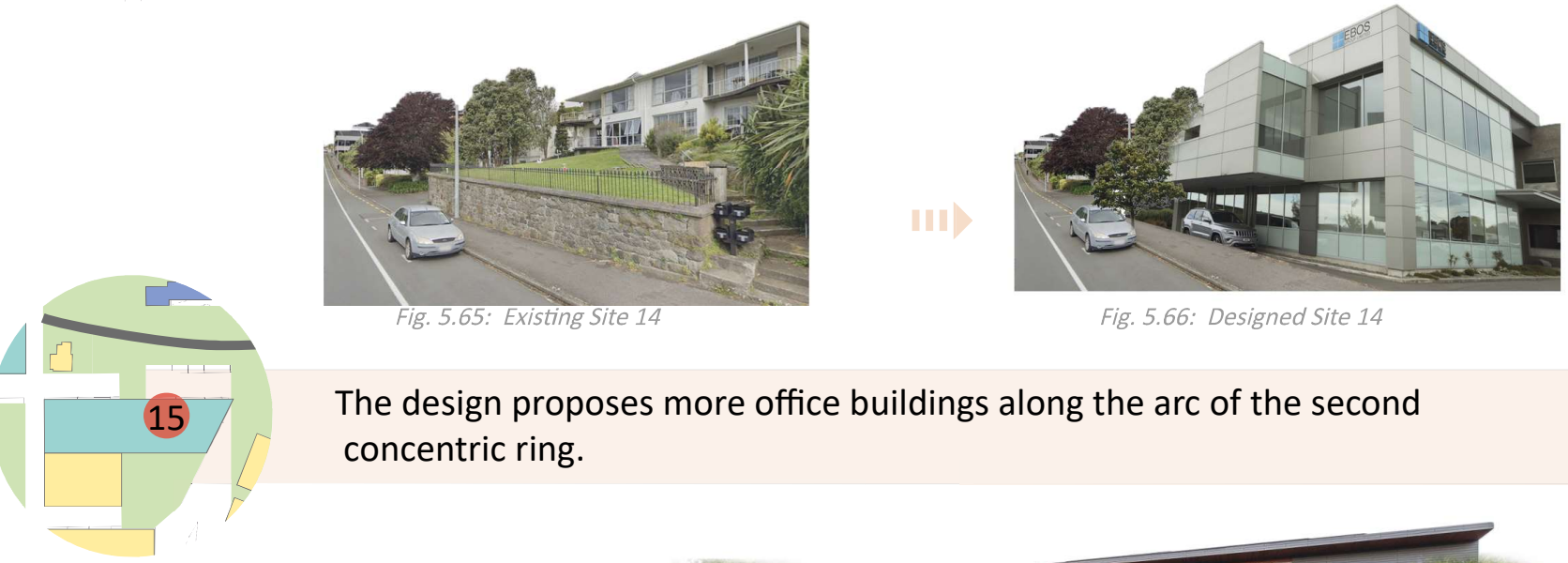

Fig. 5.66: Designed Site 14

The design proposes more office buildings along the arc of the second concentric ring.

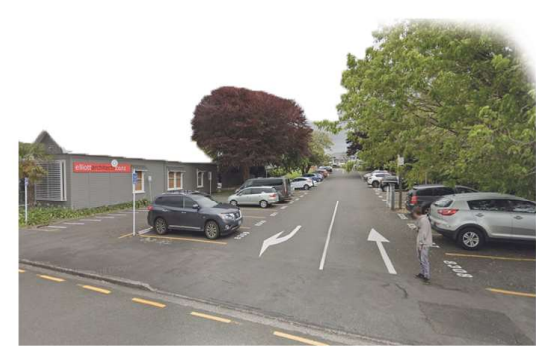

Fig. 5.67: Existing Site 15

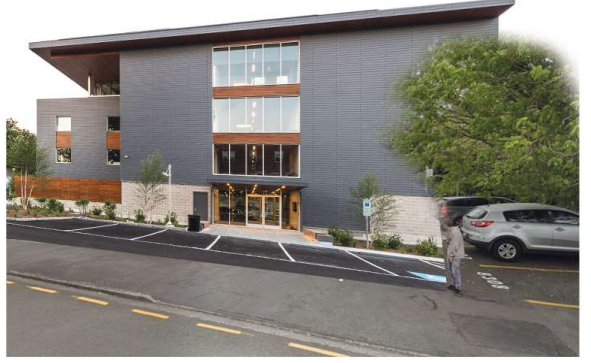

Fig. 5.68: Designed Site 15 


\section{SECONDARY PATTERN}

To recognize the planning logic behind the primary concentriccircular pattern requires of the user a recognition, and slowly growing understanding, of large-scale context. In contrast, the secondary pattern is much more obvious and conventional to the urban grid. New Plymouth's grid is deep in its history and is embedded in the memory of every citizen. By strengthening and emphasis the legibility of 4 selected north-south avenues, the secondary pattern aims to de-emphasize the east-west directionality which currently prevails, and direct people towards the primary concentric-circular pattern; triggering the user's mental and visual recognition of both secondary and primary systems while they are walking along these streets.

The following studies examine the masterplan's realization on these four streets. Their function and form are adjusted to accommodate the re-designated traffic flow and pedestrian movement. CNC printed foam models are testing the design outcome. 


\subsection{Master-plan Finalization}

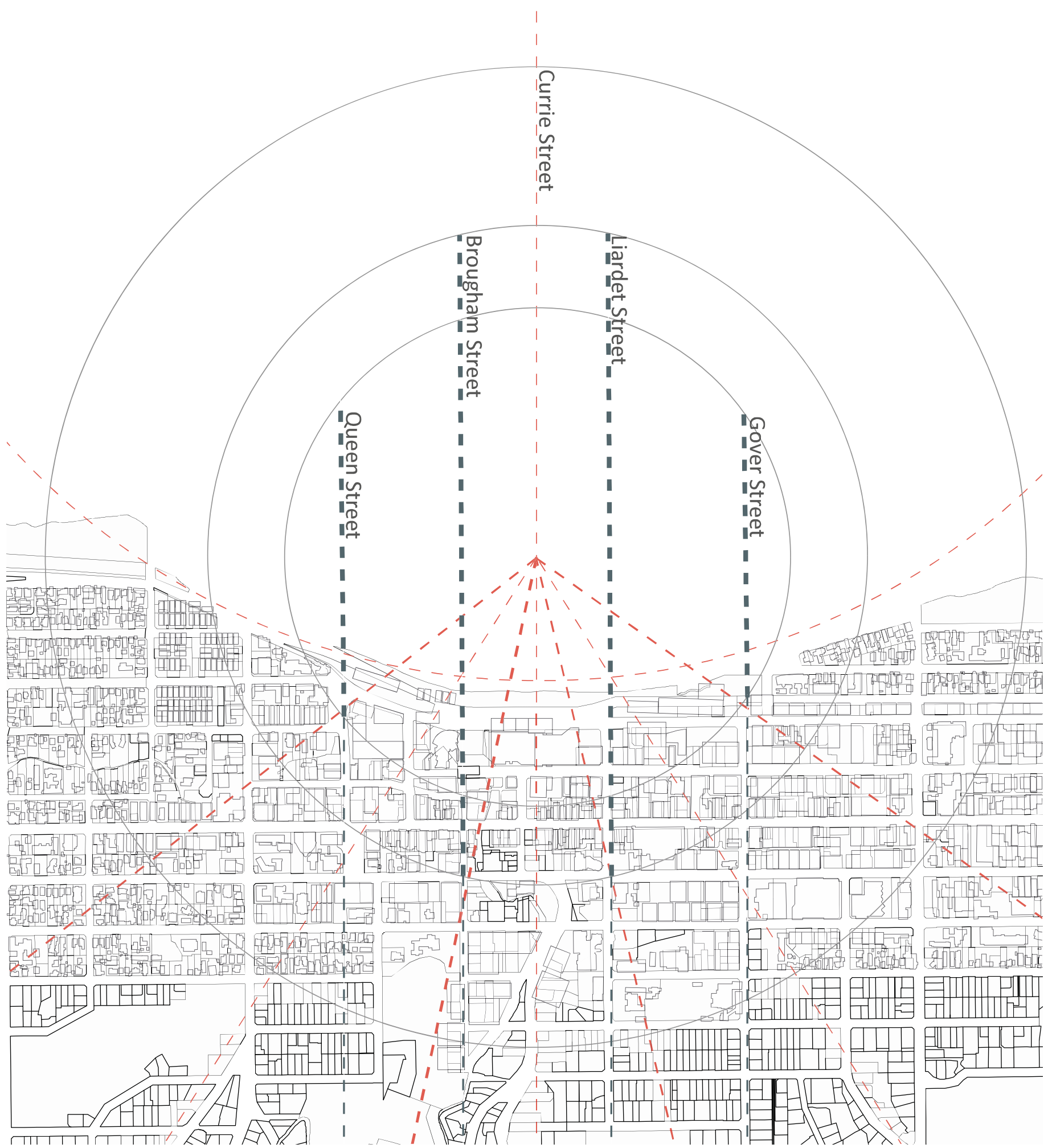


Pedestrian and traffic systems are defined by the primary pattern, building function-change, and increasing open space. More Intense pedestrian movement is expected within the inner cicle; therefore, the traffic flow is minimized in this area by changing double-lane driveways to single-lane. This will ensure pedestrian-friendly activity is supported in the centre close to the coastline.

\section{Designated pedestrian movement-intensity}

\section{Pedestrian density}

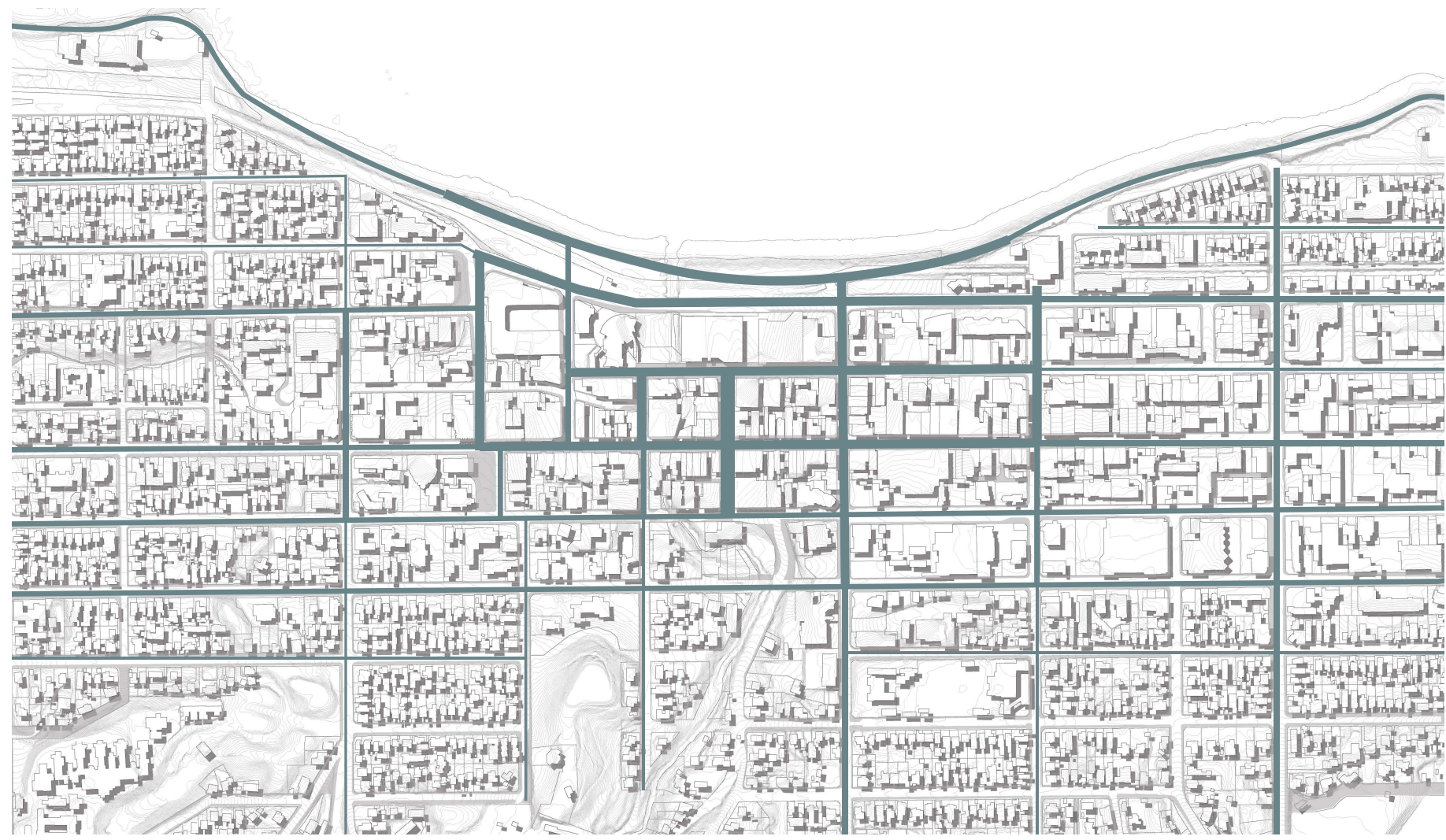

Fig. 5.70: Proposed Pedestrian Arrangement 
Traffic will be reduced on State Highway 44, the coastal driveway; turning it into a pedestrian-friendly slow-speed street. Traffic entering the coastal driveway will be controlled by changing the neighbouring street to a single-lane driveway. State Highway 44 will no longer be the main connection to the port, with Dawson Street now becoming a new fast-speed driveway. Dawson street is spatially symmetrical to State Highway 45 where they travel north-south.

\section{$[=]$ Shared Street}

Traffic density

Traffic direction

\section{$1-1$}

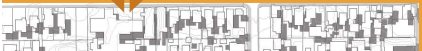

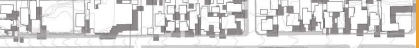

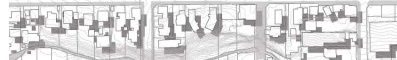

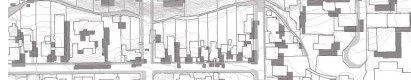

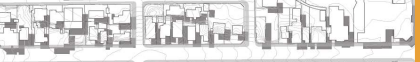

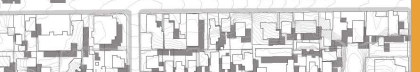

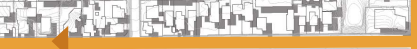

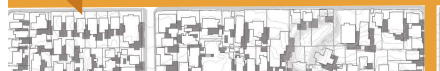

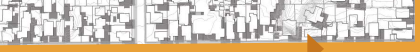

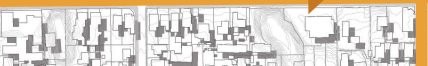

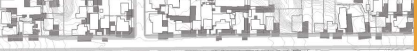

ind wh whind

$\rightarrow \infty$

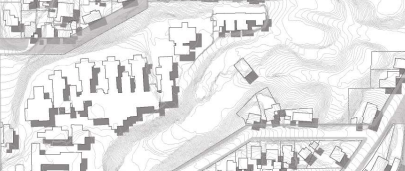

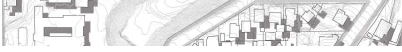

Fig. 5.71: Proposed Traffic Arrangem

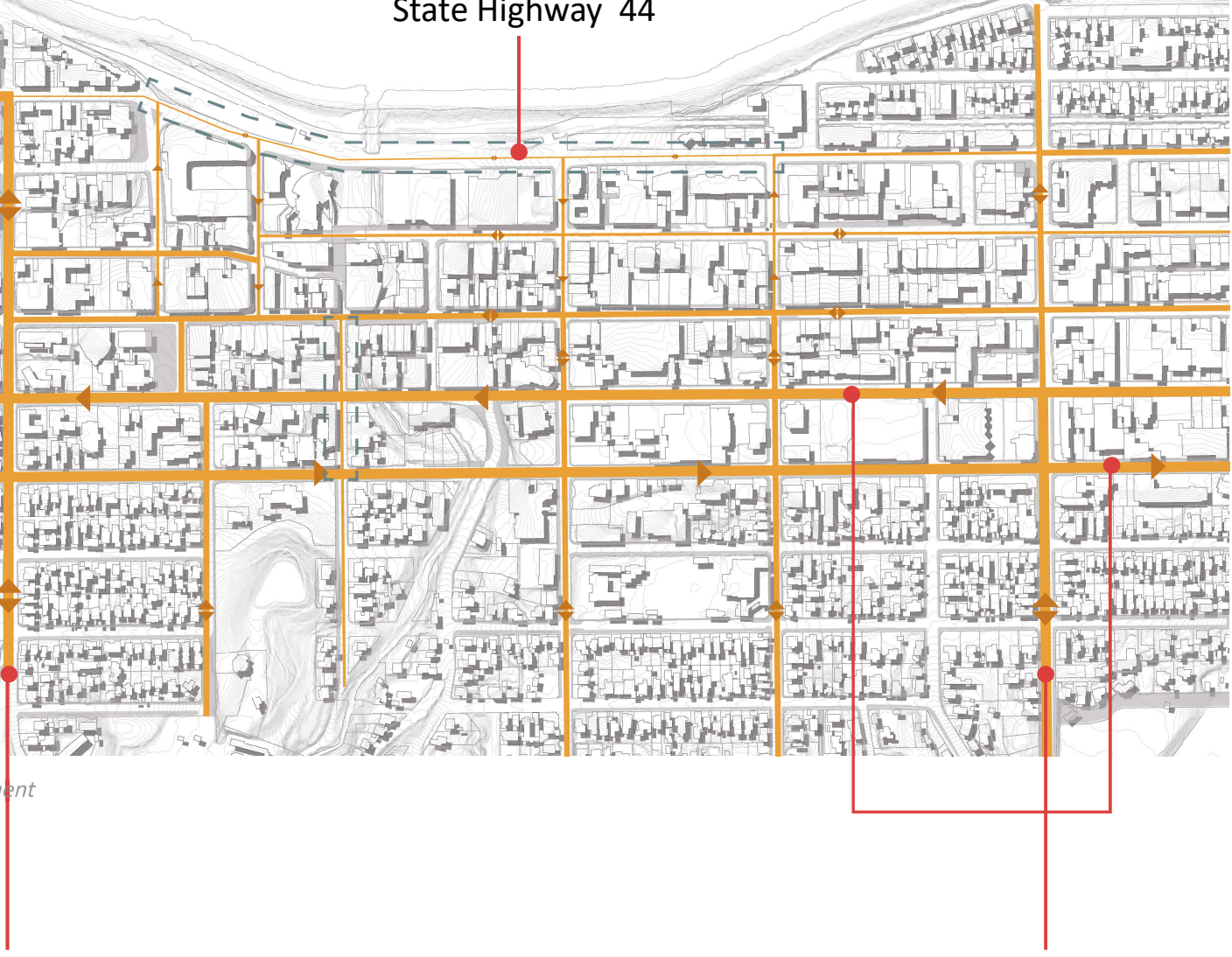

Dawson Street 


\section{Queen Street}

The design proposes Queen Street become a northward-one-way street, with the existing, reoriented, World War One cenotaph at its northern end, and a bell tower at its southern end. The famous Len Lyn Centre is located at the southern end of the street.

\section{Before}
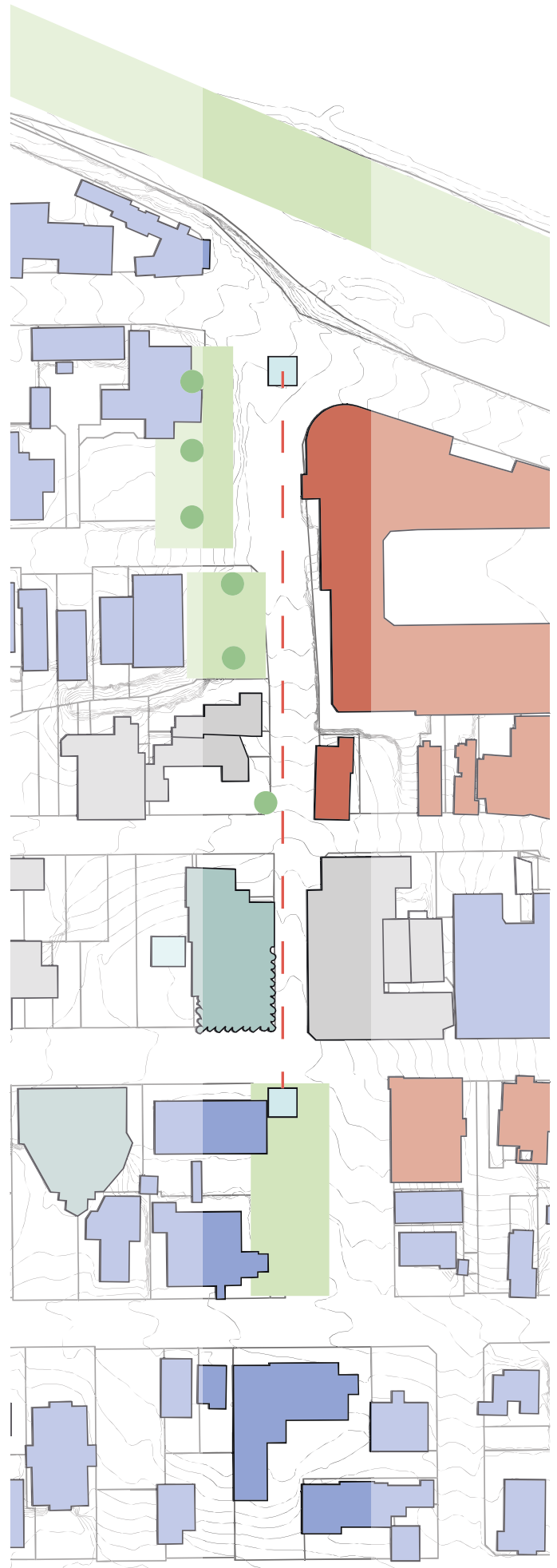

Fig. 5.72: Existing Queen Street Layout
Before

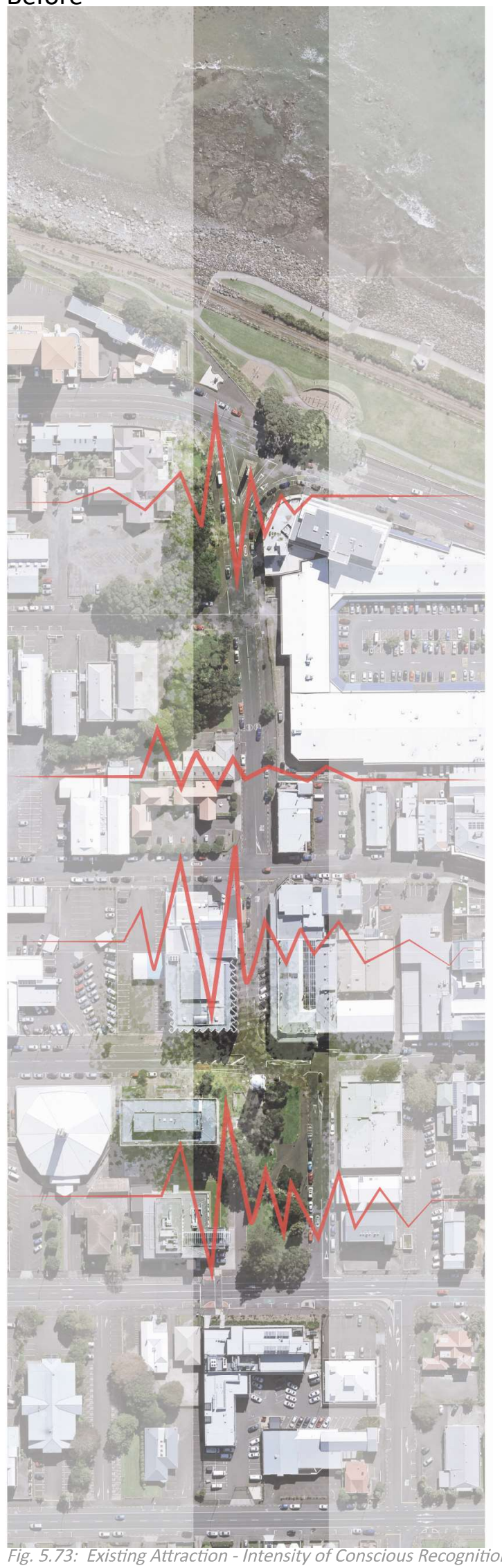


Retail

Mixed-use, residential/retail

Residential
Office

Industrial

Greenery

After

After
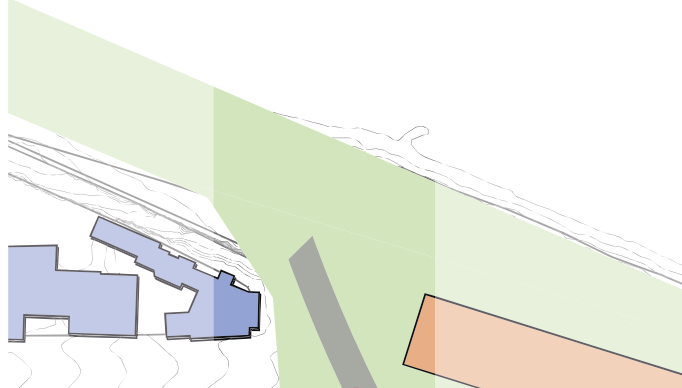

Drive through Plaza,
connecting street and proposed memorial
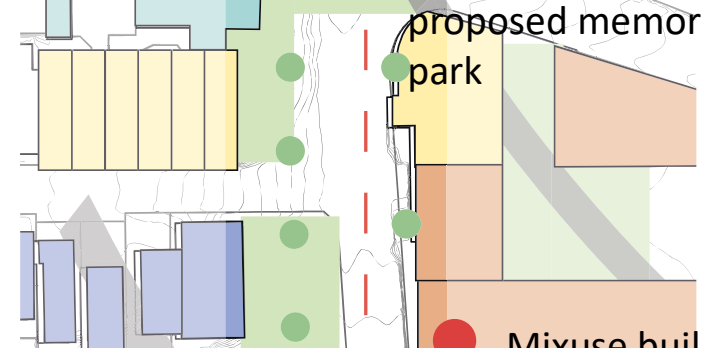

Daylighting stream

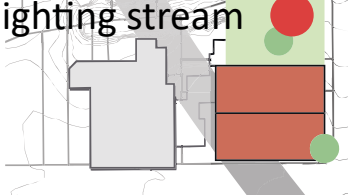

Mixuse building fronta
facing towards street
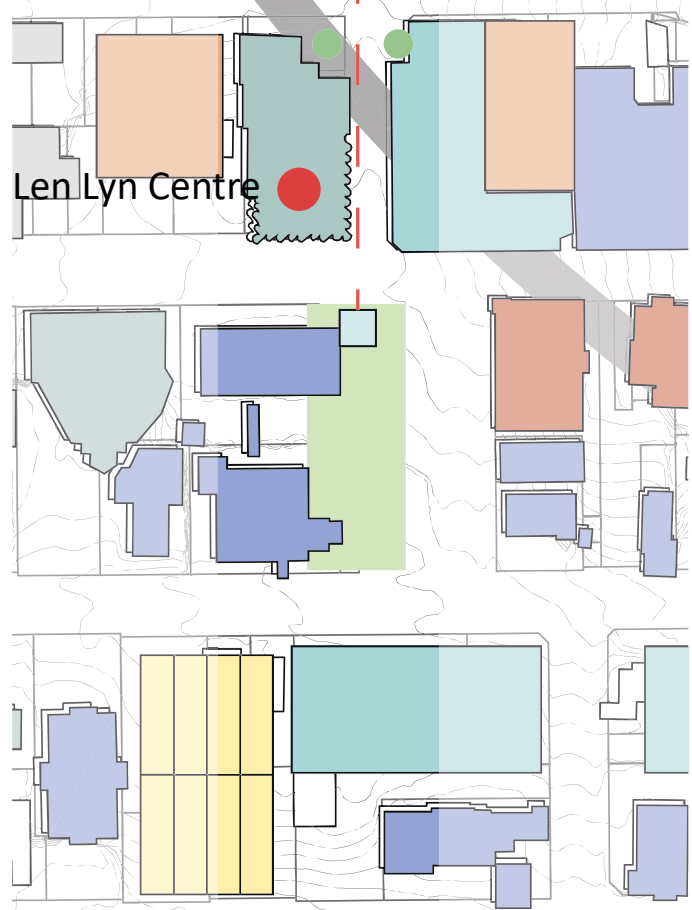

Fig. 5.74: Proposed Queen Street Layout

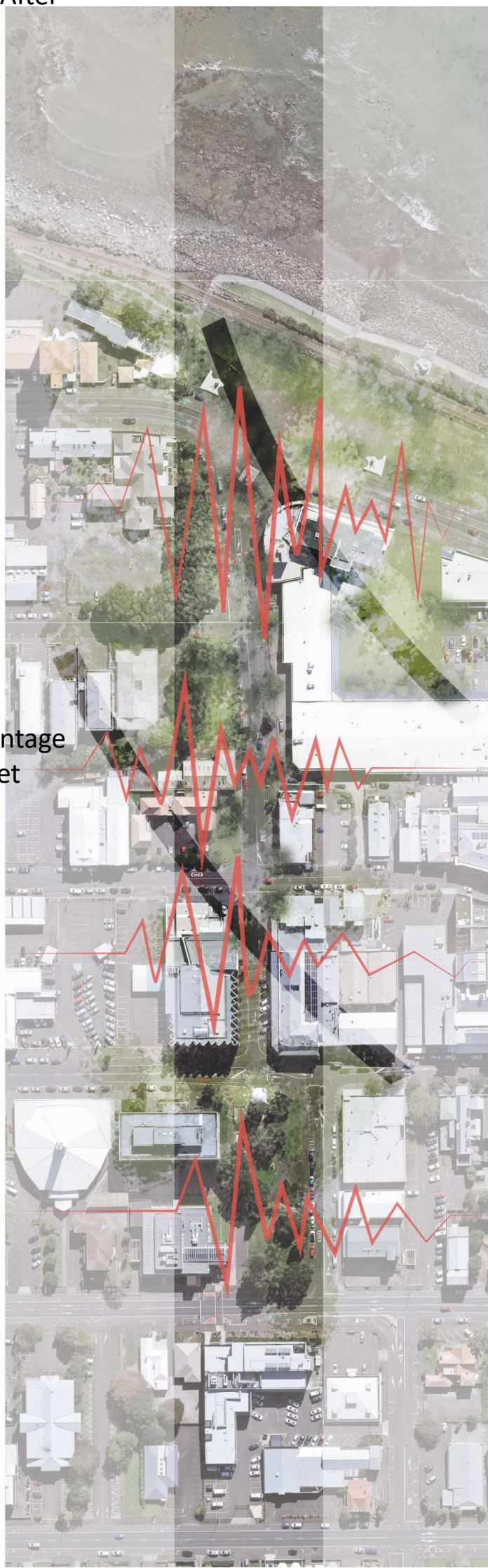




\subsection{Master-plan Finalization}

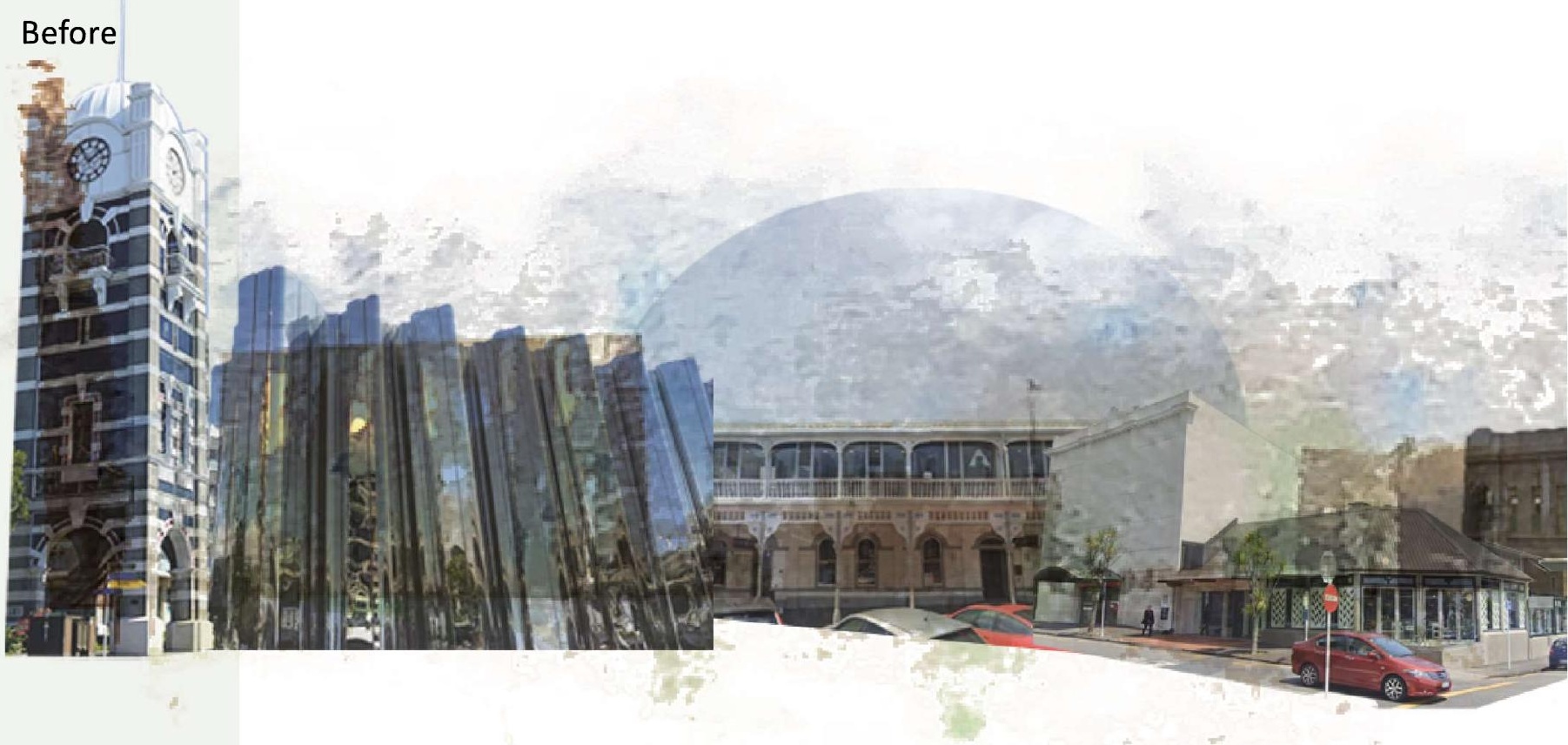

\section{After}
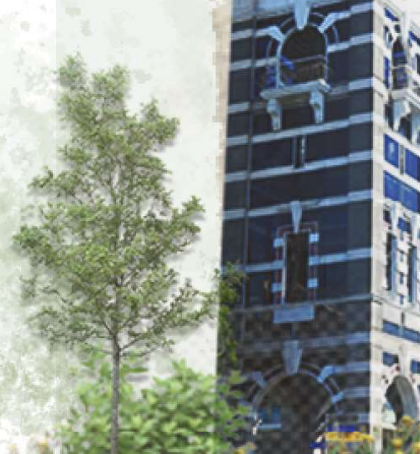


\subsection{Master-plan Finalization}

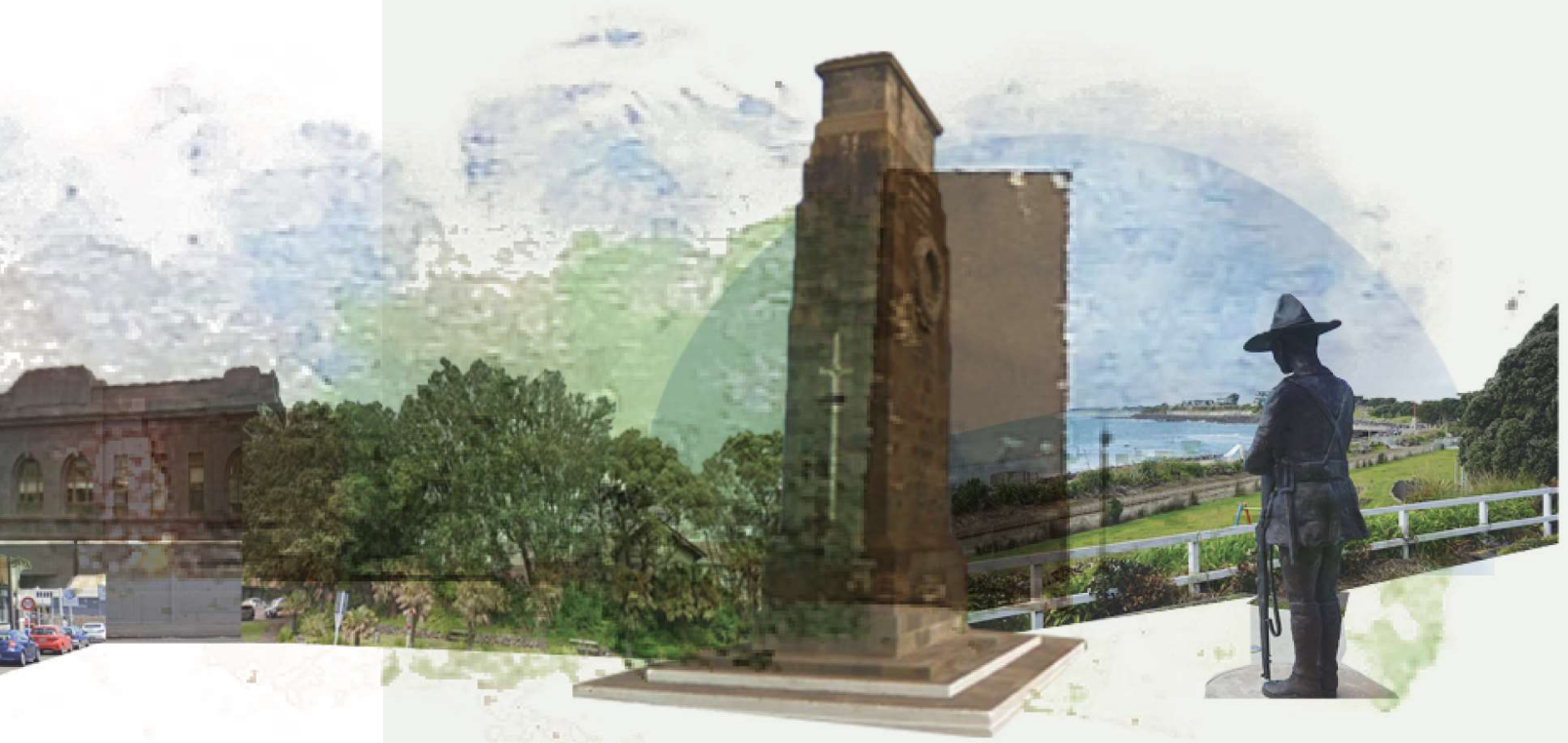

Fig. 5.77: Existing Street Photo Montage

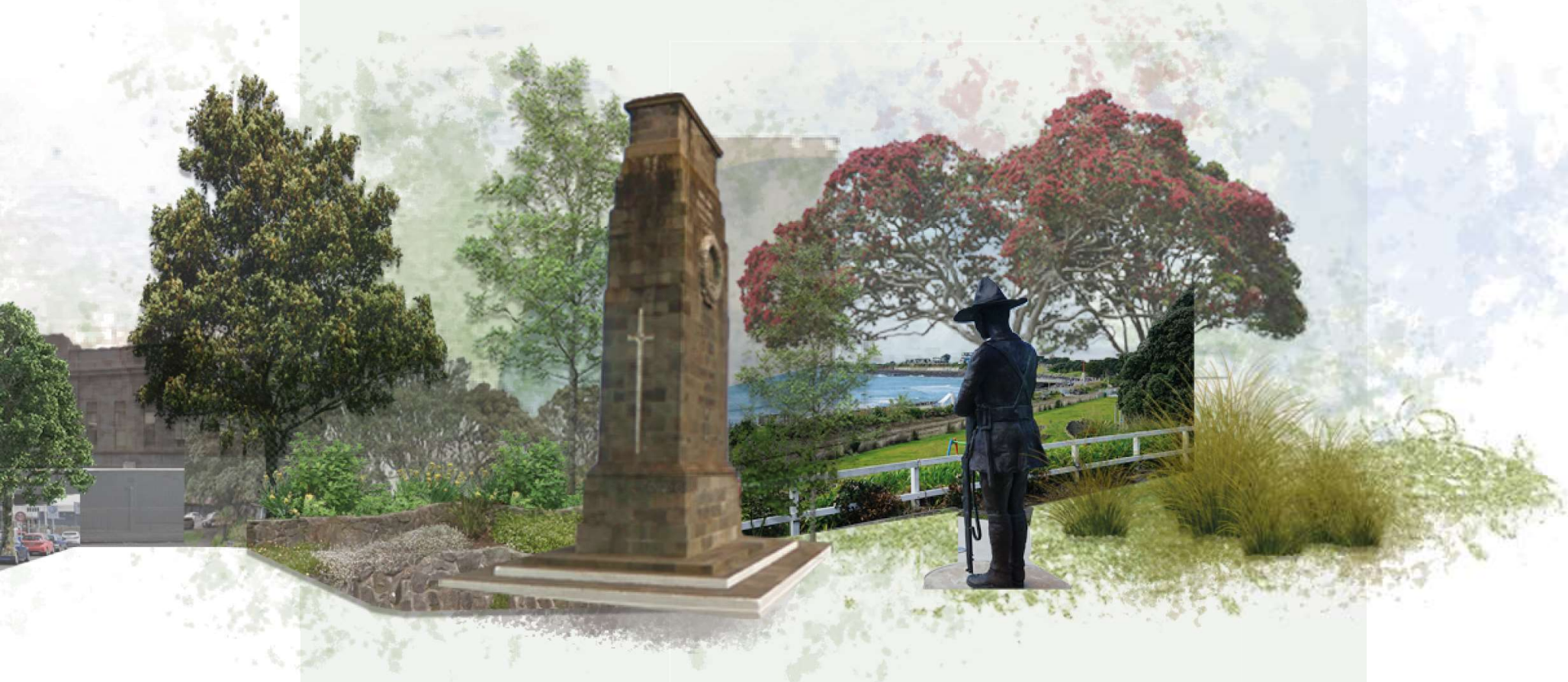

Fig. 5.78: Proposed Street Photo Montage 


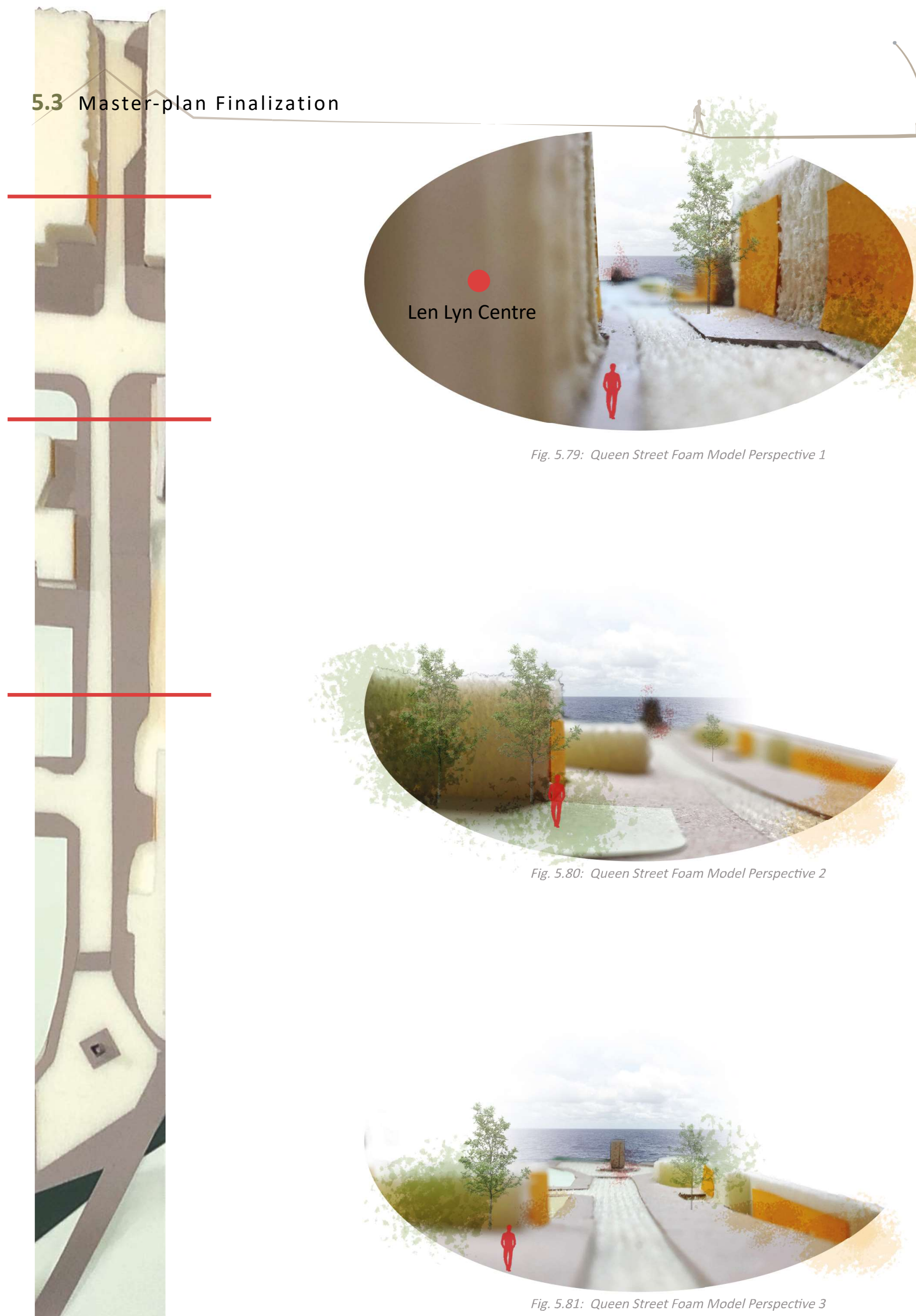




\subsection{Master-plan Finalization}

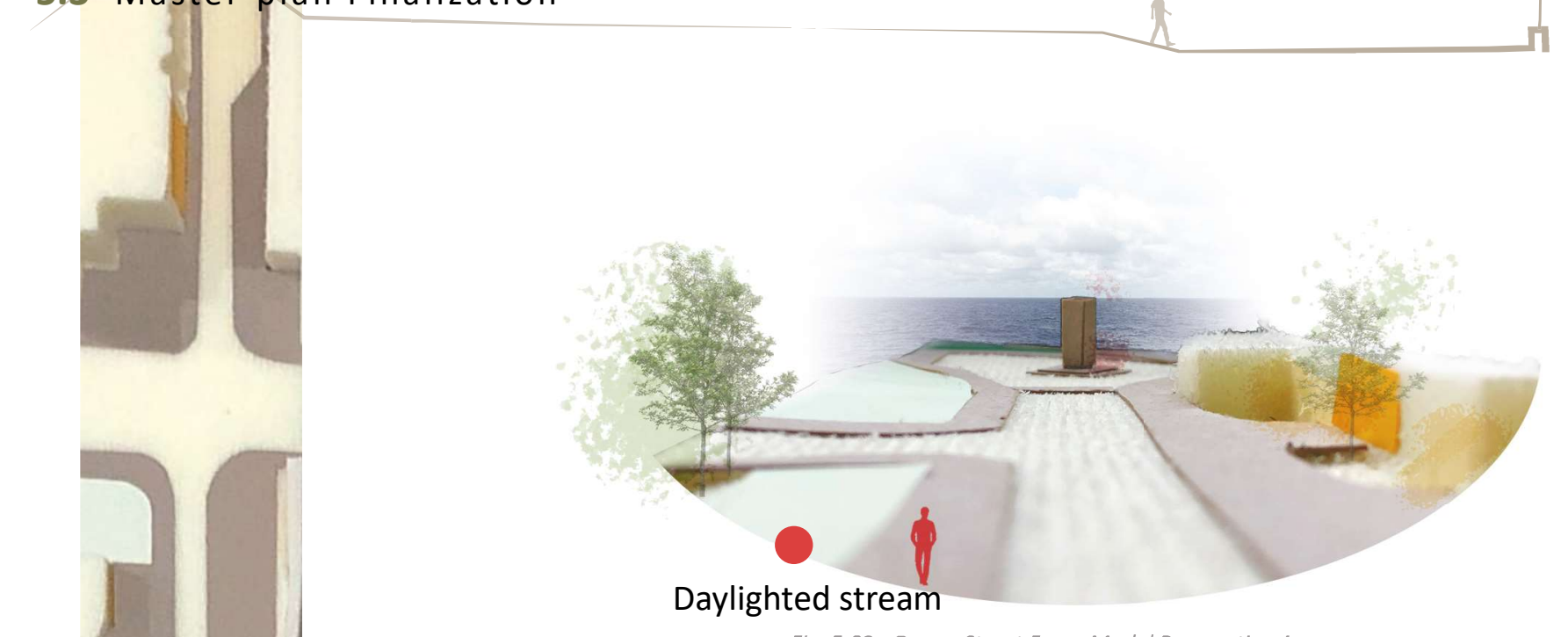

Fig. 5.82: Queen Street Foam Model Perspective 4

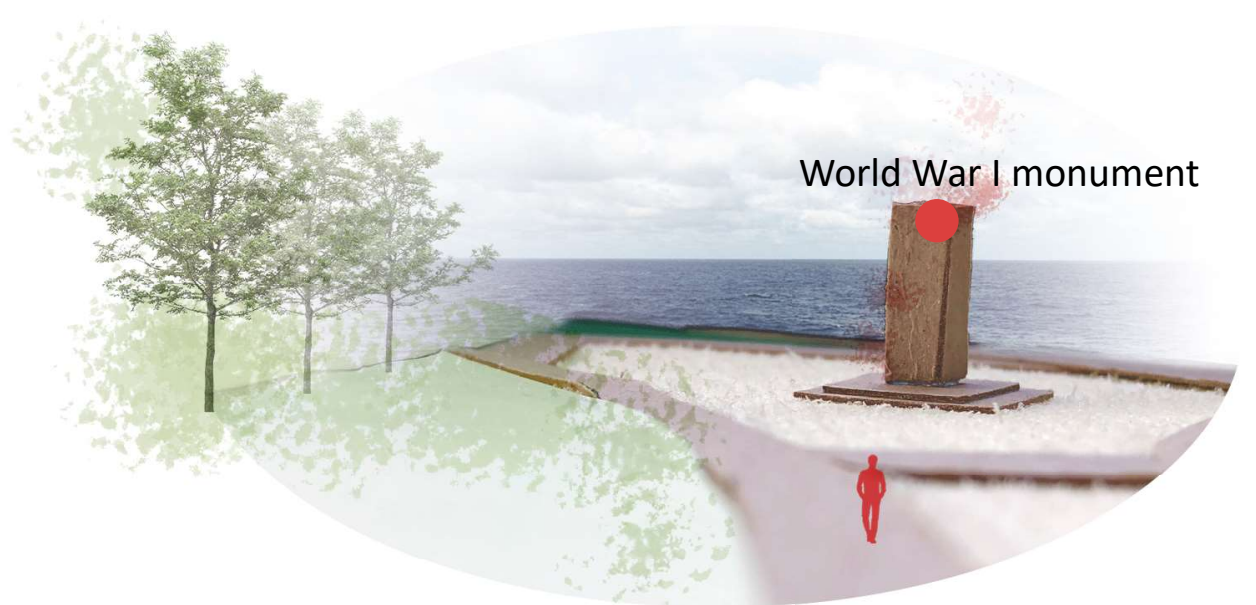

Fig. 5.83: Queen Street Foam Model Perspective 5

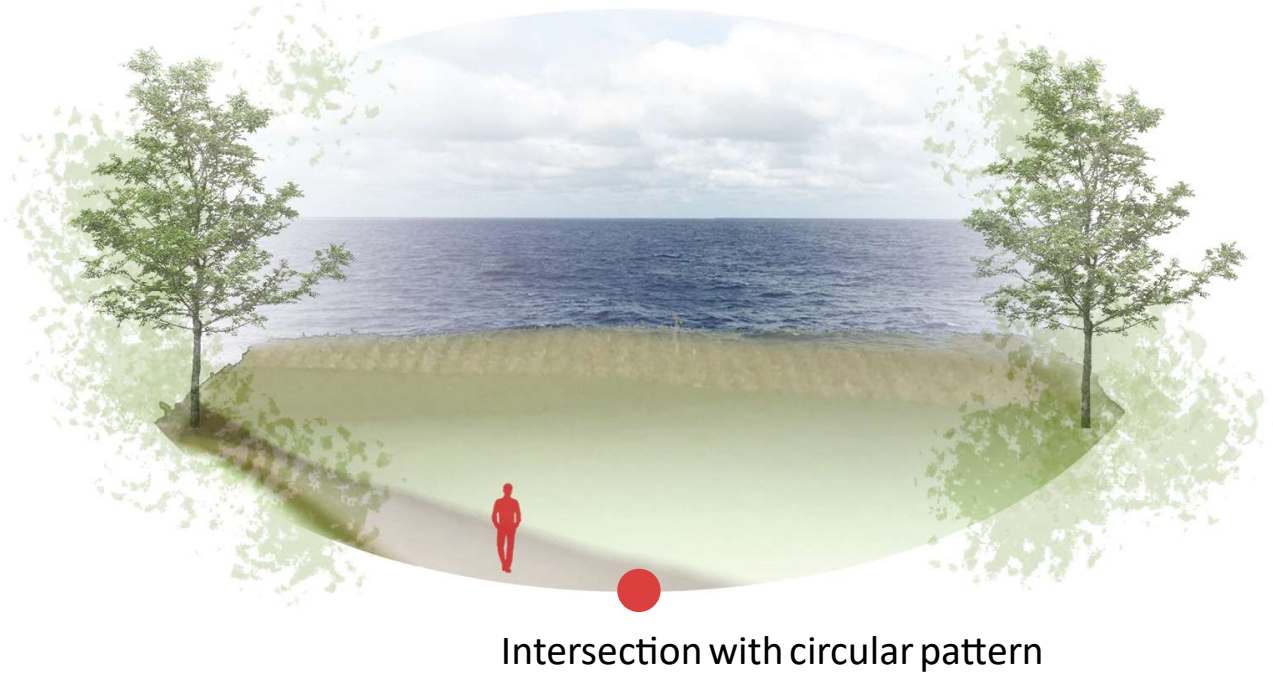

Fig. 5.84: Queen Street Foam Model Perspective 6 


\section{Brougham Street}

Brougham Street is developed into a highly active street by activated shop-fronts, decreased traffic intensity and increased pedestrian flow. The design proposes shared space, as shown in the traffic diagram. Green space at the side of Brougham street provides attractiveness for pedestrians.

Before

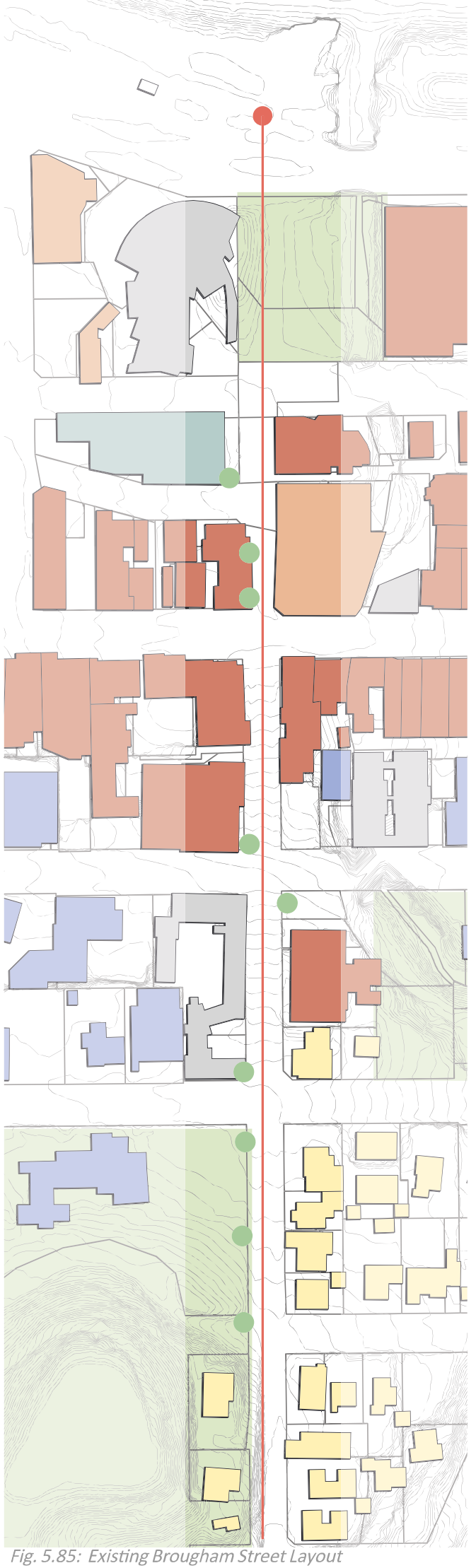

Before

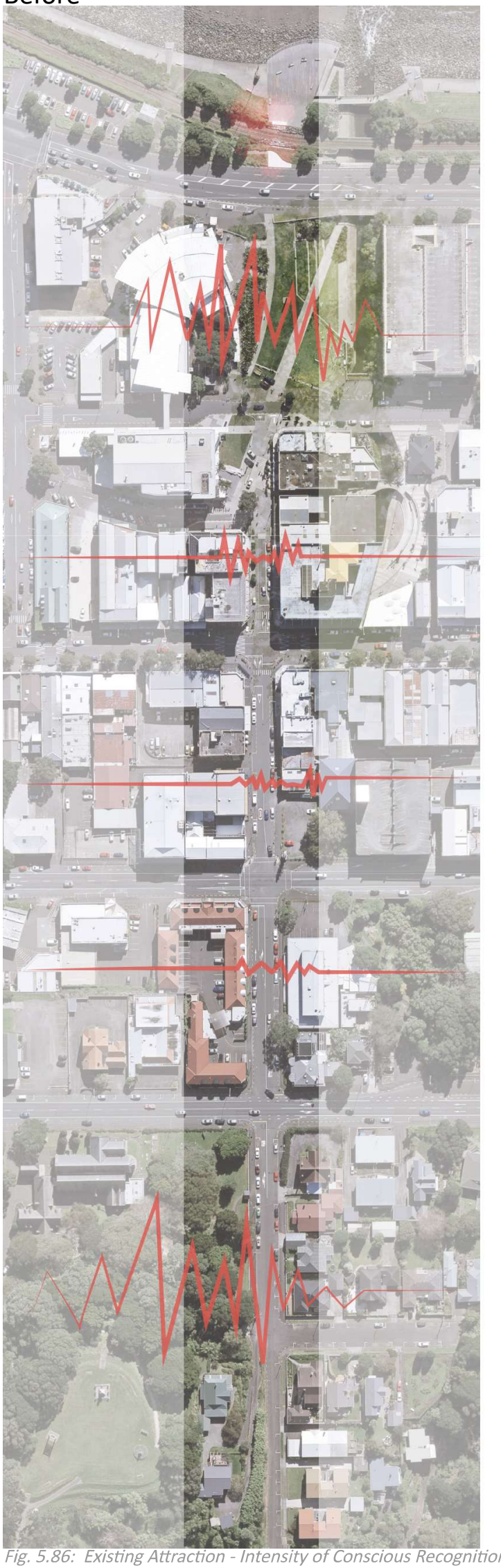


Retail

Mix-used, residential/retail

Residential
Office

Industrial

Scale:1:800@A1
After

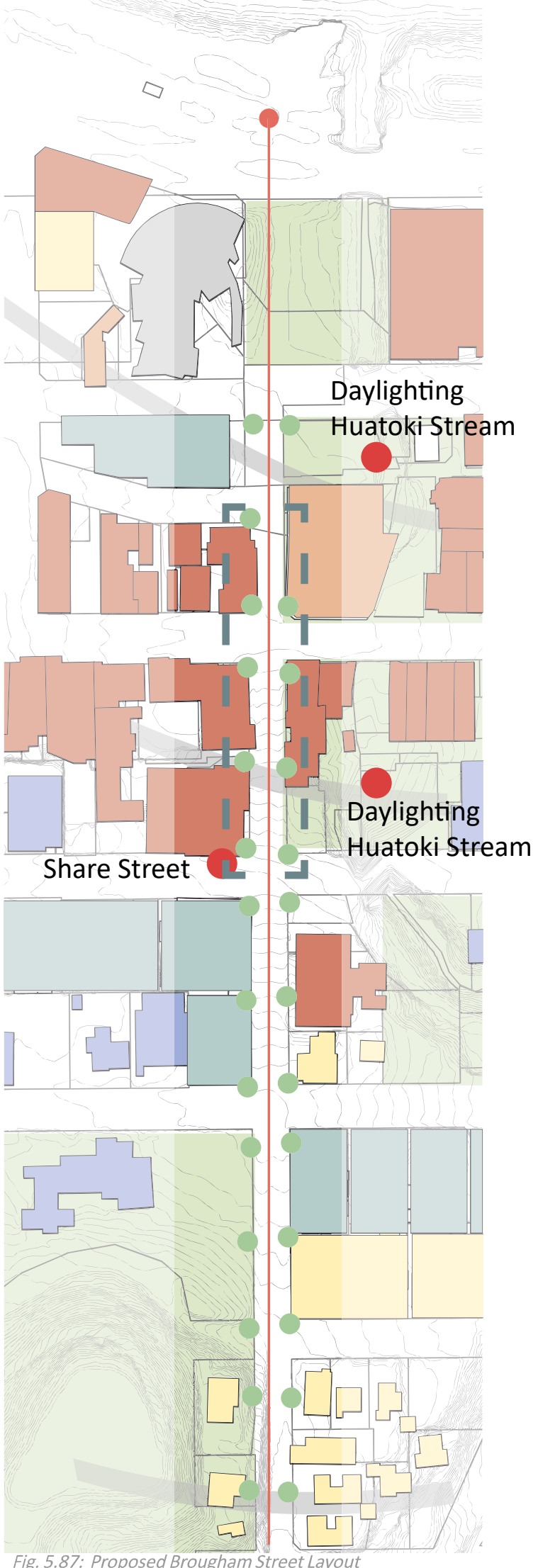

Greenery

After

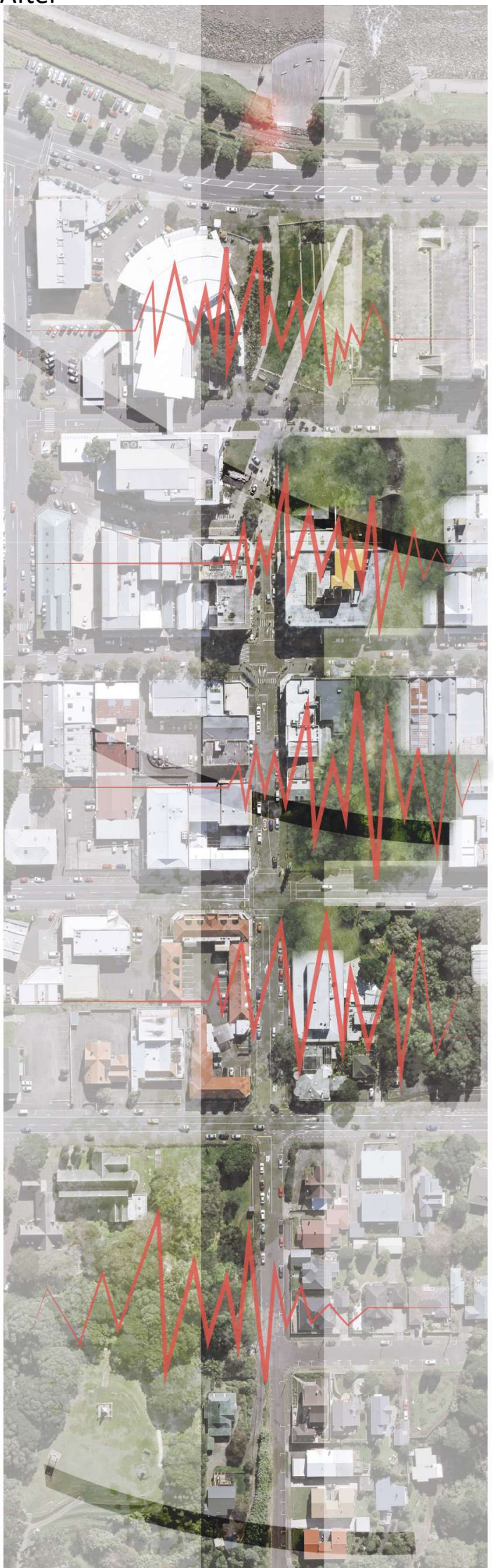




\subsection{Master-plan Finalization}

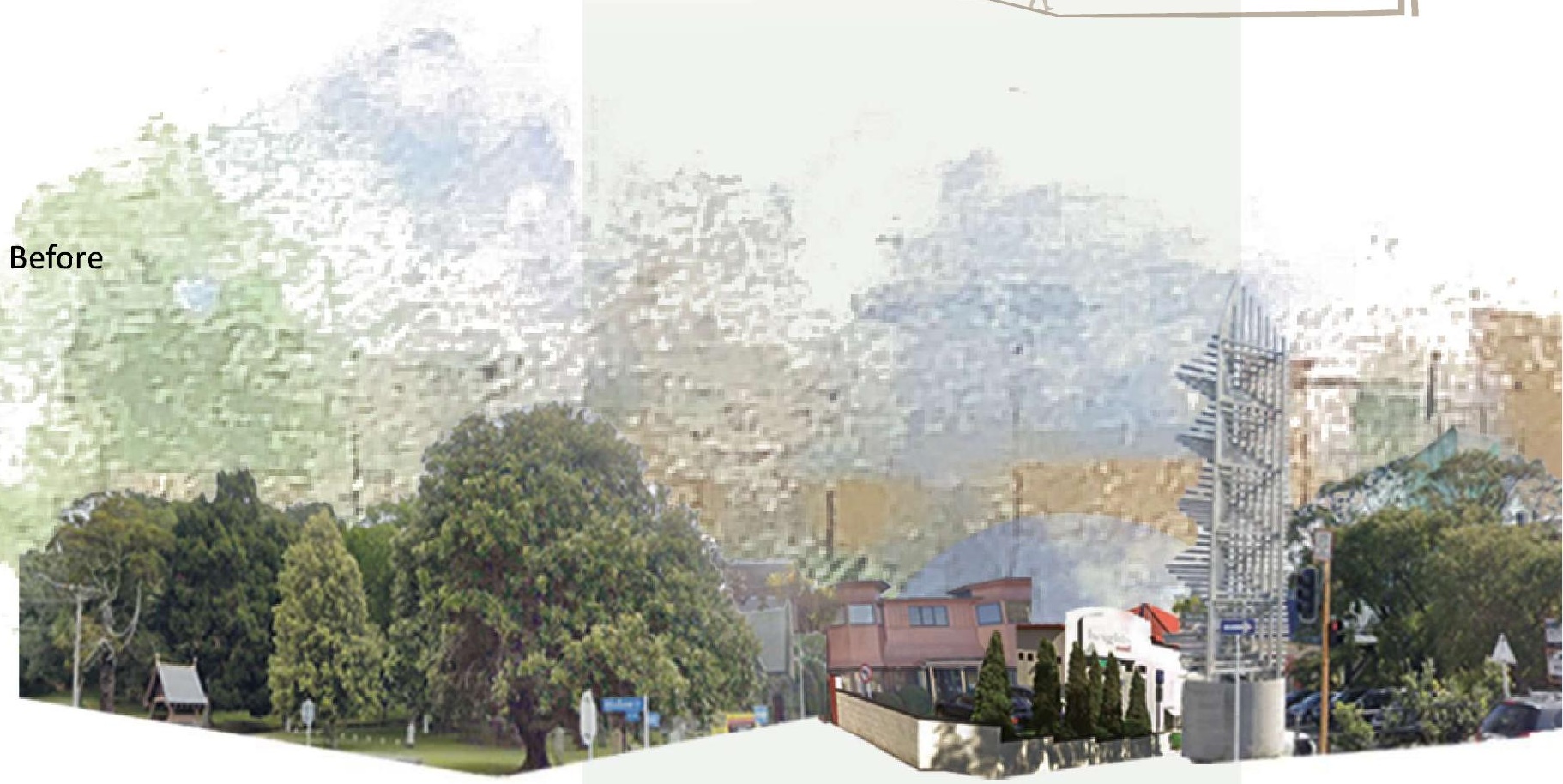

틀

\section{After}

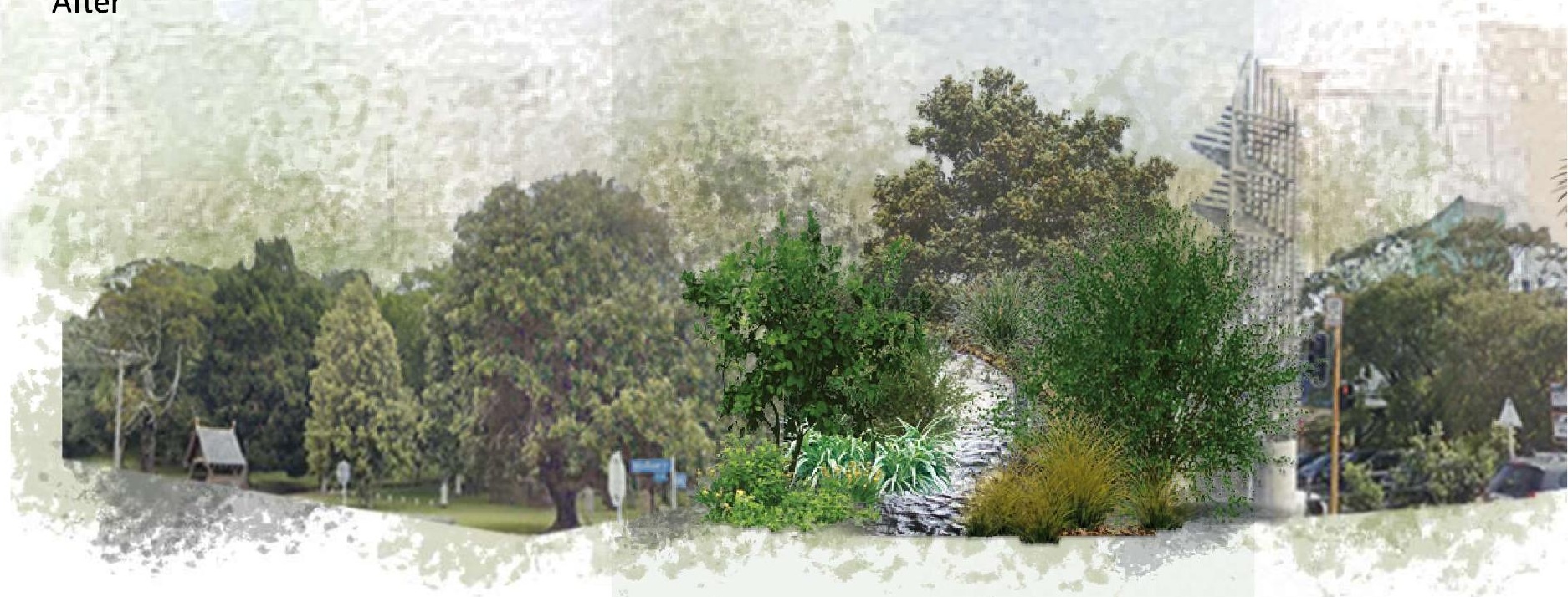


5.3 Master-plan Finalization

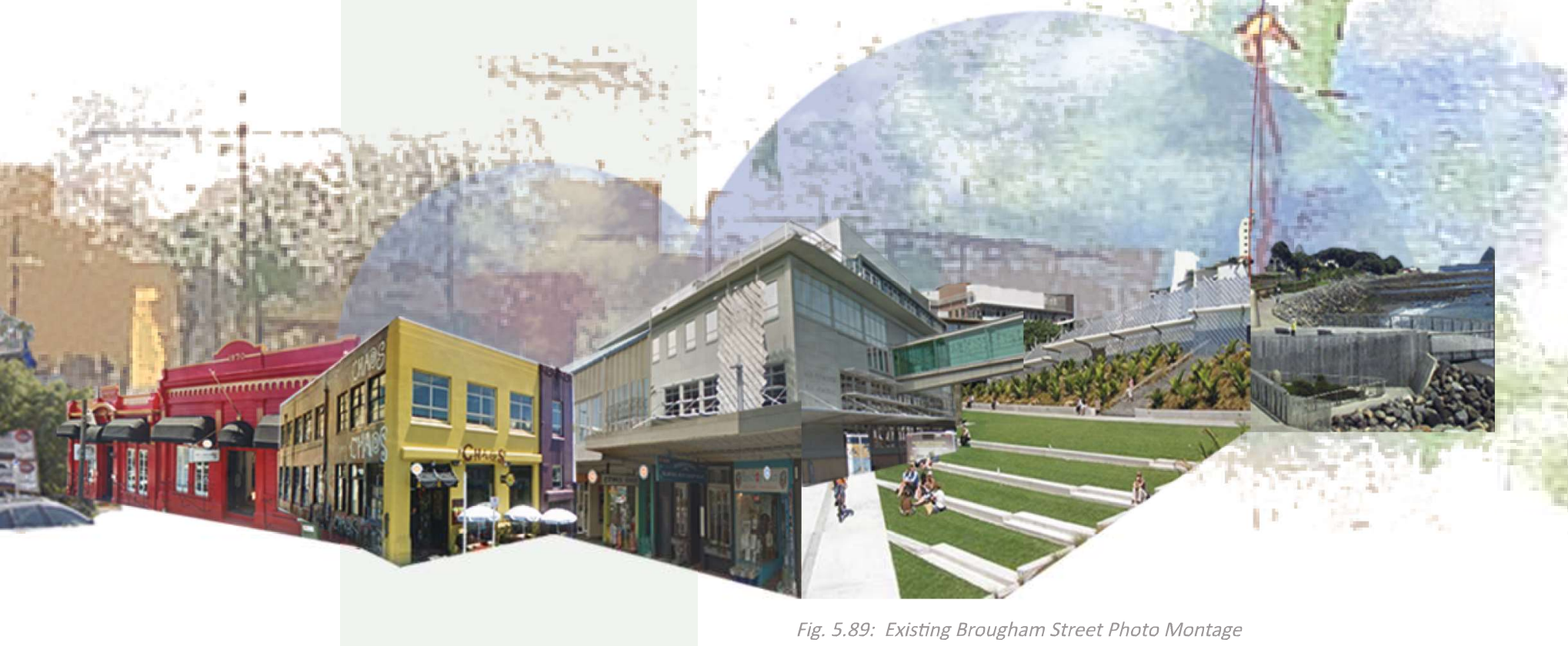

三

है

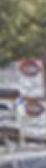

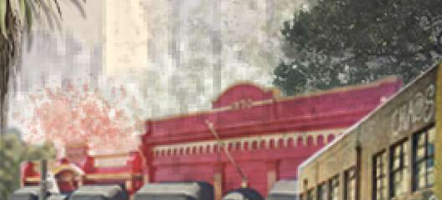

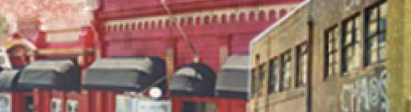
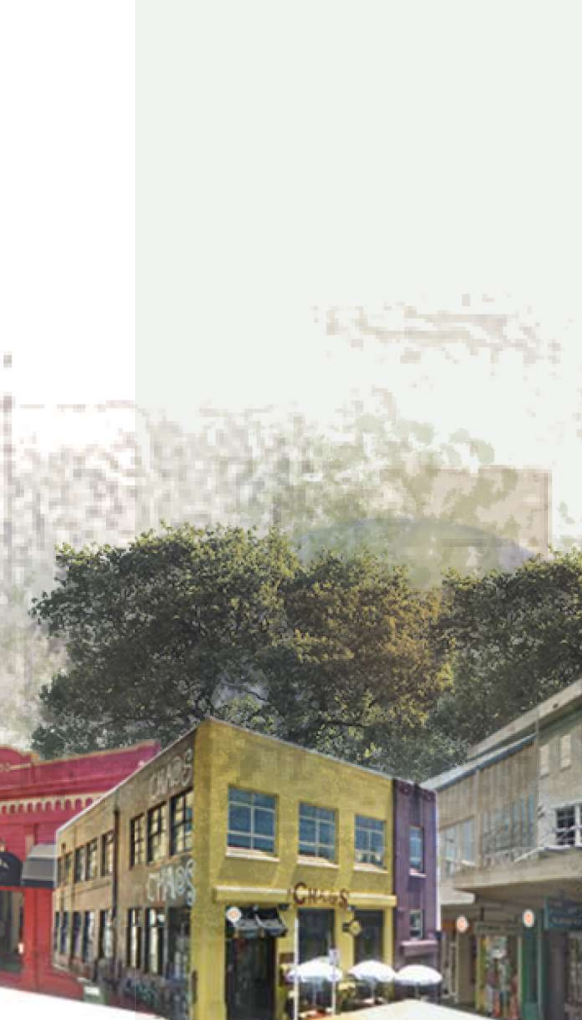

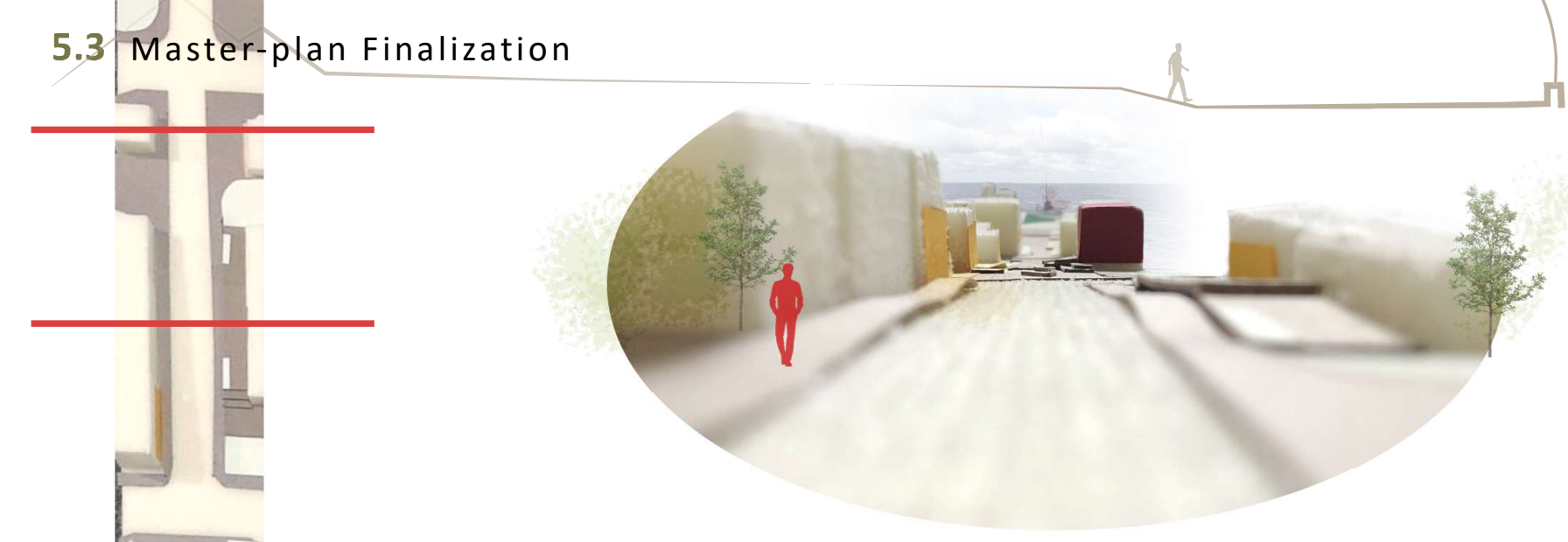

Fig. 5.92: Brougham Street Foam Model Perspective 1

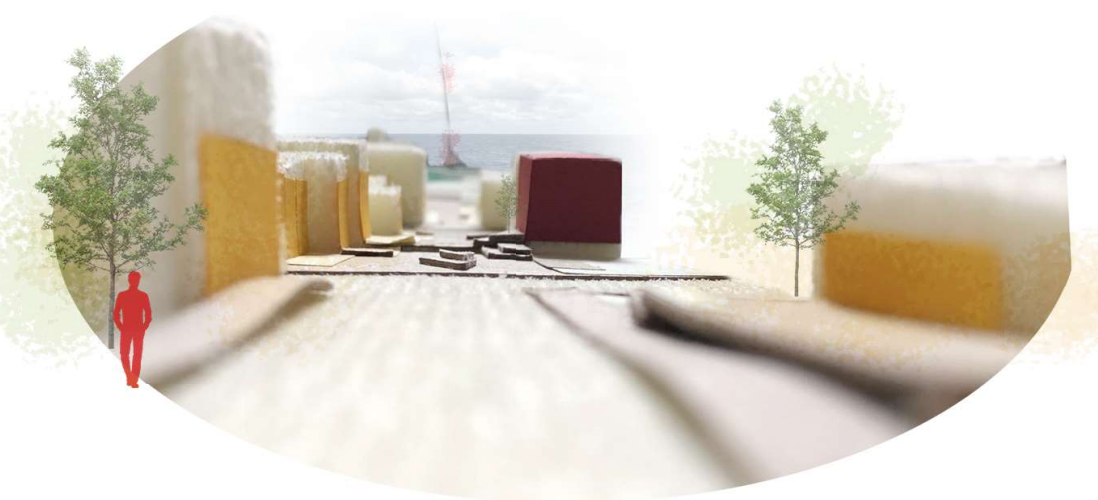

Fig. 5.93: Brougham Street Foam Model Perspective 2

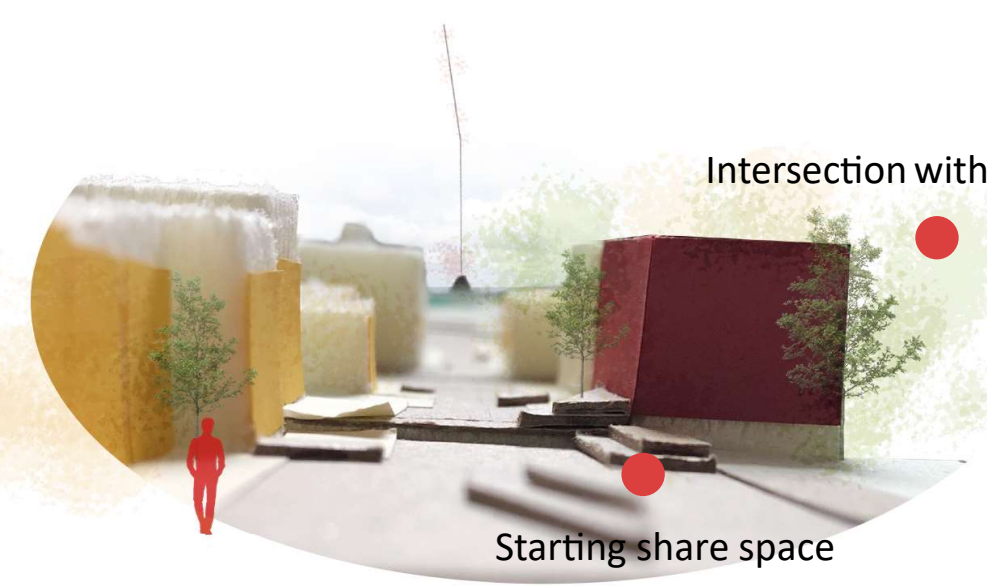

Fig. 5.94: Brougham Street Foam Model Perspective 3

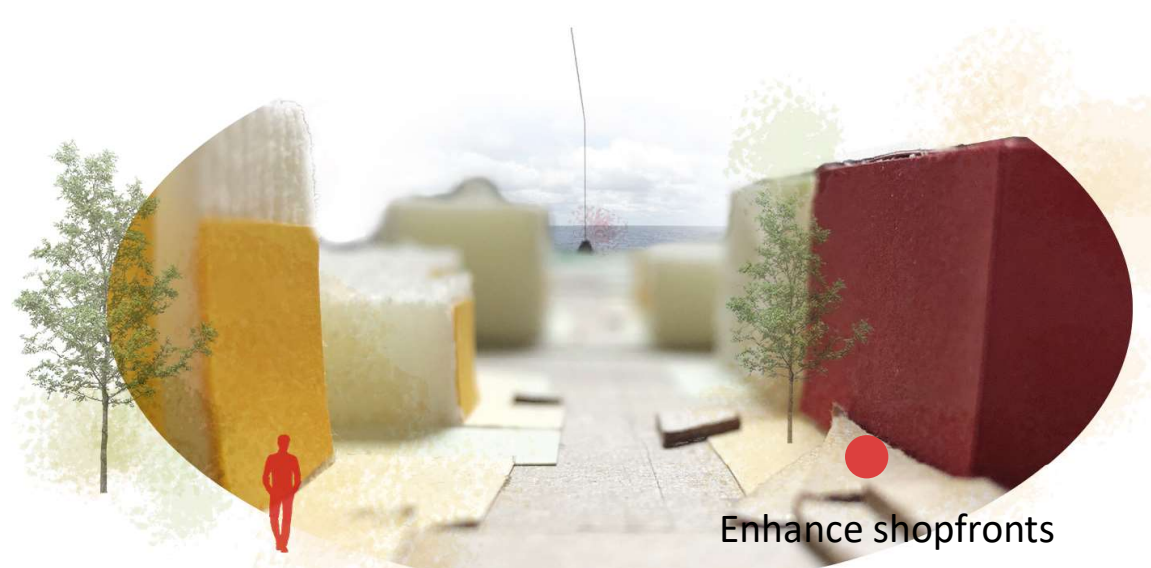




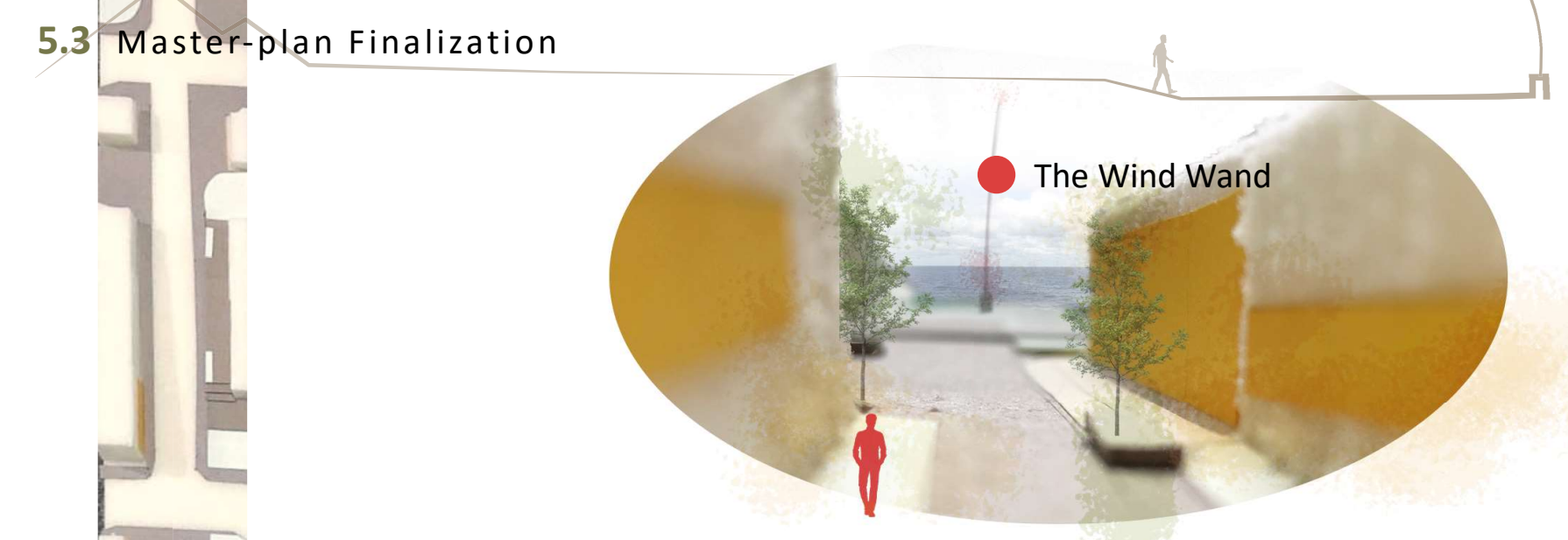

Fig. 5.97: Brougham Street Foam Model Perspective 5

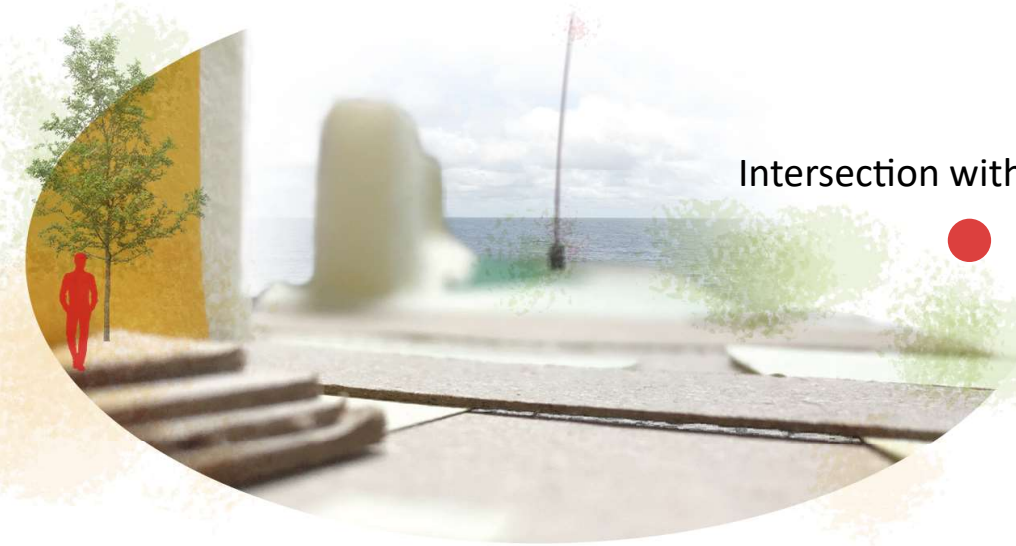

Fig. 5.98: Brougham Street Foam Model Perspective 6

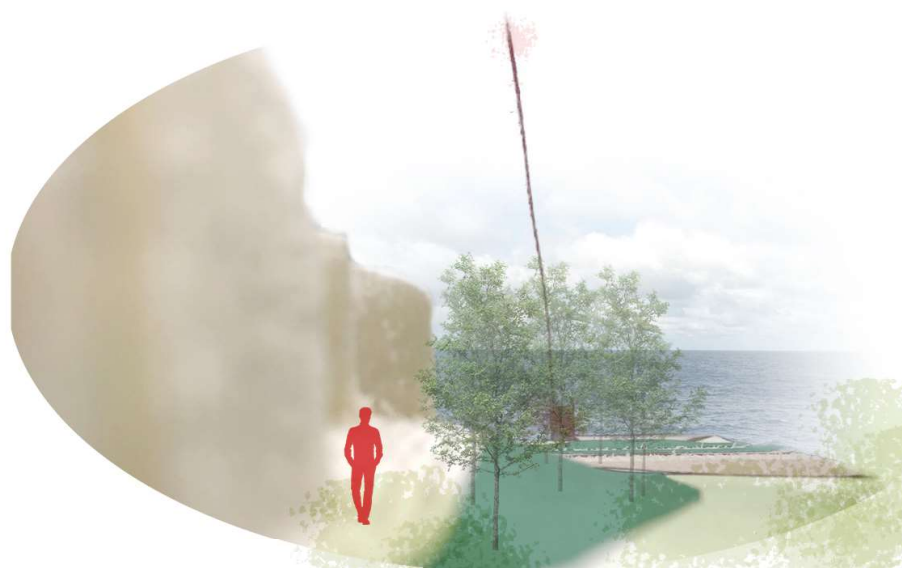

Fig. 5.99: Brougham Street Foam Model Perspective 7

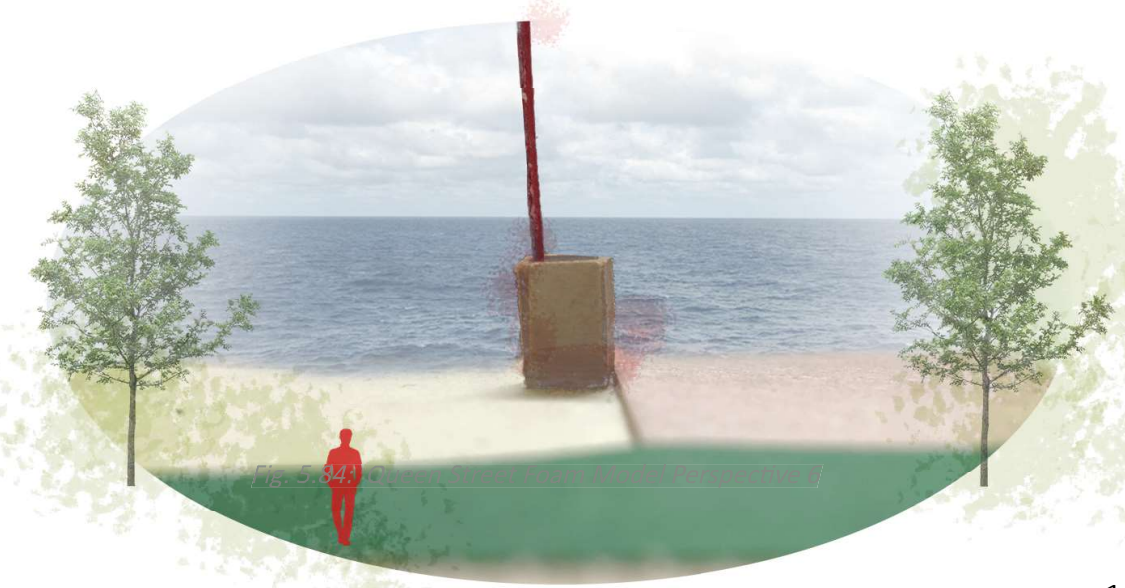




\section{Liardet Street}

Liardet Street is developed into a residential apartment-dominated street, with high-rise buildings along the northern end. Tow major churches located at central Liardet Street, follow by NPDC building, Pukekura Par located at the southern end. Planted Alnus cordata (existing species at Devon Street, the town centre) alongside Liarde Street to strengthen the visual connection.

Before
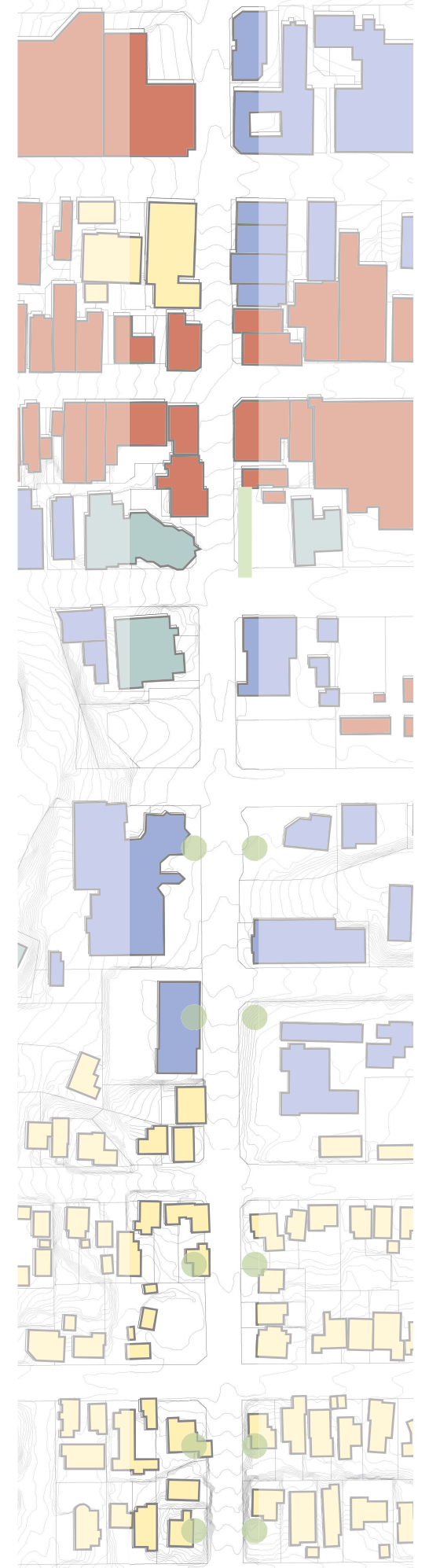

Before

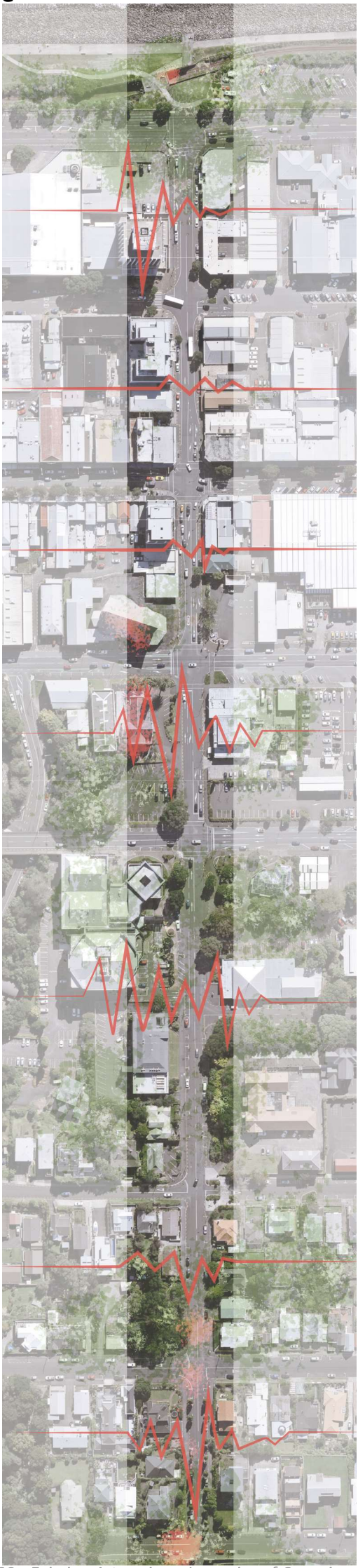


Retail

Mixed-use, residential/retail

Residential

Church

After
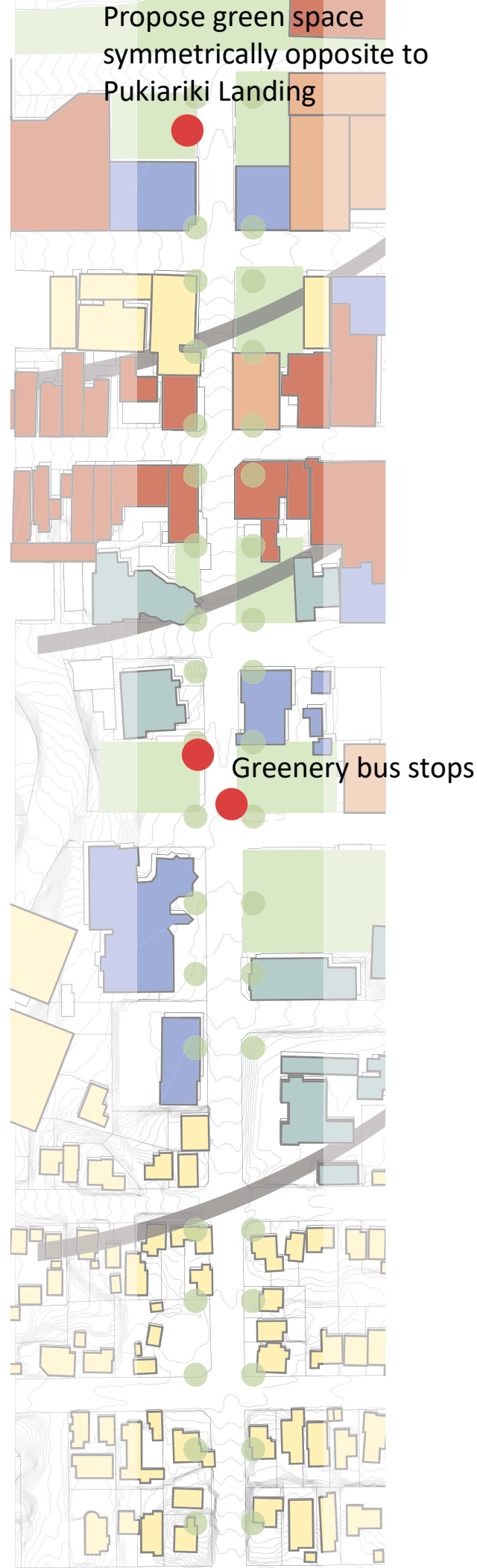

Office

Industrial

Scale: 1:1200@A1

After

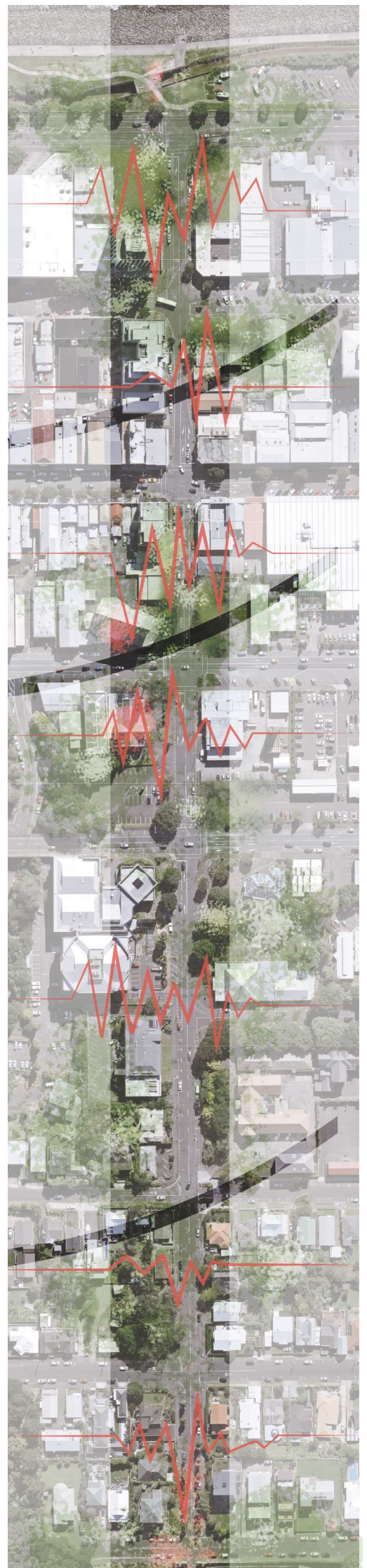


5.3 Master-plan Finalization
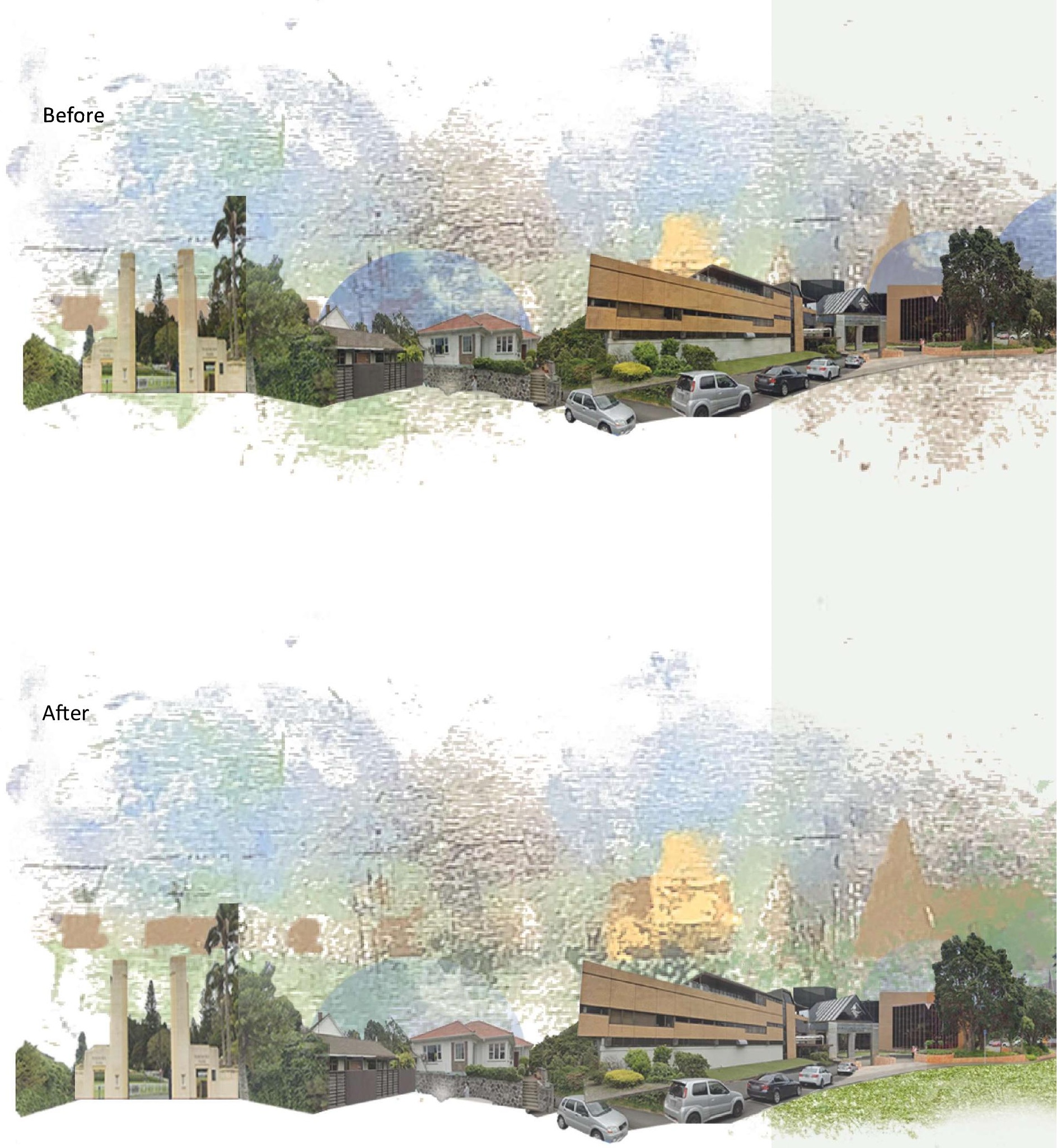


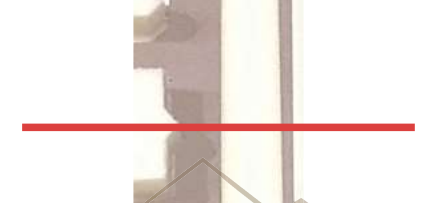

5.3 Master-plan Finalization
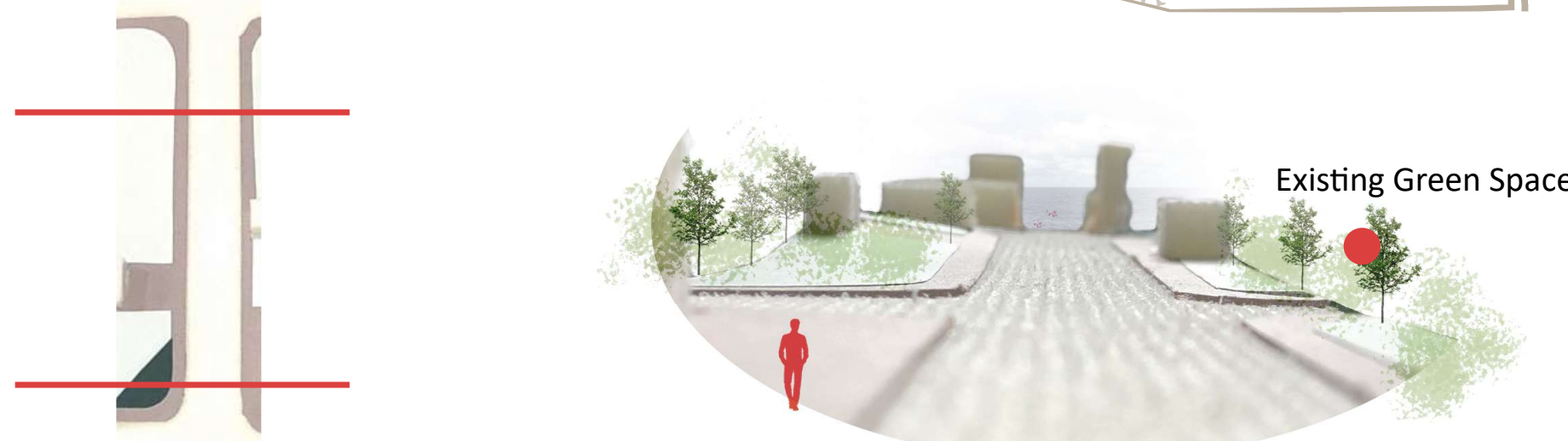

Fig. 5.108: Liardet Street Foam Model Perspective 1
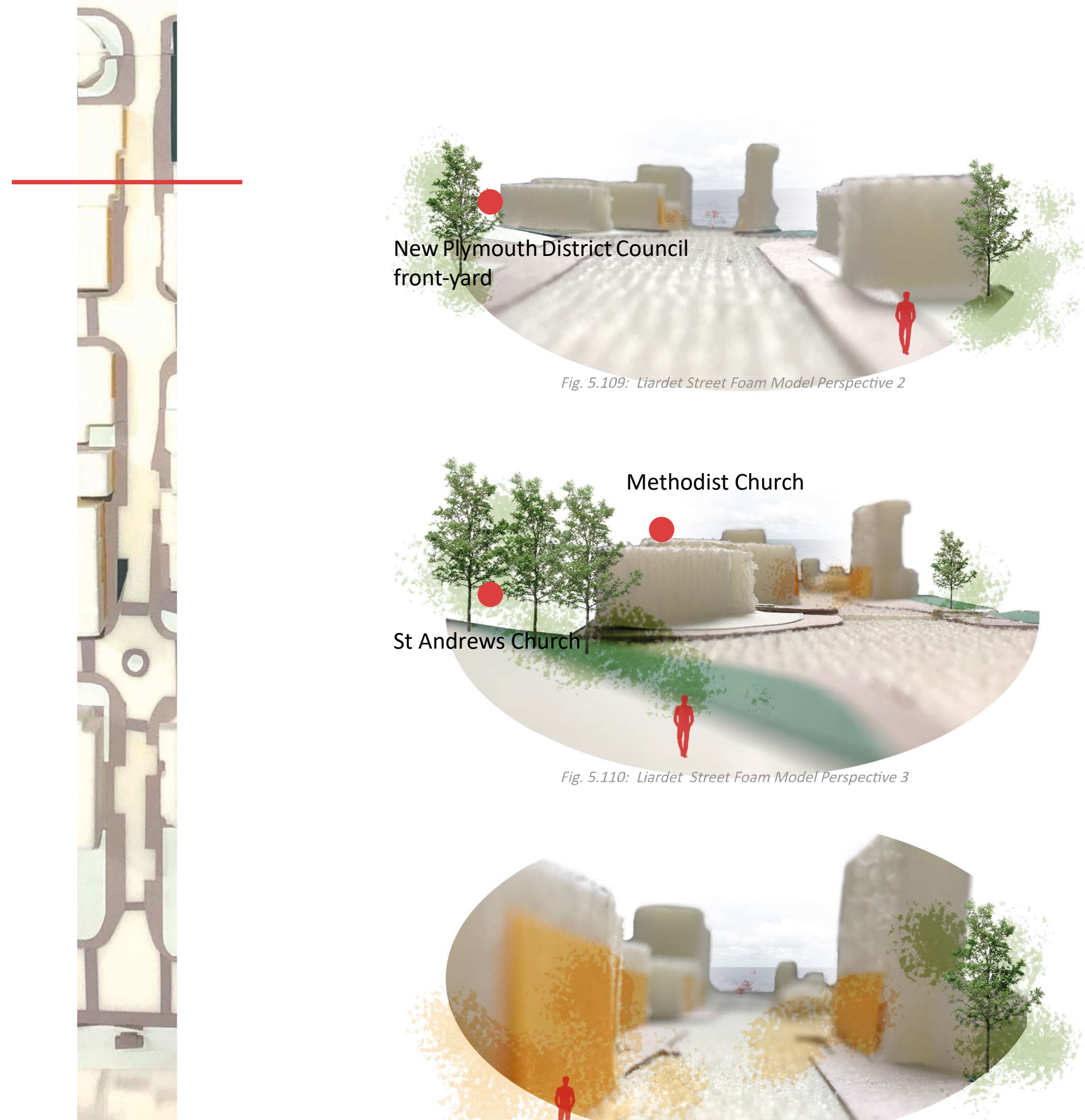

Fig. 5.109: Liardet Street Foam Model Perspective 2

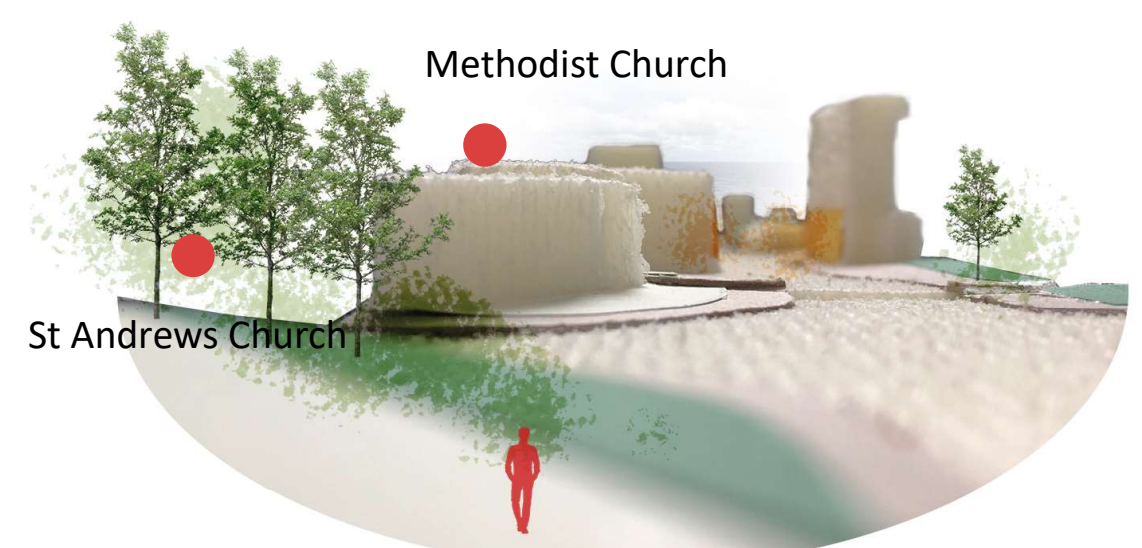

Fig. 5.110: Liardet Street Foam Model Perspective 3

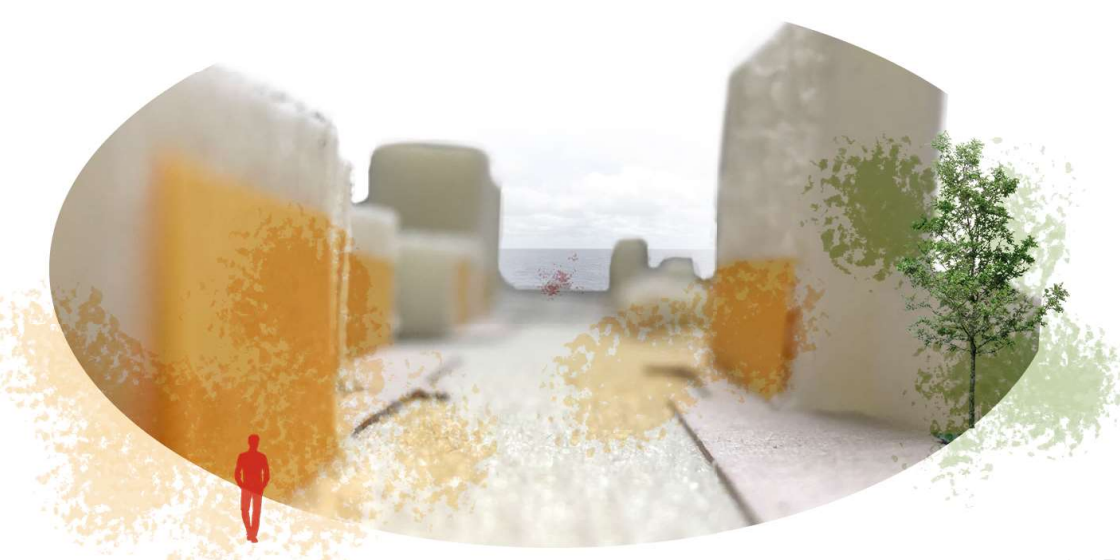




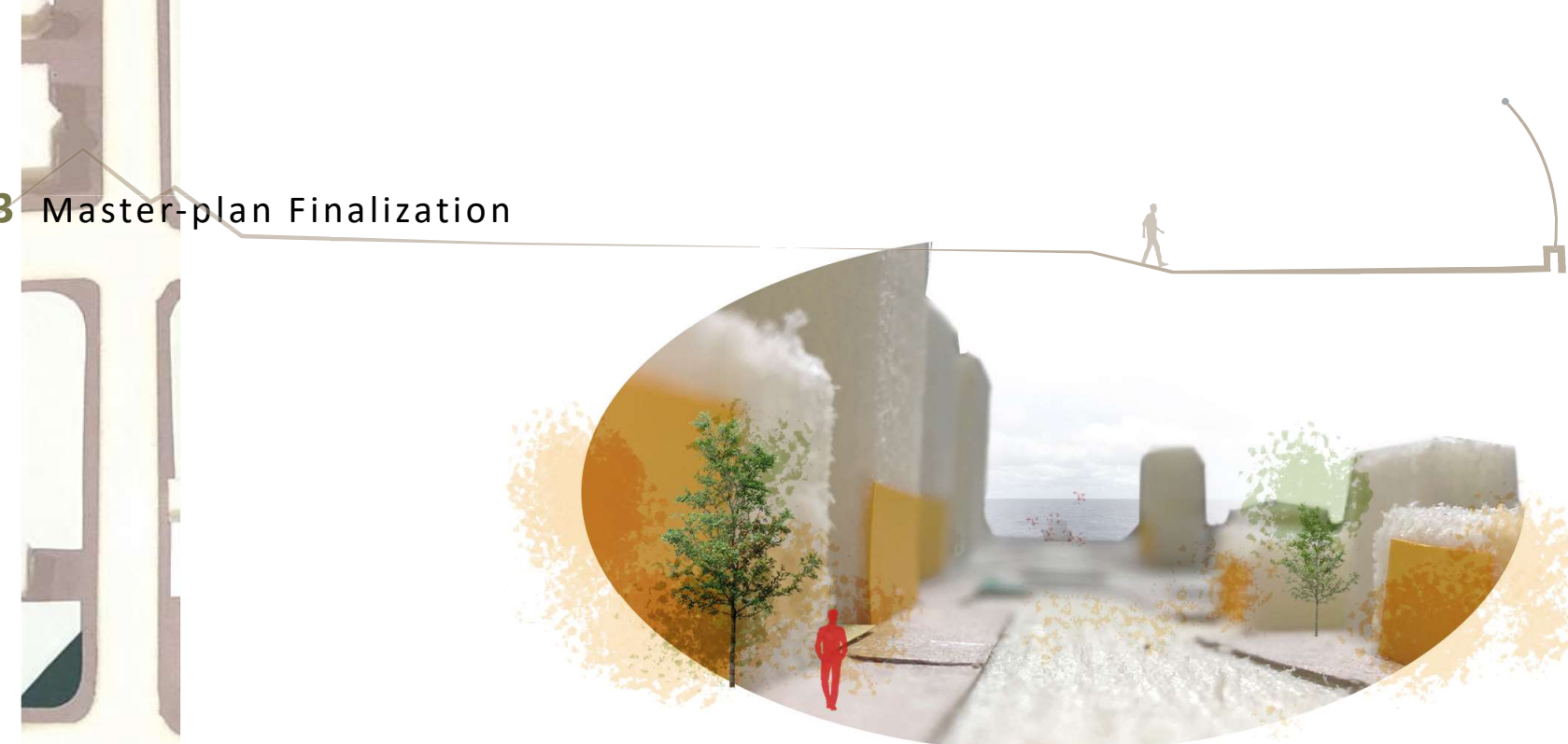

5.3 Master-plan Finalization

Fig. 5.113: Liardet Street Foam Model Perspective 5
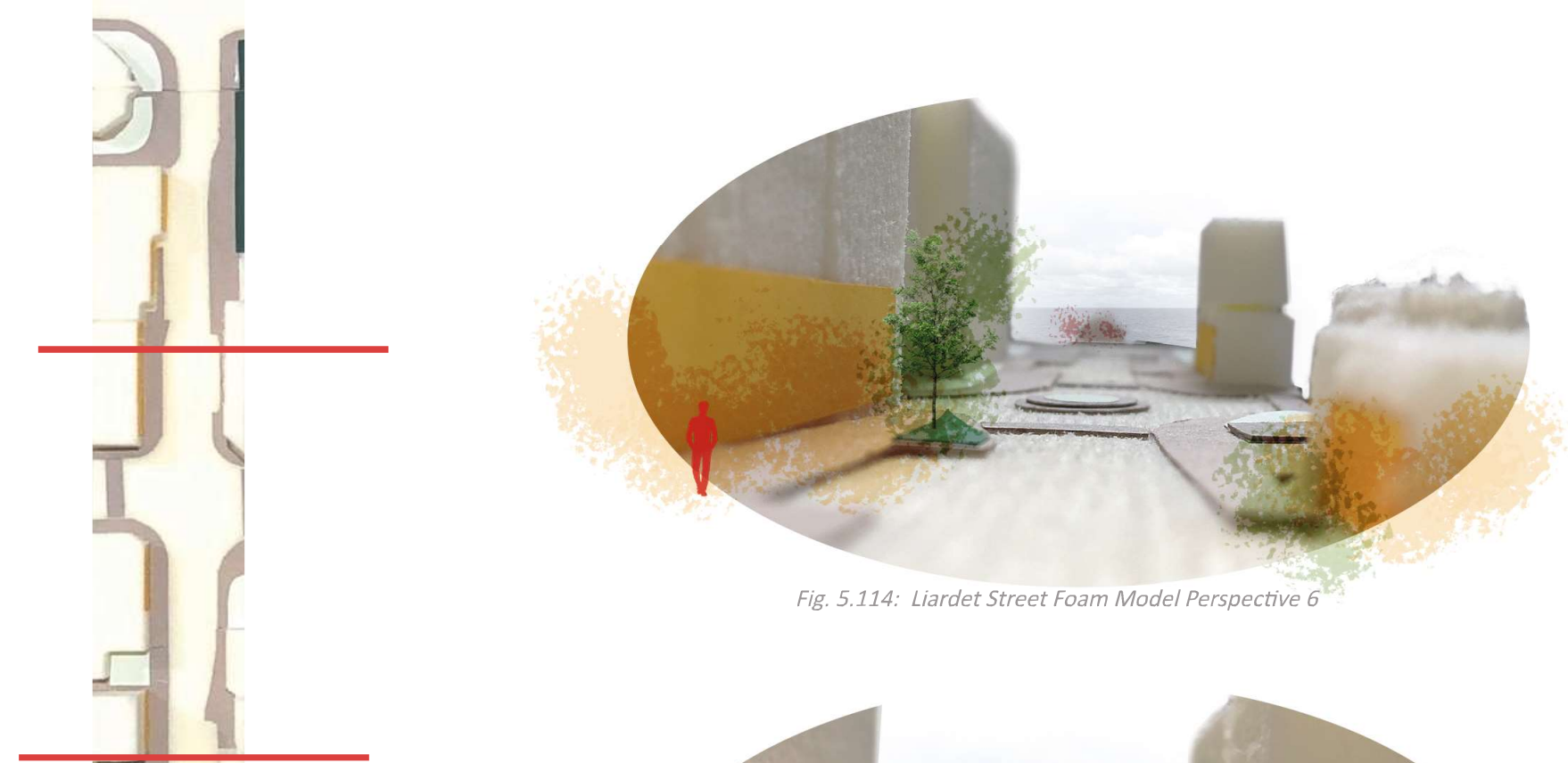

Fig. 5.114: Liardet Street Foam Model Perspective 6
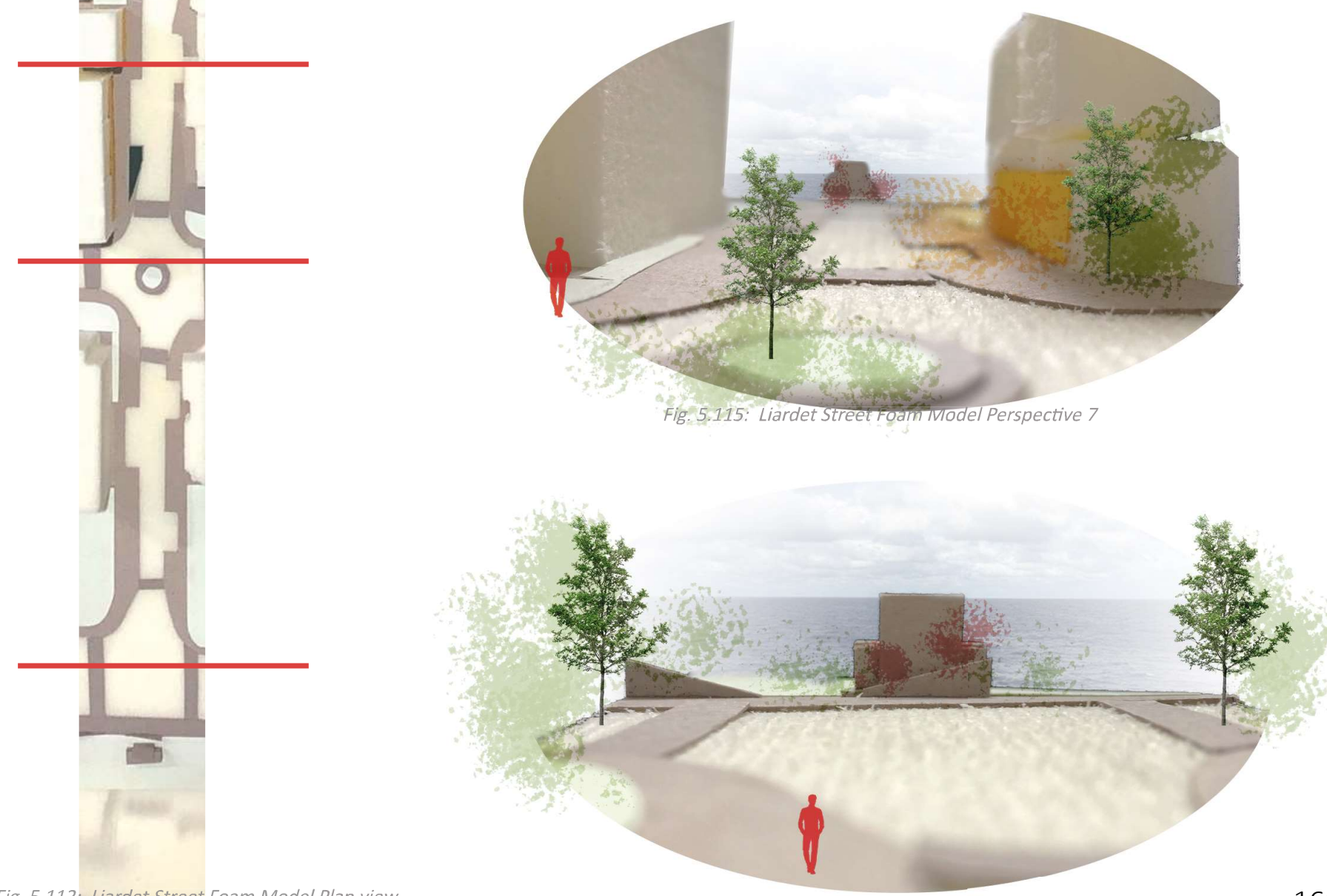


\section{Gover Street}

The design proposed mixed-use apartments along Gover Street, with active shops below. Re-locate existing industrial buildings alongside proposed fast-speed roads (Dawson Street). A Maori War Memorial is proposed at the northern end of this street by taking over the existing Bunnings building. This Maori War Memorial is symmetrically opposite to the WWI Memorial at Queen Street.

Before
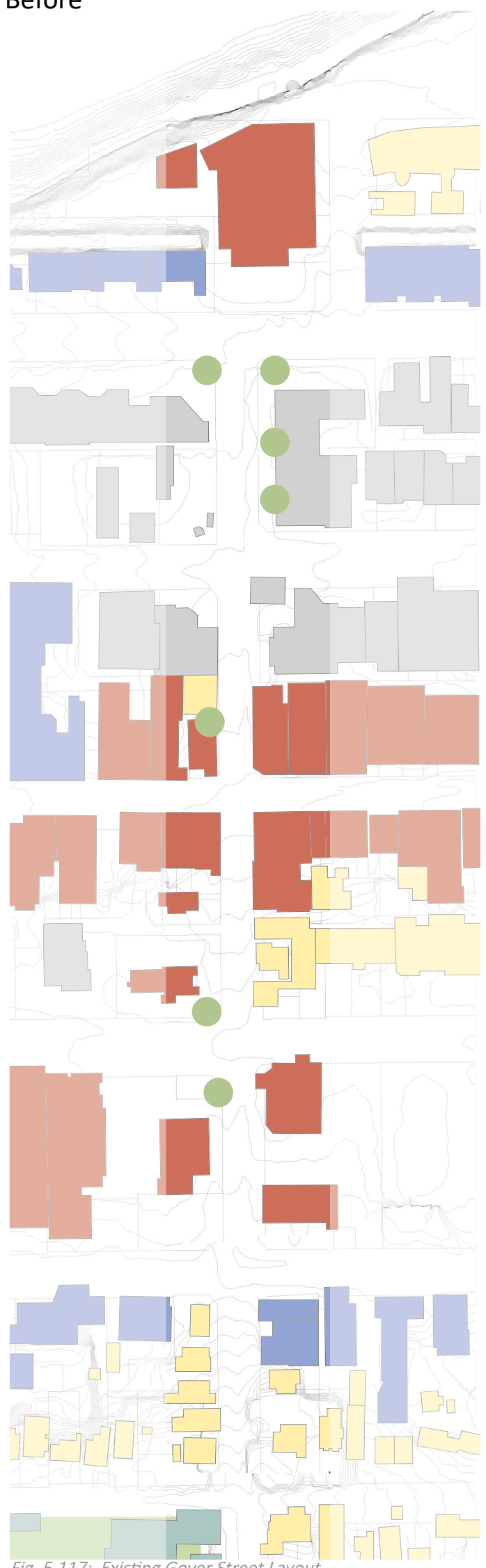

Before

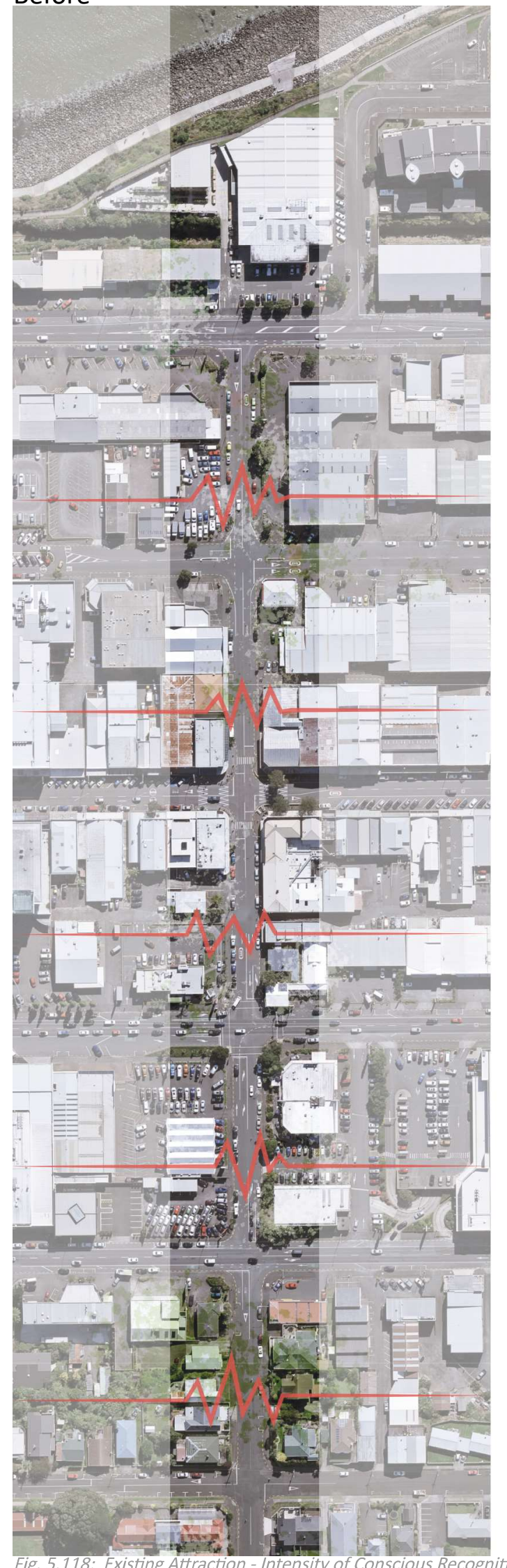


Retail

Mixed-use, residential/retail

Residential
Office

Industrial

Greenery
After
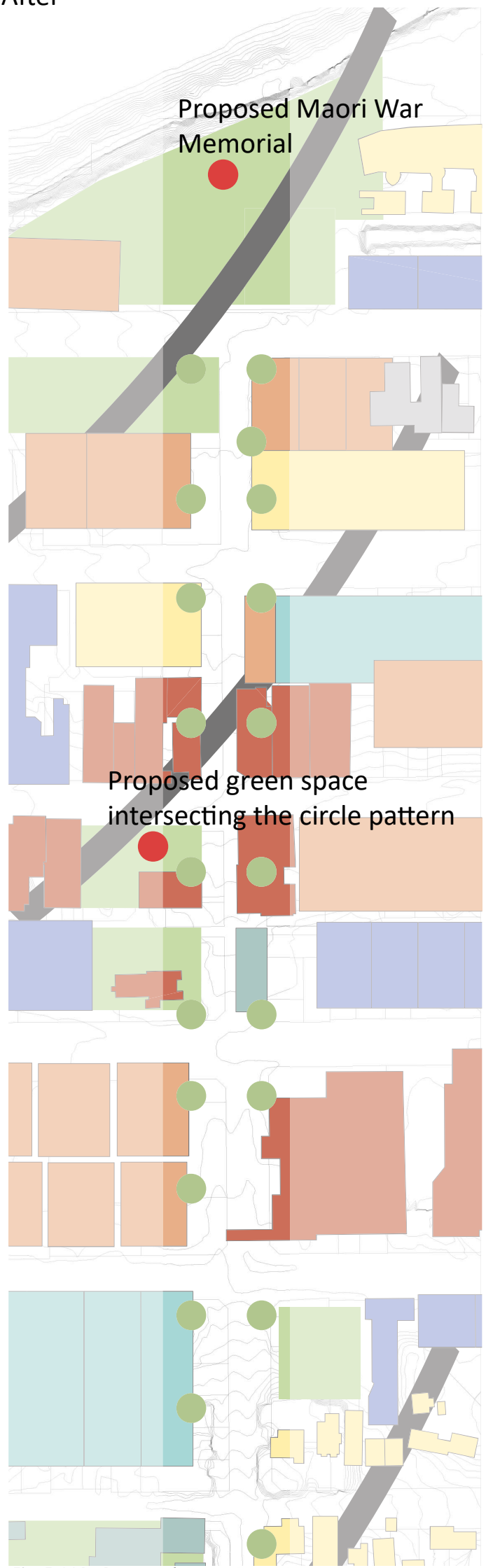

Fig. 5.119: Proposed Gover Street Layou
After

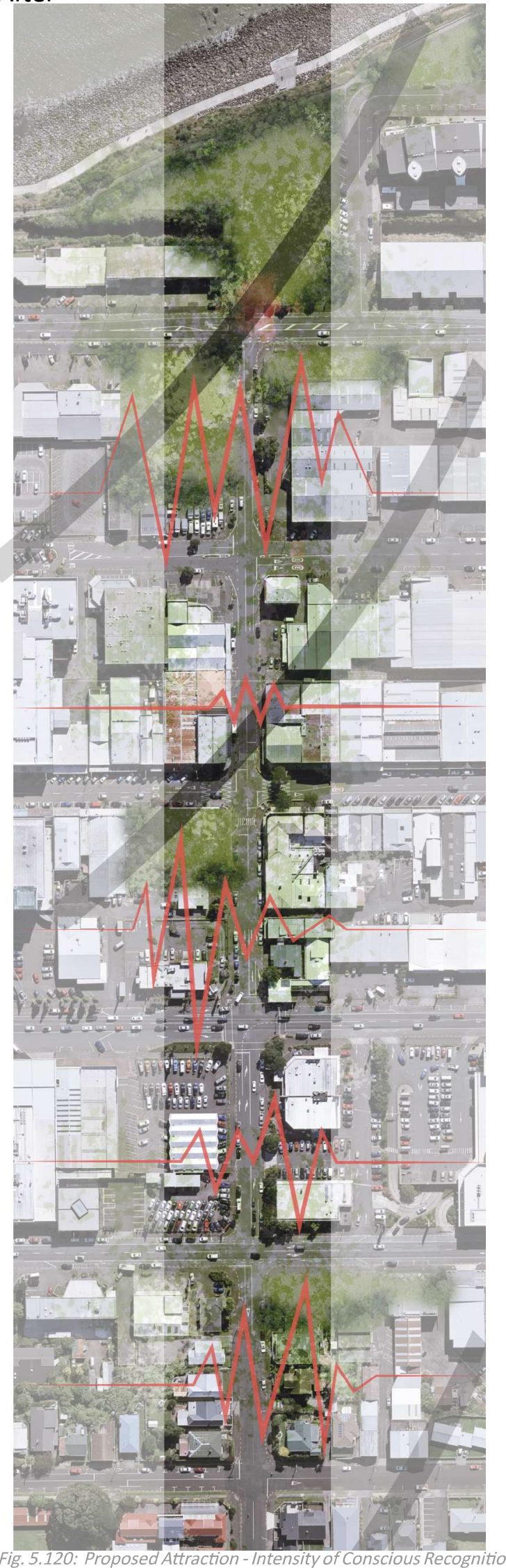




\subsection{Master-plan Finalization}

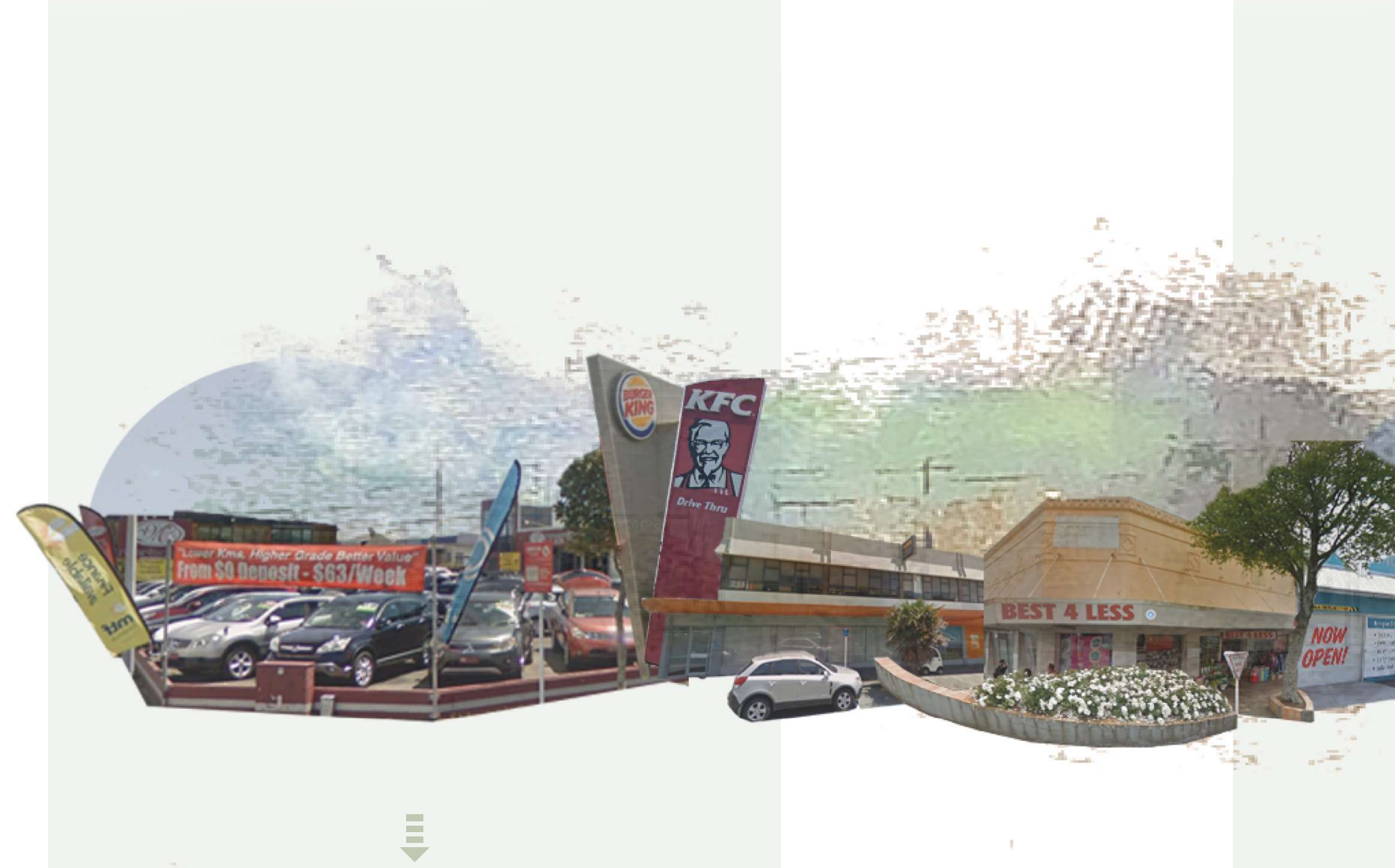




\subsection{Master-plan Finalization}

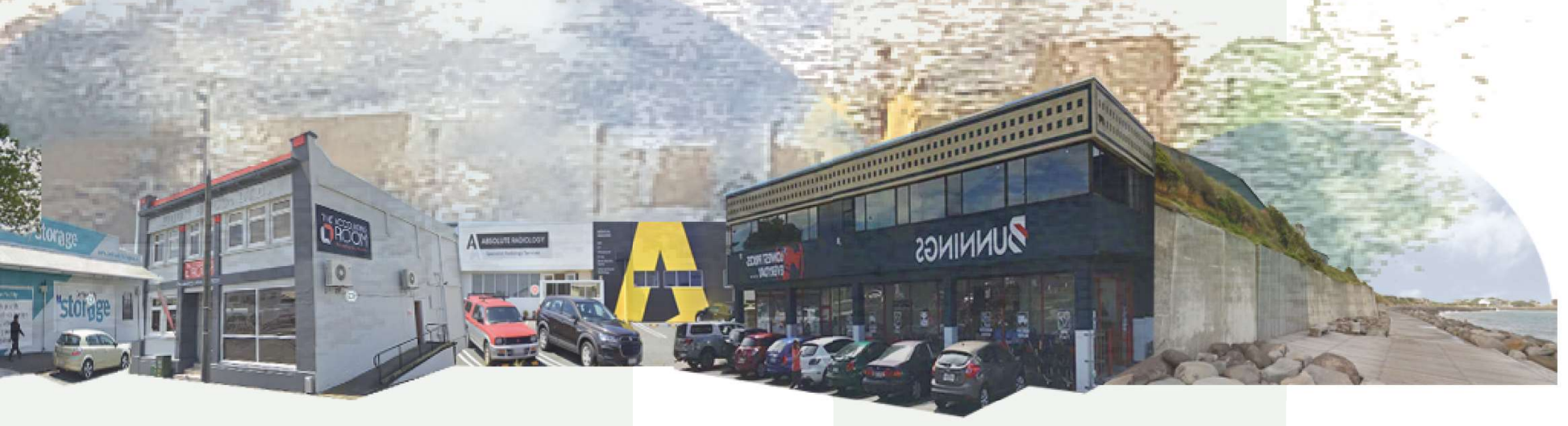

Fig. 5.121: Existing Gover Street Photo Montage

틀

言

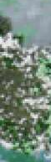


5.3 Master-plan Finalization

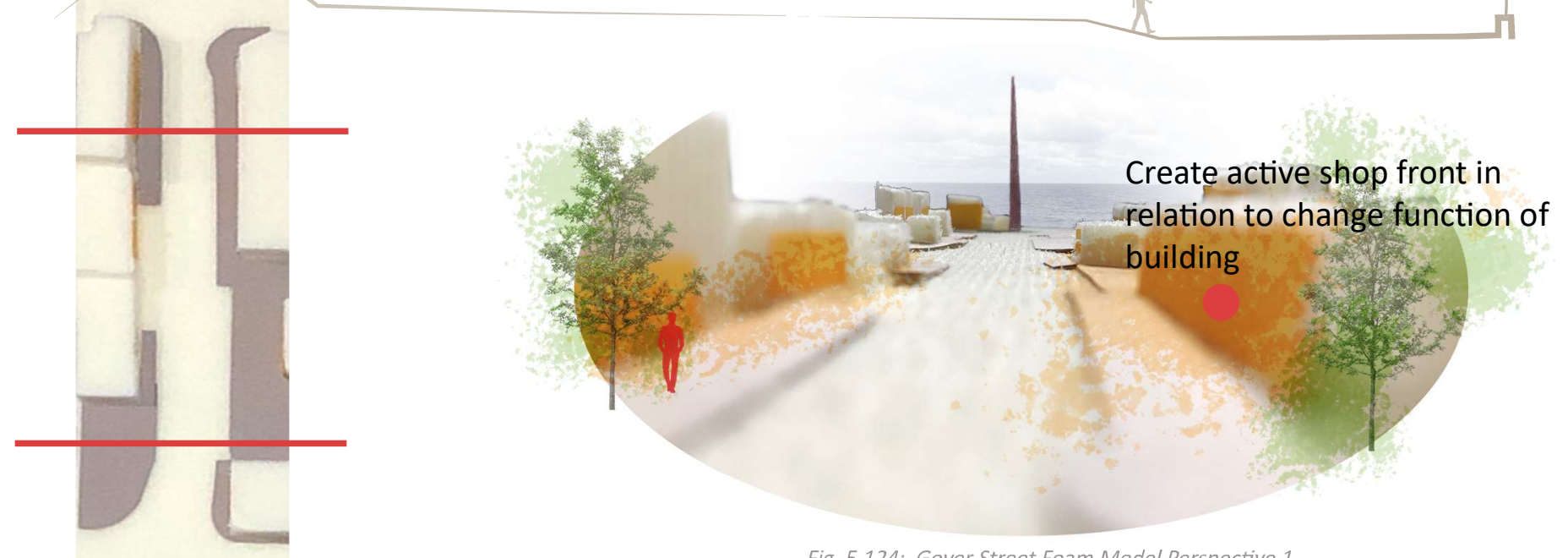

Fig. 5.124: Gover Street Foam Model Perspective 1
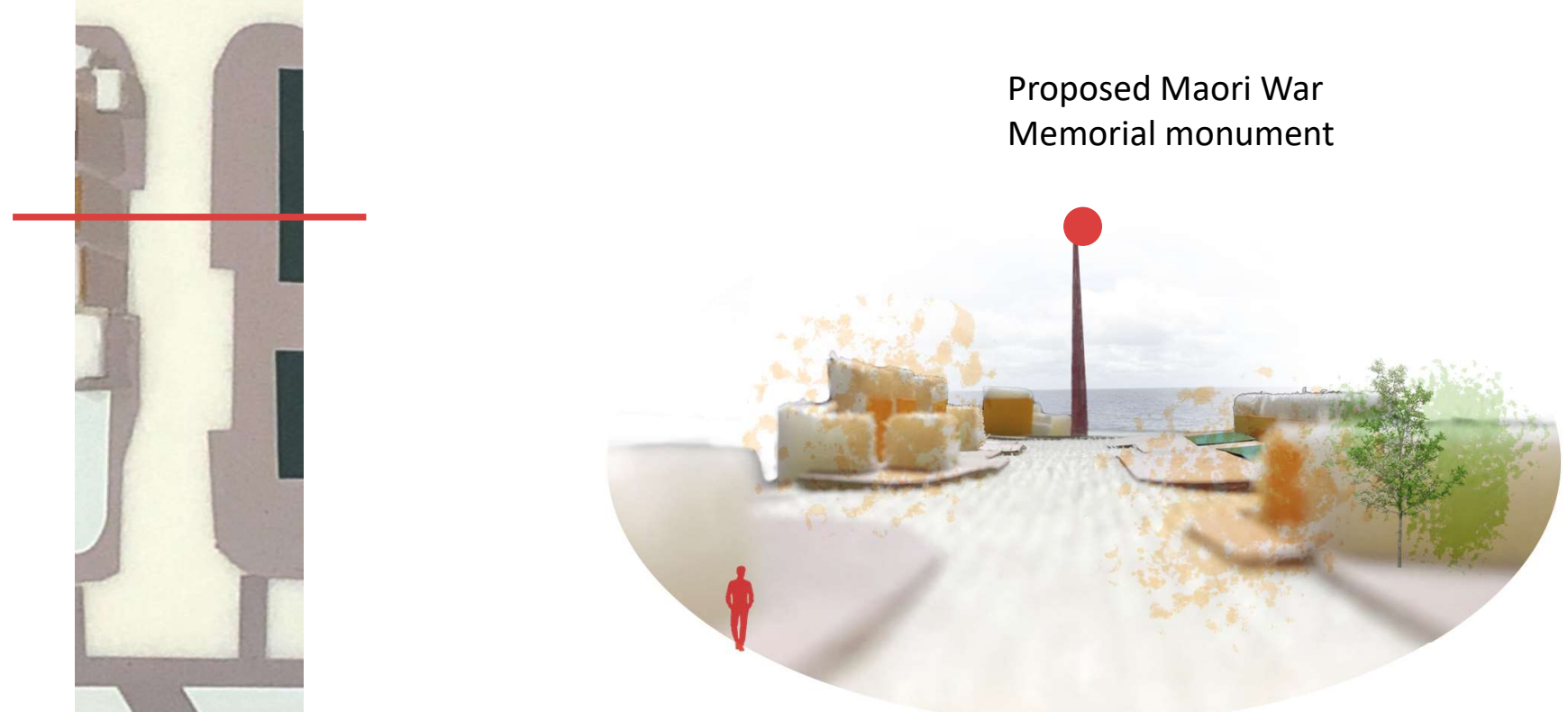

Fig. 5.125: Gover Street Foam Model Perspective 2

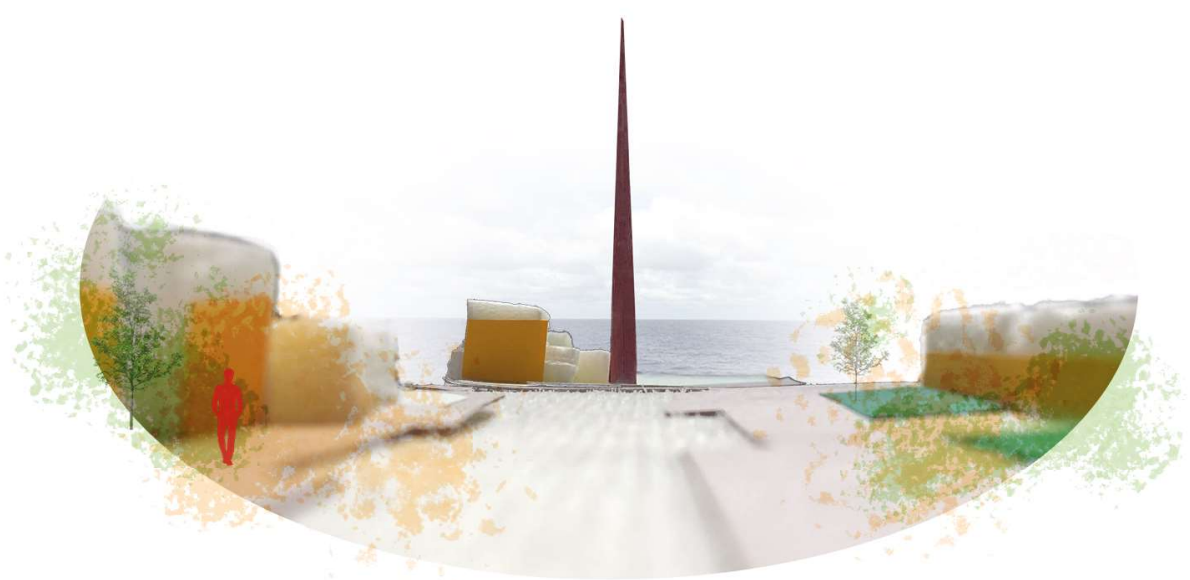

Fig. 5.126: Gover Street Foam Model Perspective 3 

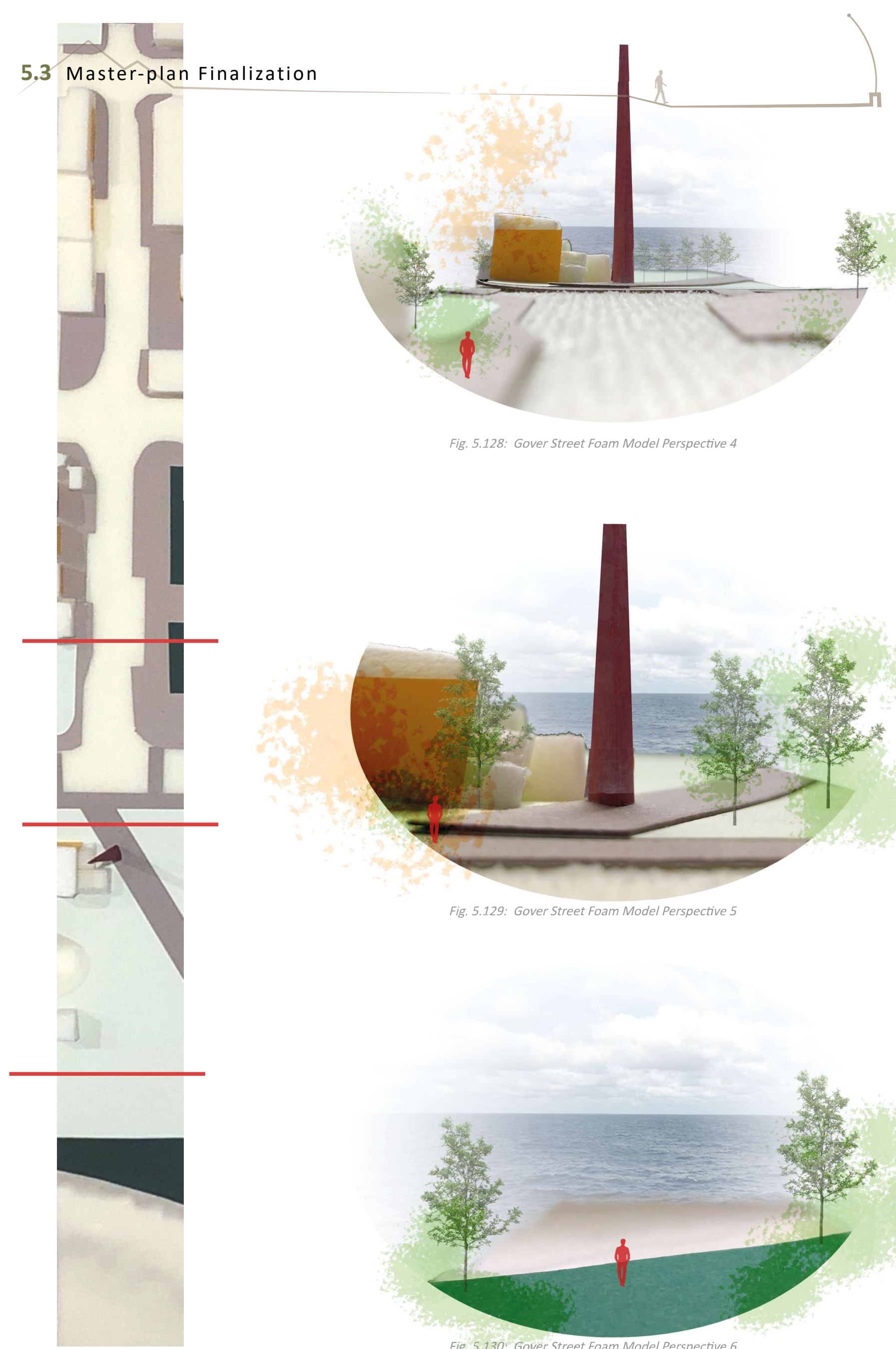

Fig. 5.128: Gover Street Foam Model Perspective 4

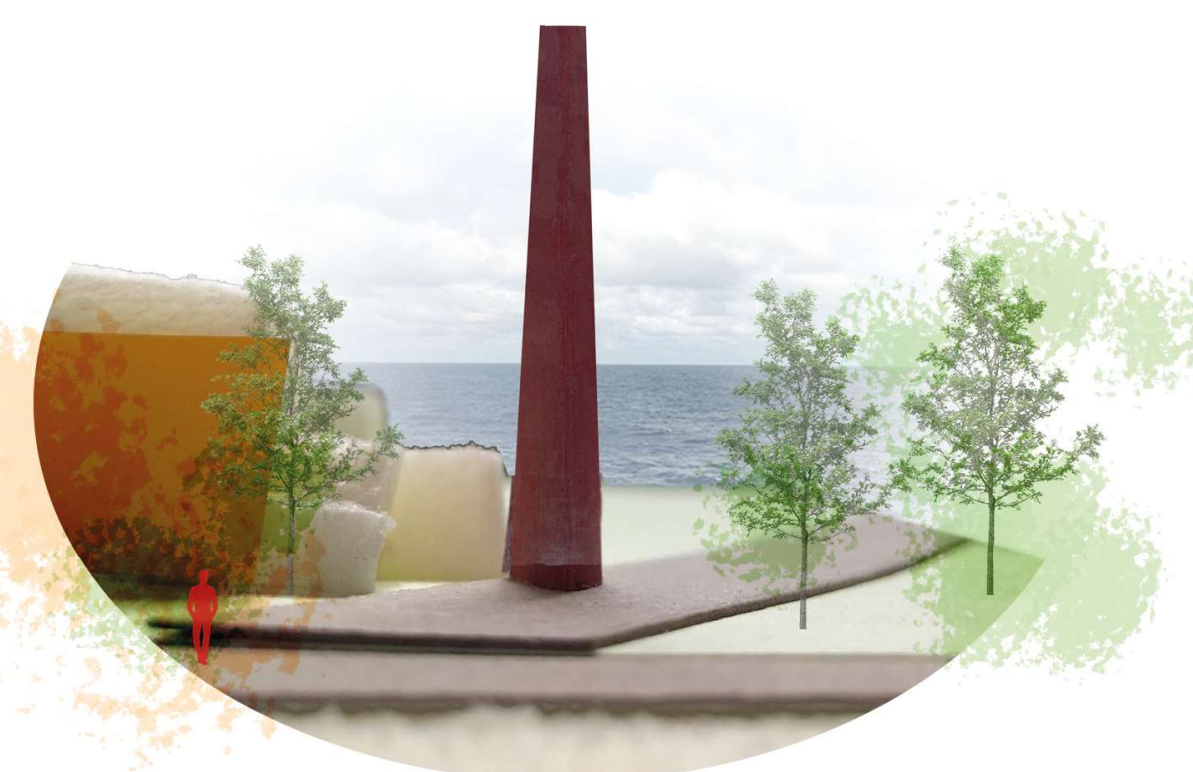

Fig. 5.129: Gover Street Foam Model Perspective 5

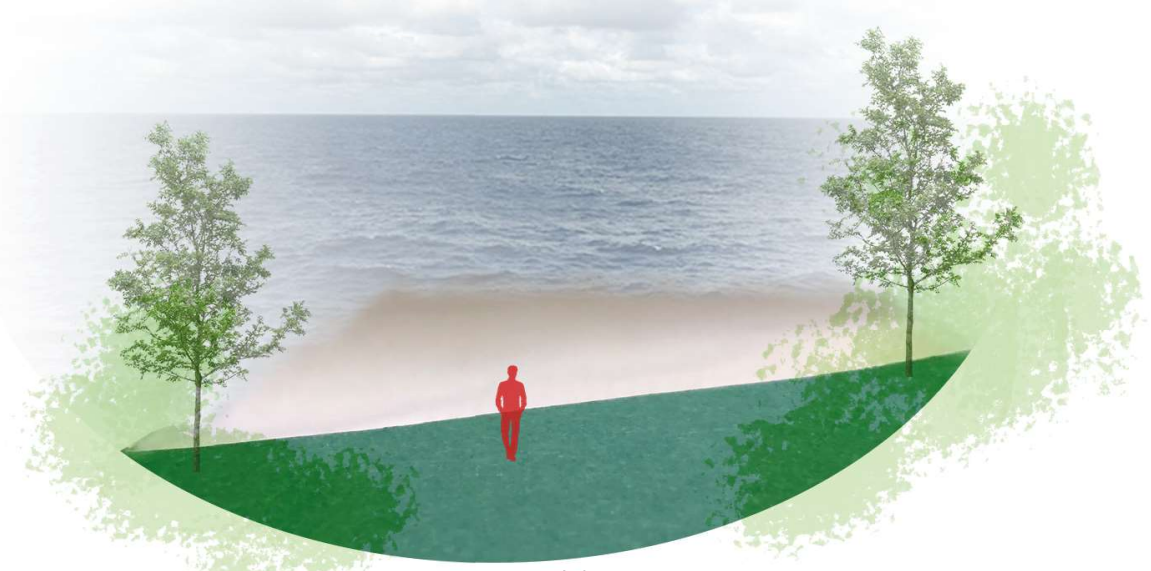

Fig. 5.130: Gover Street Foam Model Perspective 6 
Watercolours painted over the site map, to test out the urban system after design. The most conspicuous mark is the inner circle, which circles the new activity-centre to its north. Heavy green colours at the east and west end of the inner circle indicate the intersection between the two proposed urban patterns and the coastline. The second circle of the primary pattern appears as a dotted line, connecting to the inner circle and the coastal line through north-south attractions.
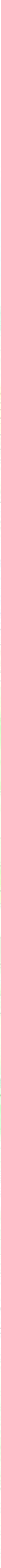


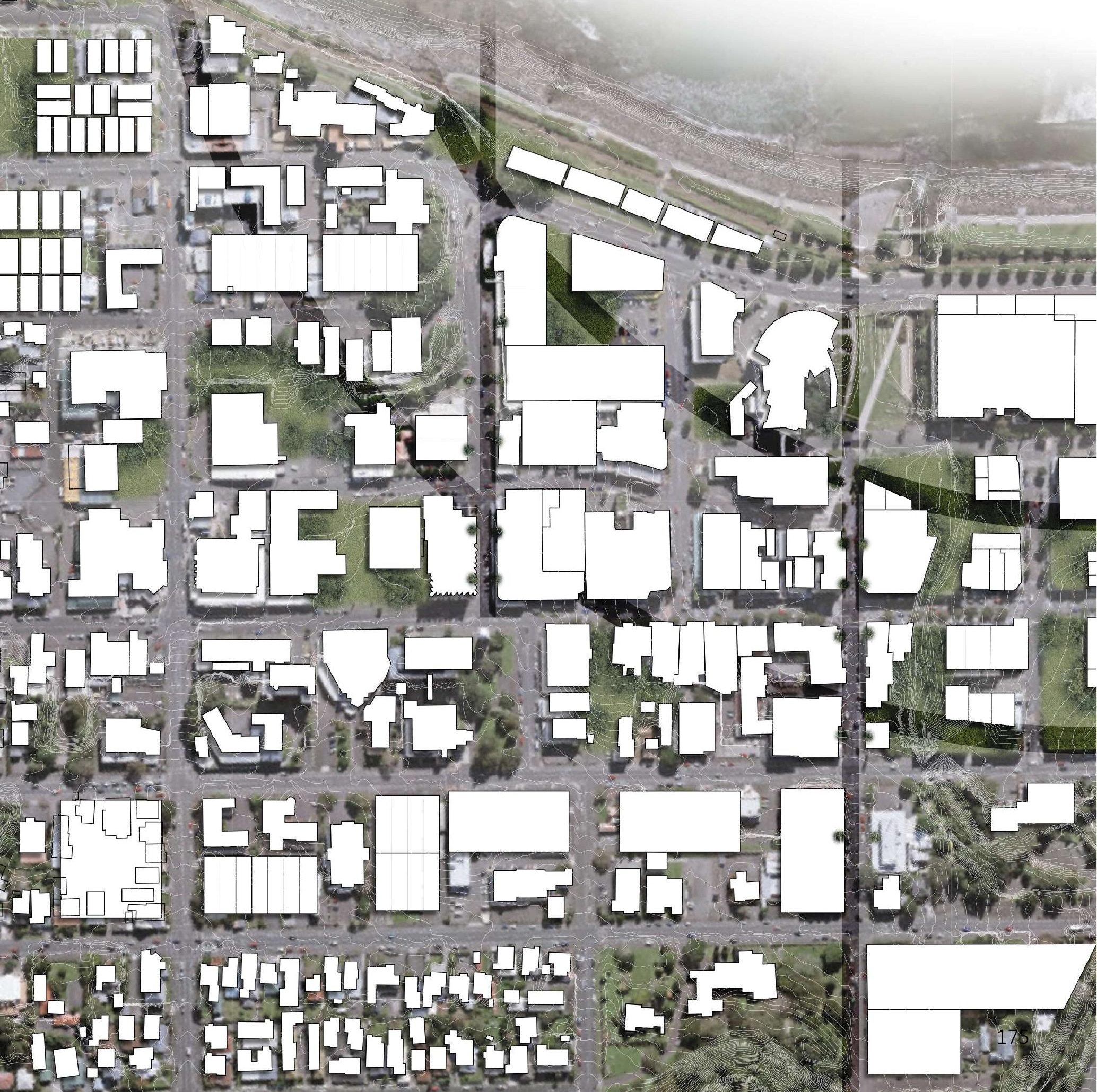




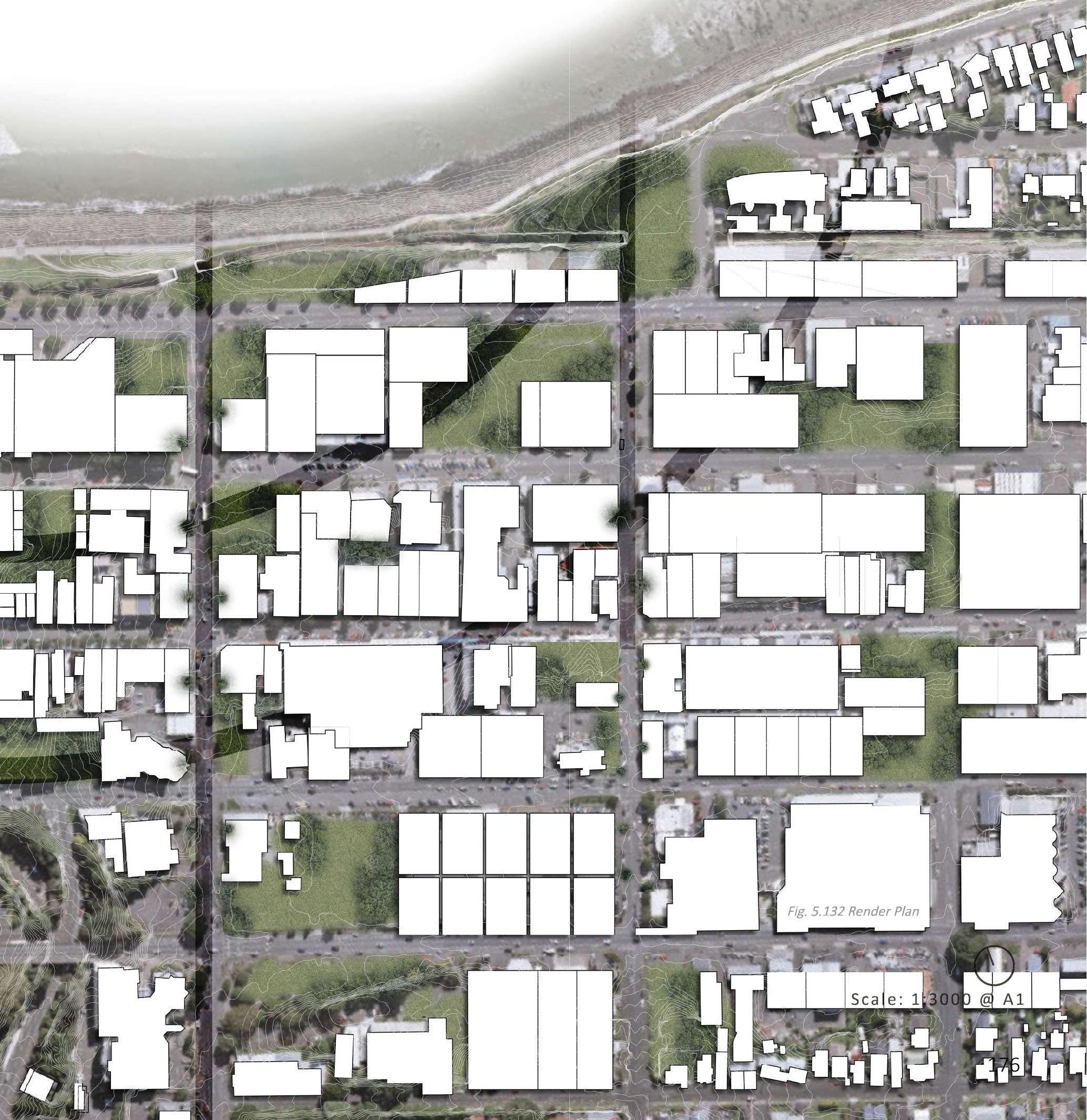


Four sites are identified as important in this chapter will proceed towards a detailed design in the next chapter, in order to clarify the master plan and patterns. Site 1 and 2 are symmetrical opposite to each other, they are the intersection between the two proposed urban patterns and the coastline. Site 3 and 4 create a connection from the coastline to the inland vegetated area, enrich the urban concrete surface by daylighting a historically significant stream.

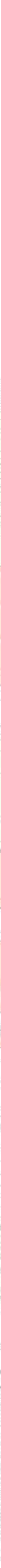




\begin{tabular}{|c|c|}
\hline Retail & Office \\
\hline Mixed-use, residential/retail & Mixed-use, residential/office \\
\hline Age-friendly accommodation & Industrial \\
\hline Residential & Greenery \\
\hline
\end{tabular}

Detial desionsite 1 Ch
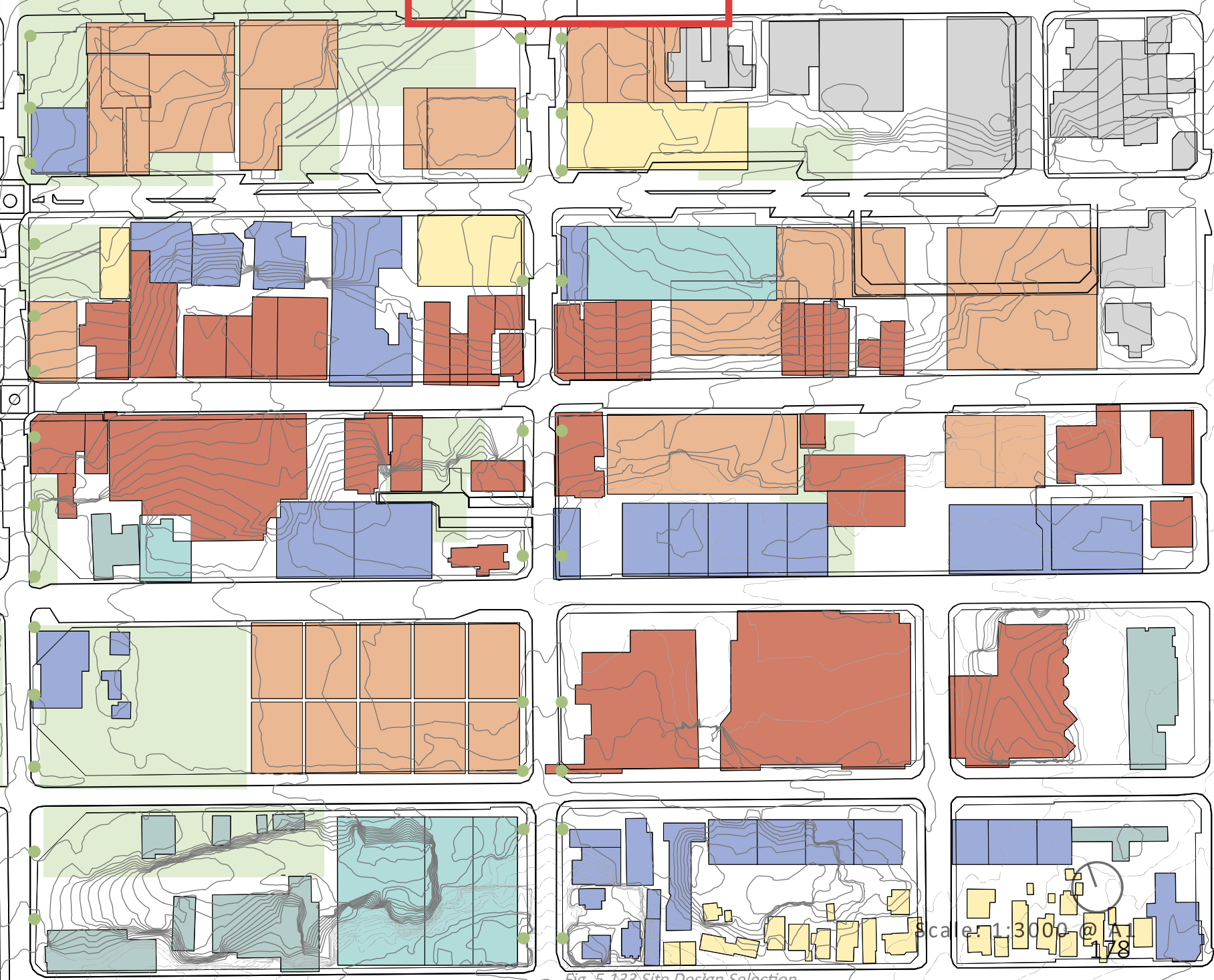


\section{DEVELOPMENT STAGES}

Citizens would realize the concentric circle pattern based on a high degree of completion to the master plan design. A development stages proposal allows communication of the concentric circle pattern through the progression of construction. In this case, the urban construction process becomes a new history and identity of the city.

\section{Stage 1}

Clear site for developing mixed-use building complex to accommodate business and residents keeps the city operates as it should.

\section{Stage 2}

Demolish those buildings that are relocated to their function at the previous stage and apply the design master plan proposal to the cleared site. Prioritize the development of active buildings within the inner concentric circle. Allow the image of the new activity centre to be recognized by citizens, developed Green space along with the building within the inner circle.

\section{Stage 3}

Subjects within the second circle require shifting building functions, which required long-term negotiation between business owners. Green space design should follow the building arrangement in order to communicate the second circle.

\section{Stage 4}

Once the building arrangement complete, the concentric circle pattern would be recognized by citizens. The new urban format would change how people use space. Therefore, adding further detailed street development and small site design to the site based on the master plan outcome. 


\section{6}

SITE DESIGN

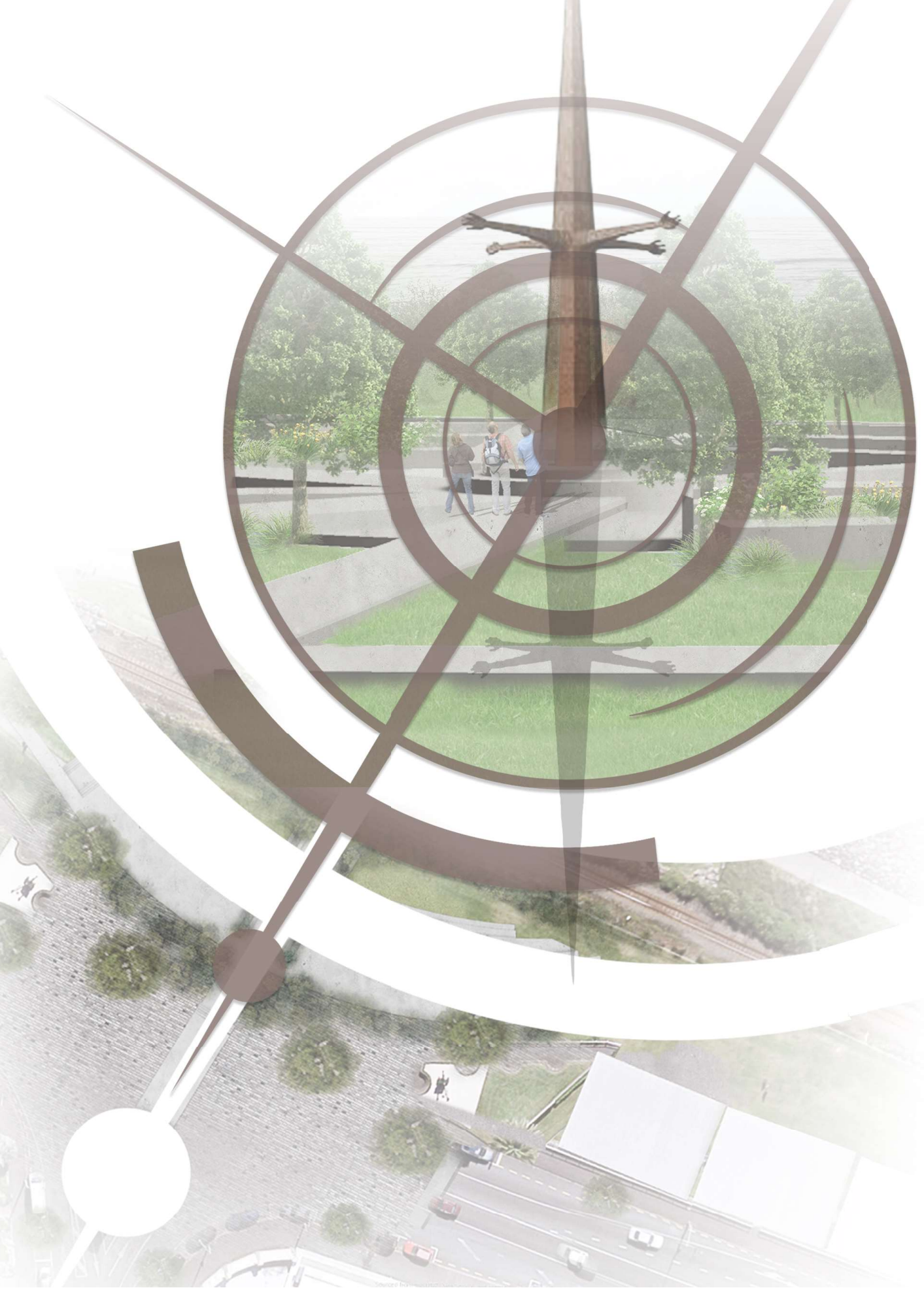


Four strategic sites are selected for detailed design. Site 1 and 2 are symmetrically opposite to each other. Site 2 is proposed a Maori War Memorial, opposite the existing World War I Memorial at site 1. Both war memorial communicates a significant historical event, which every New Plymouth's citizen can relate to. The proposing war memorials strengthen citizen's self-identity and tide their memories to the city.

Site 3 and 4 are connected sites, but they aim to daylight Huatoki Stream and enhance the pedestrian living experience around it with different design strategies. Site 3 and 4 built a connection from Pukekura Park to the waterfront, designed to perform a graduate transition between vegetated town belt to concrete paved urban area.

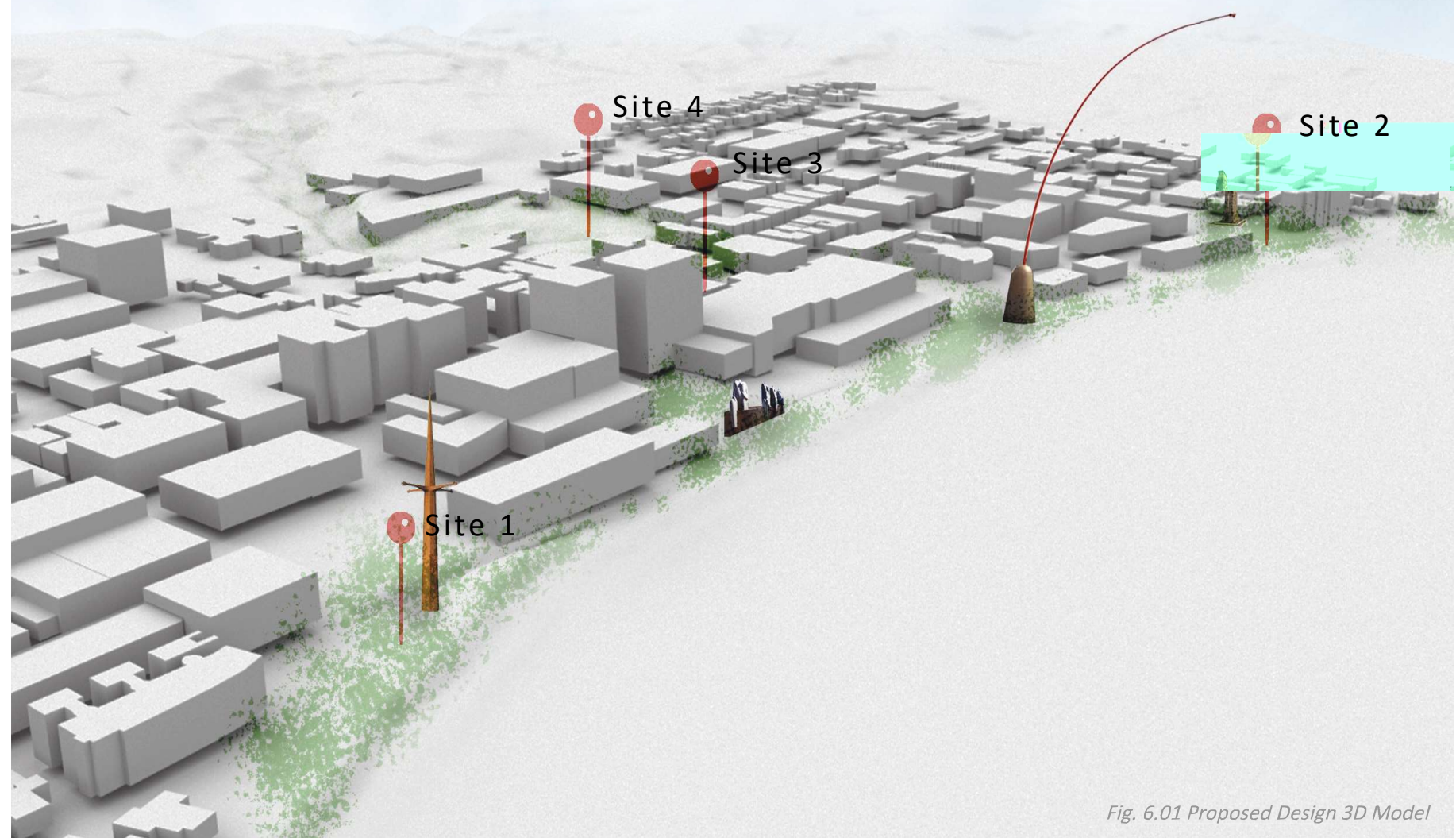




\section{Site 1}

Maori War Memorial

\section{Taranaki Wars and Pai Mārire}

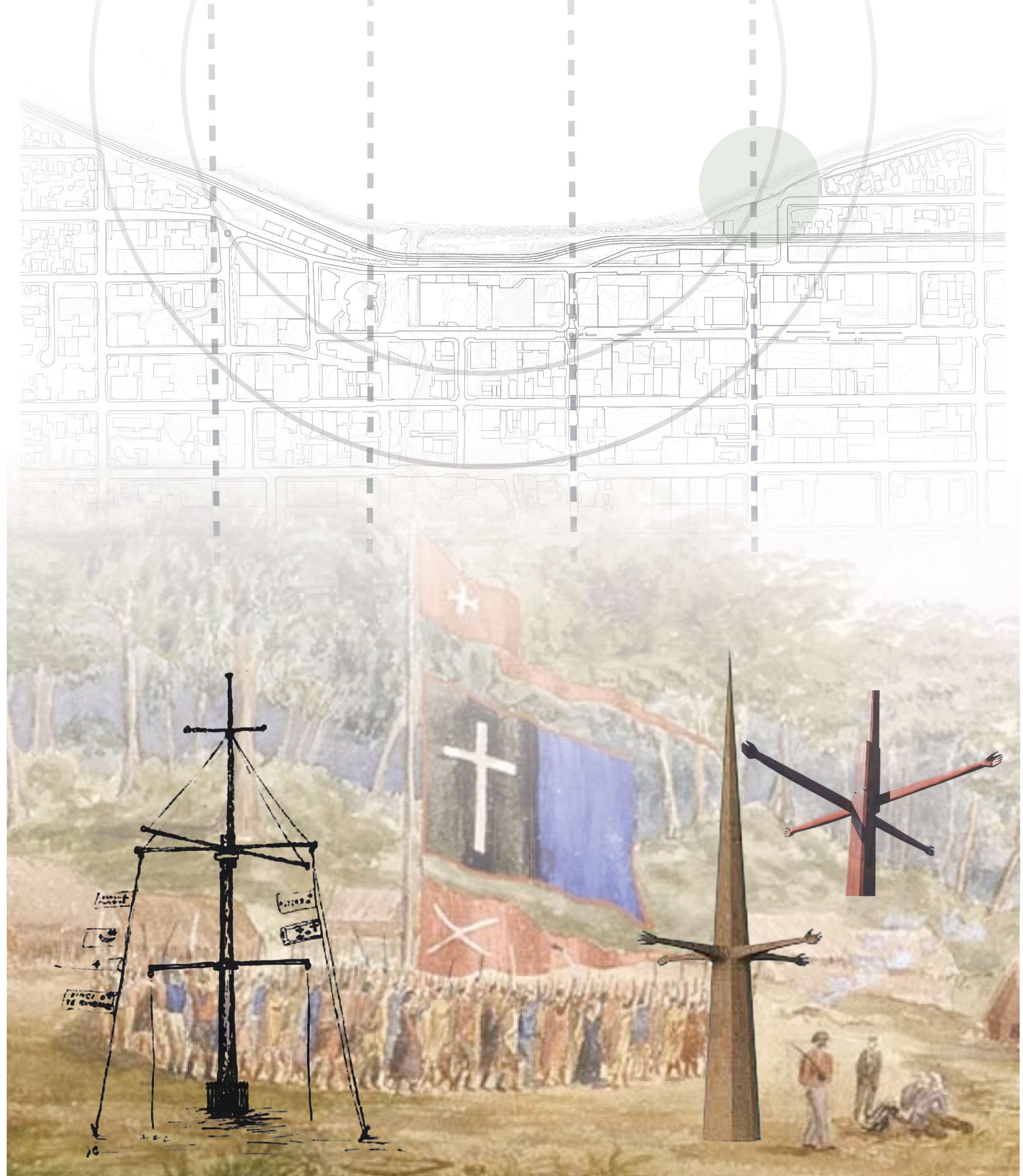




\section{Taranaki War}

The North Taranaki War was an armed conflict over land ownership and sovereignty that took place between Māori and the New Zealand government in the Taranaki district of New Zealand's North Island from March 1860 to March 1861. Maps identify major battle fields around New Plymouth.

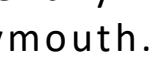

\section{Pai Mārire}

In 1862 a new religious faith, Pai Mārire, grew out of the conflict over land in Taranaki. The Pai Mārire movement, also known as Hauhau, was a syncretic Māori religion or cult founded in Taranaki by the prophet Te Ua Haumēne. Pai Mārire incorporated biblical and Mãori spiritual elements, founded with peaceful motives-its name means "Good and Peaceful".

The diagram to the right is a symbol of Pai Marire, the Niu Pole. Niu poles were raised by adherents of the Pai Mārire faith and were used in religious rituals. The first Niu pole was made from the mast of a ship. Hauhau warriors carry out rituals, walking around Niu pole before departing to battle.

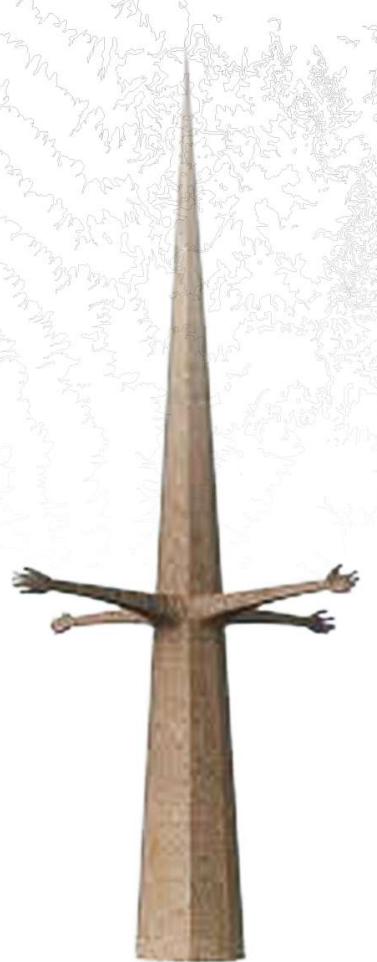


This design incorporates the idea of Hauhau warriors walking around the Niu pole before battle, and abstracts this ritual action into a design shape, directing people to move around the central pole in a circle. Each diagonal pathway points towards one of the battlefields identified on the previous page. The northeast pathway is designed to be wider than others, and points to the centre of the primary circular pattern as identified in the master plan.

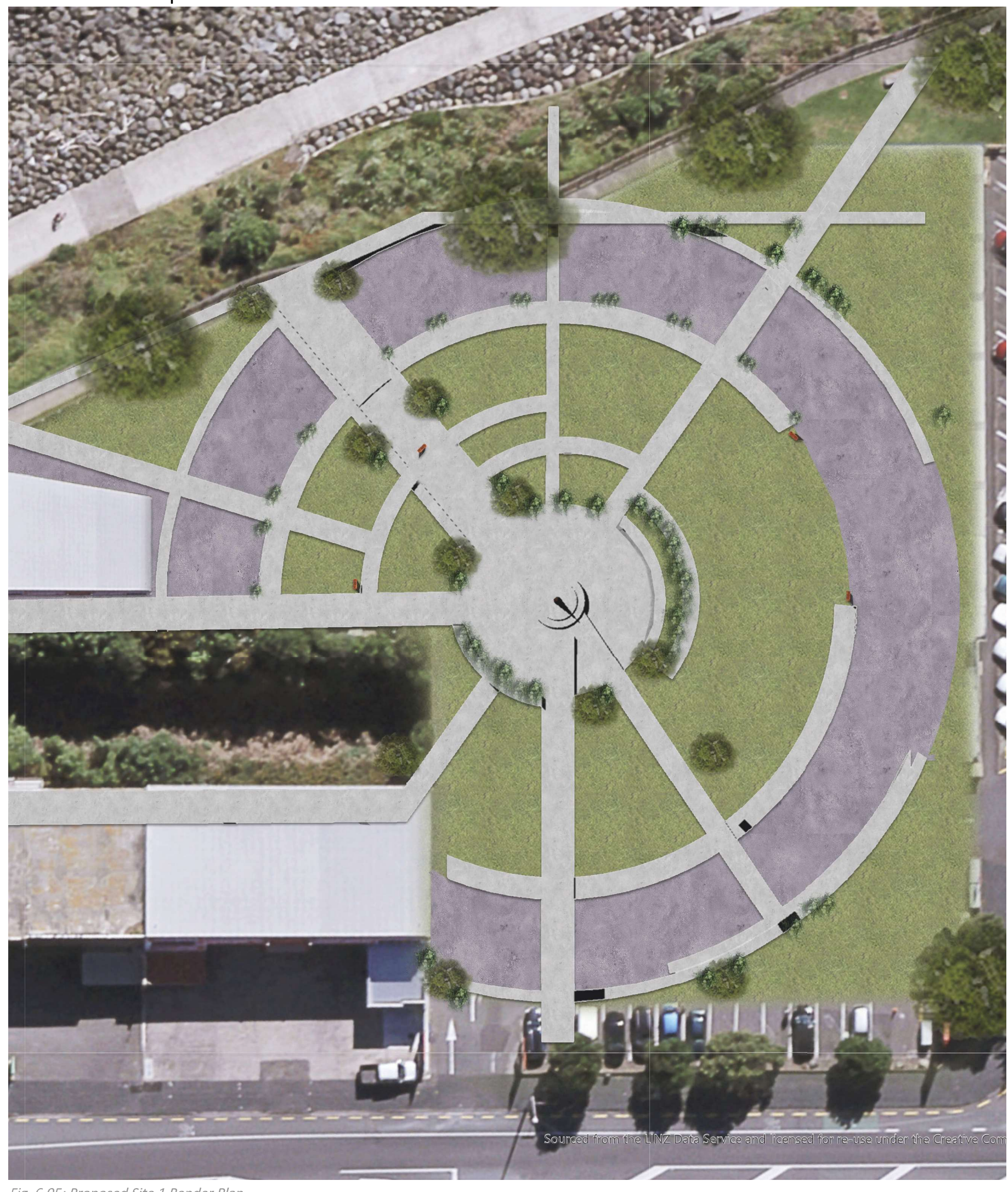




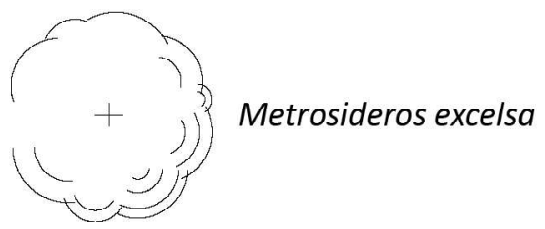

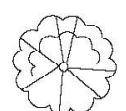

Alnus cordata

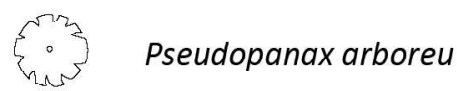

(1) Cordyline australis

(6) Libertia grandiflora

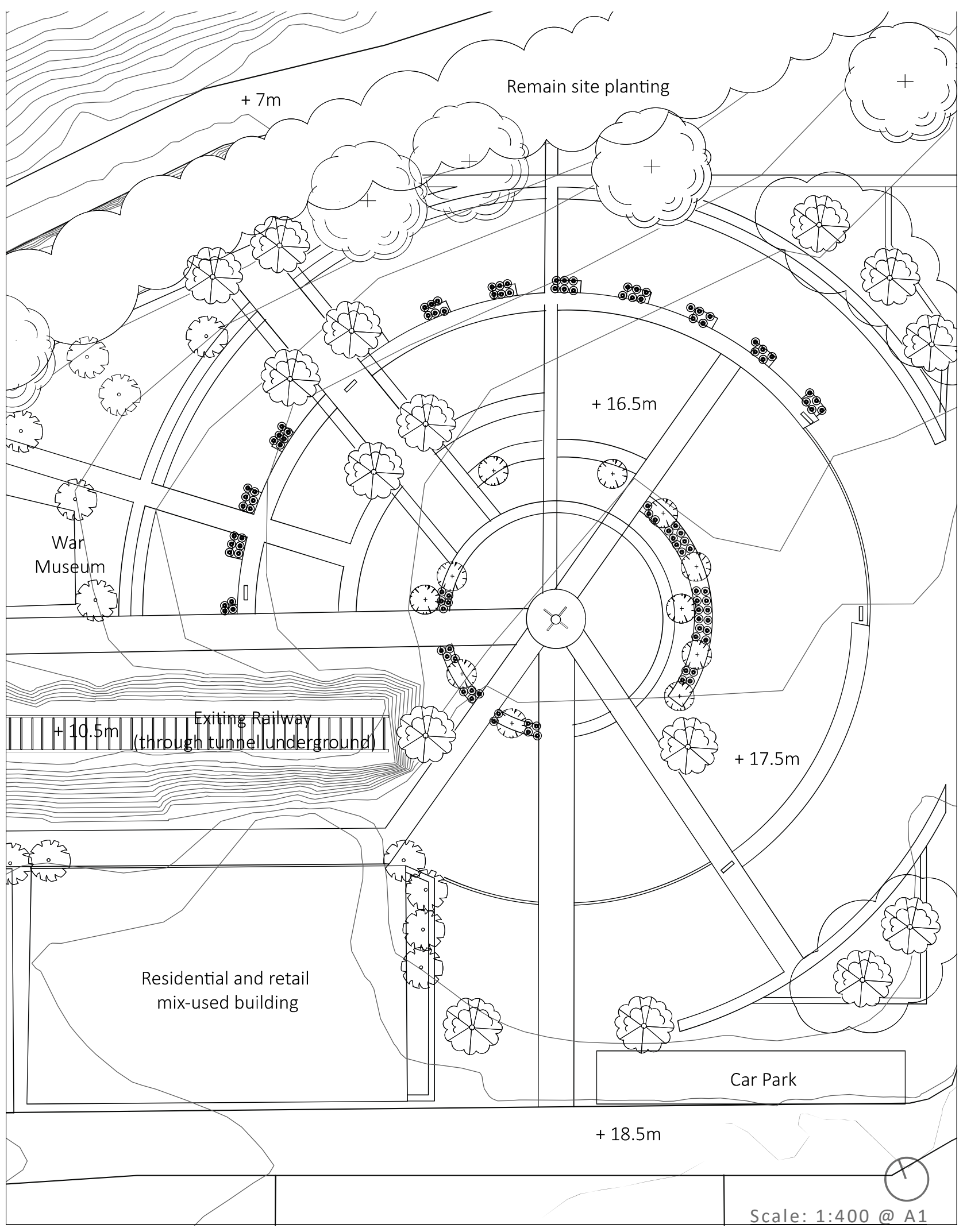


6.1 Maori War Memorial

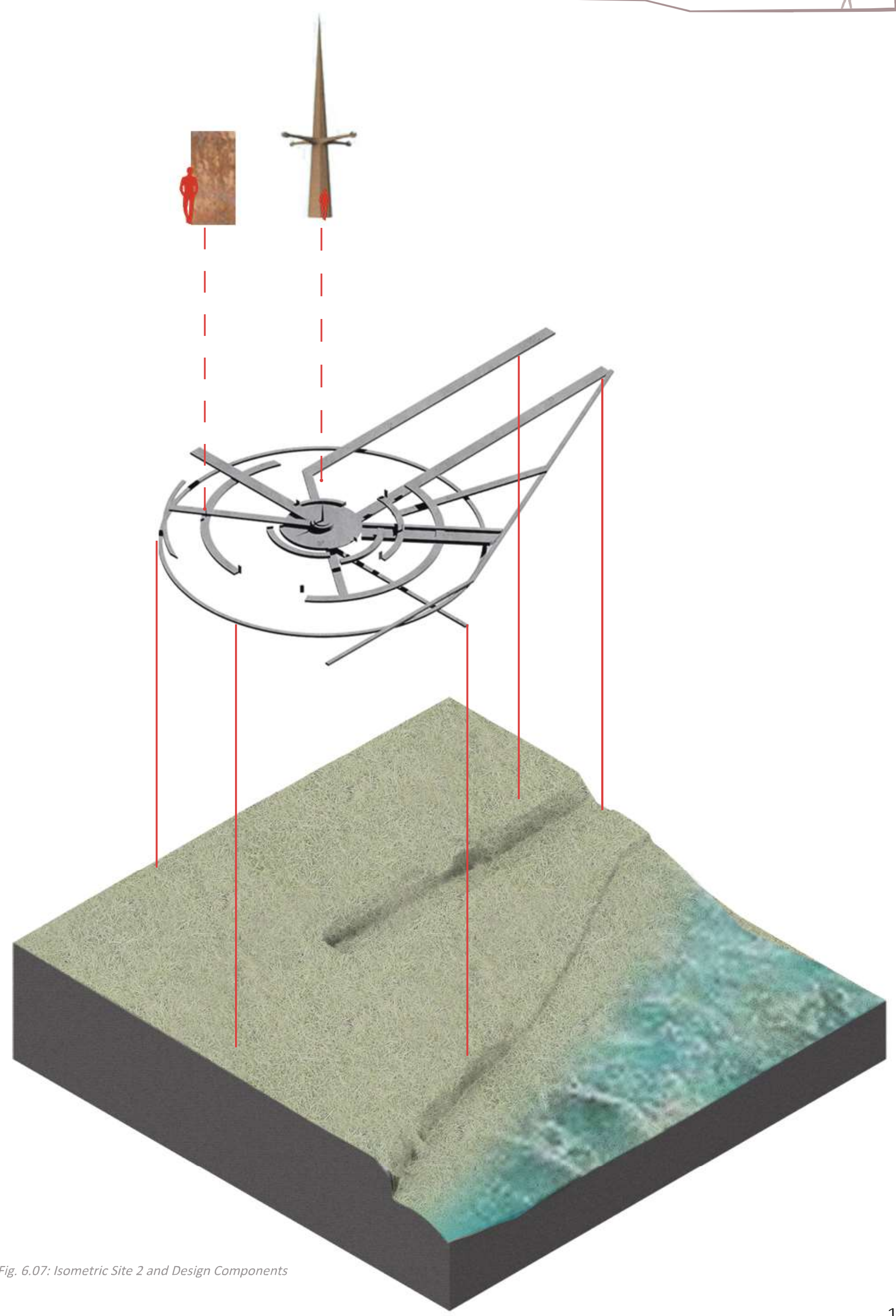




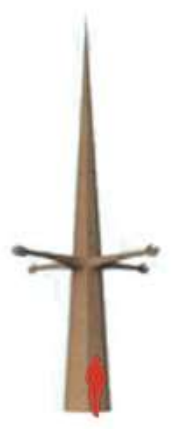

Niu Pole Pai Mārire

Height $8 \mathrm{~m}$

Central element of this design, emphasize the significant of Hauhau culture.

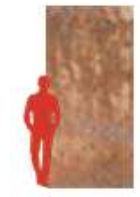

Corten steel panel

Height 2.5

Placement marking a battlefield of Nothern Taranaki War

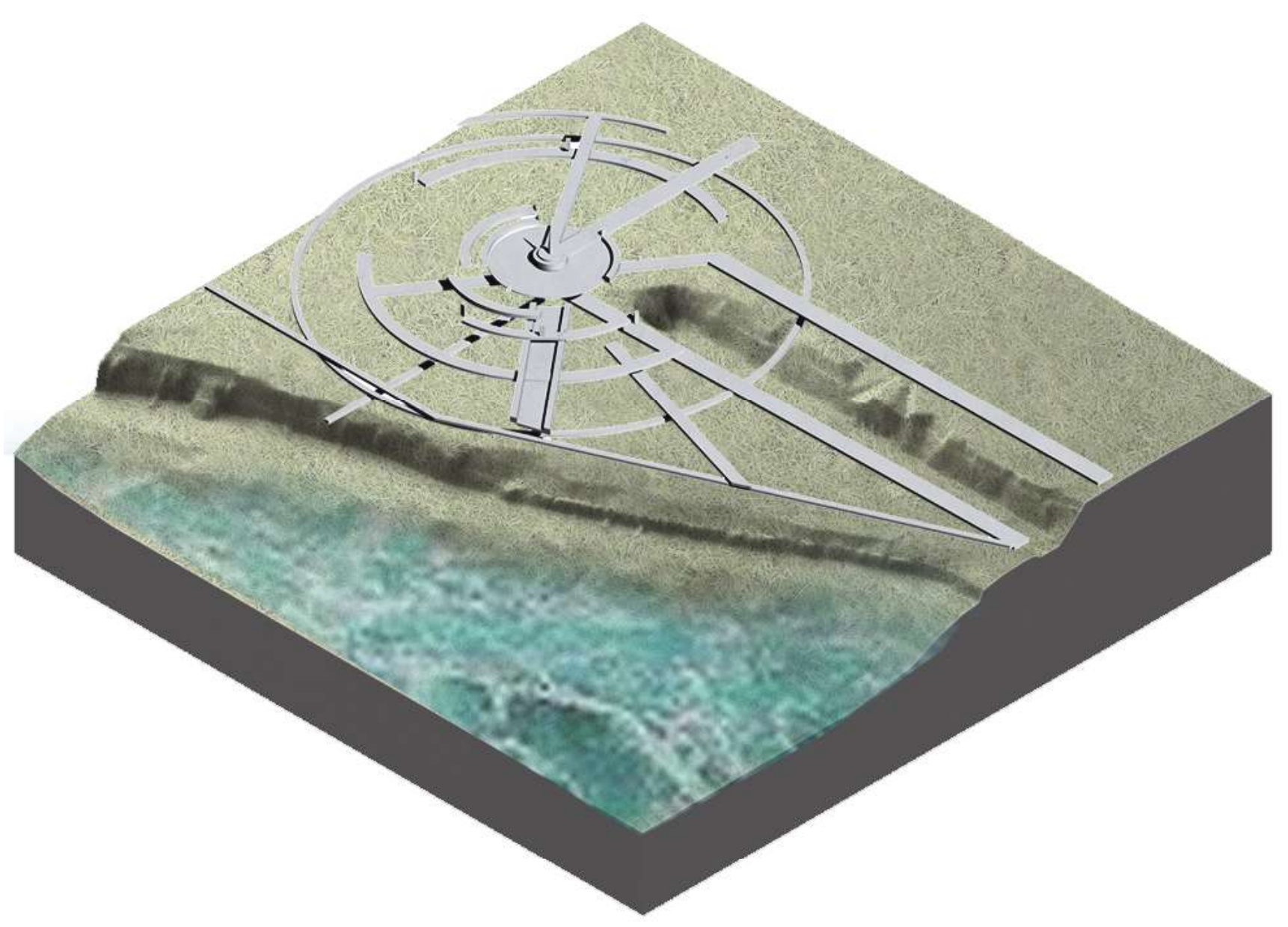




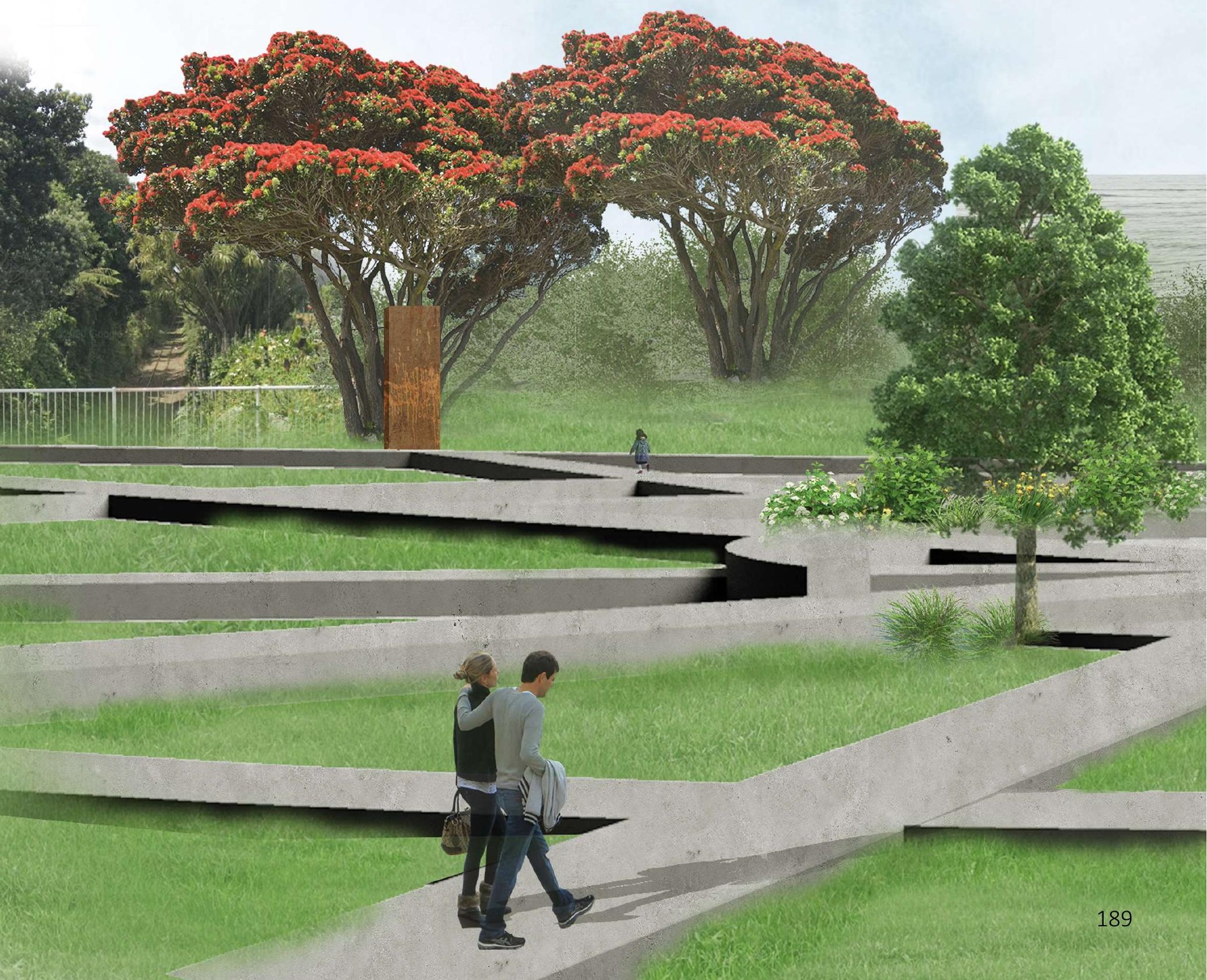




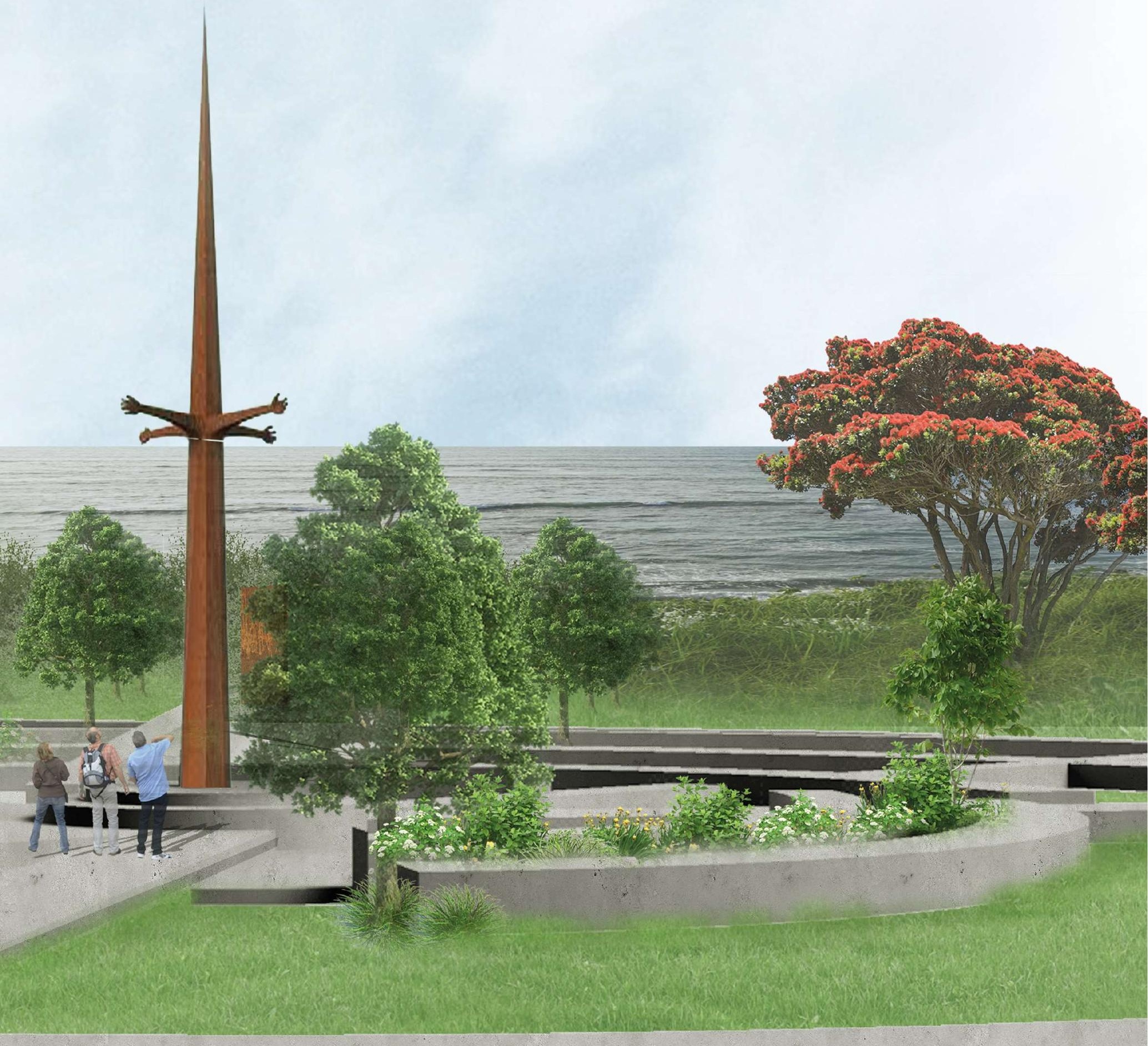


6.2 World War Memorial

\section{Site 2}

World War I Memorial

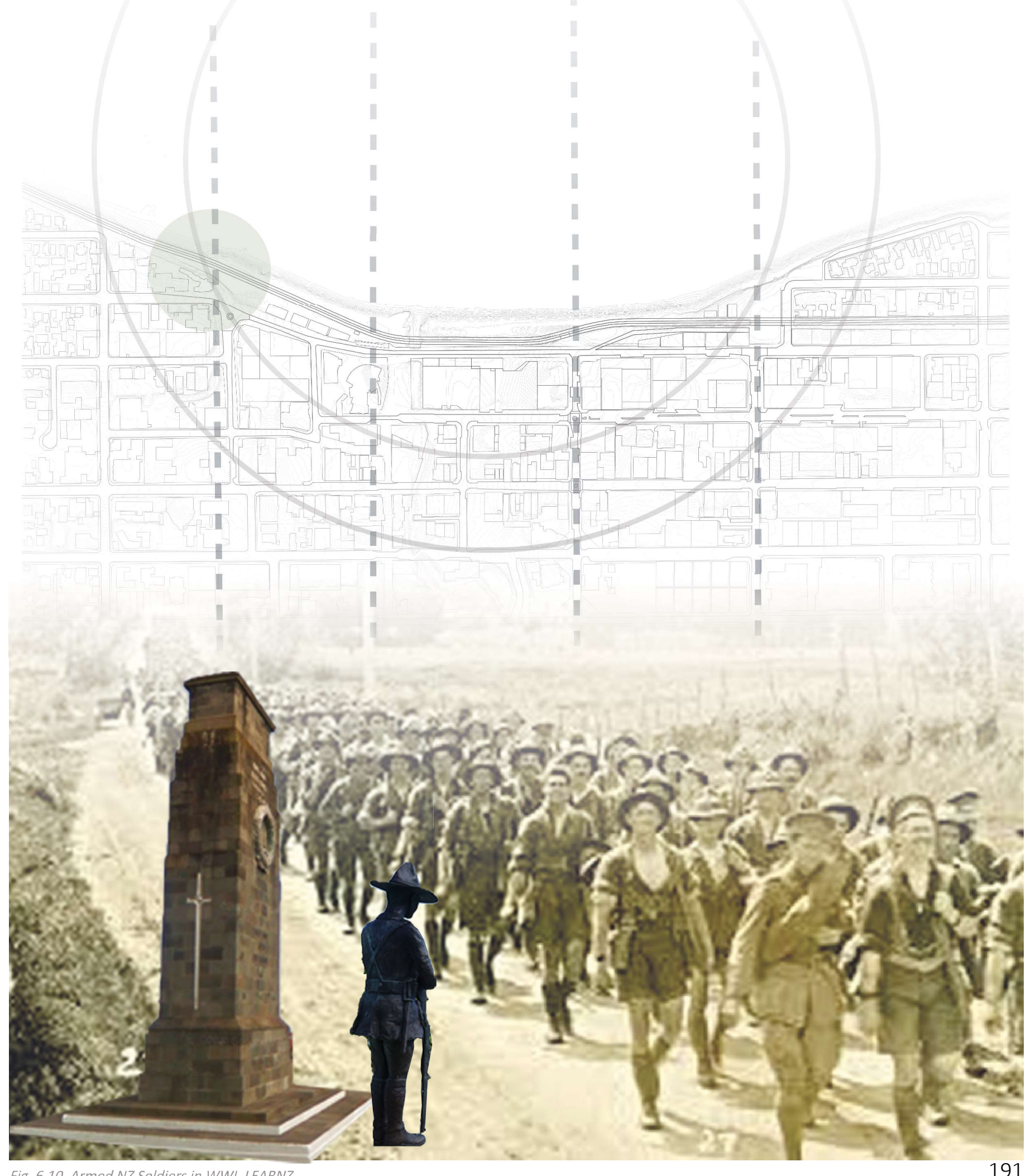




\section{Taranaki War}

New Zealand went to war following Britain's declaration of war on Germany at the start of the First World War in 1914. New Zealand's Armed Forces fought in the Gallipoli Campaign and on the Western Front.

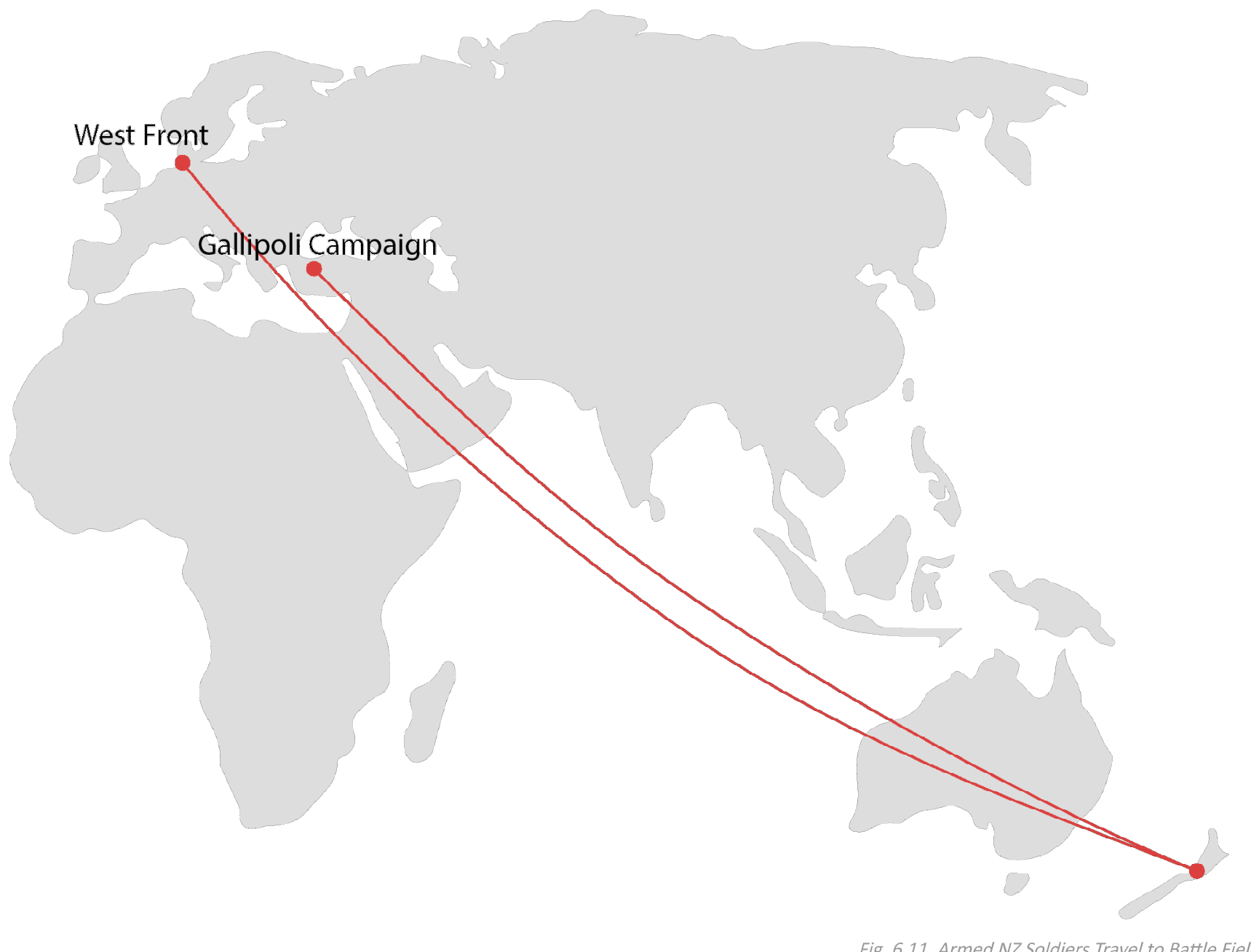


The design derives from the journey that NZ soldiers travelled to participate on the battlefield in Europe. Two mature Metrosideros exelsa (Pohutukawa) trees are planted at each side of the curving structure. With the sunrise from the east, the shadow of the eastern Pohutukawa will project onto the curved surface, which symbolizes NZ soldiers' departure. The shadow-projection of the trees shift to the west during the afternoon, and disappears after sunset, representing soldiers leaving their country and never returning.

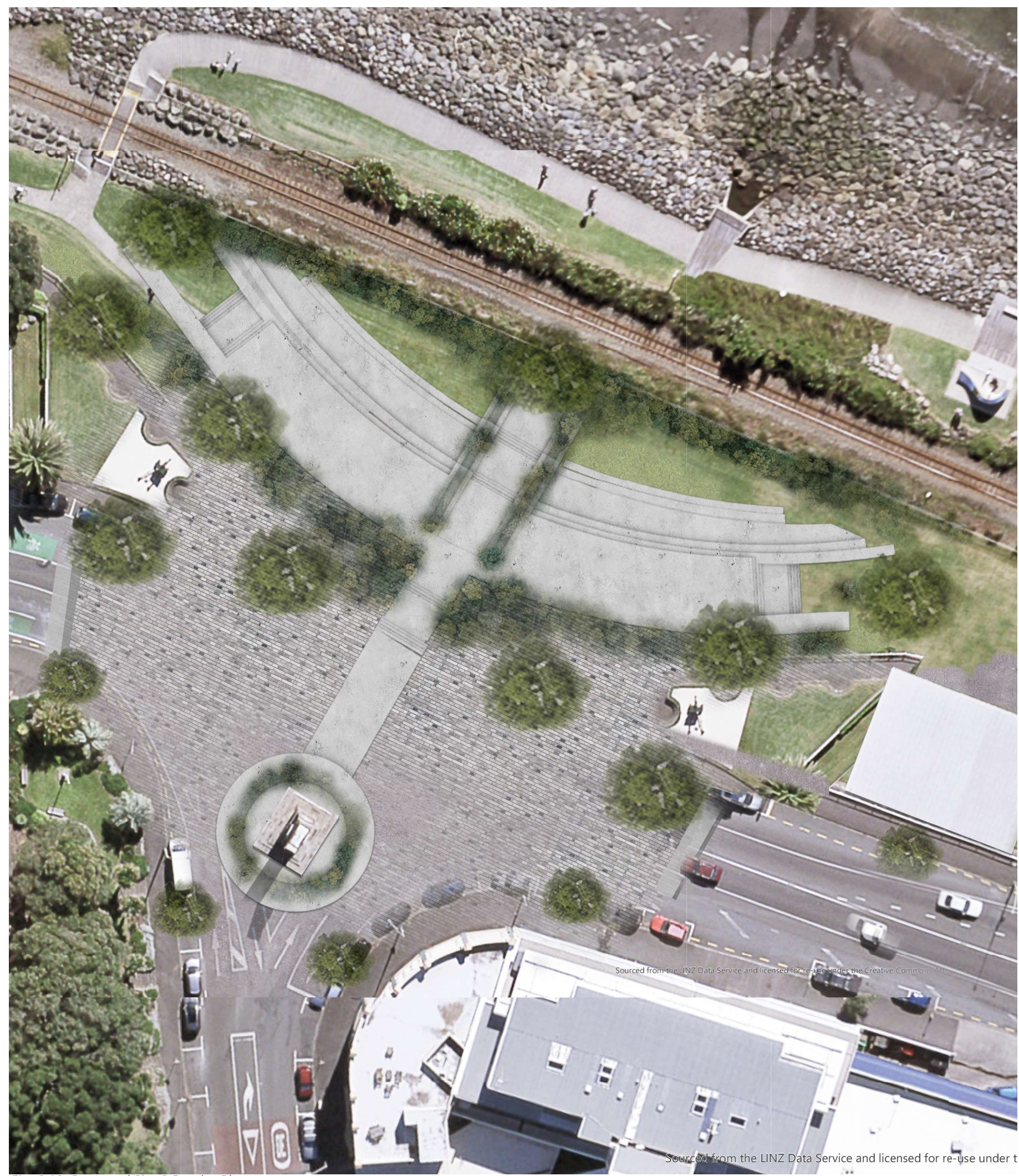


6.2 World War Memorial

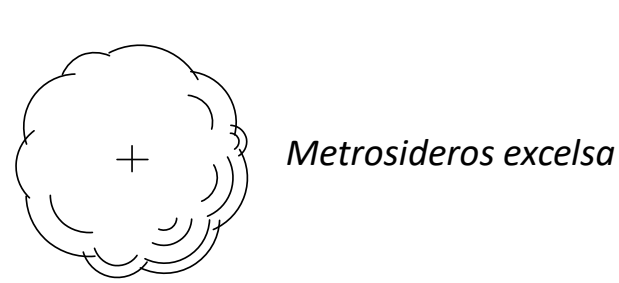

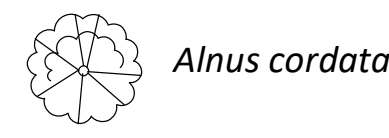

1

Alnus cordata

- Pimelea prostrata
9 Chionochloa rubra

(.) Anemanthele lessoniana

* Pachystegia rufa

Ophiopogon japonicus

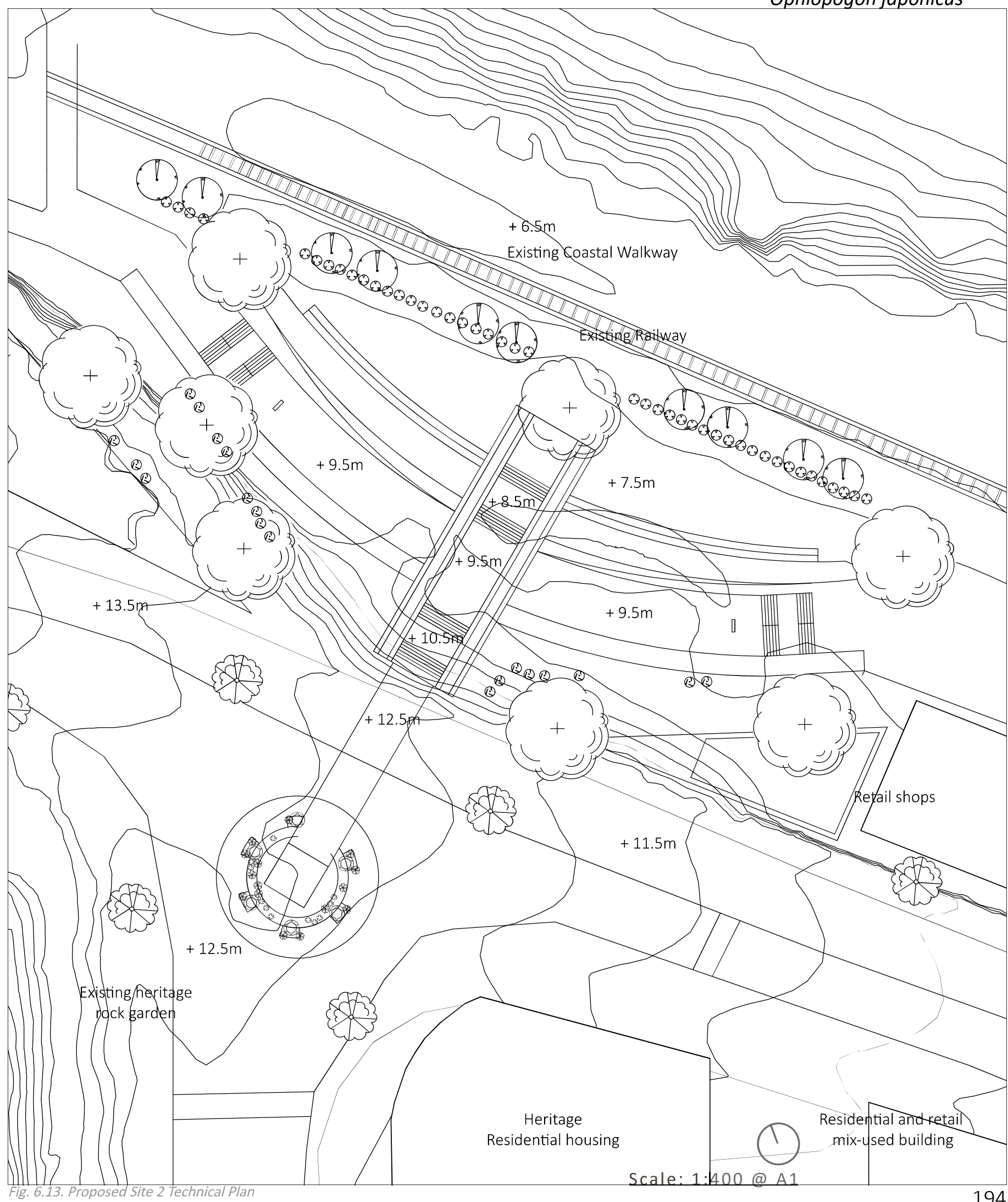




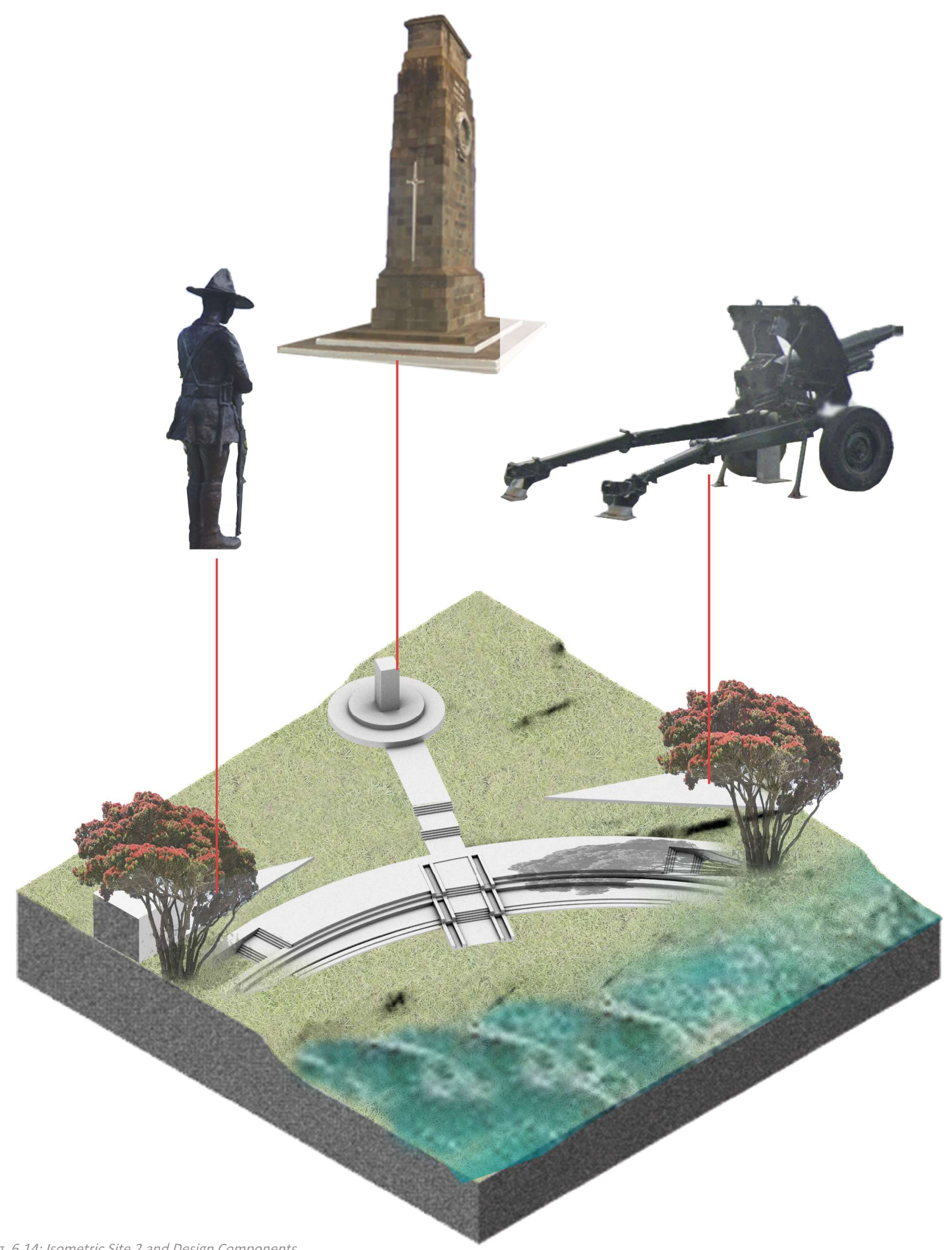




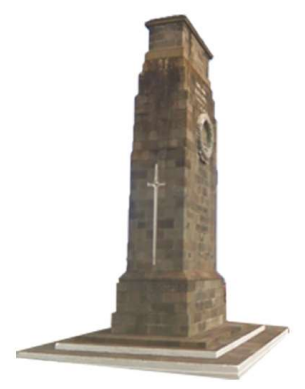

Existing WWI monumnt

Height $2.5 \mathrm{~m}$

Existing monument turned $20^{\circ}$ facing the axis of symmetrical memorial design, which pointed towards the centre of the concentric circle pattern.

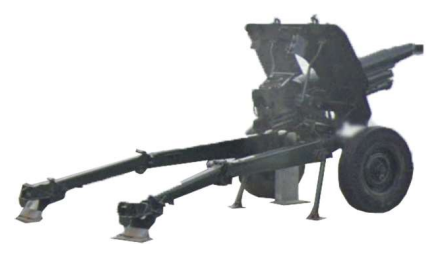

Existing sculpture Height $1 \mathrm{~m}$

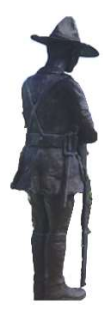

Existing sculpture

Height $1.5 \mathrm{~m}$

Moving this sculpture opposite to the cannon sculpture. 


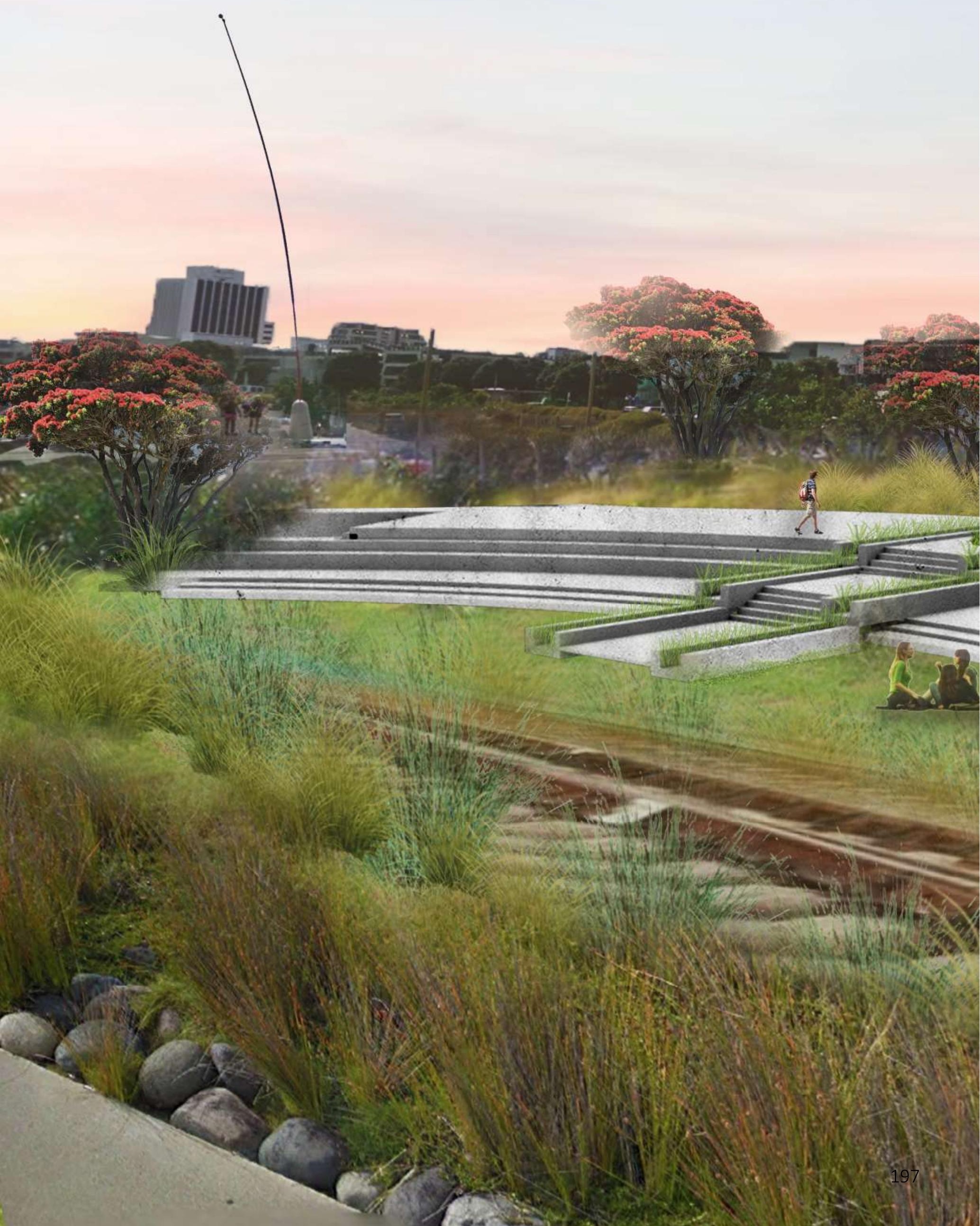




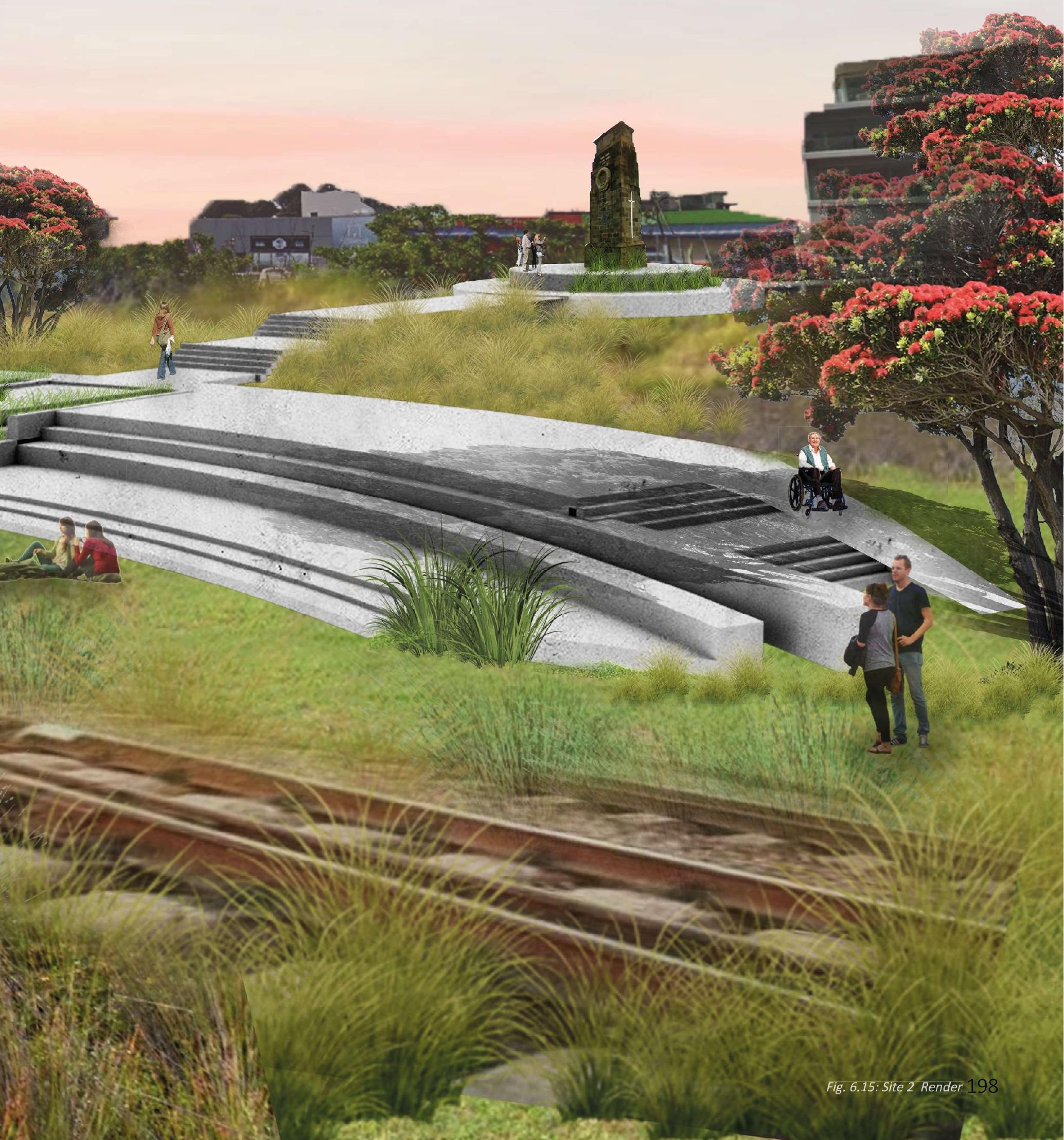




\section{Site 3}

Huatoki Plaza

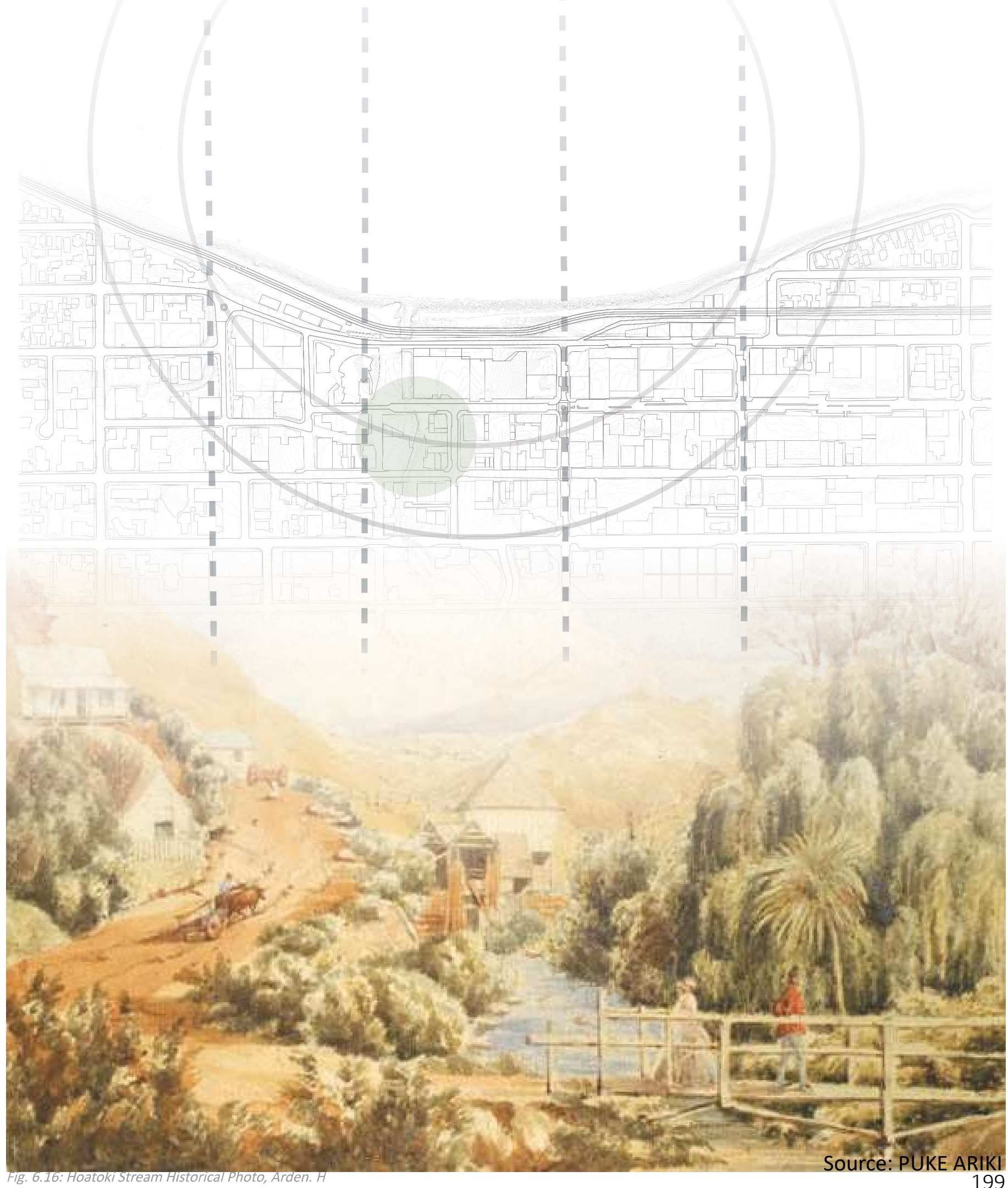




\section{Huatoki Stream}

Huatoki stream rises one kilometre outside the National Park boundary on the foothills of the Pouakai Range. The river flows through farmland to the outskirts of New Plymouth where it enters a native forest reserve. (NPDC, 2019).

\section{Historical Value}

The Huatoki has an important place in the history of the New Plymouth region. It is an important resource for Maori as it served as an access route inland, a border, and a spiritual connection to Mt Taranaki. Alongside Huatoki Stream, andesite rock provided Maori with resources to make toki (adzes). Fishing rights along Huatoki Stream were the cause of battles between the people of Puke Ariki and Waimanu (NPDC, n.d). (NPDC, 2019).

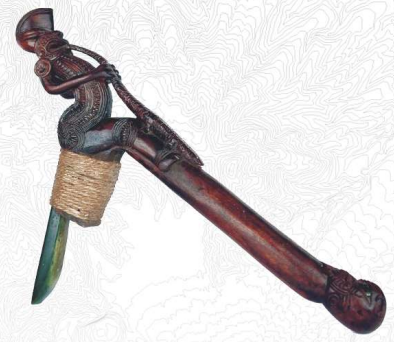

Toki (Adze)

Fig. 6.17. Toki, Museum of NZ

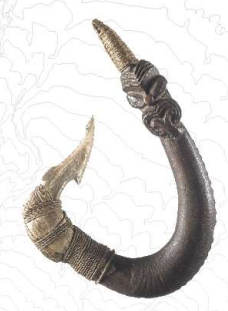

Matau (Hook) Fig. 6.18. Matau, NZGEO

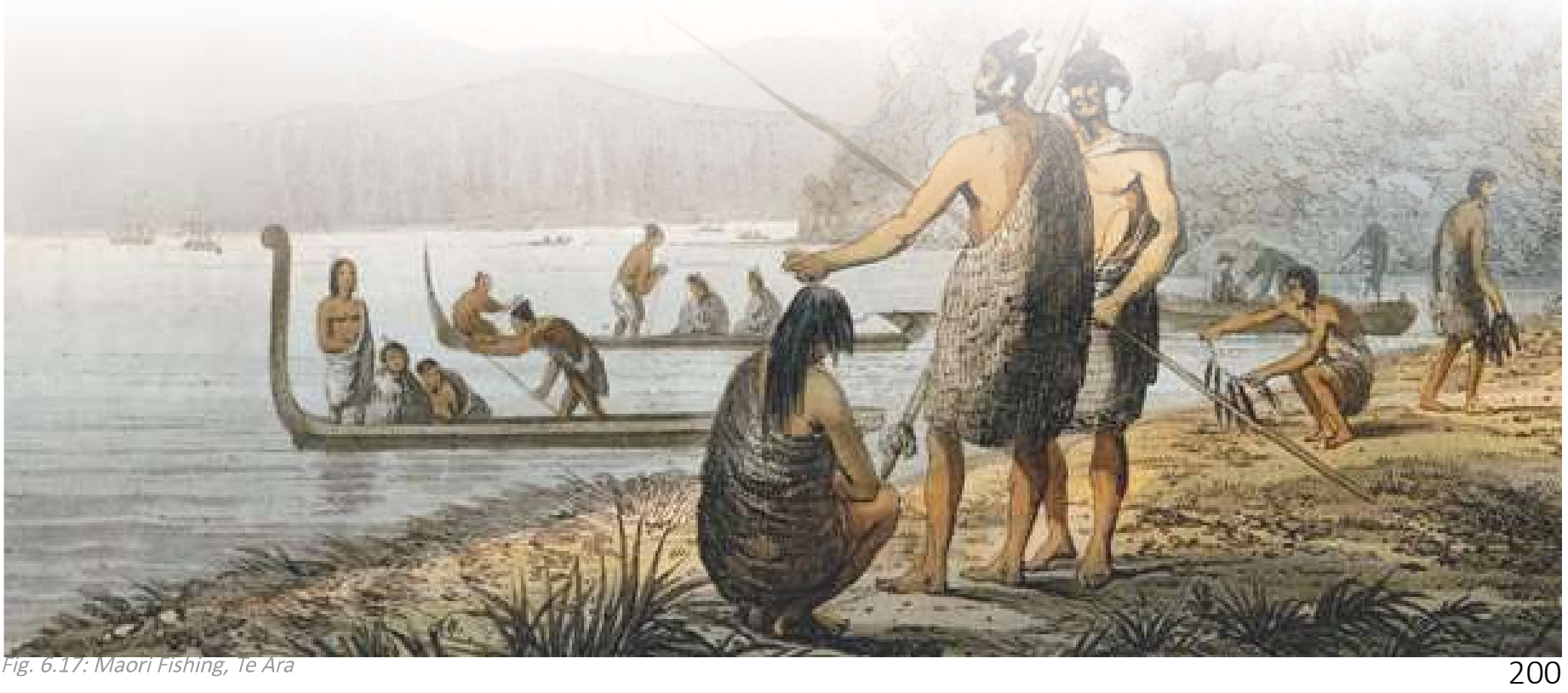


Turning the Huatoki Plaza into a vegetation-covered amenity space, the design proposes active shops alongside it. It celebrates the historical and cultural value of Huatoki Stream by applying a terrace design looking down towards the stream, with minimum coverage, and allowing access to the water. The shape of the terrace design symbolizes a matau, a Maori fishing tool. This shape can be observed from a bridge connecting the east and west bank. The bridge traces the circle pattern as defined in the master plan. People can walk under the bridge. They can also walk under State Highway 44 to access site 4. Planting species are chosen to create an extension from site 4.

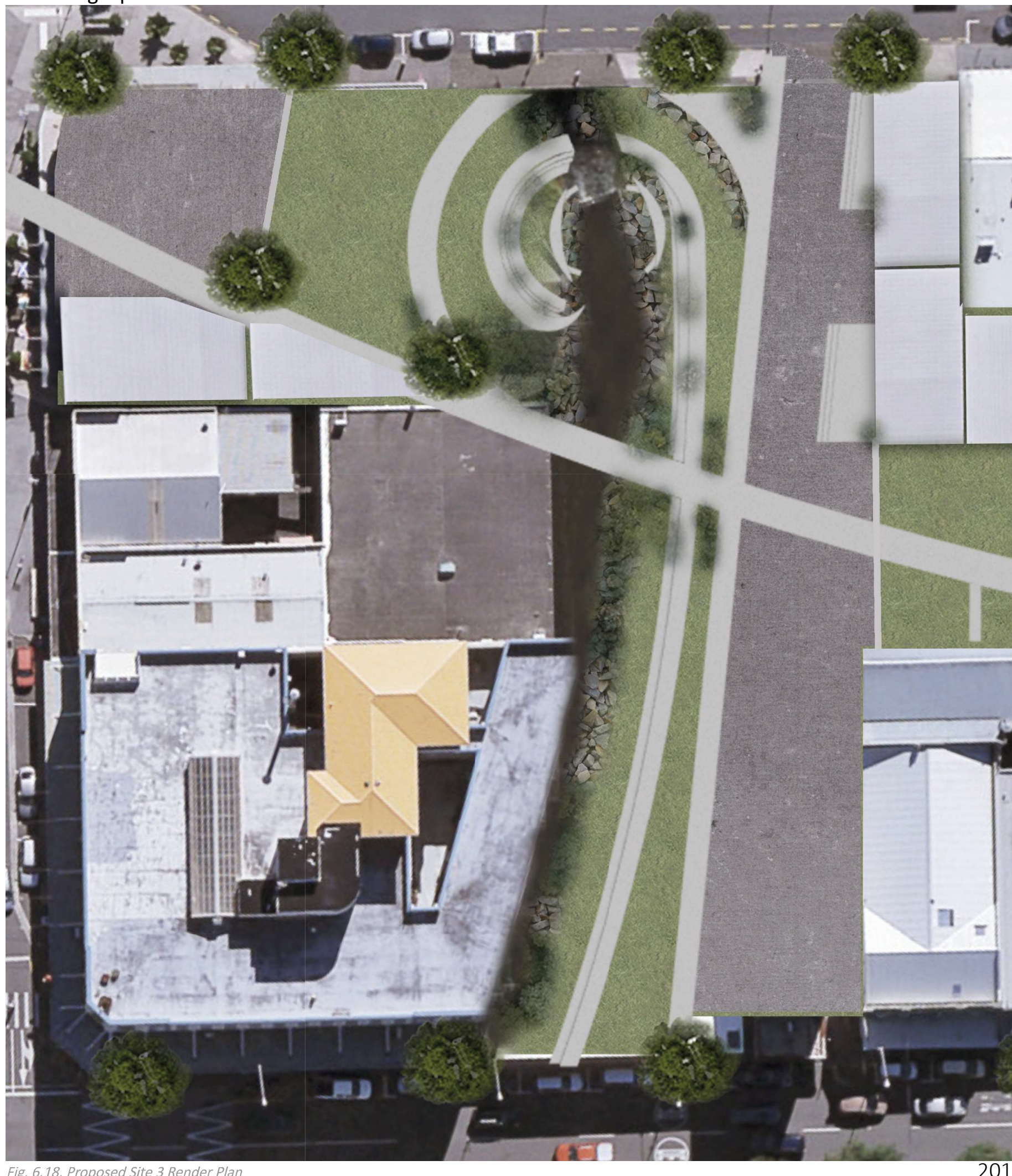




\begin{tabular}{|c|c|c|c|c|}
\hline Alnus cordata & 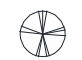 & Phormium tenax & $\odot$ & Carex secta \\
\hline Cordyline australis & Q & Apodasmia similis & o & Carex virgata \\
\hline
\end{tabular}

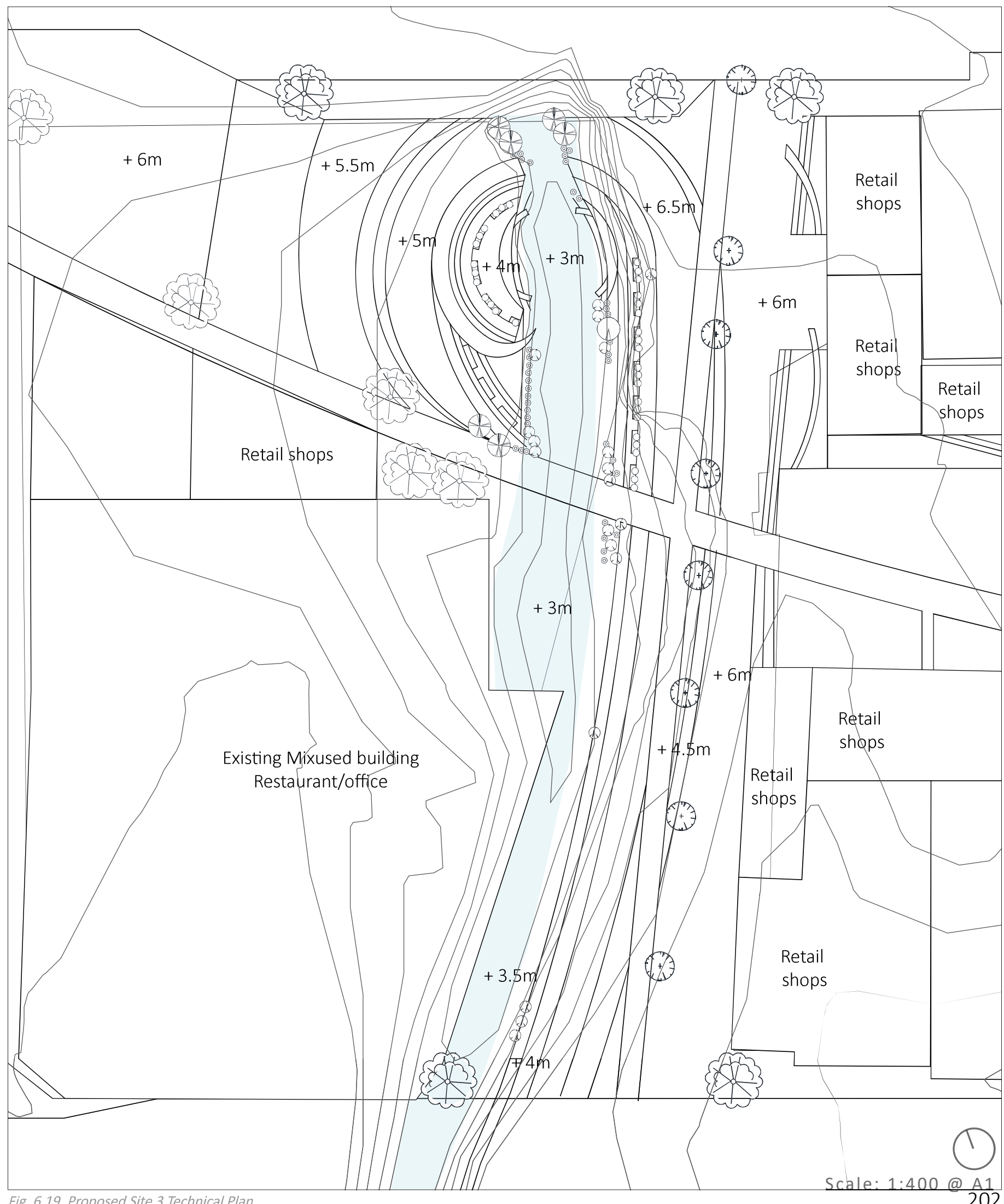




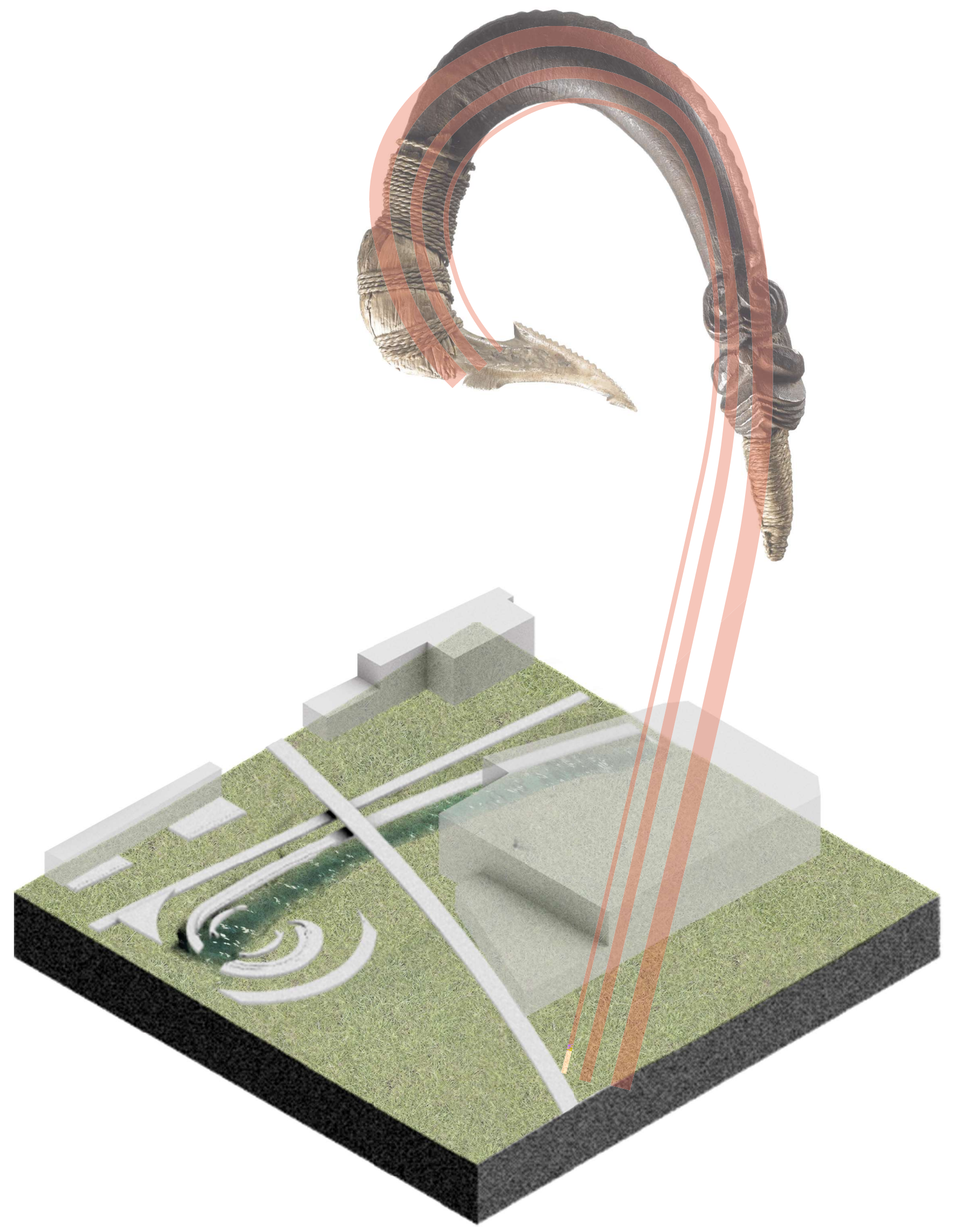


People can walk under the State Highway 44 to access site 4 . through a underbridge tunnel

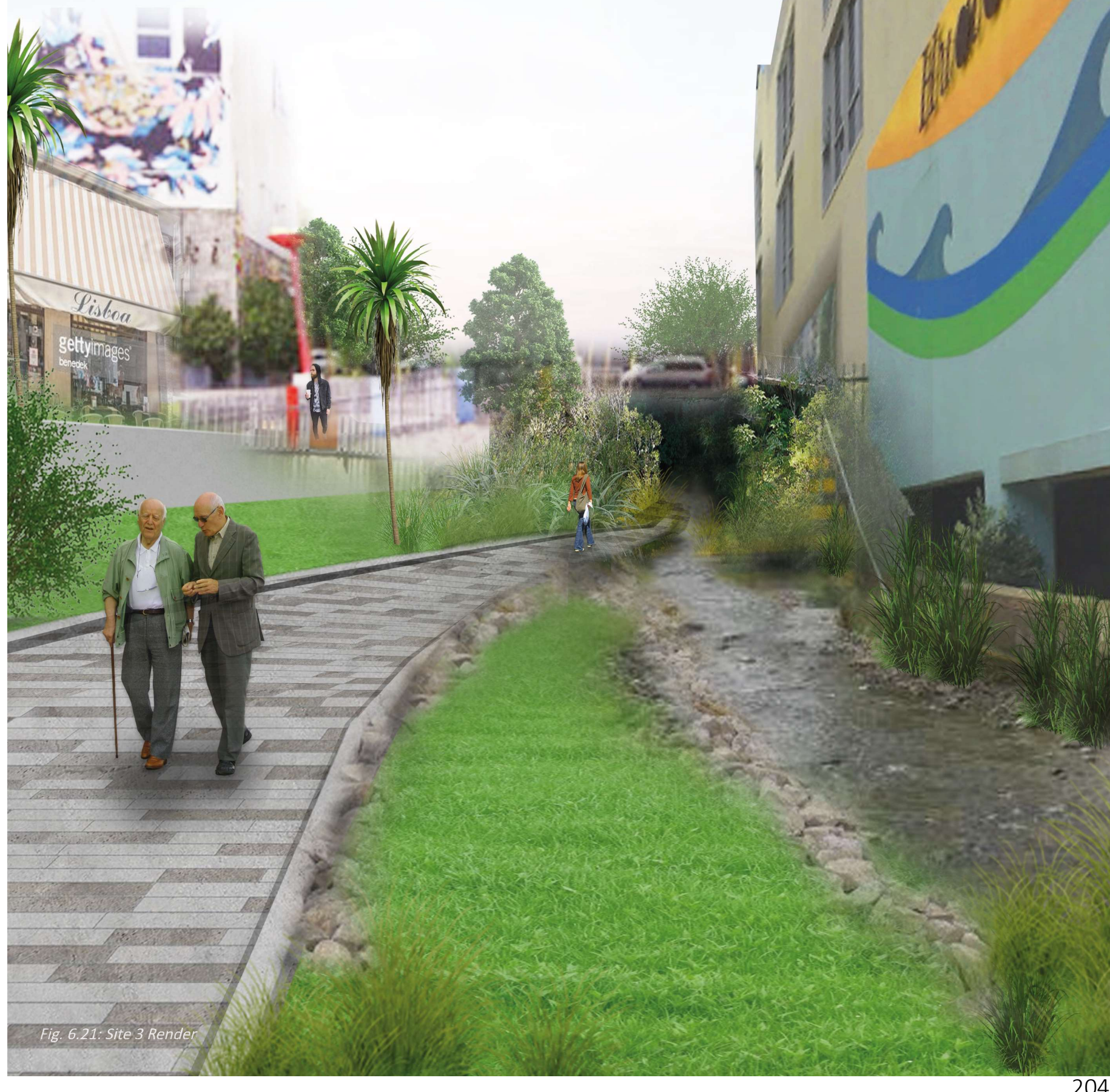




\section{Site 4}

\section{Huatoki Stream Reforestation}

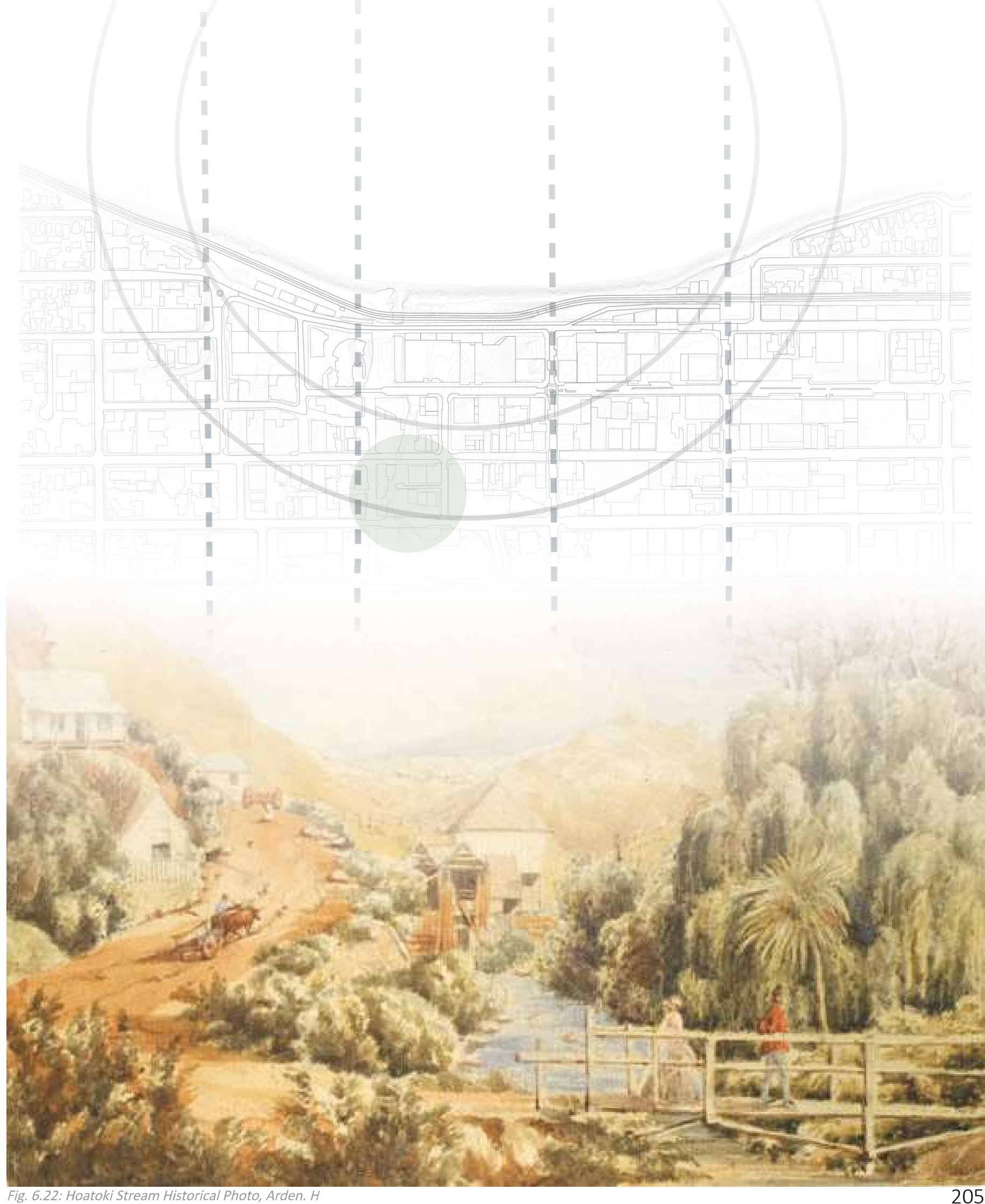




\section{Huatoki Stream}

Huatoki stream has high-value significance, as it should. Part of the stream is buried underground; other parts have been designed unsympathetically, to yield to the urban grid system. Concrete and asphalt separate the central area from the town belt; Huatoki walkway stops, and the stream is buried when it meets the State Highway.

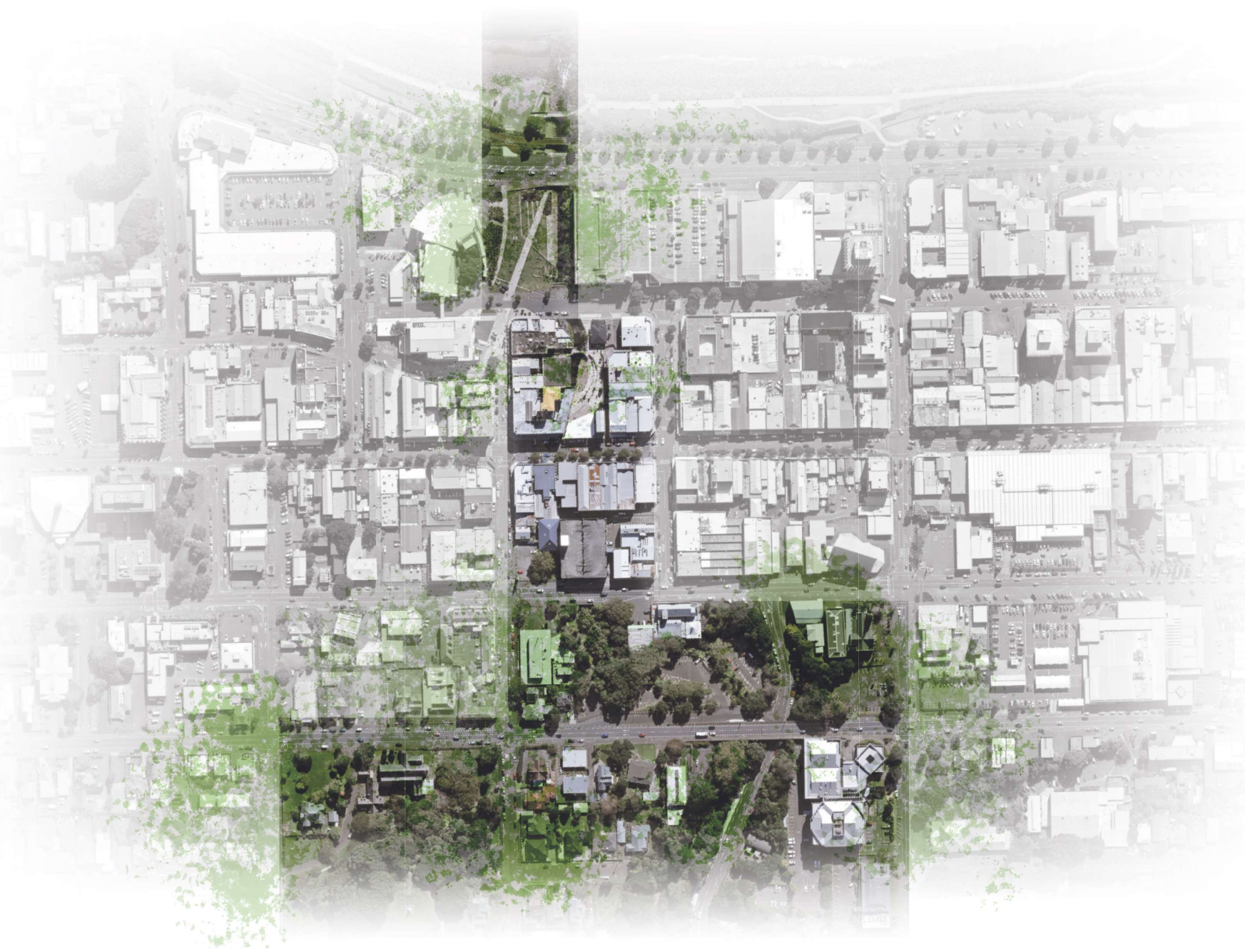


Site 4 is a connection point from New Plymouth's town belt to its urban area; it creates a green corridor with site 3 to ensure a pedestrian-friendly walking environment along Huatoki Stream to the coastal walkway. Site 4 creates an image for the future by reforesting the cleared site. A nursery provides vegetation for planting, raised from seedlings; here citizens can witness the formation of a reforested urban space.

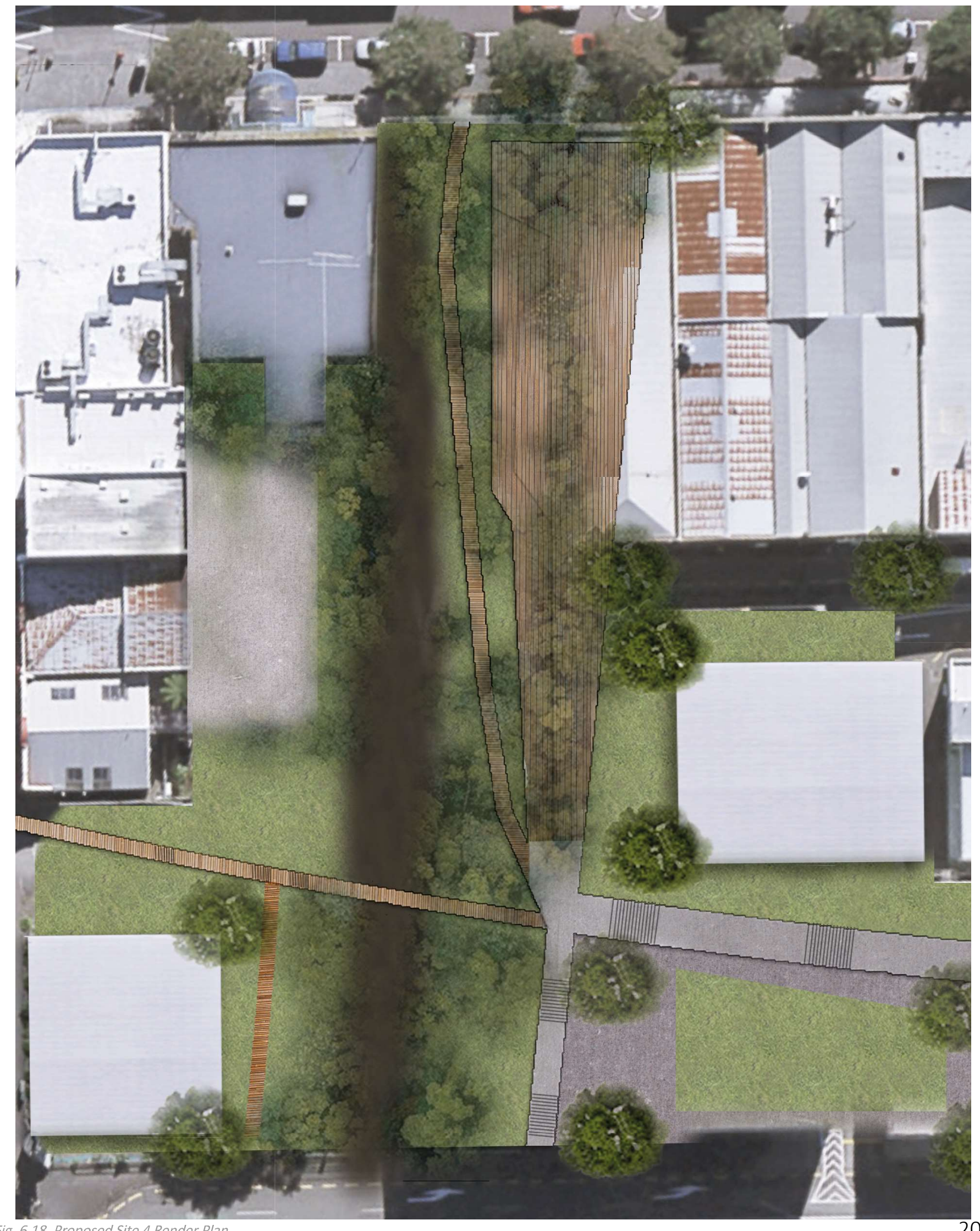


6.4 Huatoki Stream Reforestation

- Carex secta

- Carex virgata

(i) Libertia grandiflora

Q Apodasmia similis

* Parablechnum novae-zelan

A Phormium tenax

Hustroderia toetoe

Cordyline australis
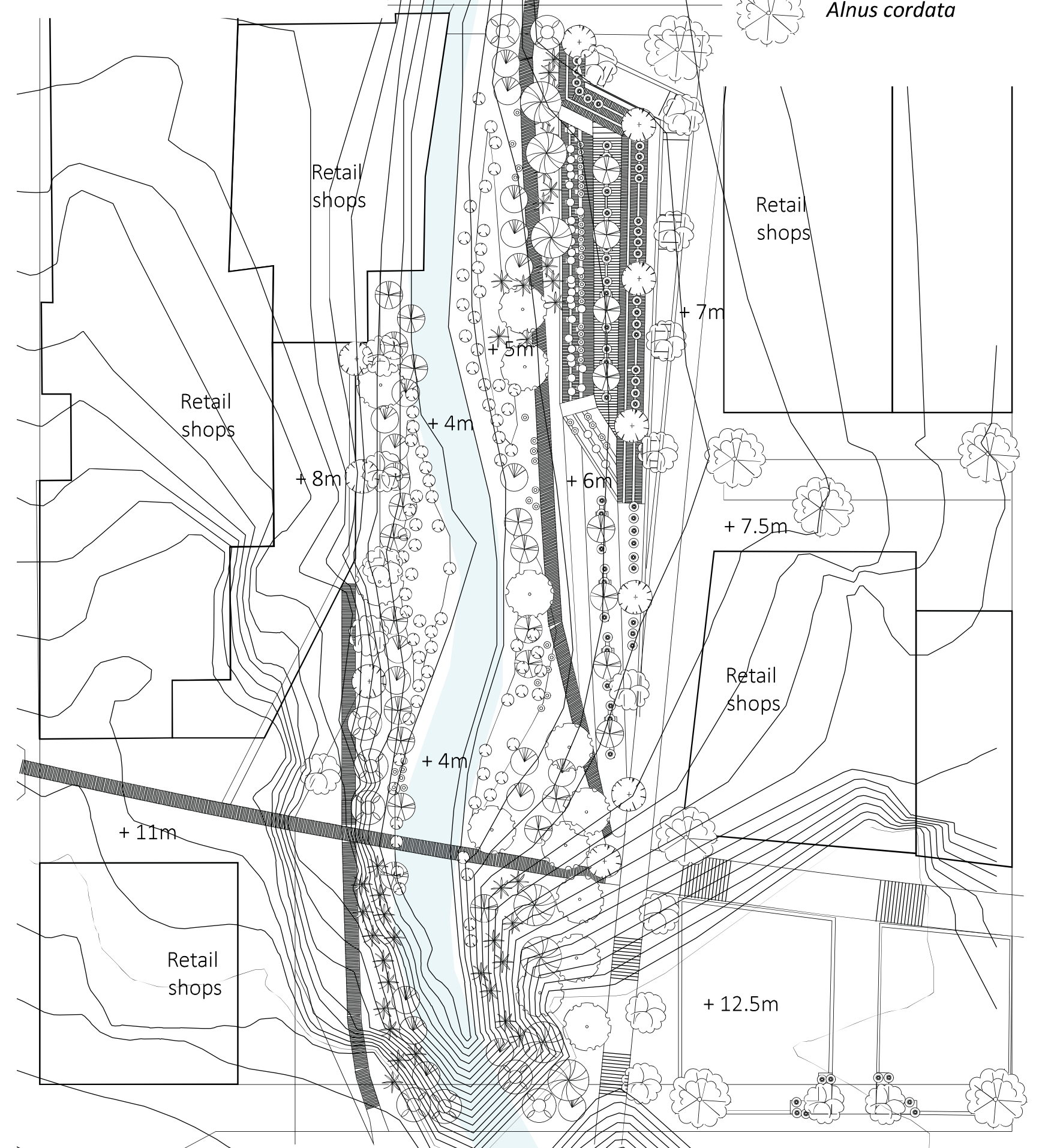

Stale: 1:400@A1

(8) Myrsine australis

$\$$ Pneumatopteris pennigera

(2) Leptospermum scoparium

Pennantia corymbosa

Alnus cordata shops 
Year 1
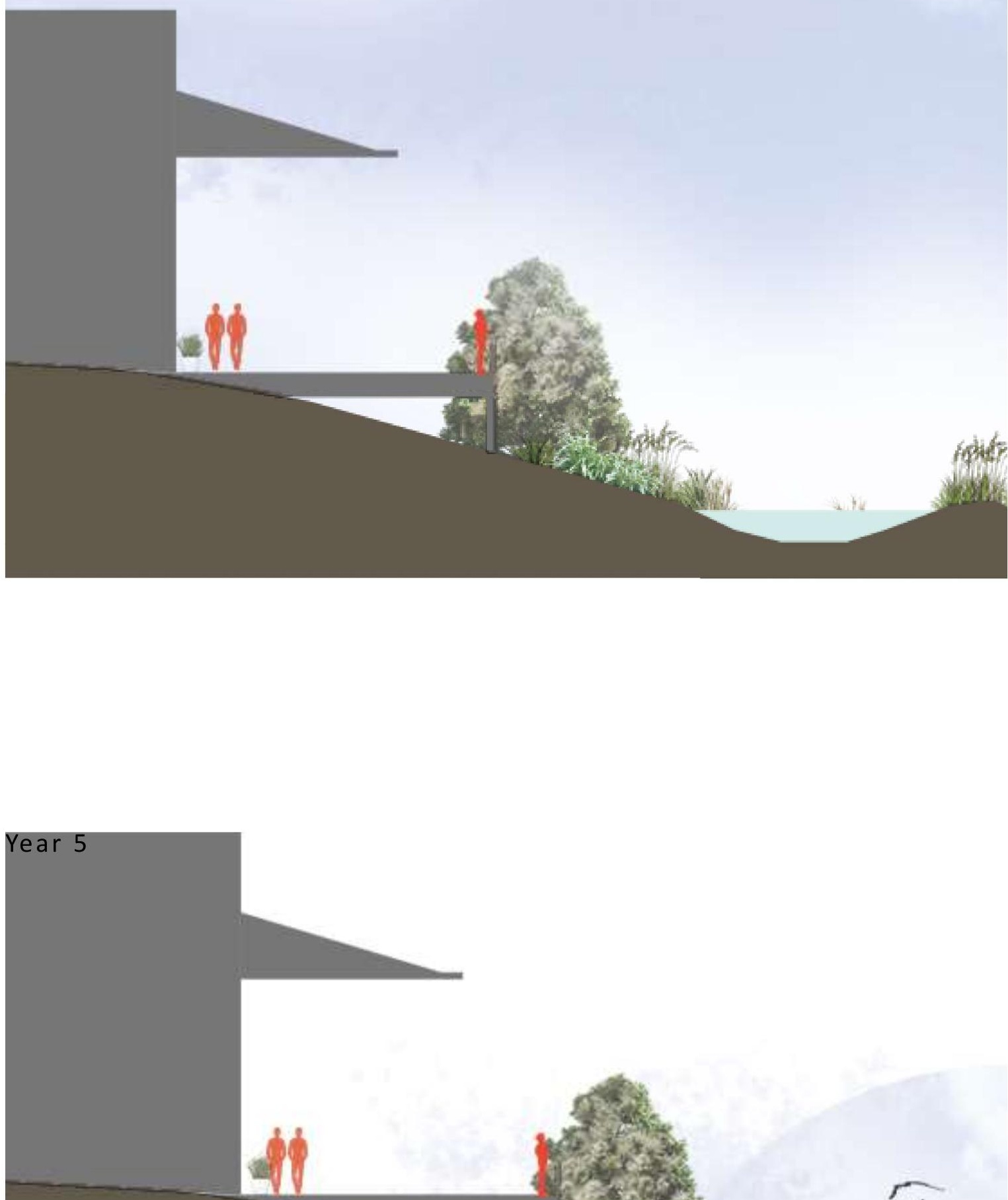

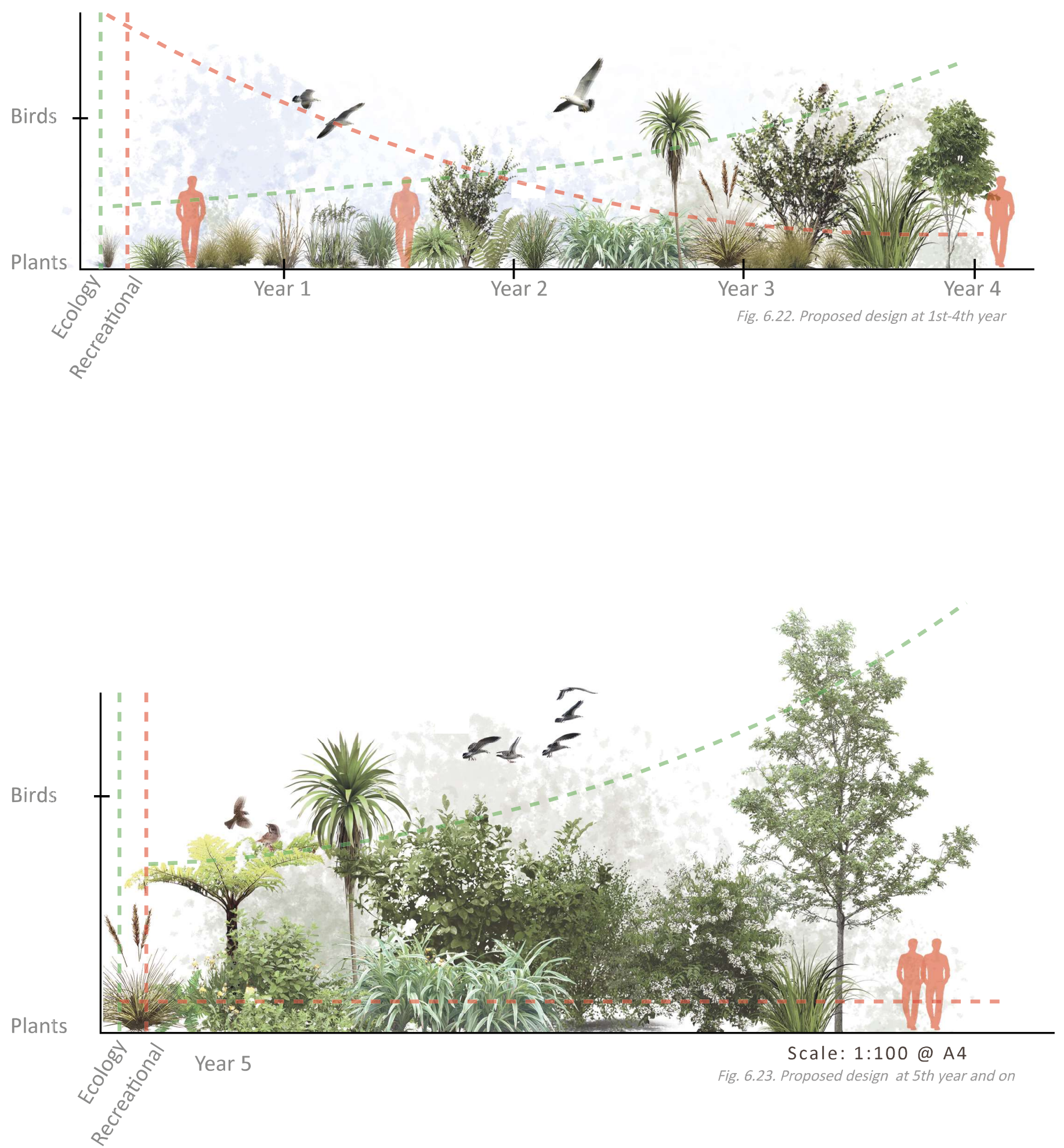

Scale: 1:100@A4

Fig. 6.23. Proposed design at 5 th year and on 


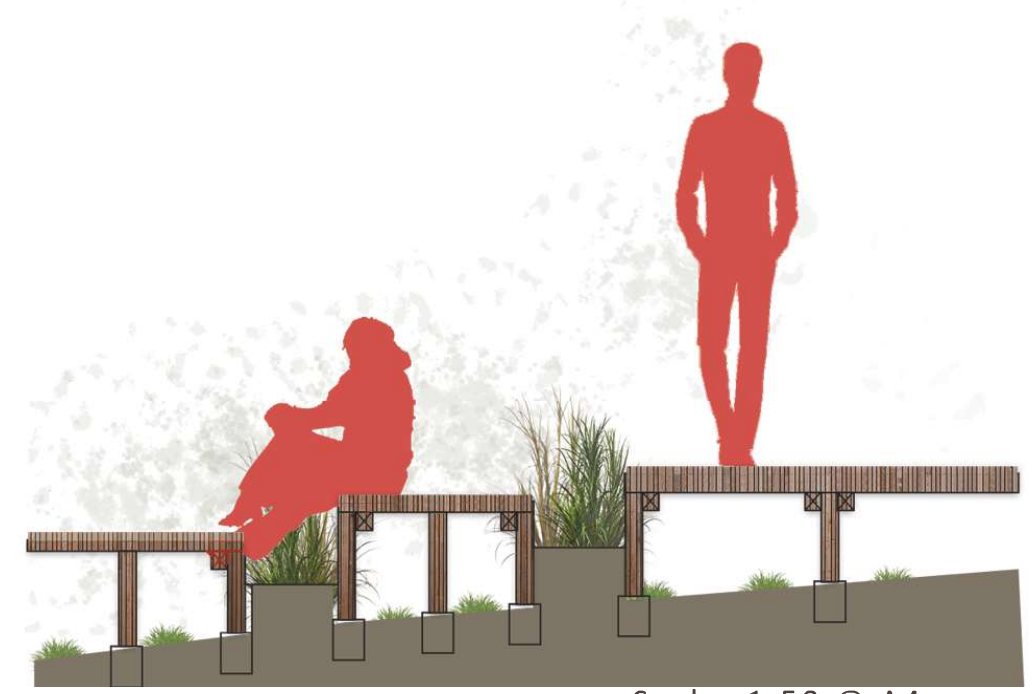

Scale: 1:50@A4

Fig. 6.24. Vegetation planted between timber gaps

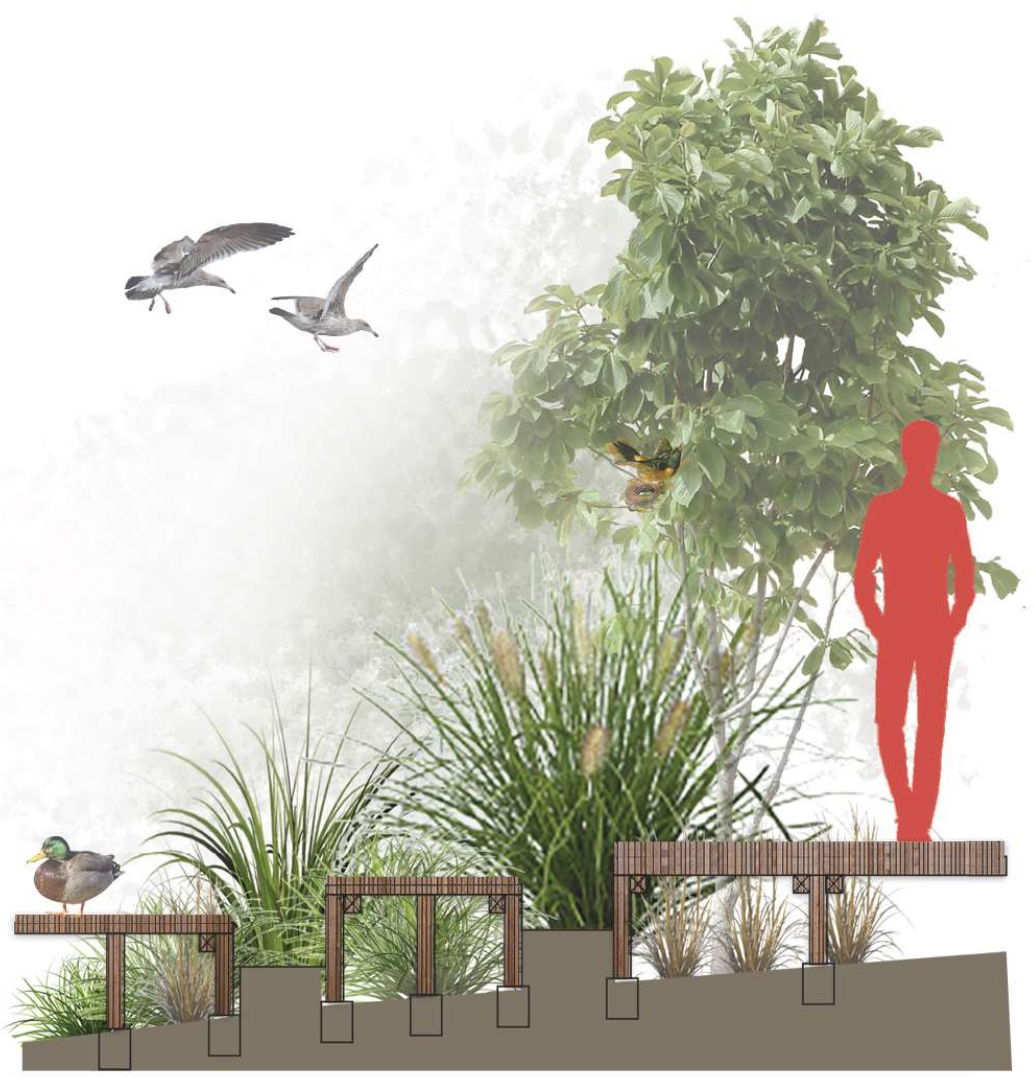

Scale:1:50@A4

Fig. 6.25. Vegetation planted will cover the timber deck 


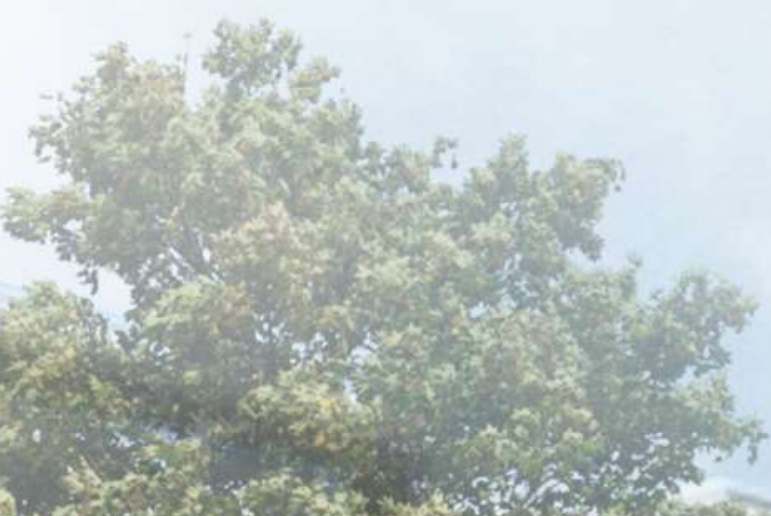

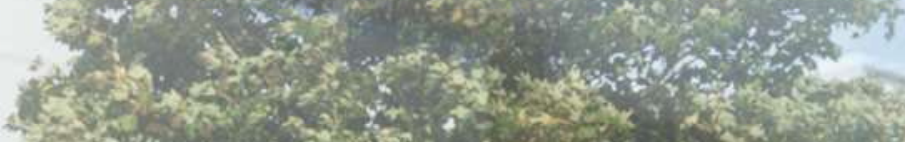

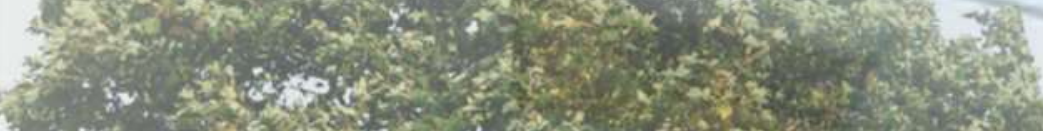

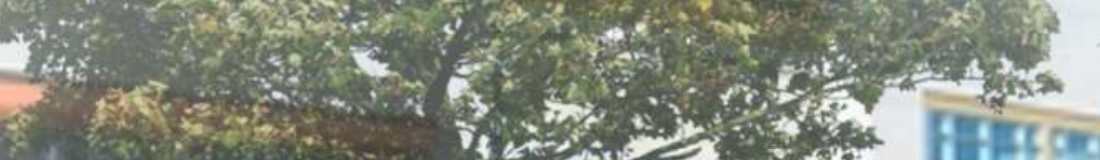

I

19.

(2)

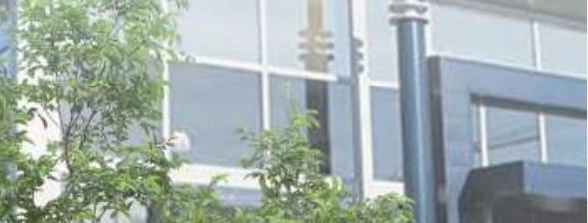

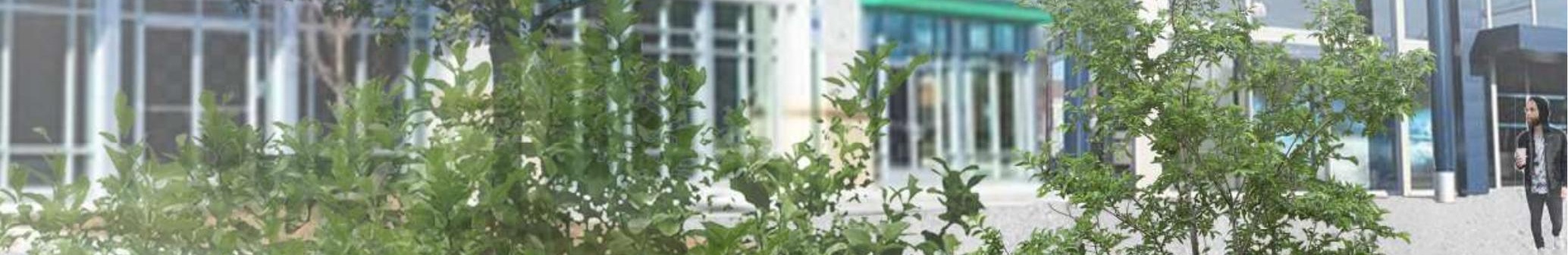

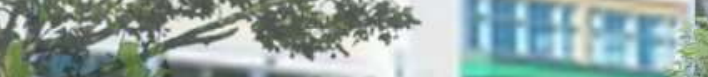

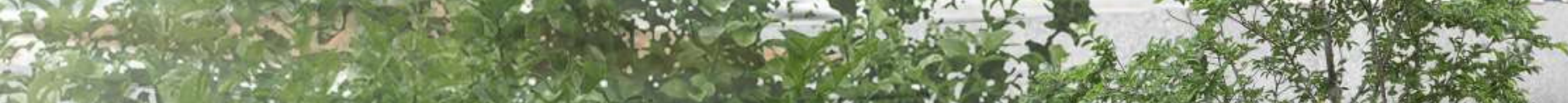

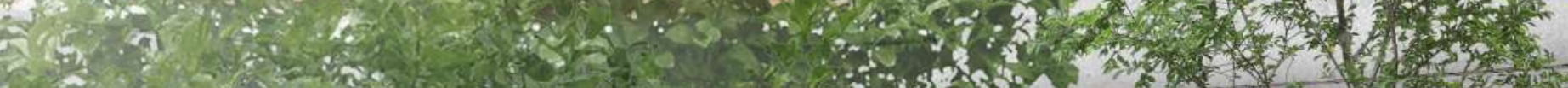

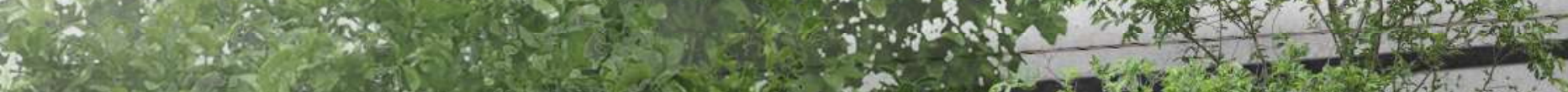

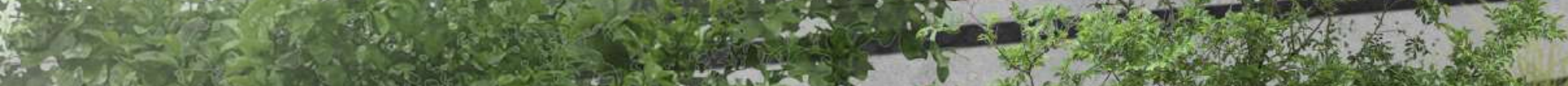

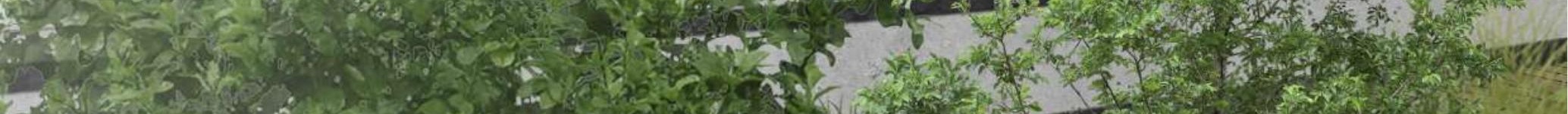

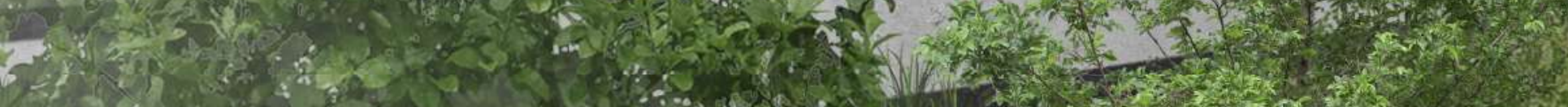

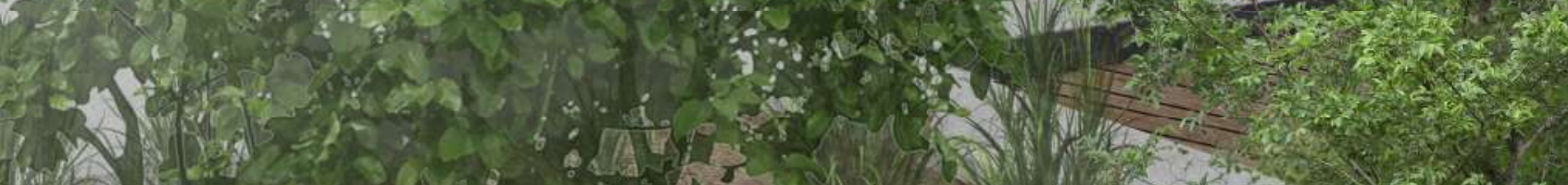

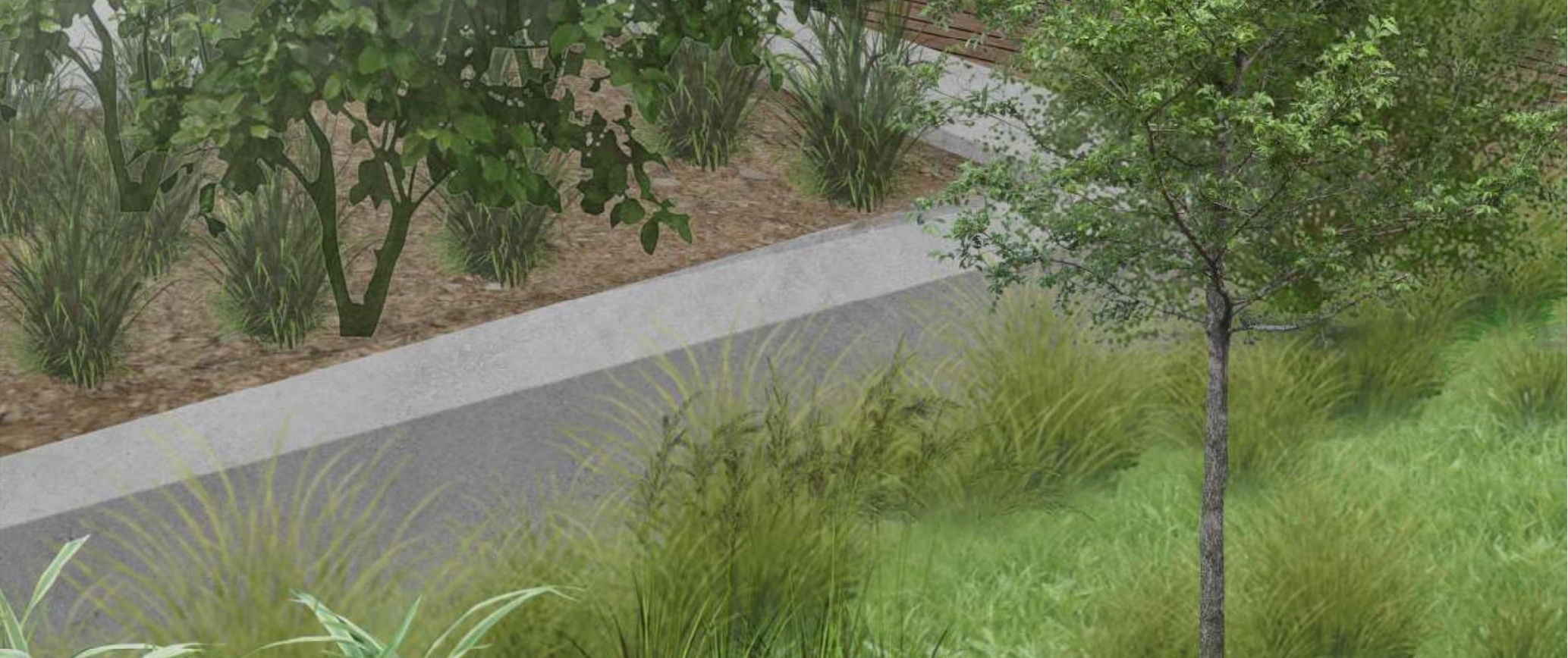

20. (a) 


\section{sers

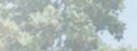 \\ i.}

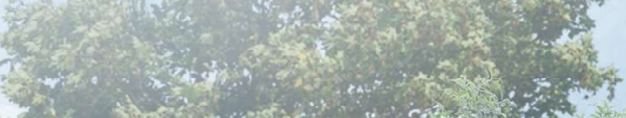

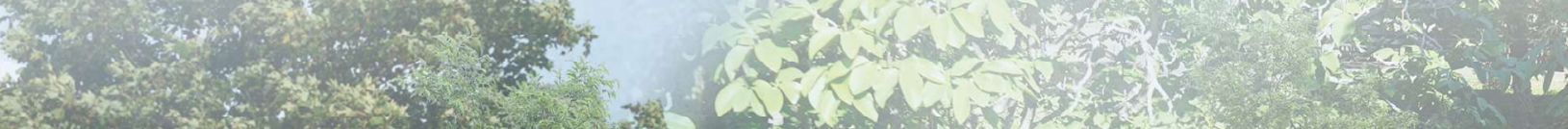

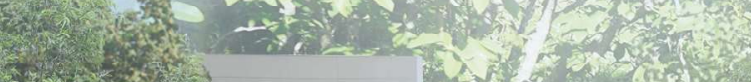
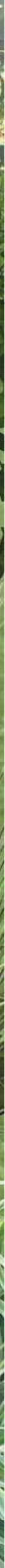


\section{7}

\section{CONCLUSION}

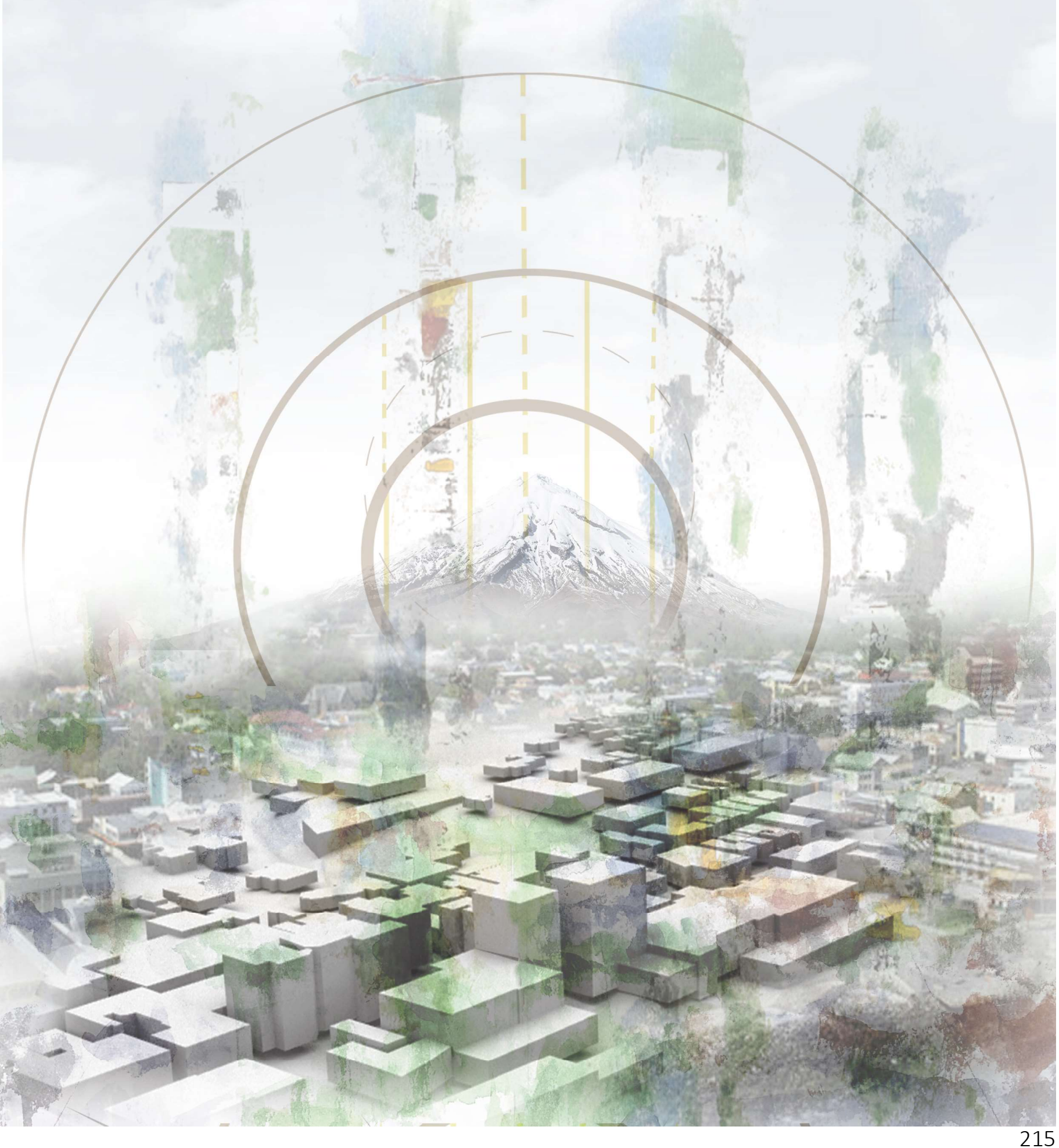




\section{Reflection}

Humans' imagination of their landscape reflects their self-identity, evoking a sense of belonging with their living environment. The problem that arises for the discipline is: cities around the world are designed homogeneously, they are losing their identity, as well as their imaginability.

New Plymouth Central Area is a representative urban space under this problematic context. This design-led research has investigated the site through a range of scales, methods, and testing; developed an intuitive design method and a physical design solution that creates and re-creates people's mental image of New Plymouth's Central Area.

There are multiple solutions towards designing the identity of the city and its legibility, but this research took an abstract approach to understanding the concept of identity. Impressionist artworks inspired the research method. The research process relied on painting and crafting techniques, a process which has differentiated it from contemporary theory - those theories that looked only into physical design elements and cognitive landscape perception. The intuitional design method abstracted the mental imagination process from a small-scale to a large-scale, as the research outcome. It allowed a deeper understanding of the mental image and its connection to physical design.

The physical design process tested the intuitional design method and applied it to design decision-making. The design implemented a new mental pattern for the urban system, in order to connect instant experiment into a large-scale recognition. The master plan emphasized urban order and pattern, which are derived from historical urban development. Site designs visually strengthened the historical and cultural identity of both New Plymouth city and the citizens themselves. In order to avoid radical changes and low feasibility solutions, this design aimed to work at a mental level and design abstractly. As a result, the primary design outcome, the urban pattern, remains hidden. Citizens would have to discover the city physically, to thereby understand the logic of patterns. The city's image is a buildingup process. The city's image of a tourist would look different from the city's image of a citizen. This method ties citizens' identity to the land, allowing them to feel that they belong to the land. 


\section{Limitation}

Landscape images are the results of a two-way process between the environment and the observer. The image of a given environment may vary significantly. It is tough to make the statement that the outcome of this research will be able to represent every citizen of New Plymouth. However, it is safe to say that the conversation started between the landscape architect and citizens can proceed further with a similar design strategy.

This design has always been careful about avoiding heavy-handed designing solutions, keeps away from providing the identity from a single-minded view, and telling the story for the citizens. The concentric-circle pattern works like a palimpsest, shadow, or suggestion; of another kind of organisation, that conforms with the larger forms of mountain, topography, and sea, rather than with the grid. Noting it, the pedestrian can choose to either investigate further, or not. As a result, the design outcome might be unrealizable at a tourist's first glance or to those citizens who are not willing to perceive the landscape actively.

The concentric circle pattern would strengthen its power when the master plan is completely designed. The proposed master plan is an idealistic solution that cooperated with NPDC's design goal. This solution is debatable about the feasibility of accomplishing the master plan to the extent that the hidden pattern can be recognized. However, subjects can change flexibly, as long as the logic behind planning speaks the language of the pattern.

New Plymouth has been a treasured site, but some historically and culturally valuable sites have not been represented in detail. For instance, the precolonial Maori settlement site, historical railway. Other site issues were found in New Plymouth Central Area, such as the inactive coastal railway, the homogenized building façade, and the cheaply-designed industrial building blocks. These issues have been briefly designed through chapter 5 , but each of them would need a more detailed development strategy. As mentioned in chapter 2, the existing green space coverage is deficient. New green spaces are briefly proposed in chapter 5 , but each of these green spaces would need to be further designed with detailed landscape architecture: the design outcome of these green spaces should communicate the concentric circle pattern. The physical design solution could have been executed in a lot more detail if more time were allowed to accomplish this research. 


\section{Conclusion}

The landscape discipline has progressed during this contemporary period; it has changed and adapted to the nature of human needs and development of technology. What was seen as the right choice back in the 20th century might not be the best solution in the 21st century; in the meantime, what we believed in might be shifted by the next generations' beliefs. However, the identity of landscape is a significant topic to keep communicating through generations, so that history and culture are not forgotten through time.

Through this research, a method to enhance the landscape identity, through mental recognition, is proposed. This method sets up a conversation between the landscape architect, who understands the site history and culture, and citizens, who have their own personal memory of the site, in this particular time within the historical process. The physical design outcome sets up an ongoing pattern, prepared for future urban expansion. New Plymouth's population is growing slowly, compared to other major urban areas in New Zealand. The design outcome and the proposed master plan would ideally fit the urban requirement for the next 10-25 years. When the population grows, and the urban area expands, the concentric circle pattern could expand and form other circles further away from the proposed central activity area. Other secondary activity centres can be proposed by other landscape architects in the future, while continually communicating the urban pattern and history between generations.

This proposed design method and design outcome achieve the primary goal of the contemporary landscape discipline: a sustainable design; meeting the needs of the present without compromising the ability of future generations to meet their needs. Although the design avoids a heavy-handed approach, the design outcome is still reasonably debatable in terms of cost and energy consumption, due to building demolition and new building construction.

The intuitional design method could be further tested under other urban contexts, coordinating with landscape cognitive and environmental behaviour research in order to finalize this design theory. 


\section{8 \\ BIBLIOGRAPHY}

Bell, S. (1993). Elements of Visual Design in the Landscape. New York: Spon Press.

Frankl, P. (1986). Principles of Architectural History: The Four Phases of Architectural Style, 1420-1900. Massachusetts and London: The MIT Press.

Gauguin, P. (1936). Intimate Journals of Paul Gauguin . New York: Routledge.

Hilberseimer, L. (1946). The New Regional Pattern. Chicago: P. Theobald.

Jacobs, J. (1961). The Death and Life of Great American America Cities. United Kingdom: Random House.

Karamanea, P. (2015). Landscape, memory and contemporary design. Retrieved from ResearchGate: https://www.researchgate.net/publication/318592344_Landscape_memory_and_contemporary_design

Lynch, K. (1960). The Image of The City. Norway: Harvard University Press.

Lynch, K. (1961). The Pattern of the Metropolis. Vol.90, No.1,The Future Metropolis, pp. 79-98.

Lynch, K. (1981). A Theory of Good City Form. Cambridge, Mass: MIT Press.

Mitchell, W. (1994). Landscape and Power. Chicago: University of Chicago Press.

New Plymouth District Council. (2010). Positive Ageing Strategy. Retrieved from New Plymouth District Council: https://www.newplymouthnz.com/Council/Council-Documents/Plans-and-Strategies/Positive-Ageing-Strategy 
New Plymouth District Council. (2012). New Plymouth Central Area Urban Design Survey Results Analysis. Retrieved from New Plymouth District Council: https:// www.newplymouthnz.com/-/media/NPDC/Documents/Forms\%20and\%20Fees/ Design\%20Considerations/Design\%20Considerations\%20Urban\%20design\%20 survey\%20results\%20and\%20analysis.ashx

New Plymouth District Council. (2013). New Plymouth Central Area Urban Design Framework. Retrieved from New Plymouth District Council: https://www.newplymouthnz.com/Council/Council-Documents/Plans-and-Strategies/Central-Area-Urban-Design-Framework

New Plymouth District Council. (2019). New Plymouth District Council. Retrieved from Green Spaces Management Plan: https://www.newplymouthnz.com/-/media/ NPDC/Documents/Council/Council\%20Documents/Plans\%20and\%20Strategies/ Green\%20Space\%20Management\%20Plan.ashx

New Zealand Goverment. (2018). Urban Rural 2018 to Urban Rural Indicator 2018. Retrieved from Stats NZ : http://aria.stats.govt.nz/aria/\#ConcordanceView:uri=http://stats.govt.nz/cms/ConcordanceVersion/yg1WWVJ4FOY3kXUh

Nijhuis, S., Van Lammeren, R., \& Van Der Hoeven, F. (2011). Explore the Visual Landscape, Advances in Physiognomic Landscape Researc In The Netherlands. Research in Urbanism Series, ISSN 1875-0192.

Norberg-Schulz, C. (1979). Genius Loci: Towards a Phenomenology of Architecture. New York: Rizzoli.

Pikionis, D. (1989). Sentimental Topography. London: Architectural Association.

Schama, S. (1995). Landscape and Memory. London: HarperCollins Publishers.

Steenbergen, C., \& Reh, W. (1996). Architecture and Landscape: The Design Experiment of the Great European Gardens and Landscapes. Netherlands: Prestel.

Stenros, A. (1993). Orientation, Identification, Representation - Space and Perception in Architecture. The first EAEA (European Architectural Endoscopy Association) Conference (pp. 169-196). Tampere: European Architectural Endoscopy Association, TTKK.

Van der Werf, J., Zweerink, K., \& van Teeffelen, J. (2016). The City at Eye Level - Second and Extended version. Netherlands: Eburon Academic Publishers.

Waldheim, C. (2016). Landscape as Urbanism: A General Theory. United State: Princeton University Press. 


\section{FIGURE LIST}

Fig. 1.01 - NPDC. (2012). Survey Cloud. Retrieved from New Plymouth DistrictCouncil:

https://www.newplymouthnz.com/-/media/NPDC/Documents/Forms\%20 -and\%20Fees/Design\%20Considerations/Design\%20Considerations\%20 Urban\%20design\%20survey\%20results\%20and\%20analysis.ashx

Fig.1.02-1.06 - NPDC. (2013). NPDC Design Framework. Retrieved from New

Plymouth District Council: https://www.newplymouthnz.com/Council/ Coun-cil-Documents/Plans-and-Strategies/Central-Area-Urban-Design-Framework

Fig. 2.02-2.05 - NZ Government. (n.d). New Plymouth Historical mas. Retrieved from Mapspast: http://www.mapspast.org.nz/

Fig.2.06 - NPDC. (2013). New Plymouth Development History. Retrieved from New Plymouth District Council: https://www.newplymouthnz.com/Council/Council-Documents/Plans-and-Strategies/Central-Area-Urban-Design-Framework

Fig.2.07 - Smith, G. (n.d). Pre-colonial Maori Settlement. Retrieved from Alamy:

https://www.alamy.com/black-and-white-vintage-print-depicting-a-maori-pafortified-settlement-with-maori-people-wearing-cloaks-and-holding-spearsin-the-foreground-carved-wooden-houses-food-storage-structures-raised-onstilts-and-a-funerary-waka-canoe-planted-to-the-earth-in-the-background-located-in-new-zealand-published-in-john-george-woods-volume-the-uncivilizedraces-of-men-in-all-countries-of-the-world-being-a-comprehensive-account-oftheir-manners-and-customs-and-of-their-physical-social-mental-moral-and-religious-characteristics-1877-courtesy-internet-archive-image216974059.html 
Fig. 2.08 - Turnbull, A. (n.d). Parihaka Defeat. Retrieved from NZGEO:

https://www.nzgeo.com/stories/parihaka/

Fig. 3.01 - Monet, C. (1914-36). Water Lilies. Retrieved from MoMA:

https://www.moma.org/collection/works/80220

Fig. 3.02 - Pissarro, C. (1877). Rainbow at Pontoise. Retrieved from Daily Art

Magazine: https://www.dailyartmagazine.com/camille-pissarro-rainbo/

Fig. 3.03 - Van Gogh, V. (1890). Wheatfield with Crows. Retrieved from Van Gogh

Museum: https://www.vangoghmuseum.nl/en/collection/s0149V1962

Fig. 3.04-3.05 - Hilberseimer,L \& Mies van der Rohe,L. (1956). Lafayette Park.

Retrieved from ArcDaily: https://www.archdaily.com/455524/ad-classics-lafayette-park-mies-van-der-rohe

Fig. 3.06-3.10 Lynch,K. (1961). The Pattern of the Metropolis. Vol.90, No.1,The Future Metropolis, pp. 81-90.

Fig. 3.11- Steenbergen, C \& Reh, W. (1996). Architecture and Landscape: The Design Experiment of the Great European Gardens and Landscapes. Netherlands: Prestel.

Fig. 3.12 - Panero, J. and Zelnik, M. (1979) Human Dimension \& Interior Space. New York, Whitney Library of Design.

Fig. 3.14 - Google Map. (n.d). Luxor Temple to Hatshepsut Temple. Retrieved from Google Maps: https://www.google.co.nz/maps/@25.7203166,32.6540497,3a,75y,211.33h,90t/data=!3m8!1e1!3m6!1sAF1QipMH-4Gj0cQP3NB8042SjPilcqQz358TRU3Jj9kN!2e10!3e11!6shttps:\%2F\%2Flh5.googleusercontent.com\%2Fp\%2FAF1QipMH-4Gj0cQP3NB8042SjPilcqQz358TRU3Jj 9kN\%3Dw203-h100-k-no-pi0-ya285.93823-ro-0-fo100!7i5472!8i2736?hl=zhCN\&authuser $=0$

Fig. 3.15 - Lang, K. (2005). Luxor Temple Entrance. Retrieved from Alarm:

https://www.alamy.com/avenue-of-sphinxes-and-first-pylon-entry-karnak-temple-luxor-upper-image5111002.html

Fig. 3.16 - Cohen, B. (2015). Hatshepsut Temple. Retrieved from The Gate with Brian

Cohen: https://thegate.boardingarea.com/mortuary-temple-of-hatshepsut-in-egypt-a-photographic-essay/

Fig. 3.17 - Google. (n.d). Winter Solstice on Hatshepsut Temple. Retrieved from

Google Maps: https://www.google.co.nz/maps/@25.7378702,32.6075711,3a,75y,118.05h,90t/data=!3m8!1e1!3m6!1sAF1QipNu51j4XVB4la0xfppQDSXcK_qSSjEPoZzyLjAn!2e10!3e11!6shttps:\%2F\%2Flh5.googleusercontent. com\%2Fp\%2FAF1QipNu51j4XVB4la0xfppQDSXcK_qSSjEPoZzyLjAn\%3Dw203h100-k-no-pi0-ya4.069261-ro-0-fo100!7i5660!8i2830?hl=zh-CN\&authuser=0 
Fig. 3.18 - Holmes, R. (n.d). Valley of the Kings. Retrieved from Britannica:

https://www.britannica.com/place/Valley-of-the-Kings

Fig. 3.19 - Tausch, O. (2019, October 18). Luxor Temple. Retrieved from Wikipedia: https://en.wikipedia.org/wiki/Luxor_Temple\#/media/File:Luxor-Tempel_Pylon_08.jpg

Fig. 3.25 - Beoing, G. (2019, November 4). Paris Urban Pattern. Retrieved from

Geoff Boeing Personal Website: https://geoffboeing.com/2019/11/big-data-urban-morphology/

Fig. 3.26 - Lourenco, F. (2014, August 18). Paris. Retrieved from Projective Cities: http://projectivecities.aaschool.ac.uk/portfolio/filipe-lourenco-paris-asmetropolis/

Fig. 6.02 - Alexander Turnbull Library (1865). Watercolour depicting Pai Mārire ceremony. Retrieved from NZHistory: https://nzhistory.govt.nz/pai-marireambush-at-oakura-taranaki

Fig. 6.03 - NZ Government, (2015, December). Niu Pole Mariri. Retrieved from: https://www.nzta.govt.nz/assets/projects/cambridge/docs/201512-posterurban-design.pdf

Fig. 6.10 - LEARNZ, (n.d). Armed NZ Soldiers in WWI. Retrieved from LEARNZ:

https://www.learnz.org.nz/memorialpark134/bg-easy-f/the-first-world-warand-new-zealand\%E2\%80\%99s-involvement

Fig.6.16 - Arden. H, (1866). Huatoki Stream Historical Photo. Retrieved from Puke Ariki:

https://collection.pu-keariki.com/objects/25747/untitled-alpha-mill-and-huatokistream-carrington-road-new-plymout

Fig. 6.17- Museum of NZ. (n.d). Toki. Retrieved from Museum of New Zealand:

https://collections.tepapa.govt.nz/object/197196

Fig. 6.18 - NZGEO, (n.d), Matau. Rettrieved from NZGEO:

https://www.nzgeo.com/stories/the-lost-art-of-fishing/

Fig. 6.19 - Te Ara (n.d) Māori Fishing. Retrieved from Te Ara:

https://teara.govt.nz/en/artwork/25743/maori-fishing 
